FEB 91968

MND2062-12-7

\title{
SNAP 29 \\ Power Supply System \\ Fifth Quarterly Progress Report
}

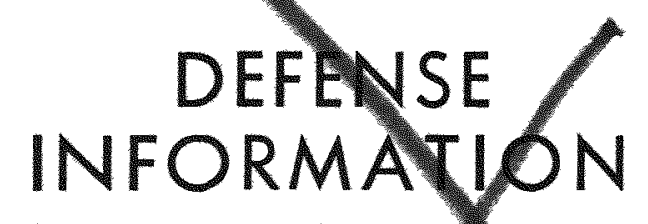

This document contains information af acting the National

Defense of the Unted States wrthr the meaning of the

Espronage Laws, Trtle 18, U.S.C, sectrof 793 and 794 ,

the transmission or revelation of which in thy manner to

an unauthorized person is prohy ted by law.

\section{$68 \quad 3132$}




\section{DISCLAIMER}

This report was prepared as an account of work sponsored by an agency of the United States Government. Neither the United States Government nor any agency Thereof, nor any of their employees, makes any warranty, express or implied, or assumes any legal liability or responsibility for the accuracy, completeness, or usefulness of any information, apparatus, product, or process disclosed, or represents that its use would not infringe privately owned rights. Reference herein to any specific commercial product, process, or service by trade name, trademark, manufacturer, or otherwise does not necessarily constitute or imply its endorsement, recommendation, or favoring by the United States Government or any agency thereof. The views and opinions of authors expressed herein do not necessarily state or reflect those of the United States Government or any agency thereof. 


\section{DISCLAIMER}

Portions of this document may be illegible in electronic image products. Images are produced from the best available original document. 

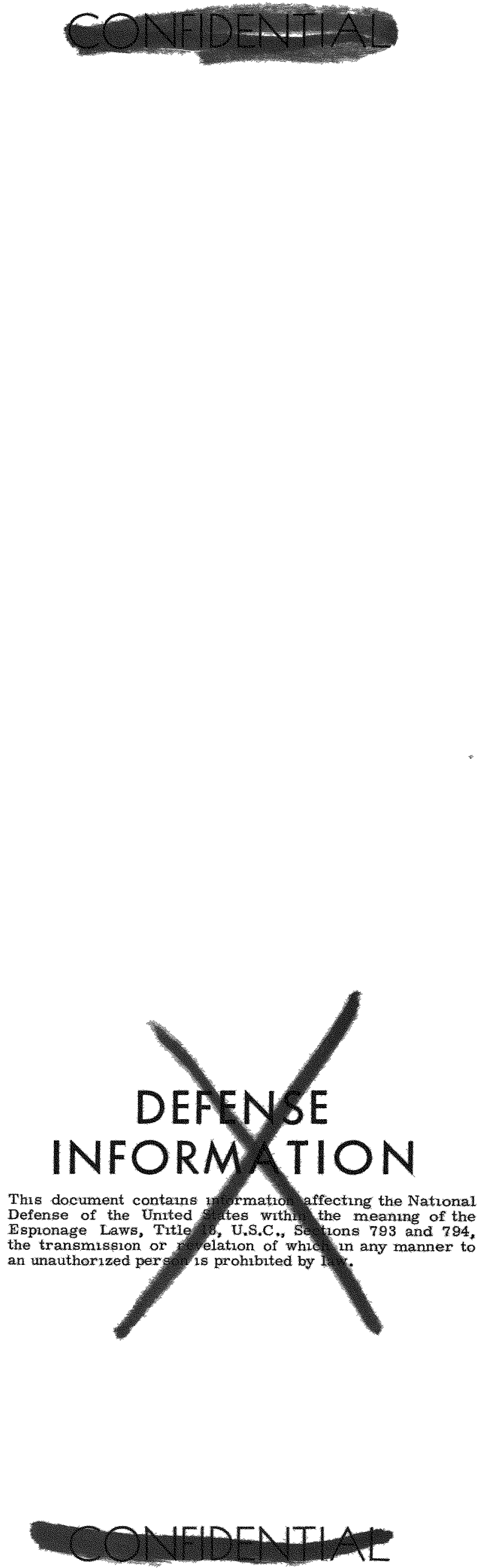
This report has been prepared under Contract $\mathrm{AT}(29-2)-2062$ with the U.S. Atomic Energy Commission

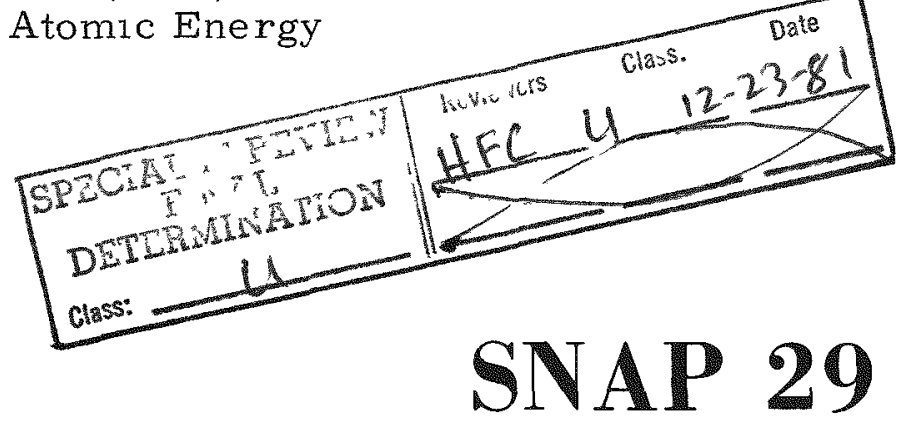

MND2062-12-7

C92A, M-3679, 52nd Edition. AEC Research and Development Report

\section{Power Supply System}

\section{Fifth Quarterly Progress Report}

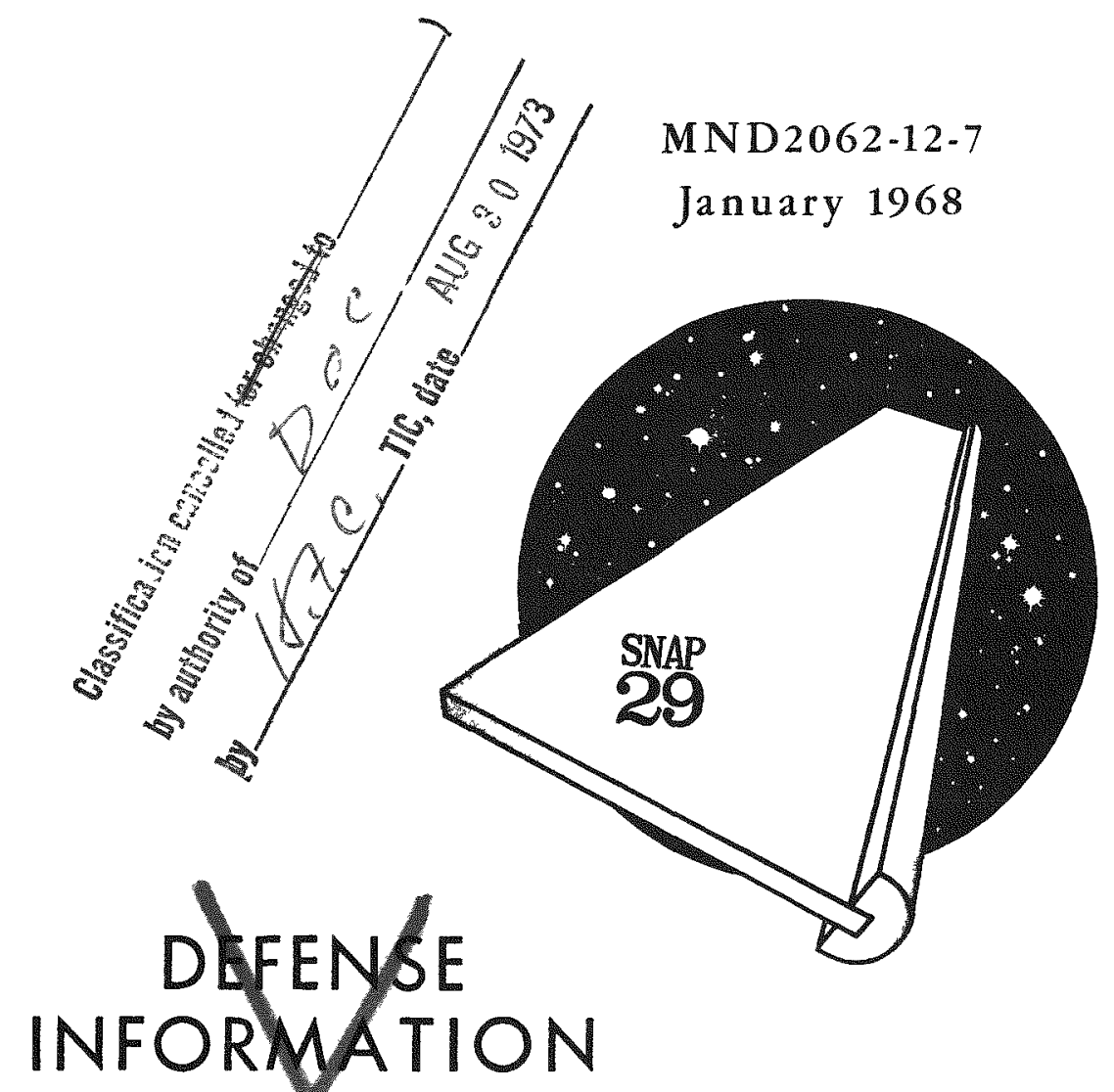

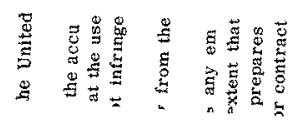
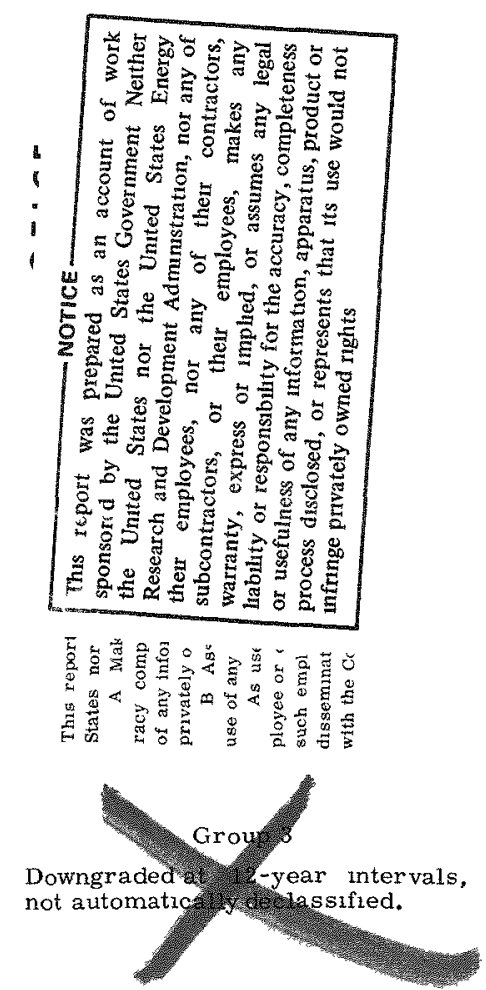

This document contains inforthation affectung the National Defense of the United Stafes swithin the meaning of the

Espionage Laws, Title 18ju.S.

the transmission or revelation $b$ wheh in any manner to

an unauthorized person prohibitive by law.

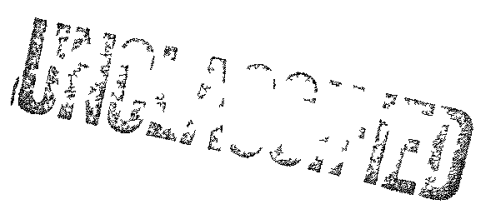





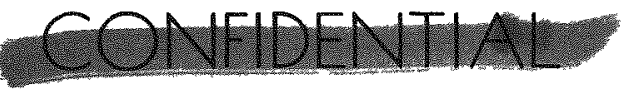

\section{FOREWORD}

This is the Fifth Quarterly Progress Report prepared under Contract AT(29-2)2062. It covers the progress of the Martin Marietta Nuclear Division on the SNAP 29 program and is prepared for the United States Atomic Energy Commission.

The report covers the period from October 1, 1967 through December 31, 1967.

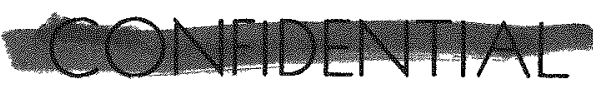

MIND2062-12-7 


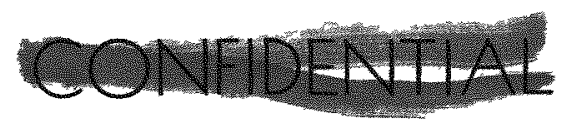

BLANK

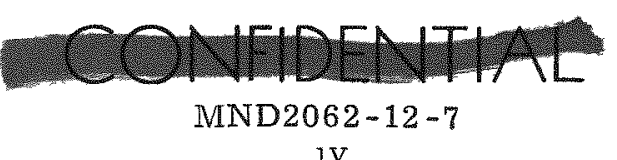




\section{CONTENTS}

Page

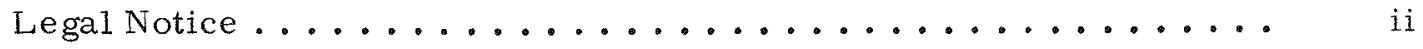

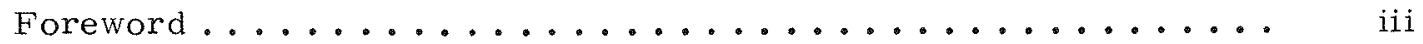

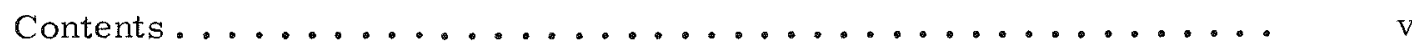

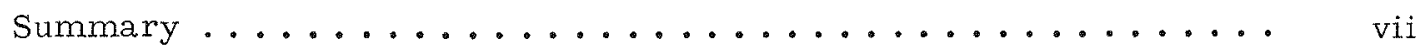

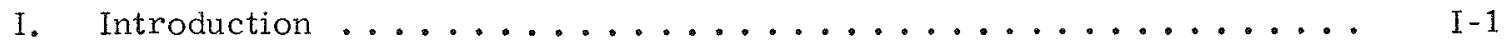

II. Radioisotope Thermoelectric Generator System--Control Point 1000.. II-1

A. Summary of Significant Accomplishments.............. II-1

B. RTG Heat Source (Isotopic) Subsystem - Control Point 1100.... II -3

C. Heat Source (Electrical) Subsystem--Control Point 1200 ..... II-56

D. Thermocouple Modules Subsystem - Control Point 1300....... II-60

E. Thermal Control Subsystem - Control Point 1500......... II-86

F. Heat Pipe Heat Rejection Subsystem--Control Point $1800 \ldots$. . II-94

G. RTG Structural Housing Subsystem--Control Point 1900 ..... II-104

III. Systems Evaluation and Integration--Control Point 3200 ........ III-1

A. Summary of Significant Accomplishments ............. III-1

B. System Interface Evaluation--Control Point $3210 \ldots \ldots$ III-1

C. System Test Integration--Control Point $3240 \ldots \ldots$ III -1

D. Advanced Technology--Control Point $3250 \ldots \ldots$ III-12

IV. Reliability--Control Point $3230 \ldots \ldots \ldots$ IV $-\ldots$

A. Summary of Significant Accomplishments .............. IV -1

B. Reliability Planning and System Analysis - Control Point $3231 \ldots$ IV -1

C. Design Evaluation and Control--Control Point $3232 \ldots \ldots$ IV -8

D. Test Program Definition and Evaluation-Control Point $3233 \ldots \ldots$ IV -14

V. Aerospace Ground Equipment System--Control Point 2000 ....... V-1

VI. Safety Evaluation and Integration--Control Point $3300 \ldots$.......... VI

A. Summary of Significant Accomplishments ............. IV -1

B. Safety Evaluation and Integration--Control Point $3310 \ldots$ VI-2

C. Aerodynamic Analysis and Tests - Control Point 3320....... VI-5

D. Impact and Burial Testing and Analyses--Control Point 3330.... VI-38

VII. Mound Laboratory Effort in Support of SNAP 29 ........... VII -

A. Summary of Significant Accomplishments.............. VII -2

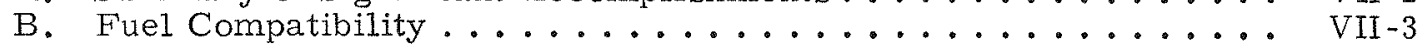

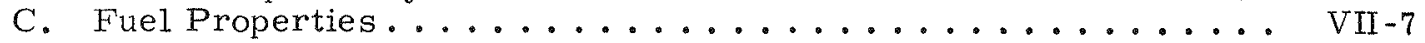

D. Material Weld and Braze Studies for Capsules and Heat Sources. VII-17

E. Polonium Fuels Encapsulation Facility.............. VII-17

Appendixes

A. Component Development Phase--Thermal Control Subsystem....

$\mathrm{A}-1$

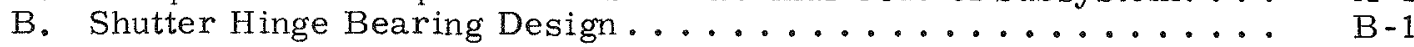

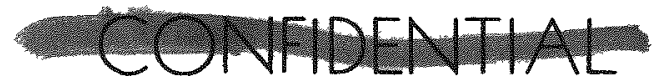

MND2062-12-7 
BLANK

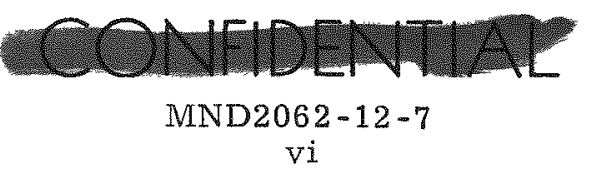




\section{SUMMARY}

\section{A. RADIOISOTOPE THERMIOELECTRIC GENERATOR SYSTEM}

Three four-module size fuel blocks have been fabricated for dynamic testing.

Fuel capsule liner burst tests were completed in this period.

Thirty simulated fuel capsules have been assembled.

The heat source parametric study was completed.

Mechanical property testing of candidate fuel block materials was completed.

Heater tests of Sanders and TRW electrical heaters were terminated and vacuum testing of three Watlow heaters was initiated.

Four piston-heat sink modules were placed on test in the steady-state loop and one piston-heat sink module was dynamically tested.

Drawings were released for a predevelopment module with a diaphragm for pressure loading the thermoelectric elements and an alternate piston-heat sink module design has been prepared.

The Thermal Control Subsystem Design Report was issued to complete the subsystem component development phase. The NaK actuator burst tests and shutter thermal vacuum test were completed and the bearing lubricant selected.

Thermal control subsystem design verification drawings have been initiated.

Four different heat pipe evaporator sections were designed and tested.

Three heat pipe condenser sections were designed and tested.

A cleaning process has been developed for the preparation of heat pipe assemblies.

The RTG structural housing design has been coordinated with developments in other subsystems.

\section{B. SYSTEM EVALUATION AND INTEGRATION}

Revisions A-1, A-2 and A-3 to the SNAP 29 Program Plan (MND2062-500, Revision A) were coordinated and delivered to the AEC during this reporting period.

Ten test series were completed during this period and seven tests are in progress.

\section{RELIABILITY}

A preliminary prediction of electric power output characteristics for the four RTG configurations has been completed.

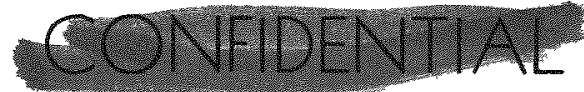


A prediction of the catastrophic reliability of the thermoelectric portion of the RTG has been calculated using the mathematical model and the T/E couple failure rate presented in the previous quarterly report.

The piston-heat sink $\mathrm{T} / \mathrm{E}$ modules beginning-of-life measured power output has been developed statistically and a comparison made to the predicted values.

\section{AEROSPACE GROUND EQUIPMENT}

Due to program redirection, effort on AGE design has been deferred until the latter part of 1968.

\section{E. SAFETY EVALUATION AND INTEGRATION}

Analog heating and motion data have been analyzed.

Impact test drop altitudes were determined.

Hypersonic force and moment wind tunnel tests and hypersonic aeroheating wind tunnel tests were completed.

Spinning edge-on trajectory and heating data were determined.

\section{F. MOUND LABORATORY EFFORT IN SUPPORT OF SNAP 29}

The $\mathrm{H}$-capsule $1200^{\circ} \mathrm{C}$ tests were stopped temporarily due to a furnace problem. Corrosion was found on several capsules.

Two follow-on experiments to the polonium air exposure test No. 2 were conducted.

Matrix impact testing was conducted.

A successful method has been developed for polonium fueling of tantalum-gadolinium matrices in an inert atmosphere.

A table of polonium fuel properties has been prepared.

Welding parameters were developed for all of the end cap designs. Cap Design 001 was chosen for the strength member. 


\section{INTRODUCTION}

The purpose of the SNAP 29 program is to develop and demonstrate a radioisotope thermoelectric generator (RTG) system that meets the following objectives:

(1) The Radioisotope Thermoelectric Technology by fabricating and electrically operating, for 144 days, two groundbased RTG demonstration type units which utilize a modular concept design that is capable of intact heat source re-entry.

(2) The Aerospace Ground Equipment Technology by fabricating and operating AGE demonstration units. of:

The SNAP 29 radioisotope thermoelectric generator (RTG) system is made up

(1) A heat source subsystem

(2) Thermoelectric module subsystem

(3) Thermal control subsystem

(4) Heat rejection subsystem

(5) Structures subsystem.

Integrated aerospace ground equipment (AGE) is provided for transportation, storage, installation of the isotopic heat source into the prototype RTG on a simulated launch pad and system checkout.

The SNAP 29 development program consists of five major tasks:

(1) Radioisotope Thermoelectric Generator System--Control Point 1000

(2) Aerospace Ground Equipment System--Control Point 2000

(3) Program Management and Control--Control Point 3100

(4) Systems Evaluation and Integration--Control Point 3200

(5) Safety Evaluation and Integration--Control Point 3300.

Chapter II presents the status of development for the radioisotope thermoelectric generator system (Control Point 1000). The RTG system consists of six subsystems:

(1) CP 1100--RTG Heat Source (Isotopic)

(2) CP 1200--Heat Source (Electrica1)

(3) CP 1300--Thermoelectric Modules

(4) CP 1500--Thermal Control

(5) CP 1800--Heat Pipe Heat Rejection

(6) CP 1900--Structures.

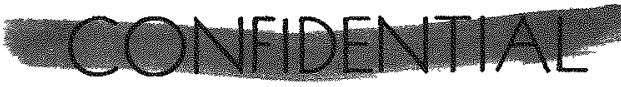

MND2062-12-7

I-1 
Chapter III relates to systems evaluation and integration (Control Point 3200 ).

Reliability is presented in Chapter IV.

Chapter V concerns the development of the aerospace ground equipment (CP 2000).

Safety evaluation and integration (CP 3300) are treated under Chapter VI.

Chapter VII represents the Mound Laboratory effort in support of SNAP 29.

Figure 1-1 represents the present schedule as proposed in the current program plan (MND-2062-500, Rev A-3).

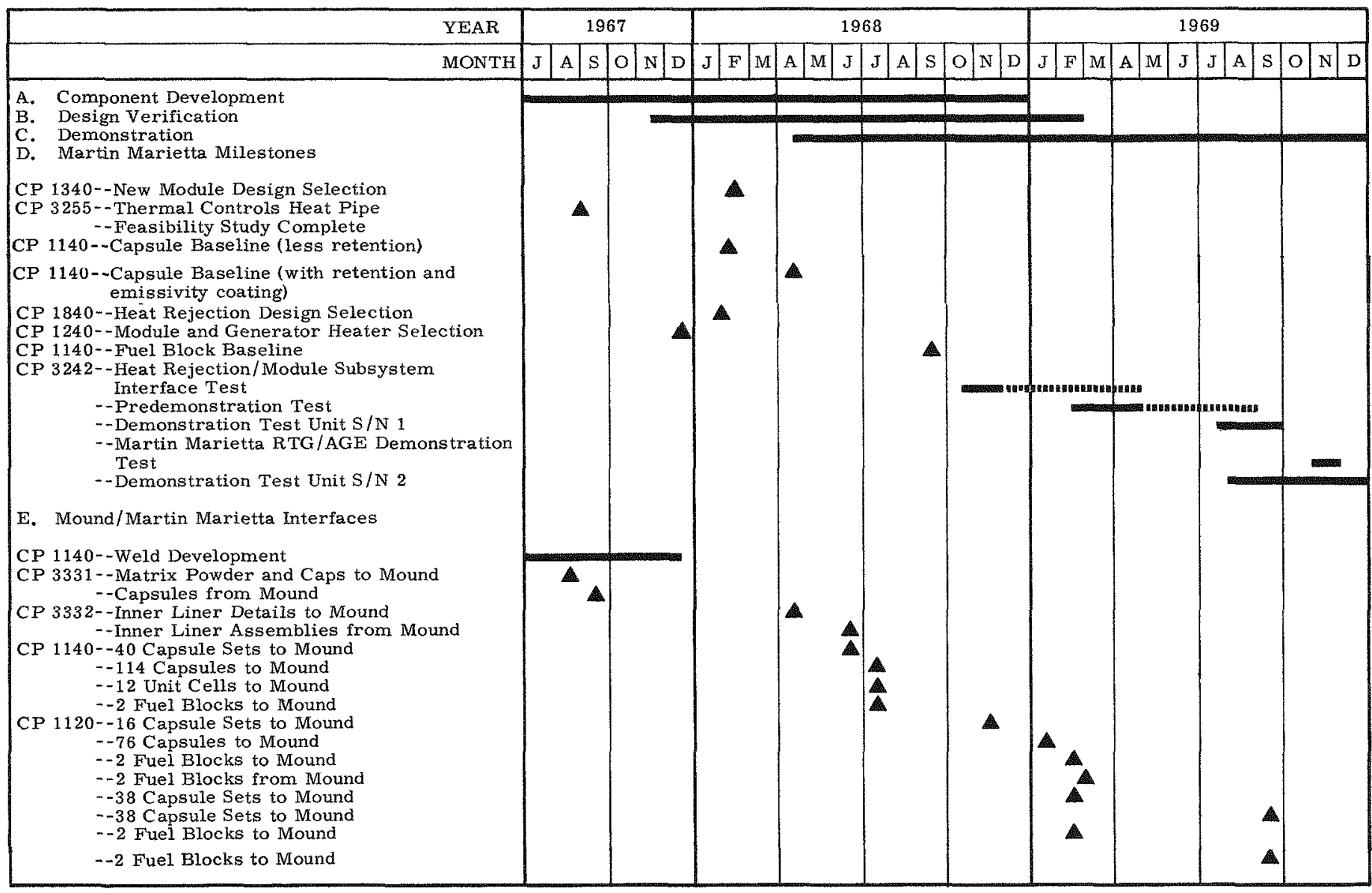

FIG. I-1. SNAP 29 MILESTONE SCHEDULE

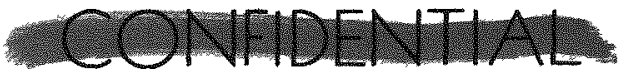

MND2062-12-7

$\mathrm{I}-2$ 


\section{RADIOISOTOPE THERMOELEC TRIC GENERATOR SYSTENI - - CONTROL POINT 1000}

The SNAP 29 RTG system goal is to demonstrate the radioisotope thermoelectr1c technology by fabricating and electrically operating, for 144 days, two ground-based RTG demonstration units which utilize a modular concept design. The heat source shall be capable of intact re-entry.

The system design life of 144 days includes a 90-day duration orbital mission. In order to more effectively accomplish the design, a control point system has been established which breaks the RTG into its major subsystems. The control point breakdown is defined below.

$$
\begin{aligned}
& \text { CP } 1100-\text {-Isotopic Heat Source Subsystem } \\
& \text { CP 1200--Electrical Heat Source Subsystem } \\
& \text { CP 1300--Thermoelectric Module Subsystem } \\
& \text { CP 1500--Thermal Control Subsystem } \\
& \text { CP 1800--Heat Pipe Heat Rejection Subsystem } \\
& \text { CP 1900--Structures, Instrumentation and Shielding Subsystem }
\end{aligned}
$$

The first phase of the program consists of design and development testing on a subsystem level in order to generate sufficient data to establish required design modifications prior to initiation of the second phase (design verification testing). On the basis of design verification tests, further design refinements will be effected in order to optimize the system design toward the stated goal. These changes will appear in the demonstration system configuration, which will demonstrate the capability of the RTG on a system level and affirm the applicability of the system to flight hardware.

\section{A. SUMMARY OF SIGNIFICANT ACCOMPLISHMENTS}

1. CP 1100--Isotopic Heat Source Subsystem

(1) Three four-module size fuel blocks have been fabricated for dynamic testing.

(2) A free capsule retention system has been added to the test program.

(3) Fuel capsule liner burst tests were completed in this period.

(4) Thirty simulated fuel capsules have been assembled.

(5) The heat source parametric study was completed.

(6) Mechanical property testing of candidate fuel block materials was completed.

2. CP 1200--Electrical Heat Source Subsystem

(1) Heater tests of Sanders and TRW electrical heaters were terminated.

(2) Vacuum testing of three Watlow heaters was initiated.

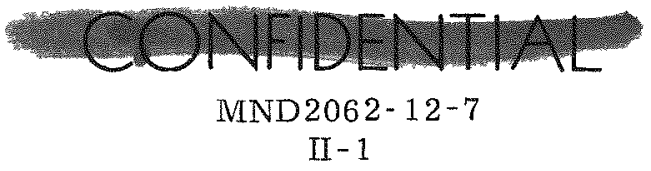


3. CP 1300--Thermoelectric Module Subsystem

(1) Four piston-heat sink thermoelectric modules were placed on test in the steady state loop.

(2) One piston-heat sink thermoelectric module was dynamically tested.

(3) Drawings were released for a predevelopment module with a diaphragm for pressure loading the thermoelectric elements.

(4) An alternate piston-heat sink module design has been prepared.

\section{CP 1500--Thermal Control Subsystem}

(1) $\mathrm{NaK}$ actuator burst tests were completed.

(2) The bearing lubricant was selected.

(3) The shutter thermal vacuum test was completed.

(4) The Thermal Control System Design Report was issued to complete the 1540 component development phase.

(5) The design verification (CP 1530) drawings have been initiated.

5. CP 1800--Heat Pipe Heat Rejection Subsystem

(1) Four different heat pipe evaporator sections were designed and tested.

(2) Three heat pipe condenser sections were designed and tested.

(3) A cleaning process has been developed for the preparation of heat pipes. 6. CP 1900--RTG Housing Structural Subsystem

(1) Housing design coordinated with developments in other control points.

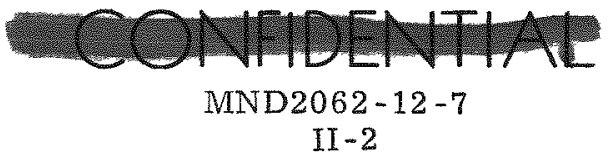




\section{B. RTG HEAT SOURCE (ISOTOPIC) SUBSYSTEM - CONTROL POINT 1100}

The objective of this task is to design, develop material, fabricate, inspect, and test an isotopic heat source capable of meeting the following requirements:

(1) To provide sufficient thermal energy to the thermoelectric modules subsystem for the generation of the required power

(2) To be capable of intact re-entry of the fuel capsules

(3) To provide full containment as required to meet safety criteria.

The development program for the heat source will consist of the following sequential phases:

CP 1140--Materials and Component Development

CP 1130--Design Verification

CP 1120 - -Demonstration Unit

\section{Summary of Accomplishments}

a. Fuel block

(1) Material properties determination

During this period, testing was initiated to verify existing material properties relative to ATJ graphite and to perform a preliminary evaluation of Carb-I-Tex material properties. The results of thermal property data obtained to date are shown in Tables II-1 through II-3. These data are incomplete at the present. It is planned that all testing will be completed during the next reporting period. For comparative purposes, typical existing property data are shown in the tables. Correlation for the ATJ is quite good. Due to the developmental nature of the Carb-I-Tex 500 (crossneedled), no reliable data are available for comparison.

TABLE II -

Measured Emittance of ATJ Graphite

\begin{tabular}{|c|c|c|}
\hline $\begin{array}{c}\text { Temperature } \\
\left({ }^{\circ} \mathrm{F}\right)\end{array}$ & $\begin{array}{c}\epsilon \\
\text { (Gier-Dunkle } \\
\text { facility) } \\
\end{array}$ & $\begin{array}{c}\epsilon \\
\text { (total } \\
\text { hemispherical) }\end{array}$ \\
\hline 500 & 0.67 & $\cdots$ \\
\hline 1000 & 0.71 & -. \\
\hline 1600 & 0.74 & 0.83 \\
\hline 2500 & 0.77 & -- \\
\hline
\end{tabular}


TABLE II -2

Measured Coefficient of Thermal Expansion of Candidate Fuel Block Materials

\begin{tabular}{|c|c|c|c|c|}
\hline Material & $\begin{array}{c}\text { Temperature } \\
\left({ }^{\circ} \mathrm{F}\right)\end{array}$ & $\begin{array}{c}\text { Relative } \\
\text { Grain } \\
\text { Direction } \\
\end{array}$ & $\begin{array}{c}\alpha \\
\left(\% /{ }^{\circ} \mathrm{F}\right) \\
\text { (measured) }\end{array}$ & $\begin{array}{c}\alpha \\
\left(\% /{ }^{\circ} \mathrm{F}\right) \\
(\text { existing data) } \\
\end{array}$ \\
\hline ATJ & 1600 & Parallel & $1.72 \times 10^{-6}$ & 1.2 to $1.6 \times 10^{-6}$ \\
\hline $\mathrm{ATJ}$ & 1600 & Perpendicular & $2.22 \times 10^{-6}$ & $1.90 \times 10^{-6}$ \\
\hline Carb-I-Tex & 1600 & Perpendicular & $2.05 \times 10^{-6}$ & - \\
\hline
\end{tabular}

TABLE II-3

Measured Thermal Conductivity of Candidate Fuel Block Materials

\begin{tabular}{|c|c|c|c|c|}
\hline Material & $\begin{array}{c}\text { Temperature } \\
\left({ }^{\circ} \mathrm{F}\right) \\
\end{array}$ & $\begin{array}{c}\text { Relative } \\
\text { Grain } \\
\text { Direction } \\
\end{array}$ & $\begin{array}{c}\mathrm{K}\left(\frac{\mathrm{Btu}-\mathrm{in} .}{\mathrm{hr}-\mathrm{ft}^{2}-{ }^{\circ} \mathrm{F}}\right) \\
(\text { measured }) \\
\end{array}$ & $\begin{array}{r}\mathrm{K}\left(\frac{\mathrm{Btu}-\mathrm{in} .}{\mathrm{hr}-\mathrm{ft}^{2}-{ }^{\circ} \mathrm{F}}\right) \\
\text { (existing data) }\end{array}$ \\
\hline ATJ & 80 & Parallel & 755 & 762 \\
\hline ATJ & 1340 & Parallel & 446 & 418 \\
\hline $\mathrm{ATJ}$ & 80 & Perpendicular & 652 & 624 \\
\hline ATJ & 1340 & Perpendicular & 358 & 336 \\
\hline Carb-I-Tex & 80 & Parallel & 44.1 & -- \\
\hline Carb-I-Tex & 1700 & Parallel & 88 & - \\
\hline Carb-I-Tex & 80 & Perpendicular & 24.6 & -- \\
\hline Carb-I-Tex & 1700 & Perpendicular & 54.8 & $-\infty$ \\
\hline
\end{tabular}

The compression testing of ATJ and Carb-I-Tex graphite specimens at $1000^{\circ}$ and $1600^{\circ} \mathrm{F}$ was completed. Test data are presented in Table II -4 . Figures II-1 through II -3 present the average values and standard deviations up to $3 \sigma$. In Fig. II-1, Curve B includes all of the ATJ data while Curve A excludes the compressive strength of specimen No. 15, which departed substantially from the indicated average.

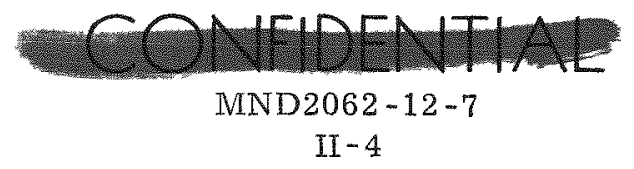



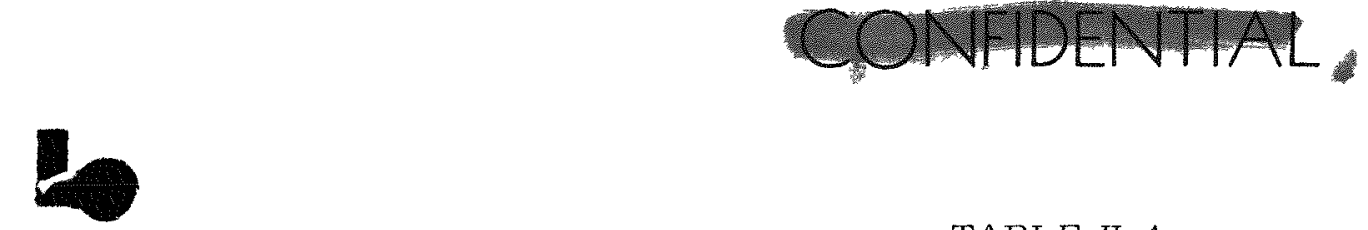

TABLE II -4

Graphite Compression Tests

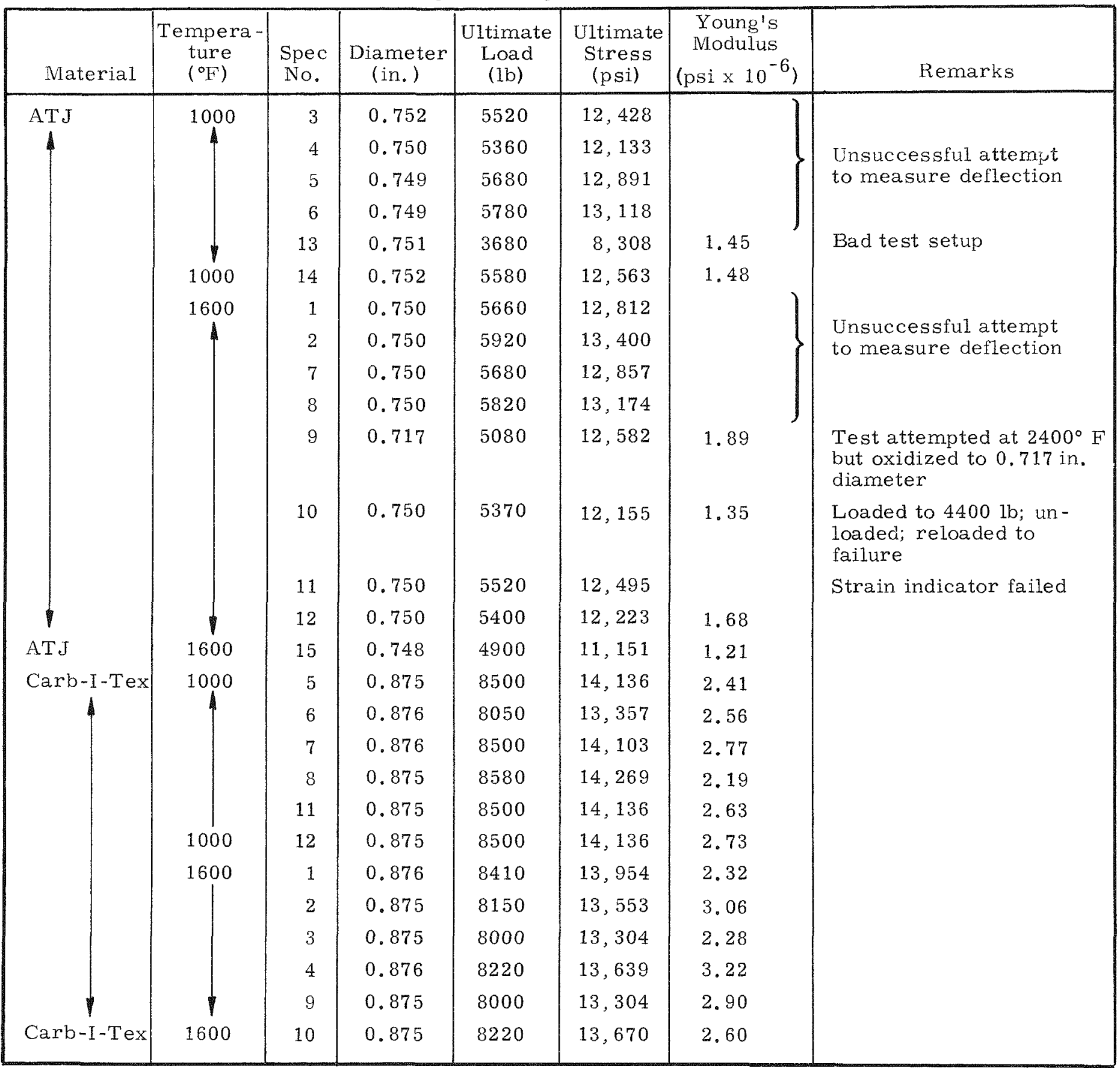

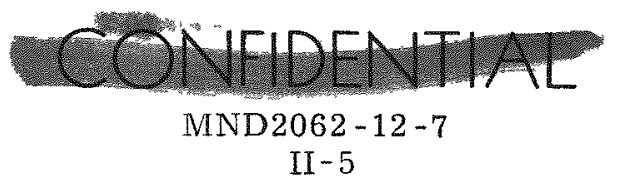




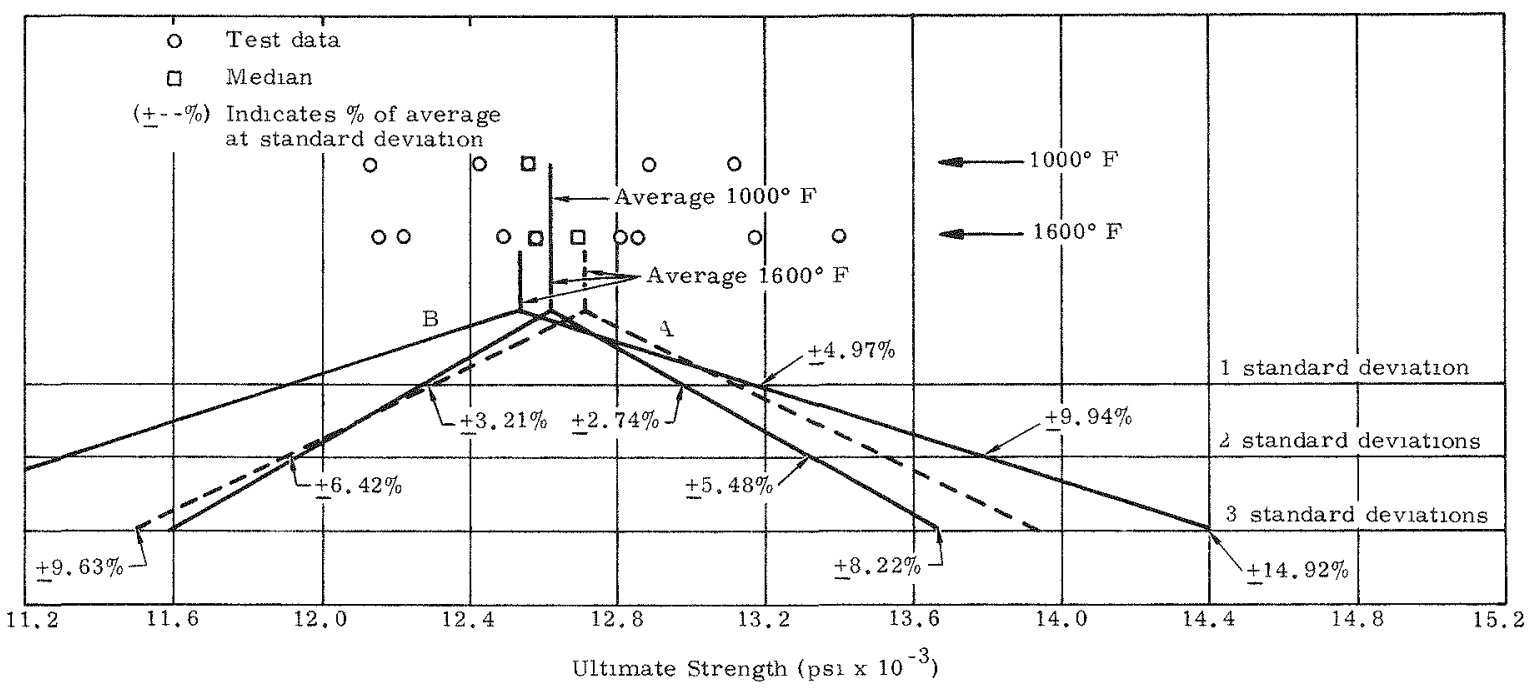

FIG. II-1. ATJ COMPRESSIVE ULTIMATE STRENGTH

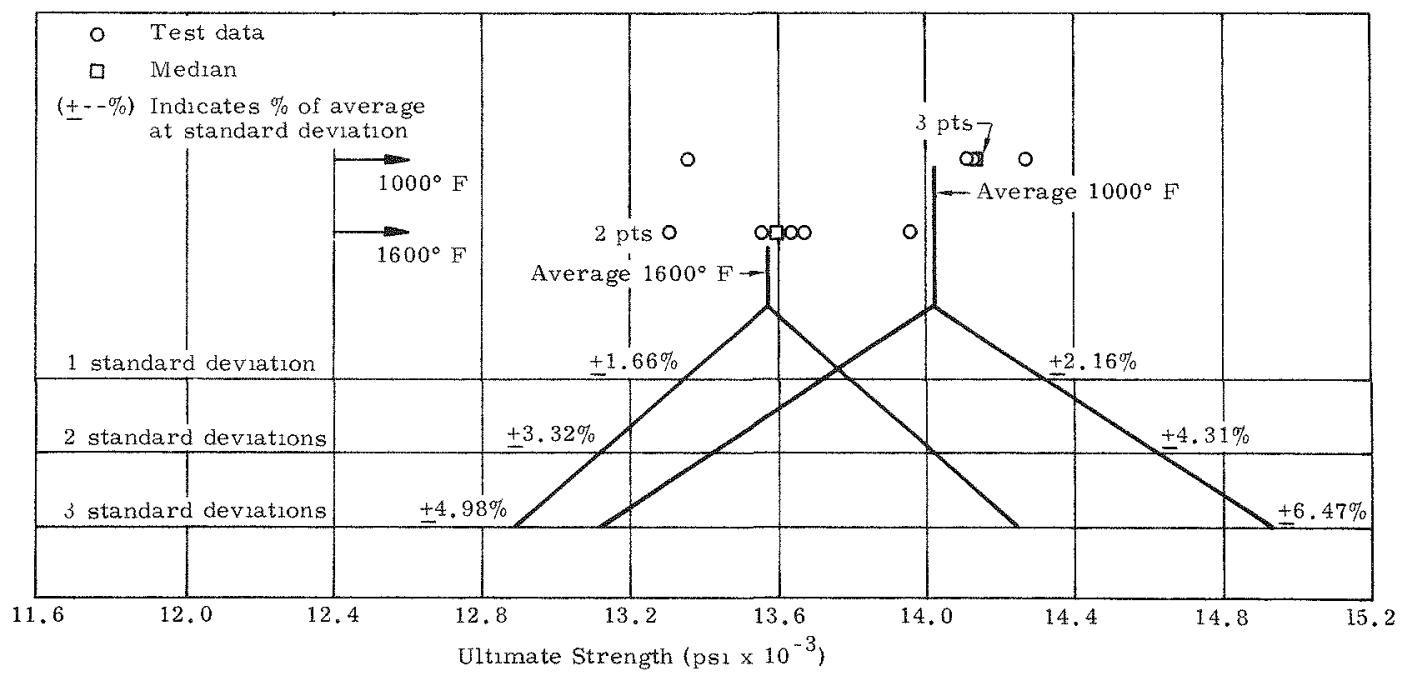

FIG. II-2. CARB-I-TEX 500 (CROSS-PLIED) COMPRESSIVE ULTIMATE STRENGTH

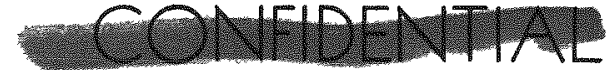

MND2062-12-7

II -6 

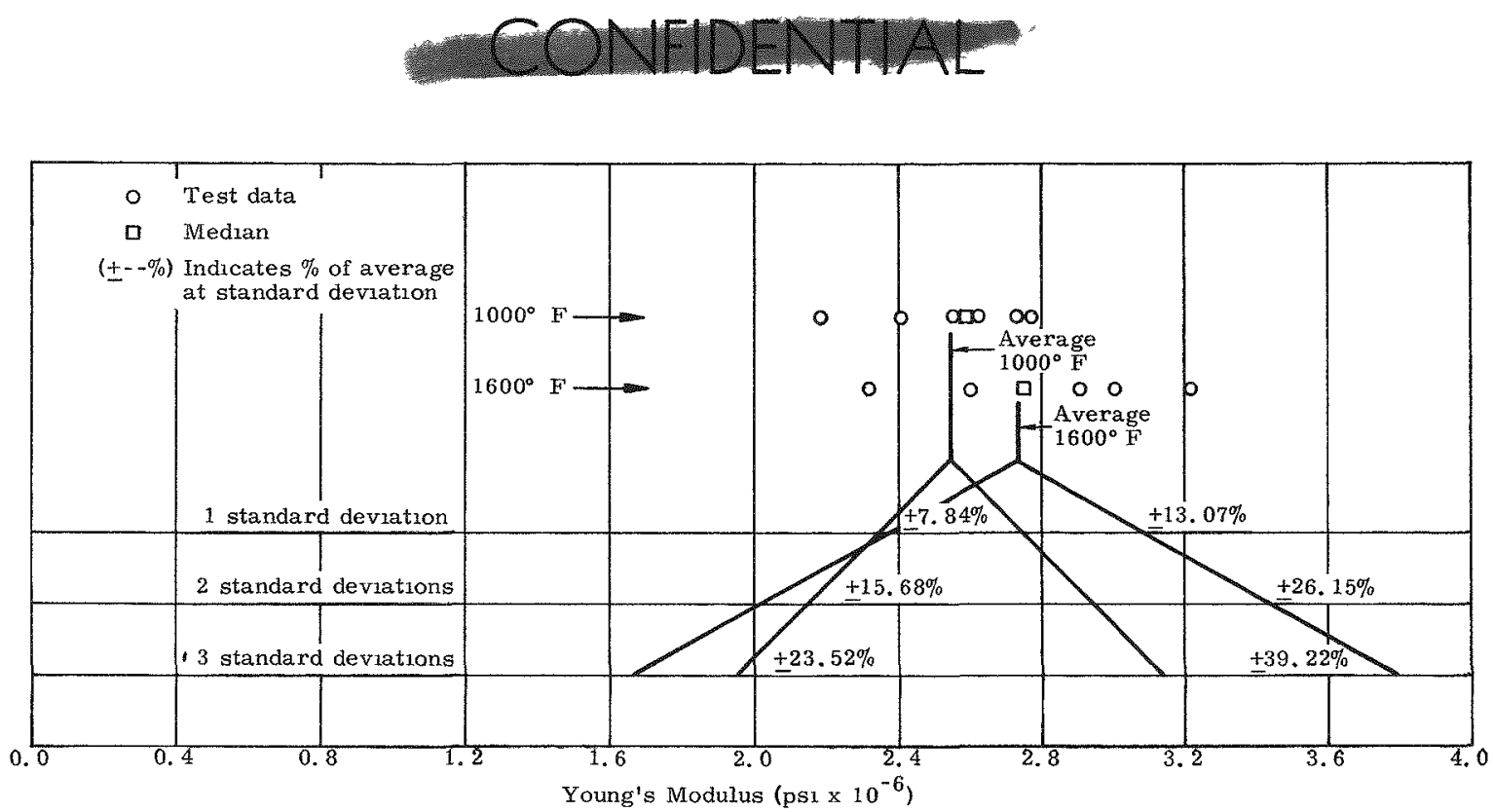

FIG. II-3. CARB-I-TEX 500 (CROSS-PLIED) COMPRESSIVE YOUNG'S MODULUS

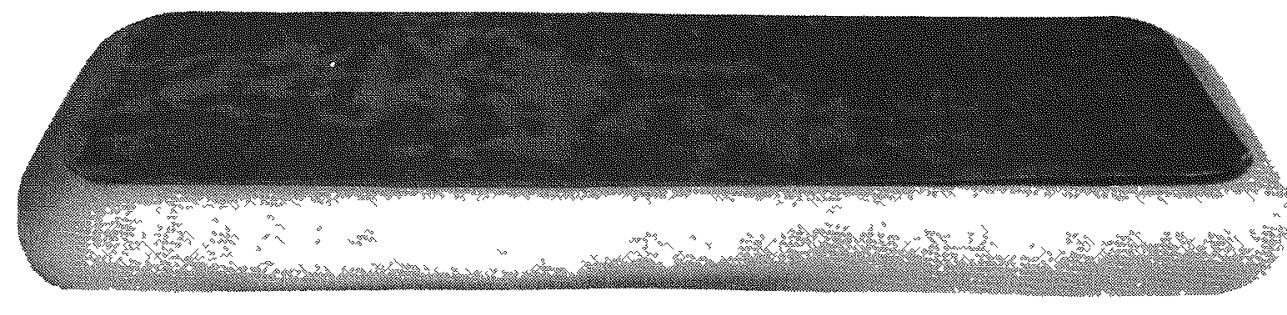

FIG. II-4. NICKEL FOIL CLAD BLOCK CM-60/CM-52 BRAZE
Fuel Block Claddıng Development

1. $0.003 \mathrm{mn}$. Ni powder diffused at $2375^{\circ} \mathrm{F}$

2. Close pores using $\mathrm{CM}-60$ Braze $\left(B N_{1}-5\right)$ at $2150^{\circ} \mathrm{F}$

3. Bond $0.002 \mathrm{in}$. N 1 foul using CMI $-52\left(\mathrm{BN}_{1}-3\right)$ at $1925^{\circ} \mathrm{F}$

Results:
1. Top--started separation

1. Top--started separation at foll edge

Fuel Block Cladding Development

1. $0.003 \mathrm{in.} \mathrm{Ni}$ powder diffused at $2375^{\circ} \mathrm{F}$

2. Close pores using $\mathrm{CM}-60$

Braze $\left(B N_{1}-5\right)$ at $2150^{\circ} \mathrm{F}$

3. Bond 0.002 in. Ni foll using $\mathrm{CM}-53\left(\mathrm{BN}_{1}-2\right)$ at $1950^{\circ} \mathrm{F}$ (one side only)

Results:

1. Top- foll contracted on

cooling and lifted $\sim 3 / 16$

1n, of ATJ graphite with it

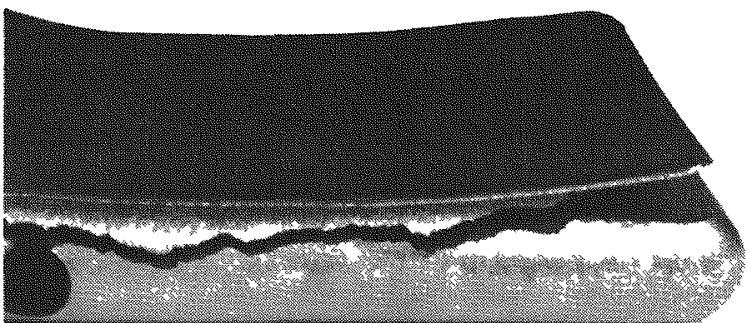

FIG. II-5, NICKEL FOIL CLAD BLOCK CM -60/CM-53 BRAZE

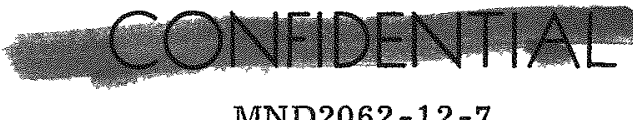

II -7 


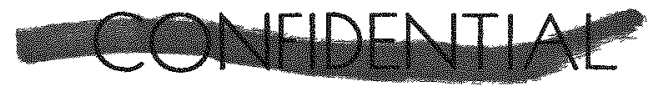

(2) Fuel block oxidation protection system

During this period, development work on a cladding system for graphite oxidation protection continued. Effort was concentrated on extending the prior effort related to applying nickel braze alloys and foils to a nickel substrate which is diffused into the graphite block. Three braze alloys have been investigated:

(1) Coast Metals $50,90.5 \% \mathrm{Ni}$

(2) Coast Metals $53,82 \% \mathrm{Ni}, 7 \% \mathrm{Cr}$

(3) Coast Metals 60, $75 \% \mathrm{Ni}, 14 \% \mathrm{Cr}$

Generally, attempts to clad graphite blocks with various material and thickness combinations of braze and foil have been unsuccessful. Typical failures, which are characterized by cracking and/or separation of the cladding are shown in Figs. II-4, II -5 and II-6. Attempts to add foil to the cladding system generally resulted in a separation propagating inward from the edges during cooldown (Figs. II-4 and II-5). In one case, a successful attachment of foil was accomplished, but a typical separation occurred during cooldown from the first thermal cycle, (room temperature to $1500^{\circ} \mathrm{F}$ during a performance evaluation test. Attempts to employ only a diffused pure nickel powder sublayer and nickel base braze alloy as a final oxidation barrier have met with limited success. A large portion of the specimens clad in this manner exhibited cracking during cooldown from the final braze cycle or early in the test sequence (Fig. II-6). One notable success was attained. The specimen consisted of a 13 -mil nickel powder sublayer diffused and sintered at $2375^{\circ} \mathrm{F}$, followed by a fivemil layer of CM-53 applied at $1950^{\circ} \mathrm{F}$, and a final surface of three mils of CM- 53 at $1950^{\circ} \mathrm{F}$. After 387 hours of thermal cycling, (room temperature to $1500^{\circ} \mathrm{F}, 10$ cycles) there was less than $1 \%$ total weight loss on a specimen $\sim 5$ by 9 by 1 inches. After the fifth cycle ( $>179$ accumulated hours) the coating was observed to separate on one side over a small area. The separation propagated during subsequent cycling until it existed over the entire surface of one side. It is interesting to note, however, that the clad remained airtight throughout the entire duration of the test, which was in excess of the two-week exposure required for the operational application. Figures II- 7 and II-8 show the specimen after completion of the ninth thermal cycle. Figure II-9 shows the sectioned specimen upon completion of the test. Attempts to duplicate this singular success have failed to date. Additional specimens are being fabricated.

Experience gained to date in the oxidation resistant clad development program leads to the following tentative conclusions:

(1) Differential thermal expansion characteristics of the clad and graphite result in failures of either the clad, graphite or interface bond during the return to lower temperatures.

(2) The presence of chromium in the braze alloy reduces the allowable elongation of the braze and/or nickel foil and, hence, hampers the ability of the clad to yield plastically during cooldown.

(3) The need to build up a relatively thick layer of clad in order to minimize the presence of pores or permeability must be traded off against the desirability of a thin clad which would more readily slave to the substrate.

(4) Diffusion of the nickel powder sublayer at $2375^{\circ} \mathrm{F}$ results in the formation of a nickel carbide interface which possesses undesirable mechanical characteristics (brittle).

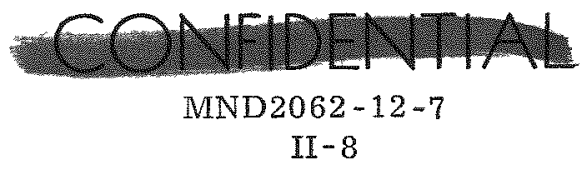




\section{CONELENTIAL}

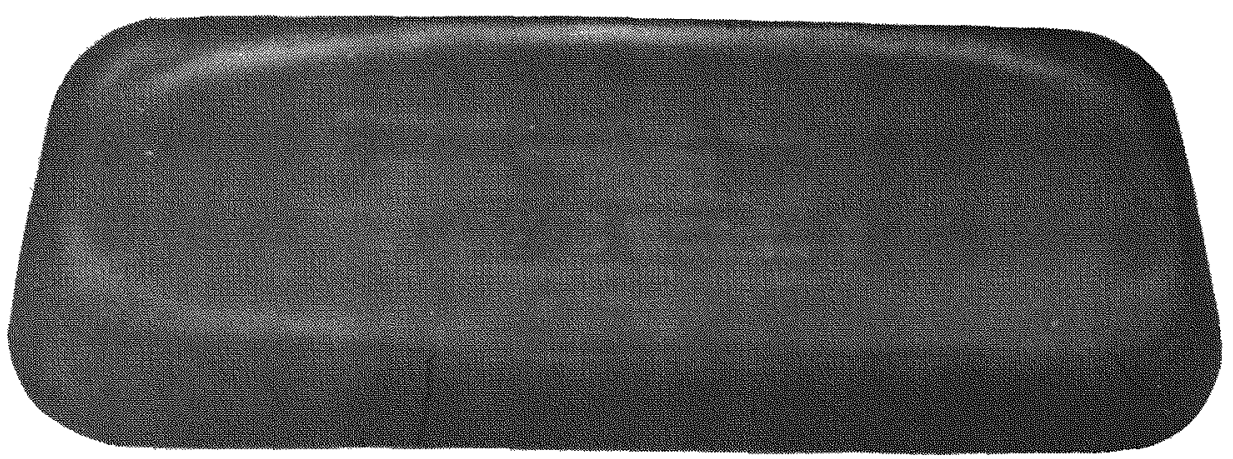

Fue1 Block Cladding Development Specimen 19

1. $0.013 \mathrm{kn}$. Ni powder diffused at $2375^{\circ} \mathrm{F}$

2. $0.005 \mathrm{in}, \mathrm{CM}-53$ at $1950^{\circ} \mathrm{F}$ (braze)

3. 0.003 in. $\mathrm{CM}-53$ at $1950^{\circ} \mathrm{F}$

(braze)

Top--graphzte oxidzzed,

cracks in coating on ends,

sides

Bottom--coating separation

FIG. II -6. CM -53 BRAZE CLAD BLOCK

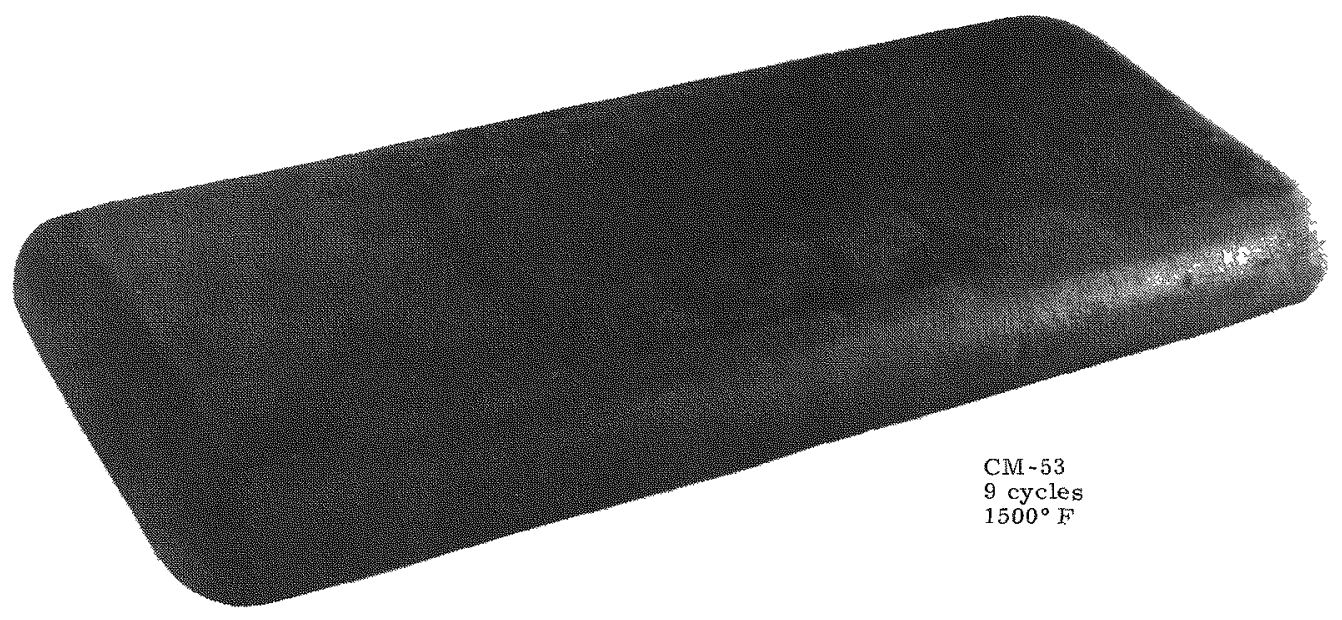

FIG. II-7. CM-53 BRAZE CLAD BLOCK AFTER NINE CYCLES (BOTTOM SURFACE)

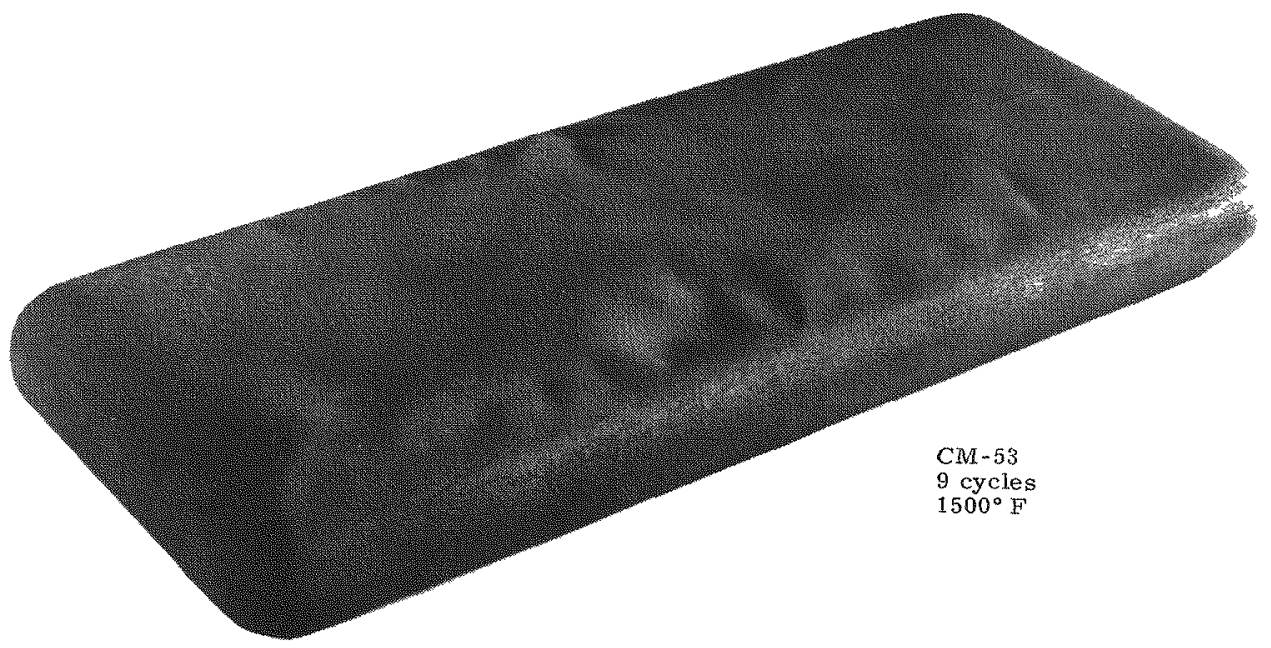

FIG. II -8. CM -53 BRAZE CLAD BLOCK AFTER NINE CYCLES (TOP SURFACE)

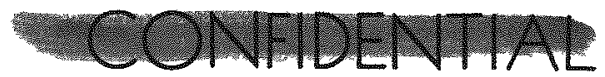

MND2062-12-7

II -9 


\section{CONFDENTAL}

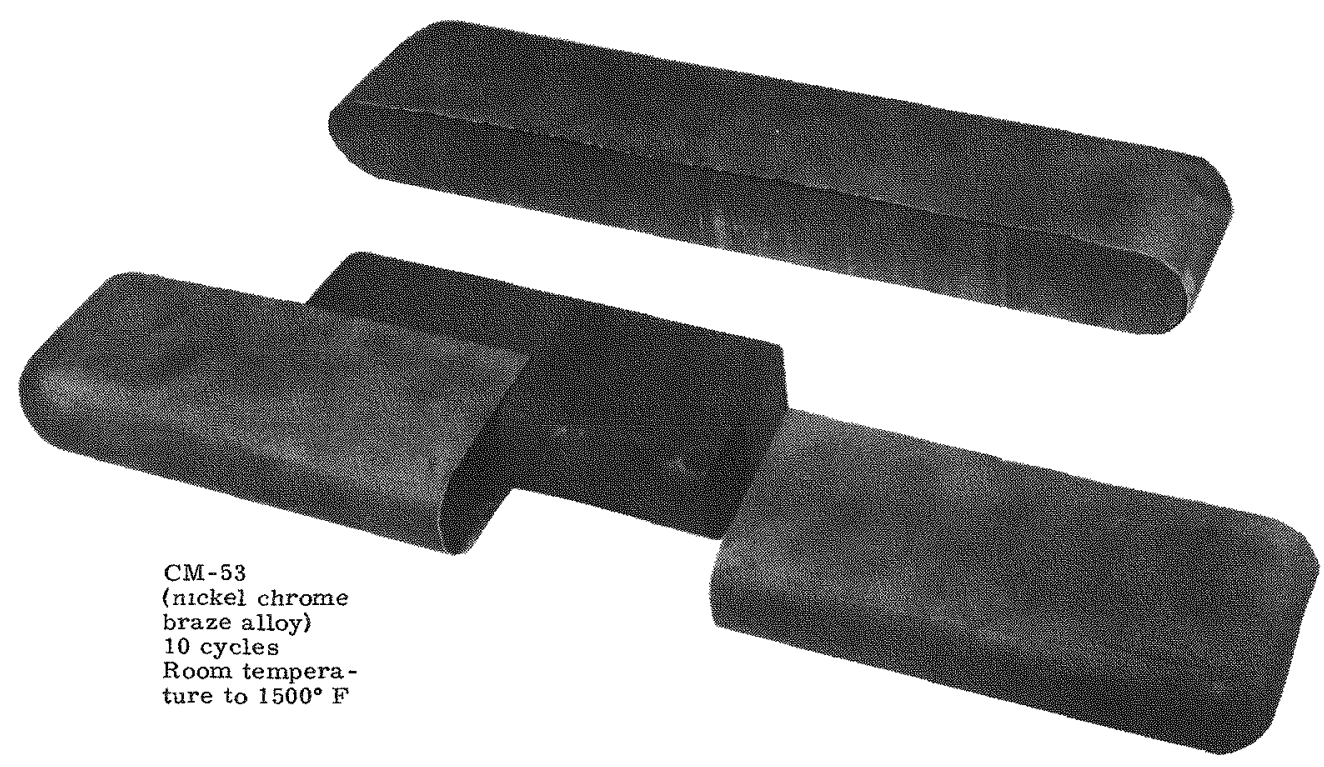

FIG II-9. SECTIONED CM-53 BRAZE CLAD BLOCK AFTER TEST

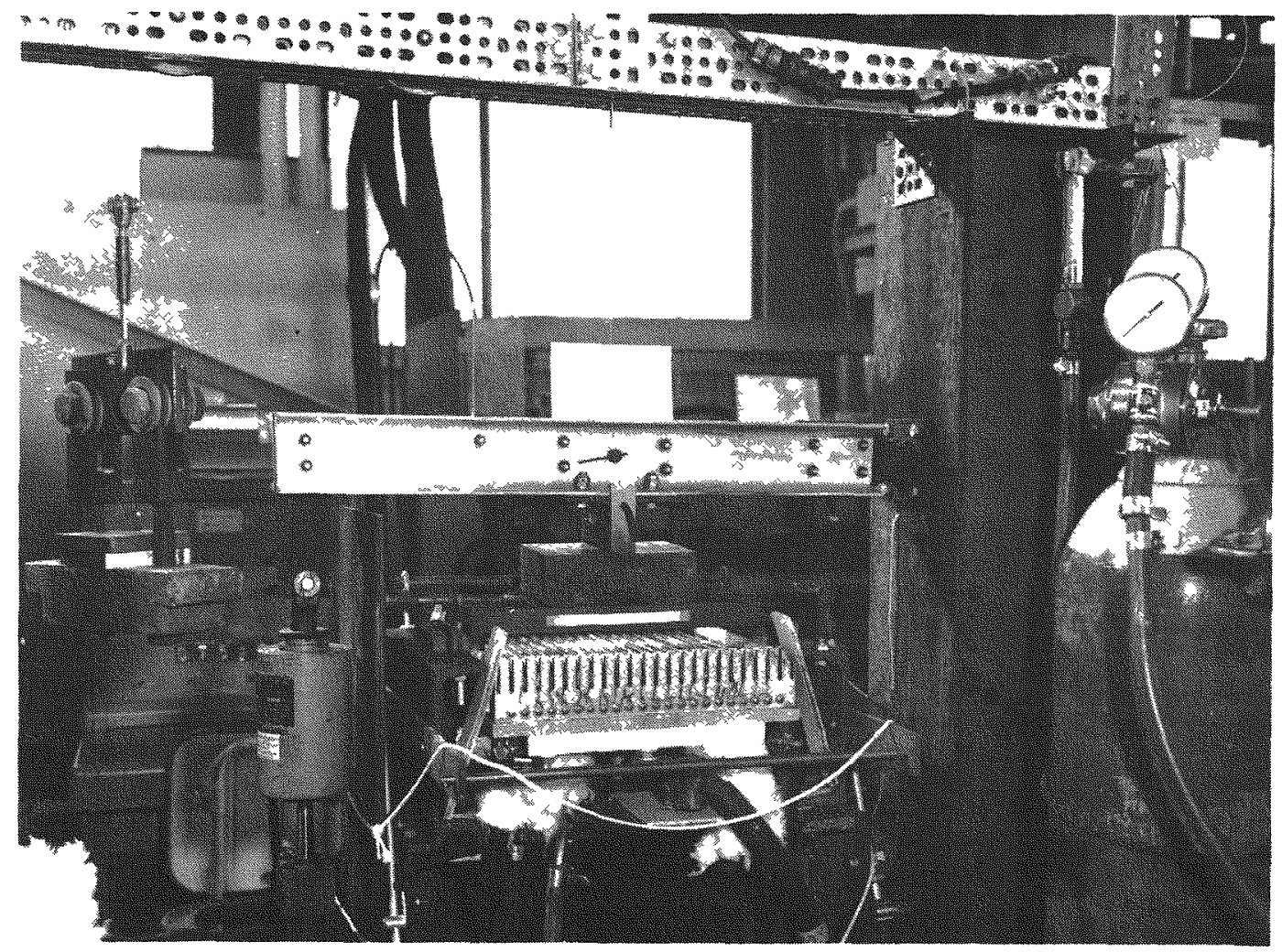

FIG. II-10 ELEMENT FLEXURE TEST FIXTURE

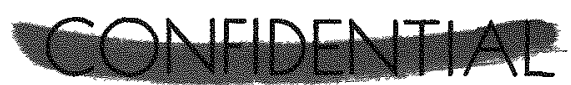

MND2062-12-7 
(5) The ability to repeatedly produce an adequate cladding system is dependent upon identifying the significant process parameters and applying a system of controls to monitor the application technique.

At present, the mechanics of cladding and the effects of possible material variables are not adequately understood. A more intensified effort should be applied in this area.

As part of the continuing effort in cladding development during the next reporting period, effort will be expended in the following areas:

(1) Examine process techniques in an attempt to reproduce the earlier success.

(2) Contact General Technologies Corporation to establish possibility of applying iridium cladding technology to the SNAP 29 program.

(3) Examine alternate approaches to cladding (i.e., canning).

(3) Graphite bonding and joints

The ATJ graphite is not manufactured in billets large enough to make a single piece fuel block. As a result, a joint must be developed. The purpose of the joint tests is to optimize the variables involved, i.e., type of cement, thickness of cement and shape of joint. All tests are flexure tests at high temperature. Phase I of the tests consists of solid ATJ beams which constitute reference for the joined specimens. Phase II optimizes the type of cement $(\mathrm{C}-9$ or $\mathrm{C}-34)$ and the glue line thickness (0.003 or 0.030 in.). Phase III optimizes joint shape. The final phase (Phase IV) consists of a nickel clad specimen with the joint parallel to the span instead of perpendicular to the span as in Phases II and III.

Phase I was completed during this reporting period and Phase II specimens are being manufactured. The results of Phase I testing (Table II -5) show good agreement with published data, although the ultimate strength of one specimen was $26 \%$ lower than the average of the other specimens.

\section{TABLE II-5}

Joint Flexure Test Results, Phase I

\begin{tabular}{|c|c|c|}
\hline $\begin{array}{c}\text { Specimen } \\
\text { No. } \\
\end{array}$ & $\begin{array}{c}\text { Ultimate } \\
\text { Flexural } \\
\text { Stress } \\
\text { (psi) } \\
\end{array}$ & $\begin{array}{c}\text { Young's } \\
\text { Modulus } \\
\text { (flexure) } \\
\left.\text { (psi x } 10^{-6}\right)\end{array}$ \\
\hline 1 & 3657 & 1.43 \\
\hline 2 & 4722 & 1.42 \\
\hline 3 & 5209 & 1.46 \\
\hline Average & 4530 & 1.44 \\
\hline $\begin{array}{l}\text { Published } \\
\text { data }\end{array}$ & 4400 & $\begin{array}{l}1.57 \\
\text { (tensile) }\end{array}$ \\
\hline
\end{tabular}

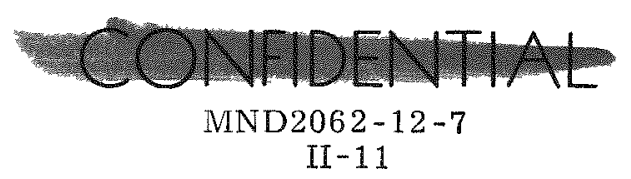


Completion of the joint selection tests will be accomplished in the next reporting period.

(4) Graphite unit cell flexural test

The current fuel block design calls for an oxidation cladding on both surfaces of the block and a quarter-inch gap between fuel capsules at the center of the block. The purpose of the element flexure tests is to determine the effect of the cladding and the discontinuity of the capsules at the center on the flexural strength of ATJ and Carb-I-Tex 500 cross-needled graphites at high temperatures.

The tests consist of three parts for each graphite material:

(1) Unit cell with a hole parallel to the span but including no capsules or cladding

(2) Unit cell with cladding but no capsules

(3) Unit cell with both cladding and capsules.

The first part of the tests has been completed, and the results are shown in Table II-6. The ultimate strength of ATJ requires no comment, but Young's modulus appears low. However, if the standard deviation of $0.166 \times 10^{6}$ published by Union Carbide is used, $1.57 \times 10^{6}$ can be reduced by a $3 \sigma$ variation to $1.07 \times 10^{6}$. The average test value of $1.22 \times 10^{6}$ is about $2 \sigma$ off of $1.57 \times 10^{6}$.

\section{TABLE II -6}

Element Flexure Tests No Capsules and No Cladding

ATJ

\begin{tabular}{|c|c|c|c|c|}
\hline $\begin{array}{c}\text { Specimen } \\
\text { No. } \\
\end{array}$ & $\begin{array}{c}\text { Ultimate } \\
\text { Flexural } \\
\text { Stress } \\
\text { (psi) } \\
\end{array}$ & $\begin{array}{c}\text { Young's } \\
\text { Modulus } \\
\left(p s i \times 10^{-6}\right) \\
\end{array}$ & $\begin{array}{l}\text { Ultimate } \\
\text { Flexural } \\
\text { Stress } \\
\text { (psi) } \\
\end{array}$ & $\begin{array}{l}\text { Young's } \\
\text { Modulus } \\
\left(\text { psi } \times 10^{-6}\right) \\
\end{array}$ \\
\hline 1 & 4850 & 1.16 & 8889 & 2.08 \\
\hline 2 & 4028 & 1.28 & 8836 & 2.31 \\
\hline Average & 4439 & 1.22 & 8862 & 2.20 \\
\hline $\begin{array}{l}\text { Published } \\
\text { data }\end{array}$ & 4400 & $\begin{array}{l}1.57 \\
\text { (tensile) }\end{array}$ & $\ldots$ & -- \\
\hline
\end{tabular}

The Carb-I-Tex 500 cross-needled flexure specimens tested exhibited a marked improvement in failure mode. Prior testing of two-dimensionally laminated Carb-I-Tex resulted in interlaminar shear failures which prevented the material from developing its full flexural strength capability. The average failing stress of the two cross-needled specimens was 8862 psi flexure. This compares with an equivalent flexure stress allowable (specimen failed in interlaminar shear) of 8929 psi for the two-dimensional laminate. Based on the limited data acquired to date, it appears that cross-needling the Carb-I-Tex, while increasing the interlaminar shear shear strength, somewhat reduces the in-plane strength of the laminate to the extent that in the specimens tested the cross needling results in no net improvement in

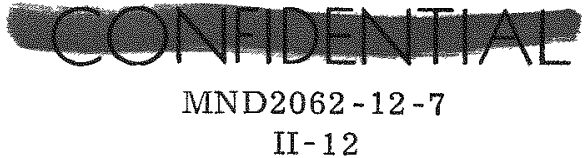


flexural strength. It is to be noted, however, that prior testing of two-dimensional laminate Carb-I-Tex in flexure across the full block and lightening holes resulted in substantially lower apparent flexure strengths (again, failure was in interlaminar shear) in the order of 2000 to $5000 \mathrm{psi}$. In this mode of loading the interlaminar shears tend to peak at the edges of the holes and the presence of cross-needling should substantially improve the performance.

Further testing of the element flexure specimens has been delayed pending selection of a fuel block cladding system. Photographs of element flexure testing are shown in Figs. II -10 , II-11 and II-12.

b. Fuel capsule

\section{(1) Weld development}

Thermal analysis of weld conditions. The outer liner end cap can be welded to the outer liner by either of two weld techniques, namely, TIG (tungsten inert gas) and EB (electron beam). The EB weld requires high vacuum conditions surrounding the fabrication setup. The TIG weld is performed in an inert gas atmosphere (helium). Either weld is performed while the liners and fuel matrix are in a chill block which has a maximum temperature of $212^{\circ} \mathrm{F}$. The accepted capsule design characteristics are as follows:

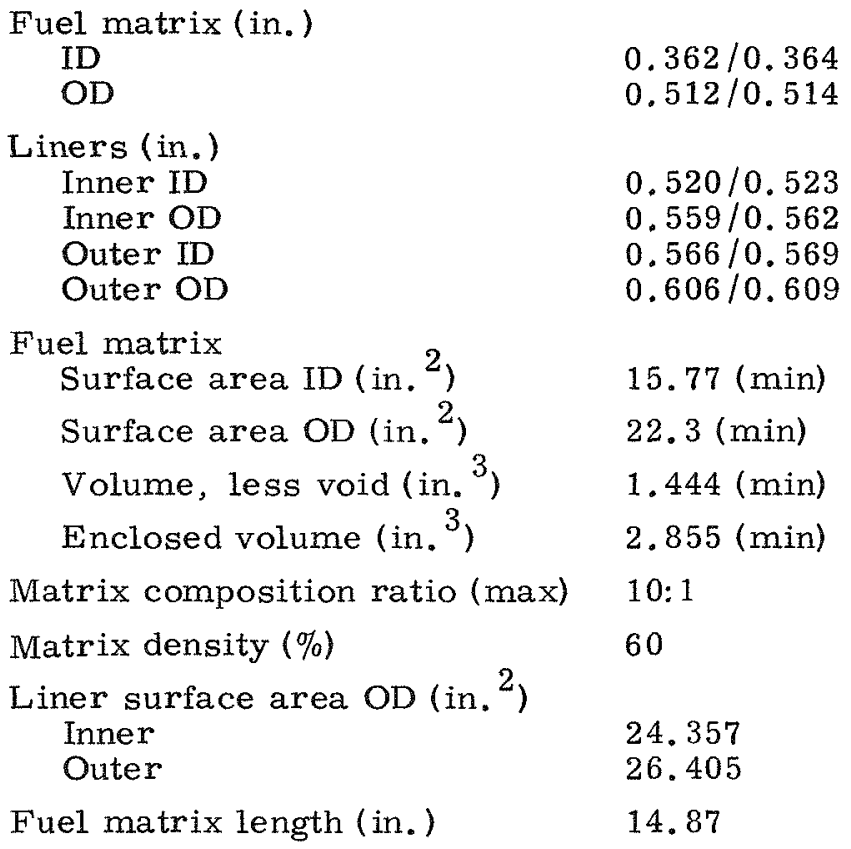

The highest value for capsule $\mathrm{Q}$ is approximately 1425 watts (at time of fuel loading), for the piston thermoelectric modules (the diaphragm $T / E$ modules are expected to require a capsule $Q$ on the order of 1350 watts). Capsule heat flux and power density based on the worst case (1425 watts/capsule) is 59.5 watts $/$ in. $^{2}$ and 60 watts/cc. The heat flux is based on the surface area of the inner liner and the power density is based on the volume of the fuel matrix less internal void. The corresponding heat flux at the OD of the outer liner is 54 watts/in. ${ }^{2}$.

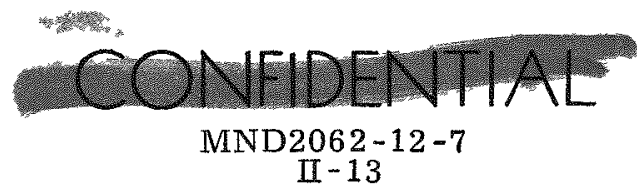




\section{CONFIDENTIAL}

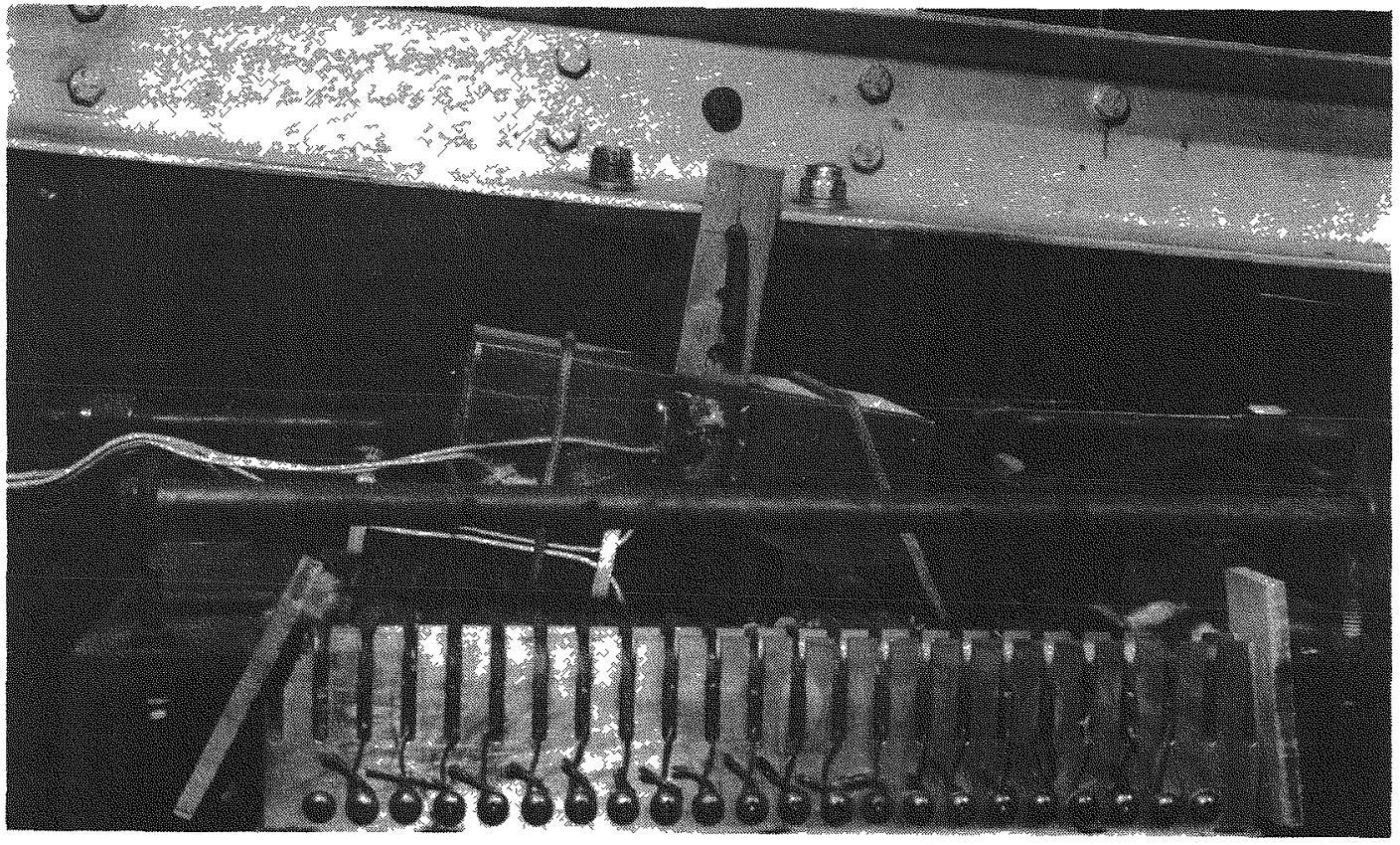

FIG. II-11. TYPICAL ELEMENT FLEXURE TEST SPECIMEN (ATJ)

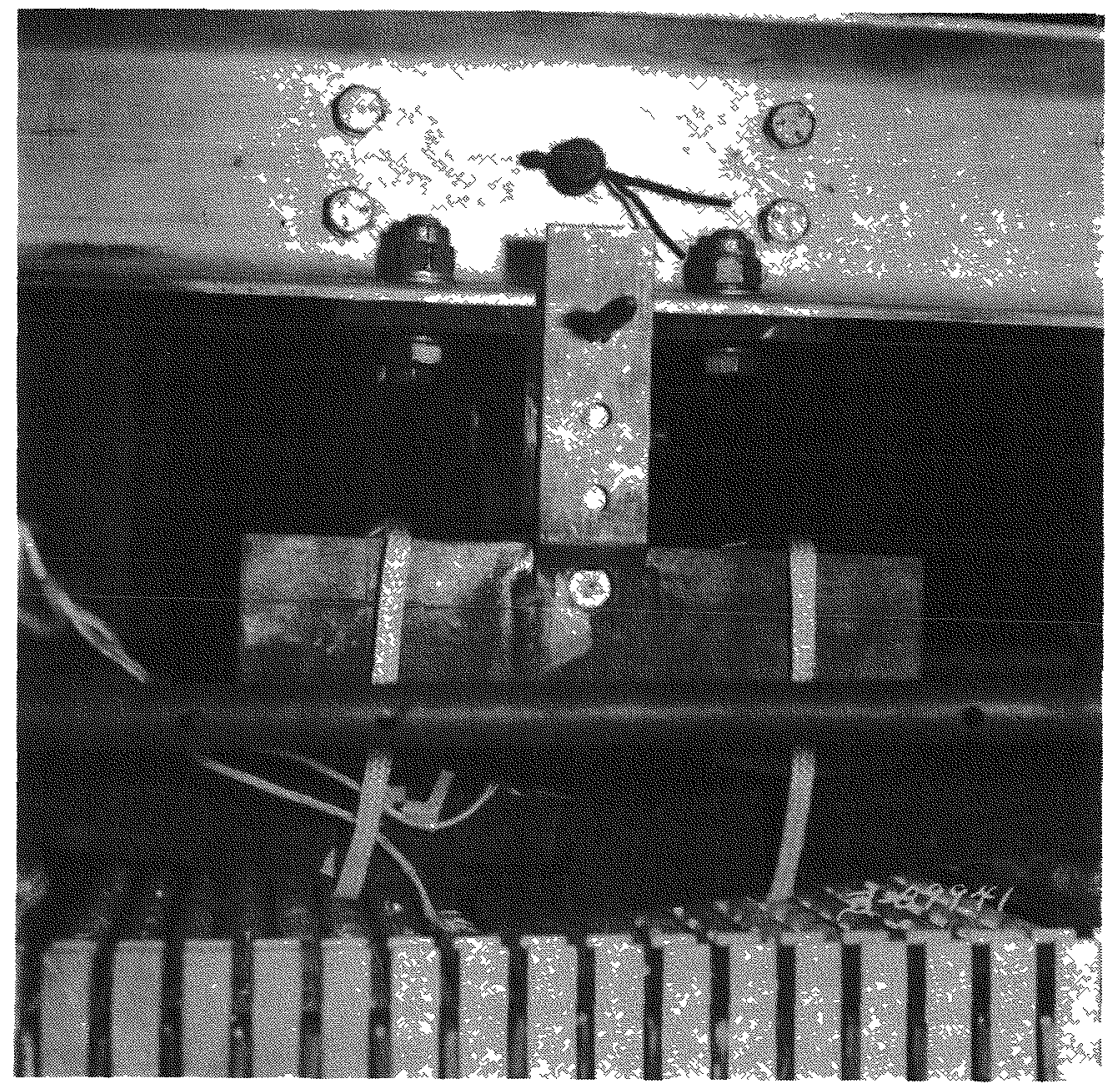

FIG. II-12. TYPICAL ELEMENT FLEXURE TEST SPECIMEN (CARB-I-TEX)

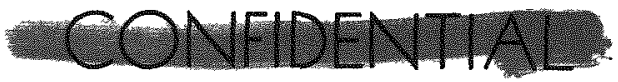

MND2062-12-7

II -14 
The initial condition analyzed was that of the EB weld in a vacuum environment where the gaps between the liners are also evacuated. The inner and outer liner temperatures for this condition were computed using the subsequent equations. These temperatures are given in Table II -7 .

TABLE II - 7

Inner and Outer Liner Temperatures

\begin{tabular}{|c|c|c|c|c|c|c|}
\hline \multirow[b]{2}{*}{$\begin{array}{l}\text { Type } \\
\text { Weld } \\
\end{array}$} & \multicolumn{6}{|c|}{$\begin{array}{c}\text { Liner } \\
\text { Temperature } \\
\left({ }^{\circ} \mathrm{F}\right)\end{array}$} \\
\hline & $\begin{array}{l}\text { Inner } \\
\text { to Outer } \\
\text { Liner** } \\
\end{array}$ & $\begin{array}{c}\text { Outer Liner } \\
\text { to Chill } \\
\text { Block** } \\
\end{array}$ & $\begin{array}{c}\text { Inner } \\
\left(\mathrm{T}_{\ell}\right) \\
\end{array}$ & $\begin{array}{c}\text { Outer } \\
\left(\mathrm{T}_{2}\right) \\
\end{array}$ & $\mathrm{T}_{\ell}-\mathrm{T}_{\ell_{2}}$ & $\mathrm{~T}_{\ell_{2}}-\mathrm{T}^{\mathrm{k}} \mathrm{C}$ \\
\hline $\mathrm{EB}$ & $\begin{array}{l}\text { Vacuum } \\
\frac{\epsilon}{=}=0.10\end{array}$ & $\begin{array}{l}\text { Vacuum } \\
\epsilon=0.19\end{array}$ & 3530 & 2550 & 980 & 2340 \\
\hline $\mathrm{EB}$ & $\begin{array}{l}\text { Vacuum } \\
\epsilon=0.10\end{array}$ & Helium & 3160 & 258 & 2900 & 46 \\
\hline $\mathrm{EB}$ & $\begin{array}{l}\text { Vacuum } \\
\epsilon=0.20\end{array}$ & Helium & 2590 光米米 & 258 & 2330 & 46 \\
\hline $\mathrm{TIG}$ & Helium & Helium & 304 & 258 & 46 & 46 \\
\hline $\begin{array}{l}{ }^{*} \mathrm{~T} \\
* * \mathrm{G}\end{array}$ & $\begin{array}{l}\text { chill bl } \\
\text { are five }\end{array}$ & $\begin{array}{l}\text { temperatur } \\
\text { ils constant }\end{array}$ & $\begin{array}{l}=212^{\circ} \mathrm{F} \\
\text { ong lengt }\end{array}$ & of can & & \\
\hline
\end{tabular}

The second EB weld condition analyzed assumed that the gap between the outer liner and the chill block is sealed and contains helium. Calculations were made for two values of effective emissivity for the liner materials, namely, 0.10 and 0.20 . Data from Mound $R \& D$ reports indicate that an average value for total emissivity of the inner liner material is 0.20 , which yields the low value for effective emissivity $(\bar{\epsilon})$. It is anticipated that the effective thermal conductivity test currently in progress will indicate the proper value to be expected for SNAP 29 design conditions.

The final evaluation was based on TIG weld conditions; i.e., both gaps are filled with helium. The liner temperatures are shown in Table II -7 .

On the basis of these results, it can be concluded that an EB weld is impractical under pure vacuum conditions because the fuel matrix melt point will be exceeded. The same would be true when the outer gap is sealed if the effective emissivity is on the order of 0.10. The temperature conditions are marginally satisfactory if the effective emissivity turns out to be on the order of 0.20 . However, the elongation of the outer liner during the weld procedure is expected to be at least $140 \mathrm{mils}$ at this temperature, which is 10 times the increase in length resulting from the weld buildup during TIG welding.

On the other hand, TIG welding generates no critical temperature conditions and results in minimum liner elongation.

From a thermal standpoint, the TIG weld is more desirable. However, Mound Laboratory personnel claim that tests have shown that double-walled test specimens

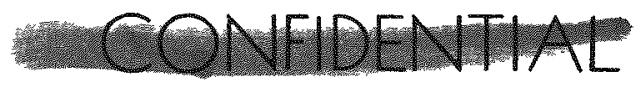

MND2062-12-7

II -15 
have had measured temperatures on the order of half the theoretically predicted values. This would indicate either higher effective emissivities than predicted or effective thermal contact between the surfaces over some percentage of the total wall surface area. If this is true, then the liner temperatures during the EB weld may not be a factor in the selection of the weld technique. Results of the effective thermal conductivity test, when available, will be applied to this problem.

Analysis of thermal conditions. The end cap to the outer liner can be welded to the outer liner by either TIG or EB welding. The thermal conditions existing in the fuel matrix, inner liner and outer liner are drastically different in each case because of the weld environmental requirements. The TIG welding is performed in an inert gas (helium) and EB welding must be done under high vacuum. The thermal conditions have been analyzed for both welding methods.

A schematic diagram of the capsule fabrication setup during weld of the outer liner end cap is shown.

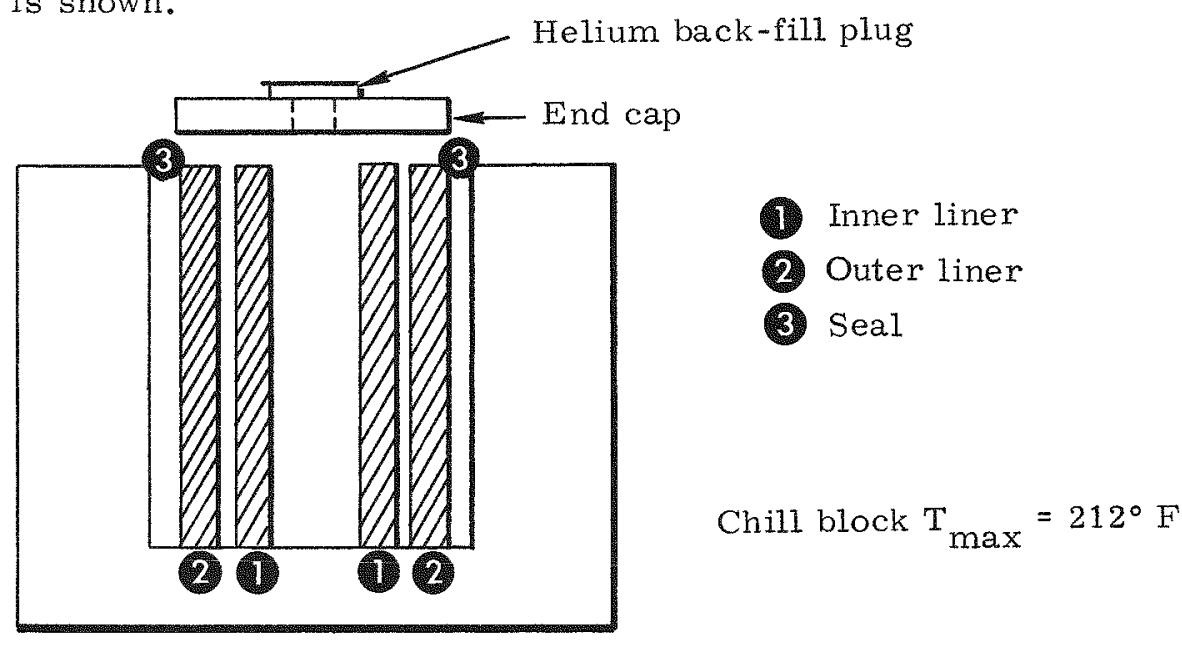

When the gap between the outer liner and the chill block is open to the vacuum environment surrounding the chill block, the temperature of the inner liner $\left(T_{1}\right)$ and outer liner $\left(\mathrm{T}_{\ell_{2}}\right)$ are

$$
Q /\left(A_{0}\right)=\sigma \bar{\epsilon}_{1}\left(T_{\ell}{ }^{4}-T_{\ell}{ }^{4}\right)
$$

and

$$
\mathrm{Q} /\left(\mathrm{A}_{1}\right)=\sigma \bar{\epsilon}_{2}\left(\mathrm{~T}_{\ell}{ }^{4}-\mathrm{T}_{\mathrm{C}}^{4}\right)
$$

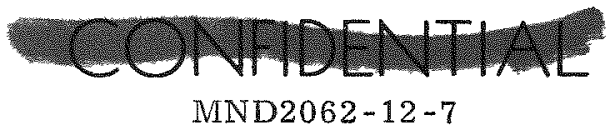


where

$\mathrm{T}_{\mathrm{C}}=$ chill block temperature $=212^{\circ} \mathrm{F}$ maximum

$\mathrm{Q} / \mathrm{A}_{0}=59.5 \mathrm{watts} / \mathrm{in} .^{2}$

$\mathrm{Q} / \mathrm{A}_{1}=54.0$ watts/in. ${ }^{2}$

$A_{0}=$ surface area of inner liner $=24.36 \mathrm{in} .{ }^{2}$

$\mathrm{A}_{1}=$ surface area of outer liner $=26.41 \mathrm{in} .^{2}$

$\bar{\epsilon}_{1}=0.11$ (based on an inner liner total emissivity of 0.20 as given in Mound $\mathrm{R}$ and $\mathrm{D}$ reports)

$\bar{\epsilon}_{2} \quad=0.19$ (based on the chill block surface emissivity of 0.80 and an outer liner emissivity of 0.20 )

thus,

$$
\mathrm{T}_{\ell_{2}}=\left[\frac{\mathrm{Q} / \mathrm{A}_{1}}{\sigma \bar{\epsilon}_{2}}+\mathrm{T}_{\mathrm{C}}^{4}\right]^{1 / 4}
$$

and

$$
\mathrm{T}_{\ell_{1}}=\left[\frac{\mathrm{Q} / \mathrm{A}_{0}}{\sigma \bar{\epsilon}_{2}}+\left\{\frac{\mathrm{Q} / \mathrm{A}_{1}}{\sigma \bar{\epsilon}_{2}}+\mathrm{T}_{\mathrm{C}}^{4}\right\}\right]^{1 / 4}
$$

When the gap between the outer liner and the chill block is sealed to retain helium, the temperatures of the inner and outer liners are

$$
\begin{aligned}
& \mathrm{Q} / \mathrm{A}_{0}=\sigma \bar{\epsilon}_{1}\left(\mathrm{~T}_{\ell_{1}}{ }^{4}-\mathrm{T}_{\ell}{ }_{2}^{4}\right) \\
& \mathrm{Q} / \mathrm{A}_{1}=\sigma \bar{\epsilon}_{2}\left(\mathrm{~T}_{\ell_{2}}{ }^{4}-\mathrm{T}_{\mathrm{C}}{ }^{4}\right)+\frac{\mathrm{k}}{\mathrm{X}_{\mathrm{L}}}\left(\mathrm{T}_{\ell_{2}}-\mathrm{T}_{\mathrm{C}}\right)
\end{aligned}
$$

where

$$
\begin{aligned}
& \mathrm{k}=\text { thermal conductivity of helium }=0.24 \mathrm{Btu} / \mathrm{ft}-{ }^{\circ} \mathrm{R}-\mathrm{hr} \\
& \mathrm{X}_{\mathrm{L}}=\text { gap width }=0.005 \text { inch }=0.000416 \text { foot }
\end{aligned}
$$

Since the temperature drop over the helium gap is relatively small, the radiation heat transfer is insignificant and

$$
\mathrm{Q} / \mathrm{A}_{1}=\frac{\mathrm{k}}{\mathrm{X}_{\mathrm{L}}}\left(\mathrm{T}_{\ell_{2}}-\mathrm{T}_{\mathrm{C}}\right)
$$

Since the TIG weld can be done in the helium environment, both gaps are filled with helium and the inner and outer liner temperatures are

$$
\mathrm{Q} / \mathrm{A}_{0}=\frac{\mathrm{k}}{\mathrm{X}_{\mathrm{L}}}\left(\mathrm{T}_{\ell_{1}}-\mathrm{T}_{\ell_{2}}\right) \text { and } \mathrm{Q} / \mathrm{A}_{1}=\frac{\mathrm{k}}{\mathrm{X}_{\mathrm{L}}}\left(\mathrm{T}_{\ell_{2}}-\mathrm{T}_{\mathrm{C}}\right)
$$

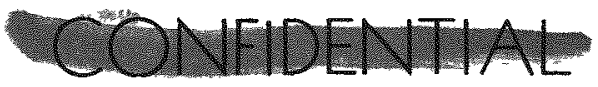


(2) Effective thermal conductivity, total composite capsule

To support and verify the analyses to define steady-state temperatures at the inner liner, liner and capsule cladding interfaces, a series of experimental tests have been initiated to establish the temperature gradients through a typical capsule composite at various internal heater power levels. The test assemblies for this series of tests have been fabricated and testing has been initiated during this reporting period. A schematic of the test setup was presented in the Fourth Quarterly Report (MND2062-09-7), page II-14.

In this test, a simulated fuel capsule is brought up to temperature in each of three environments: vacuum, argon and helium. The size of the test specimen used to establish the thermal conductivity of the inner liner, liner and capsule clad materials limits the size of the electric heater that must be inserted in the core of the specimen. Available heaters were limited to power levels of 1000 watts; therefore, it became necessary to establish the temperature conditions that could be achieved in the heater and test specimen for the three environmental conditions for the test.

An analytical evaluation of the power requirements for the electric heater used in the testing indicated that with proper insulation of the bell jar containing the test sample, all required temperature conditions could be met. It was determined that for the worst case (helium atmosphere in the test apparatus) two double-walled heat shields around the test specimen were required to achieve a temperature on the order of $2000^{\circ} \mathrm{F}$ on the inner liner. This study also showed that a power level on the order of 200 watts would be required for the vacuum portion of the test. The primary results of the study are given in Table II -8.

\section{TABLE II-8}

Calculated Effective Thermal Conductivity Test Temperatures

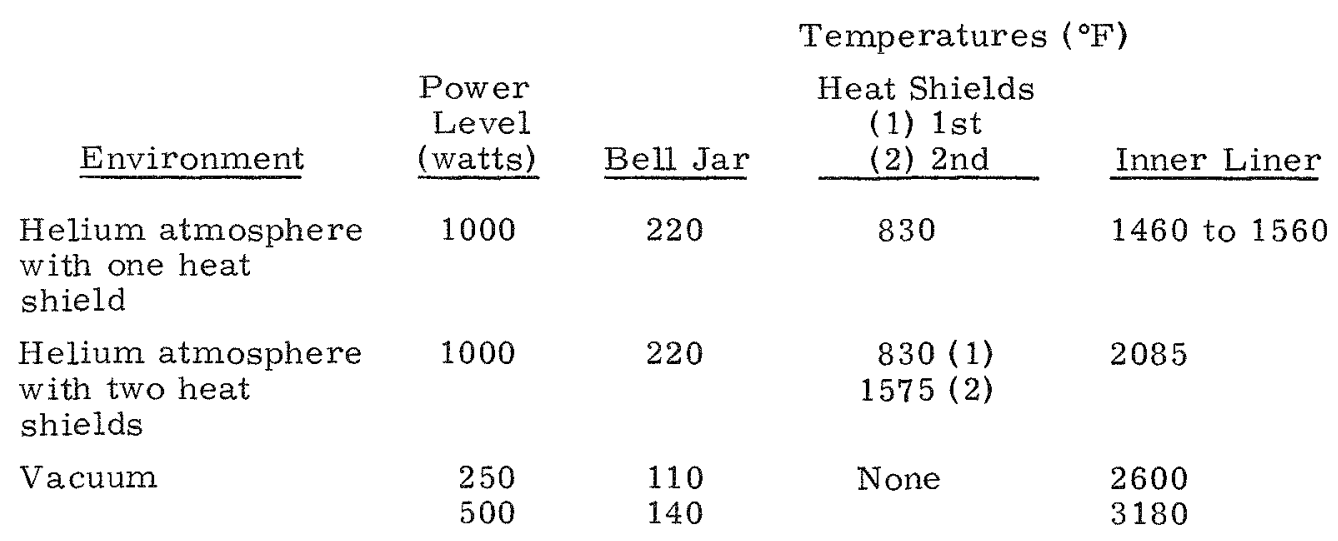

Heater temperatures, although exceeding the long duration temperature limits guaranteed by the manufacturer, are believed to be within acceptable limits for the short durations anticipated for the subject tests.

The results of the testing and a comparison between the predicted analytical results and the testing results will be reported during the next period.

(3) Liner/inner liner creep compatibility evaluation test

The objective of this series of tests is to evaluate the effect of tungsten migration on the mechanical properties of the liner material at the inner liner/liner interface.

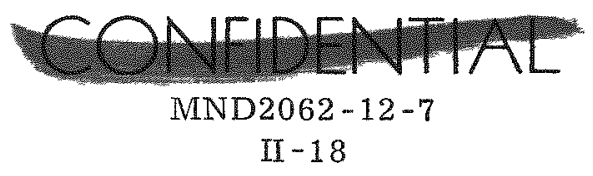


These tests assume that creep occurs at the temperatures and pressures experienced by the inner liner in contact with the liner material. This worst case condition is simulated by placing the materials in contact at time zero. A number of couples have been placed in the test couple assembly located in a glove box maintained with an inert atmosphere. During the first 20 test days, the couples are kept at $1370^{\circ} \mathrm{F}$ while the applied pressure is raised to $155 \mathrm{psi}$. Over the next 114 days, the temperature is to be kept at $2030^{\circ} \mathrm{F}$ while the pressure is increased to $1060 \mathrm{psi}$. The remaining 6 and 14 days will show a change in both temperature and pressure to $1340^{\circ}$ and $1230^{\circ} \mathrm{F}$ at 790 and $810 \mathrm{psi}$, respectively. These 154 days of environmental cycling simulate nominal mission conditions.

The first 20 days of testing have been completed. An analysis of the amount of the tungsten in each coupon was performed following 10 and 20 days of cycling. Approximately $0.12 \mathrm{wt} \%$ of tungsten was found in the tantalum after 10 days and after 20 days this value increased to 0.19 . The eight $\mathrm{Ta}-10 \% \mathrm{~W}$ coupons placed on each side of the tantalum liners were found to contain an average of $10.71 \%$ tungsten. No significant difference was found in the average tungsten concentrations after 10 and 20 days of environmental cycling although the percent of migrated tungsten had increased slightly after 20 days. Unfortunately, the slight oxidation of the test coupons prevented any mechanical property data from being taken. Effort is presently underway to prevent further oxidation of the test coupons during the remaining 134 days of environmental treatment.

\section{(4) Capsule cladding environmental compatibility test}

The purpose of this series of tests is to establish that the materials which comprise the fuel block, coatings, capsule cladding, and liner are compatible with each other under prelaunch and mission temperatures, times and atmospheres. A series of couples has been placed in the environmental conditions outlined in Table II-9. The first 44 days of cycling have been completed and post-test analyses on each coupon initiated. Visual examination indicates that there has been no incompatibility between any of the materials tested. Metallographic, X-ray diffraction and emission spectrographic analyses are presently in progress. The remaining series of test couples are now undergoing the final $90-$ day treatment in vacuum at $1850^{\circ} \mathrm{F}$.

\section{TABLE II -9}

Mission Life Environmental Conditions

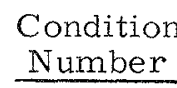

2

3

4

5

$\begin{array}{clll}\begin{array}{c}\text { Temperature } \\ \left({ }^{\circ} \mathrm{F}\right)\end{array} & \begin{array}{c}\text { Time } \\ \text { (days) }\end{array} & & \text { Status } \\ 300 & 20 & \text { Complete } \\ 1230 & 10 & \text { Complete } \\ 1500 & 14 & \text { Complete } \\ 1830 & 90 & \\ 2500 & & 2 \mathrm{~min} & \\ 1500 & 40 \mathrm{~min} & \end{array}$

(5) Capsule liner burst tests

The fuel capsule liner burst tests were performed in accordance with "SNAP 29 Fuel Capsule Weld Development Program," MN-1140-1, Revision B and completed during this period. A summary of the burst test pressures experienced during the room temperature tests is given in Table II-10. Figures II-13 and II-14 show typical failed test specimens. Following the liner burst tests, a number of the test specimens were sectioned to obtain oxygen and nitrogen contents in the weld area and

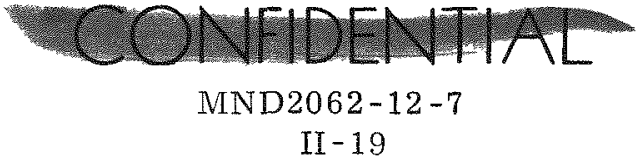


TABLE II-10

Burst Test Summary

End Cap

Configuration*

Assembly No.

$-001 / 009$

Type

Mound Laboratory

Martin Marietta

Specimen Burst Pressure

Specimen Burst Pressure

$1 \mathrm{ML}$

(psi)

No. (psi)

$1 \mathrm{ML}-3$

6600

$1 \mathrm{MM}-5$

6200

$1 \mathrm{ML}-4$

7000

1 MM-7

7000

1 MIM-9

6000

$-003 / 019 \quad$ TIG

$3 \mathrm{ML}-2$

$9600+$

$3 \mathrm{MM}-7$

5400

$3 \mathrm{ML}-3$

$9600+$

$3 \mathrm{MM}-8$

5600

3 ML-4

$9600+$

3 MM -9

7800

$-005 / 029$

TIG

5 ML-2

8000

5 MIM-2

5000

5 ML-3

$9600+$

$5 \mathrm{MIN}-3$

7400

$5 \mathrm{ML}-4$

8000

5 MM -5

7000

$-007 / 039$

EB

7 ML-2

8900

$7 \mathrm{MM}-8$

2600

$7 \mathrm{ML}-3$

6700

7 MM -10

5000

$7 \mathrm{ML}-4$

8600

$-011 / 049$

EB

$11 \mathrm{ML}-2$

9000

11 MM -2

5600

$11 \mathrm{ML}-3$

$9600+$

$11 M M-3$

9600

$11 \mathrm{ML}-4$

5600

$11 \mathrm{MI}-4$

4400

*Drawing 466A1141016

Note: $9600+$ is in excess of test equipment burst capability.

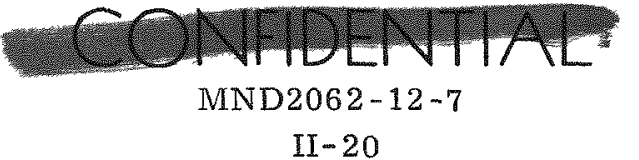




\section{CONFIDENIAL}

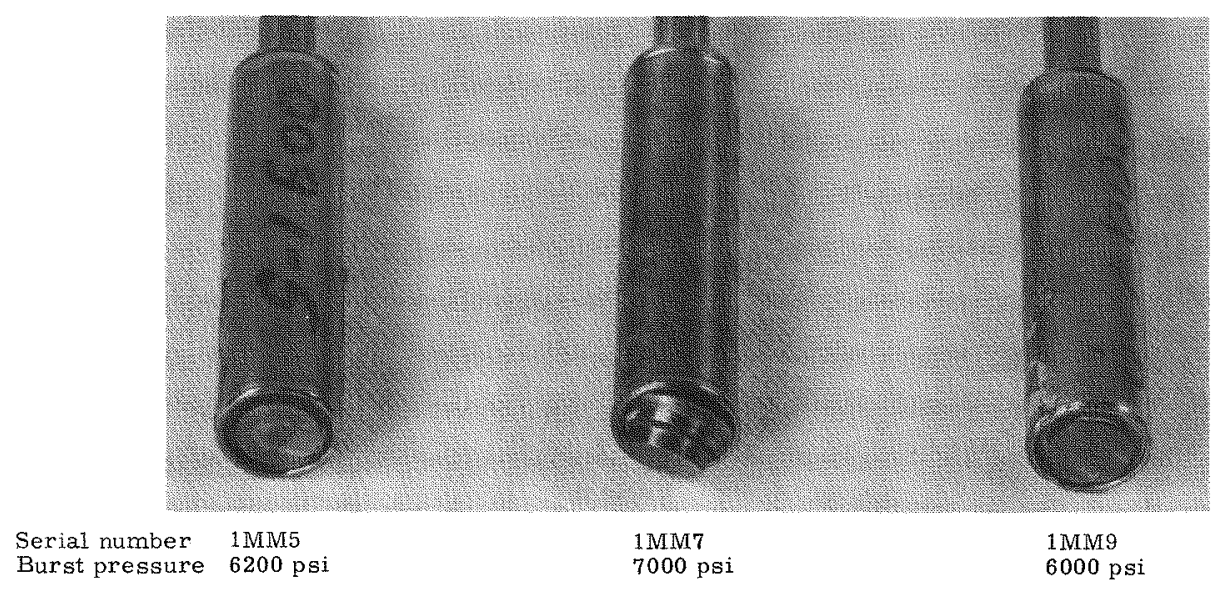

FIG. II-13. -001 CAP DESIGN LINER BURST TEST SPECIMENS (MARTIN MARIETTA)
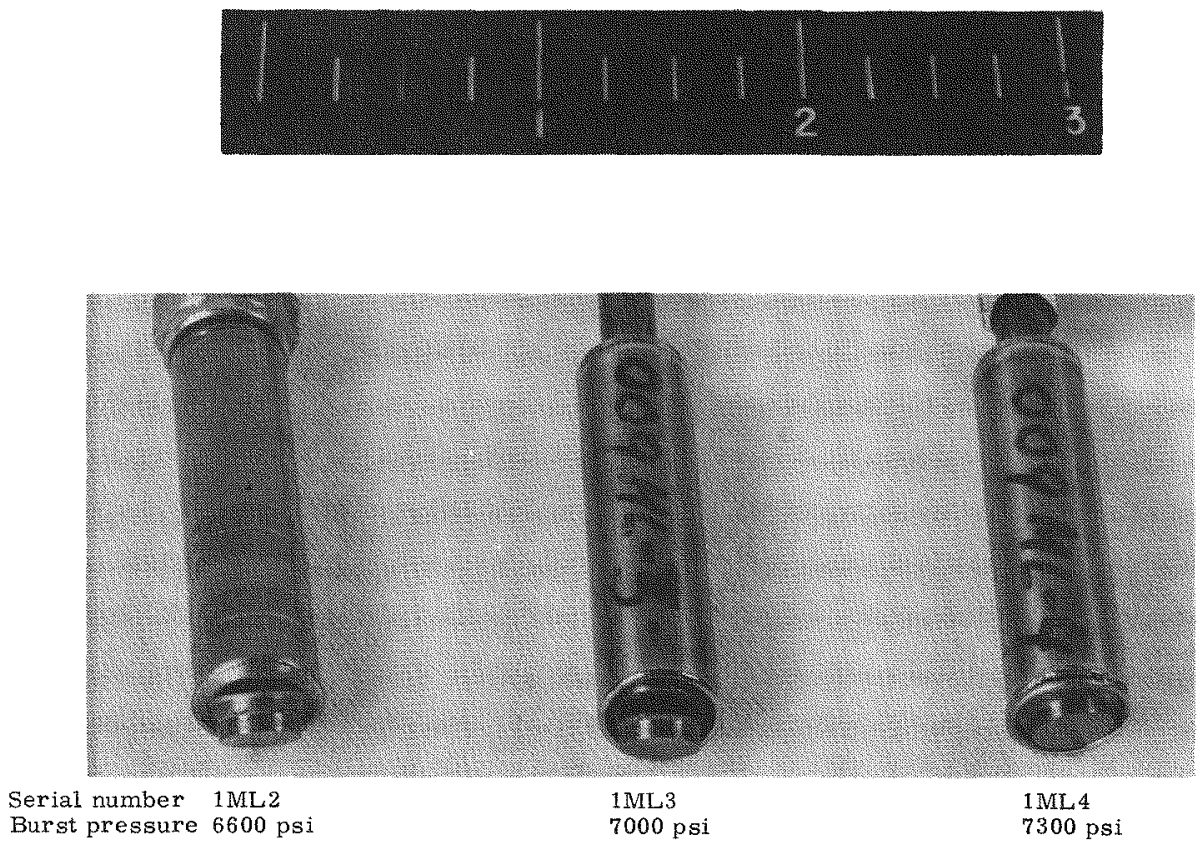

FIG. II-14. -001 CAP DESIGN LINER BURST TEST SPECIMENS (MOUND LABORATORIES)

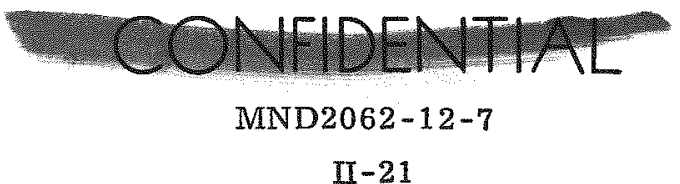


hardness readings. Table II -11 presents these data along with the burst pressure of the particular specimen and the average weld penetration of the destructively tested pretest weld samples. In addition to the information given in these tables, data were accumulated in the areas of weld grain size, ease of fabrication and thermal and tolerance considerations. The objective of this effort was to permit the selection of a liner end cap design to best satisfy SNAP 29 design requirements, Mound Laboratory handling and welding requirements and capsule operational conditions as defined by concurrent fuel form/liner compatibility tests. In most cases test data and/or experience were inconclusive with respect to the elimination of any of the five end cap designs (3 TIG and $2 \mathrm{~EB}$ types). It was therefore proposed that each design be evaluated against a series of criteria with respect to potential use for the required application (i.e., satisfactory (S) or unsatisfactory (U)). Where neither of these ratings was established, a development uncertainty exists and a problem rating (P) was given. Pertinent comments relative to the selection criteria are briefly summarized:

(1) Oxygen content--High and low values were encountered for each weld type. Since no correlation was apparent a (P) rating was given for each design and further investigations will be considered by Martin Marietta and Mound.

(2) Hardness in weld area--Microhardness measurements indicated ductile welds in all cases.

(3) Burst pressure--Maximum pressure buildup in the capsule is computed to be approximately 1400 psi (hot). All burst tests (cold) exceeded this pres sure.

(4) Thermal data--For the EB weld, problems are foreseen in designing the chill block to maintain a gas interface between the chill block and liner. Resultant excessive fuel temperatures and relative thermal expansion differences between the liner and inner liner are possible. Since TIG welds avoid this problem due to gas conductivity, (S) ratings were given all TIG designs and (P) ratings given both EB designs.

(5) Tolerance aspects--Axial weld bead buildup occurs in designs 001 and 003 with associated tolerance uncertainties. Weld buildup diametrically can be limited below two mils on designs 001, 007 and 011 . Minimal side buildup is mandatory due to limited clearance between liner and clad and the importance of avoiding post-weld dressing on hot capsules.

(6) Weld operation--Liner orientation is vertical for designs 001 and 003 and horizontal for designs 005, 007 and 011. Although a vertical position is preferred, all types are considered satisfactory. Ease of cap handling is best for 001 design. Cap fit up and assembly ease is also best for the 001 design. Designs 003 and 011 indicated problems and 005 and 007 were unsatisfactory. Although designs 007 and 011 required vent holes for weld gas bleed and helium backfill, no problem was anticipated. Vent holes, however, represent additional operational steps.

(7) Burst specimen fabrication experience--Weld penetration was best for the 001 and 011 designs. Weld consistency was best for the 001, 003 and 011 designs.

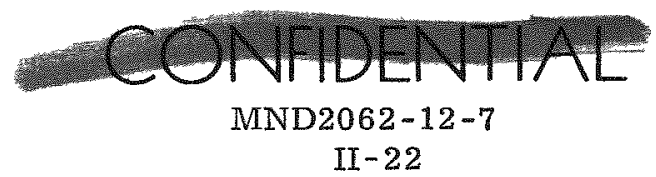




\section{TABLE II-11}

Post-Burst Test Evaluation

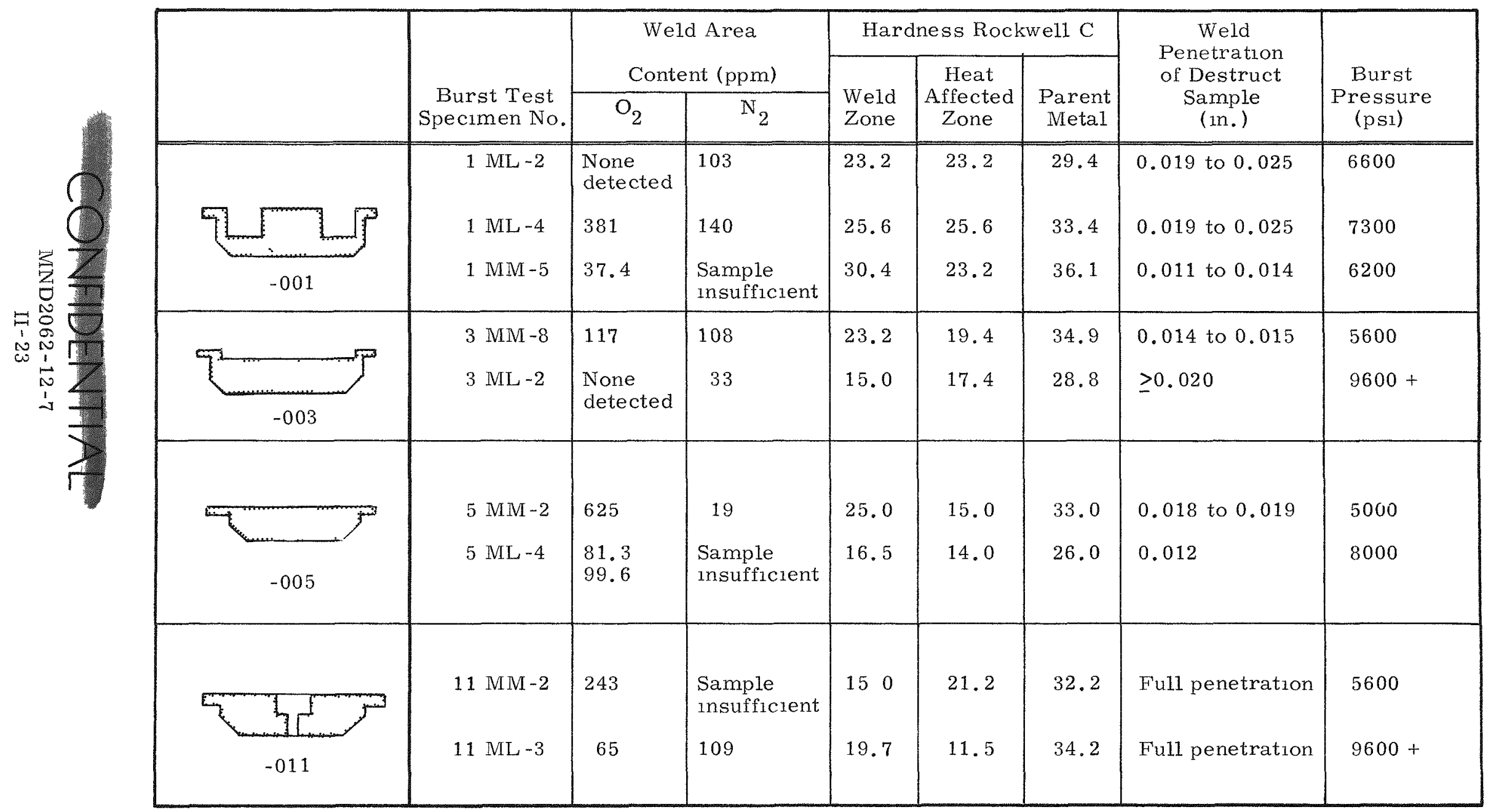




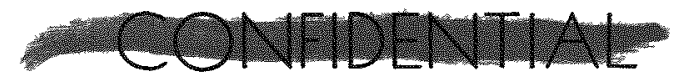

Table II-12 summarizes the ratings given for each end cap against the criterion listed. It was concluded that the 466A1141016-001 TIG weld design best met all requirements for the SNAP 29 liner end cap. The major concern is control of oxygen content in the weld zone. (This concern exists for all TIG and EB welds.) Martin Marietta and Mound Laboratory will review the possible additional effort necessary to determine the degree of control to be maintained and what oxygen content level is detrimental. The 466A1141016-011 EB weld end cap was selected as the backup design subject to verification of the potential high temperatures during welding in vacuum conditions. If the temperatures should be too high, as determined by the SNAP 29 effective thermal conductivity test, the EB weld design will be dropped.

\section{TABLE II - 12}

Capsule Liner End Cap Evaluation Summary

\begin{tabular}{|c|c|c|c|c|c|}
\hline \multirow[b]{2}{*}{ Criterion } & \multicolumn{5}{|c|}{ End Cap Design } \\
\hline & $\begin{array}{l}001 \\
\text { TIG } \\
\end{array}$ & $\begin{array}{l}003 \\
\text { TIG } \\
\end{array}$ & $\begin{array}{l}005 \\
\text { TIG } \\
\end{array}$ & $\begin{array}{l}007 \\
\mathrm{~EB}\end{array}$ & $\begin{array}{l}011 \\
\mathrm{~EB}\end{array}$ \\
\hline $\begin{array}{l}\text { Post-Burst Test Evaluation } \\
\text { Oxygen content } \\
\text { Microhardness weld area }\end{array}$ & $\begin{array}{l}\mathrm{P} \\
\mathrm{S}\end{array}$ & $\begin{array}{l}\mathrm{P} \\
\mathrm{S}\end{array}$ & $\begin{array}{l}\mathrm{P} \\
\mathrm{S}\end{array}$ & $\begin{array}{l}\mathrm{P} \\
\mathrm{S}\end{array}$ & $\begin{array}{l}\mathrm{P} \\
\mathrm{S}\end{array}$ \\
\hline Burst Pressure & $\mathrm{S}$ & $\mathrm{S}$ & $\mathrm{S}$ & $\mathrm{S}$ & S \\
\hline $\begin{array}{l}\text { Thermal Data--Weld Operation } \\
* \text { Chill block/liner } \Delta \mathrm{T} \\
\text { Inner liner temperature }\end{array}$ & $\mathrm{S}$ & $\mathrm{S}$ & $\mathrm{S}$ & $\mathrm{P}$ & $\mathrm{P}$ \\
\hline $\begin{array}{l}\text { * Fuel compatibility problem } \\
\text { * Differential thermal expansion }\end{array}$ & $\begin{array}{l}S \\
S\end{array}$ & $\begin{array}{l}S \\
S\end{array}$ & $\begin{array}{l}S \\
S\end{array}$ & $\begin{array}{l}\mathrm{P} \\
\mathrm{P}\end{array}$ & $\begin{array}{l}\mathrm{P} \\
\mathrm{P}\end{array}$ \\
\hline $\begin{array}{l}\text { Tolerance Aspects } \\
\text { Weld buildup } \\
\text { Liner length } \\
\text { Liner diameter }\end{array}$ & $\begin{array}{l}P \\
S\end{array}$ & $\begin{array}{l}\mathrm{P} \\
\mathrm{P}\end{array}$ & $\begin{array}{l}\mathrm{S} \\
\mathrm{P}\end{array}$ & $\begin{array}{l}S \\
S\end{array}$ & $\begin{array}{l}S \\
S\end{array}$ \\
\hline $\begin{array}{l}\text { Weld Operation } \\
\text { Liner orientation } \\
\text { *ase of cap handling } \\
\text { Vent hole requirements } \\
\text { * Ease of welding and number of steps }\end{array}$ & $\begin{array}{l}\mathrm{S} \\
\mathrm{S} \\
\mathrm{S} \\
\mathrm{S}\end{array}$ & $\begin{array}{l}\mathrm{S} \\
\mathrm{P} \\
\mathrm{S} \\
\mathrm{P}\end{array}$ & $\begin{array}{l}\mathrm{S} \\
\mathrm{P} \\
\mathrm{S} \\
\mathrm{U}\end{array}$ & $\begin{array}{l}\mathrm{S} \\
\mathrm{P} \\
\mathrm{S} \\
\mathrm{U}\end{array}$ & $\begin{array}{l}\mathrm{S} \\
\mathrm{P} \\
\mathrm{S} \\
\mathrm{P}\end{array}$ \\
\hline $\begin{array}{l}\text { Burst Specimen Fabrication Experience } \\
\text { Weld penetration } \\
\text { Consistency }\end{array}$ & $\begin{array}{l}S \\
S\end{array}$ & $\begin{array}{l}P \\
S\end{array}$ & $\begin{array}{l}\mathrm{P} \\
\mathrm{P}\end{array}$ & $\begin{array}{l}P \\
P\end{array}$ & $\begin{array}{l}S \\
S\end{array}$ \\
\hline
\end{tabular}

Strain gage data from the liner burst test are currently being reduced and interpreted. A preliminary structural analysis of the welded liner end caps is presented.

(6) Structural evaluation of welded liner end caps

One of the more important aspects of fuel capsule structural integrity consists of the ability of various types of welded liner end caps to withstand an internal pressure

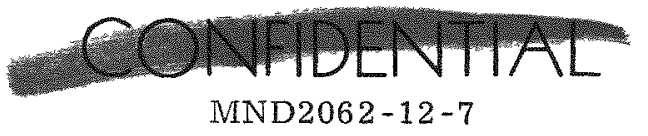




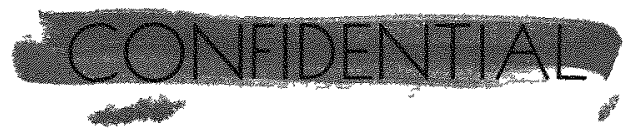

associated with generator operation, system re-entry, isotopic fuel decay, etc. To investigate end cap design and weldment efficiency, 30 subsize test specimens were fabricated per Drawing 466A1141016, 15 by Mound Laboratory and 15 by Martin Marietta.

Figure II-15a provides a sketch of the test specimen and Fig. II-15b illustrates the five end cap-weldment configurations. All burst tests were conducted at room temperature. The test specimens were pressurized over a short time interval to minimize creep deformation.

As shown by Fig. II -15b, the major difference between end cap configurations was the thickness of the end cap. Sixty percent of the specimens were TIG welded and the remainder were welded by an electron beam process. Each end cap was optically examined, radiographed and checked with dye penetrant. A number of strain gages were installed on many specimens and the failed specimens were macroand micro-photographed.

The capsule liners are fabricated from $\mathrm{Ta}-10 \% \mathrm{~W}$ with the following certified mechanical properties as a result of two tensile tests:

\begin{tabular}{|c|c|c|c|}
\hline & $\begin{array}{c}\text { Ultimate } \\
\text { Tensile } \\
\text { (psi) } \\
\end{array}$ & $\begin{array}{l}\text { Yield } \\
\text { (psi) } \\
\end{array}$ & Elongation (\%) \\
\hline & 96,100 & 83,500 & 26 \\
\hline & 96,800 & 84,300 & 25 \\
\hline Mean value & 96,450 & 83,900 & 25.5 \\
\hline
\end{tabular}

For a cylindrical pressure vessel manufactured of a ductile material, the majority of failures occur in the side wall as a result of circumferential or hoop stresses exceeding the ultimate capability. Although the discontinuity stresses are initially high at the end cap-shell interfaces, these stresses tend to redistribute from yielding and plastic flow. The end cap greatly deforms and attempts to approach a hemispherical shape. However, due to the heat applied during welding, the material's crystalline nature is radically changed in the heat-affected zone and often results in a very low magnitude of elongation unless the fabricated part is annealed for stress relief and reheat treated.

All of the test specimens for this study failed in the weld area and thus the full potential capability was not achieved. Reheat treatment is impossible since the welding must be accomplished remotely and the finished product is a fueled capsule. In order to attempt an evaluation of the test results, the actual burst pressure will be compared with a hypothetical pressure based upon rupture of the side wall. The comparison or ratio between the se two pressures will be labeled the theoretical weld efficiency. In addition, the magnitude of the discontinuity stresses will be investigated for the various end cap configurations.

From a plasticity analysis of the instability of a thin-walled cylindrical vessel subjected to internal pressure, one of the many burst equations is presented where the burst pressure is.

$$
P_{b}=\frac{4 \sigma_{u}\left(\frac{t_{0}}{d_{0}}\right)}{\sqrt{3} e^{n}}
$$

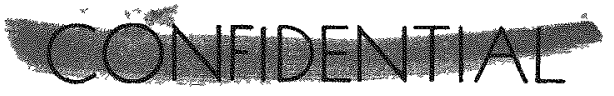

MND2062-12-7

II -25 


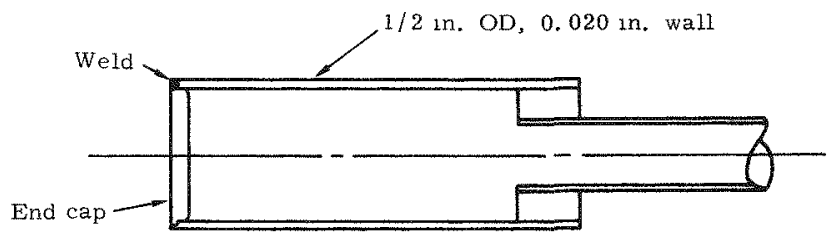

a. Test Specimen Configuration

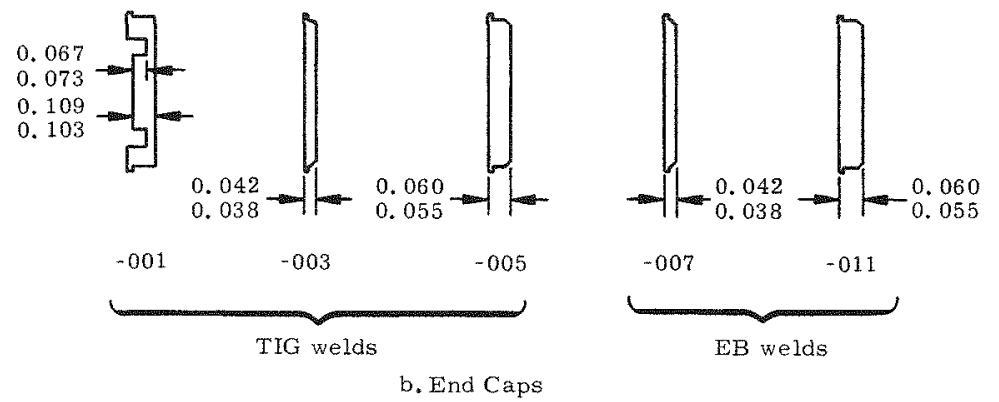

FIG, II-15. LINER CAP CONEIGURATIONS

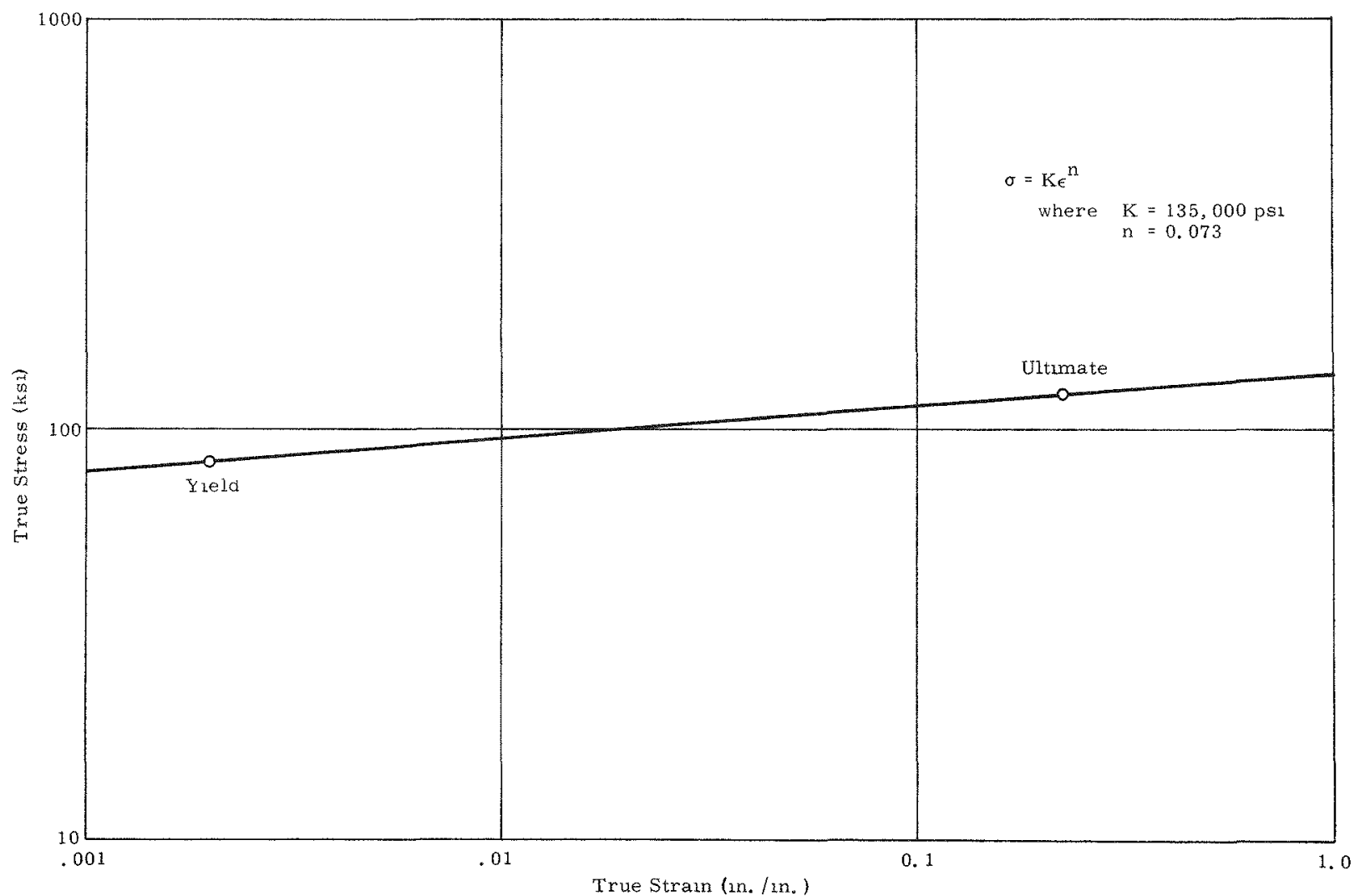

FIG. II - 16. TRUE STRESS-STRAIN--Ta-10W AT ROOM TEMPERATURE

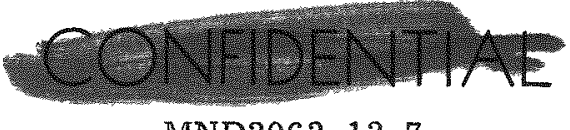

MND2062-12-7

II -26 
where

$$
\begin{aligned}
\sigma_{u} & =\text { true ultimate strength } \\
t_{0} & =\text { original wall thickness } \\
& =0.020 \text { inch } \\
\mathrm{d}_{0} & =\text { initial internal diameter } \\
& =0.460 \text { inch } \\
\mathrm{n} & =\text { material strain hardening coefficient }
\end{aligned}
$$

The general form of a stress-strain curve is,

$$
\sigma \quad=K e^{n}
$$

where $\sigma$ and $\epsilon$ are true stress and true strain, respectively, as opposed to engineering stress and strain. True stress and true strain in terms of engineering stress $\left(\sigma_{0}\right)$ and $\operatorname{strain}\left(\epsilon_{0}\right)$ are,

$$
\begin{aligned}
& \sigma \quad=\sigma_{0}\left(1+\epsilon_{0}\right) \\
& \epsilon=\ln \left(1+\epsilon_{0}\right)
\end{aligned}
$$

Using the mean values of the material certification tests previously presented,

$$
\begin{aligned}
& \epsilon_{\mathrm{u}}=\ln 1.255=0.2271 \mathrm{in} . / \mathrm{in} . \\
& \epsilon_{\mathrm{y}}=\ln 1.002=0.002 \mathrm{in} . / \mathrm{in} . \\
& \sigma_{\mathrm{u}}=96,450(1.255)=121,000 \mathrm{psi} \\
& \sigma_{\mathrm{y}}=83,500(1.002)=83,670 \mathrm{psi}
\end{aligned}
$$

Plotting these data on a log-log plot (Fig. II-16), the slope of the resulting curve represents the strain hardening coefficient and stress value corresponding to $1 \mathrm{in.} / \mathrm{in}$. strain is the constant $K$.

$$
\rightarrow \sigma=135,000 \epsilon^{0.078}
$$

A value for burst pressure can now be readily attained where,

$$
\begin{aligned}
P_{b} & =\frac{4(121000)\left(\frac{0.020}{0.460}\right)}{\sqrt{3} e^{0.078}} \\
& =11,230 \mathrm{ps} 1
\end{aligned}
$$

Table II -13 presents the test burst pressure of each specimen and the weld efficiency based upon the theoretical burst pressure derived.

The thicknesses of the welded end caps are $0.042 / 0.038$ and $0.060 / 0.055$ for 003 and 005 end cap configurations, respectively (Fig. II-15b). Taking $E=25 \times 10^{6}$ psi and $v=0.3$ and applying a unit internal pressure, the membrane plus discontinuity stresses are calculated at the end cap-cylinder interface. Maximum stresses in the

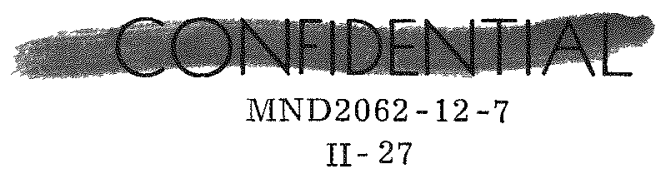


TABLE II -13

Burst Test Data

Martin Marietta Specimens

Mound Laboratory Specimens

\begin{tabular}{|c|c|c|c|c|}
\hline $\begin{array}{l}\text { End Cover } \\
\text { and Weld* } \\
\end{array}$ & $\begin{array}{c}\text { Burst Pressure } \\
\text { (psi) }\end{array}$ & $\begin{array}{c}\text { Weld Efficiency } \\
(\%)\end{array}$ & $\begin{array}{c}\text { Burst Pressure } \\
\text { (psi) }\end{array}$ & $\begin{array}{c}\text { Weld Efficiency } \\
(\%)\end{array}$ \\
\hline 001 & 6200 & 55.2 & 7000 & 62.3 \\
\hline 001 & 7000 & 62.3 & 7300 & 65.0 \\
\hline 001 & 6000 & 53.4 & 6600 & 58.7 \\
\hline 003 & 5400 & 48.0 & 9600 & 85.5 \\
\hline 003 & 5600 & 49.9 & 9600 & 85.5 \\
\hline 003 & 7800 & 69.4 & 9600 & 85.5 \\
\hline 005 & 5000 & 44.5 & 9600 & 85.5 \\
\hline 005 & 7400 & 65.9 & 8000 & 71.2 \\
\hline 005 & 7000 & 62.3 & 8000 & 71.2 \\
\hline 007 & 2600 & 23.1 & 6700 & 59.6 \\
\hline 007 & 5000 & 44.5 & 8600 & 76.5 \\
\hline 007 & & & & \\
\hline 011 & 5600 & 49.9 & 9600 & 85.5 \\
\hline 011 & 9600 & 85.5 & 5600 & 49.9 \\
\hline 011 & 4400 & 39.2 & & \\
\hline
\end{tabular}

*Refer to Fig. II $-15 b$.

end cap and center deflection are also obtained. All results are presented in Table II -14. Assuming a material yield strength of $83,670 \mathrm{psi}$, the internal pressure required to initiate yielding is also presented.

\section{(7) Creep rupture analysis}

The following analysis provides an evaluation of the structural capability as sociated with the SNAP 29 fuel capsules based upon seven hypothetical missions and their associated internal pressure and temperature histories.

Mission 1 may be considered the typical nominal mission including a period of orbital operation followed by re-entry and terrestrial impact. After impact, the monotonic decrease in temperature and the resultant capsule internal pressure is a direct result of isotope decay.

Mission 2 represents a hypothetical liftoff at 30 days after fueling, followed by an immediate abort and re-entry. It is assumed that the fuel capsules are deposited in an environment which yields a peak capsule temperature of $2500^{\circ} \mathrm{F}\left(2960^{\circ} \mathrm{R}\right)$ with no subsequent change in environment.

Missions 3 through 7 include orbital operation of $X$ days followed by re-entry and impact. As in Mission 2, the peak capsule temperature of $2500^{\circ} \mathrm{F}$ is assumed followed by isotopic decay. For any mission from generator fueling to re-entry and impact, the internal pressure within the capsules and temperature of the capsules are time dependent. As a direct result of these environment histories, creep strain is implied.

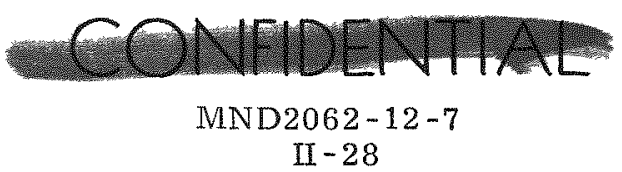




\section{TABLE II -14}

Membrane and Discontinuity Stresses

\begin{tabular}{|c|c|c|c|c|c|c|c|c|}
\hline & $\begin{array}{c}\sigma_{z_{1}} \\
(p s i) \\
\end{array}$ & $\begin{array}{c}{ }^{\sigma}{ }_{z_{0}} \\
\text { (psi) } \\
\end{array}$ & $\begin{array}{c}{ }^{\sigma}{ }_{1} \\
\underline{(p s i)} \\
\end{array}$ & $\begin{array}{r}{ }^{\sigma} \theta_{0} \\
(p s i) \\
\end{array}$ & $\begin{array}{c}\sigma_{r_{1}} \\
\text { (psi) }\end{array}$ & $\begin{array}{c}\sigma_{0} \\
(p s i) \\
\end{array}$ & $\begin{array}{c}\delta \\
(\text { in.) } \\
\end{array}$ & $\begin{array}{c}\text { Yield Pressure } \\
\left(p_{s i}\right)\end{array}$ \\
\hline $\begin{array}{l}\text { Case } 1(003 \text { and } 007) \\
\text { Maximum end cap } \\
\text { thickness } \\
\qquad \begin{array}{l}t_{c}=0.020 \\
t_{h}=0.042\end{array}\end{array}$ & 61.01 & -49.01 & 2.69 & -13.24 & -25.8 & 30.0 & $76.6 \times 10^{-8}$ & 1370 \\
\hline $\begin{array}{l}\text { Case } 2(003 \text { and } 007) \\
\text { Minimum end cap } \\
\text { thickness } \\
\qquad \begin{array}{l}t_{c}=0.020 \\
t_{h}=0.038\end{array}\end{array}$ & 67.60 & -55.60 & 2.05 & -14.98 & -29.76 & 34.76 & $95.6 \times 10^{-8}$ & 1238 \\
\hline $\begin{array}{l}\text { Case } 3(005 \text { and } 011) \\
\text { Maximum end cap } \\
\text { thickness } \\
\qquad \begin{array}{l}t_{c}=0.020 \\
t_{h}=0.060\end{array}\end{array}$ & 41.49 & -29.49 & 4.41 & -8.09 & -14.74 & 16.91 & $32.04 \times 10^{-8}$ & 2015 \\
\hline $\begin{array}{l}\text { Case } 4(005 \text { and } 011) \\
\text { Minimum end cap } \\
\text { thickness } \\
\qquad t_{c}=0.020 \\
t_{h}=0.055\end{array}$ & 45.53 & -33.53 & 4.09 & -9.17 & -17.10 & 19.64 & $40.28 \times 10^{-8}$ & 1837 \\
\hline $\begin{aligned} \text { Key: } & =\text { cylinder wall th } \\
c & =\text { end cap thickne } \\
b_{z_{1}} & =\text { cylinder meridi } \\
z_{1} & =\text { cylinder meridi } \\
z_{0} & =\text { cylinder hoop s } \\
\theta_{1} & =\text { cylinder hoop } \mathrm{s}\end{aligned}$ & $\begin{array}{l}\text { ckness } \\
\text { s } \\
\text { n stress, }\end{array}$ & $\begin{array}{l}\text { outside } \\
\text { de surfa }\end{array}$ & urface & \multicolumn{5}{|c|}{$\begin{aligned} \sigma_{\mathrm{r}_{1}} & =\text { end cap radial stress, inside surface } \\
\sigma_{\mathrm{r}_{0}} & =\text { end cap radial stress, outside surface } \\
\delta & =\text { maximum end cap deflection } \\
+ & \rightarrow \text { tension } \\
+ & \rightarrow \text { compression }\end{aligned}$} \\
\hline
\end{tabular}




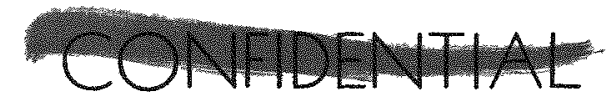

The fuel capsule design is based upon a concentric array of three cylindrical shells surrounding the fuel matrix. The three 0.020 -inch thick shells include tantalum, Ta-10\%W and platinum-rhodium where the $\mathrm{Ta}-10 \% \mathrm{~W}$ is considered the structural member and resists the internal pressure which develops. For this analysis, the structural capability of the other two shells will be neglected. The nominal mean radius of the structural liner is $0.2843+\mathrm{h} / 2$ where $\mathrm{h}$ is the wall thickness.

The creep analysis employed within this report is based on the linear cumulative damage theory with the following assumptions:

(1) The rate of life consumption is dependent only on the instantaneous state of stress and temperature. That is, the creep strain rate $\dot{\epsilon}$ is independent of prior creep history at different temperature and/or stress levels.

(2) The rate of life consumption can be evaluated by steady state stress rupture data, in this instance by the Larson-Miller parameter, and the percentage of life consumed in a given time interval at a given stress and temperature is that time divided by the rupture time for this stress.

(3) These fractions or percentages can be summed and fracture occurs when the sum is $100 \%$.

For the case of a cylindrical thin shell of revolution, the maximum stress occurs in the hoop or circumferential direction and is given by,

$$
\sigma_{\theta}=p \frac{\mathrm{R}}{\mathrm{h}}
$$

where $\mathrm{p}=$ internal pressure, $\mathrm{R}_{\mathrm{m}}=$ mean radius and $\mathrm{h}$ is the wall thickness. The stress for a finite interval of time is associated with a particular Larson-Miller parameter value where the parameter is defined as,

$$
K=(T+460)\left(C+\log _{10} t_{R}\right) \times 10^{-3}
$$

where $\mathrm{T}=$ temperature $\left({ }^{\circ} \mathrm{F}\right), t_{\mathrm{R}}$ is time ( $\mathrm{min}$ ) and $\mathrm{C}$ is an arbitrary constant usually 20 , dependent upon curve fitting of the test data points. It should be noted that creep studies of pressure tubes have shown that if one calculates hoop stress from the equation, the observed creep is equivalent to that of a uniaxial test at the same stress.

For the Larson-Miller plot for Ta-10\%W, Fig. II-17 is included.

Figures II -18 and II -19 provide the pressure and temperature histories, respectively, for the seven missions of interest. For each mission the required liner wall thickness determined is based upon:

(1) Creep-to-rupture at end of mission

(2) $80 \%$ of the stress-to-rupture at the end of the mission.

The latter may be considered as a design value. The required thicknesses for each case investigated are provided in Table II-15.

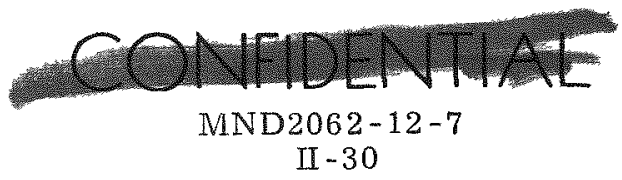



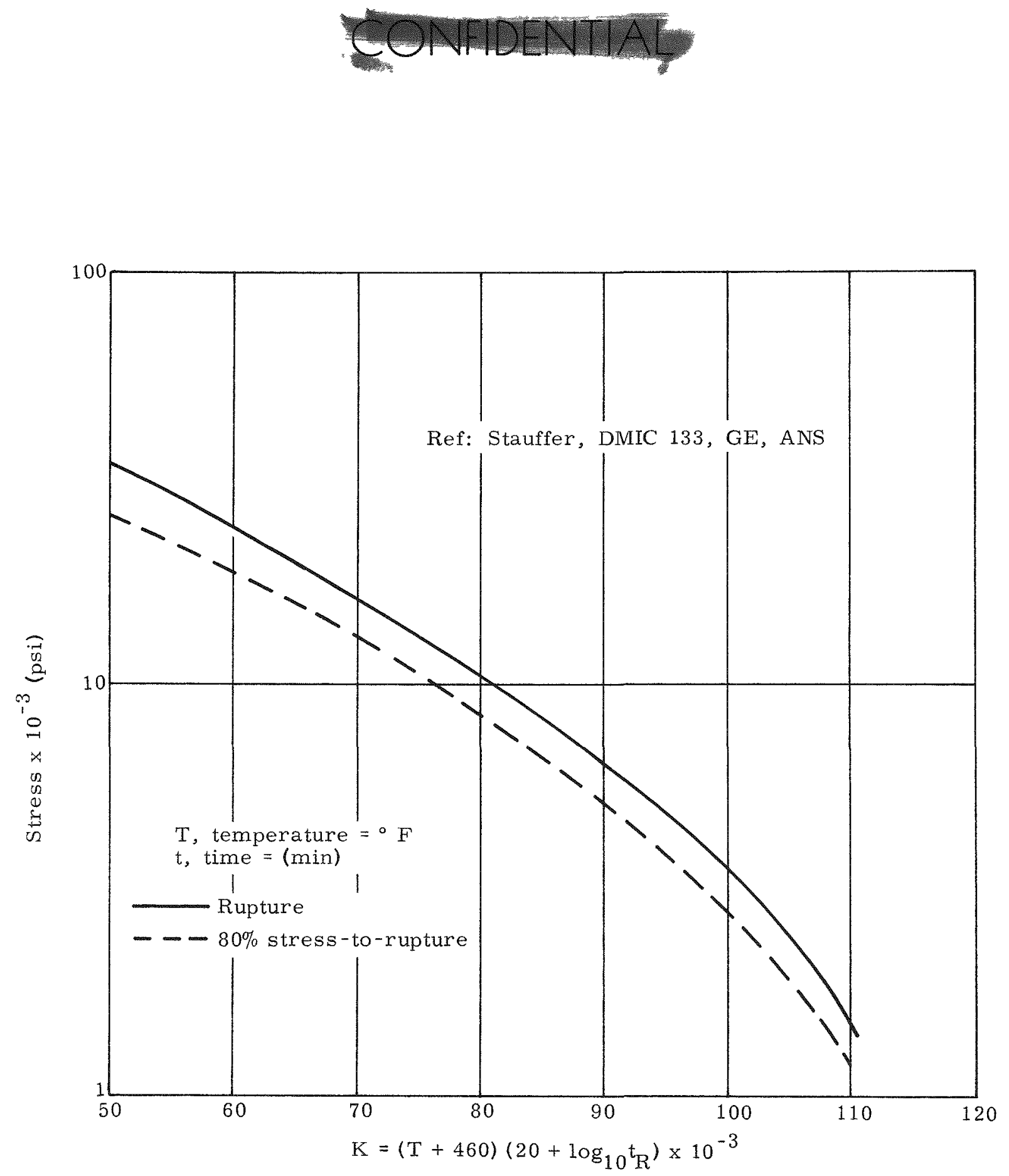

FIG. II-17. LARSON-MILLER CREEP RUPTURE FOR Ta-10W

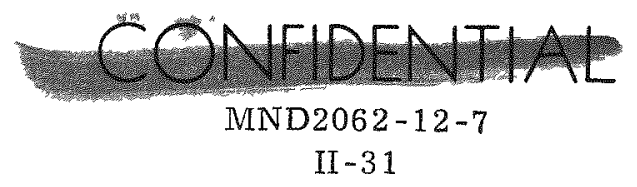



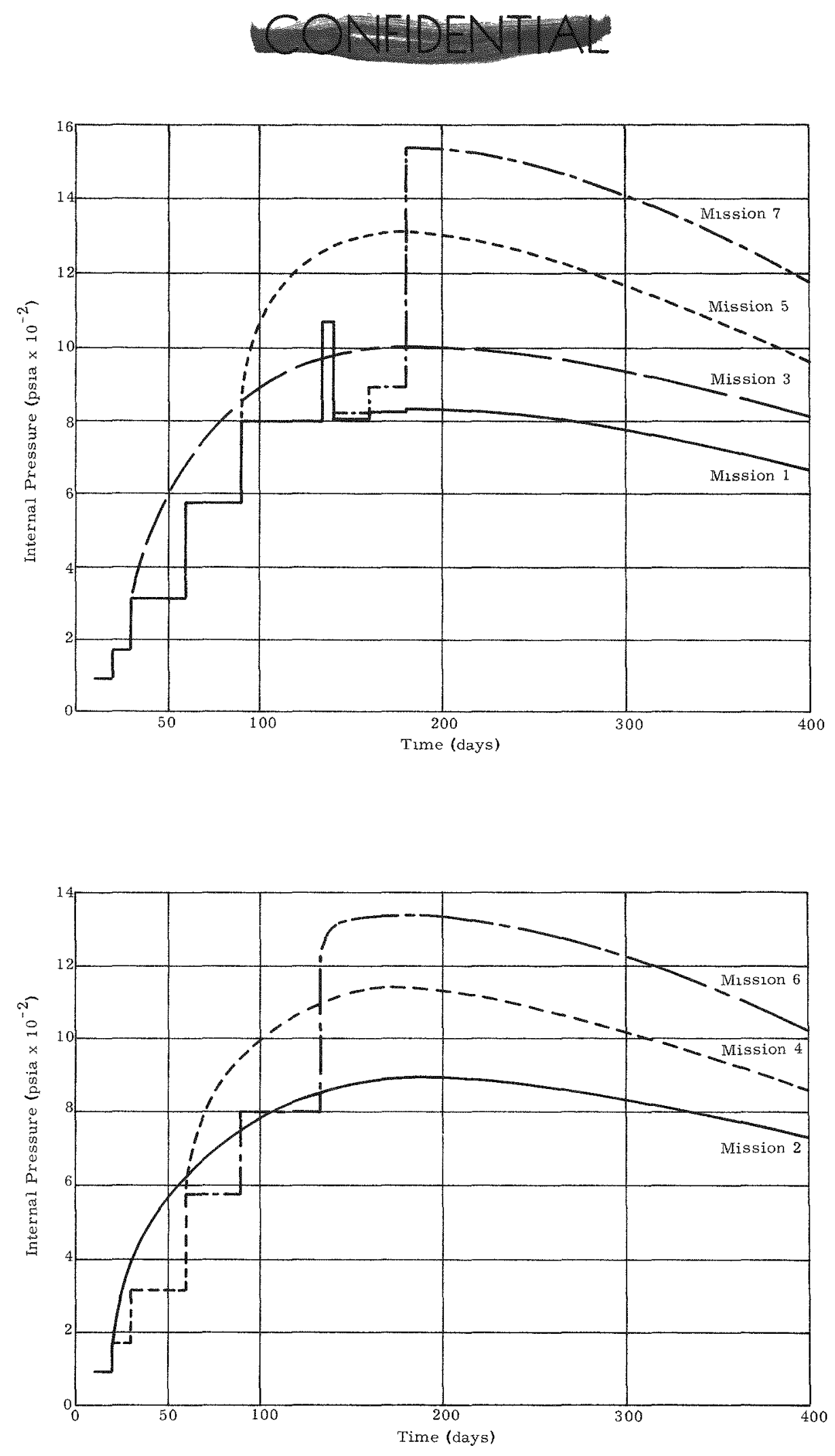

FIG. II-18. PRESSURE HISTORY

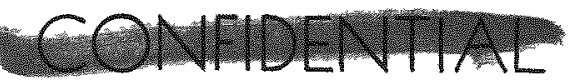

MND2062-12-7 

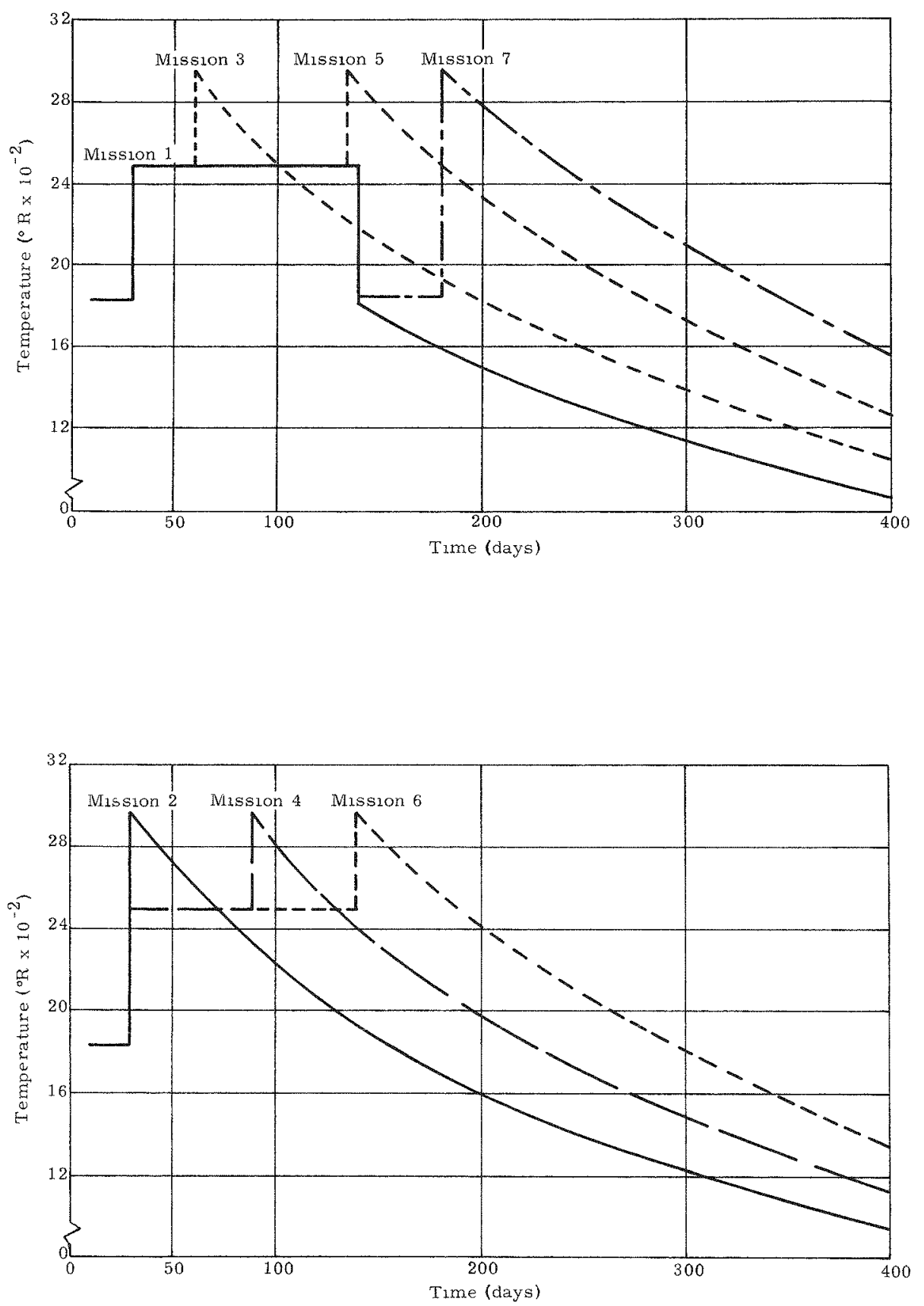

FIG. II-19. TEMPERATURE HISTORY

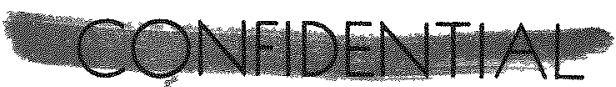

MND2062-12-7

II -33 
TABLE II -15

\begin{tabular}{|c|c|c|}
\hline \multirow[b]{2}{*}{ Mission } & \multicolumn{2}{|c|}{$\begin{array}{c}\text { Liner Wall Thickness } \\
\text { Required (in.) }\end{array}$} \\
\hline & Rupture & $80 \%$ Stress to Rupture \\
\hline 1 & 0.0129 & 0.0163 \\
\hline 2 & 0.0093 & 0.0116 \\
\hline 3 & 0.0134 & 0.0169 \\
\hline 4 & 0.0180 & 0.0228 \\
\hline 5 & 0.0228 & 0.0290 \\
\hline 6 & 0.0248 & 0.0313 \\
\hline 7 & 0.0292 & 0.0371 \\
\hline
\end{tabular}

As was initially stated, the present fuel capsule design incorporates an 0.020 inch thick Ta-10\%W liner. It can be seen from Table II-15 that theoretically the liners for Missions 1 through 4 would survive the loading histories. This is particularly encouraging since the probability of occurrence of these latter missions is remote.

c. Heat source

(1) Emittance coating development

The objective of this series of tests is to select and qualify an emittance coating for each of the fuel block, hot plate and capsule cladding substrates. The qualification criterion for the emittance coatings is that it must retain an emittance of 0.8 or greater after cycling under prelaunch and mission temperatures, times and atmospheres. After selection, it will be necessary to develop methods of coating applications to the substrates which will ensure satisfactory mechanical or chemical bonds during the environmental cycling.

Five candidate emissivity coatings have been selected for application to the three substrate materials, Haynes -25, Inconel 600 and platinum-20\% rhodium. These were tested for their emittance values during the prelaunch and mission environmental conditions. The calcium titanate and black hot paint coatings were applied in accordance with Process Specifications 466A1343045 and 466A1343047, respectively. The lithoid coatings $\mathrm{C} 10 \mathrm{~A}$ and $\mathrm{CZS}$ have been applied in accordance with the manufacturer' $\mathrm{s}$ recommendations. The plasma technique was used to apply the iron titanate coating to the three substrates. All of the Gier-Dunkle discs and hemispherical cups are being subjected to the environmental conditions shown in Table II-16.

The first 54-day exposure for each substrate has been completed. Black hot paint and iron titanate retained satisfactory emissivity values $(>0.80)$ after this initial period. Calcium titanate appears to degrade in contact with air at the test temperatures. How ever, similar specimens in helium and vacuum appear satisfactory. A failure of the Gier-Dunkle apparatus is delaying some emissivity measurements at this time. Repair time is estimated to be about one month. When data taking is complete, values will be reported.

It has been observed that iron titanate will require an intermediate material in order to overcome differences in the thermal expansion characteristics. Nickel aluminide is currently being evaluated as the intermediate substrate with GierDunkle discs undergoing the environmental treatments outlined in Table II-16.

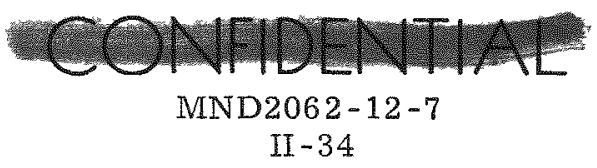


$\underline{\text { TABLE II-16 }}$

Test Environments and Boundary Conditions for Emissivity Evaluation

\begin{tabular}{|c|c|c|c|c|}
\hline Item & Substrate & $\begin{array}{c}\text { Exposure } \\
\left.\text { Temperature ( }{ }^{\circ} \mathrm{F}\right) \\
\end{array}$ & Medium & Duration (days) \\
\hline Hot plate & Haynes - 25 & $\begin{array}{l}1200 \\
1200\end{array}$ & $\begin{array}{l}\text { Air } \\
\text { Vacuum }\end{array}$ & $\begin{array}{l}54 \\
90\end{array}$ \\
\hline \multirow[t]{2}{*}{$\begin{array}{l}\text { Capsule } \\
\text { cladding }\end{array}$} & $\mathrm{Pt}-20 \% \mathrm{Rh}$ & 1850 & $\begin{array}{l}\text { Helium } \\
\text { and ATJ } \\
\text { graphite }\end{array}$ & 54 \\
\hline & & 1850 & $\begin{array}{l}\text { Vacuum } \\
\text { and ATJ } \\
\text { graphite }\end{array}$ & 90 \\
\hline $\begin{array}{l}\text { Fuel } \\
\text { block }\end{array}$ & Inconel 600 & $\begin{array}{l}1600 \\
1600\end{array}$ & $\begin{array}{l}\text { Air } \\
\text { vacuum }\end{array}$ & $\begin{array}{l}54 \\
54\end{array}$ \\
\hline
\end{tabular}

(2) Heat source assembly techniques

Capsule/fuel block assembly methods are still in the preliminary stage. An initial list of characteristics and capabilities which the heat source assembly box and fuel block transportation cask will have are listed.

Heat source assembly box

(1) Helium atmosphere of $1000 \mathrm{ppm} \mathrm{O}_{2}$ maximum

(2) Fixture to hold and rotate block about its $\mathrm{Y}$ axis (normal to plane of block)

(3) Means for installing/removing fuel capsules and plugs

(4) Means for brazing/rebrazing cladding over closure plugs

(5) Compliance section to mate with the fuel block transportation cask. This section must provide support to the fuel block during transfer operation.

Fuel transportation cask

(1) Gripper assembly to move fuel block into or out of heat source assembly box

(2) Capability of being purged and sealed under inert gas atmosphere

(3) Ability to leak check the fuel block by helium sniffing process.

A tentative flow diagram for the assembly of a heat source has been formulated and is presented in Fig. II -20 .

(3) Hot four-module size ATJ heat source dynamic test

Three graphite fuel blocks, two of ATJ and one of needled Carb-I-Tex 500, have been fabricated (Figs. II -21, II -22 and II-23). These fuel blocks will be vibration tested in the hot condition $\left(\sim 1500^{\circ} \mathrm{F}\right)$ and are representative of the current four module design size.

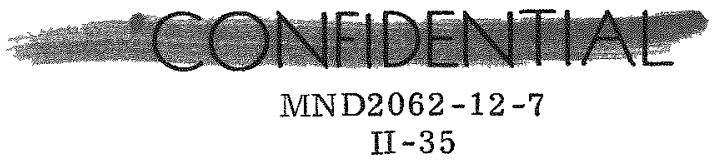




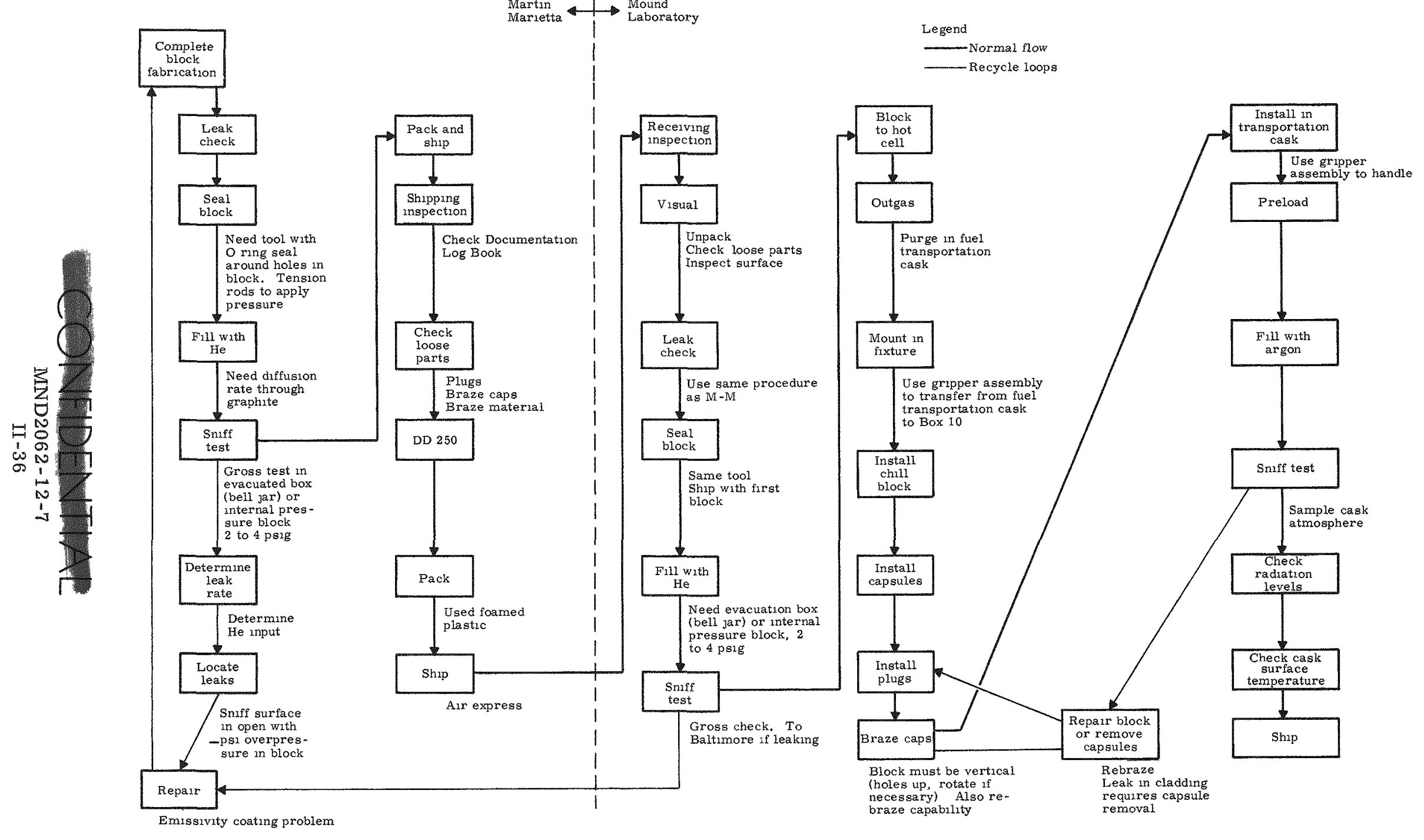

FIG. II-20. FUEL BLOCK FLOW DIAGRAM 


\section{Conndental}

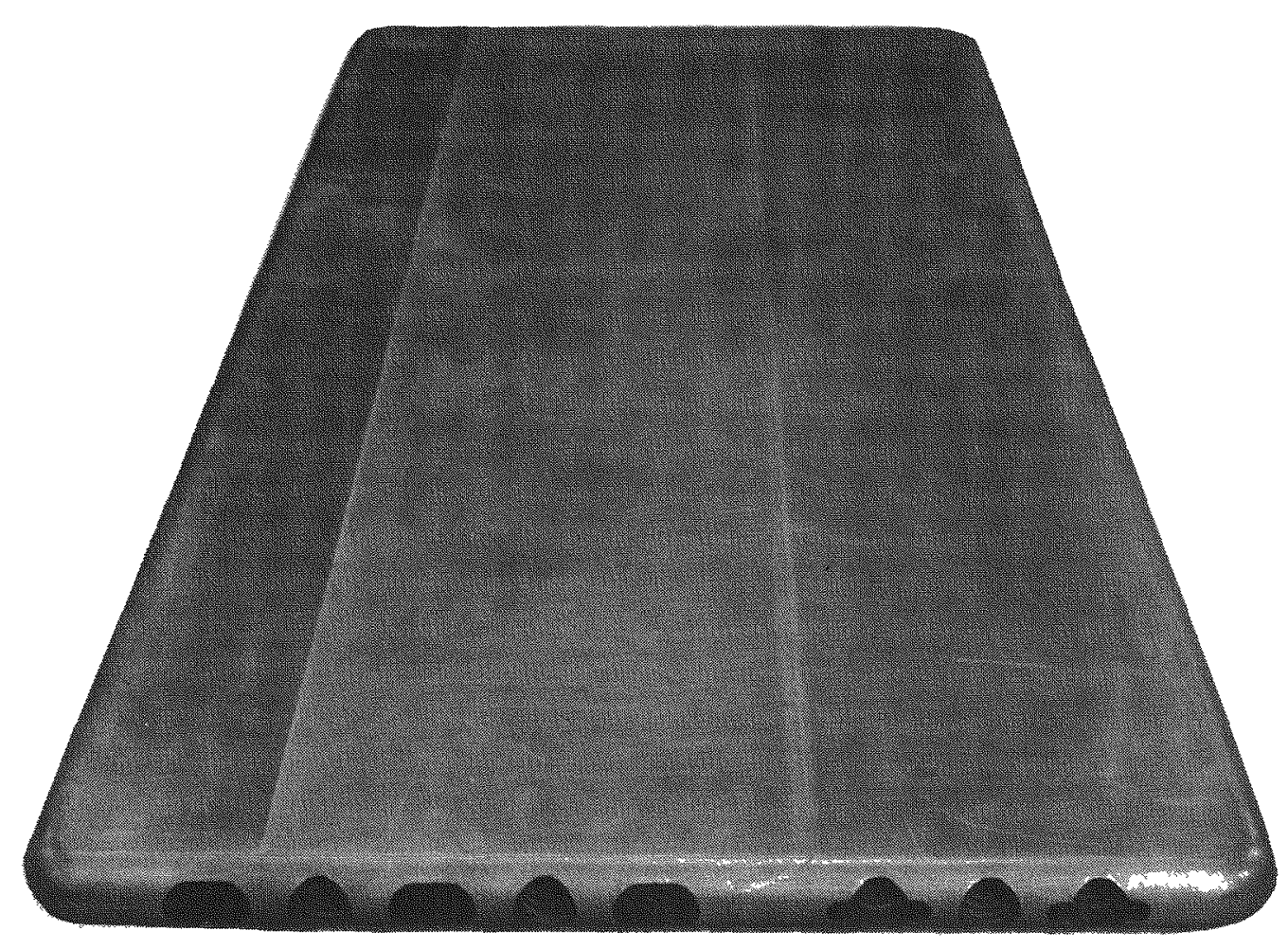

FIG II-21 FOUR MODULE FUEL BLOCK FOR DYNAMIC TEST (ATJ)

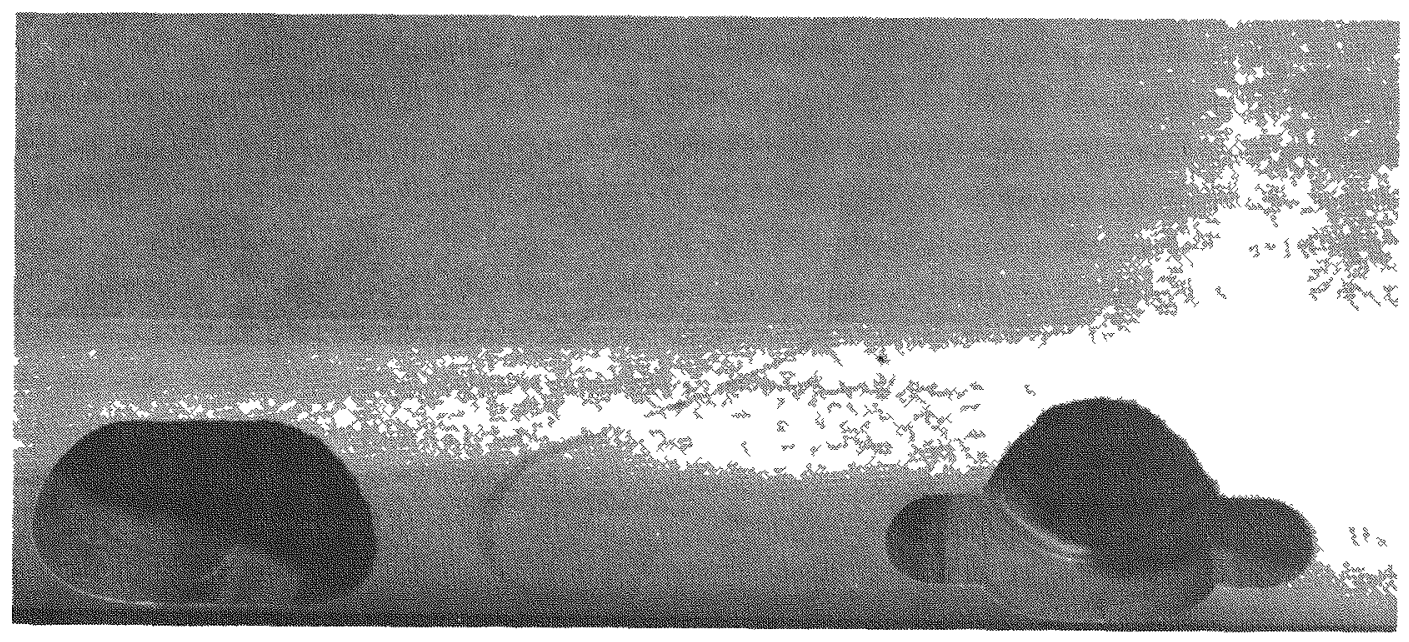

FIG II-22 CLOSEUP OF ATJ DYNAMIC TEST FUEL BLOCK EDGE DETAILS (NOTE JONT)

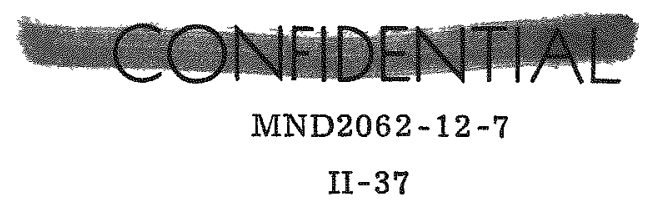




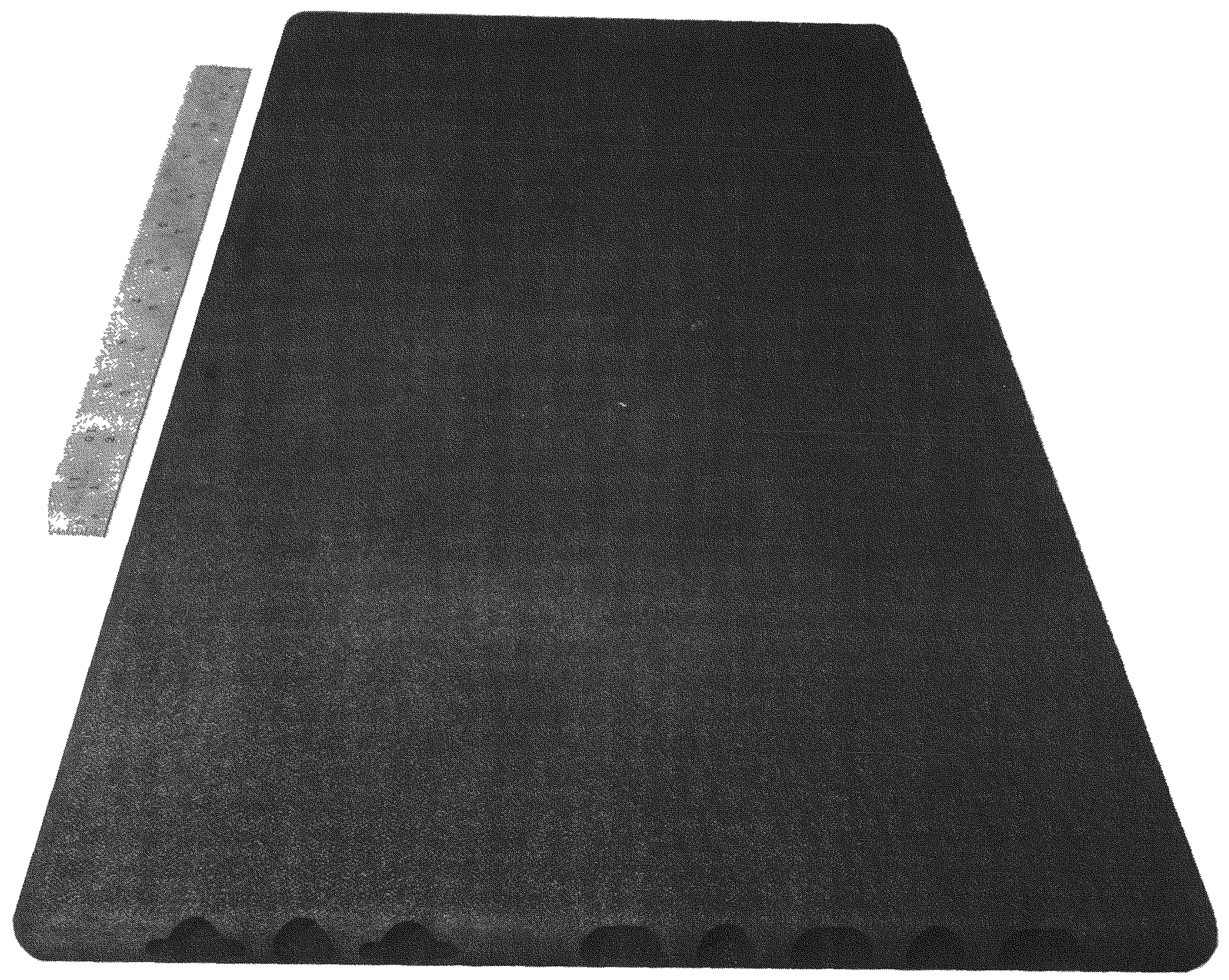

FIG. II-23. FOUR-MODULE FUEL BLOCK FOR DYNAMIC TEST (CARB-I-TEX)

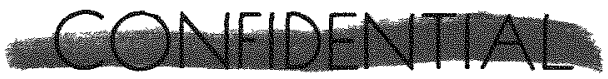

MND2062-12-7

II -38 
In addition to testing the positive capsule retention system mentioned in the previous quarterly report, it has been decided to vibration test a free capsule retention system. Basically, this system consists of cylindrical capsules free to move within the capsule to hole design clearance limitations. Two variations of this free system will be tested. One variation will include nickel alloy felt pads between the capsules and between each capsule and its closure plug, while the other concept will not include pads. A successful test will permit a major simplification of the fuel block design and of the fuel capsule. Refurbishment of the electrical heater block to be used in the heat source vibration test has been completed (Fig. II -24).

\section{(4) Heat source parametric thermal analysis}

A parametric thermal analysis of the SNAP 29 heat source, thermal control system and structural housing for the diaphragm T/E module RTG design employ ing six $\mathrm{T} / \mathrm{E}$ modules was completed during this period. The purpose of the parametric study was to evaluate a range of design conditions and material characteristics in order to establish thermal inventory requirements and the temperatures of critical components (i.e., inner liner and fuel block). The study was parametric in the following variables:

(1) Three and four capsules per module

(2) Module hot plate temperatures of $1125^{\circ}, 1212^{\circ}$ and $1350^{\circ} \mathrm{F}$

(3) Carb-I-Tex and ATJ graphite fuel blocks

(4) Mission times--BOL = day 30, MOL $=$ day 82 and $E O L=$ day 134

(5) Surface emissivities of $0.7,0.8$ and 0.9 for the hot plate, fuel block, fuel block bore and capsule oxidation clad coating

(6) Argon and vacuum atmosphere in the gap between the fuel block and the capsule.

These design parameters were analyzed, with respect to the combinations shown in Table II-17, for both three and four capsules per module.

To achieve the objective of this parametric analysis, tradeoff data between the two types of fuel block materials, the hot plate temperatures, the number of fuel capsules, the gap atmospheres and material characteristics (emissivity) with respect to their effect on capsule total thermal inventory requirements and capsule internal temperature were performed. The results of the analysis will be reported in detail in the next quarterly report. A brief summary of results is presented here.

The heat source was divided into three primary components for purposes of thermal analysis, namely, the fuel block, the fuel capsule and the structural housing. Fuel block temperatures and fuel capsule thermal inventory were determined for EOL design conditions (minimum acceptable Q) initially. The BOL and MOL information was generated from the basic EOL data which were increased $10 \%$ to account for fuel loading tolerances. Thus, the capsule maximum thermal inventory and the capsule temperatures were established as a function of time from encapsulation. Figure II -25 shows representative thermal inventory data from the study since the thermal inventory did not change significantly for the other design conditions analyzed. The capsule total thermal inventory required is approximately 1450 watts for a three-capsule per module design and approximately 1100 watts for a fourcapsule per module design. The minimum total thermal inventory for the sixmodule RTG is approximately 24 kilowatts. The maximum thermal inventory would therefore be $\sim 26.4$ kilowatts.

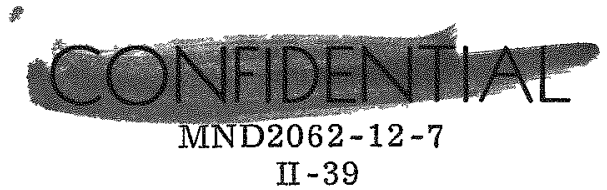



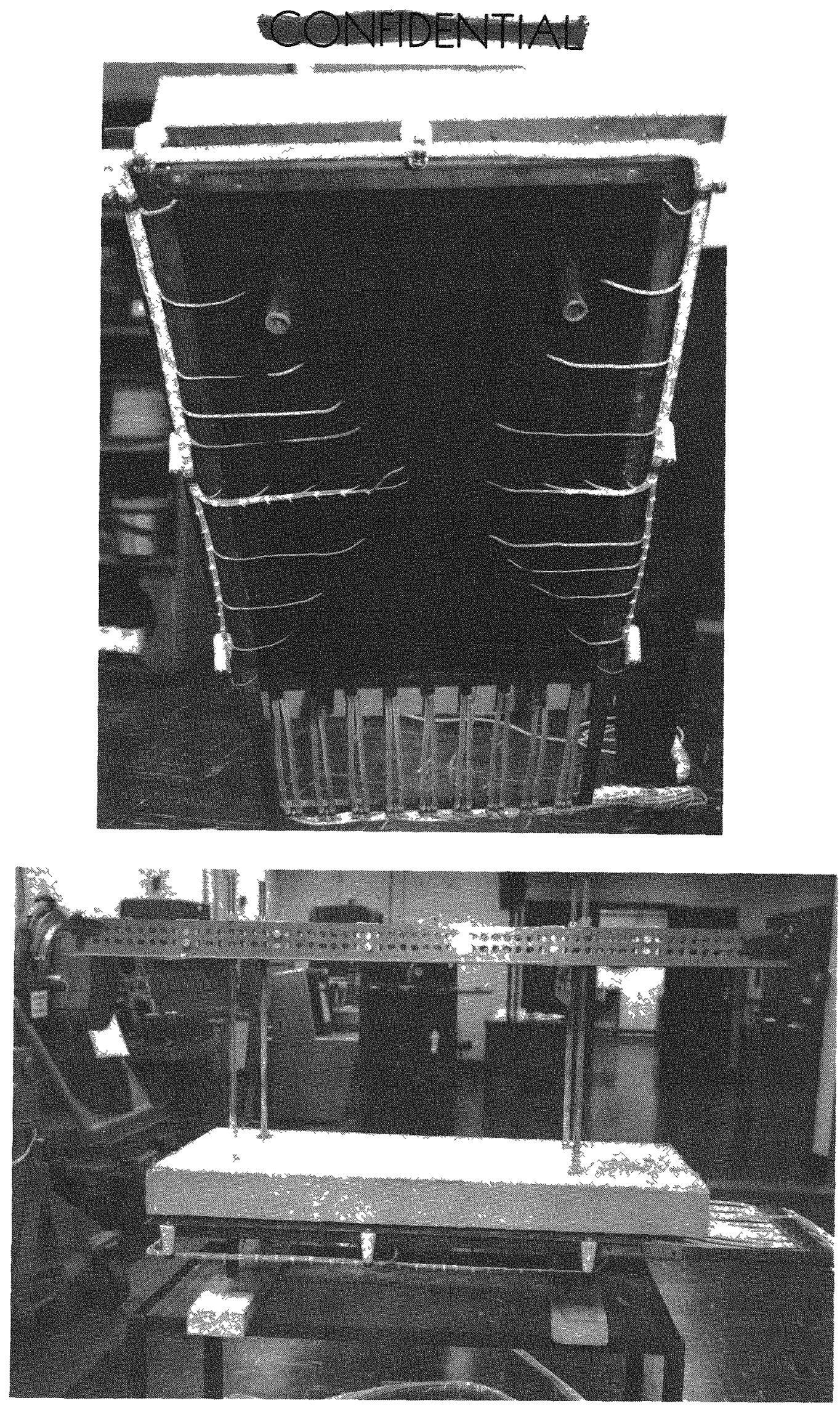

FIG. II-24 ELECTRIC HEATER BLOCK FOR DYNAMIC TEST OF FUEL BLOCK

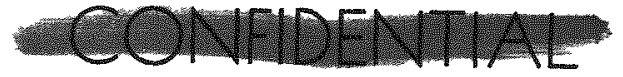

MND2062-12-7

II -40 


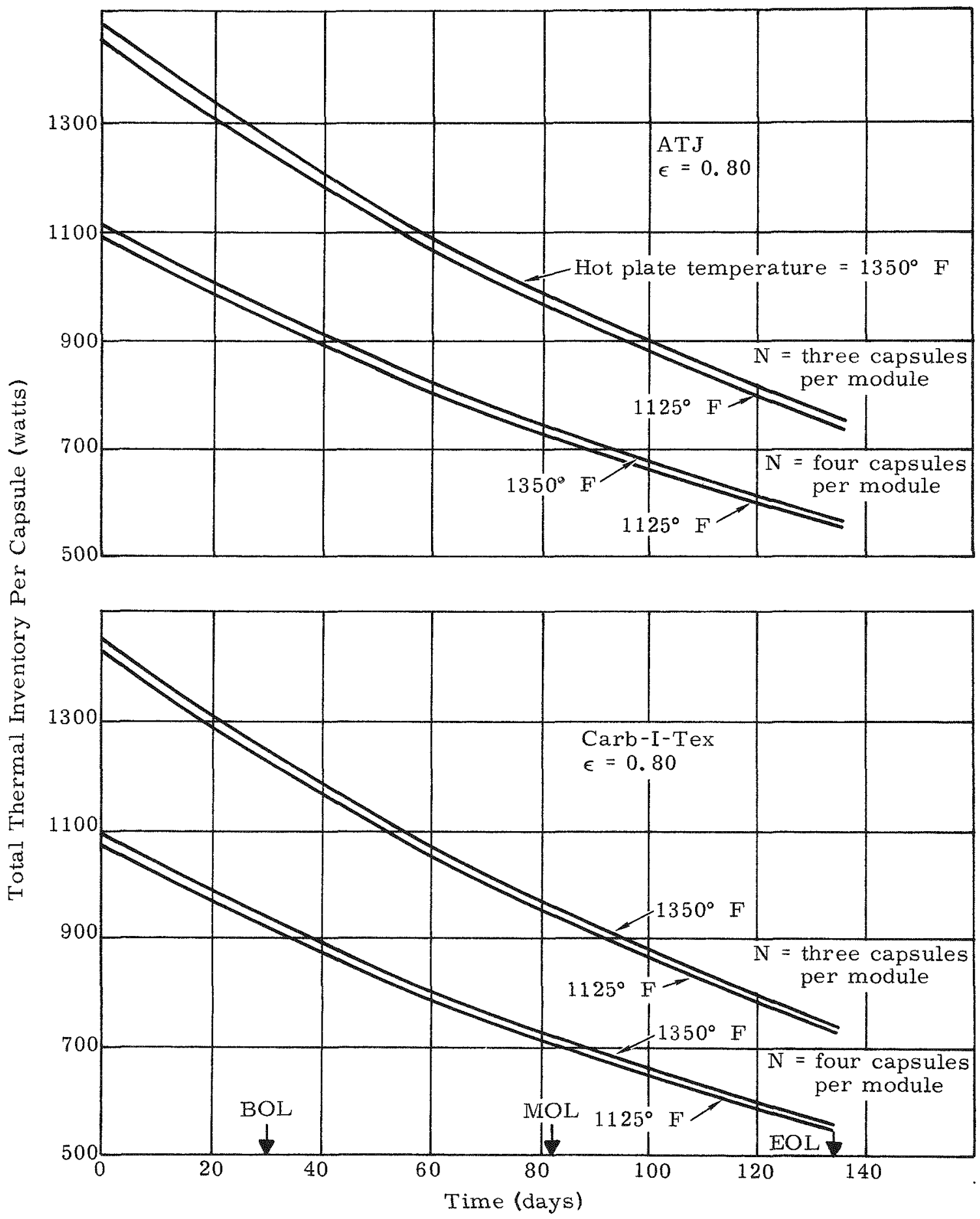

FIG. II -25. TOTAL THERMAL INVENTORY PER CAPSULE VERSUS TIME INCLUDING $10 \%$ FUEL LOADING TOLERANCE

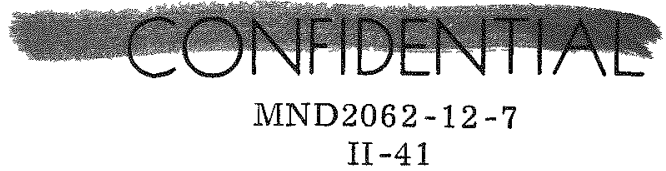


TABLE II - 17

Matrix of Thermal Analysis Parameters

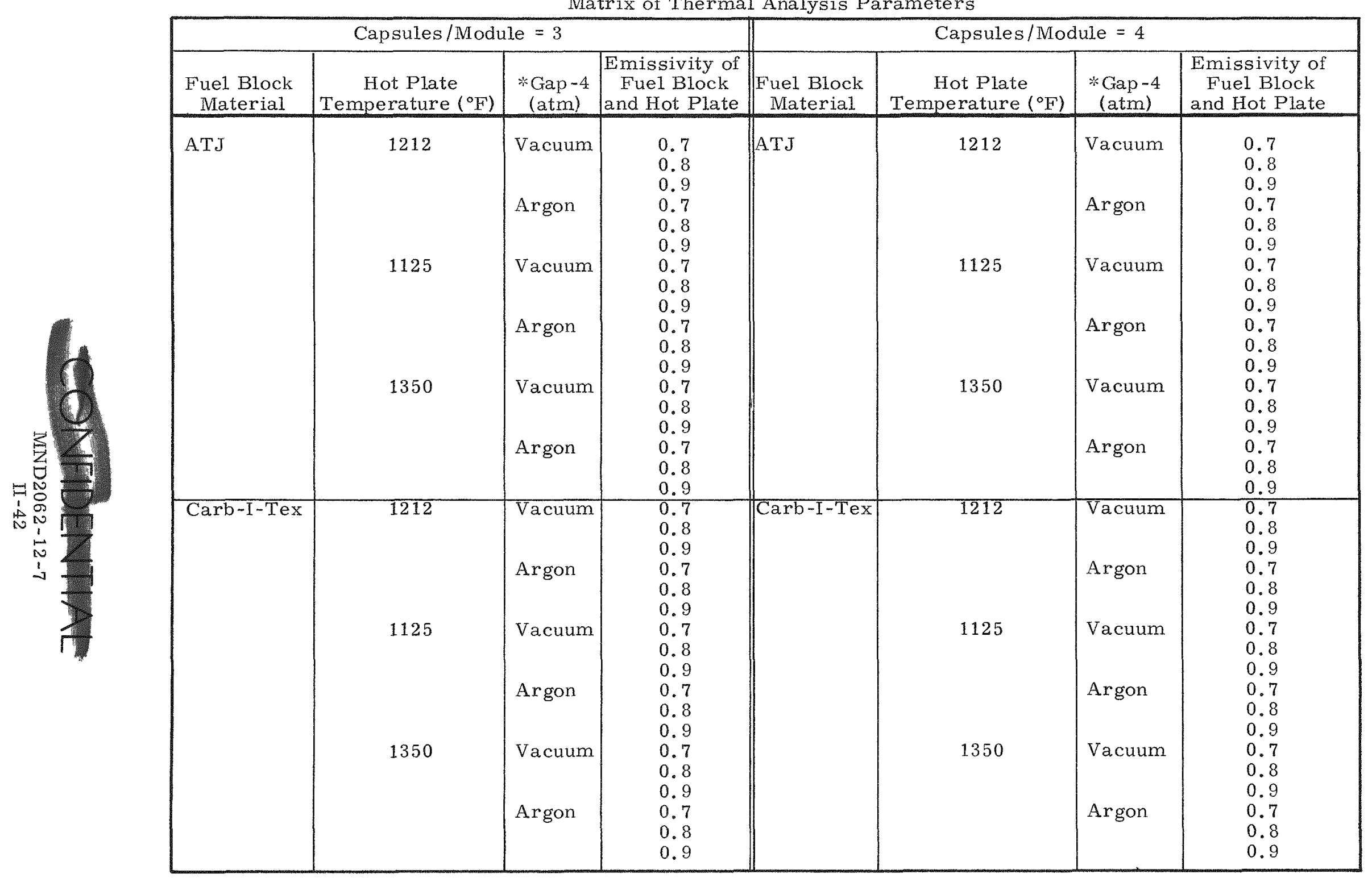

(1) Data for BOL and MOL conditions are computed after capsule $\mathrm{Q}$ is determined for $\mathrm{EOL}$ using values in this chart.

(2) Heat to thermoelectric modules $=6041 \mathrm{Btu} / \mathrm{hr}$ per module.

*Gap-4 is between capsule cladding and graphite block. 
The thermal efficiency of the RTG at EOL design conditions (minimum acceptable thermal inventory) is defined as the ratio of useful heat to the thermoelectric module to the total thermal inventory. The distribution of capsule thermal inventory and the resulting thermal efficiency are given for a typical design in Table II -18 .

Thus, a thermal efficiency on the order of $80 \%$ can be expected. The efficiency of the Carb-I-Tex fuel block system will be slightly higher than a system utilizing an ATJ fuel block.

Fuel block and fuel capsule temperature data are also of interest. Fuel block bore temperatures are extremely sensitive to emissivity of the critical surfaces (fuel block, capsule clad and hot plate) and to temperature of the hot plate. Figure II-26 illustrates the se two facts by the high rate of change of the temperature with both the emissivity and hot plate temperature. However, the number of capsules per module had little appreciable effect on the fuel block bore temperature.

The critical inner liner temperature of the fuel capsule is also extremely sensitive to emissivity as shown by Figs. II-27 and II-28. Hot plate temperature also produces a significant change in capsule inner liner temperature. The capsule inner liner temperature is somewhat higher for the Carb-I-Tex fuel block than for the ATJ fuel block. Inner liner-fuel matrix temperature compatibility has been established for a temperature of $1000^{\circ} \mathrm{C}$. Compatibility temperature testing at $1200^{\circ} \mathrm{C}$ was recently initiated because preliminary analyses indicated capsule temperatures would actually fall in the $1100^{\circ}$ to $1200^{\circ} \mathrm{C}$ range. Figures II -27 and II -28 confirm these predictions. A four-capsule per $\mathrm{T} / \mathrm{E}$ module design utilizing an ATJ fuel block provides the best chance of maintaining capsule inner liner temperature below the $1100^{\circ} \mathrm{C}$ limit--the current $1000^{\circ} \mathrm{C}$ limit, for all practical purposes, cannot be maintained.

The effects of design parameters on heat source characteristics are summarized in Table II-19.

The general conclusions from this study are:

(1) A four-capsule per module RTG (24 capsules) will best meet the capsule inner liner temperature requirements

(2) An extension of the inner liner-to-fuel matrix compatibility temperature limit to at least $1100^{\circ} \mathrm{C}$ is essential.

(5) Limitations on fuel capsule thermal inventory

The results of the parametric thermal analysis study and the desire to retain the three-capsule per module fuel block design necessitated that the thermal inventory capacity of the current capsule geometric design be determined. Capsule thermal inventory is limited by geometric considerations (volume, thickness, clearance tolerances, etc.), fuel loading characteristics and helium pressure buildup.

A parametric study of these factors with respect to their influence on thermal inventory limits has been performed. Preliminary results indicate that the RTG thermal inventory cannot be achieved with a three-capsule per module design which requires that the capsule have a thermal inventory of approximately 1450 watts.

Figure II-29 shows the effect of temperature and capsule outer liner design strength limits on the fuel capsule thermal inventory capacity. For example, a capsule internal temperature at re-entry of $2600^{\circ} \mathrm{F}$ (which is optimistically based on

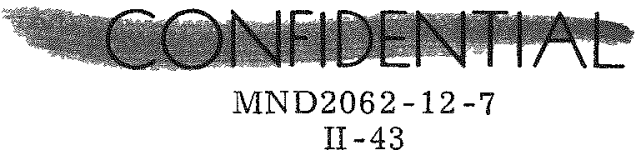




\section{TABLE II -18}

Typical System Thermal Efficiency at EOL Design Conditions $\left(\overline{\mathrm{T}}_{\mathrm{H}}=1050^{\circ} \mathrm{F}\right.$ and $\left.\overline{\mathrm{T}}_{\mathrm{C}}=350^{\circ} \mathrm{F}\right)$

\begin{tabular}{|c|c|c|c|c|c|c|c|c|}
\hline \multirow{2}{*}{$\begin{array}{l}\text { Fuel } \\
\text { Block }\end{array}$} & \multirow{2}{*}{$\begin{array}{c}\text { Emissivity } \\
(\epsilon)\end{array}$} & \multirow{2}{*}{$\begin{array}{l}\text { Capsules/ } \\
\text { Module } \\
\end{array}$} & \multirow{2}{*}{$\begin{array}{c}\text { Hot Plate } \\
\text { Temperature }\left({ }^{\circ} \mathrm{F}\right)\end{array}$} & \multirow{2}{*}{$\begin{array}{l}\text { Total Q } \\
\text { at EOL } \\
\text { (watts) }\end{array}$} & \multicolumn{3}{|c|}{ Losses (watts) } & \multirow{2}{*}{$\begin{array}{c}\text { Efficiency } \\
n\end{array}$} \\
\hline & & & & & T/E Module & Housing & Shutter & \\
\hline \multirow[t]{2}{*}{$\mathrm{ATJ}$} & 0.8 & 18 & 1212 & 677 & 50 & 69 & 18 & 79.7 \\
\hline & & 24 & & 509 & 38 & 52 & 15 & 79.4 \\
\hline \multirow[t]{2}{*}{ Carb-I-Tex } & & 18 & & 664 & 50 & 56 & 18 & 81.4 \\
\hline & & 24 & & 498 & 38 & 41 & 15 & 81.1 \\
\hline
\end{tabular}

TABLE II-19

Effect of Design Parameters on Heat Source Characteristics

\section{Effect On}

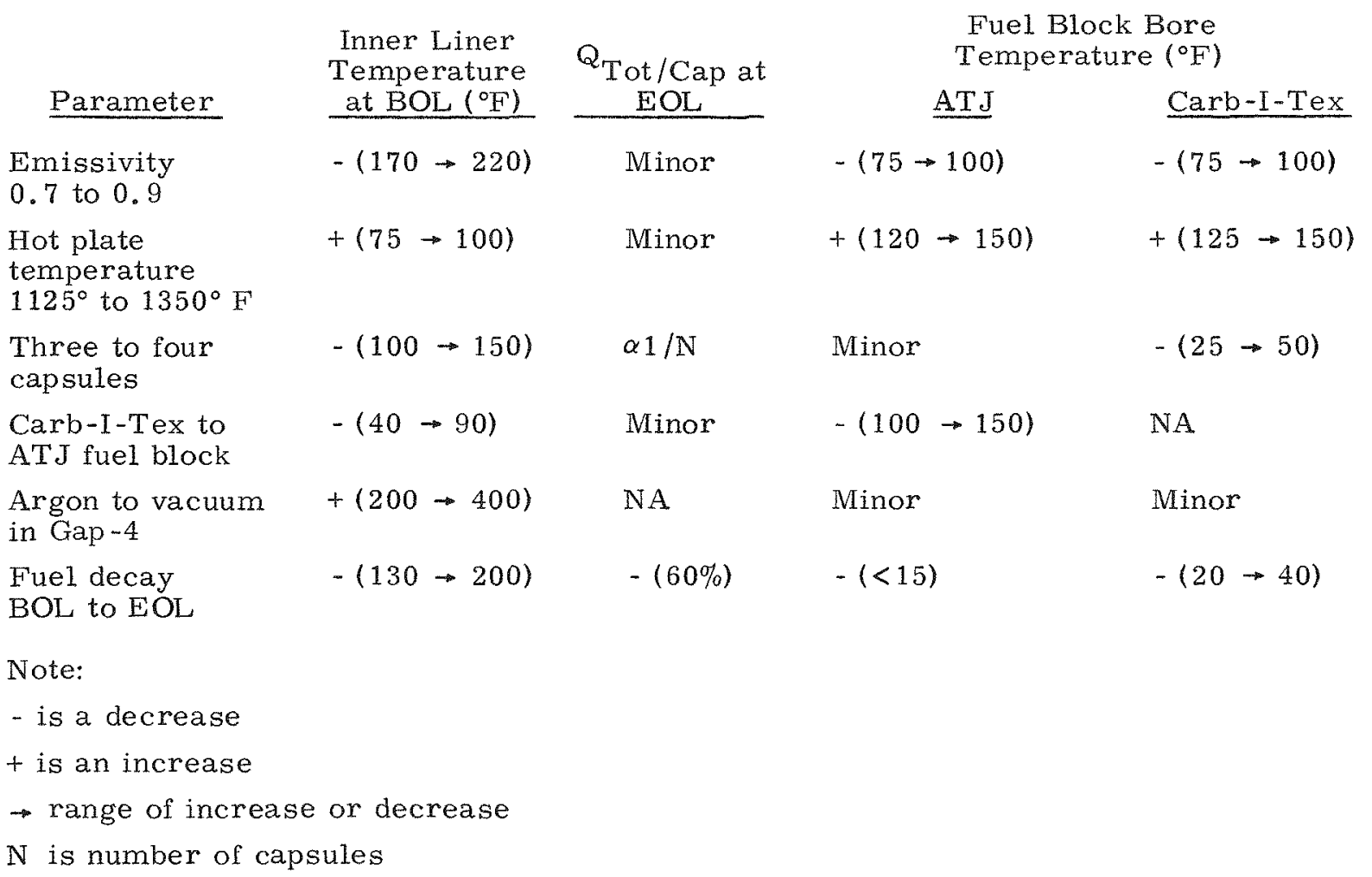



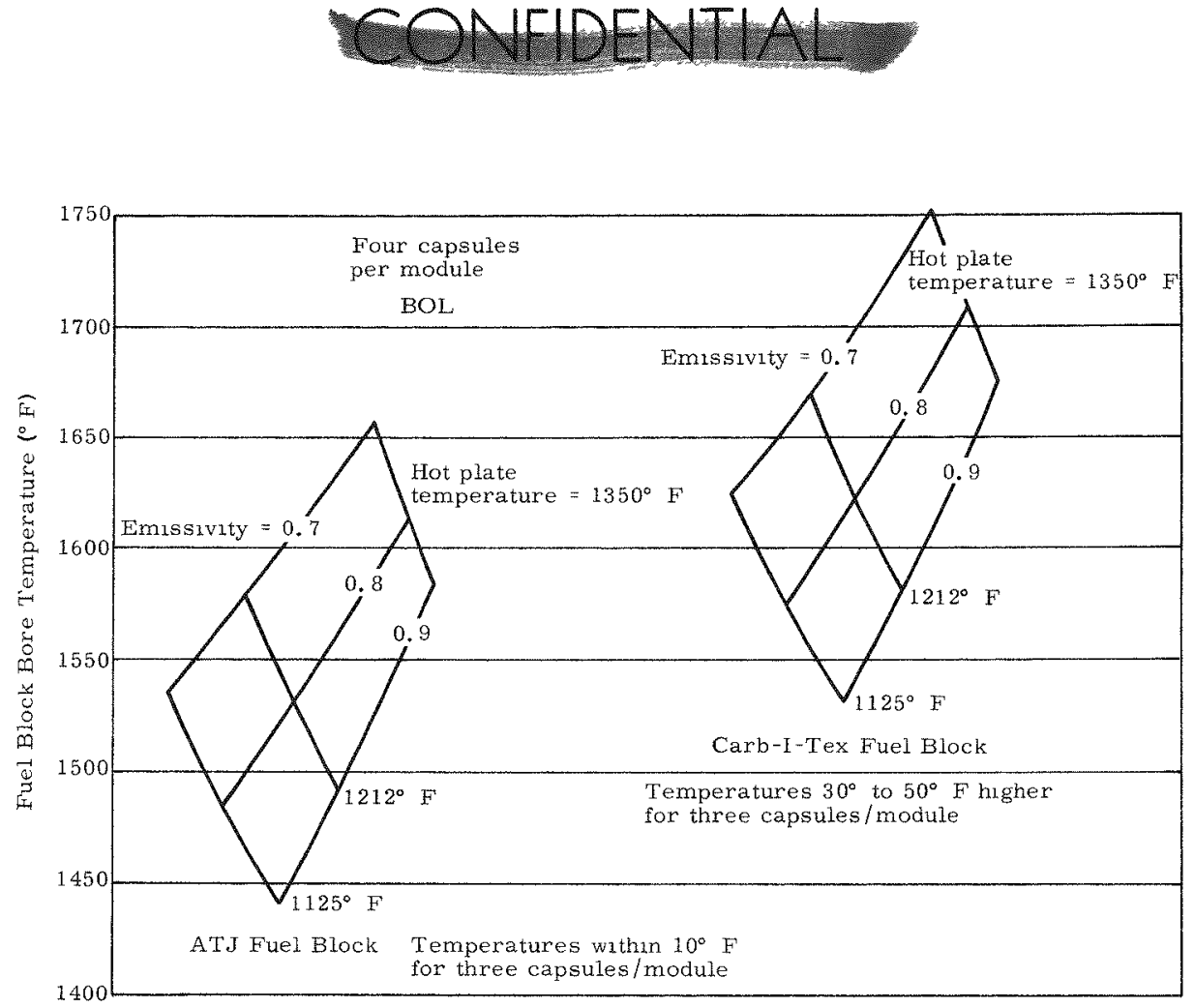

FIG. II-26. FUEI BIOCK BORE TEMPERATURE VERSUS EMISSIVITY AND HOT PLATE TEMPERATURE

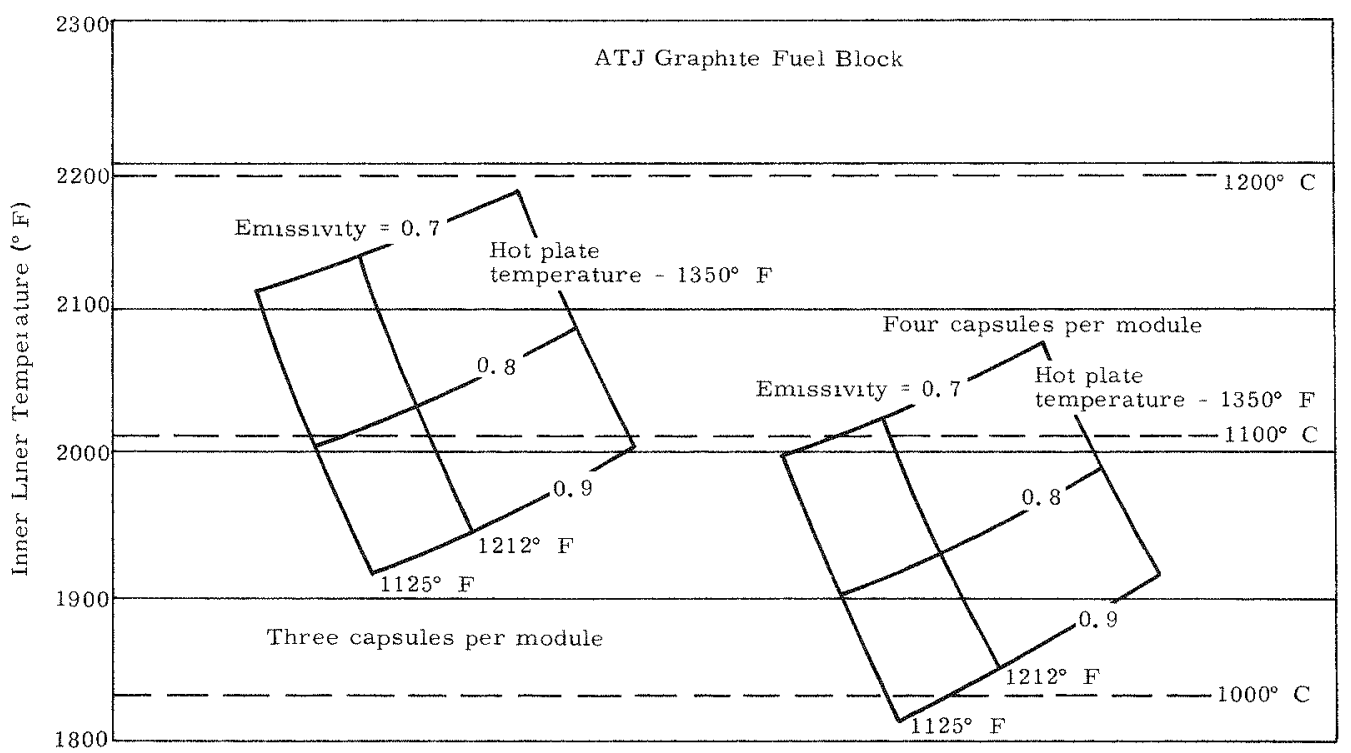

FIG. II-27. INNER LINER TEMPERATURE AT BOL VERSUS EMISSIVITY AND HOT PLATE TEMPERATURES

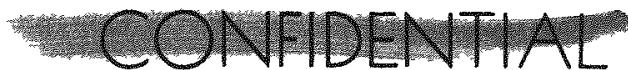

MND2062-12-7 


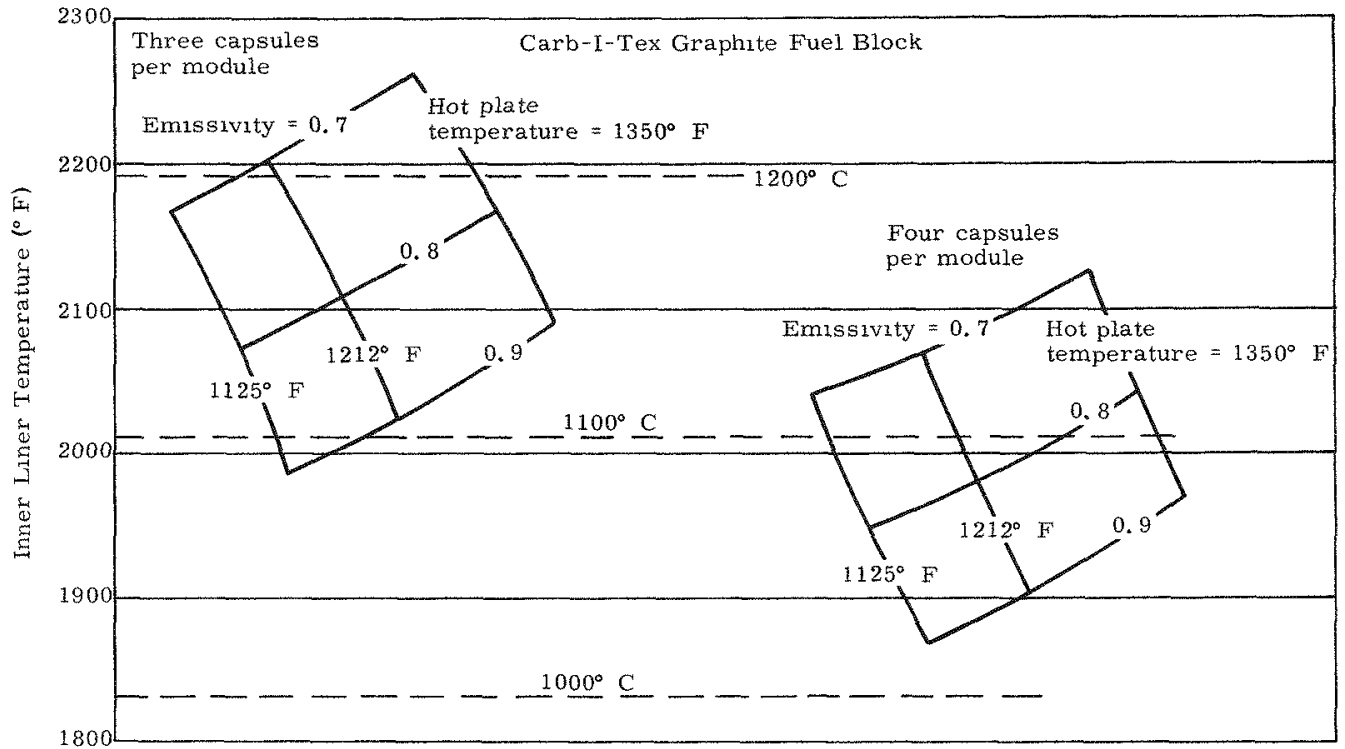

FIG. II- 28. INNER LINER TEMPERATURE AT BOL VERSUS EMISSIVITY AND HOT PLATE TEMPERATURE

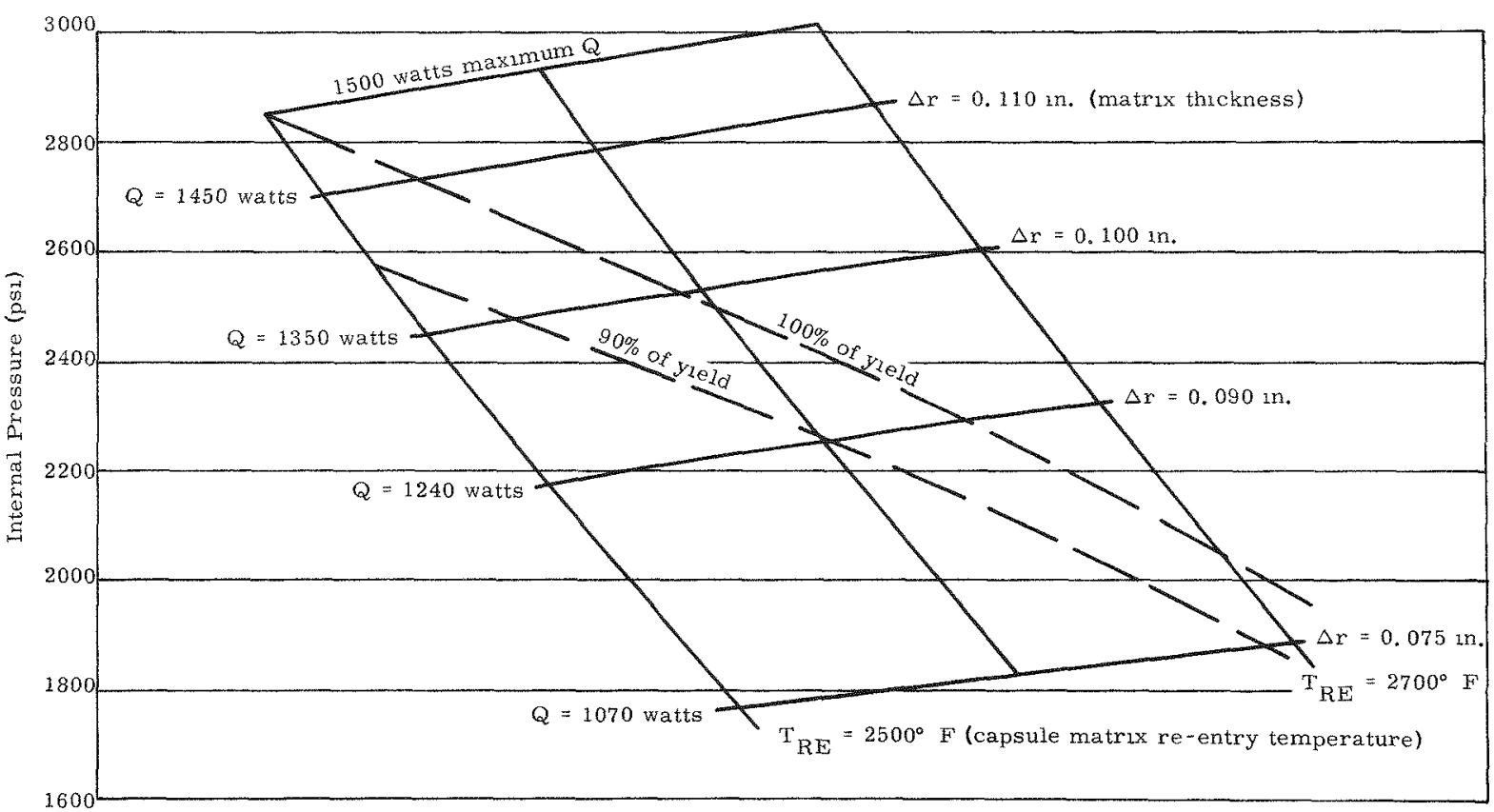

FIG. II -29. RESULTS OF CAPSULE PARAMETRIC STUDY

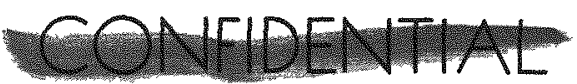

MND2062-12-7

II -46 
re-entry trajectory studies) and an outer liner design point of $90 \%$ yield strength will limit the thermal inventory of a capsule to approximately 1240 watts. This is well below the 1450 watts/capsule required of a three-capsule per module design. On the other hand, a four-capsule per module design, which requires that the capsule have a total thermal inventory at encapsulation of approximately 1100 watts, would be feasible for immediate re-entry after a 134 -day mission.

The final results of this study will be published early in the next reporting period.

(6) Structural housing thermal losses

The thermal losses from the structural housing around the fuel block, shutters and $\mathrm{T} / \mathrm{E}$ modules have been determined for a reference eight-module RTG (Fig. II$30)$ by means of computer analysis techniques. The heat distribution with respect to critical dimensions and surface areas was then tabulated for this specific design. The RTG configurations utilizing a different number of T/E modules and/or a different arrangement of the modules were evaluated with respect to changes in the critical dimensions and surface areas on the assumption that the structure of the components remains essentially unchanged for different module arrangements. Finally, dimensional ratios and the heat distribution data for the eight-module design were combined to yield estimates of the housing thermal losses for all of the configurations (module variations) considered. Figure II-31 shows possible arrangements for other RTG systems. The modular housing surrounds the se modules similar to a picture frame. The thermal losses from the housing of each of these configurations relative to the thermal losses of the eight-module reference configuration are shown in Table II -20 .

\section{TABLE II -20}

Heat Lost from RTG Housing (watts)

(includes heat from shutter and $\mathrm{T} / \mathrm{E}$ module sides, top and bottom)

Interface Temperature

Fuel Capsule/ Fuel Block $\left({ }^{\circ} \mathrm{F}\right)$
1300

1400

1500

1600

1700

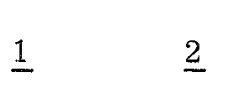

Nonoutgassed Insulation
Modular Arrangements

$\underline{3} \quad \underline{4} \quad \underline{5}$

$\underline{5}$

$\underline{6}$

7 

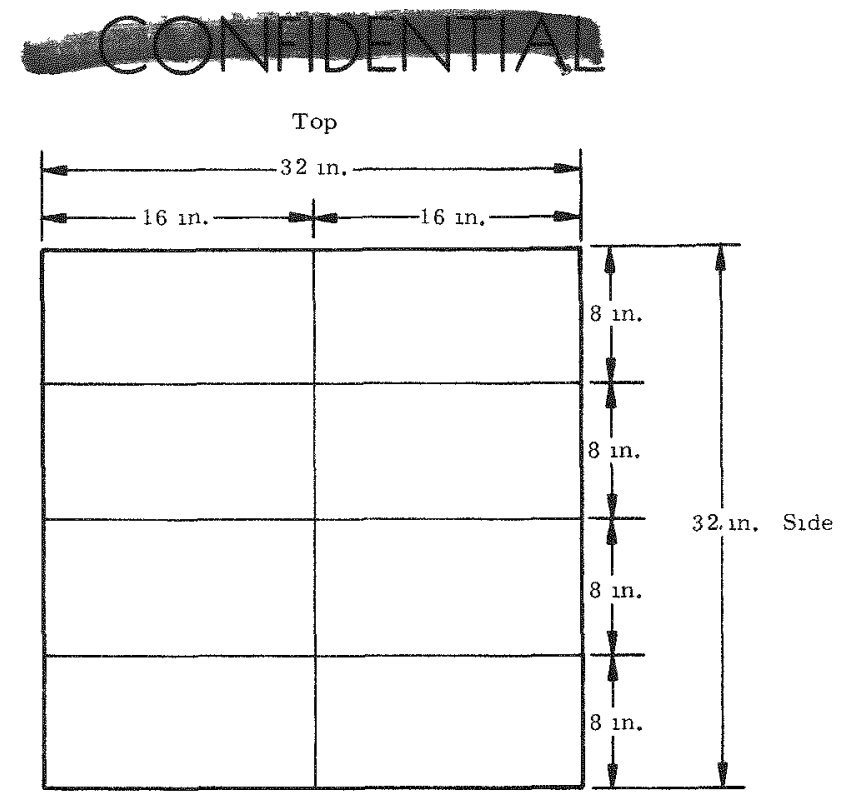

Arrangement 1

FIG. II-30. CONFIGURATION FOR AN EIGHT-MODULE GENERATOR

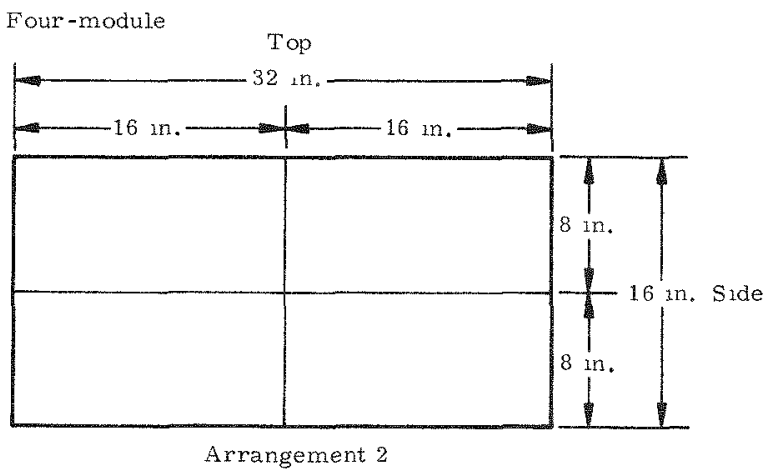

Arrangement 2

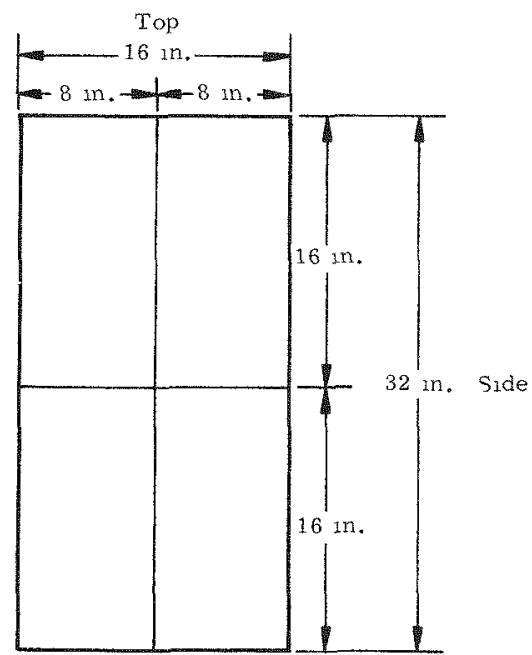

Arrangement 3

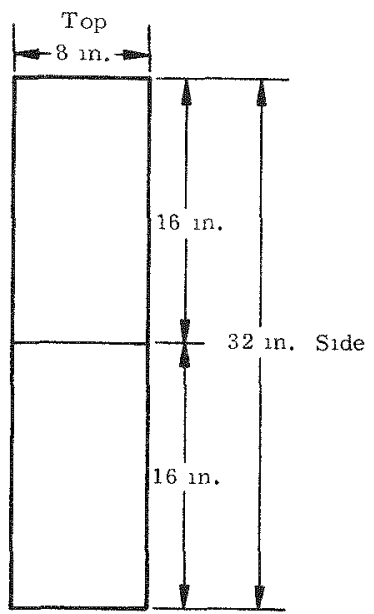

Arrangement 5

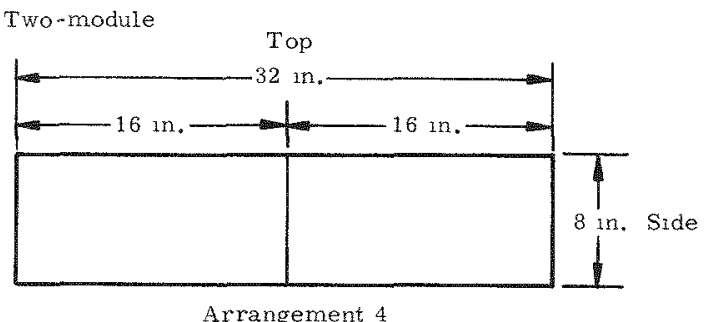

Two-module

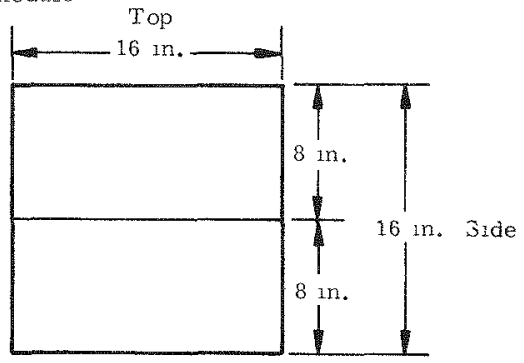

Arrangement 6

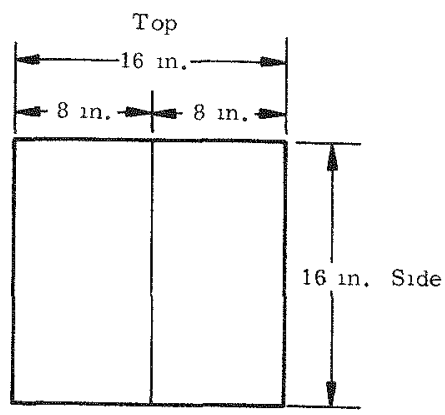

Arrangement 7

FIG. II-31. MODULE GENERATOR CONFIGURATION

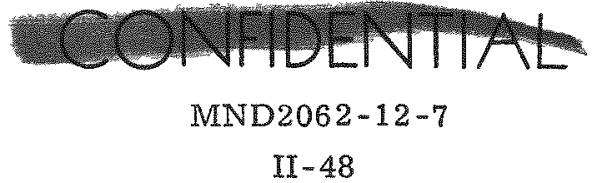


(7) Re-entry heating analysis

The two-, four-, six- and eight-module size fuel blocks were examined using the two-dimensional analytical model, shown in Fig. II-32, for an initial flight path angle of -3 degrees. This analysis supplemented the results for an initial angle of -0.1 degree presented in the previous Quarterly Report. The heating data used were based on Martin Marietta hot shot wind tunnel tests. The initial fuel block temperature was assumed to be $1600^{\circ} \mathrm{F}$. The capsule temperature was selected to be compatible with the assumptions made regarding the gap.

The peak capsule temperatures are listed in Table II-21. The variation from one size block to the next is approximately $50^{\circ} \mathrm{F}$ with the smallest size being the hottest. The highest level temperature histories for a four-module block of the block and capsule are shown in Figs. II -33 and II-34 for the tumbling and oscillating re-entry modes.

TABLE II -21

Peak Capsule Temperatures During Re-entry

Block Size

$\begin{gathered}\text { Dimensions } \\ \text { (in.) }\end{gathered}$
Modules
(No.)

Temperatures for Re-entry Modes $\left({ }^{\circ} \mathrm{F}\right)$

$35.63 \times 32.68$

8

Broadside

Oscillating

Tumbling

$27.20 \times 32.68$

6

2590

2660

2530

$18.79 \times 32.68$

2620

2690

2550

$18.79 \times 17.39$

4

2670

2740

2580

$10.35 \times 32.68$

2

2740

2810

2620

2820

2890

2670

These results are based on:

(1) Heating distributions obtained from Martin Marietta hot shot data

(2) Initial path angle $=-3.0$ degrees

(3) Initial velocity $=25,690 \mathrm{fps}$

(4) Fuel block material--ATJ graphite

(5) Two-dimensional analytical model (Fig. II-32)

(6) Factor on nominal heat flux $=1.25$

(7) Vacuum gap between block and capsule.

As aerodynamic heating data become available from the recently conducted Arnold Engineering Development Center (AEDC) Tunnel B tests, the aerothermal analysis of the modular block configurations will be updated. At present, only an edge-on spin re-entry mode has been analyzed using AEDC data. A threedimensional model, shown in Fig. II-35, was used in the analysis. As with previous work, a 1.25 design factor was applied to the heating rate.

Table II-22 presents the peak capsule and fuel block temperatures for the edge-on spin mode. Figure II-36 shows the peak capsule temperature histories.

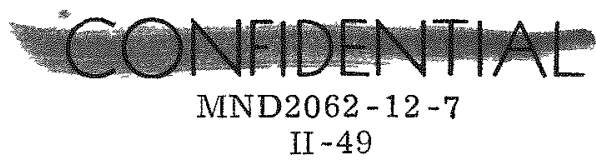




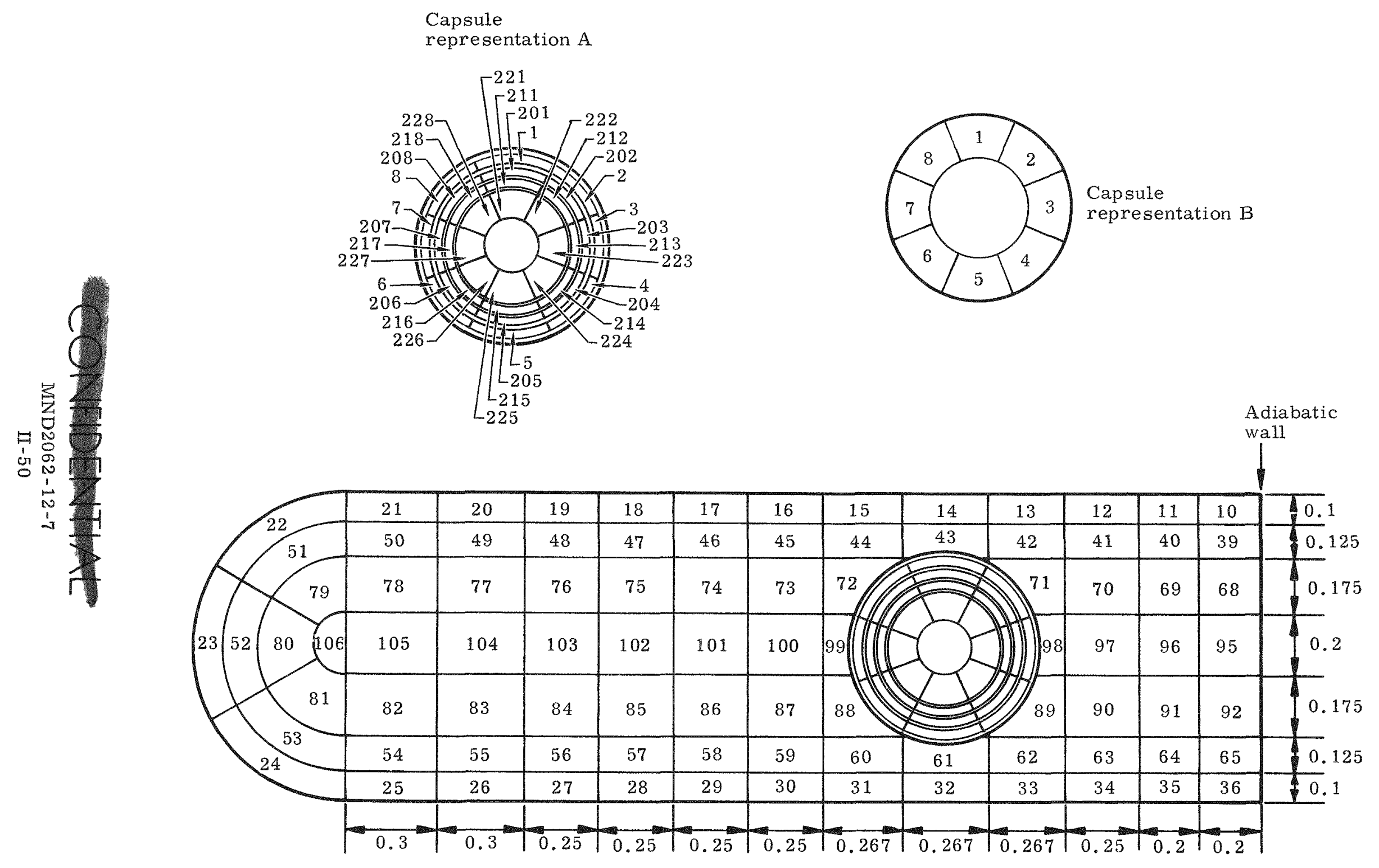

FIG. II-32. TWO-DIMENSIONAL THERMAL MODEL, 2.5 IN. EDGE WIDTH, 1 IN. THICK 


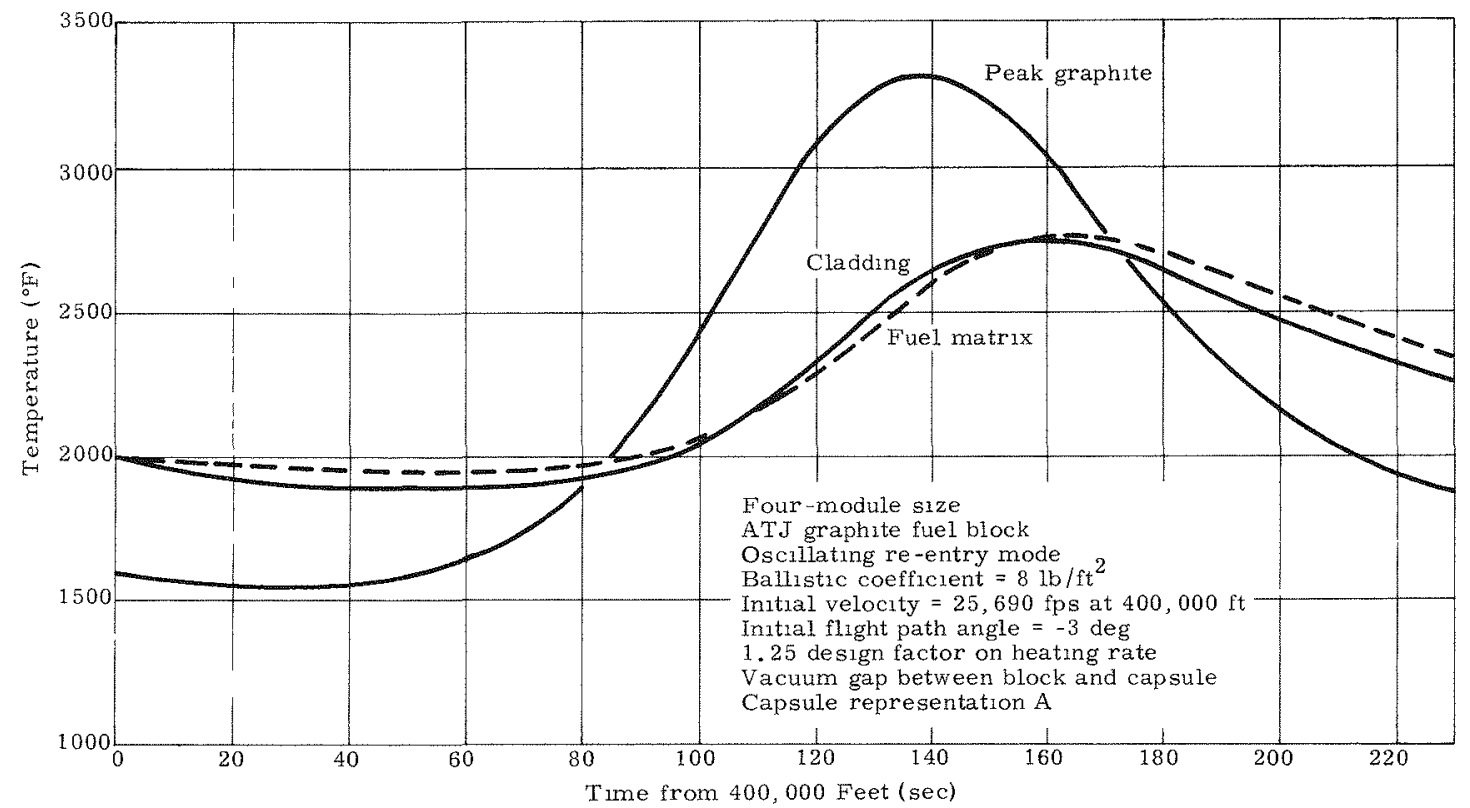

FIG. II-33. RE-ENTRY TEMPERATURE HISTORIES--OSCILLATING MODE

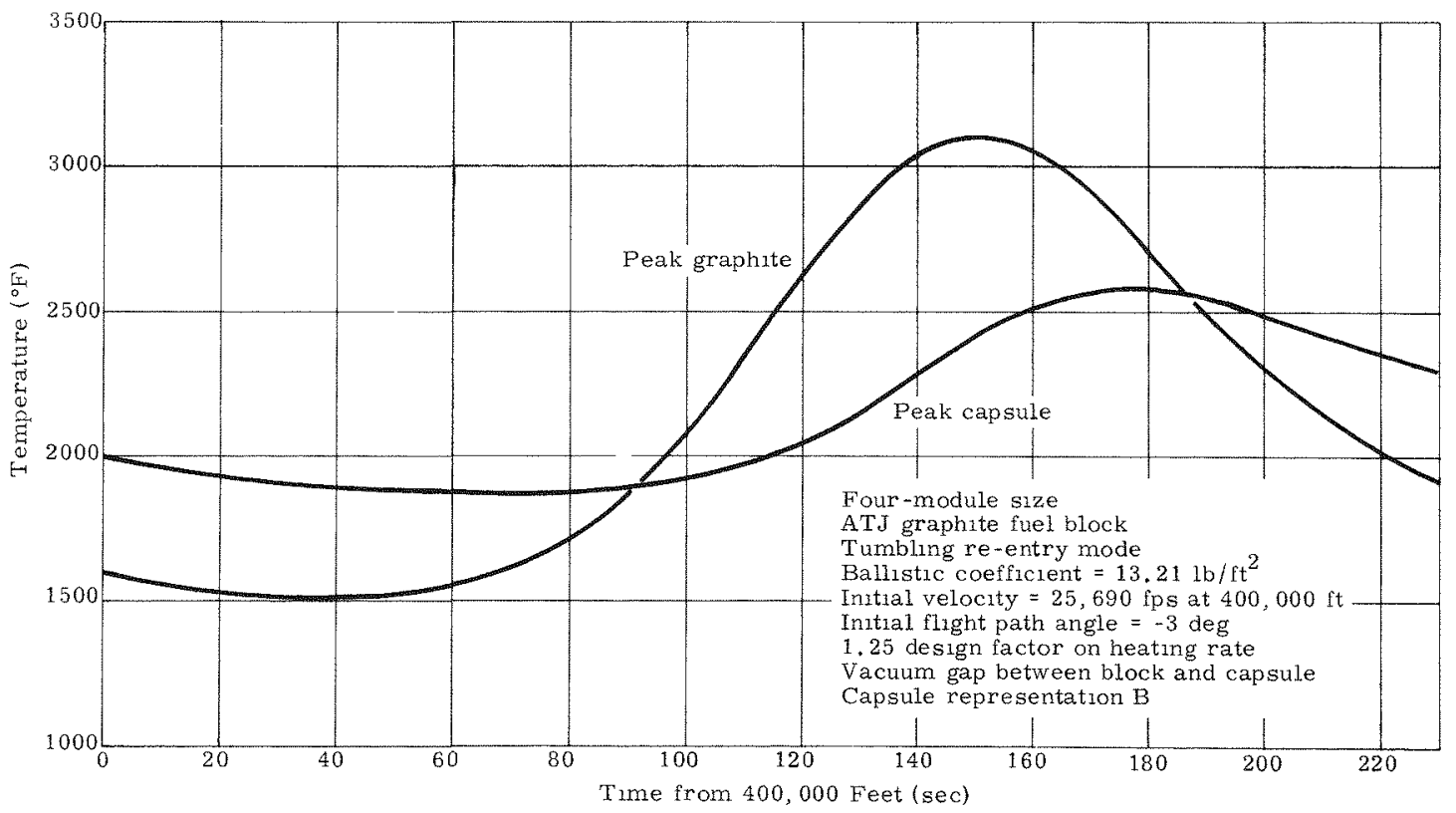

FIG. II-34. RE-ENTRY TEMPERATURE HISTORIES--TUMBLING MODE

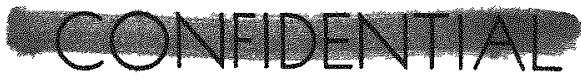

MND2062-12-7

II -51 


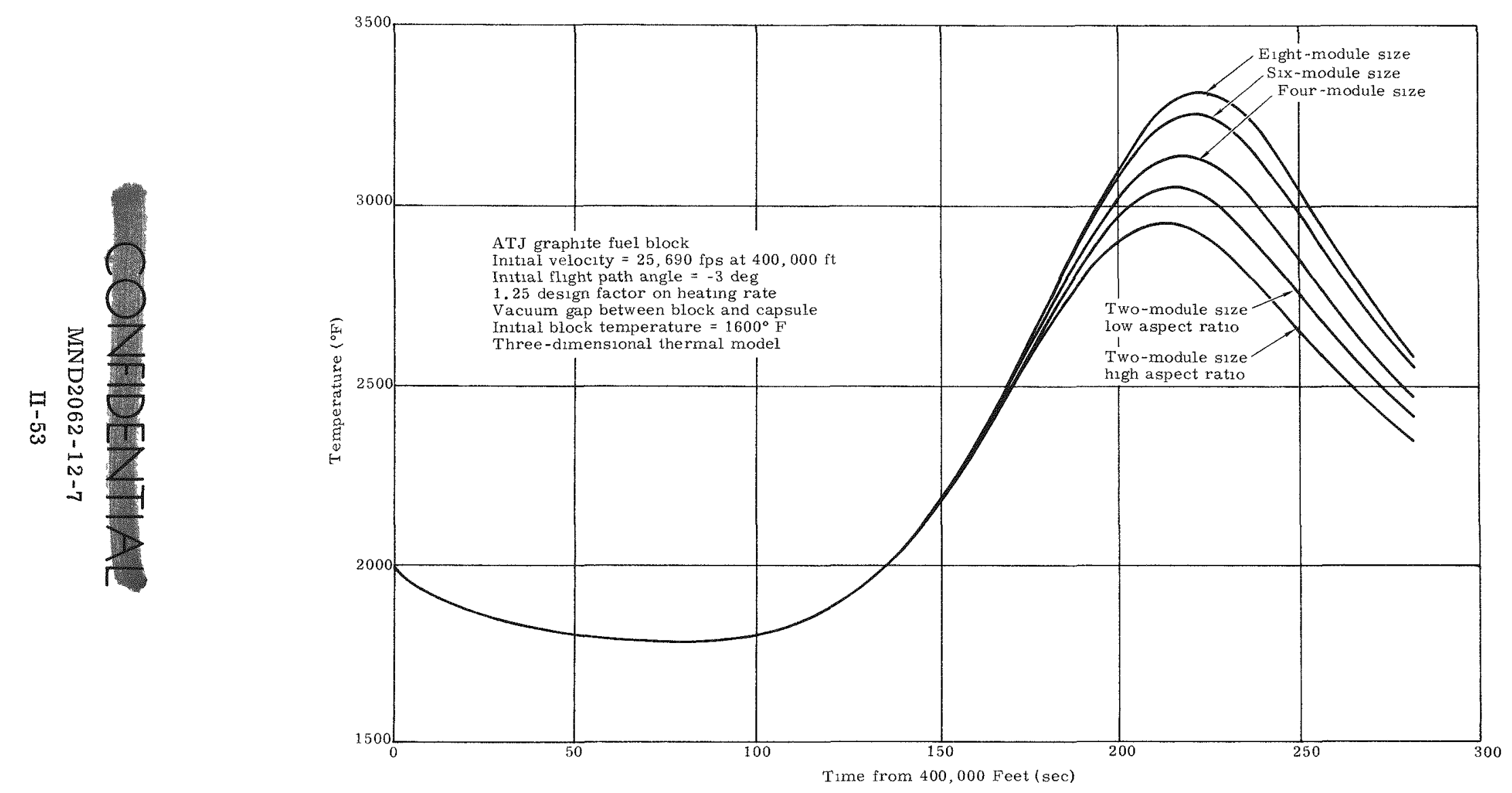

FTG. II -36. CAPSULE TEMPERATURE HISTORIES--EDGE-ON SPIN RE-ENTRY MODE 
TABLE II -22

Peak Edge-on Spin Re-entry Temperatures

Block Size

\begin{tabular}{ccccc}
$\begin{array}{c}\text { Dimensions } \\
(\text { in.) }\end{array}$ & Modules (No.) & & \multicolumn{2}{c}{ Temperature $\left({ }^{\circ} \mathrm{F}\right)$} \\
\cline { 1 - 1 } $35.63 \times 32.68$ & 8 & & 3310 & 5600 \\
$27.20 \times 32.68$ & 6 & 3250 & 5500 \\
$18.79 \times 32.68$ & 4 & 3140 & 5290 \\
$18.79 \times 17.39$ & 2 & 3050 & 5140 \\
$10.35 \times 32.68$ & 2 & 2950 & 4950
\end{tabular}

Results are based on:

(1) Heating distributions obtained from AEDC Tunnel B data

(2) Initial path angle $=-3$ degrees

(3) Initial velocity $=25,690 \mathrm{fps}$

(4) Fuel block material--ATJ graphite

(5) Three-dimensional analytical model (Fig. II-35)

(6) Factor on nominal heat flux $=1.25$

(7) Vacuum gap between block and capsule

A thermal model suitable for analyzing the tumbling mode of re-entry of a SNAP 29 heat source has been formulated. The model has been coded for the thermochemical ablation program (T-CAP IV) and the thermal analyzer program (TAP III) and is presently being checked out. The T-CAP IV code will be used to determine thermochemical effects during re-entry. TAP III is a nonablative code and will be used in conjunction with T-CAP IV to determine the influence of these thermochemical effects on the peak temperature of a SNAP 29 fuel heat source during re-entry.

(8) Re-entry heating tests

Test specimens have been designed that will be used to evaluate the effects of the predicted SNAP 29 re-entry thermal environment on the two candidate fuel block materials (ATJ graphite and Carb-I-Tex 500 cross-needled graphite) and on mock-up models of the SNAP 29 fuel block assembly. There are three basic test specimen designs:

Material screening models. Twenty-six models $(2-1 / 2$ inch diameter by $\approx 4$ inch long) are to be used to obtain surface recession data and evaluate material characteristics such as spallation, cracking, compatibility with cladding, etc.

Edge member models. Six 6 by 4 by 1 -inch ATJ graphite and six 3 by 4 by 1 -inch Carb-I-Tex graphite models are to be used in the evaluation of the capsule retainer design, compatibility of graphite with cladding and graphite bond lines.

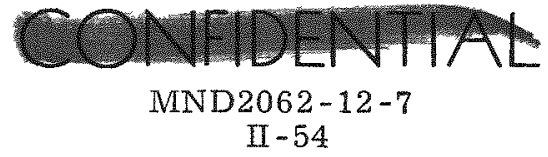


Mock-up correlation models. Twelve $6-1 / 2$ by $6-1 / 2$ by 1 -inch ATJ graphite models are to be used to obtain temperature history data at approximately 12 internal locations during exposure to constant heat fluxes. These data will be used for correlation with analytical predictions.

Two types of calorimeters have been designed that will be used to measure the heat flux to the test configurations being tested. They are:

Copper slug calorimeters. Single copper slug calorimeters are used during the initial calibration of the tunnel and multislug copper calorimeters are used for actual heat flux measurements prior to test.

Gardon gage calorimeter. A water-cooled Gardon gage calorimeter has been designed to measure the heat fluxes to the mock-up correlation models. Thirteen Gardon gages are located such that the heat flux distribution can be well defined over the surface of the $6-1 / 2$ by $6-1 / 2$ by 1 -inch configurations while they are in elther test orientation, i.e., edge-on or broadside.

The material screening models have been manufactured. Eight of these models require that an oxidation cladding be applied to the external surface of the graphite. The components for the edge member models and the mock-up correlation models have been manufactured. Instrumentation and assembly of these models will be accomplished after the external surfaces of the graphite components have been clad.

The components of the copper slug calorimeters have been fabricated. Assembly and instrumentation of these calorimeters is $85 \%$ complete.

The testing is being performed in the Martin Marietta Corporation one-megawatt plasma arc facility according to Development Test Procedure (Dev-TP) 1140-11. To date, eight ATJ graphite and four Carb-I-Tex graphite specimens have been tested to the calibrated test conditions given on Table II-23. The test data have not been reduced, therefore only limited information is available at this time. Surface temperatures were measured and recorded with an optical pyrometer. The peak temperatures recorded on the surface were approximately $3500^{\circ}$ to $4200^{\circ} \mathrm{F}$ for the $\mathrm{ATJ}$ and Carb-I-Tex models, respectively. Internal temperatures at distances of $1 / 2$ and 1 inch from the initial surface were measured and recorded continuously during test with tungsten rhenium thermocouples. The quality of all temperature measurements appears to be very good. Total recession ranged between 0.015 and 0.150 inch.

TABLE II -23

Plasma Arc Test Conditions

\begin{tabular}{|c|c|c|c|c|c|c|}
\hline $\begin{array}{l}\text { Graphite } \\
\text { Type } \\
\end{array}$ & $\begin{array}{l}\text { Quantity } \\
\text { Tested }\end{array}$ & 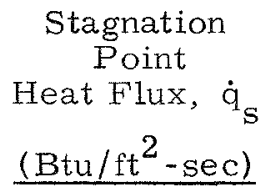 & $\begin{array}{c}\text { Stagnation } \\
\text { Enthalpy, hs } \\
(\text { Btu } / 1 \mathrm{bm}) \\
\end{array}$ & $\begin{array}{c}\text { Stagnation } \\
\text { Pressure, } \mathrm{p}_{\mathrm{s}} \\
(\mathrm{atm}) \\
\end{array}$ & $\begin{array}{l}\text { Test } \\
\text { Time } \\
\text { (sec) }\end{array}$ & $\begin{array}{c}\text { Nozzle } \\
\text { Diameter } \\
\text { (in.) } \\
\end{array}$ \\
\hline $\mathrm{ATJ}$ & 2 & 255 & 10,850 & 0.074 & 170 & 3.0 \\
\hline Carb-I-Tex & 2 & 255 & 10,850 & 0.074 & 170 & 3.0 \\
\hline $\mathrm{ATJ}$ & 2 & 255 & 10,850 & 0.074 & 280 & 3.0 \\
\hline $\mathrm{ATJ}$ & 2 & 86 & 9,500 & 0.015 & 250 & 3.0 \\
\hline Carb-I-Tex & 2 & 86 & 9,500 & 0.015 & 250 & 3.0 \\
\hline $\mathrm{ATJ}$ & 2 & 86 & 9,500 & 0.015 & 350 & 3.0 \\
\hline
\end{tabular}

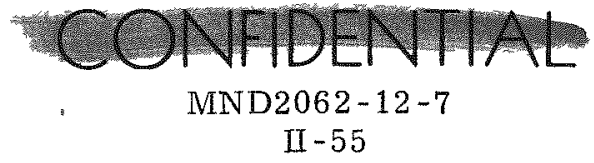




\section{HEAT SOURCE (ELECTRICAL) SUBSYSTEM--CONTROL POINT 1200}

The objective of this task is the development and qualification of electrical heat sources for the thermoelectric module and generator which simulate the thermal characteristics of the isotopic heat source. The task is divided into the following subtasks.

CP 1240--Heat Source (Electrical) Subsystem, Component Development

CP 1230--Heat Source (Electrical) Subsystem, Design Verification

CP 1220--Heat Source (Electrical) Subsystem, Demonstration Unit

Effort was continued during this reporting period on the component development of the electric heat source for the $\mathrm{T} / \mathrm{E}$ modules and of the generator electric heat source.

\section{Summation of Accomplishments}

During this period, life tests were initiated on the module and generator heaters from Watlow, Sanders and TRW. Thermal cycle tests of the Watlow and TRW heaters were also initiated (Fig. II - 37). Due to the high failure rate of the Sanders module and generator heaters on life test, they were not included in the thermal cycle tests.

Of the five TRW module heaters for life test, three failed. Failure analyses are being performed on all failed heaters. As discussed in the previous quarterly report, the problem with the Sanders heaters appears to stem consistently from the design of the heater element to lead joint. It is expected that the results of the failure analysis will verify this fact. Results of failure analysis of the TRW heaters are unavailable at this time.

The need to reduce program costs, coupled with the performance history of the TRW and Sanders electrical heaters, has resulted in the termination of all further testing of these heaters. The results of life, thermal cycle and vibration performance testing of Watlow heaters in related subsystem component tests have resulted in a high degree of confidence in their capability.

Although the Watlow heaters have the required temperature and life capability, their performance in a vacuum is not known. A simplified vacuum test was devised where three of the Watlow module size heaters were placed in a vacuum chamber with suitable insulation to permit the heaters to reach the desired temperature. The heaters were operated at 1000 watts, $1700^{\circ} \mathrm{F}$, and a vacuum which reached $10^{-7}$ torr for a period of five days. At that time it was necessary to shut down to repair feedthroughs in the test fixture. The test will be resumed early in January.

The status of the electrical heaters at the time of termination of the originally planned program is shown in Table II- 24.

A further problem experienced on the static module tests has been a poor thermal distribution on the hot side of the thermoelectric module.

A typical example of the measured thermal gradients on the electric heater block is shown in Fig. II-38. Each point represents a thermocouple location on the heater block. The upper reading at each point was taken 10/28/67 where the lower reading was taken 12/15/67. The heater block in this case is located in $\mathrm{T} / \mathrm{E}$ module $\mathrm{S} / \mathrm{N} 001$. Lengthwise gradients as high as $120^{\circ} \mathrm{F}$ exist.

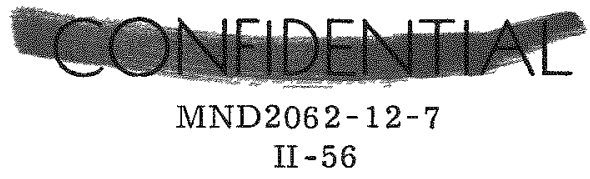




\section{CóONEDEN}

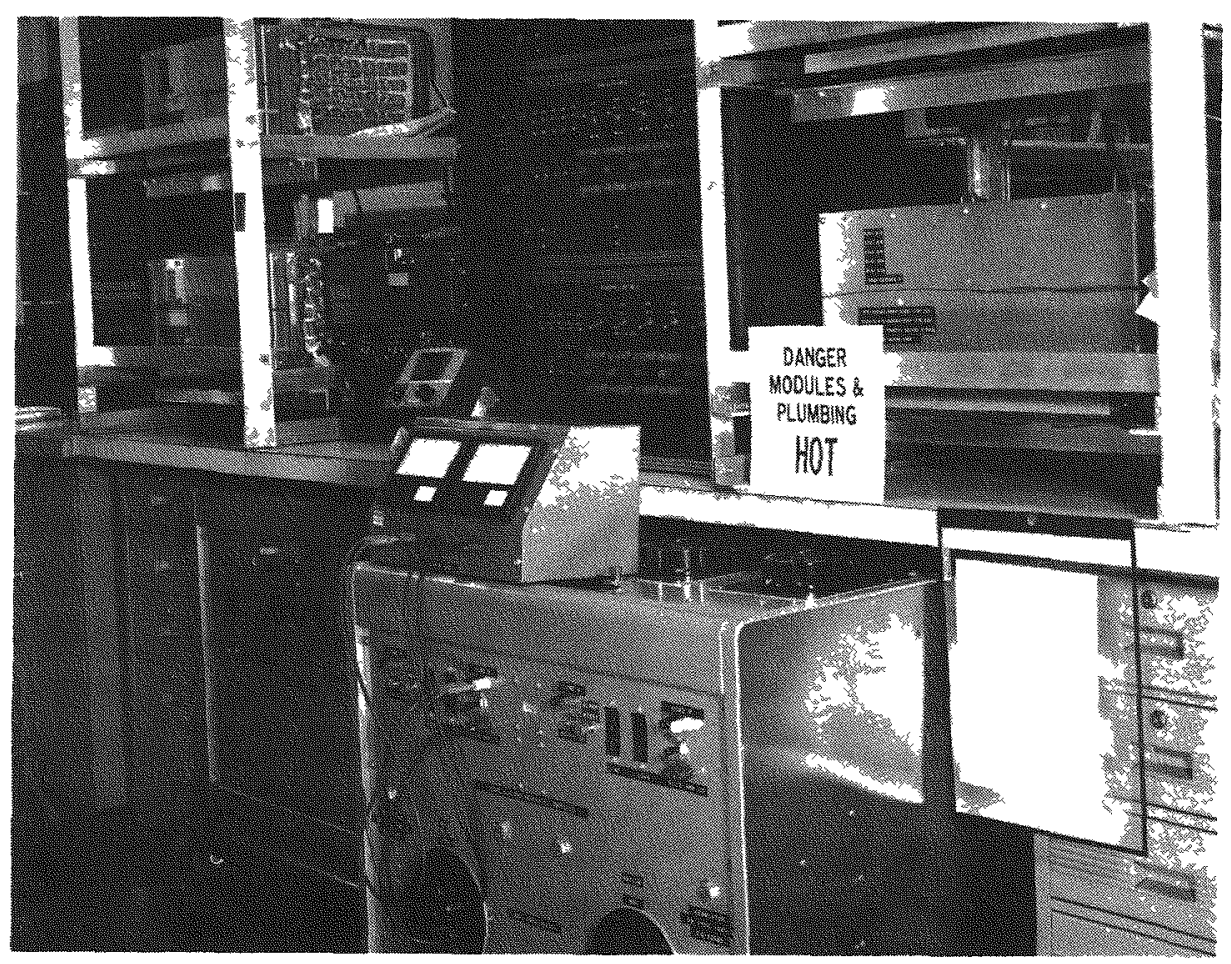

FIG. II-37. ELECTRIC HEATER THERMAL CYCLE TEST AREA

$\frac{1451}{+}$

$\stackrel{1442}{+}$
$\underset{1455}{1442}$
+ $\frac{1382}{+}$

1446
+
1470

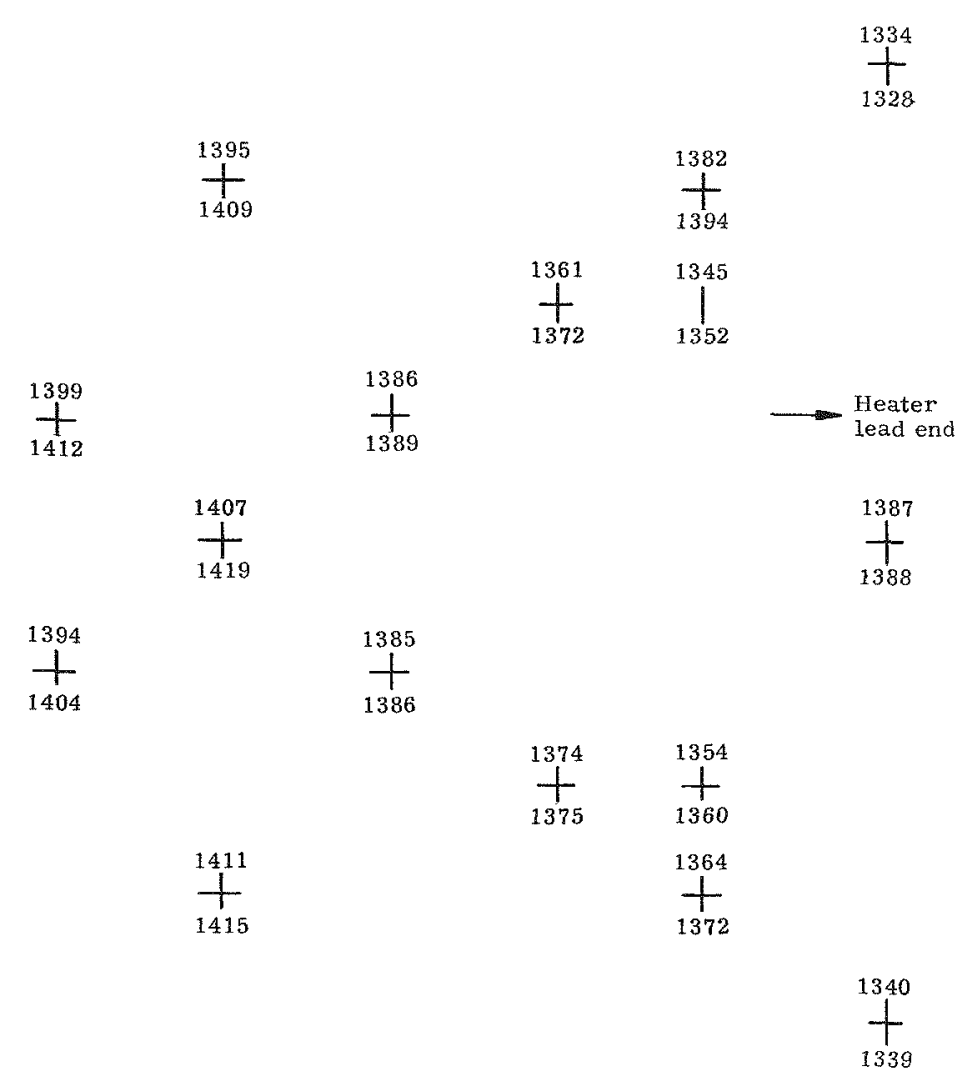

FIG. II-38. TYPICAL HEATER BLOCK THERMAL GRADIENT 


\section{TABLE II-24}

Electric Heater Status at Termination

\begin{tabular}{|c|c|c|c|c|c|}
\hline \multirow[b]{2}{*}{ Vendor } & \multirow[b]{2}{*}{ Test } & \multicolumn{2}{|l|}{ Generator } & \multicolumn{2}{|c|}{ Module } \\
\hline & & Failed & Good & Failed & Good \\
\hline \multirow[t]{5}{*}{ Sanders } & Life & $\begin{array}{l}2 * * ; 1 \text { one, } 1 \text { short } \\
1 * \text { open }\end{array}$ & 2 & $\begin{array}{l}3 * * \text { open } \\
1 * \text { open }\end{array}$ & 1 \\
\hline & $\mathrm{T} / \mathrm{C}$ & $4 *$ open & 1 & $1 *$ & 4 \\
\hline & $\mathrm{T} / \mathrm{V}$ & $4 *$ open & 1 & 0 & 5 \\
\hline & Vib & 0 & 3 & 0 & 3 \\
\hline & Shock & 0 & 3 & $1 *$ & 2 \\
\hline \multirow[t]{5}{*}{ TRW } & Life & $1 * *$ short & 4 & $\begin{array}{l}2 * * \text { open } \\
1 * \text { open }\end{array}$ & 2 \\
\hline & $\mathrm{T} / \mathrm{C}$ & 0 & 5 & 0 & 5 \\
\hline & $\mathrm{T} / \mathrm{V}$ & 0 & 3 & 0 & 3 \\
\hline & Vib & 0 & 3 & 0 & 3 \\
\hline & Shock & 0 & 3 & 0 & 3 \\
\hline \multirow[t]{5}{*}{ Watlow } & Life & 0 & 5 & 0 & 5 \\
\hline & $\mathrm{T} / \mathrm{C}$ & 0 & 5 & $2 * *$ open & 3 \\
\hline & $\mathrm{T} / \mathrm{V}$ & 0 & 3 & 0 & 3 \\
\hline & $\mathrm{Vib}$ & 0 & 3 & 0 & 3 \\
\hline & Shock & 0 & 3 & 0 & 3 \\
\hline
\end{tabular}

* failed during fabrication * *ailed during heater test

A relatively simple test program has been devised to determine if the cause is in the heaters, the heater block or in the module. A static test fixture will be used with a water jacket from the heater test program (Fig. II-39). In order that the heater block will be exposed to similar temperature and emissivity characteristics as in a module test, a stainless steel plate is inserted between the cooling jacket and the heater block. The plate has been coated with hot paint black on both sides, and thermocouples have been attached. This test will start early in January.

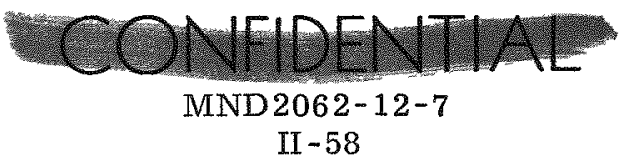




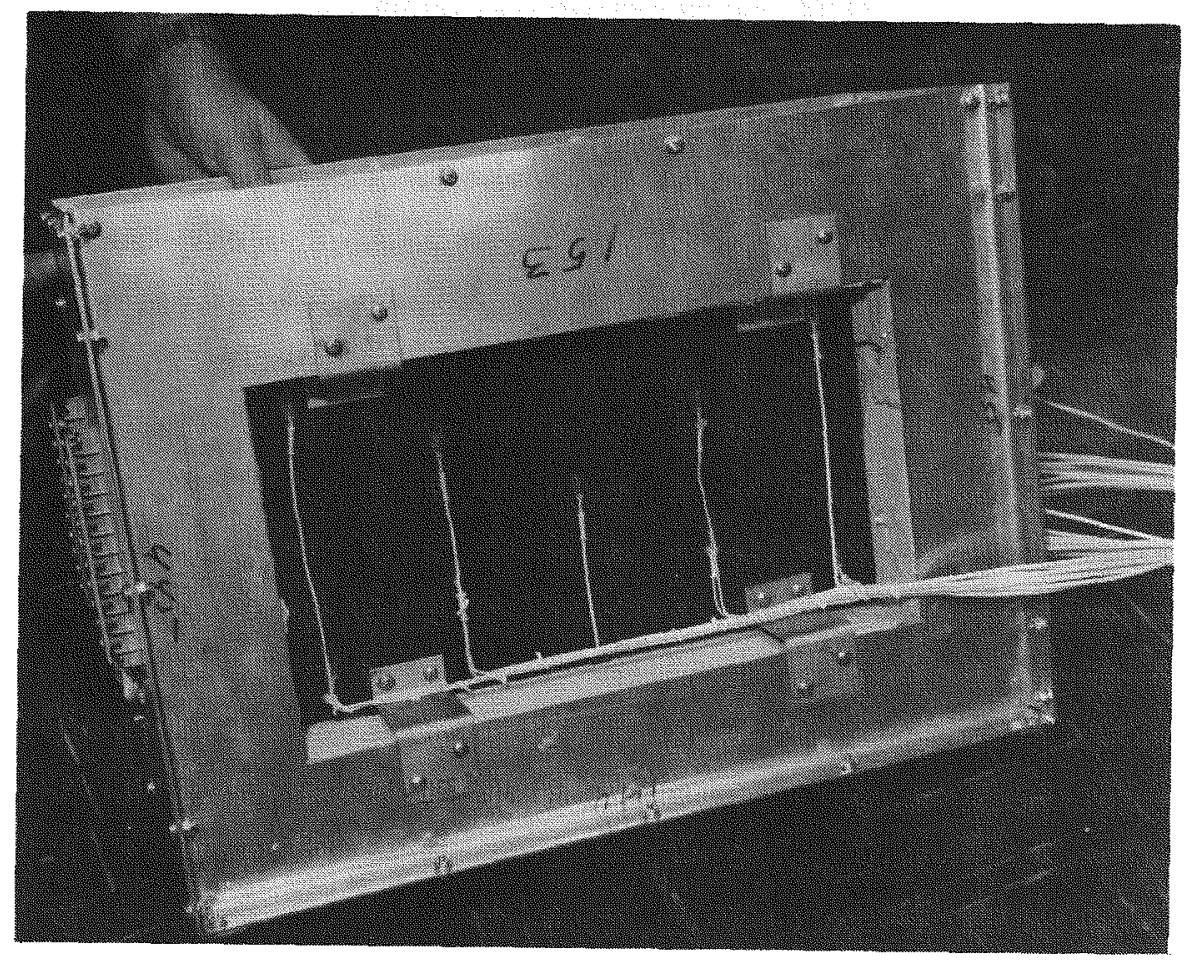

FIG. II -39. ELECTRIC HEATER BLOCK THERMAL GRADIENT EVALUATION TEST FIXTURE

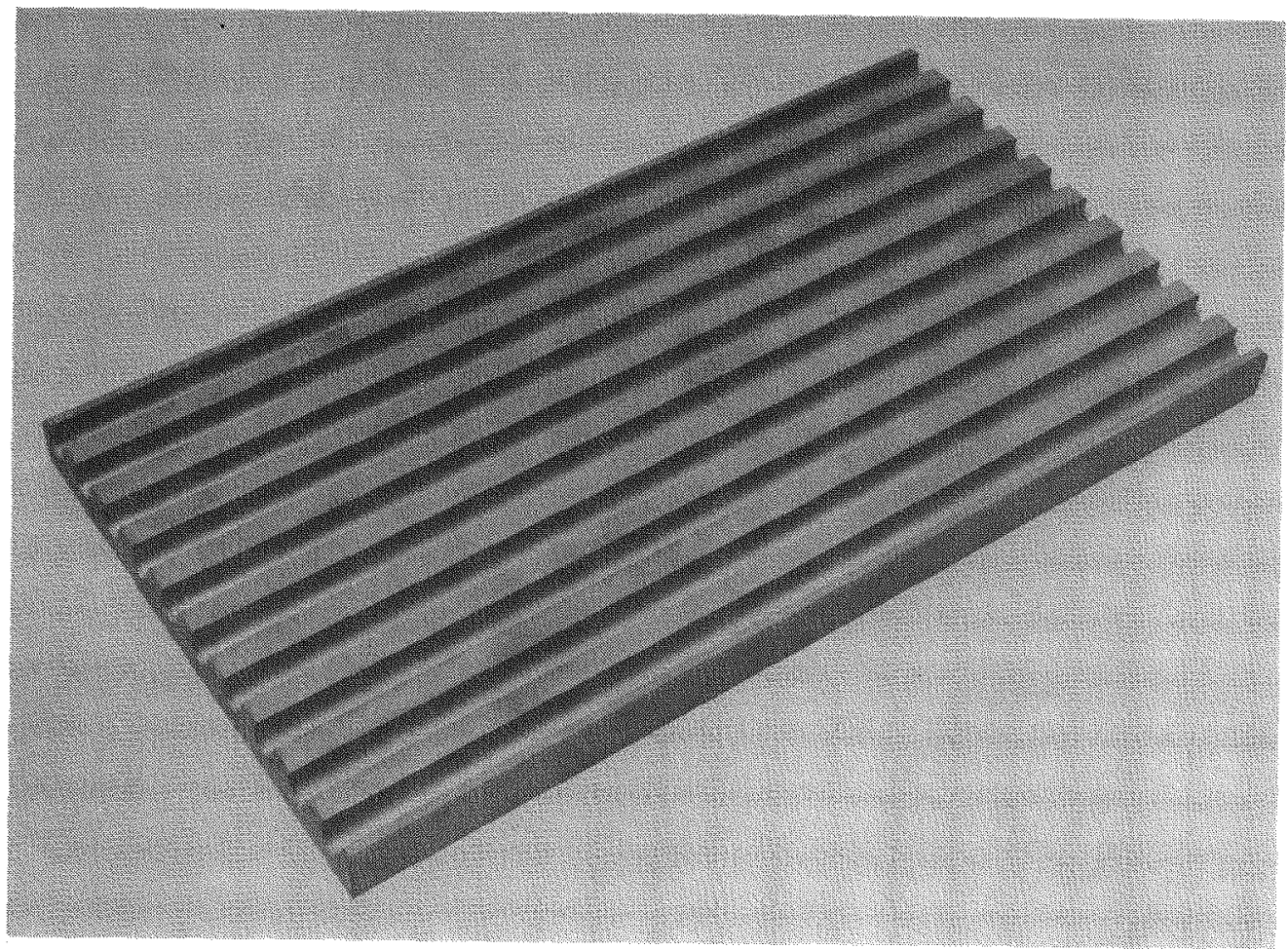

FIG. II-40. DIAPHRAGM T/E MODULE BERYLLIUM COLD PLATE

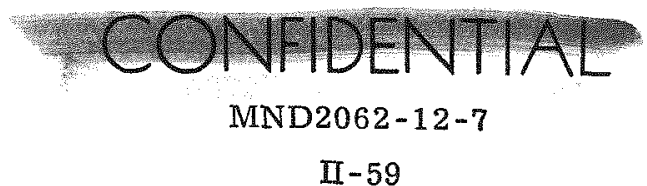




\section{THERMOELECTRIC MODULES SUBSYSTEM--CONTROL POINT 1300}

The objective of this task is to develop a thermoelectric module subsystem which will withstand the predicted dynamic and environmental conditions and produce the required power output over the mission life with high reliability.

The thermoelectric module subsystem is designed, fabricated, inspected and tested under this task. The basic philosophy in the module development program is to develop module components on an individual basis and then integrate the components into module assemblies. The assembled modules will then be subjected to performance and environmental testing for reliability data and design verification. Modules will then be fabricated and acceptance tested for use in demonstration RTG units. Commensurate with this philosophy, the work effort has been broken down into the following control points:

$$
\begin{aligned}
& \text { CP 1340--T/E Module Subsystem, Component Development } \\
& \text { CP 1330--T/E Module Subsystem, Design Verification } \\
& \text { CP } 1320^{-}-\mathrm{T} / \mathrm{E} \text { Module Subsystem, Demonstration Unit. }
\end{aligned}
$$

At the present time, five piston-heat sink modules (Fig. II-50, Third Quarterly Report) and one diaphragm module (Fig. II-38, Fourth Quarterly Report) are being manufactured for evaluation testing.

\section{Summary of Accomplishments}

a. T/E module design and development

During this reporting period, fabrication of the five piston-heat sink modules was completed. Four of the modules (S/N 001, 003, 004, 005) were put into long term performance testing. The fifth module ( $\mathrm{S} / \mathrm{N}$ 002) was submitted to an initial performance check and then was put into vibration tests.

A design study was started on a piston-spring-type module which incorporates a beryllium heat sink and hot plate. This study includes investigation of beryllium oxide for the pistons. A configuration layout has been completed for this design, and preliminary drawings have been submitted to procurement for pricing of the beryllium components.

Sketch-type drawings of the diaphragm module were issued to manufacturing for fabrication of one predevelopment module. Fabrication of this module involved development of new processes and techniques. One process is the brazing of beryllium to Haynes-25. This process is used for both the heat sink and hot plate assemblies. Another process is for the spray coatings on the heat sink assembly. The coatings provide electrical insulation between the $T / E$ conversion assembly and the heat sink and also have sprayed copper discs to permit bonding of the $\mathrm{T} / \mathrm{E}$ conversion assembly to the heat sink for maximum thermal conductivity.

The heat sink and hot plate have been completed for the diaphragm module. The full-size diaphragm, assembled on the hot plate, is undergoing test. The T/E couples are being assembled into the heat sink/conversion assembly.

The diaphragm module predevelopment unit will be subjected to an initial performance check and then to vibration testing. The results of the tests on the piston-heat sink and diaphragm modules will be compared prior to the design selection.

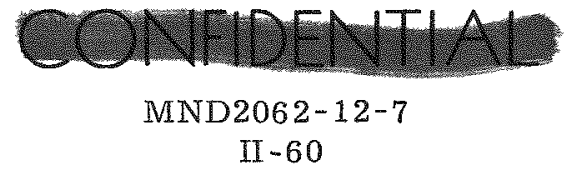


Formal drawings for the diaphragm module have been prepared. These drawings are being held for incorporation of changes resulting from manufacturing development. Fabrication is also being withheld pending design selection.

Photographs of the diaphragm T/E module components are shown in Figs. II-40 through II -43 .

A small diaphragm specimen was subjected to a long term test at operating temperature and pressure. The pressurization medium was helium. The pressure and temperature were maintained for 832 hours. The helium leak rate throughout the test was $1.9 \times 10^{-9} \mathrm{cc} / \mathrm{sec}$ which is well below the required level. A detailed description of this test was presented in the Fourth Quarterly Report (page II-41).

b. Thermoelectric couples

In the event the pressure diaphragm in the diaphragm $\mathrm{T} / \mathrm{E}$ module develops a leak, the mechanical pressure on the thermoelectric conversion assembly could approach zero. Tests are being performed in the couple testers to evaluate the impact of this contingency upon the couple performance. Results of the tests to date are presented in Table II -25 .

\section{TABLE II-25}

Couple Performance Versus Mechanical Pressure

\begin{tabular}{|c|c|c|c|c|c|}
\hline \multirow[b]{2}{*}{ Couple No. } & \multirow{2}{*}{$\begin{array}{l}\text { Pressure } \\
\text { (psi) }\end{array}$} & \multicolumn{2}{|c|}{ Power (milliwatts) } & \multirow[b]{2}{*}{ Test $(h r)$} & \multirow[b]{2}{*}{ Remarks } \\
\hline & & Initial & Present & & \\
\hline $29-009-10$ & 0 & 1279 & 1270 & 626 & \\
\hline $29-009-07$ & 0 & 1247 & 1268 & 649 & \\
\hline $29-009-04$ & 0 & 1196 & 1184 & 897 & \\
\hline $29-012-08$ & 0 & -- & -- & -- & \\
\hline \multirow[t]{2}{*}{$29-009-01$} & 0 & 1261 & 1187 & 957 & Possibly a bad heater \\
\hline & Average & 1246 & 1227 & & \\
\hline $29-012-07$ & 40 & 1287 & 1368 & 167 & \\
\hline $29-009-08$ & 40 & 1227 & 1172 & 765 & \\
\hline $29-012-05$ & 40 & 1397 & 1406 & 163 & \\
\hline $29-009-05$ & 40 & 1303 & 1228 & 860 & \\
\hline \multirow[t]{2}{*}{$29-009-02$} & 40 & 1276 & 1244 & 763 & One thermal cycle \\
\hline & Average & 1298 & 1284 & & \\
\hline $29-009-06$ & 80 & 1240 & 1197 & 795 & \\
\hline $29-009-09$ & 80 & 1298 & 1321 & 767 & \\
\hline $29-012-03$ & 80 & 1303 & 1282 & 285 & \\
\hline $29-009-03$ & 80 & 1208 & 1169 & 837 & Water leak in tester \\
\hline \multirow[t]{2}{*}{$29-012-04$} & 80 & $* 1203$ & -- & -- & Tester malfunction \\
\hline & Average & 1262 & 1242 & & \\
\hline
\end{tabular}

Note: Uncorrected data, but there is no more than a 1 or $2 \mathrm{mv}$ discrepancy in any of the individual legs.

*Excluded from average.

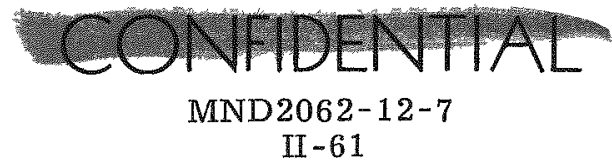




\section{CONFDENTAE}

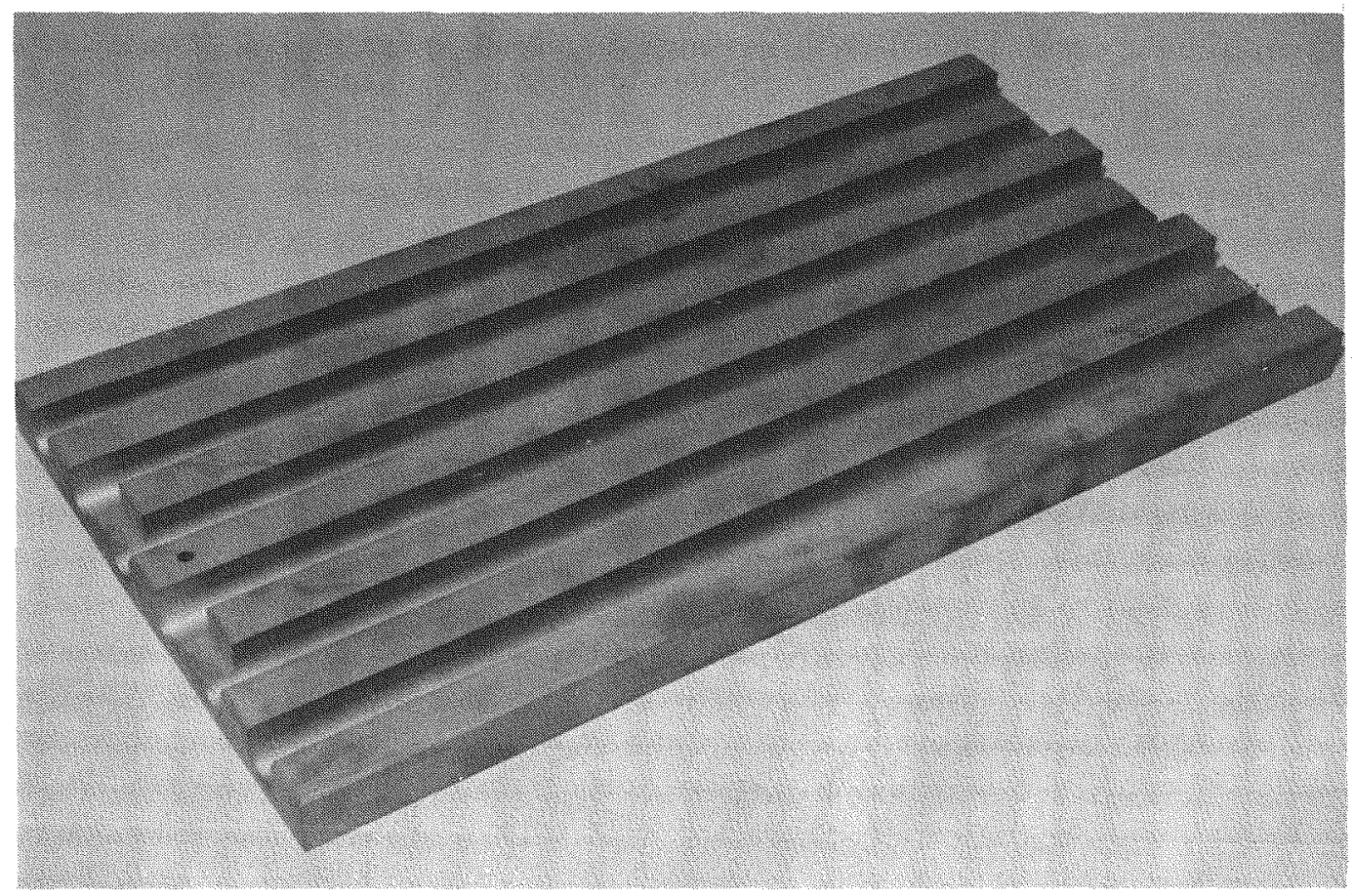

FIG. II-41. DIAPHRAGM T/E MODULE BERYLLIUM HOT PLATE

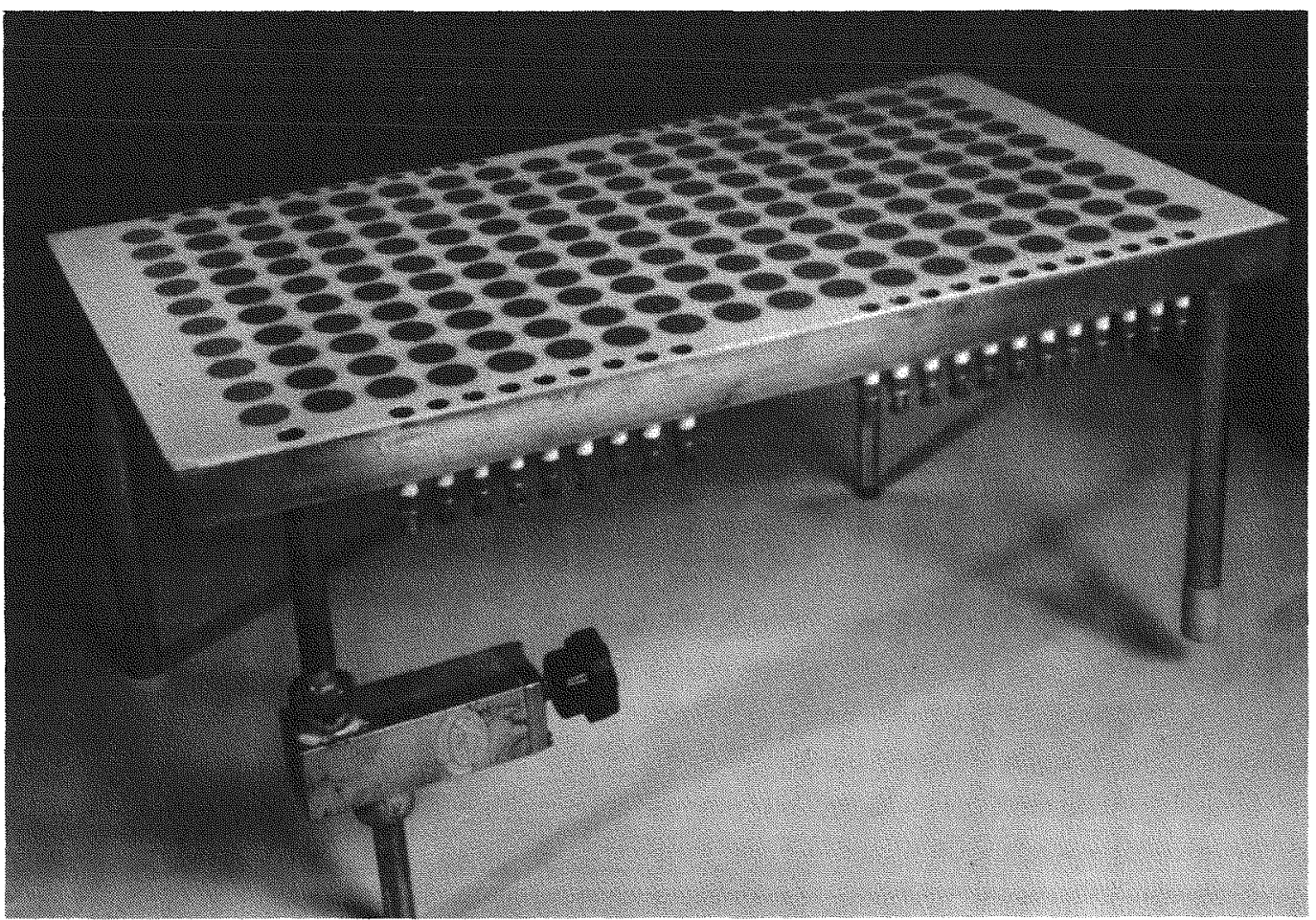

FIG. II-42. DIAPHRAGM MODULE COLD END HARDWARE ASSEMBLY

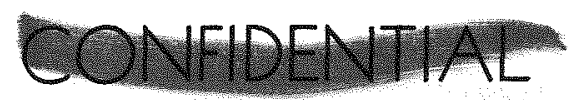

MND2062-12-7

II -62 


\section{CONFIDENTIAL}

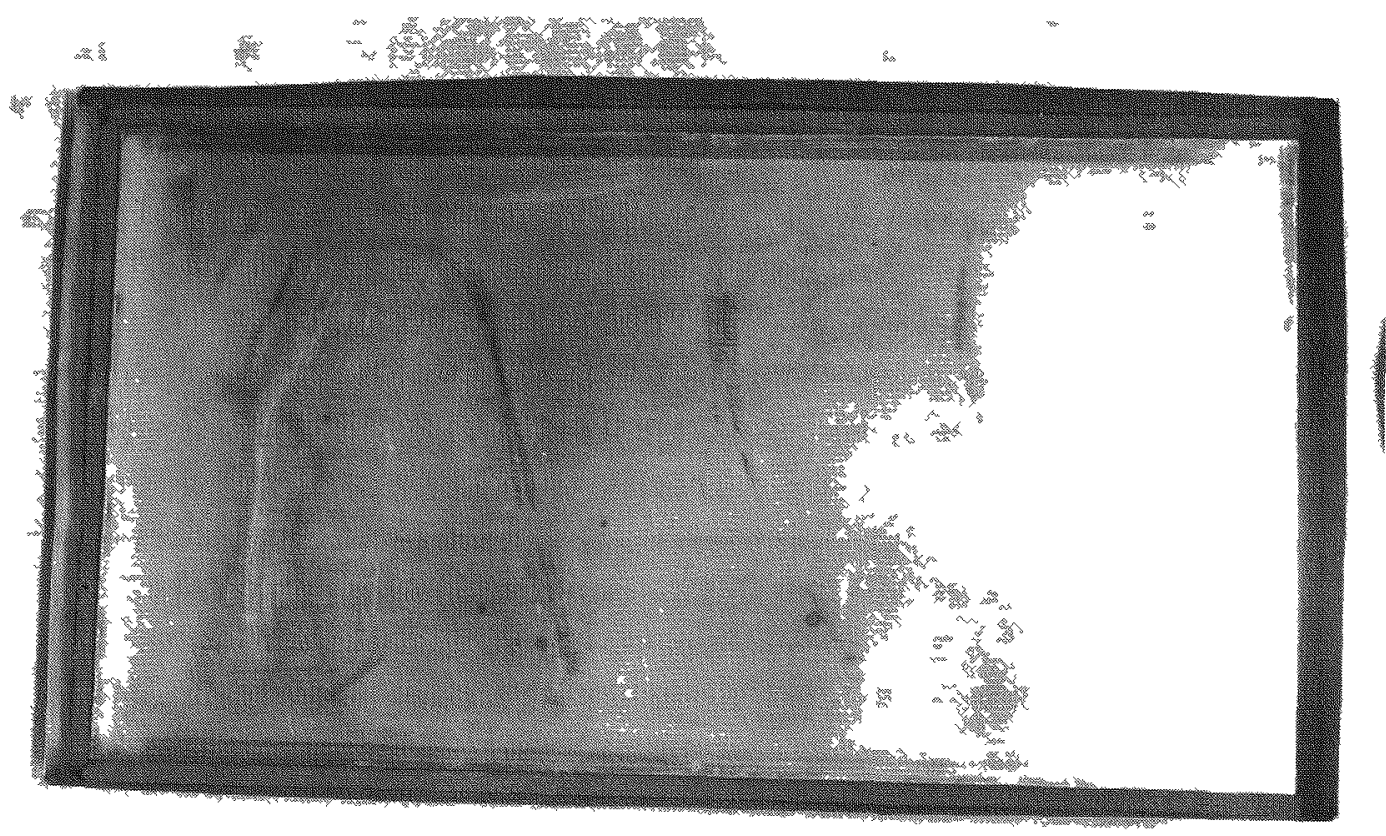

FIG. II 43, DIAPHRAGM MODULE HOT PLATE ASSEMBLY

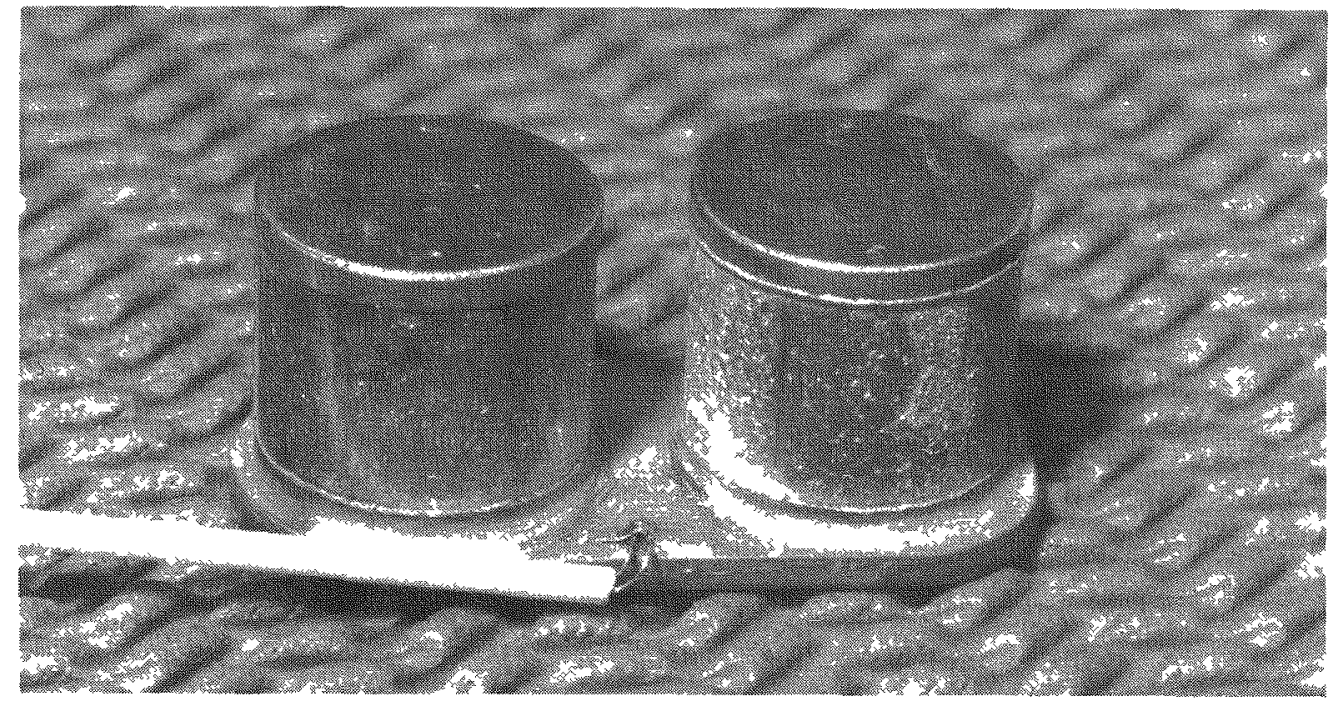

FIG II-44. THERMOELECTRIC COUPLE WITH THERMOCOUPLE INSTALLED ON HOT SHOE

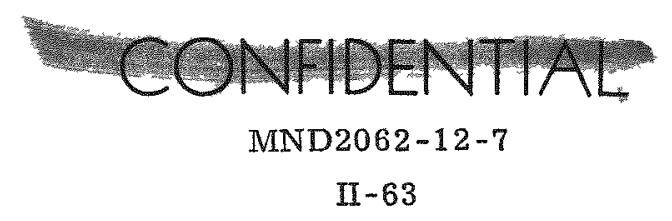


The degradation based on the averages reported are $1.5,1.1$ and $1.5 \%$ for the 0 , 40 and 80 psi pressures, respectively, in the hours indicated. Comparison of the initial and present averages of the three categories of couples reveals no substantial differences. These tests are continuing.

A photograph of a $\mathrm{T} / \mathrm{E}$ couple assembly with a thermocouple installed on the hot shoe is shown in Fig. II-44. This is a typical instrumentation installation for use in the test modules.

c. $T / E$ module analysis

(1) Piston-heat sink module temperature distribution

An analysis was performed to determine the analytical temperature distribution of the SNAP 29 piston-heat sink T/E module for the following EOL design conditions:

$$
\begin{aligned}
& \text { Hot junction temperature }=1050^{\circ} \mathrm{F} \\
& \text { Cold junction temperature }=350^{\circ} \mathrm{F} \\
& 2 \mathrm{~N}-3 \mathrm{P} \mathrm{T} / \mathrm{E} \text { couples } \\
& \text { Contact resistivity }=750 \mu \Omega-\mathrm{cm}^{2} \\
& \text { Net power - } 93 \text { watts (90 couples in primary circuit) } \\
& \text { - } 90 \text { watts ( } 86 \text { couples in primary circuit) }
\end{aligned}
$$

A module with 90 couples in the primary circuit will be used for testing while a module with 86 couples in the primary circuit and four couples in the secondary (pump) circuit was to be the actual piston-heat sink module design with the dynamic NaK coolant system.

Table II-26 presents the piston-heat sink module temperature distribution for the design conditions previously stated. There were three sources for the test data employed in this analysis. They were the following:

(1) Research Module $S / N 1$ performance tests

(2) Research Module $S / N 4$ performance tests

(3) Piston-heat sink $\Delta \mathrm{T}$ tests.

\section{TABLE II-26}

Thermoelectric Module Temperature Distribution for Piston-Heat Sink Module Design

$\begin{array}{lc}\quad \text { Position } & \left.\text { Average Temperature }{ }^{\circ} \mathrm{F}\right) \\ \text { External hot plate surface }\left(\mathrm{T}_{\mathrm{HP}}\right) & \sim 1125 \\ \text { Hot junction }\left(\mathrm{T}_{\mathrm{HJ}}\right) & \sim 1050 \\ \text { Cold junction }\left(\mathrm{T}_{\mathrm{CJ}}\right) & \sim 350 \\ \text { Piston }\left(\mathrm{T}_{\mathrm{P}}\right) & \sim 329 \\ \text { Heat sink }\left(\mathrm{T}_{\mathrm{HS}}\right) & \sim 272 \\ \text { Coolant channel wall }\left(\mathrm{T}_{\mathrm{C}}\right) & \sim 208 \\ \text { Fin root of radiator }\left(\mathrm{T}_{\mathrm{R}}\right) & \sim 193 \\ \text { Hot end temperature gradient }=\Delta \mathrm{T}_{\mathrm{HP}-\mathrm{HJ}}=\sim 75^{\circ} \mathrm{F} \\ \text { Cold end temperature gradient }=\Delta \mathrm{T}_{\mathrm{CJ}-\mathrm{C}}=\sim 142^{\circ} \mathrm{F}\end{array}$

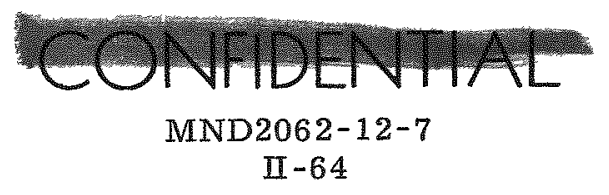


The temperature gradient from the hot junction to the external hot plate surface $\left(\Delta \mathrm{T}_{\mathrm{HP}-\mathrm{HJ}}\right)$ was determined with the aid of $\mathrm{S} / \mathrm{N} 1$ module test data. A thermal conductance for the hot end was calculated using data at 2202, 6475 and 11, 049 hours accumulated test time. A conductance of $290 \mathrm{Btu} / \mathrm{hr}-\mathrm{ft}^{2}-^{\circ} \mathrm{F}$ was employed to estimate a piston-heat sink $\Delta \mathrm{T}_{\mathrm{HP}-\mathrm{HJ}} \simeq 75^{\circ} \mathrm{F}$. For the average hot junction of $1050^{\circ} \mathrm{F}$, this yields the external hot plate temperature of $\sim 1125^{\circ} \mathrm{F}$ shown in Table II-26.

The temperature gradient from the cold junction to the coolant channel wall $\left(\Delta \mathrm{T}_{\mathrm{CJ}-\mathrm{C}}\right)$ was based on the results of $\mathrm{S} / \mathrm{N} 4$ module tests and piston-heat sink $\Delta \mathrm{T}$ tests. An S/N $4 \Delta \mathrm{T}_{\mathrm{CJ}-\mathrm{C}}$ of approximately $70^{\circ} \mathrm{F}$ was adjusted to reflect the cold end hardware dimensions and material properties. Figures II -45 and II -46 show the respective cold end hardware configurations used for this analysis.

The cold end temperature gradient $\left(\Delta \mathrm{T}_{\mathrm{CJ}-\mathrm{C}}\right)$ consists of the following three temperature differences:

(1) Cold junction piston temperature difference $\left(\Delta \mathrm{T}_{\mathrm{CJ}-\mathrm{P}}\right)$

(2) Piston-heat sink temperature difference $\left(\Delta T_{P-H S}\right)$

(3) Heat sink-coolant wall temperature difference $\left(\Delta T_{H S}-C\right)$.

In other words,

$$
\Delta \mathrm{T}_{\mathrm{CJ}-\mathrm{C}}=\Delta \mathrm{T}_{\mathrm{CJ}-\mathrm{P}}+\Delta \mathrm{T}_{\mathrm{P}-\mathrm{HS}}+\Delta \mathrm{T}_{\mathrm{HS}-\mathrm{C}^{*}}
$$

To determine what fraction of $\Delta \mathrm{T}_{\mathrm{CJ}-\mathrm{C}}$ each temperature difference represented, experimental results of the piston-heat sink $\Delta \mathrm{T}$ test were used. Table II-27 shows the recommended fractional values employed in this analysis and the preliminary values based on research module $\mathrm{S} / \mathrm{N} 4$ data.

Table II-28 presents the calculations used to estimate the cold end hardware temperature gradients. Table II-29 presents the quantitative values used in Table II-28. The heat rejected per element of cold end hardware was 9.4 watts. Martin Marietta Research Module S/N 4 Test Report (466A1343631) indicated that the performance of the $\mathrm{S} / \mathrm{N} 4$ module was below expectations and that the source of the difficulty had not been determined. In light of this, the heat rejected per element of cold end hardware could not be determined precisely. However, a range of $\sim 4.7$ to $\sim 5.5$ watts per cold end element could be calculated as shown later in this section. In this analysis, the heat rejected per element of cold end hardware, for the S/N 4 module, was assumed to be $\sim 4.7$ watts. This value made the estimated SNAP $29 \Delta \mathrm{T}_{\mathrm{CJ}-\mathrm{C}}$ a conservative number.

Based on this discussion, the SNAP $29 \Delta \mathrm{T}_{\mathrm{CJ}-\mathrm{C}}$ was estimated to be $\sim 142^{\circ} \mathrm{F}$ which, along with the average cold junction temperature of $350^{\circ} \mathrm{F}$, yielded the coolant channel wall temperature $\left(\sim 208^{\circ}\right.$ F) shown in Table II-26.

Research module S/N 4 data indicated that the SNAP $29 \Delta \mathrm{T}_{\mathrm{CJ}-\mathrm{C}}$ should be $\sim 115^{\circ} \mathrm{F}$ for the $2 \mathrm{~N}-3 \mathrm{P}$ piston-heat sink module. The difference between $115^{\circ} \mathrm{F}$ and the $142^{\circ} \mathrm{F}$ presented herein arose from the following considerations:

(1) The breakdown of $\Delta T_{C J-C}$ was not the same for each estimate (see Table II-27)

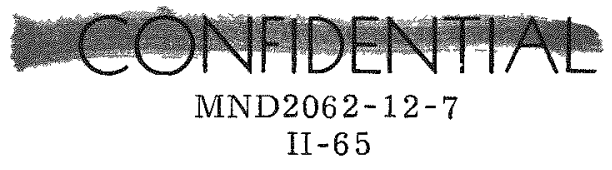



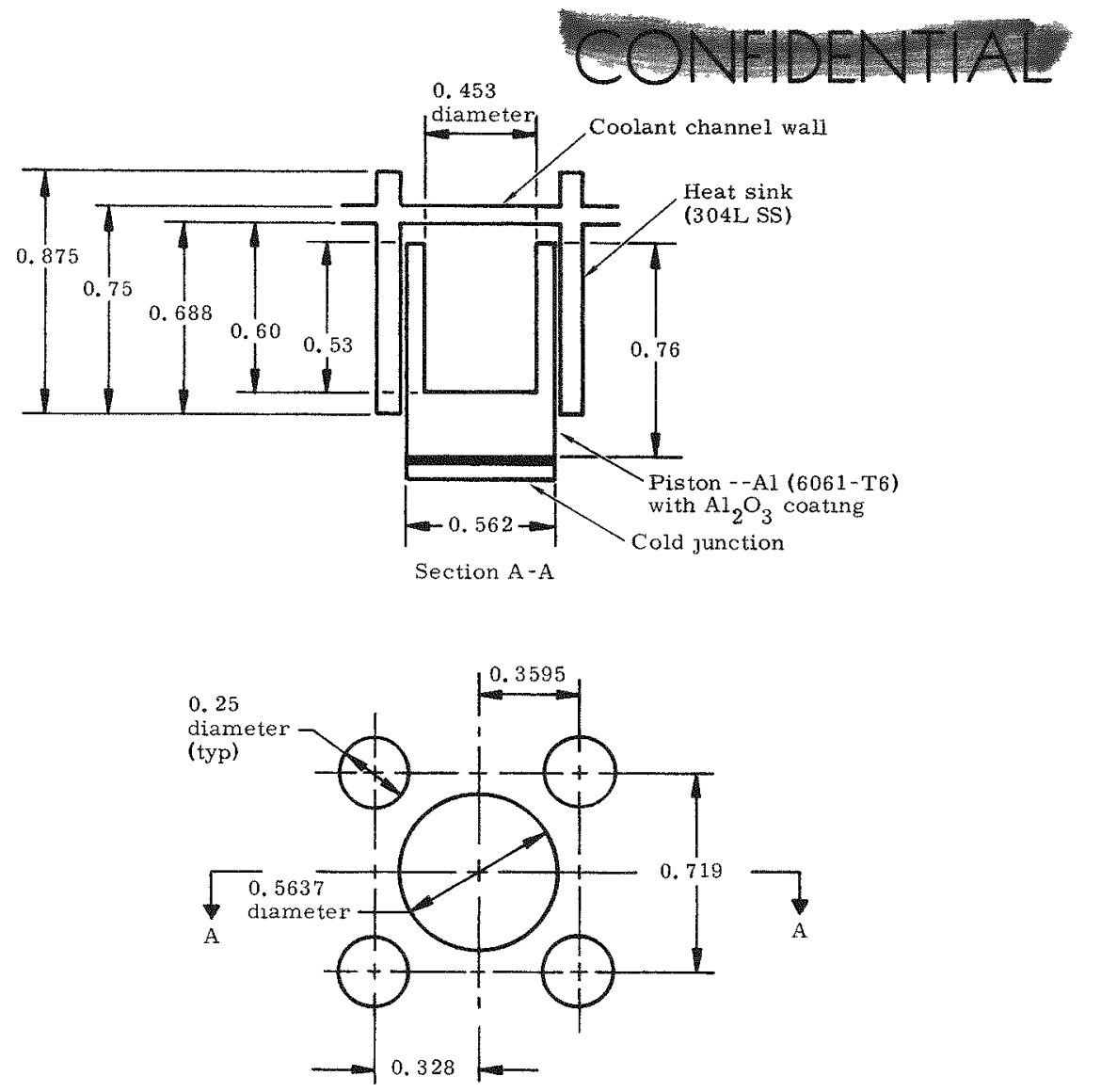

FIG. II -45. RESEARCH MODULE S/N-4 ELEMENT OF COLD END HARDWARE

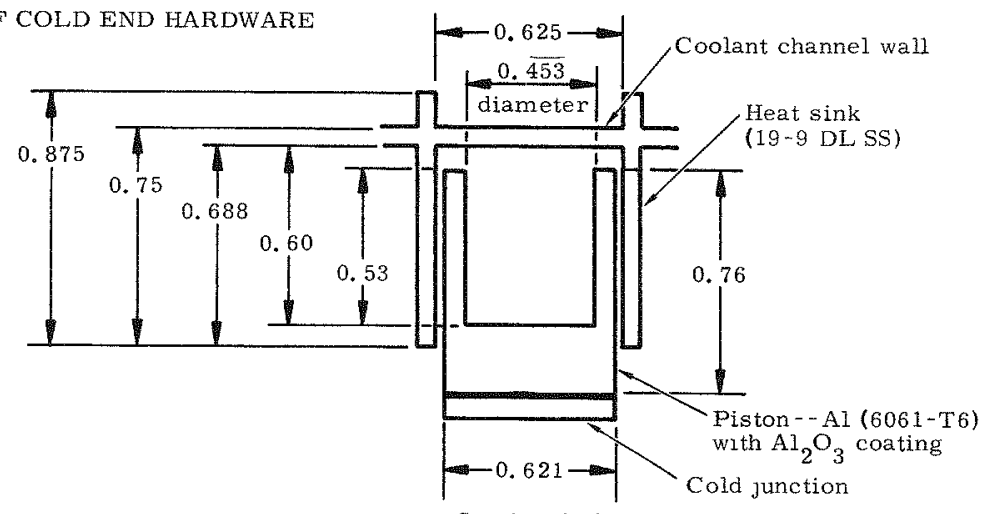

Section $A-A$

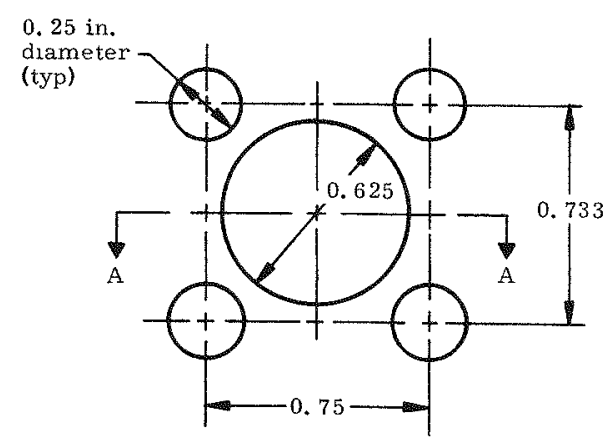

FIG. II -46. SNAP 29 PISTON HEAT SINK MODULE COLD END HARDWARE

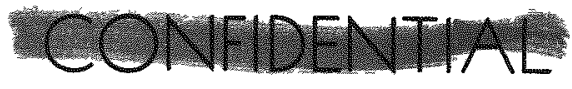

MND2062-12-7 
(2) The heat rejected per element of cold end hardware (SNAP 29) was assumed to be $\sim 6.5$ watts for the $115^{\circ} \mathrm{F}$ gradient, whereas the heat rejected per element of cold end hardware is $\sim 9.4$ watts for the design conditions previously stated.

The temperature gradient from the coolant channel wall to the radiator fin root was calculated as $\sim 15^{\circ} \mathrm{F}$ for the dynamic coolant system using liquid NaK. This yielded the radiator fin root temperature of $\sim 193^{\circ} \mathrm{F}$ shown in Table II-26. The test data to date on the piston-heat sink modules indicate that the predicted cold end $\triangle T$ values are somewhat high. Measured values are generally in the range of $80^{\circ}$ to $100^{\circ} \mathrm{F}$.

\section{TABLE II- 27}

Breakdown of Cold End Hardware Temperature Gradient $\left(\Delta \mathrm{T}_{\mathrm{CJ}-\mathrm{C}}\right)$ Values used in analysis: (piston-heat $\operatorname{sink} \Delta \mathrm{T}$ test data)

Cold junction - piston gradient

$$
\Delta \mathrm{T}_{\mathrm{CJ}-\mathrm{P}}=0.18 \Delta \mathrm{T}_{\mathrm{CJ}-\mathrm{C}} \quad \therefore \Delta \mathrm{T}_{\mathrm{CJ}-\mathrm{P}}(\mathrm{S} / \mathrm{N} 4)=12.6^{\circ} \mathrm{F}
$$

Piston-heat sink gradient

$$
\Delta \mathrm{T}_{\mathrm{P}-\mathrm{HS}}=0.45 \Delta \mathrm{T}_{\mathrm{CJ}-\mathrm{C}}
$$$$
\therefore \Delta \mathrm{T}_{\mathrm{P}-\mathrm{HS}}(\mathrm{S} / \mathrm{N} 4)=31.5^{\circ} \mathrm{F}
$$

Heat sink-coolant channel wall gradient

$$
\Delta \mathrm{T}_{\mathrm{HS}-\mathrm{C}}=0.37 \Delta \mathrm{T}_{\mathrm{CJ}-\mathrm{C}} \quad \therefore \Delta \mathrm{T}_{\mathrm{HS}-\mathrm{C}}(\mathrm{S} / \mathrm{N} 4)=25.9^{\circ} \mathrm{F}
$$

Preliminary values from $\mathrm{S} / \mathrm{N} 4$ module performance

Cold junction - piston gradient

$$
\Delta T_{C J-P}=0.15 \Delta T_{C J-C}
$$

Piston-heat sink gradient

$$
\Delta \mathrm{T}_{\mathrm{P}-\mathrm{HS}}=0.43 \Delta \mathrm{T}_{\mathrm{CJ}-\mathrm{C}}
$$

Heat sink - coolant channel wall gradient

$$
\Delta \mathrm{T}_{\mathrm{HS}-\mathrm{C}}=0.42 \Delta \mathrm{T}_{\mathrm{CJ}-\mathrm{C}}
$$

\section{TABLE II -28}

Estimate of SNAP $29 \Delta \mathrm{T}_{\mathrm{CJ}-\mathrm{C}}$

\section{Cold Junction - piston gradient}

$$
\begin{aligned}
\left(\Delta \mathrm{T}_{\mathrm{CJ}-\mathrm{P}}\right)_{\mathrm{S}-29} & =\left(\Delta \mathrm{T}_{\mathrm{CJ}-\mathrm{P}}\right)_{\mathrm{S} / \mathrm{N} 4}\left(\frac{\mathrm{A}_{\mathrm{S} / \mathrm{N} 4}}{\mathrm{~A}_{\mathrm{S}-29}}\right)_{\mathrm{CJ}-\mathrm{P}}\left(\frac{\mathrm{Q}_{\mathrm{S}-29}}{\mathrm{Q}_{\mathrm{S} / \mathrm{N} 4}}\right) \\
& =(0.18)(70)\left(\frac{0.248}{0.303}\right)\left(\frac{9.4}{4.7}\right)=\sim 21^{\circ} \mathrm{F}
\end{aligned}
$$


TABLE II -28 (continued)

Piston - heat sink gradient

$$
\begin{aligned}
\left(\Delta \mathrm{T}_{\mathrm{P}-\mathrm{HS}}\right)_{\mathrm{S}-29} & =\left(\Delta \mathrm{T}_{\mathrm{P}-\mathrm{HS}}\right)_{\mathrm{S} / \mathrm{N} 4}\left(\frac{\mathrm{A}_{\mathrm{S} / \mathrm{N} 4}}{A_{\mathrm{S}-29}}\right)_{\mathrm{P}-\mathrm{HS}}\left(\frac{\mathrm{Q}_{\mathrm{S}-29}}{\mathrm{Q}_{\mathrm{S} / \mathrm{N} 4}}\right) \\
& =(0.45)(70)\left(\frac{1.091}{1.206}\right)\left(\frac{9.4}{4.7}\right)=\sim 57^{\circ} \mathrm{F}
\end{aligned}
$$

Heat sink - coolant channel wall gradient

$$
\begin{aligned}
\left(\Delta \mathrm{T}_{\mathrm{HS}-\mathrm{C}}\right)_{\mathrm{S}-29} & =\left(\Delta \mathrm{T}_{\mathrm{P}-\mathrm{HS}}\right)_{\mathrm{S} / \mathrm{N} 4}\left(\frac{\mathrm{k}_{\mathrm{S} / \mathrm{N}} 4}{\mathrm{k}_{\mathrm{S}-29}}\right)_{\mathrm{HS}}\left(\frac{\mathrm{A}_{\mathrm{S} / \mathrm{N}} 4}{\mathrm{~A}_{\mathrm{S}}-29}\right)_{\mathrm{HS}}\left(\frac{\mathrm{Q}_{\mathrm{S}-29}}{\mathrm{Q}_{\mathrm{S} / \mathrm{N} 4}}\right) \\
& =(0.37)(70)\left(\frac{10.2}{8.4}\right)\left(\frac{0.196}{0.194}\right)\left(\frac{9.4}{4.7}\right)=\sim 64^{\circ} \mathrm{F} \\
\left(\Delta \mathrm{T}_{\mathrm{CJ}-\mathrm{C}}\right)_{\mathrm{S}-29} & =\Delta \mathrm{T}_{\mathrm{CJ}-\mathrm{P}}+\Delta \mathrm{T}_{\mathrm{P}-\mathrm{HS}}+\Delta \mathrm{T}_{\mathrm{HS}-\mathrm{C}} \\
& =21+57+64 \\
\left(\Delta \mathrm{T}_{\mathrm{CJ}-\mathrm{C}}\right)_{\mathrm{S}-29} & =\sim 142^{\circ} \mathrm{F}
\end{aligned}
$$

TABLE II -29

Constants used in Table II -28

Cold junction - piston gradient

$$
\begin{array}{lll}
A & \left.=\text { area of piston (in. }{ }^{2}\right) \\
A_{S / N 4} & =0.248 \mathrm{in.}^{2} & \left(\frac{A_{S / N ~ 4}}{A_{S-29}}\right)_{C J-P} \\
A_{S-29}=0.303 \mathrm{in.}^{2} & =\frac{0.248}{0.303}=0.819
\end{array}
$$

Piston - heat sink gradient

$$
\begin{aligned}
& A \\
& \left.=\text { piston -heat sink engagement area (in. }{ }^{2}\right) \\
& A_{S / N 4}=1.091 \mathrm{in.}{ }^{2} \quad\left(\frac{A_{S / N ~ 4}}{A_{S-29}}\right)_{P-H S}=\frac{1.091}{1.206}=0.906 \\
& A_{S-29}=1.206 \mathrm{in.}^{2}
\end{aligned}
$$

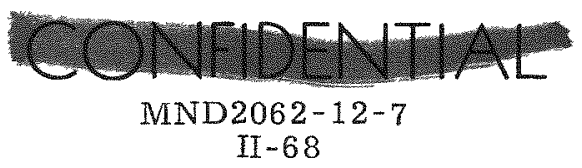




\section{TABLE II-29 (continued)}

Heat sink - coolant channel wall gradient

A $\quad=$ area of conduction in heat $\operatorname{sink}\left(\mathrm{in} .{ }^{2}\right.$ )

$\mathrm{A}_{\mathrm{S} / \mathrm{N} 4}=0.196 \mathrm{in.}^{2}$

$\mathrm{A}_{\mathrm{S}-29}=0.194 \mathrm{in}^{2}$

$\left(\frac{A_{S / N ~ 4}}{A_{S-29}}\right)_{H S}=\frac{0.196}{0.194}=1.01$

$\mathrm{k}=$ heat sink thermal conductivity $\left(\mathrm{Btu} / \mathrm{hr}-\mathrm{ft}-^{\circ} \mathrm{F}\right)$

$\mathrm{k}_{\mathrm{S} / \mathrm{N} 4}=10.2 \mathrm{Btu} / \mathrm{hr}-\mathrm{ft}-^{\circ} \mathrm{F}$

$\mathrm{k}_{\mathrm{S}-29}=8.4 \mathrm{Btu} / \mathrm{hr}-\mathrm{ft}-^{\circ} \mathrm{F} \quad\left(\frac{\mathrm{k}_{\mathrm{S} / \mathrm{N} 4}}{\mathrm{k}_{\mathrm{S}-29}}\right)_{\text {HS }}=\frac{10.2}{8.4}=1.215$

Heat rejected per element of cold end hardware

$\mathrm{Q}_{\mathrm{S} / \mathrm{N} 4}=\sim 4.7$ watts

$\mathrm{Q}_{\mathrm{S}-29}=\sim 9.4$ watts
$\frac{\mathrm{Q}_{\mathrm{S}-29}}{\mathrm{Q}_{\mathrm{S} / \mathrm{N} 4}}=\frac{9.4}{4.7}=2.0$

The research module $\mathrm{S} / \mathrm{N} 4$ test report indicated that the open circuit voltage for the $\mathrm{S} / \mathrm{N} 4$ module was $\sim 20 \%$ below the predicted value. The source of this difficulty has not been determined. A summary of predicted and experimental module performance parameters is shown in the tabulation.

\section{Summary of S/N 4 . Nodule Performance Parameters}

\begin{tabular}{|c|c|c|c|}
\hline & $\begin{array}{c}\text { Measured } \\
\text { Data } \\
\end{array}$ & Case 1 & Case 2 \\
\hline \multicolumn{4}{|l|}{ Junction temperature $\left({ }^{\circ} \mathrm{F}\right)$} \\
\hline Hot & 927 & 927 & $828^{*}$ \\
\hline Cold & 341 & 341 & 341 \\
\hline Open circuit voltage (volts) & 5.43 & $6.80^{*}$ & 5.43 \\
\hline Net power output (watts) & 44.5 & 44.5 & 44.5 \\
\hline Contact resistivity $\left(\mu \Omega-\mathrm{cm}^{2}\right)$ & - & $6000 *$ & $2000^{*}$ \\
\hline Heat to $\mathrm{T} / \mathrm{E}$ elements (watts) & - & $940^{*}$ & $800^{*}$ \\
\hline
\end{tabular}

Case 1 was based on the measured hot junction temperature plus the predicted open circuit voltage. Case 2 was based on an estimated hot junction using the experimental open circuit voltage. In both cases, the experimental cold junction temperature and net power output were used.

The parameters determined by analytical methods were obtained with the aid of the thermoelectric code VINCE-TOM. The material properties used for the analysis were $3 \mathrm{M}$ Company $2 \mathrm{~N}$ and $2 \mathrm{P}$ data (TEDN0030-TEDP0040).

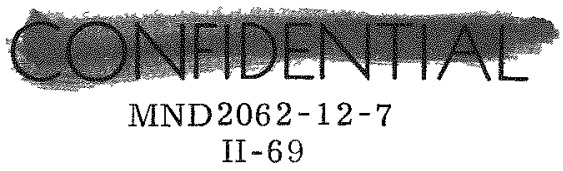


The heat rejected per element of cold end hardware was determined using the following formula:

$$
Q_{\text {rej/element }}=\frac{Q_{\text {elements }}+Q_{\text {insulation }} \text { - power output }}{\text { number of elements }}
$$

where $\mathrm{Q}_{\text {insulation }}$ was the parasitic heat loss through the module insulation ( 40 watts for $S / N$ ).

$$
\begin{aligned}
& \text { Case 1: } Q_{\text {rej/element }}=\frac{940+40-44.5}{168}=\sim 5.5 \text { watts } \\
& \text { Case 2: } Q_{\text {rej/element }}=\frac{800+40-44.5}{168}=\sim 4.7 \text { watts }
\end{aligned}
$$

Case 2 was employed in this analysis (i. e., 4.7 watts) in order to present a conservative estimate of $\Delta \mathrm{T}_{\mathrm{CJ}-\mathrm{C}}$.

(2) $I^{2} R$ losses for piston-heat sink module

The $I^{2} R$ power losses in the piston-heat sink module have been determined analytically. The results apply to one module with 90 couples in the power circuit and are shown in Fig. II- 47 as a function of the current flowing from the module. Module tests in progress indicate a BOL current of $\sim 27.5$ amperes which results in $\sim 8.6$ watts per module lost through Joule heating.

The $I^{2} \mathrm{R}$ losses for the diaphragm module have also been evaluated and the results are presented in Fig. II-48. It can be seen that for the EOL current of $\sim 27.5$ amperes, the losses are $\sim 8.1$ watts.

\section{(3) Electrical circuit tradeoff study}

An electrical circuit tradeoff study for the cold straps and internal wire of an S-29 module was performed during this period. The analysis dealt with the $I^{2} R$ losses and weight of the copper cold straps and internal wire. It was found that, for a design goal of one watt loss per pound of component, the cold strap thickness should be increased to $\sim 0.034$ inch and the internal wire diameter to $\sim 0.25$ inch (AWG 2 wire). Table II-30 shows a comparison of the present electrical circuit performance and the alternate (i. e., watt loss/lb) electrical circuit performance. A potential savings of $\sim 3.45$ watts over the current design is indicated for the alternate design. This would incur a weight increase of $\sim 0.78$ pound.

(4) BeO piston-Be heat sink cold end study

A preliminary study has been performed to determine the temperature difference between the cold junction and heat pipe wall for a piston-Be heat sink $\mathrm{T} / \mathrm{E}$ module with BeO pistons. The results are based on a preliminary design (Fig. II -49).

Figure II-50 shows the thermal model employed in this study. It is a one-half unit cell of the piston-Be heat sink module cold end hardware and includes the BeO piston, beryllium heat sink and nickel heat pipe. The steady state temperatures were determined using the linearized inversion matrix technique and the 360-44 computer.

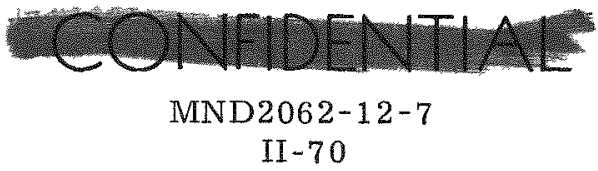




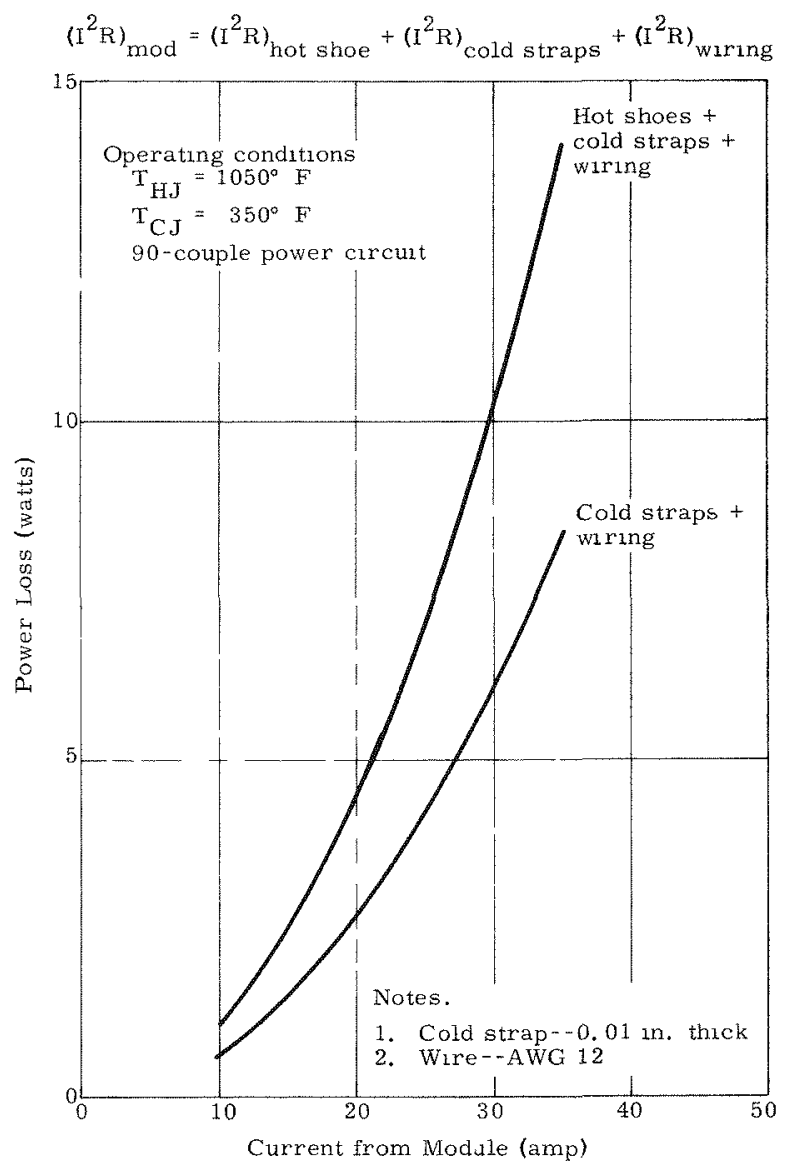

FIG. II-47. I ${ }^{2} R$ LOSSES FOR PISTON HEAT SINK MODULE

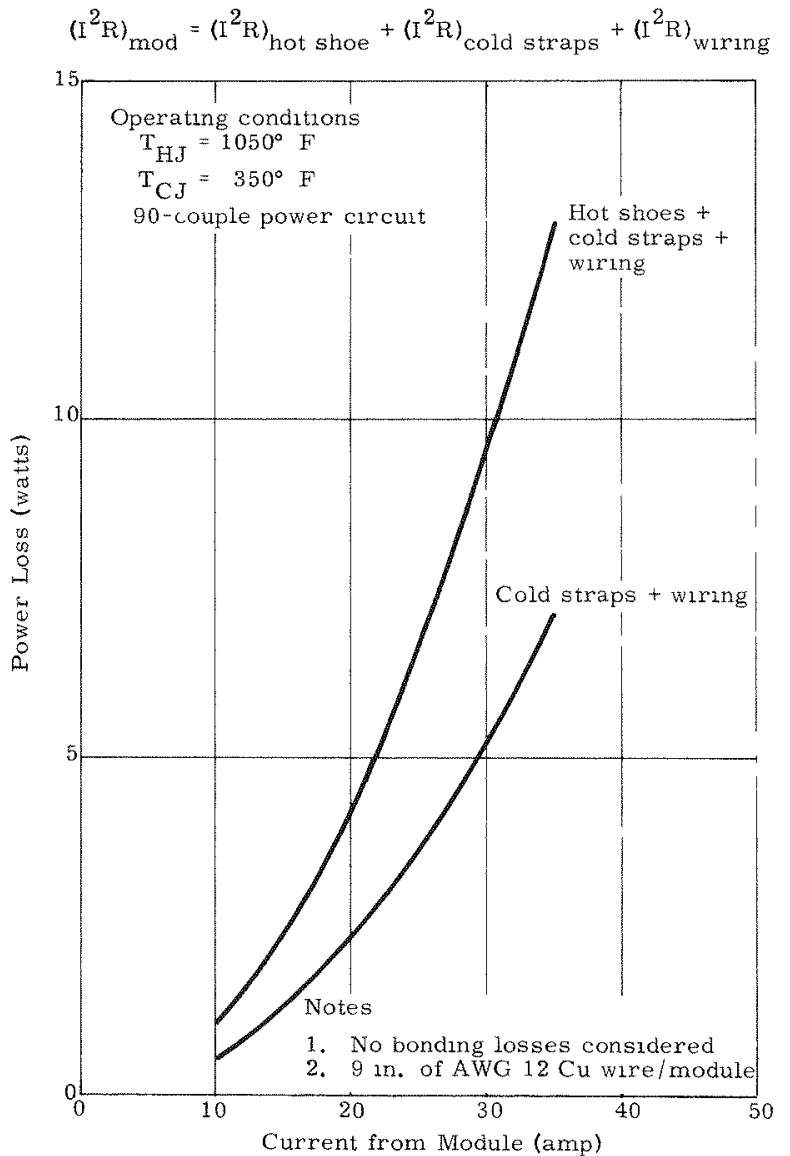

FIG. II-48. $I^{2} R$ LOSSES IN DIAPIRAGM IMODULE

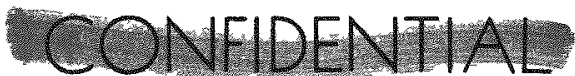

MND2062-12-7

II -71 

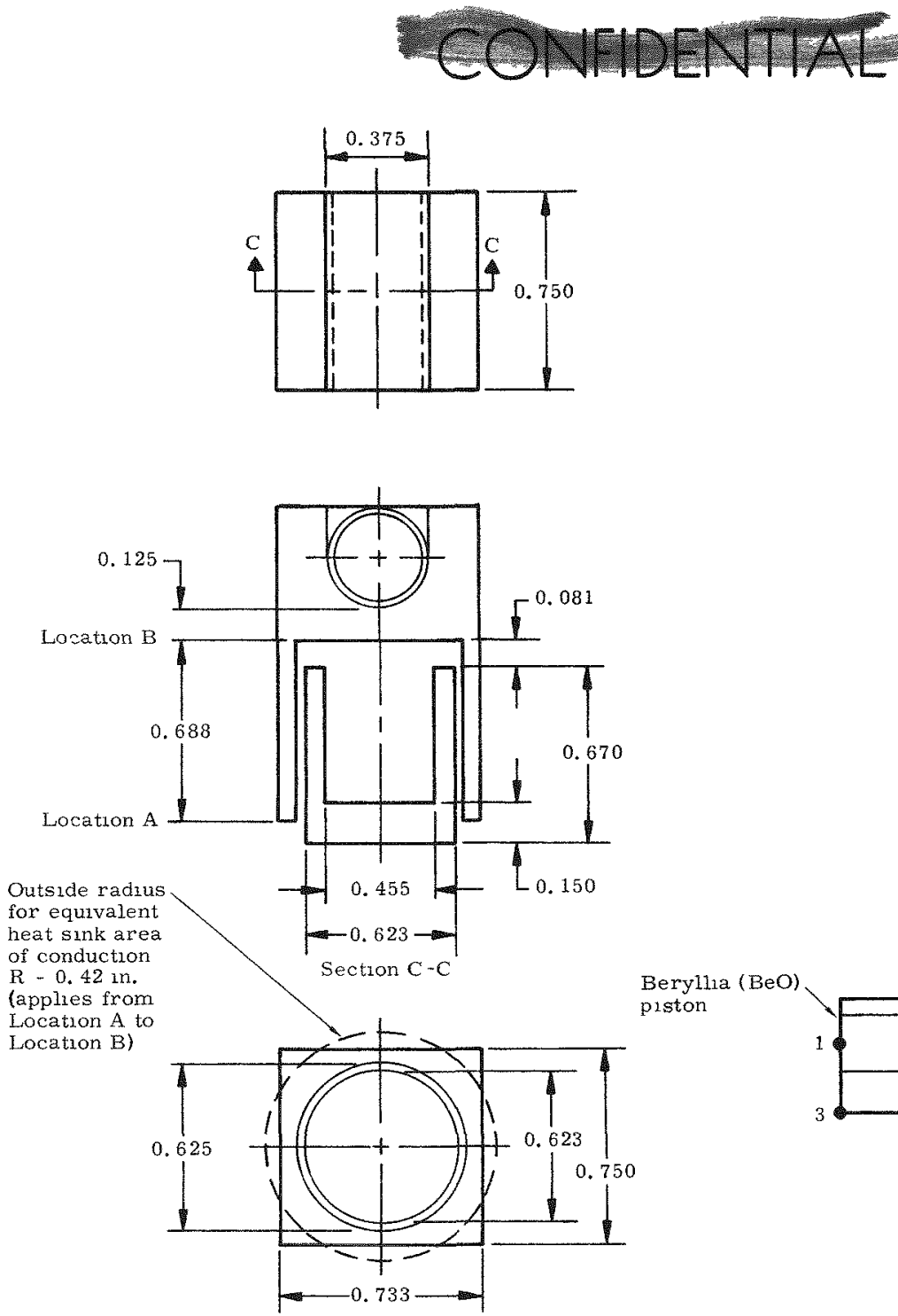

FIG. II 49. PRELIMINARY DESIGN OF UNIT CELL OF PISTON-BERYLLIUM HEAT SINK MODULE

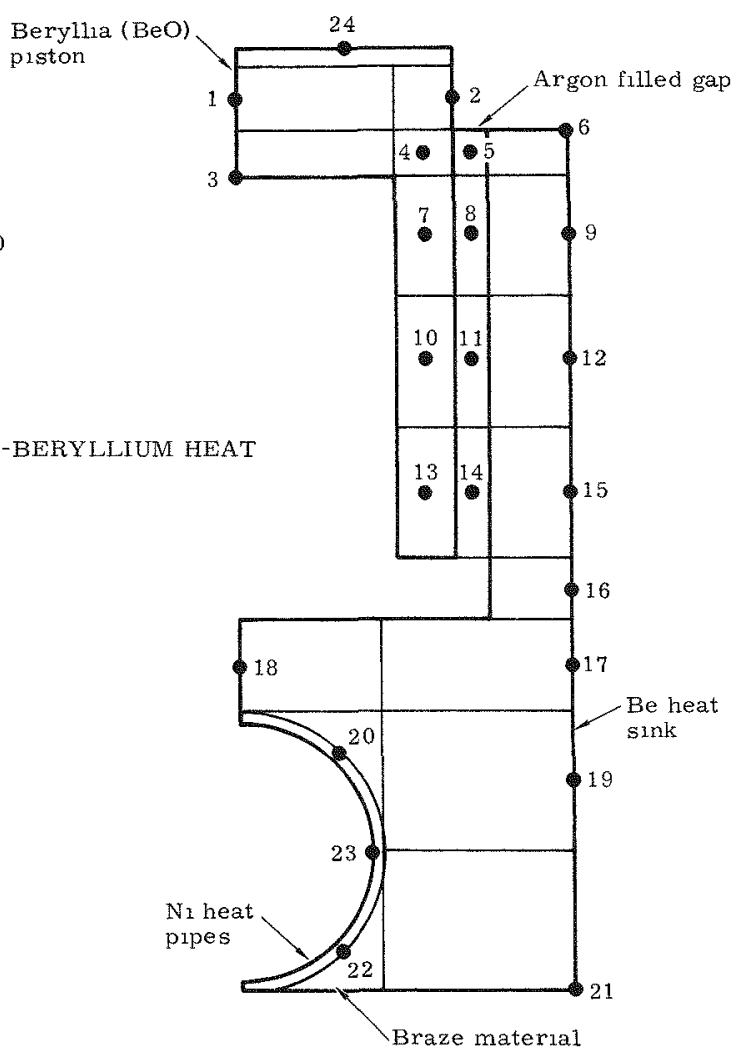

FIG. II-50. THERMAL MODEL--PISTON-BERYLLIUM HEAT SINK MODULE

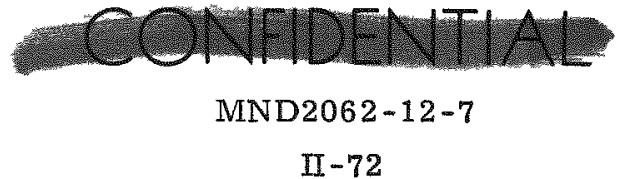




\section{TABLE II -30}

Comparison of Cold Strap Electrical Performance

Designs

\begin{tabular}{|c|c|c|}
\hline & Current & Alternate: \\
\hline Cold strap thickness (in.) & 0.01 & 0.034 \\
\hline Diameter of wire (in.) & $\begin{array}{l}0.808 \\
\text { (AWG 12) }\end{array}$ & $\begin{array}{l}0.250 \\
\text { (AWG 2) }\end{array}$ \\
\hline Current (amp) & $\sim 27.5$ & $\sim 27.5$ \\
\hline$\left(I^{2} R\right)$ cold straps (watts) & 3.0 & 0.90 \\
\hline$\left(I^{2} R\right)$ wire ${ }^{\text {(watts) }}$ & 1.5 & 0.15 \\
\hline Weight ${ }_{\text {cold strap }}(\mathrm{lb})$ & 0.26 & 0.90 \\
\hline Weight $_{\text {wire }}(\mathrm{lb})$ & 0.015 & 0.15 \\
\hline$\left(\frac{I^{2} R}{\text { weight }}\right)_{\text {cold straps }}($ watts $/ 1 b)$ & 11.6 & 1.0 \\
\hline$\left(\frac{\mathrm{I}^{2} \mathrm{R}}{\text { weight }}\right)_{\text {wire }}$ (watts/lb) & 100 & 1.0 \\
\hline
\end{tabular}

The model is based on the following assumptions:

(1) No thermal resistance exists at bonded interfaces

(2) The heat rejection rate is 9.4 watts per element of cold end hardware (i.e., per cell)

(3) A 0.001 inch argon-filled gap exists between the BeO piston and beryllium heat sink

(4) The following thermal conductivities apply:

$$
\begin{aligned}
& \text { Beryllium }=90 \mathrm{Btu} / \mathrm{hr}-\mathrm{ft}-^{\circ} \mathrm{F} \\
& \text { Beryllia }(\mathrm{BeO})=27 \text { or } 90 \mathrm{Btu} / \mathrm{hr}-\mathrm{ft}-^{\circ} \mathrm{F} .
\end{aligned}
$$

The two $\mathrm{BeO}$ thermal conductivities include the range of material densities (115 to $180 \mathrm{lb} / \mathrm{ft}^{3}$, respectively) being considered for use in the piston. Table II-31 and Figs. II-51 and II-52 show a summary of the results of this study. The range of cold junction-heat pipe temperature differentials is $\sim 65^{\circ}$ to $82^{\circ} \mathrm{F}$, corresponding to a range of $\mathrm{BeO}$ densities of $\sim 115$ to $180 \mathrm{lb} / \mathrm{ft}^{3}$, respectively.

Table II-31 shows a $25^{\circ} \mathrm{F}$ temperature gradient from the cold junction to the piston. This value is based on an interface conductance of $\sim 600 \mathrm{Btu} / \mathrm{hr}-\mathrm{ft}^{2}-{ }^{\circ} \mathrm{F}$, determined from the SNAP 27 Fourth Quarterly Report. For the SNAP 29 copper strap-aluminum piston interface, with a lead disc between the surfaces, the interface conductance would be $\sim 720 \mathrm{Btu} / \mathrm{hr}-\mathrm{ft}^{2}-^{\circ} \mathrm{F}$ resulting in $\sim 21^{\circ} \mathrm{F}$ temperature gradient.

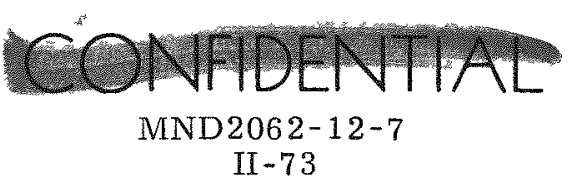




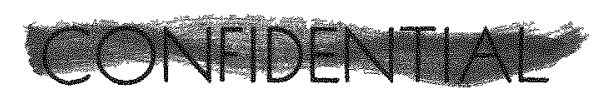

BeO $K=27.0 \mathrm{Btu} / \mathrm{hr}-\mathrm{ft}-{ }^{\circ} \mathrm{F}$

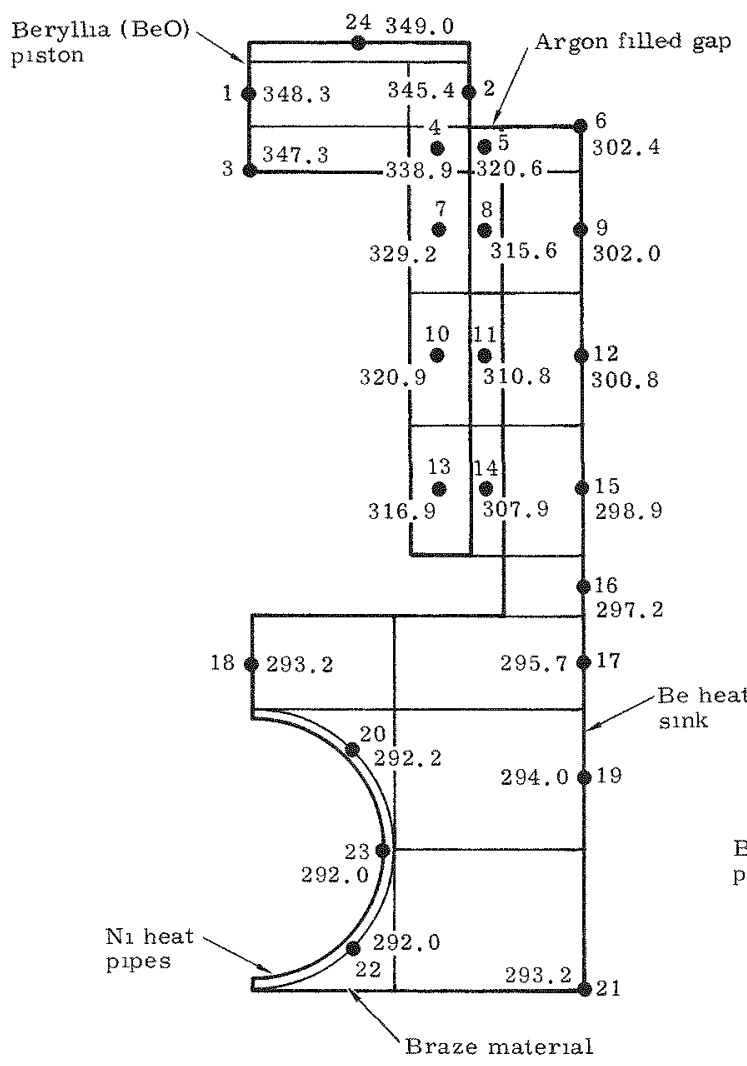

FIG. II-51. THERMAL MODEL--PISTON-BERYLLIUM HEAT SINK MODULE

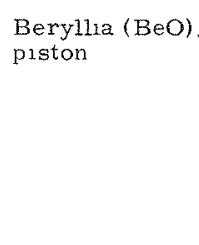

BeO $\mathrm{K}=90.0 \mathrm{Btu} / \mathrm{hr}-\mathrm{ft}-{ }^{\circ} \mathrm{F}$
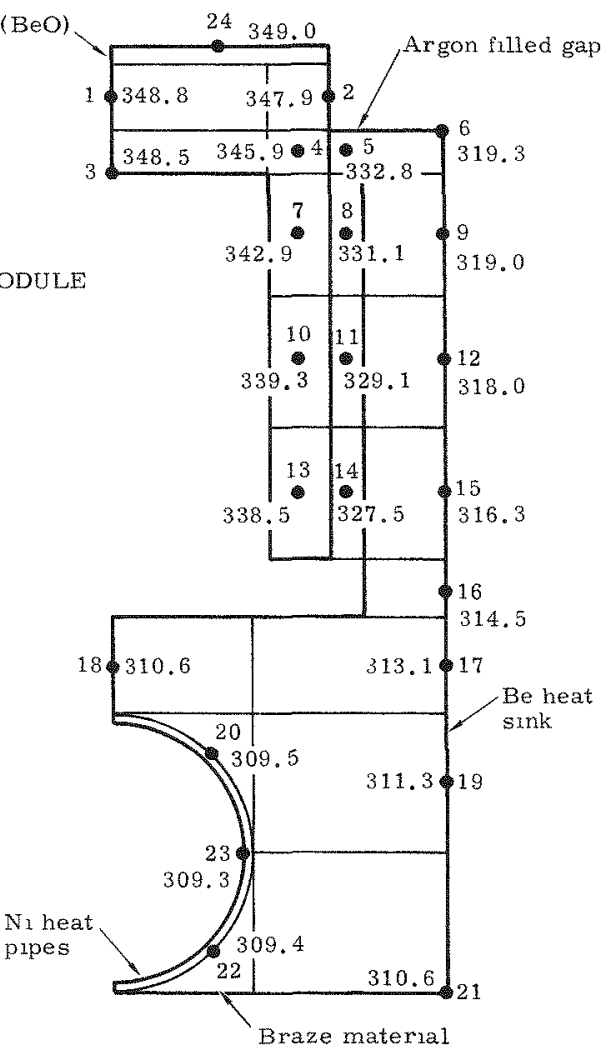

FIG. II -52. THERMAL MODEL--PISTON-BERYLLIUM HEAT SINK MODULE

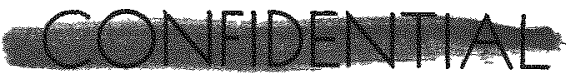

MND2062-12-7 


\section{TABLE II-31}

Cold End Hardware Temperature Gradients Piston-Be Heat Sink Module

$\begin{array}{lll}\text { Piston material (BeO) density }\left(\mathrm{lb} / \mathrm{ft}^{3}\right) & 115 & 180 \\ \text { Argon gap thickness (in.) } & 0.001 & 0.001 \\ \text { BeO thermal conductivity }\left(\mathrm{Btu} / \mathrm{hr}-\mathrm{ft}-^{\circ} \mathrm{F}\right) & 27 & 90 \\ \Delta \mathrm{T}_{\text {cold junction to piston }}\left(^{\circ} \mathrm{F}\right) & 25 * & 25^{*} \\ \Delta \mathrm{T}_{\text {piston to heat sink }}(\text { Nodes } 2-6)\left({ }^{\circ} \mathrm{F}\right) & 47 & 30 \\ \Delta \mathrm{T}_{\text {cold junction }- \text { heat } \operatorname{sink}}\left(^{\circ} \mathrm{F}\right) & 72 & 55 \\ \Delta \mathrm{T}_{\text {heat sink }} \text { heat pipe }(\mathrm{Nodes} 6-23)\left({ }^{\circ} \mathrm{F}\right) & 10 & 10 \\ \Delta \mathrm{T}_{\text {cold end hardware }}\left(^{\circ} \mathrm{F}\right) & 82 & 65\end{array}$

*Based on SNAP 27 data, $\mathrm{h} \cong 600 \mathrm{Btu} / \mathrm{hr}-\mathrm{ft}^{2} /-^{\circ} \mathrm{F}$

Commercial availability seems to indicate that the high density Beryllia $\left(\sim 180 \mathrm{lb} / \mathrm{ft}^{3}\right)$ may be obtained. This would result in the lower temperature gradient across the cold end hardware and represent a weight increase per module of $\sim 0.9$ pound over the lower density (and lower thermal conductivity) BeO.

(5) Diaphragm module hot plate study

A diaphragm module hot plate assembly analysis was performed to evaluate the $\Delta T$ across the plate. Figure II- 53 shows that a temperature gradient of $\sim 11^{\circ}$ to $15^{\circ} \mathrm{F}$ is predicted from the hot plate surface to the part of the diaphragm in contact with the beryllium hot plate. A temperature gradient of $\sim 44^{\circ} \mathrm{F}$ is predicted near the Haynes -25 side member.

(6) Cold stack $\Delta T$ analysis

The cold stack design was changed to include two layers of nickel aluminide and to reduce the lead disc and Haynes -25 thicknesses. These changes provide a calculated $5.5^{\circ} \mathrm{F} \Delta \mathrm{T}$ for a perfectly bonded cold stack at SNAP 29 EOL operating conditions. Figure II -54 shows the analytical model and the results are presented in Fig. II-55.

d. T/E module test results

(1) Life test

A summary of the spring piston module life test data obtained during this reporting period is presented in Tables II -32 through II -35 and Figs. III-1 through III-8. The cold end $\Delta \mathrm{T}$ values appear to be stabilizing in the $85^{\circ}$ to $90^{\circ} \mathrm{F}$ range, the estimated $\Delta \mathrm{T}$ was approximately $142^{\circ} \mathrm{F}$. Module S/N 4 was cooled down to repair a leak detected on 12/11/67. Evaluation of the effect of the leak on module performance and repair are in progress. Figure II -56 shows the test loop in operation.

(2) Vibration test

A test directive (NTD-1340-05) for vibration environmental testing of one pistonheat sink type and one diaphragm-type thermoelectric module was prepared and released

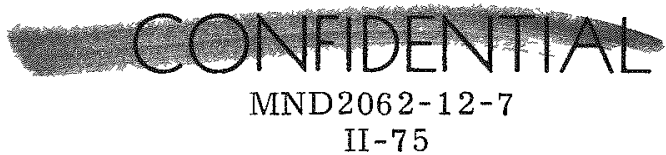




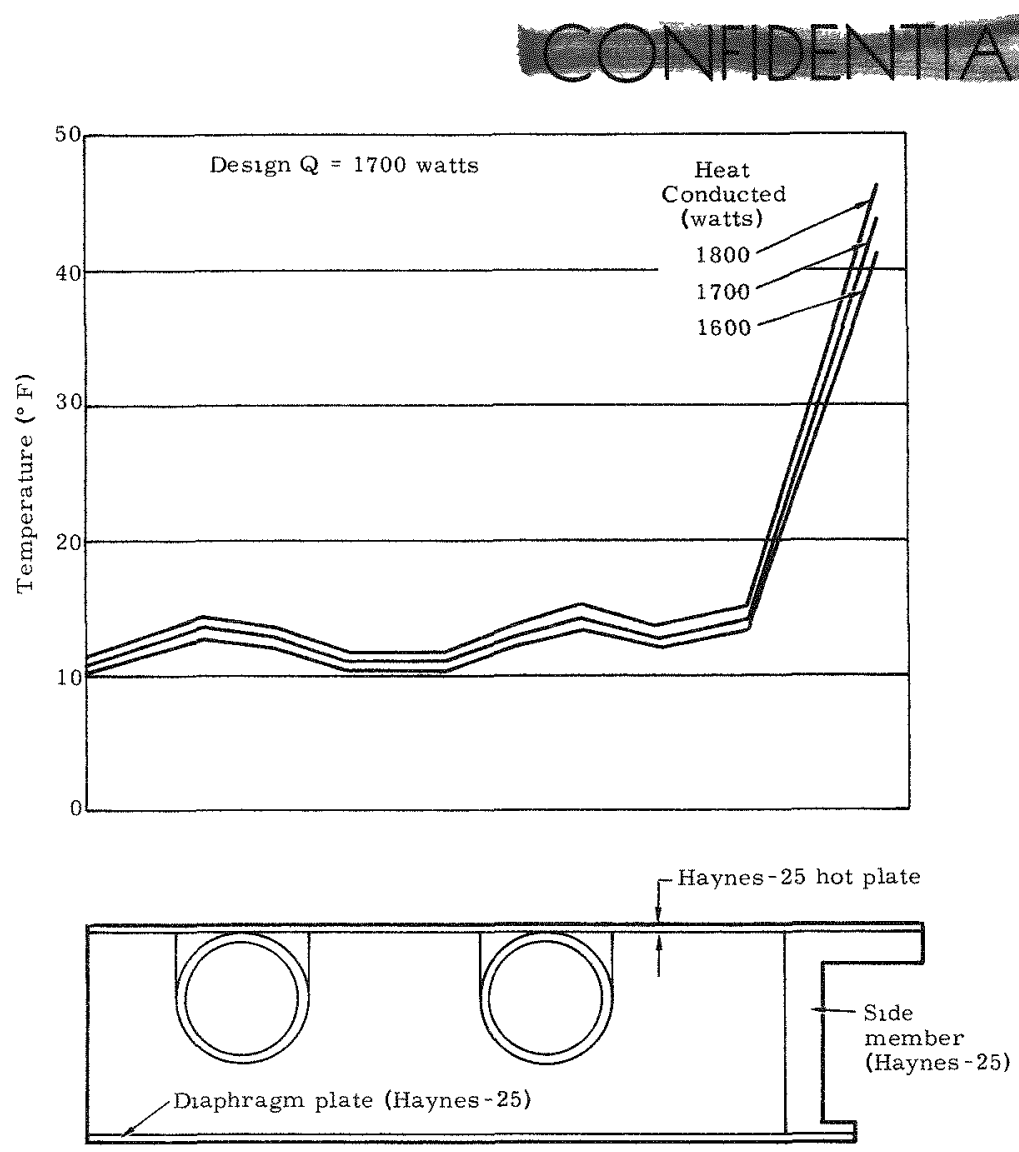

FIG. II-53. TEMPERATURE GRADIENT PROFILE--HAYNES-25 HOT PLATE TO DIAPHRAGM PLATE

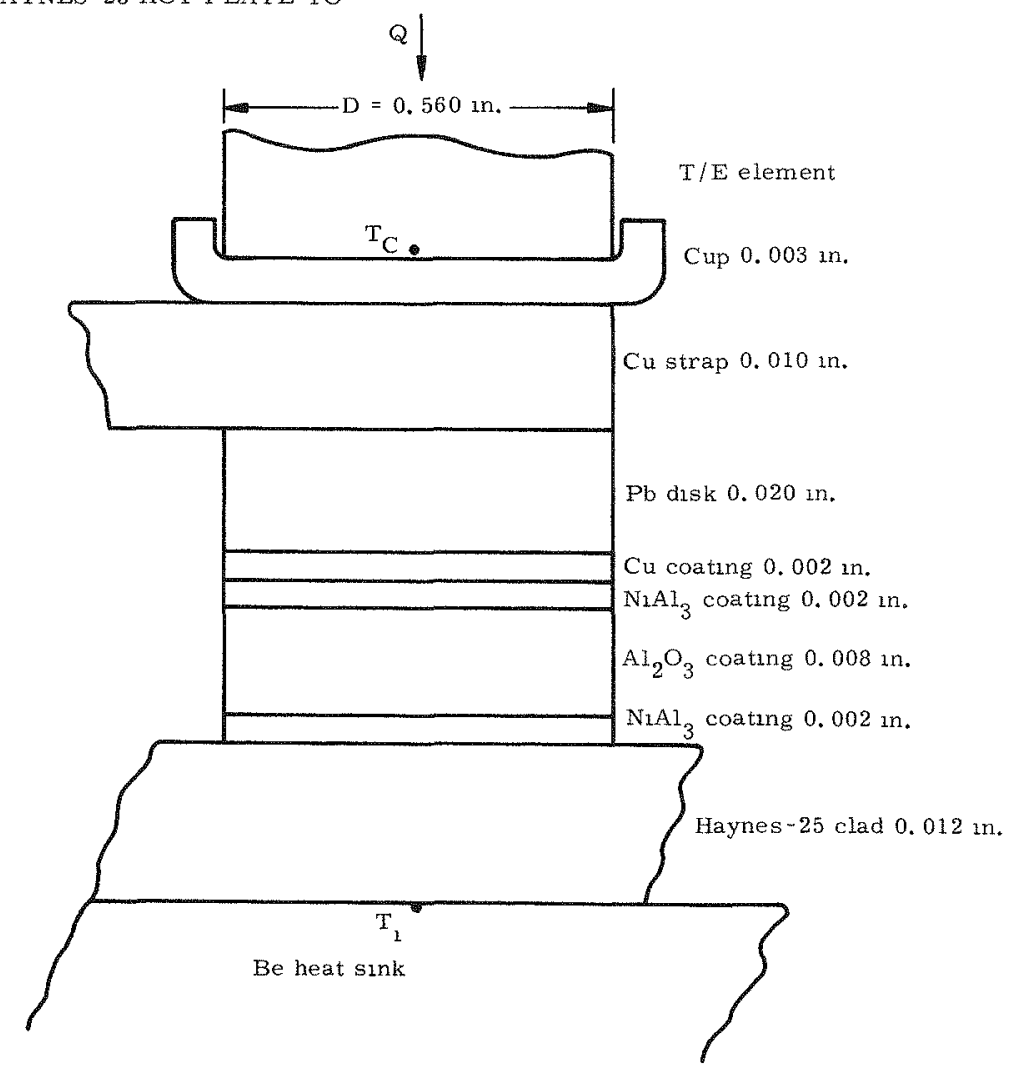

FIG. II-54. MODEL FOR COLD STACK THERMAL ANALYSIS

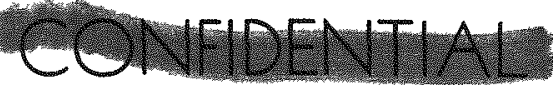

MND2062-12-7

II -76 


\section{- CONFIDENTHAL}

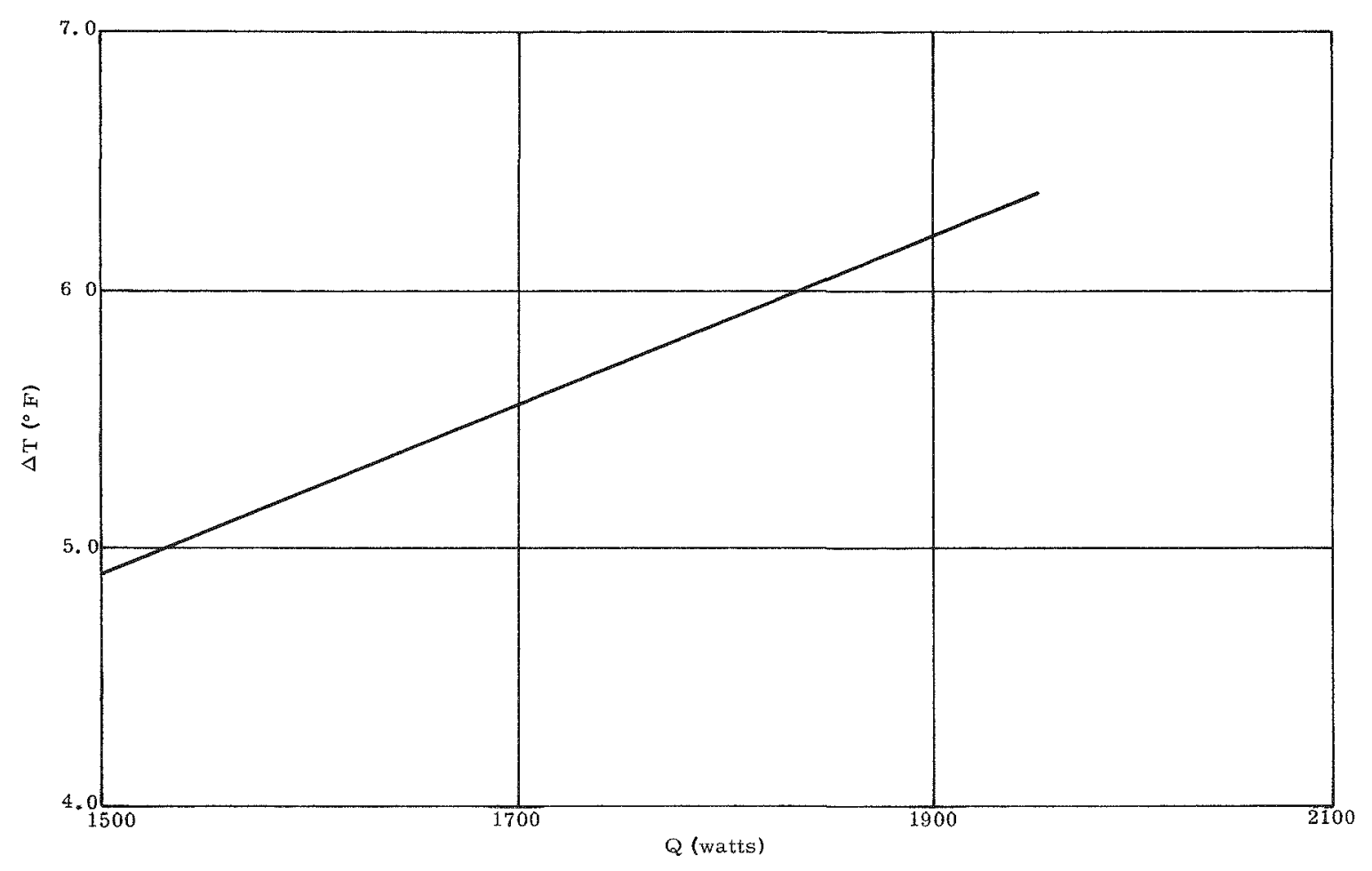

FIG. II 55. COLD STACK $\triangle \mathrm{T}$

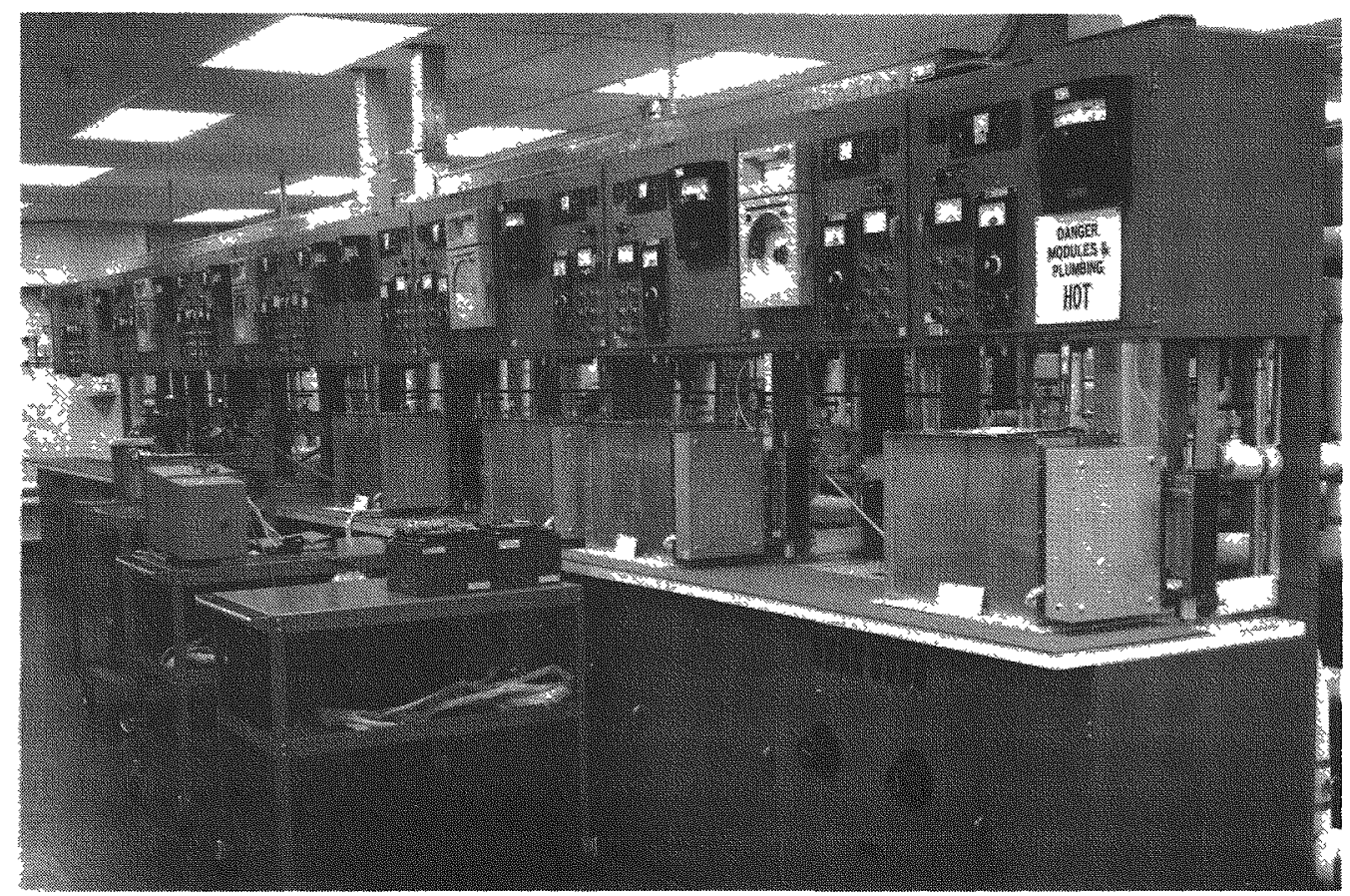

FIG. II-56, SNAP 29 T/E MODULE TEST LOOP

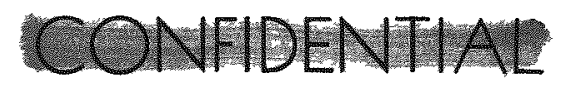

MND2062-12-7 
TABLE II-32

SNAP 29 Spring Piston Module Data Module S/N-001

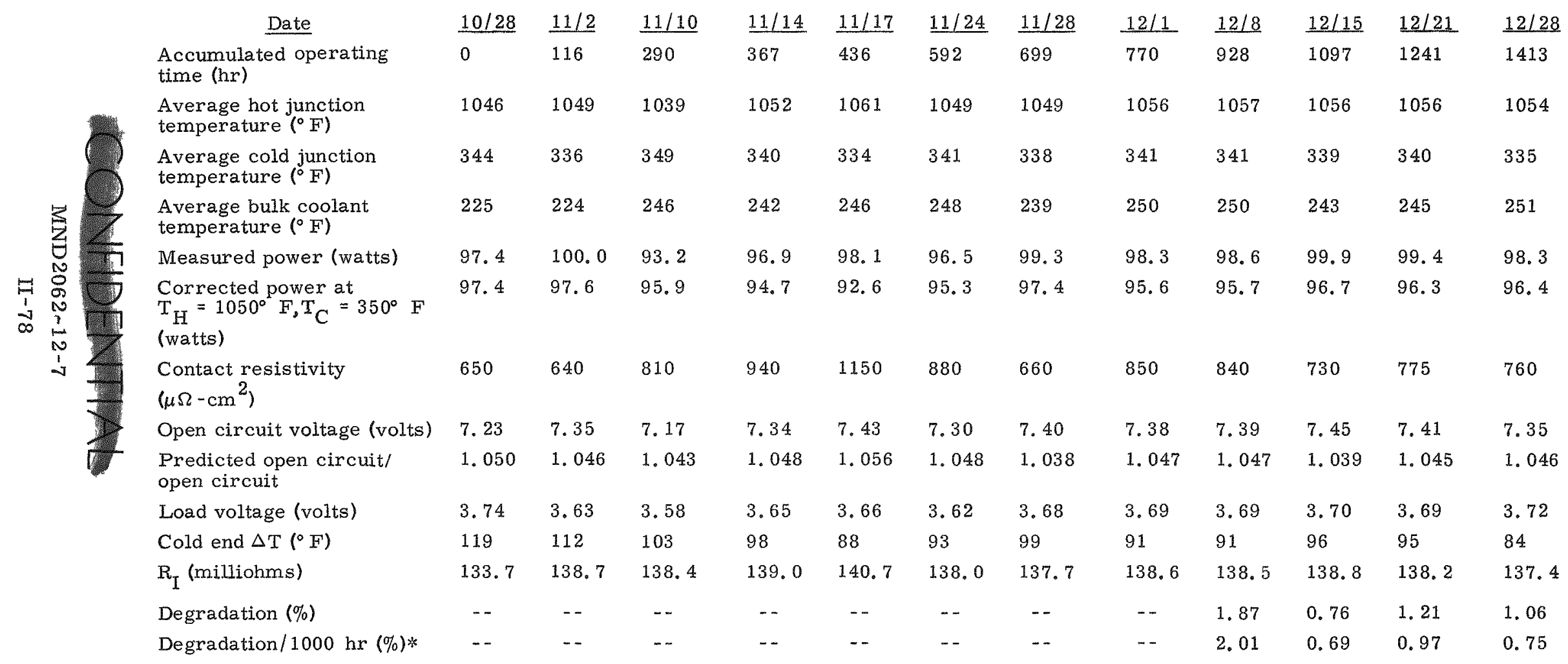

*Degradation based on corrected power 
TABLE II-33

\begin{tabular}{|c|c|c|c|c|c|c|c|c|c|}
\hline Date & $11 / 7$ & $11 / 8$ & $11 / 17$ & $11 / 24$ & $12 / 1$ & $12 / 8$ & $12 / 15$ & $12 / 22$ & $12 / 29$ \\
\hline $\begin{array}{l}\text { Accumulated operating } \\
\text { time }(\mathrm{hr})\end{array}$ & 0 & 42 & 256 & 426 & 587 & 747 & 917 & 1086 & 1254 \\
\hline $\begin{array}{l}\text { Average hot junction } \\
\text { temperature }\left({ }^{\circ} \mathrm{F}\right)\end{array}$ & 1043 & 1038 & 1049 & 1054 & 1051 & 1047 & 1052 & 1052 & 1047 \\
\hline $\begin{array}{l}\text { Average cold junction } \\
\text { temperature }\left({ }^{\circ} \mathrm{F}\right)\end{array}$ & 343 & 328 & 332 & 335 & 329 & 329 & 327 & 332 & 323 \\
\hline $\begin{array}{l}\text { Average bulk coolant } \\
\text { temperature }\left({ }^{\circ} \mathrm{F}\right)\end{array}$ & 254 & 252 & 248 & 245 & 244 & 246 & 245 & 252 & 250 \\
\hline Measured power (watts) & 103.7 & 106.4 & 108.3 & 109.0 & 108.6 & 108.4 & 109.3 & 107.3 & 108.5 \\
\hline $\begin{array}{l}\text { Corrected power at } \\
\mathrm{T}_{\mathrm{H}}=1050^{\circ} \mathrm{F}, \mathrm{T}_{\mathrm{C}}=350^{\circ} \mathrm{F} \\
\text { (watts) }\end{array}$ & 103.6 & 103.9 & 104.6 & 104.8 & 103.6 & 103.9 & 103.5 & 102.9 & 103.1 \\
\hline $\begin{array}{l}\text { Contact resistivity } \\
\left(\mu \Omega-\mathrm{cm}^{2}\right)\end{array}$ & 30 & 0 & -50 & -65 & 35 & 0 & 45 & 105 & 80 \\
\hline $\begin{array}{l}\text { Open circuit voltage } \\
\text { (volts) }\end{array}$ & 7.45 & 7.53 & 7.66 & 7.67 & 7.70 & 7.65 & 7.76 & 7.65 & 7.72 \\
\hline $\begin{array}{l}\text { Predicted open circuit/ } \\
\text { open circuit }\end{array}$ & 1.017 & 1.012 & 1.006 & 1.011 & 1.008 & 1.008 & 1.004 & 1.013 & 1.005 \\
\hline Load voltage (volts) & 3.77 & 3.82 & 3.80 & 3.82 & 3.90 & 3.93 & 3.93 & 3.91 & 3.96 \\
\hline Cold end $\Delta T\left({ }^{\circ} \mathrm{F}\right)$ & 89 & 76 & 84 & 90 & 85 & 83 & 82 & 80 & 73 \\
\hline $\mathrm{R}_{\mathrm{I}}$ (milliohms) & 133.9 & 133.2 & 135.6 & 134.8 & 136.3 & 134.8 & 137.8 & 136.3 & 137.1 \\
\hline Degradation $(\%) *$ & -- & -- & -- & -- & - & 0.28 & 0.14 & 0.71 & 0.47 \\
\hline Degradation $/ 1000 \mathrm{hr}(\%) *$ & -- & -- & -- & - & -- & 0.38 & 0.16 & 0.66 & 0.38 \\
\hline
\end{tabular}

*Degradation based on corrected power 
TABLE II-34

SNAP 29 Spring Piston Module Data

Module S/N-004

\begin{tabular}{|c|c|c|c|c|c|c|}
\hline Date & $11 / 12$ & $11 / 15$ & $11 / 16$ & $11 / 23$ & $11 / 30$ & $12 / 7$ \\
\hline $\begin{array}{l}\text { Accumulated operating } \\
\text { time }(\mathrm{hr})\end{array}$ & 0 & 65 & 90 & 269 & 433 & 591 \\
\hline $\begin{array}{l}\text { Average hot junction } \\
\text { temperature }\left({ }^{\circ} \mathrm{F}\right)\end{array}$ & 1040 & 1021 & 1044 & 1058 & 1059 & 1048 \\
\hline $\begin{array}{l}\text { Average cold junction } \\
\text { temperature }\left({ }^{\circ} \mathrm{F}\right)\end{array}$ & 339 & 323 & 337 & 336 & 335 & 336 \\
\hline $\begin{array}{l}\text { Average bulk coolant } \\
\text { temperature }\left({ }^{\circ} \mathrm{F}\right)\end{array}$ & 253 & 233 & 238 & 245 & 241 & 243 \\
\hline Measured power (watts) & 103.5 & 104.6 & 107.2 & 108.8 & 110.1 & 107.4 \\
\hline $\begin{array}{l}\text { Corrected power at } \\
\mathrm{T}_{\mathrm{H}}=1050^{\circ} \mathrm{F}, \mathrm{T}_{\mathrm{C}}=350^{\circ} \mathrm{F} \\
\text { (watts) }\end{array}$ & 103.2 & 105.2 & 105.7 & 103.7 & 104.7 & 104.7 \\
\hline $\begin{array}{l}\text { Contact resistivity } \\
\left(\mu \Omega-\mathrm{cm}^{2}\right)\end{array}$ & 70 & -95 & -130 & 20 & -60 & -60 \\
\hline $\begin{array}{l}\text { Open circuit voltage } \\
\text { (volts) }\end{array}$ & 7.69 & 7.69 & 7.87 & 8.01 & 8.04 & 7.92 \\
\hline $\begin{array}{l}\text { Predicted open circuit / } \\
\text { open circuit }\end{array}$ & 0.983 & 0.971 & 0.968 & 0.973 & 0.970 & 0.969 \\
\hline Load voltage (volts) & 3.85 & 3.85 & 3.82 & 3.82 & 3.88 & 3.83 \\
\hline Cold end $\Delta \mathrm{T}\left({ }^{\circ} \mathrm{F}\right)$ & 86 & 90 & 99 & 91 & 94 & 93 \\
\hline $\mathrm{R}_{\mathrm{I}}$ (milliohms) & 143.0 & 143.8 & 144.5 & 147.0 & 146.7 & 145.6 \\
\hline Degradation $(\%) *$ & -- & - & - & -- & -- & -1.48 \\
\hline Degradation/1000 hr $(\%) *$ & -- & - & -- & - & - & -2.50 \\
\hline
\end{tabular}




\section{TABLE II -35}

SNAP 29 Spring Piston Module Data

Module S/N-005

\begin{tabular}{|c|c|c|c|c|c|c|c|}
\hline Date & $11 / 25$ & $11 / 26$ & $12 / 3$ & $12 / 10$ & $12 / 17$ & $\underline{12 / 25}$ & $12 / 31$ \\
\hline $\begin{array}{l}\text { Accumulated operating } \\
\text { time }(\mathrm{hr})\end{array}$ & 0 & 43 & 190 & 365 & 534 & 718 & 878 \\
\hline $\begin{array}{l}\text { Average hot junction } \\
\text { temperature }\left({ }^{\circ} \mathrm{F}\right)\end{array}$ & 1054 & 1048 & 1054 & 1046 & 1057 & 1061 & 1053 \\
\hline $\begin{array}{l}\text { Average cold junction } \\
\text { temperature }\left({ }^{\circ} \mathrm{F}\right)\end{array}$ & 339 & 335 & 336 & 337 & 334 & 338 & 336 \\
\hline $\begin{array}{l}\text { Average bulk coolant } \\
\text { temperature }\left({ }^{\circ} \mathrm{F}\right)\end{array}$ & 248 & 245 & 246 & 246 & 250 & 246 & 249 \\
\hline Measured power (watts) & 108.9 & 109.1 & 110.0 & 109.8 & 110.0 & 111.1 & 110.0 \\
\hline $\begin{array}{l}\text { Corrected power at } \\
\mathrm{T}_{H}=1050^{\circ} \mathrm{F}, \mathrm{T}_{\mathrm{C}}=350^{\circ} \mathrm{F} \\
\text { (watts) }\end{array}$ & 105.6 & 106.5 & 106.2 & 108.3 & 105.0 & 105.8 & 106.2 \\
\hline $\begin{array}{l}\text { Contact resistivity } \\
\left(\mu \Omega-\mathrm{cm}^{2}\right)\end{array}$ & -120 & -185 & -165 & -315 & -75 & -135 & -165 \\
\hline $\begin{array}{l}\text { Open circuit voltage } \\
\text { (volts) }\end{array}$ & 7.81 & 7.80 & 7.89 & 7.91 & 7.94 & 7.95 & 7.89 \\
\hline $\begin{array}{l}\text { Predicted open circuit/ } \\
\text { open circuit }\end{array}$ & 0.989 & 0.985 & 0.981 & 0.966 & 0.981 & 0.984 & 0.980 \\
\hline Load voltage (volts) & 3.93 & 3.85 & 3.91 & 3.93 & 3.96 & 3.99 & 4.0 \\
\hline Cold end $\Delta \mathrm{T}\left({ }^{\circ} \mathrm{F}\right)$ & 91 & 90 & 90 & 91 & 84 & 92 & 85 \\
\hline $\mathrm{R}_{\mathrm{I}}$ (milliohms) & 140.1 & 139.3 & 141.4 & 142.4 & 143.3 & 142.2 & 141.5 \\
\hline Degradation $(\%) *$ & -- & -- & -- & -2.58 & 0.60 & -0.20 & -0.60 \\
\hline Degradation/1000 hr $(\%) *$ & -- & -- & - & -7.08 & 1.12 & -0.28 & -0.68 \\
\hline
\end{tabular}

*Degradation based on corrected power 
for implementation during this period. The vibration environments for the $\mathrm{T} / \mathrm{E}$ modules are: $3.0 \mathrm{~g}$ peak, sinusoidal and $29.1 \mathrm{~g} \mathrm{rms}$, random vibration, consistent with the program Design Criteria Document, MND-2062-1000, Revision A (July 1 , 1967). These tests were completed on December 13-14, 1967 for the piston-heat sink-type $\mathrm{T} / \mathrm{E}$ module S/N-002.

Table II-36 shows the chronological sequence of the testing. The internal resistance, $R_{I}$, was approximately constant throughout the test. The low corrected power after the test could be due to erroneous thermocouple readings. Three of the nine thermocouples failed during the test and three others are not consistent with earlier readings. Further evaluation of the modules will be made after the start of performance tests.

Post-test inspection of the dynamic test module revealed some leaks in the side skins. An evaluation of the cause of the leaks is presently underway and the necessary repairs are being implemented to prepare the module for life testing. Figures II-57 and II-58 show the test setup at the Martin Marietta, Nuclear C-210 shaker facility. Removal of the module from the fixture after test revealed severe damage to the $M i n-K$ insulation in the test fixture (Fig. II -59) and separation of a substantial portion of the instrumentation wires on the hot plate (Fig. II-60). Post-test evaluation of these problems has resulted in the recommendation of remedial measures which will be applied on all subsequent tests.

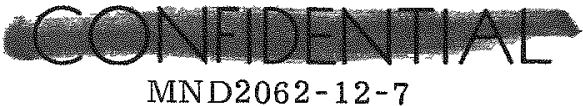




\section{CONFIDENTALA}

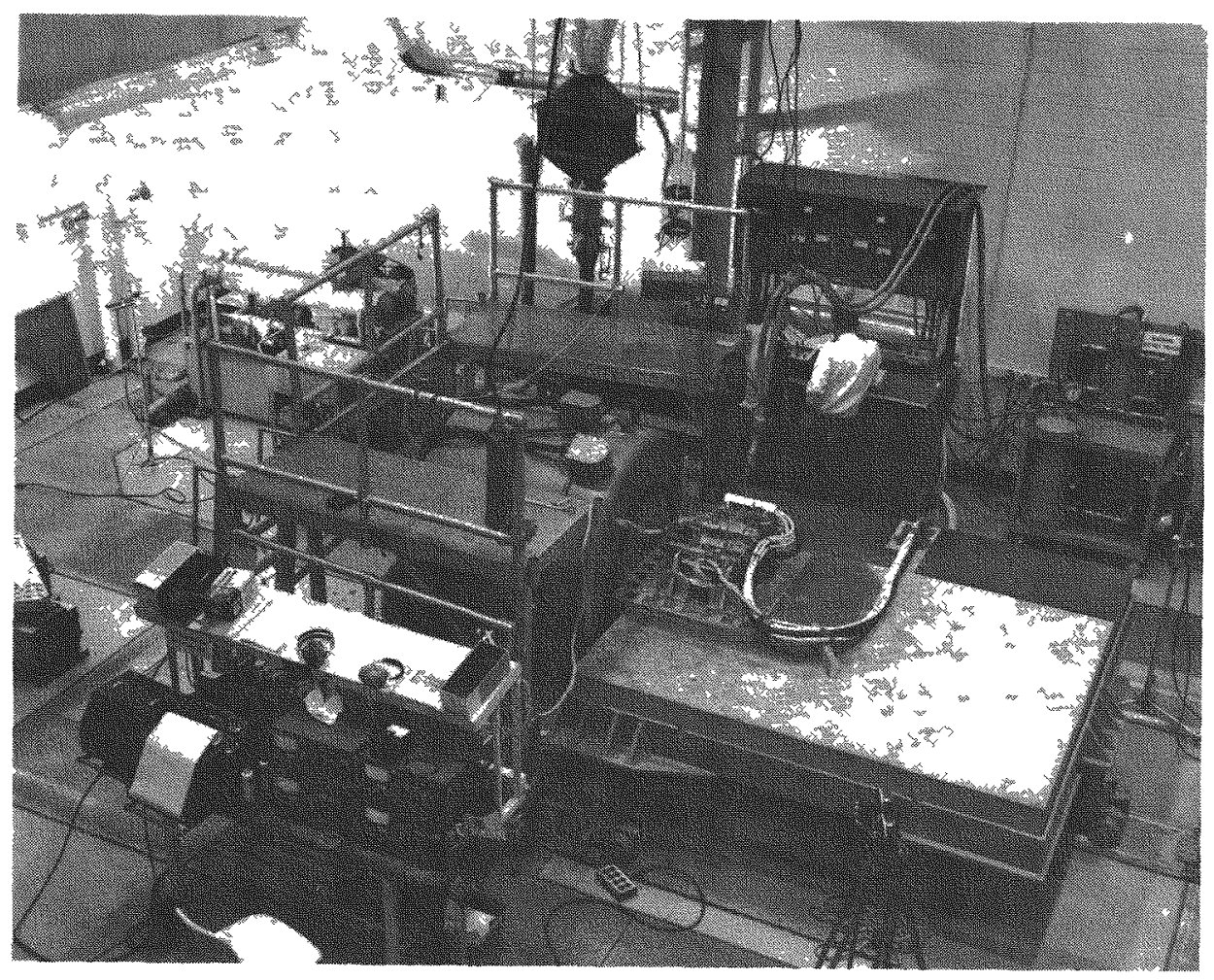

FIG. II-57. S/N $002 \mathrm{~T} / \mathrm{E}$ MODULE DYNAMIC TEST

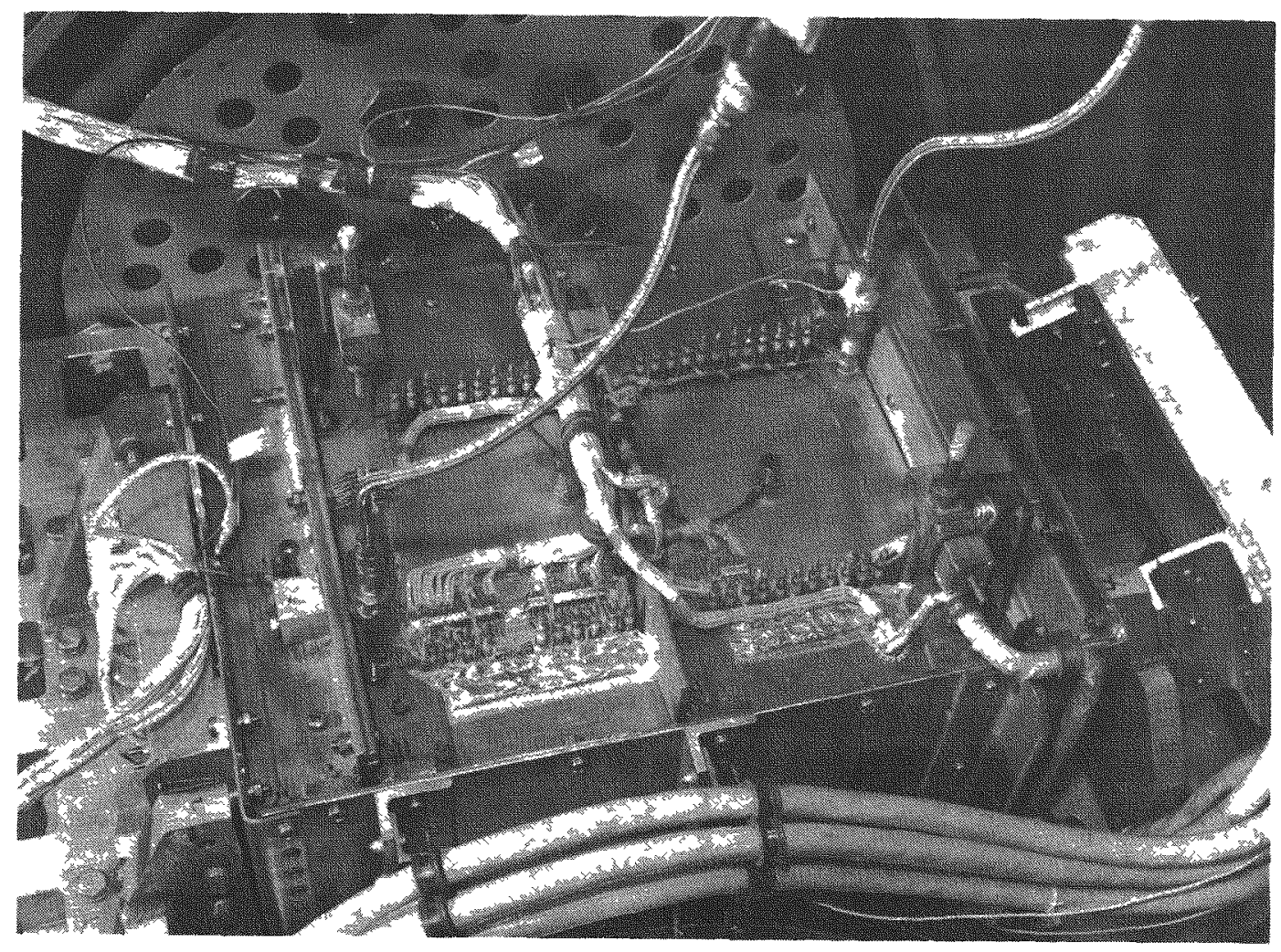

FIG. II-58. S/N 002 DYNAMIC TEST T/E MODULE IN FIXTURE

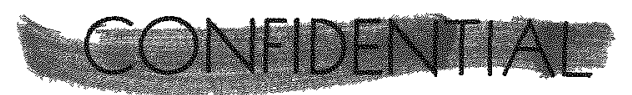

MND2062-12-7

II-83 


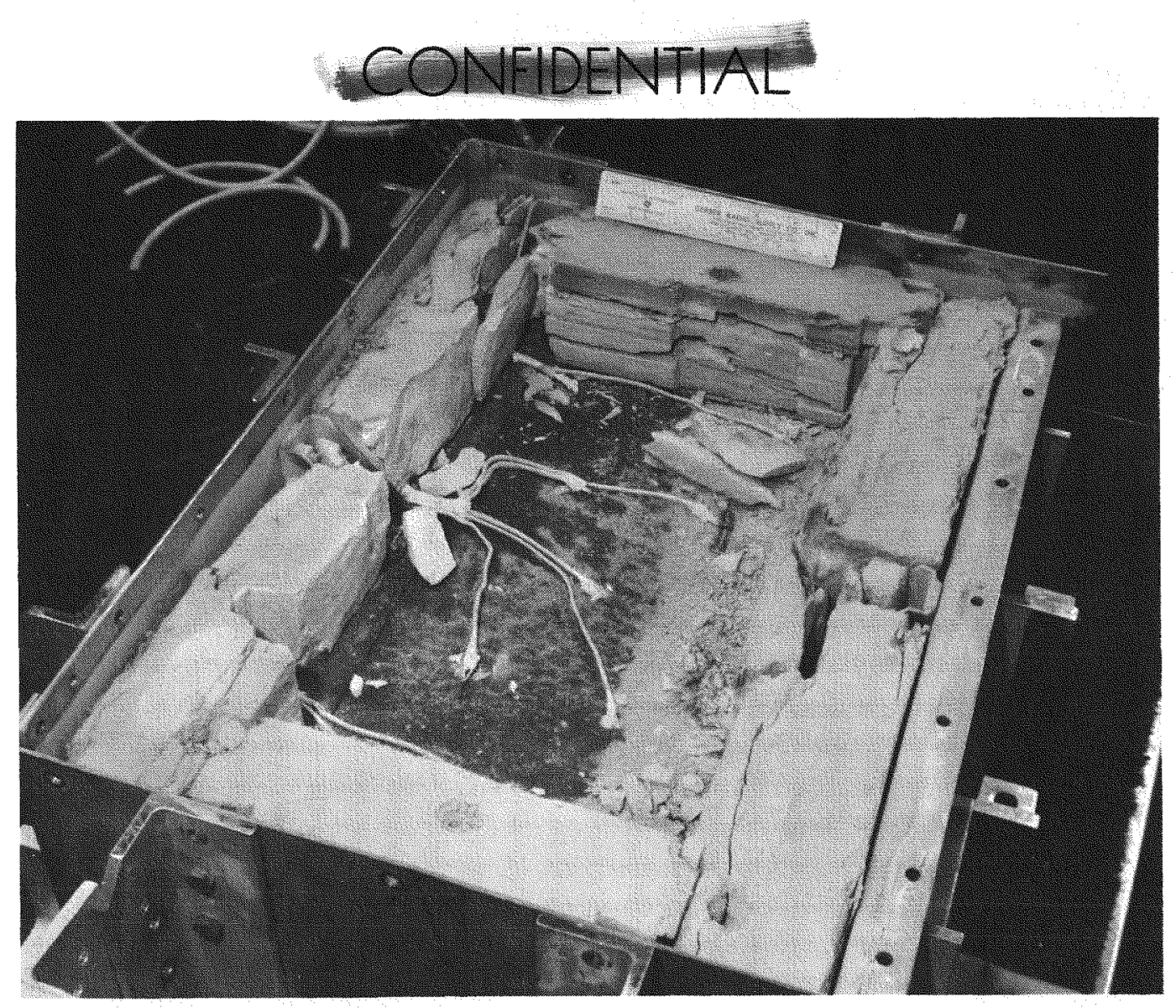

FIG. II-59. S/N 002 DYNAMIC TEST FIXTURE WTTH MODULE REMOVED

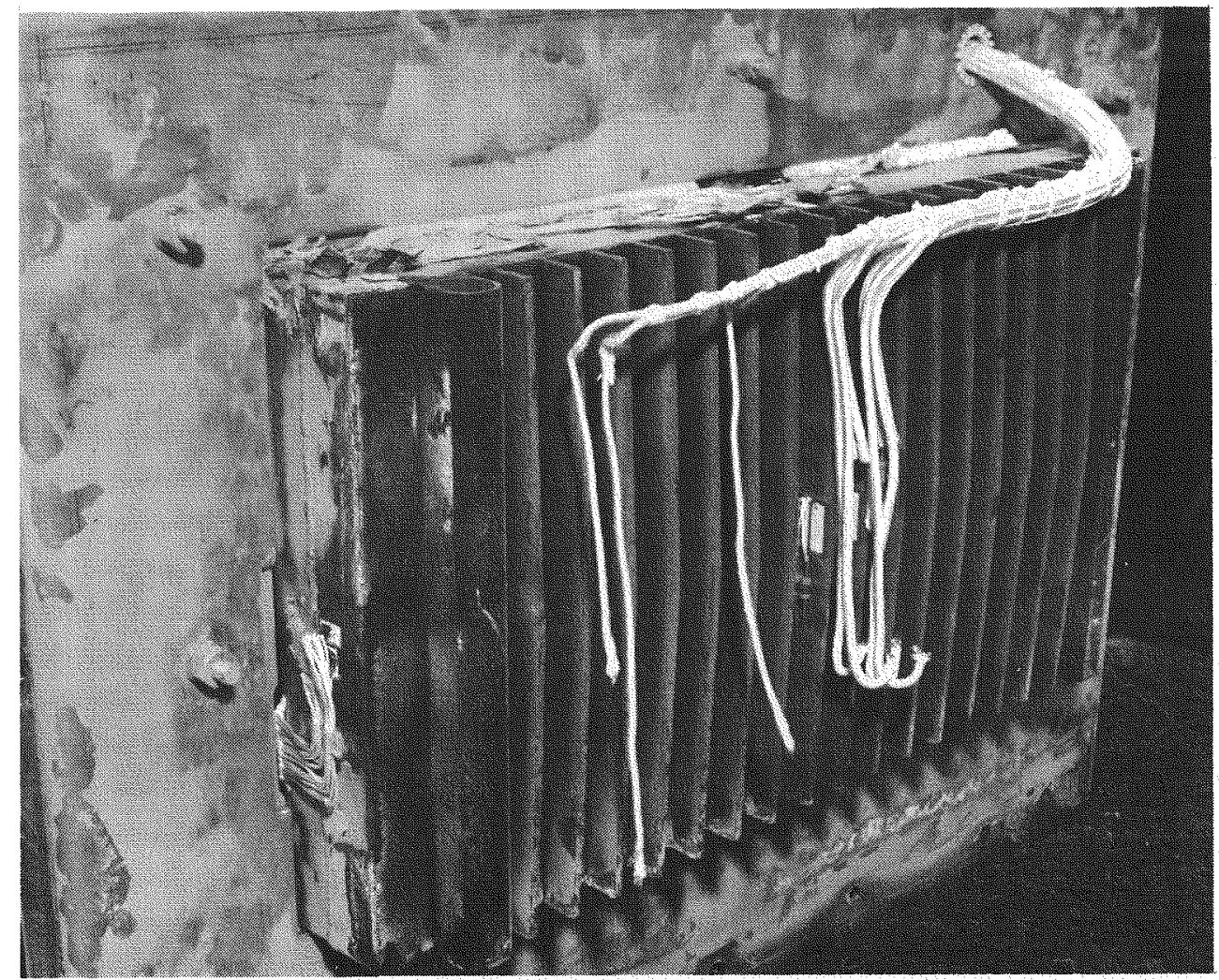

FIG. II 60. S/N 002 DYNAMIC MODULE--HOT PLATE SIDE OF MODULF AFTER REMOVAL FROM FIXTURE

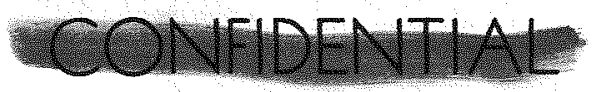

MND2062-12-7

II -84 
TABLE II-36

S/N-002 Vibration Performance

\begin{tabular}{|c|c|c|c|c|c|c|c|c|}
\hline Date & Event & $\begin{array}{l}\overline{\mathrm{T}}_{\mathrm{H}} \\
\left({ }^{\circ} \mathrm{F}\right) \\
\end{array}$ & $\begin{array}{l}{ }_{\overline{\mathrm{T}}_{\mathrm{C}}} \mathrm{C} \\
\left({ }^{\circ} \mathrm{F}\right) \\
\end{array}$ & $\begin{array}{l}\text { Measured } \\
\text { Power } \\
\text { (watts) } \\
\end{array}$ & $\begin{array}{c}\text { Corrected Power at } \\
\mathrm{T}_{\mathrm{H}}=1050, \mathrm{~T}_{\mathrm{C}}=350 \\
\text { (watts) }\end{array}$ & $\begin{array}{l}\overline{\mathrm{T}}_{\mathrm{H}_{2} \mathrm{O}} \\
\left.(\stackrel{\circ}{ })^{-}\right)\end{array}$ & $\begin{array}{c}\mathrm{R}_{\mathrm{I}} \\
\text { (milliohms) } \\
\end{array}$ & $\begin{array}{l}\text { Cold End } \Delta T \\
\quad\left({ }^{\circ} \mathrm{F}\right)\end{array}$ \\
\hline $11 / 21$ & End of outgassing** & 1050 & 345 & 105.3 & 103.8 & 250 & 131.5 & 90 \\
\hline \multirow[t]{3}{*}{$12 / 13$} & $\begin{array}{l}\text { Pre-sine*** } \\
\text { Sine }(z \text { axis })\end{array}$ & 1053 & 339 & $105.9 *$ & $101.8 *$ & 244 & $135.1 *$ & 95 \\
\hline & $\begin{array}{l}\text { Post - sine } \\
\text { (1 hr recovery) }\end{array}$ & 1052 & 340 & 109.4 & 105.7 & 245 & 130.6 & 95 \\
\hline & Random ( $\mathrm{z}$ axis) & & & & & & & \\
\hline \multirow[t]{4}{*}{$12 / 14$} & $\begin{array}{l}\text { Recovered random ** } \\
(\sim 22 \mathrm{hr})\end{array}$ & 1052 & 341 & 107.2 & 103.9 & 246 & 130.6 & 95 \\
\hline & Sine ( $x$ axis) & & & & & & & \\
\hline & $\begin{array}{l}\text { Post-sine ( } 30 \\
\text { minimum recovery) }\end{array}$ & 1047 & 344 & 108.2 & 107.3 & 247 & 133.5 & 97 \\
\hline & Random ( $\mathrm{x}$ axis) & & & & & & & \\
\hline $12 / 15$ & $\begin{array}{l}\text { Recovered random } * * \\
(\sim 18 \mathrm{hr})\end{array}$ & 1057 & 332 & 105.8 & 98.6 & 241 & 130.6 & 91 \\
\hline
\end{tabular}

*Current measured to two figures only, effects starred numbers $* *$ Steady-state operation 


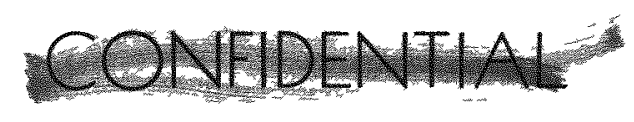

\section{E. THERMAL CONTROL SUBSYSTEM - CONTROL POTNT 1500}

The objective of the effort within this control point is to develop a thermal control system which will maintain the thermoelectric module hot junction temperature within the prescribed limits during generator operation.

The thermal control system consists of a shutter assembly (six shutters); an actuator assembly (two sets, each consisting of an actuator, reservoirs, interconnecting tubing); and a linkage and bearing assembly which interconnects the actuators to the shutter. The system working fluid is the eutectic alloy of NaK.

Development of the complete system is achieved in the following sequence:

$$
\begin{aligned}
& \text { CP 1540--Component Development } \\
& \text { CP 1530--Design Verification } \\
& \text { CP 1520--Demonstration Unit }
\end{aligned}
$$

\section{Summary of Accomplishments}

\section{a. Component development (CP 1540)}

The CP 1540 component development phase was completed during this period. A design report was issued to close out this phase. This report is presented in its entirety as Appendix A of this quarterly report.

\section{(1) NaK actuators}

The NaK actuator burst tests were completed during this reporting period. Tests were conducted on a total of six actuators, three of which were previously tested in the actuator cycling tests and three previously unused specimens. The tests were conducted at a temperature of $400^{\circ} \mathrm{F}$ and utilized oil as the working fluid. Failure occurred in all six specimens at pressures between 3500 and 3700 psig. X-ray examination disclosed that failure occurred in the adjusting bellows of the actuator in all six specimens. In addition, the primary bellows showed evidence of yielding in all six specimens.

\section{(2) Bearing lubricant tests}

Test data from the bearing lubricant test were reduced, and a lubricant selection was made. The lubricant selected is tungsten diselenide with a sodium silicate binder. The selection was based upon data obtained from the test and from available literature. Selection criteria were wear, friction coefficients, oxidation, vacuum, chemical, and radiation stability. The Iubricants evaluated included:

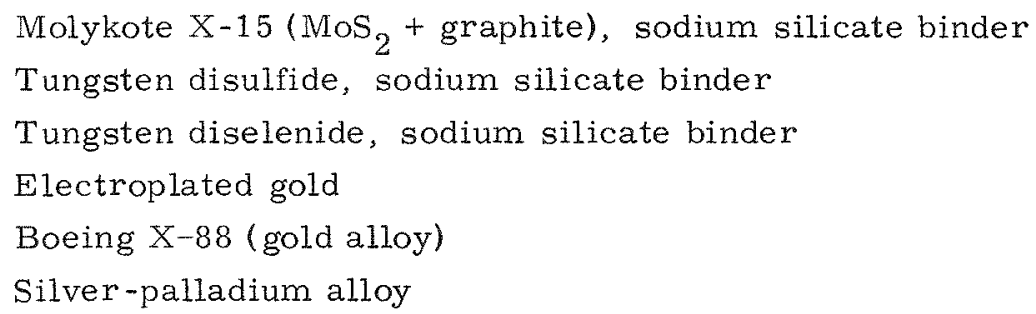

Two additional specimens were included in the test to simulate the actuator sliding joints (chrome plate on 17-4 PH in the external joint and Type 321 CRES steel in the

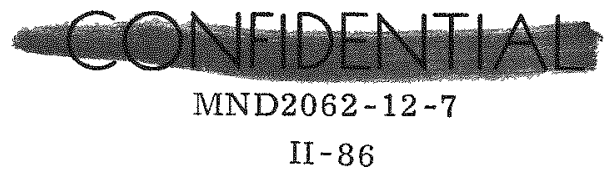




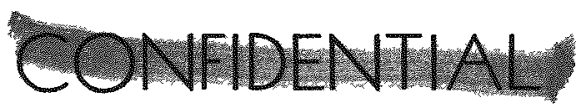

internal joint. Wear of the joints was negligible. Friction results indicate the need for additional lubricant on the actuator shaft.

The Bearing Design Report was released during this reporting period. This report includes bearing design analysis, test results and lubricant selection criteria and is presented as Appendix B of this quarterly report.

\section{(3) Shutter thermal vacuum tests}

This test was completed during this reporting period. The objective of this test was to determine the effectiveness of the shutter design in limiting the heat loss from the fuel block to space in the closed or EOL condition. The test article consisted of one-half of the shutter system ( 3 shutters) instrumented with thermocouples and mounted in the closed position (Fig. II-61). The three shutters covered an area of about $3.5 \mathrm{ft}^{2}$ since they were initially sized for the original eight-module RTG configuration. Each shutter is approximately 5 inches wide and 33.7 inches long and is composed of a 1/2-inch thick titanium honeycomb protected by $M$ in- $K 2000$ insulation. The Min-K 2000 insulation is encased in Haynes-25, two-mil foil which is perforated along the shutter edges to reduce heat conduction from the heat source side to the outer face. The shutter area for one-half the current six-module RTG would be about $75 \%$ of the area tested.

Prior to the thermal/vacuum tests, the Min-K 2000 insulation was baked out, and the Haynes-25 foil (inner shutter surface) was oxidized by operating the test fixture in air.

The test fixture consisted of a box, insulated with DynaQuartz insulation, the top of which accepted the three-shutter test assembly and the interior of which contained an electrical heat source. A separate DynaQuartz lid which was covered with multilayer vacuum-type insulation was also provided to cover the opening produced when the shutters were removed from the test fixture. This insulation was selected to provide a low heat loss through the lid.

Two separate thermal/vacuum tests were conducted. In one test the shutters were installed in the test fixture, and in the second the shutters were replaced by the insulation lid. In each test, the electrical power required to maintain the heat source at various temperatures was recorded. Using the data from the two tests, the heat loss through the fixture (tare loss) and the shutter parasitic heat loss were determined as follows:

$$
q_{\text {tare }_{2}}=P(e)_{2}-q_{1 i d}=P(e)-\left(k A \frac{\Delta T}{\Delta X}\right)_{1 i d}
$$

where:

$$
\begin{array}{ll}
\mathrm{P}(\mathrm{e})_{2} & =\text { total electrical power input in Test } 2 \\
\Delta \mathrm{T}_{\text {lid }} & =\text { measured temperature drop across the lid } \\
\mathrm{k} & =\text { thermal conductivity of DynaQuartz } \\
\Delta \mathrm{X} & =\text { thickness of DynaQuartz lid }
\end{array}
$$

Note: Since the lid heat loss was small compared to the total power input, the error in determining the tare loss is small.

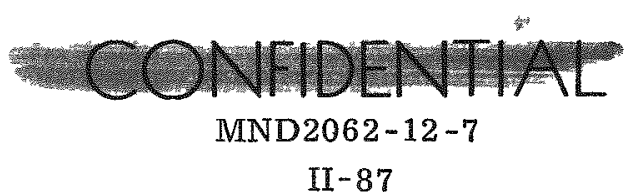



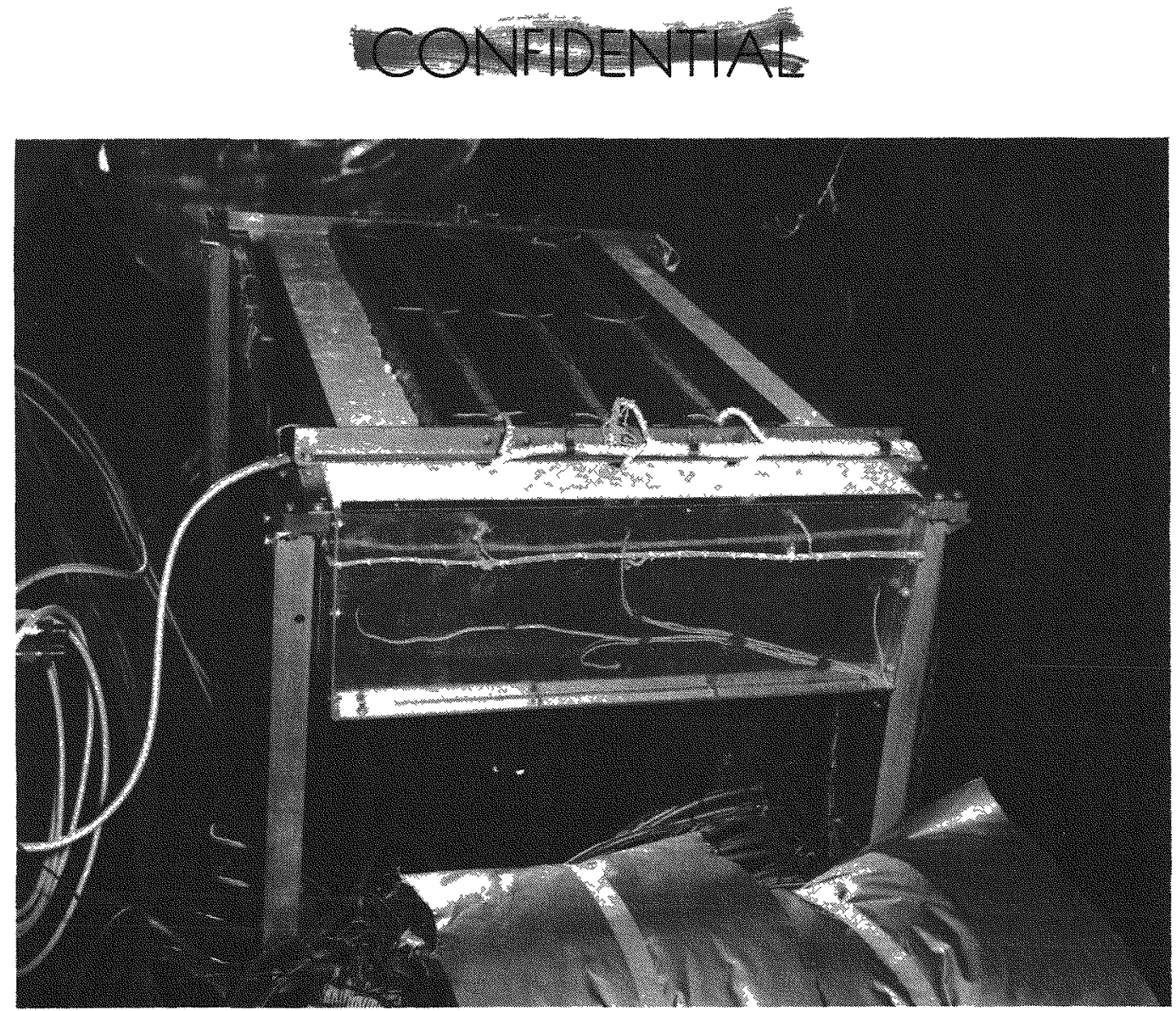

FIG. II-61. SHUTTER THERMAL VACUUM TEST SPECIMEN

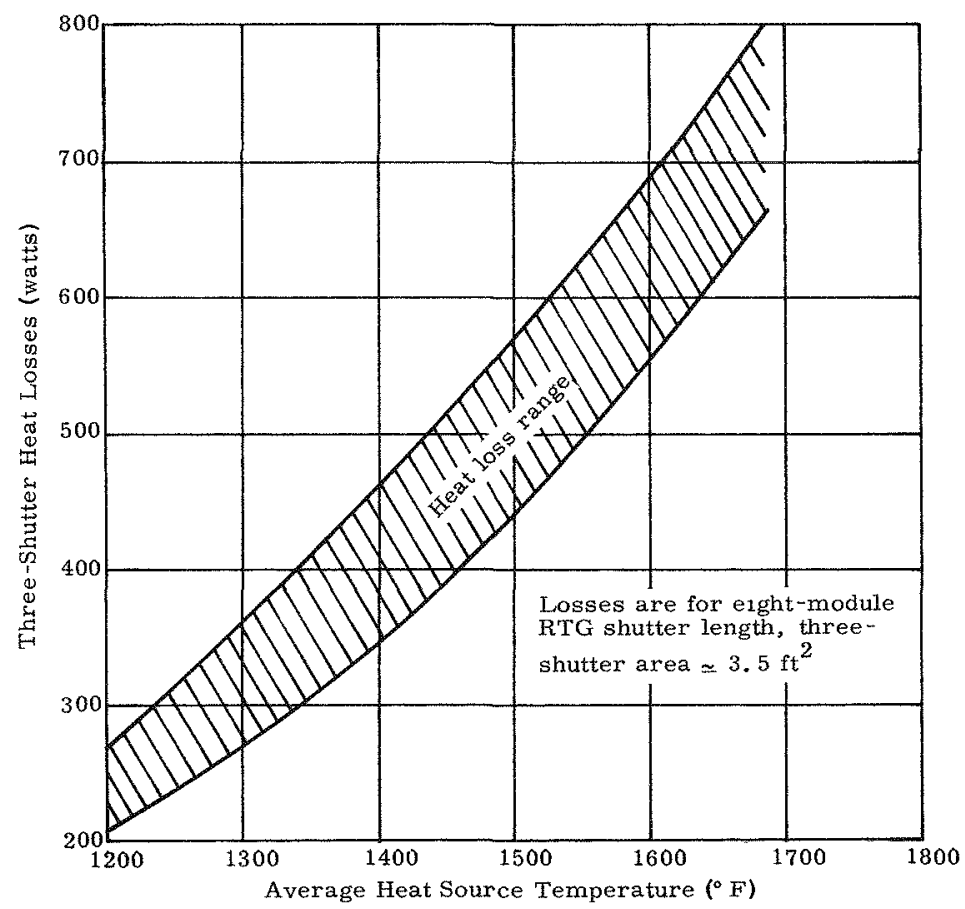

FIG. II-62. PREDICTED SHUTTER HEAT LOSSES AS A FUNCTION OF THE HEAT SOURCE TEMPERATURE

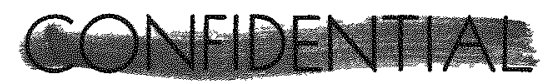

MND2062-12-7 


$$
\mathrm{q}_{\text {shutters }}=\mathrm{p}(\mathrm{e})_{1}-\mathrm{q}_{\text {tare }_{1}}
$$

where

$$
q_{\operatorname{tare}_{1}}=q_{\operatorname{tare}_{2}}
$$

The heat loss through the three shutters in the closed position is presented in Fig. II -62 as a function of heat source temperature. A band of values is shown to cover the possible errors in determining the parasitic loss; in particular, the mismatch between the shutter assembly edges and the test fixture housing which resulted in some additional heat loss due to direct radiation from the heat source past the shutter edges. At EOL conditions, the shutter parasitic heat loss is estimated to be about $6 \%$ for the six-module RTG configuration.

Subsequent to the shutter performance test, the emittances of samples taken from the shutter test assembly were determined in the Gier-Dunkle facility. Several samples were taken from both the Haynes -25 foil side of the shutter (inside) and the titanium $\mathrm{H} / \mathrm{C}$ face (outside) of the shutter. The emittance data are presented in Table II-37 and compared with the values assumed for the preliminary shutter analysis conducted prior to the test. The shutters were numbered 1,2 and 3 where the center shutter was number 2 .

\section{TABLE II -37}

\begin{tabular}{|c|c|c|c|}
\hline $\begin{array}{l}\text { Sample } \\
\text { Location }\end{array}$ & $\begin{array}{c}\text { Temperature } \\
\left({ }^{\circ} \mathrm{F}\right)\end{array}$ & $\begin{array}{c}\text { Emittance } \\
\epsilon_{\mathrm{IR}} \\
\end{array}$ & $\begin{array}{c}\text { Solar } \\
\text { Absorptance } \\
\alpha_{\mathbf{S}}\end{array}$ \\
\hline Sample 1 & 1200 & 0.63 & 0.86 \\
\hline Shutter 3 & 1500 & 0.65 & \\
\hline $\begin{array}{l}\text { Haynes }-25 \\
\text { oxidized }\end{array}$ & 1700 & 0.66 & \\
\hline Sample 2 & 1200 & 0.57 & 0.86 \\
\hline Shutter 2 & 1500 & 0.60 & \\
\hline $\begin{array}{l}\text { Haynes }-25 \\
\text { oxidized }\end{array}$ & 1700 & 0.61 & \\
\hline
\end{tabular}

\section{Shutter Parasitic Heat Loss Test Emittance Data}

Note: Assumed value for oxidized Haynes $-25=0.6$.

$\begin{array}{cccc}\text { (3) Sample 1 } & 300 & 0.17 & 0.62 \\ \text { Shutter 3 } & 500 & 0.19 & \\ \text { Ti H/C face } & 700 & 0.21 & \\ & 900 & 0.23 & 0.62 \\ \text { (4) Sample 2 } & 300 & 0.20 & \\ \text { Shutter 2 } & 500 & 0.21 & \\ \text { Ti H/C face } & 700 & 0.23 & \\ & 900 & 0.25 & \end{array}$

Note: Assumed value for $\mathrm{Ti} H / \mathrm{C}$ face plate $=0.20$.

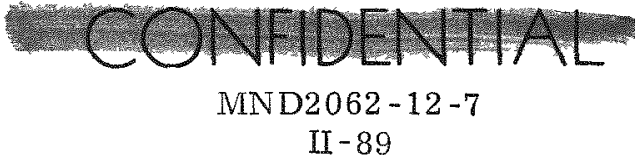


It should be noted that the actual values of the Haynes-25 emittances were probably slightly higher than the measured values because the oxidized coating was partially abraded off in some areas of the samples in preparation (i.e. , in flattening the corrugation or bead which was formed in the foil for structural reasons).

\section{(4) Shutter actuator reservoir placement evaluation}

Late last quarter, a review of the method of sensing the module hot plate temperature was made by the Design Group in an attempt to develop this portion of the thermal control system design more in keeping with the modular concept. This study led to a recommendation that only two of the module hot plates, in any given RTG configuration (i.e., whether two-, four-, six-or eight-modules), be utilized for sensing the hot plate temperature. The primary advantages of this approach are the ability to replace modules without breaking NaK lines, the ability to make tube connections between the module and actuator prior to installation in the RTG housing and the ability to clean, fill, seal and adjust the NaK system prior to installation. The potential disadvantage which had to be resolved was the possible inability of such a system to respond to local temperature excursions or failure conditions in the nonsensed modules rapidly enough.

Accordingly, a thermal analysis of the new approach was conducted (Fig. II-63). The evaluation first established the fact that for normal operation (i.e., no failures in the modules), the reliability of this approach was approximately the same as when all modules were sensing. When failures occur in one or more of the modules, an emergency (or safety) problem results, and the most severe case is the unlikely double failure of both the helium gas diaphragm and the argon gas seal in one module at near EOL conditions (shutters closed). The analysis showed that based on a sixmodule ATJ graphite fuel block (four capsules/module) design, the fuel block was capable of conducting enough excess thermal energy away from the failed module area into the sensing module location to open the shutters sufficiently to reject the excess heat and minimize the local temperature excursion. The double failure analyzed resulted in an estimated fuel block surface temperature of $1705^{\circ} \mathrm{F}$ which is $165^{\circ} \mathrm{F}$ above the normal fuel block operating surface temperature of $1540^{\circ} \mathrm{F}$. This result is somewhat conservative because no lateral heat loss from the failed module was assumed.

\section{(5) Shutter design characteristics as function of modular size}

During this period, a brief analysis was performed to evaluate the impact of modular RTG sizes on the shutter design characteristics.

Table II -38 presents a shutter weight breakdown for various RTG configurations. These weights are based upon an optimized honeycomb, wherein the facing thickness is reduced from 0.020 inch for the present eight-module shutter, and also where the total honeycomb thickness is reduced from 0.50 inch.

\section{b. Design verification (CP 1530)}

Design and analysis of the CP 1530 design verification subsystem components began during this period. Initial design work was completed on the shutter hinge bearing, incorporating the results of the CP 1540 lubricant evaluation test. The bearing drawing (466A1531012) and the lubricant application process specification (466A1533022) have been completed and released.

The actuator drawing has been revised to include the addition of a lubricant film to the actuator rod. The drawing, 466PN48S001, has also been released.

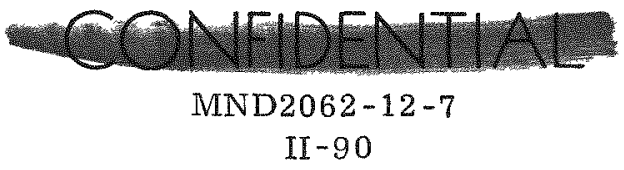



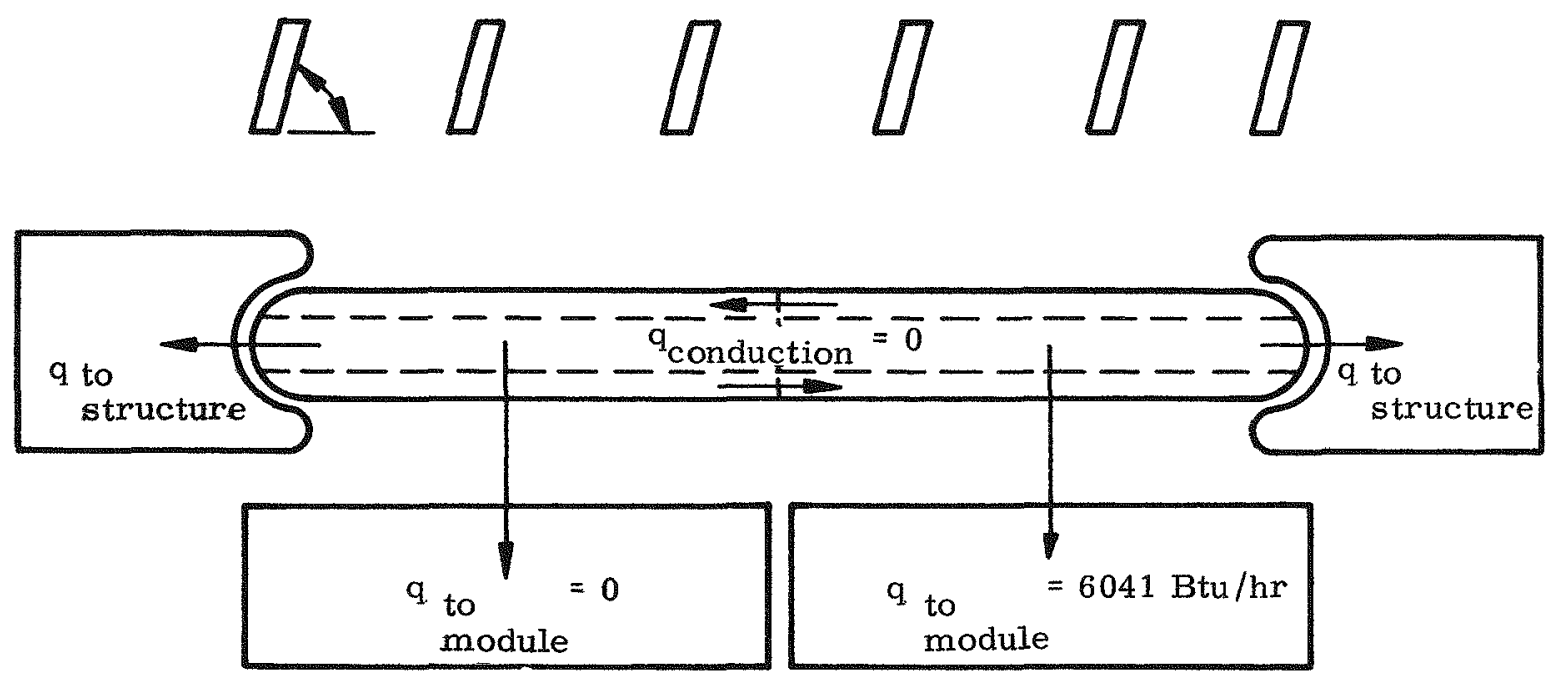

Failed module Normally operating module with $\mathrm{NaK}$ sensing reservoir

Section A-A

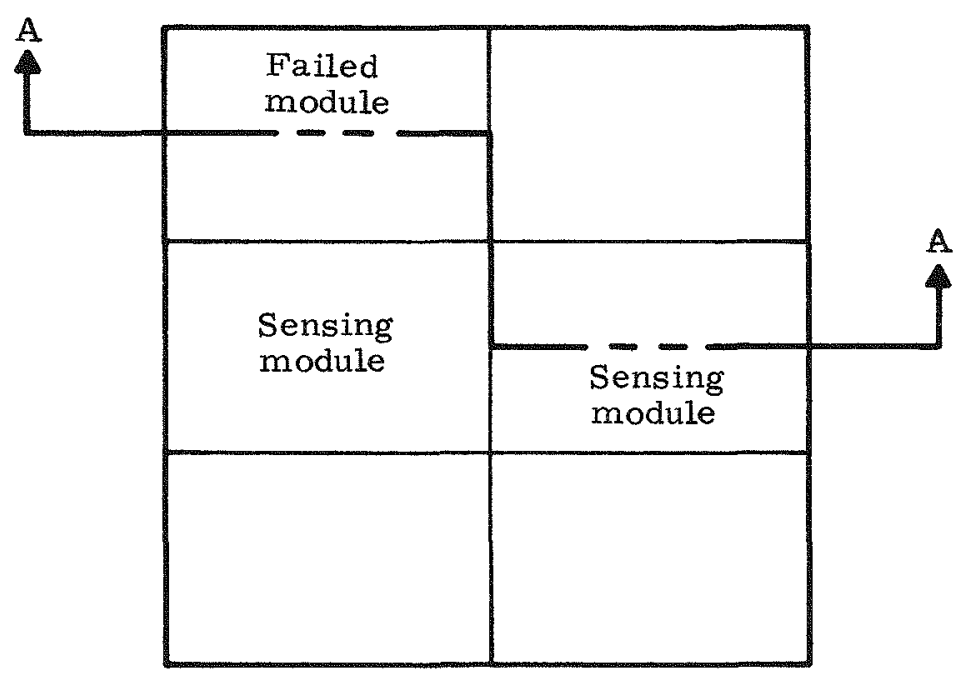

FIG, II-63. SYSTEM SCHEMATIC

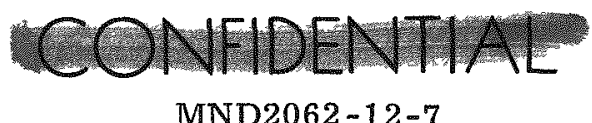

II -91 
TABLE II -38

Shutter Weights and Structural Characteristics as a Function of RTG Size

Shutter Description

\begin{tabular}{|c|c|c|c|c|c|c|c|}
\hline RTG Size & $\begin{array}{l}\text { Shutter } \\
\text { Length* } \\
\text { (in.) } \\
\end{array}$ & $\begin{array}{l}\text { Honeycomb } \\
\text { Dimensions } \\
\text { (in.) } \\
\end{array}$ & $\begin{array}{c}\begin{array}{c}\text { Shutter } \\
\text { Deflection } * * \\
\text { (in.) }\end{array} \\
\end{array}$ & $\begin{array}{l}\text { Natural } \\
\text { Frequency } \\
\text { (cps) } \\
\end{array}$ & $\begin{array}{c}\text { Weight } \\
\text { per } \\
\text { Shutter } \\
\text { (1b) } \\
\end{array}$ & $\begin{array}{l}\text { Shutters } \\
(\text { No.) } \\
\end{array}$ & $\begin{array}{c}\text { Total } \\
\text { Shutter } \\
\text { Weight } \\
\text { (1b) } \\
\end{array}$ \\
\hline $\begin{array}{l}\text { Two modules } \\
\text { stacked horizontally }\end{array}$ & 8.27 & $\begin{array}{l}0.012 \text { facing } \\
0.25 \text { height }\end{array}$ & 0.029 & 169 & 1.20 & 6 & 7.20 \\
\hline Four modules & 16.88 & $\begin{array}{l}0.012 \text { facing } \\
0.375 \text { height }\end{array}$ & 0.18 & 68 & 2.13 & 6 & 12.78 \\
\hline Six modules & 25.06 & $\begin{array}{l}0.012 \text { facing } \\
0.50 \text { height }\end{array}$ & 0.427 & 44.4 & 2.94 & 6 & 17.64 \\
\hline $\begin{array}{l}\text { Eight modules } \\
\text { (existing shutter) }\end{array}$ & 33.72 & $\begin{array}{l}0.020 \text { facing } \\
0.50 \text { height }\end{array}$ & 0.87 & 30.8 & 4.38 & 6 & 26.88 \\
\hline
\end{tabular}

Notes: *1. Length of shutter proper. Length to pivot points not shown. $* * 2$. At $67 \mathrm{~g}$ load. 
The shutter design has been revised to incorporate relief notches in the Haynes -25 foil which retains the Min-K insulation. This counteracts the condition which caused cracks to appear in the foil during both the CP 1540 shutter vibration and shutter thermal performance tests. In addition, the design has also been revised to move the shutter trunnion shaft closer to the center of gravity of the shutters, thereby eliminating a dynamic unbalance condition. This condition could theoretically have resulted in relatively large dynamic loads to the linkage and actuators, although this did not prove to be a problem on the dynamic shutter test. It is anticipated that the shutter assembly drawing, 466A1531011, will be released during the next reporting period.

The actuator-reservolr assembly and installation drawing, 466 A1531014, was completed during this period and will be released during the next period.

A study of the shutter closing spring design was made in preparation for the linkage design. The results of this study indicated that either of two designs, one consisting of torsion springs, the other consisting of a spring-loaded link, would provide better shutter performance. A selection will be made and incorporated in the design of the linkage early in the next reporting period.

An additional study was initiated to determine the feasibility of eliminating the lock which latches the shutters in the 90 -degree open position in the event of a major heat rejection system failure. A design decision is pending the results of a thermal analysis now being conducted. 


\section{F. HEAT PIPE HEAT REJECTION SUBSYSTEM--CONTROL POINT 1800}

The objective of this effort is to develop a static heat rejection subsystem capable of dissipating the waste heat from the thermoelectric module subsystem to a space environment over the life of the mission. Development has been divided into the following sequential efforts:

$$
\begin{aligned}
& \text { CP } 1840 \text {--Heat Pipe Heat Rejection Subsystem - Component Development } \\
& \text { CP } 1830 \text {--Heat Pipe Heat Rejection Subsystem - Design Verification } \\
& \text { CP } 1820 \text {--Heat Pipe Heat Rejection Subsystem - Demonstration Unit }
\end{aligned}
$$

\section{Summary of Accomplishments}

\section{a. Water heat pipe performance tests}

By the end of the previous quarter, a number of seven-foot, $7 / 16$-inch OD water heat pipes had been performance tested in a preliminary screening program. In addition, the first 15 -foot heat pipe had just been built and put on test. All but one of the seven-foot heat pipes employed single wick geometries, the fifth employed a hybrid wick (i.e., different wick geometry in the evaporator section than in the condenser section). The various wick geometries employed for these seven-foot single wick heat pipes are listed at the top of Table II-39 along with a brief summary of results. The seven-foot, 7/16-inch OD hybrid wick heat pipe result is presented in the lower half of the table. These preliminary tests led to the conclusion that single wick geometry heat pipes would not be capable of meeting the SNAP 29 requirements. The annular and corrugated wick heat pipes were subject to local boiling and instabilities in the evaporator wick and high temperature drops probably due to the presence of the fine mesh (200) screen used to form the wick and the relatively large thickness of the water layer. The artery configurations, while operating satisfactorily over the seven-foot length and in the 7/16-inch diameter tube, would probably not be able to transport the required heat ( $>200$ watts/pipe) over a 15 -foot length in the selected $3 / 8$-inch OD tube size. The hybrid wick configuration showed great promise, not only because of high heat transport capability and relative insensitivity to elevation, but mainly by confining the high liquid flow resistance to the evaporator section the pipe could be lengthened without serious performance degradation.

Accordingly, the screening program was reoriented toward hybrid heat pipes early this quarter. A large number of eight-foot, 3/8-inch OD, and several 15-foot, $3 / 8$-inch OD hybrid heat pipes were built and tested as can be seen from the list in Table II -39. To supplement the Table II -39 heat pipe descriptions, a more detailed description of the configurations evaluated during this period is presented.

\section{(1) Evaporator sections}

Corrugated type. This was fabricated from 200 mesh (0.010-in. diameter wire) screen. The triangular corrugations were approximately 0.035 inch deep by 0.050 inch wide at the base and totaled 1 - in number around the inside of the $3 / 8$-inch diameter tube.

Dual screen type. Two evaporators were made of this configuration, one using a layer of 30 mesh screen and a layer of 40 mesh screen, while the other was built of two layers of 20 mesh (0.018-in. diameter wire) screen.

Multiscreen type. Three designs were fabricated of this type; one with four layers

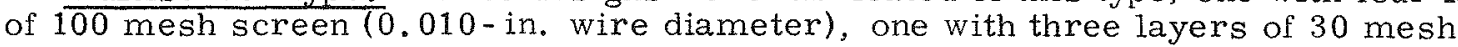

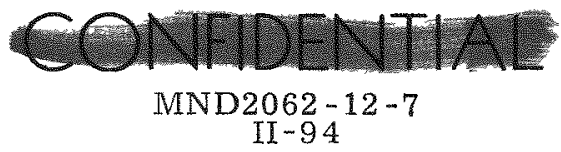


screen (0.010-in. wire diameter) and one using two layers of 30 mesh $(0.010-$ in. wire diameter) with an inner liner of $60 \mathrm{mesh}(0.011$ - in. wire diameter) screen.

Dual artery type. This design was made with a 100 mesh screen against the inner wall of the tube and two 0.09 -inch diameter arteries made from 200 mesh screen attached to the 100 mesh screen.

\section{(2) Condenser section}

Annulus type. Two hundred mesh screen $(0.0021-$ mil diameter wire) with spacer rods of $0.020 \mathrm{mil}$ wire to size the annulus.

Corrugated type. Made of corrugated 200 mesh screen (same as evaporator).

Dual artery type. Same as evaporator

As the quarter progressed, the performance trends for hybrid heat pipes became evident, and the decision was made to build and test the more promising hybrid heat pipes with bends of various radii in both the condenser and evaporator sections. By the end of the quarter, a number of bent heat pipes had been built and a few of them had been successfully tested (Table II-39). The results are discussed in a later section. In addition, test fixtures were completed for vibration, shock and acceleration tests of the most promising hybrid wick heat pipe configurations. The pipes which will be used for these initial dynamics tests are indicated on Table II-39.

\section{(3) General test procedure}

In performance testing the heat pipes, each pipe is initially subjected to a high power (230-watt input) start-up test from room temperature conditions to determine if it will burn out (i.e., the evaporator wick starts to dry out) during warmup. If no dryout accurs during this test, the maximum heat transport $\left(\mathrm{q}_{\mathrm{max}}\right.$ ) of the pipe is determined at $300^{\circ}$ and $350^{\circ} \mathrm{F}$ and at three elevations of the evaporator section (level, $-1 / 4$ inch and $-1 / 2$ inch). This is done by turning on a forced air convection heat exchanger, which covers the condenser section of the pipe, when the pipe temperature reaches $300^{\circ} \mathrm{F}$. Power and airflow are continuously adjusted to keep the test tem perature constant until dry out occurs.

A formal procedure for determining the incipience of burnout (or dryout) was documented this period. The procedure was determined after careful analysis of all of the experimental data gathered to date and appears to correctly indicate the start of dryout in every instance. The procedure consists of stabilizing the heat pipe at the test temperature and at a power level below dryout. The power is then increased in small increments while holding the test temperature at the selected value with forced convection cooling on the condenser section. Dryout is determined by graphically depicting the temperature differences between three sets of thermocouples on the heat pipe as a function of power input level. The three sets of thermocouples are as follows:

(1) The first thermocouple on the evaporator section and the first thermocouple in the transport section

(2) The first thermocouple on the evaporator section and the next to last thermocouple on the evaporator

(3) The first and second thermocouples on the evaporator section.

When the percentage increase in one or more of the $\Delta \mathrm{Ts}$ is inordinately larger than the percentage increase in power input, dryout of the evaporator wick has started. The last stable reading is then considered to be $q_{\max }$ for that temperature level.

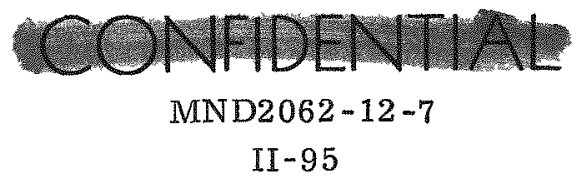


TABLE II-39

\section{Summary of Water Heat Pipe Tests}

\section{Wick Type \\ Evaporator/Condenser}

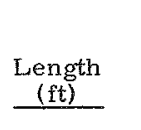

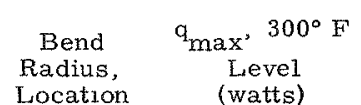

(watts)

Single Wick Configurations

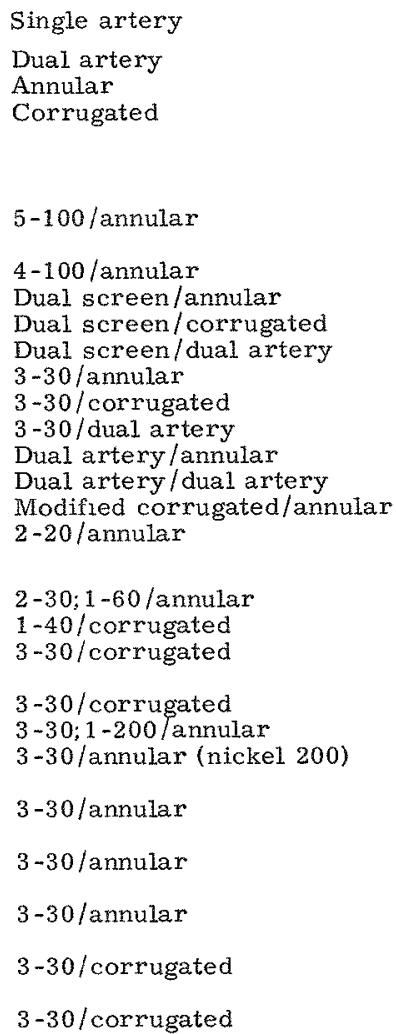

$\begin{array}{ll}7 / 16 & \text { Straight } \\ 7 / 16 & \text { Straight } \\ 7 / 16 & \text { Straight } \\ 7 / 16 & \text { Straight }\end{array}$

152
282
$102 *$
$<120 *$

Hybrid Wick Configurations
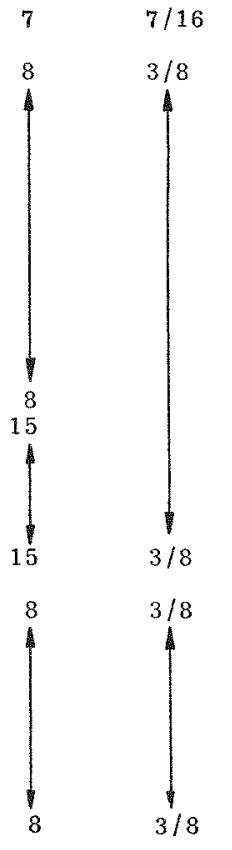

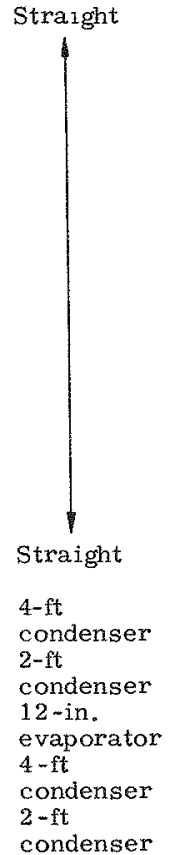

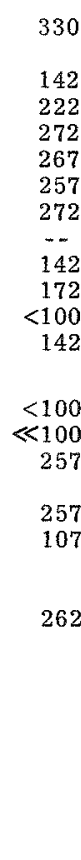

\begin{tabular}{l} 
230-Watt \\
Fast \\
Startup \\
\hline
\end{tabular}

$$
-
$$$$
-
$$$$
--
$$$$
10
$$$$
\begin{aligned}
& 5 \text { to } 6 \\
& 7 \\
& 10 \\
& 12 \text { to } 15
\end{aligned}
$$

Total

Heat

$\triangle T\left({ }^{\circ} \mathrm{F}\right)$

Comments

Not $q_{\max }$

Heat flux limited

Heat flux limited

\begin{tabular}{|c|c|c|}
\hline$-\infty$ & 20 to 30 & $\begin{array}{l}\text { Tube not drawn } \\
\text { down }\end{array}$ \\
\hline Passed & 10 & \\
\hline 1 & $\begin{array}{l}17 \\
20\end{array}$ & $\begin{array}{l}\text { For vibration } \\
\text { shock testing }\end{array}$ \\
\hline & 20.6 & \\
\hline 1 & & For vibration \\
\hline Passed & 14.7 & shock testing \\
\hline- & -- & On test \\
\hline Falled & 8 & \\
\hline Failed & 9 & \\
\hline Falled & $=-$ & Heat flux limited \\
\hline Passed & 10.3 & $\mathrm{q}_{\text {max }}$ unexplainably \\
\hline Failed & $\rightarrow$ & Heat flux limited \\
\hline Failed & -- & \\
\hline Passed & 13 to 14 & $\begin{array}{l}\text { Standard precon- } \\
\text { ditioning }\end{array}$ \\
\hline $\begin{array}{l}\text { Passed } \\
\text { Failed }\end{array}$ & 13 to 14 & $\begin{array}{l}\text { Evaporator stored } \\
\text { Heat flux limited }\end{array}$ \\
\hline & & $\begin{array}{l}\text { Life test for gas } \\
\text { buildup }\end{array}$ \\
\hline Passed & 14.3 & For centrifuge test \\
\hline
\end{tabular}

*Limited due to local bolling in evaporator wick. 
If the heat pipe fails to pass the high power startup test, it is recovered, cooled, the temperature raised in smaller power increments and $\mathrm{q}_{\max }$ determined.

(4) Results of hybrid wick, water heat pipe screening tests

Analysis and evaluation of the results of the hybrid wick water heat pipe screening tests listed in Table II - 39 have led to the following general conclusions.

Evaporator wicks employing several layers of screen having the same mesh size exhibit acceptable temperature drops, stable performance, good startup and recovery characteristics and are capable of meeting the $q_{\max }$ equal to $200+$ watts criteria of the SNAP 29 system with adequate performance margin. Screen mesh sizes in the 30 to 40 range appear to be best. However, the poor result on the 2-20 mesh pipe is not easily explainable since, based on the correlations performed to date, it should have performed much better. Since multiple layers of the mesh sizes between 30 and 100 were not tested parametrically, the conclusion that $30-40$ mesh is optimum is somewhat tenuous. In addition, the effect on performance of wire diameter for a given mesh size has not been investigated extensively, so that the optimum combination of mesh size and wire diameter is not known. However, for the finer mesh sizes (e.g., 100 and above), a greater number of layers appears necessary to provide sufficient liquid flow area in the wick, and this can result in excessive $\Delta \mathrm{T}$ through the evaporator wick (cf. 4-100 and 5-100 mesh configurations).

Layers of screen of different mesh size can be utilized effectively for an evaporator wick if the selection is made carefully. For example, the dual screen configuration (one layer of 30 mesh and one layer of 40 mesh), where the 40 mesh screen was next to the vapor space, provided nearly the same performance as the three-layer, 30 mesh evaporator. The objective of placing the finer mesh screen at the liquid-vapor interface is to obtain the greater pumping power associated with the finer screen. When water (or any other relatively low thermal conductivity fluid) is the transport fluid, the presence of a fine screen at the innermost layer covering coarser mesh screen layers was found to be highly undesirable (for example, see the $8-\mathrm{ft}(2)-30$, and (1) -60 and the 15 -ft (3) -30 and (1) -200 configurations). The presence of the fine mesh screen appears to trap the larger vapor bubbles formed in the coarse screen below and dry out due to local boiling, beginning at power levels much below the theoretical heat transport limit. Note that if all screen layers are fine (at least up to $100 \mathrm{mesh}$, the local boiling problem does not appear.

Evaporator configurations, such as the modified corrugated, corrugated and annulus, which utilize low flow resistance wicks having large liquid layers next to the tube wall, are also limited by local boiling problems. In this case, however, part of the problem lies with the low conducting fluid layer, and part probably is due to the fact that in order to form these wicks a 200 mesh screen was used. This very fine screen tends to trap any bubbles formed in the wick, thus promoting rapid dryout of the wick by a sort of vapor lock phenomenon. It is unknown whether coarser mesh screens would ameliorate this problem or not because forming the stiffer, coarser mesh screens into these configurations proved difficult, and none were tested.

No particular problems have been experienced with the butt joints used to mate hybrid wicks as long as the gap between the wicks is kept less than the evaporator pore size. However, configurations such as the dual artery-annular heat pipe (Table II -39) appear to be limited in transport capability by the fact that the pore size in the condenser section is actually smaller than that in the evaporator section. Therefore, unless evidence to the contrary is found, configurations employing this reverse combination are not recommended.

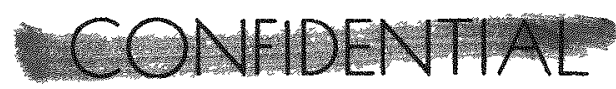

MND2062-12-7

II -97 
To date, only one evaporator configuration has been tested with three different condenser designs. The dual screen evaporator section was tested with annular, corrugated and dual artery condensers (see Table II -39). The results suggest that the corrugated approach is superior, however, the exror in the $\mathrm{q}_{\max }$ data is estimated at \pm 10 watts so that for all practical purposes the dual artery condenser is as good. The annular condenser does appear inferior to the corrugated design, based on several tests (dual screen and three-layer, 30 mesh tests), but since the annular condenser is easier to bend, judgment is being reserved until after the performance tests on comparable bent pipes.

As anticipated, based on theoretical considerations, lengthening the condenser section, a hybrid wick heat pipe, from 8 to 15 feet, did not significantly degrade the heat transport capabilities. As mentioned earlier, this is because a large percentage of the total flow resistance exists in the evaporator section which was not changed ( 8 and $15 \mathrm{ft}$, three layer, 30/corrugated in Table II-39).

In the latter part of this reporting period, the first bent heat pipe was successfully tested. This configuration consisted of a three layer, 30 mesh evaporator and a $20-$ mil annular condenser with the condenser section bent to a four-foot radius. The bend was made without the use of a mandrel in the pipe, and X-rays showed some deformation in the condenser wick. Despite this, the heat pipe operated as well as its counterpart straight pipe (see Table II-39). The four-foot radius bend was selected for this pipe because it matches the curvature of the centrifuge apparatus upon which this pipe and a three-layer, 30 mesh/corrugated pipe will be checked for acceleration effects. Four other bent heat pipes have been built and are currently on test as indicated in Table II-39.

To date a total of six 15-foot, 3/8-inch OD hybrid heat pipes have been fabricated. All pipes, except one, were made of Type 321 SS with Type 316 SS wicking. The remaining one was made of $\mathrm{Ni} 200$ and was fabricated to compare the gas generation in a nickel pipe with that in a stainless steel pipe. Three of the stainless steel pipes have identical wick configurations, i.e., three layers, 30 mesh evaporator and a corrugated condenser. The first of these pipes was preconditioned before test, using the standard procedure utilized on all pipes to date, i.e., bakeout of the evaporator section under vacuum after assembly of the entire pipe, and filling with outgassed water without the evaporator section being exposed to the atmosphere after bakeout. The second unit was preconditioned and fabricated in a manner similar to that anticipated in practice, i.e., the evaporator section alone was baked out in a vacuum oven ( $2 \mathrm{hr}$ at $500^{\circ} \mathrm{F}$ ), the open end covered with a dust cap and stored on a shelf for three to four days. The condenser and evaporator sections were then joined, the pipe evacuated and filled with outgassed water. Performance tests on these two units indicated no difference in $\mathrm{q}_{\max }$ levels. The third 15 -foot unit in this series was prepared identical to the second, except that it was not stored for several days prior to assembly. This unit is currently on test.

All $\mathrm{q}_{\max }$ data presented in Table II-39 are thermal watts. The values of test fixture heat loss (tare loss) which have been subtracted from the electrical power inputs are based on experimentally determined values of heat loss through the heater block insulation. The experimentally determined values of tare loss are presented.

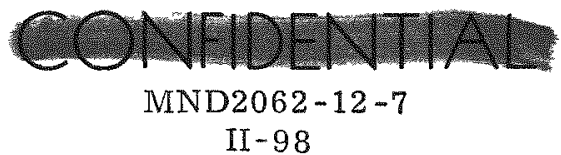


Experimental Heat Loss from Heat Pipe Test

\begin{tabular}{|c|c|}
\hline $\begin{array}{c}\text { Transport } \\
\text { Temperature } \\
\left({ }^{\circ} \mathrm{F}\right) \\
\end{array}$ & $\begin{array}{c}\text { Tare } \\
\text { Loss } \\
\text { (watts) } \\
\end{array}$ \\
\hline 250 & 13 \\
\hline 275 & 15.6 \\
\hline 300 & 18 \\
\hline 325 & 20.2 \\
\hline 350 & 22 \\
\hline
\end{tabular}

Figure II-64 shows some of the heat pipes on test (note curved pipe).

b. Cleaning procedures

Cleaning of the component parts for a heat pipe has been recognized as a critical item to attain good performance. As developed under this program, the method found most practical and effective is a cleaning procedure utilizing the following sequence of operation:

(1) Vapor degrease

(2) Alkaline cleaning

(3) Water rinse

(4) Passivate

(5) Water rinse

(6) Demineralized water wash

(7) Dry out.

c. RTG radiator configuration studies

In the Fourth Quarterly Report, the results of an analysis of the radiator area re quirements versus the thermoelectric cold junction temperature for a six $-\mathrm{T} / \mathrm{E}$ dia phragm module RTG system were reported. It was shown that integration of the SNAP 29 system with a 10 -foot diameter vehicle would necessitate raising the $\mathrm{T} / \mathrm{E}$ cold junction temperature to approximately $375^{\circ} \mathrm{F}$, since the maximum radiator area is fixed by the vehicle circumference and the generator width. The results showed the required total heat pipe length (from centerline of $\mathrm{RTG}$ to end of radiator) as a function of cold junction temperature and temperature drop from cold junction-toradiator fin root. These results were extended this quarter to include a larger range of cold junction-to-radiator fin root temperature drops--up to $150^{\circ} \mathrm{F}$. The extended range curve is presented in Fig. II -65.

\section{d. Brazed tube radiator panel study}

Evaluation of alternate brazed tube radiator panel designs was performed this quarter. The concept consists of brazing together side-by-side active heat pipes to form the radiator panel. Various heat pipe cross sections were evaluated including

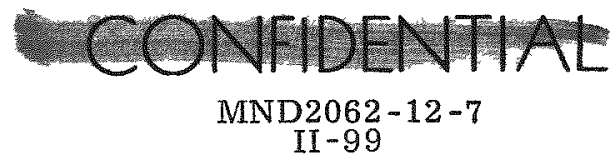



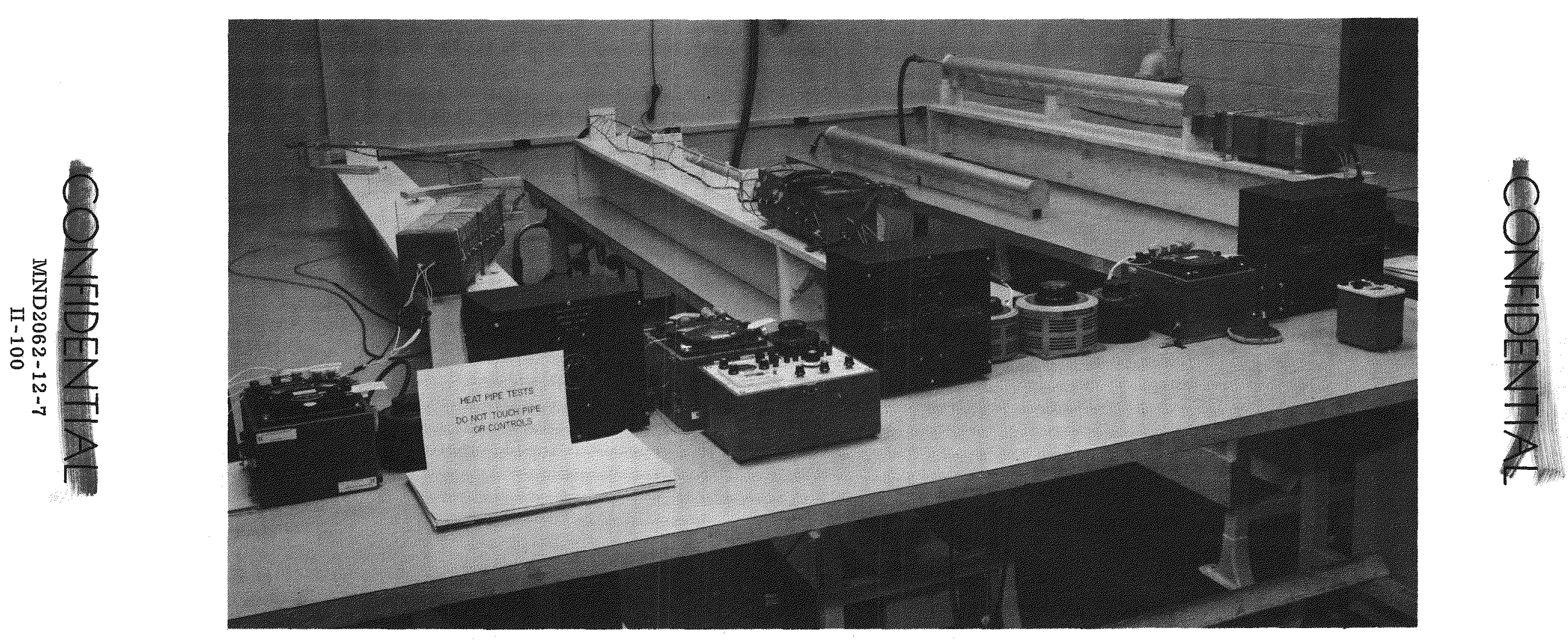

FIG. II-64. HEAT PIPE TEST AREA 


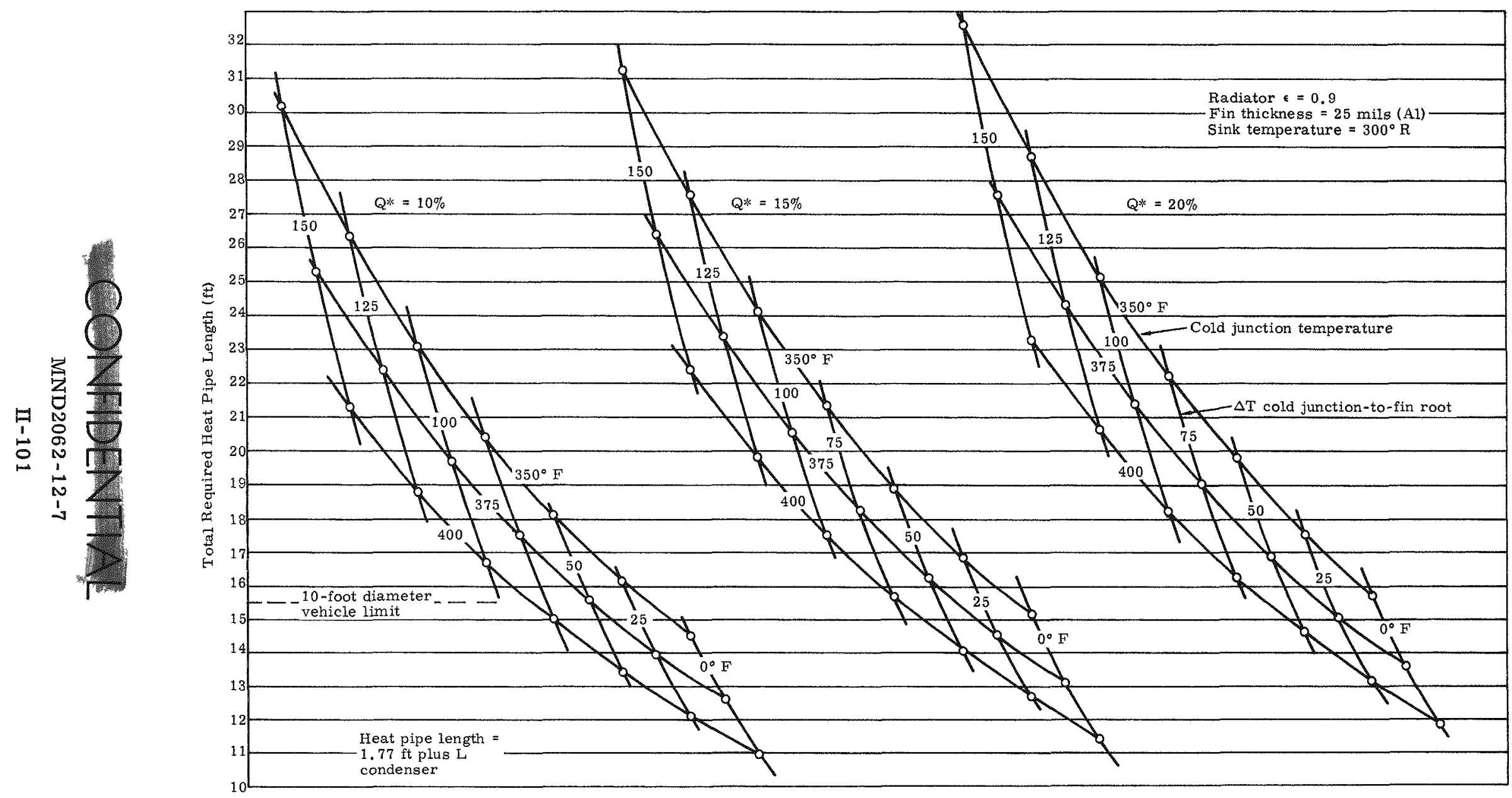

FIG. II-65. TOTAL HEAT PIPE LENGTH VERSUS COLD JUNCTION TEMPERATURE, $\triangle T$
COLD JUNCTION-TO-FIN ROOT AND Q* CORRECTION FACTOR 
circular, elliptical, square, and D-shaped tubes (Fig. II-66). Heat rejection system weights were computed for several of these designs, and these weights compared with the present system weight. None of the brazed tube panel designs proved to be lighter in weight than the present design. Figure II-67 compares the weight of the present design with the circular and elliptical brazed tube panel designs as a function of equivalent tube diameter. The lightest weight brazed system is shown to be some 10 to 11 pounds heavier per module than the present design. Detailed weight analyses were not conducted on designs d and e of Fig. II-66 because stress analysis indicated that these would be heavier than the present design and offered no particular advantage over the brazed circular tube design.

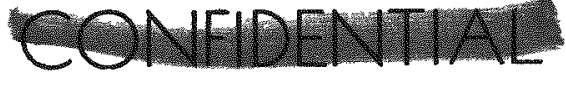

MND2062-12-7

II -102 


\section{CONGBENA}

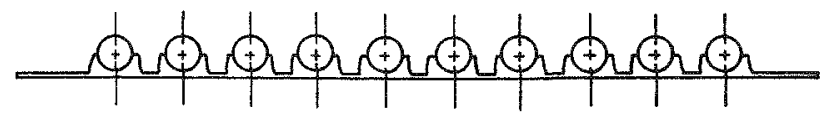

a.

Present design

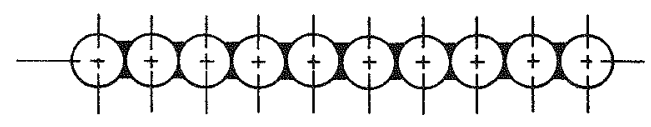

b.

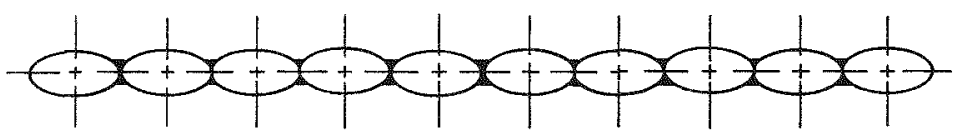

c.

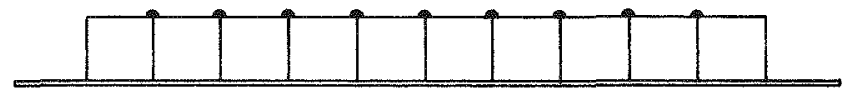

d.

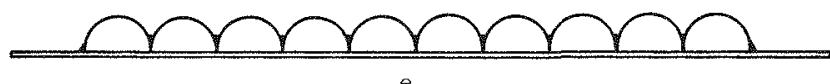

FIG. II-66, RADIATOR PANEL DESIGNS

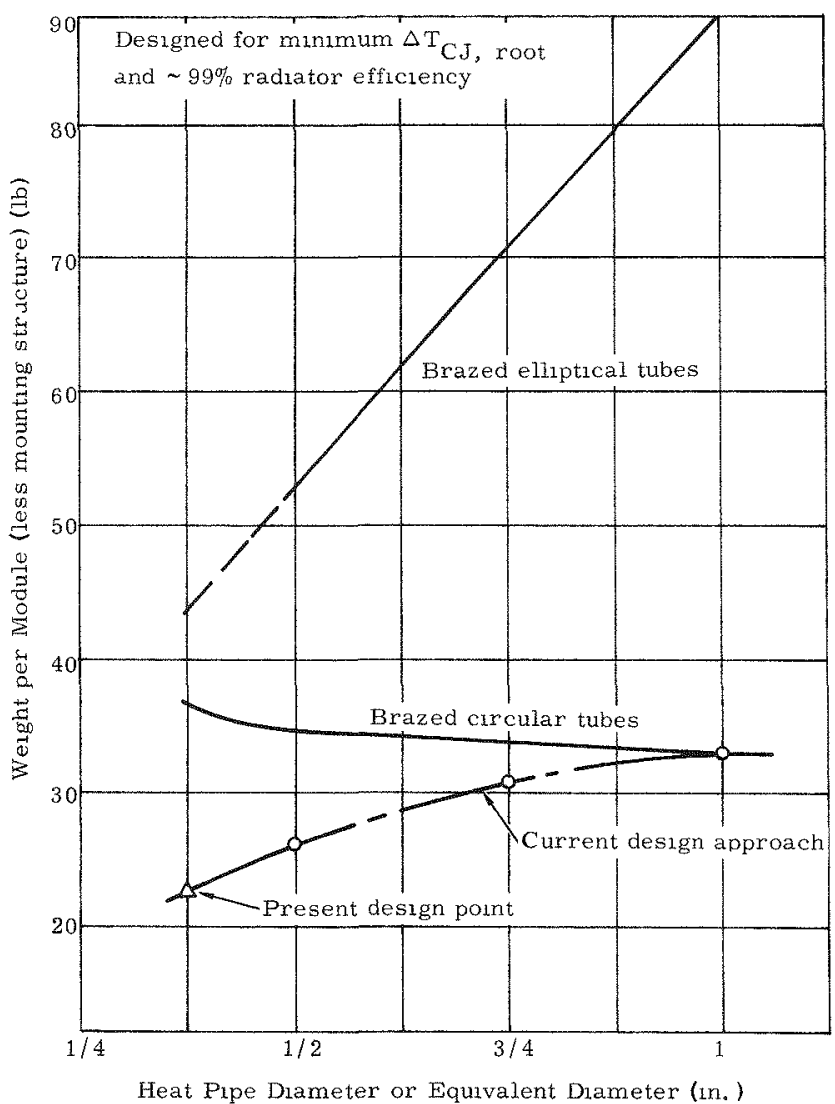

FIG. II-67. COMPARISON OF BRAZED TUBE PANEL APPROACH WITH THE PRESENT DESIGN APPROACH

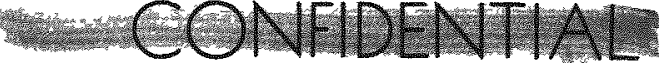

MND2062-12-7

II-103 


\section{G. RTG HOUSING STRUCTURAL SUBSYSTEM--CONTROL POINT 1900}

The objective of the effort within this control point is to develop a minimum weight housing structure which maintains the parasitic heat losses within acceptable limits, supports the various subsystems in their proper orientation, provides for remote loading of the fuel block, provides for ejection of the fuel block and provides a means of attaching the RTG to the vehicle supports. As part of the reprogramming, instrumentation is now covered under the individual control points where it is used.

Development of the complete structure is achieved in the following sequence:

CP 1940--Component Development

CP 1930--Design Verification

CP 1920--Demonstration Unit

This report includes work conducted under CP 1940 during this reporting period.

\section{Summary of Accomplishments}

Because of the close interrelationship of the RTG housing structure with the fuel block, this control point is still in the 1940 component development phase. The basic design of the structure has been determined; however, detail design is dependent upon fuel block size. This will be established during the next reporting period at which time detail design of the structure will commence.

During the interim period, layout studies have been conducted to determine the effects of various module designs and the modifications necessary to accommodate the heat rejection system heat pipes. A review of fuel block preload requirements and devices was also performed during this period. An evaluation study of the various springs which provide the motive power for fuel block ejection was started during this period. The purpose of this study is to optimize weight and space requirements for these devices. The use of nested helical springs, torsion bar springs, cantilever beam springs and torsion springs is being investigated. This study will be concluded during the next reporting period.

A fuel block separation study was continued during this period. The purpose of this study is to define the various separation parameters such as dynamic pressures, and to review the various possible separation techniques in order to define the optimum system for this application. This study will be concluded during the next reporting period.

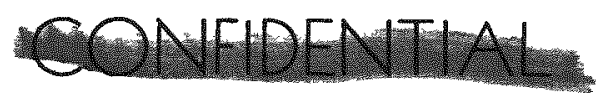




\section{SYSTEMS EVALUATION AND INTEGRATION--CONTROL POINT 3200}

Control of the overall system baseline design, coordination and integration of SNAP 29 RTG system and its associated AGE into the simulated launch complex, and demonstration of system performance and reliability objectives are conducted under this task as well as Advanced Technology effort. Four subtasks were utilized in performing this effort during the reporting period.

$$
\begin{aligned}
& \text { CP } 3210-\text {-Systems Interface Evaluation } \\
& \text { CP } 3230-\text {-Reliability (reported in Chapter IV) } \\
& \text { CP } 3240-\text {-Systems Test Integration } \\
& \text { CP } 3250-\text {-Advanced Technology }
\end{aligned}
$$

\section{A. SUMIMARY OF SIGNIFICANT ACCOMPLISHIENTS}

Revisions A-1, A-2 and A-3 to the SNAP 29 Program Plan (MND-2062-500, Revision A) were coordinated and delivered to the AEC during this reporting period.

Ten test series were completed during this period and seven tests are in progress.

An advanced technology conceptual design, using Pu-238 as a fuel, was prepared.

Parametric data on the use of $3 \mathrm{~N}-3 \mathrm{P}$ material were completed.

\section{B. SYSTEM INTERFACE EVALUATION--CONTROL POINT 3210}

The objectives of the system interface evaluation include the dissemination of design constraint criteria and disciplines to control RTG/AGE systems design, development, fabrication, test and reporting to properly satisfy program requirements.

Logistic activities relating to program reporting, material/parts-release/control and liaison support of integration efforts are provided.

\section{Program Plan}

During the current period, Revisions A-1, A-2 and A-3 to the SNAP 29 Program Plan (MND2062-500, Revision A) were coordinated and delivered to the AEC. These revisions covered modifications to and finally deletion of the Advanced Technology subtask (CP 3250), deleted the Technology Review Board and associated effort, deleted further testing of alternate electrical heaters (CP 1200) and modified the test plan on the heat pipe development effort (CP 1800). Details of these changes are covered under the individual control points involved.

\section{SYSTEM TEST INTEGRATION--CONTROL POINT 3240}

This section presents a brief overall review of the test status and results. Specific test results influencing the design of components and the system are being reported under the section covering the subsystem or task concerned.

The fuel capsule liner burst test has been completed and the data have been reduced. All preliminary work has been done in preparation for the four-mod lle fuel block vibration test. It is anticipated that the test will take place during the next

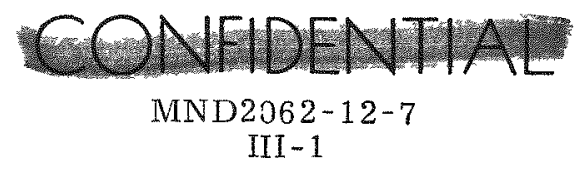


quarter. The plasma arc development screening tests on graphite material have been started and will be completed next period.

A major change in direction of the electrical heater test program took place during this period, based on the results of the testing. The following tests were started during this quarter:

$$
\begin{aligned}
& \text { Module Heater Life Test } \\
& \text { Modıle Heater Cycle Test } \\
& \text { Generator Heater Life Test } \\
& \text { Generator Heat Cycling Test }
\end{aligned}
$$

Numerous failures were encountered that are described more fully under Chapter II-C. As a result of the problems with Sanders and TRW heaters and the good results, to date, with Watlow heaters, it was decided to terminate comparative tests early in December and the tests listed were stopped December 6, 1967. Two heater tests are currently in progress on Watlow heaters.

During the latter part of December, new heaters were received for test. These will include eight individual heater tests to determine the heat gradient over the length of the heater sheath and heater block tests, utilizing interchange of heater element insert configurations to determine the best $\Delta T$ across the module heater block. Three test modules are being utilized in these latter tests. The results will be utilized to determine vendor modification requirements or selectivity and configuration of insertion in the module heater block.

A test was started on three Watlow heaters in vacuum. Testing was terminated temporarily when the electrical through put connector failed. The through put plate has been redesigned and fabricated, and the three heaters have been reinstrumented.

The piston-heat sink module vibration tests in the vertical and minor horizontal axes were completed on December 15, 1967. Sine vibration to a maximum of $3 \mathrm{~g}$ for 25 minutes and random vibration to a level of $29.1 \mathrm{~g}$ for three minutes were imposed on the test specimen. The module test fixture experienced minor structural damage such as Min-K breaking and shifting, shearing of the heater mounting bolts and thermocouple and strain gauge separation. Data reduction and analysis are in progress.

Four piston-heat sink modules (S/N 001, 003, 004 and 005) have been placed on test. Outgassing, power checks and parametric tests (see Figs. III-1 through III-4) have been completed and the modules have been placed on 150-day performance test at matched load. The following is the module status:

$\begin{array}{rr}\frac{\text { S/N }}{001} & \begin{array}{c}\text { Test time } \\ \text { (hr) }\end{array} \\ 003 & 1447 \\ * 004 & 1265 \\ 005 & 713 \\ & 829\end{array}$

*This module was removed temporarily from test when a gas leak occurred. Testing will resume when the leak is repaired.

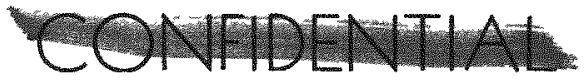

MND2062-12-7

III -2 

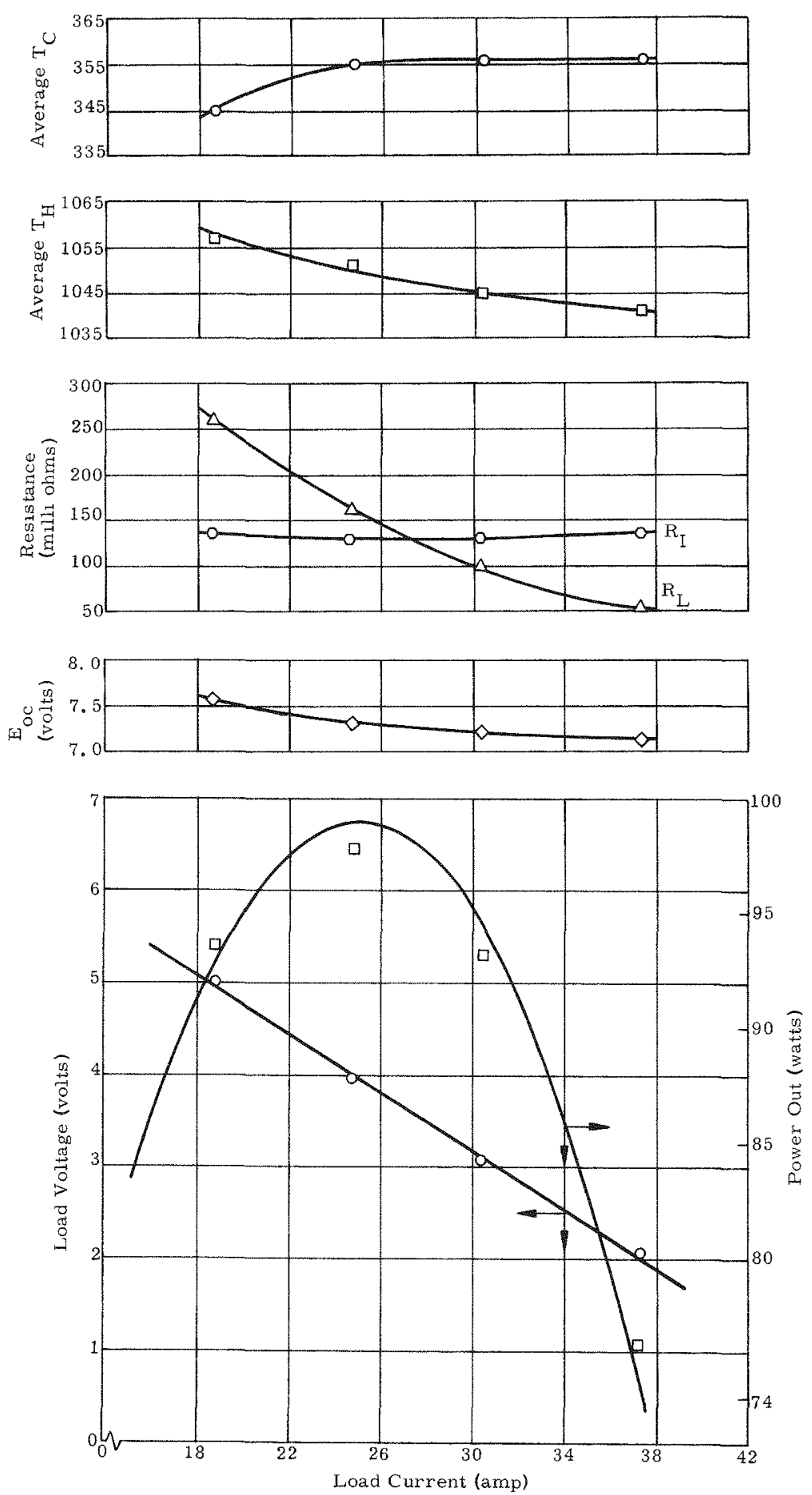

FIG. III-1. PISTON-HEAT SINK MODULE S/N 001 PARAMETRIC TEST

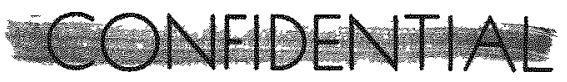

MND2062-12-7

III -3 

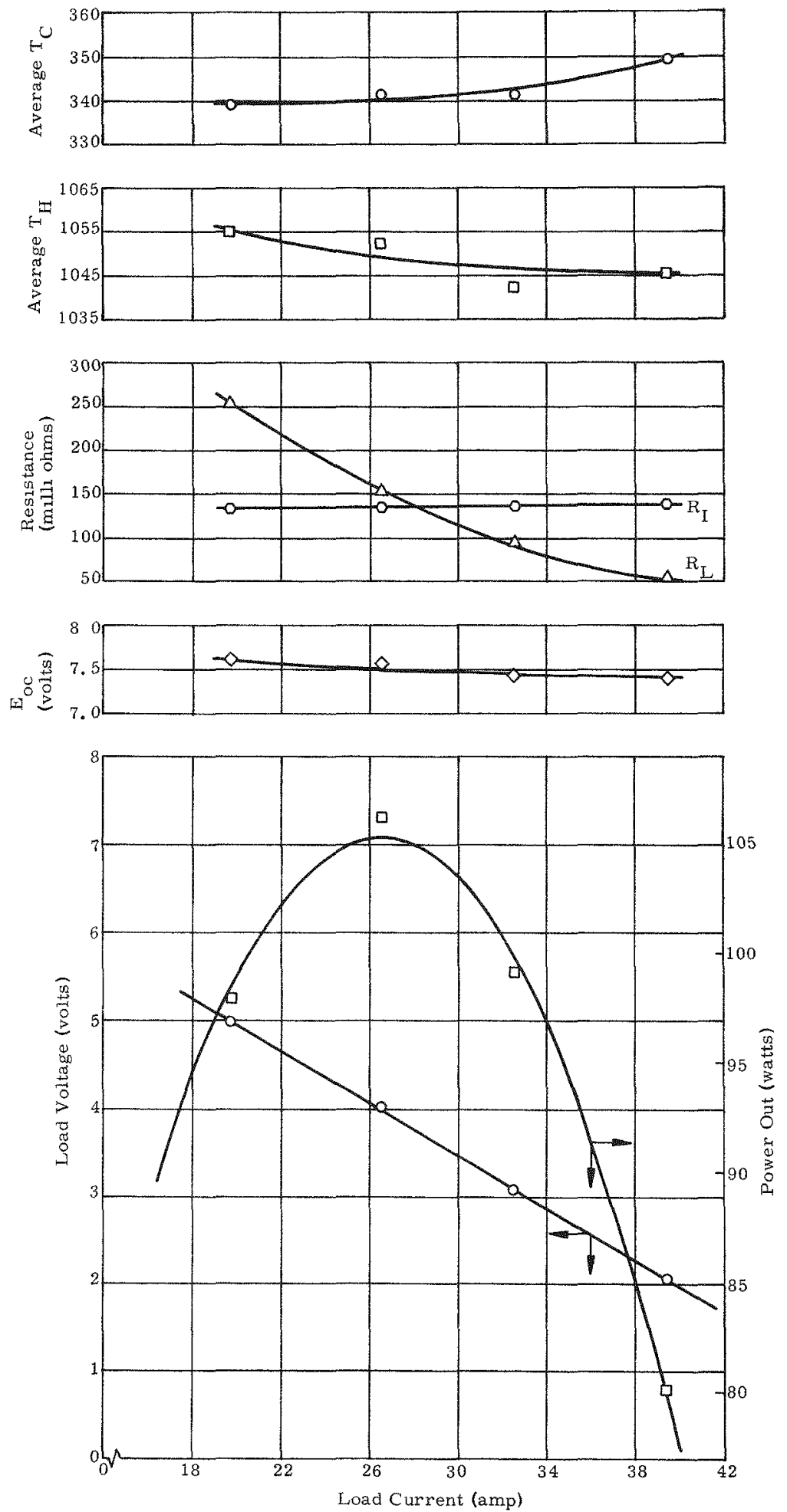

FIG. III-2. PISTON-HEAT SINK MODULE S/N 003 PARAMETRIC TEST

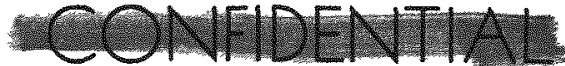

MND2062-12-7

III -4 


\section{CONFIDENTIAE}
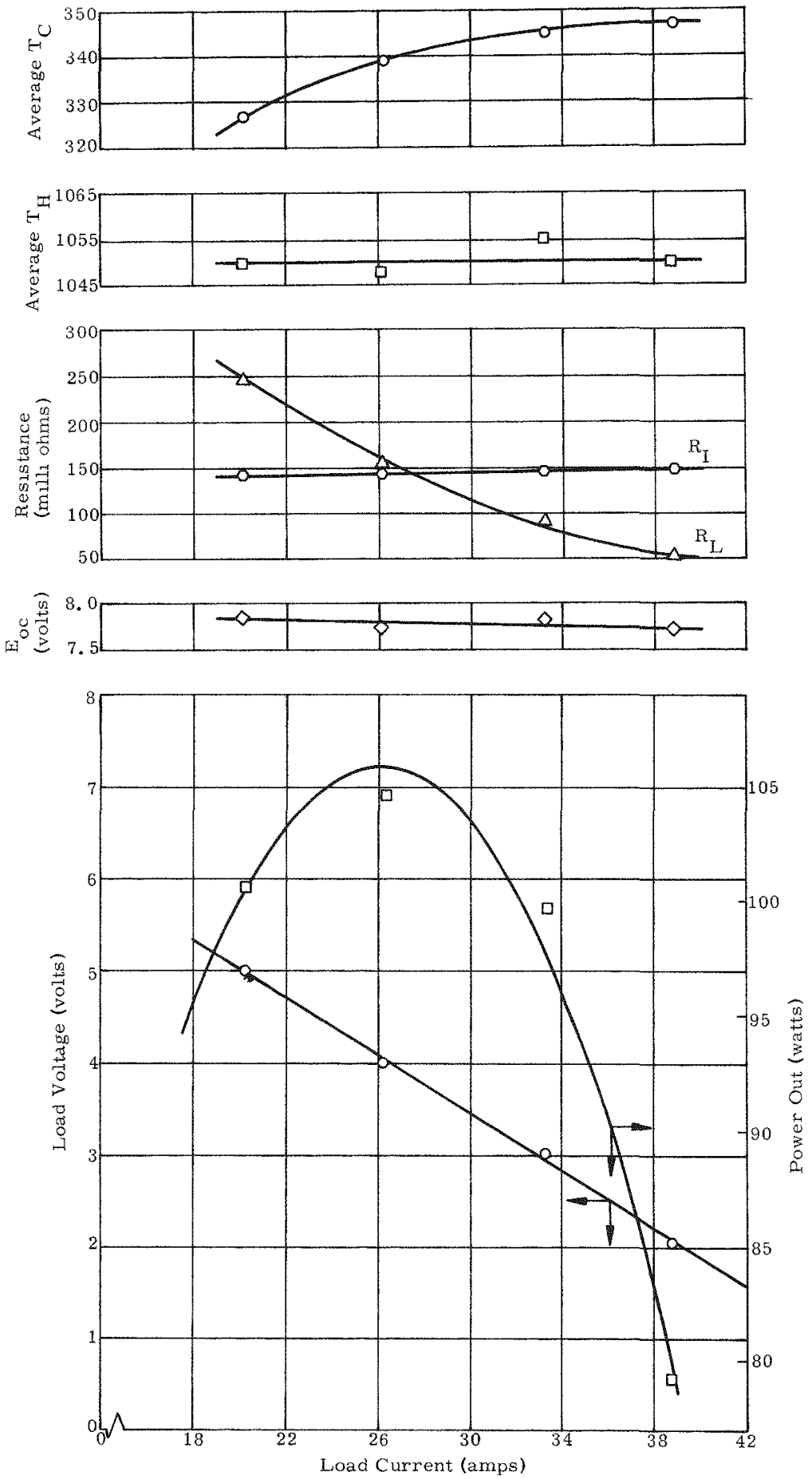

FIG. III-3. PISTON-HEAT SINK MODULE S/N 004 PARAMETRIC TEST

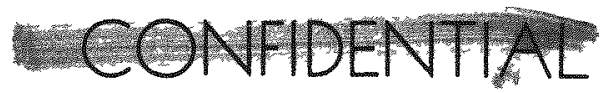

MND2062-12-7

III -5 

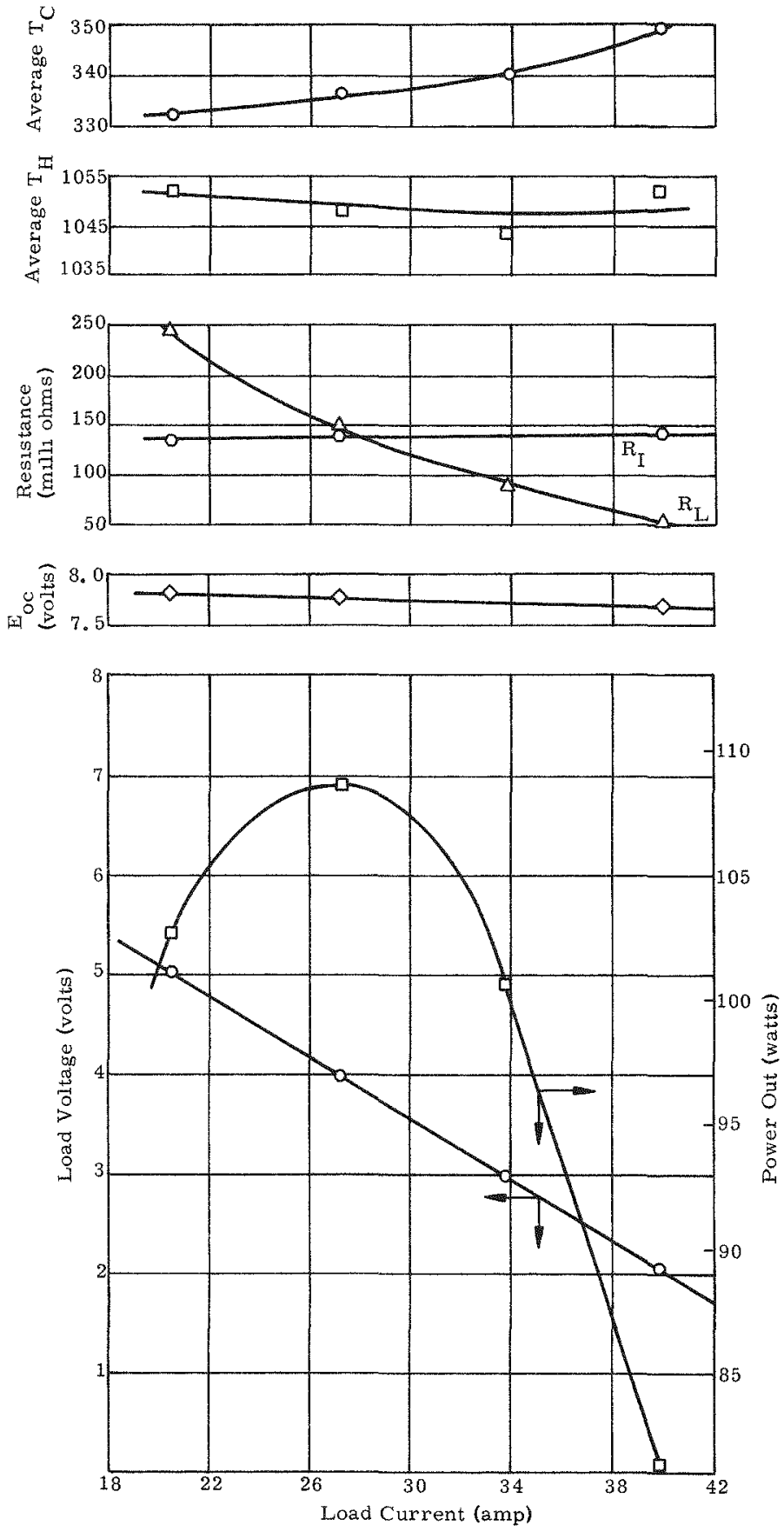

FIG. III-4. PISTON-HEAT SINK MODULE S/N O05 PARAMETRIC TEST

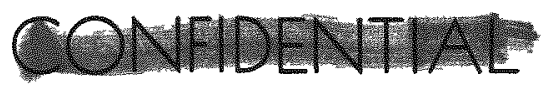

MND2062-12-7 
Performance test histograms for each of the static modules are attached to this report as Figs. III -5 through III -8 .

This information is presented in more detail in Chapter II, Section D.

All testing on the component development of the thermal control subsystem was completed this quarter with the finishing of the bellows actuation overpressure (burst) test and the shutter thermal performance test. The results of this effort are given in Appendix $\mathrm{A}$.

Heat pipe screening tests continued daring this period with detail results reported in Chapter II, Section E.

A 12-heat pipe test schedule has been set up to cover eight-foot heat pipe testing. Eleven heat pipes have been tested per schedale.

Three bent heat pipes of the following configurations are now on test:

\begin{tabular}{llll} 
S/N & Evaporator & Condenser & \multicolumn{1}{c}{ Bend } \\
08B4 & Multiscreen & Annulus & $4 \mathrm{ft}$ radius in condenser \\
08B4C & Multiscreen & $\begin{array}{l}\text { Corrugated } \\
\text { annulus }\end{array}$ & $4 \mathrm{ft}$ radius in condenser \\
08CS12 & Multiscreen & Annulus & $1 \mathrm{ft}$ radius in transport
\end{tabular}

Three 15-foot, straight heat pipes have undergone $q_{\text {max }}$ tests during this time period. Two additional 15-foot pipes are now undergoing $\mathrm{q}_{\max }$ tests.

Two eight-foot heat pipes are being installed on the vibration fixture in preparation for testing.

Testing continued in the Safety Task with the results reported in detail in Chapter VI. The hypersonic force and moment test, together with the hypersonic aerodynamic heating test, were completed at AEDC.

Twenty matrix test specimens, consisting of fuel matrices enclosed in a capsule, were subjected to shock loads representative of re-entry impact. Eight of the specimens were impacted with loads applied along the centerline axis, the remainder of the specimens were tested against radial loading. The specimens were preheated and tested at a nominal temperature of $1000^{\circ} \mathrm{F}$.

The Phase I drop test was cond leted to obtain information about the SNAP 29 fuel block and capsules under terminal velocity impact conditions. The test specimen consisted of two graphite blocks, each containing 24 capsules. The drop altitude was 1250 feet. The blocks were broken at impact, and the capsules located at the corner of impact were deformed.

Six graphite fuel blocks with instrumented capsules have been shipped to Sandia's Water Jet Impact Test Facility. These were radiographed before and after shipment. After a successful calibration test, the first instrumented block was impacted at a 30-degree angle at 100 fps.

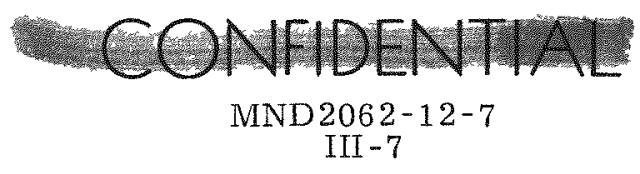




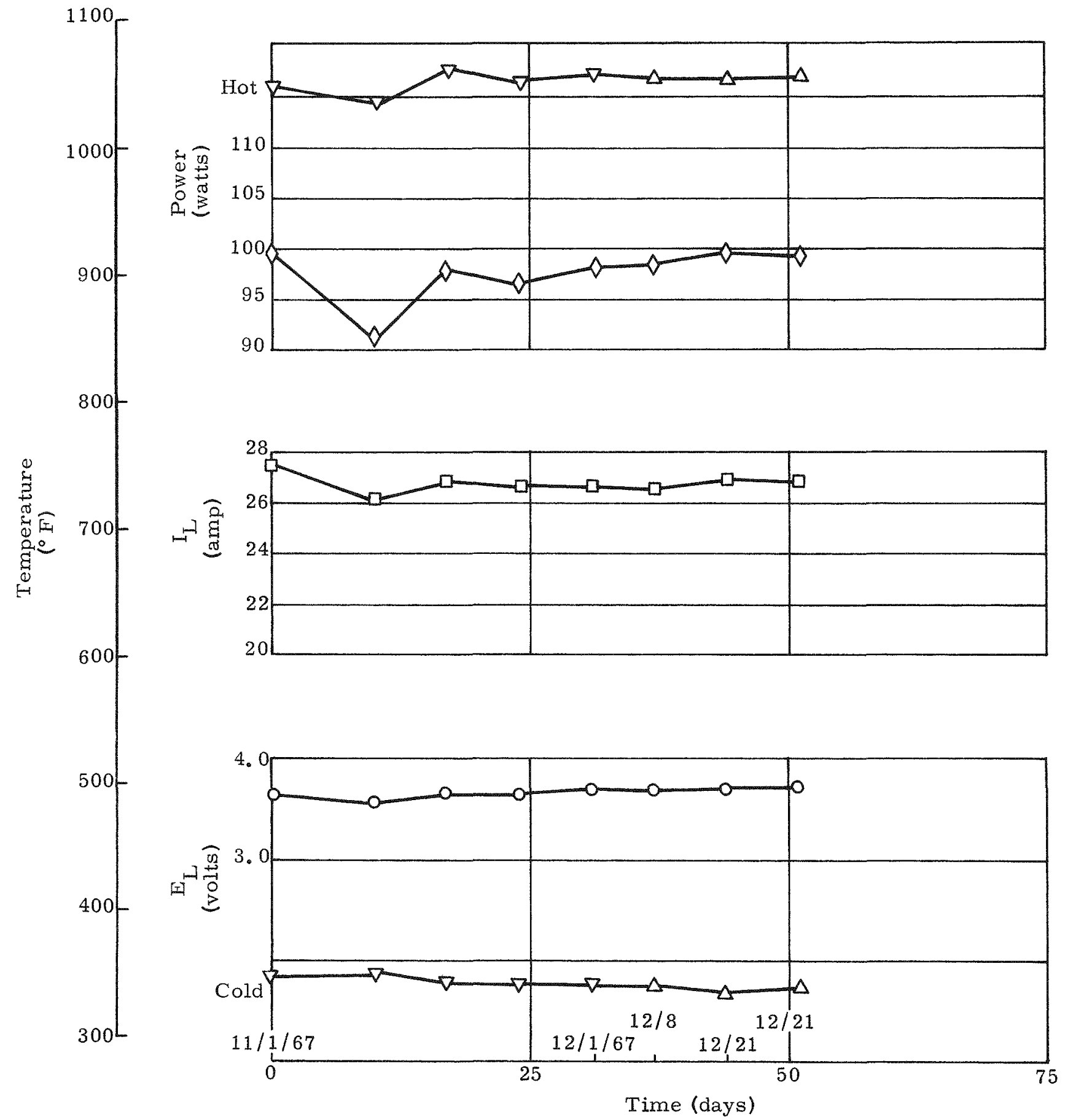

FIG. III-5. PISTON-HEAT SINK MODULE S/N 001 PERFORMANCE HISTORY

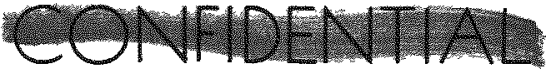

MND2062 - 12-7

III -8 


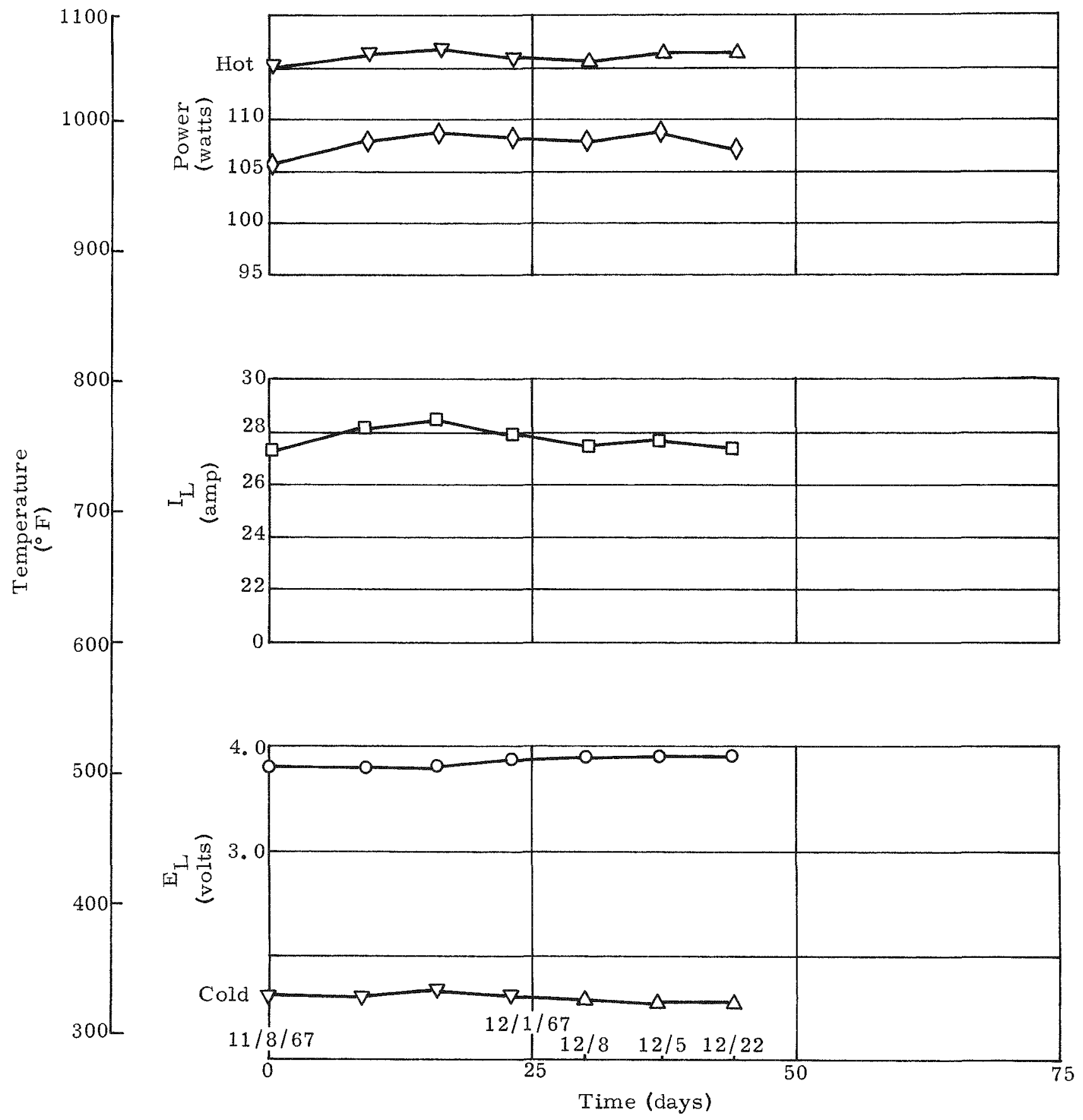

FIG. III-6. PISTON-HEAT SINK MODULE S/N 003 PERFORMANCE HISTORY 

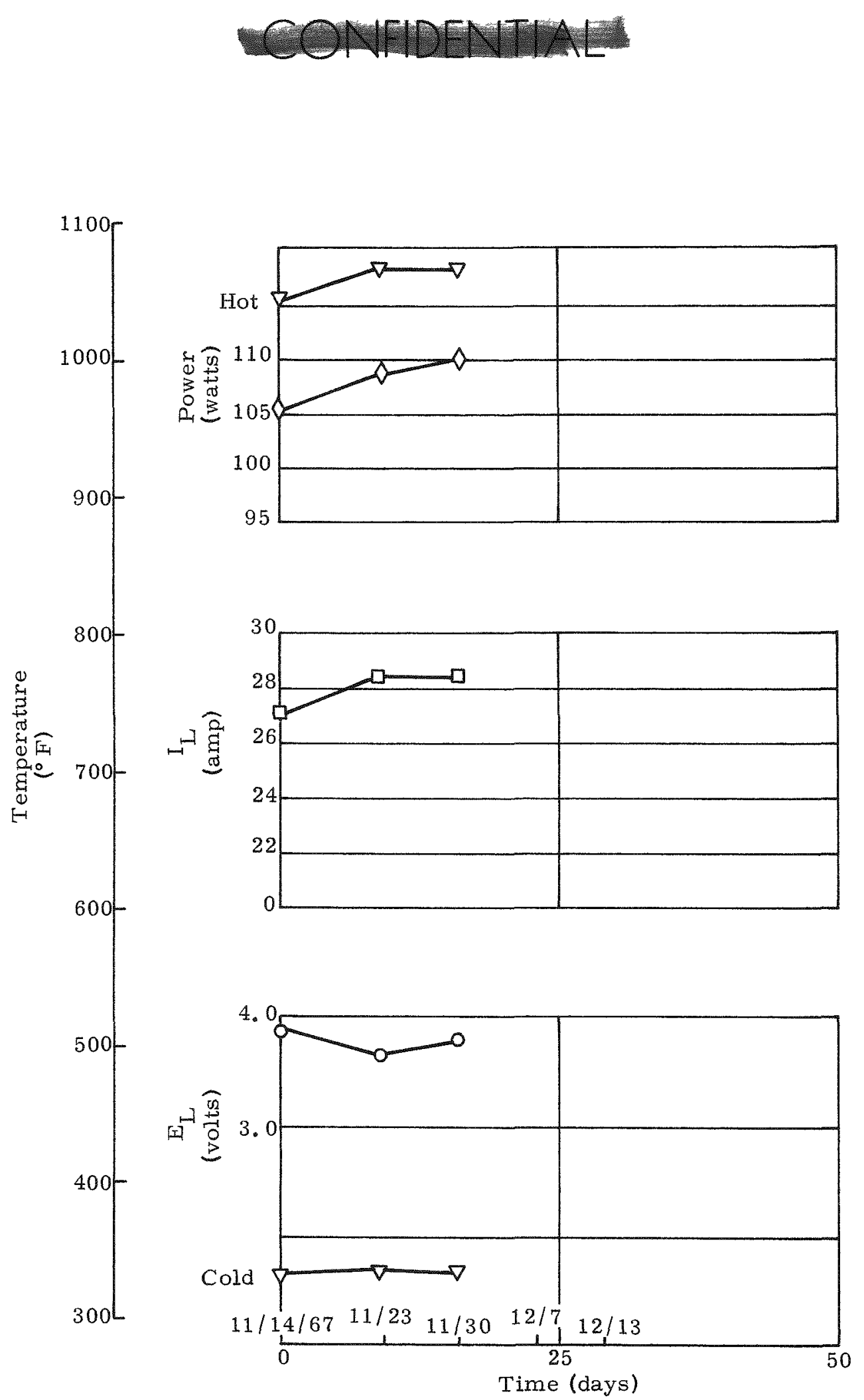

FIG. III -7. PISTON-HEAT SINK MODULE S/N 004 PERFORIMANCE HISTORY 


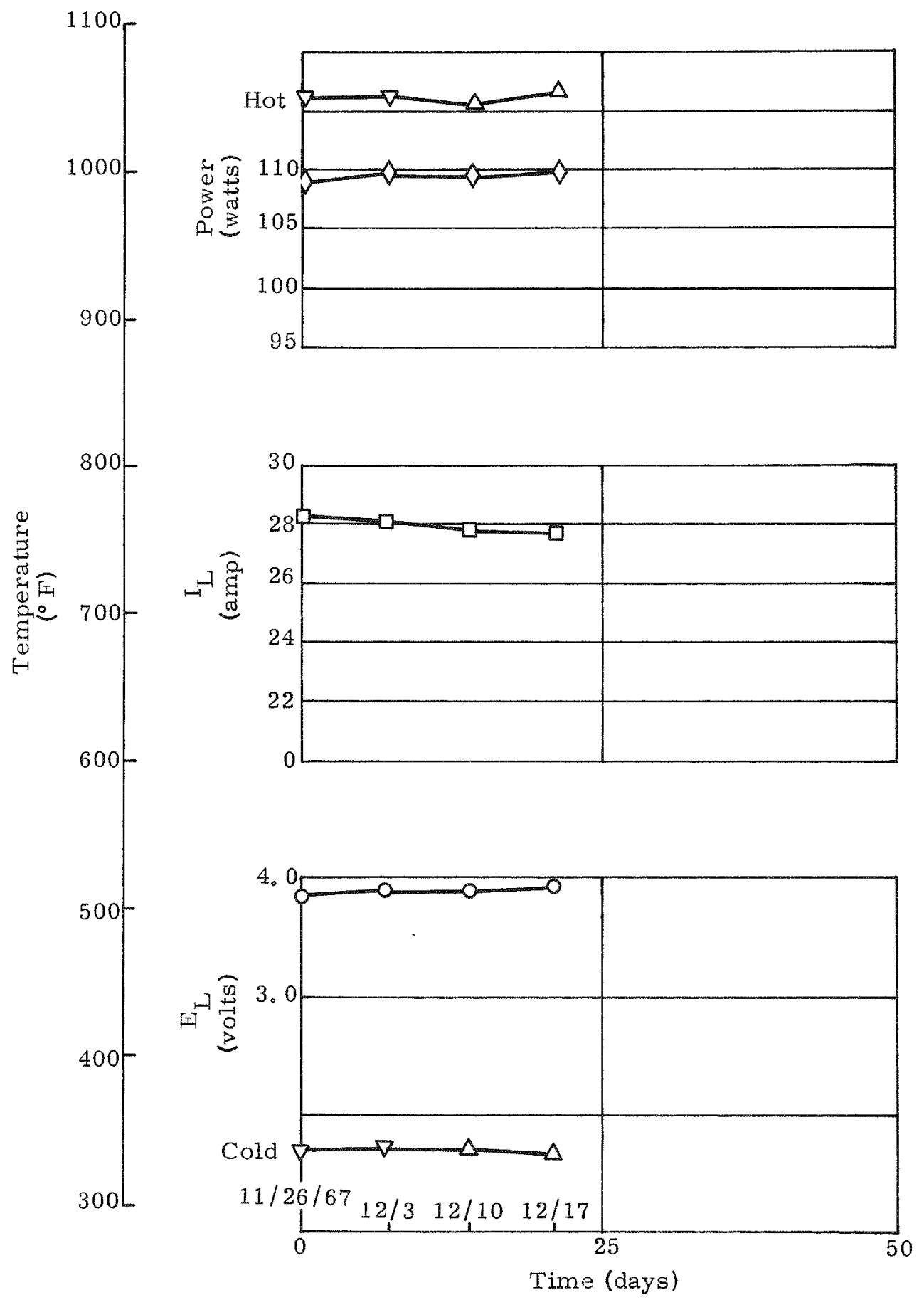

FIG. III-8. PISTON-HEAT SINK MODULE S/N 005 PERFORMANCE HISTORY

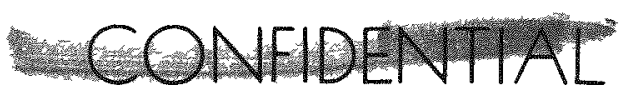

MND2062-12-7

III -11 
At the present, the following tests are in progress:

\section{Control Point}

$\begin{array}{ll}\text { Plasma Arc Development Screening } & 1140 \\ \text { Heater Vacuum } & 1240 \\ \text { Heater Temperature Gradient } & 1240 \\ \text { Module Life } & 1340 \\ \text { Heat Pipe Screening } & 1840 \\ \text { Water Jet Impact } & 3330 \\ \text { Project PYRO } & 3340\end{array}$

The following list includes the tests that were completed this quarter:

Capsule Liner Burst

Piston-Heat Sink Module Vibration

Shutter Thermal Performance

Bellows Actuator Overpressure

Hypersonic Force and Moment

Hypersonic Aerodynamic Heating

Fuel Matrix Impact

Phase I Drop Test

Project PYRO (two tests)

\section{Control Point}

1140

1340

1540

1540

3320

3320

3330

3330

3340

\section{ADVANCED TECHNOLOGY--CONTROL POINT 3250}

\section{Advanced Heat Source Technology (CP 3251)}

The literature survey on the various fuels ( $\mathrm{Pu}-238, \mathrm{Po}-210, \mathrm{Sr}-90, \mathrm{Cm}-244$, $\mathrm{Tm}-171$ and $\mathrm{Pm}-147)$ and fuel forms being considered for the advanced heat source task has been completed and a summary of this study has been prepared for distribution. Such properties as half-life, fuel form, melting point, density, power density, specific power, type of radiation, shielding required, and compatibility will be presented.

A conceptual design for a $\mathrm{Pu}-238$ ( $\mathrm{PuO}$ microspheres) fueled, long-lived SNAP 29 heat source was completed. The fuel capsules were assumed to be continuously vented to the environment, and the side dimensions of the flat-plate type fuel block were assumed to be those of the present Po-210 fueled "four module "fuel block. For the same heat input to the thermoelectric modules, the Pu-238 heat source weight was determined to be 1.00 pounds, with a thickness of 1.5 inches.

2. Advanced Thermoelectric Technology (CP 3253)

Parametric performance data for $3 \mathrm{M}$ Company $3 \mathrm{~N}$ and $3 \mathrm{P}$ thermoelectric material have been completed. The data were evaluated and compared with the present $2 \mathrm{~N}$ and 3 P SNAP 29 materials.

\section{Cancellation of Advanced Technology Effort}

As a result of CCP-11 to the SNAP 29 contract, effort on this subtask was terminated for the current contract period.

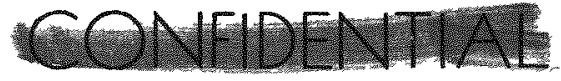

MND2062-12-7

III -12 
IV. RELIABILITY-CONTROL POINT 3230

The SNAP 29 reliability program has been proceeding in accordance with the tasks and schedule presented in the SNAP 29 Program Plan. The plan establishes the management and technical reliability controls necessary to implement an effective and economically planned and integrated reliability program in support of design, procurement, fabrication and test. To accomplish the overall program most effectively, three major work areas have been established. These are:

CP $3231--P l a n n i n g$ and System Analysis

CP 3232 --Design Evaluation and Approval

CP 3233 --Test Program Definition and Evaluation

The three work areas are further subdivided into tasks for planning and control purposes. The tasks breakdown follows that developed in the plan and is used for presenting the information under Sections B through D.

\section{A. SUMMARY OF SIGNIFICANT ACCOMPLISHMENTS}

A preliminary prediction of electric power output characteristics for the four RTG configurations has been completed. The prediction was developed from $\mathrm{T} / \mathrm{E}$ couple and $\mathrm{T} / \mathrm{E}$ module test data.

A prediction of the catastrophic reliability of the thermoelectric portion of the RTG has been calculated using the mathematical model and T/E couple failure rates presented in the previous quarterly report.

A prediction of the electric power output characteristics for the $T / E$ module has been presented. The prediction uses for its basis the production $\mathrm{T} / \mathrm{E}$ couple test data.

The five piston-heat sink $\mathrm{T} / \mathrm{E}$ modules beginning-of -life measured power output has been developed statistically and a comparison made to the predicted values.

\section{B. RELIABILITY PLANNING AND SYSTEM ANALYSIS-- CONTROL POINT 3231}

\section{System Analysis}

a. RTG electric power reliability--catastrophic mode

The power output of an RTG decreases with increased operating time due to either catastrophic failures or drift (degradation) of the $T / E$ couples. Catastrophic failures result in an abrupt step decrease or total loss of output power, whereas drift occurs in a slow and more linear fashion. Individual catastrophic failures of the $T / E$ couples may be reflected as an increase in degradation with the amount of degradation depending on the degree of redundancy incorporated in the circuit network.

The overall power output reliability is determined from a combination of these two modes along with all other factors contributing to failures or drift.

The results of the investigation to establish the effect of catastrophic $\mathrm{T} / \mathrm{E}$ couple failures on the SNAP 29 electrical system and to develop the design criteria to compensate for such failures are presented. The three areas included in the investigation are:

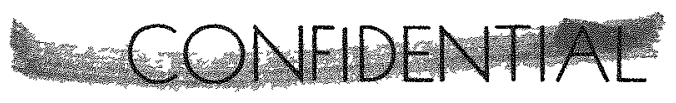

MND2062-12-7

IV -1 
(1) The probability of system failure during the 144-day operating life

(2) The effect of any $\mathrm{T} / \mathrm{E}$ couple failures on electric power output

(3) The over design criteria necessary to compensate for the loss of power.

The effect of couple degradation on power output is covered under CP 3232.

The SNAP 29 system is modular in construction with each module consisting of 90 series-parallel connected $\mathrm{T} / \mathrm{E}$ couples. There are two parallel connected couples in each series-connected group. The number of series groups will be 90, 180, 270 and 360 for the two-, four-, six-and eight-module RTG configurations, respectively. The catastrophic reliability of a series-parallel modular RTG has been determined using the mathematical model presented in the SNAP 29 Fourth Quarterly Progress Report. The couple failure rate was derived by applying the chi-squared distribution method of computation, at a $50 \%$ confidence level, to the data accumulated from RTG having series connected $\mathrm{T} / \mathrm{E}$ couples using lead telluride elements of either $2 \mathrm{~N}-2 \mathrm{P}$ or $2 \mathrm{~N}-3 \mathrm{P}$ configuration. The failure rate for $\mathrm{T} / \mathrm{E}$ couples was established at $0.003988 /$ 1000 hours at a 50\% confidence level (SNAP 29 Fourth Quarterly Progress Report). It is assumed that couples failed in the open circuit mode only, and that the failure of one or more couples does not effect the failure rate of the remaining couples in the RTG.

Referring to Fig. IV-1, reliability is presented as a function of percent of mission time for one through five allowed couple failures for the mission time of 144 days. The curves in the figure are based on a total of 180 series groups and represent the four-module RTG configuration.

The curves shown in Fig. IV -2 provide a composite of the individual RTG curves (Fig. IV -1 being a typical representation) for a $100 \%$ mission time of 144 days. In Fig. IV -2 reliability is presented as a function of the number of series-connected $\mathrm{T} / \mathrm{E}$ couple groups for one through five allowed couple failures. It can be seen, that for allowed failures greater than three, the curves tend to converge and there is no significant increase in reliability. A list of predicted reliability for a complete 144day mission is given in Table IV -1. This table indicates the predicted reliability of the four RTG configurations for one, two and three allowed couple failures.

TABLE IV -1

Predicted Reliability for 144-Day Mission

\begin{tabular}{llccccc}
\multicolumn{1}{c}{$\begin{array}{c}\text { RTG } \\
\text { Configuration }\end{array}$} & $\begin{array}{c}\text { Two } \\
\text { Modules }\end{array}$ & $\begin{array}{c}\text { Four } \\
\text { Modules }\end{array}$ & $\begin{array}{c}\text { Six } \\
\text { Modules }\end{array}$ & $\begin{array}{c}\text { Eight } \\
\text { Modules }\end{array}$ \\
\cline { 1 - 1 } Allowed & 1 & & 0.999680 & 0.998800 & 0.997400 & 0.995400 \\
couple & 2 & & 0.999996 & 0.999977 & 0.999932 & 0.999845 \\
failures & 3 & 0.999998 & 0.999996 & 0.999993 & 0.999994
\end{tabular}

The following analysis establishes a method of determining the effect of catastrophic failures on RTG power output. This analysis considers the open failure mode only. The short mode failures will not be considered since the couple short-circuit probability is considered negligible.

The effect of an open-circuit couple failure is to decrease the net RTG power output. There is not, however, a direct relationship between percentage couple failures and

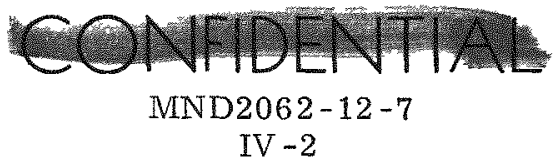




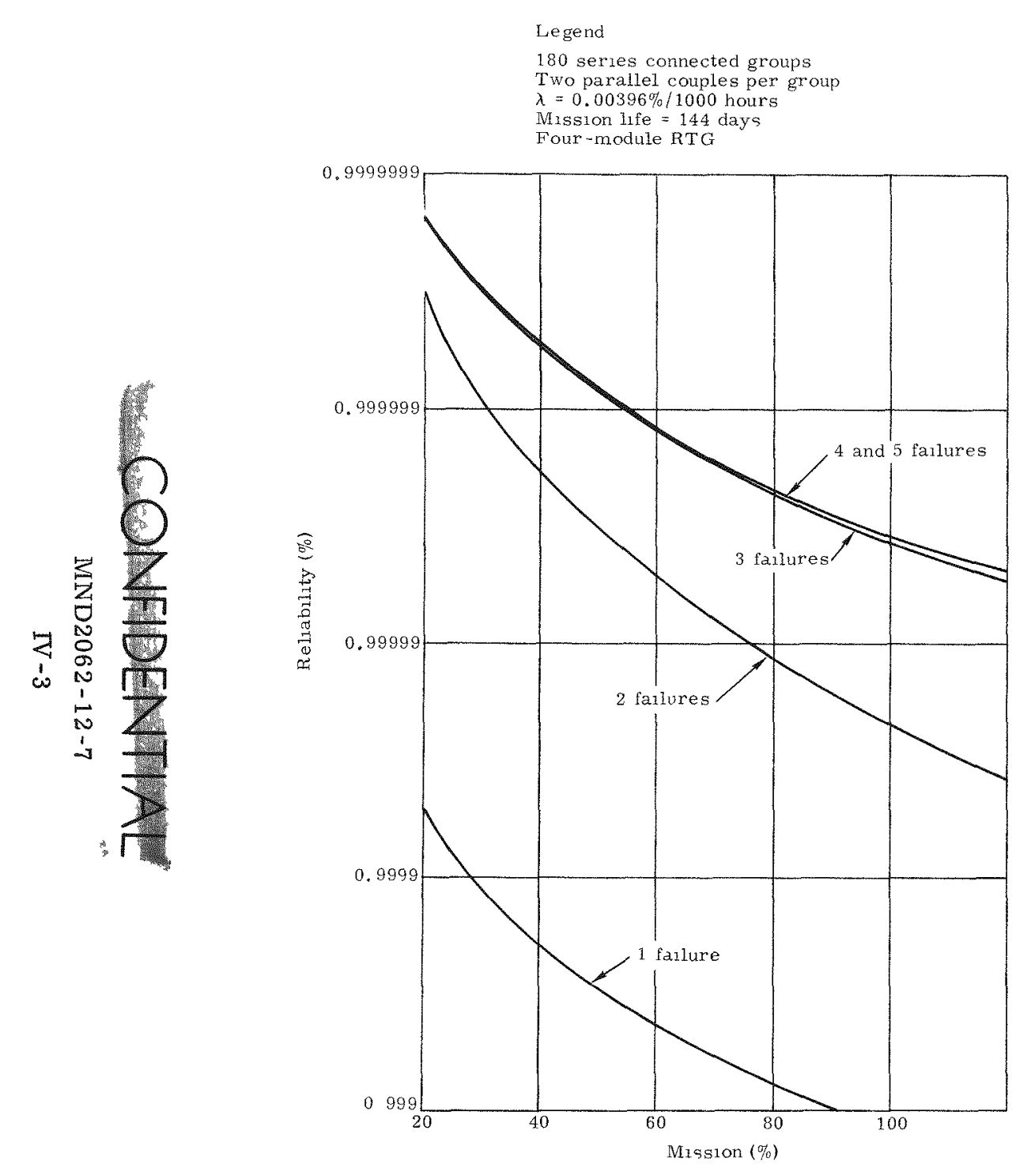

FIG IV 1. SNAP $29 \mathrm{~T} / \mathrm{E}$ COUPLE RELIABILITY

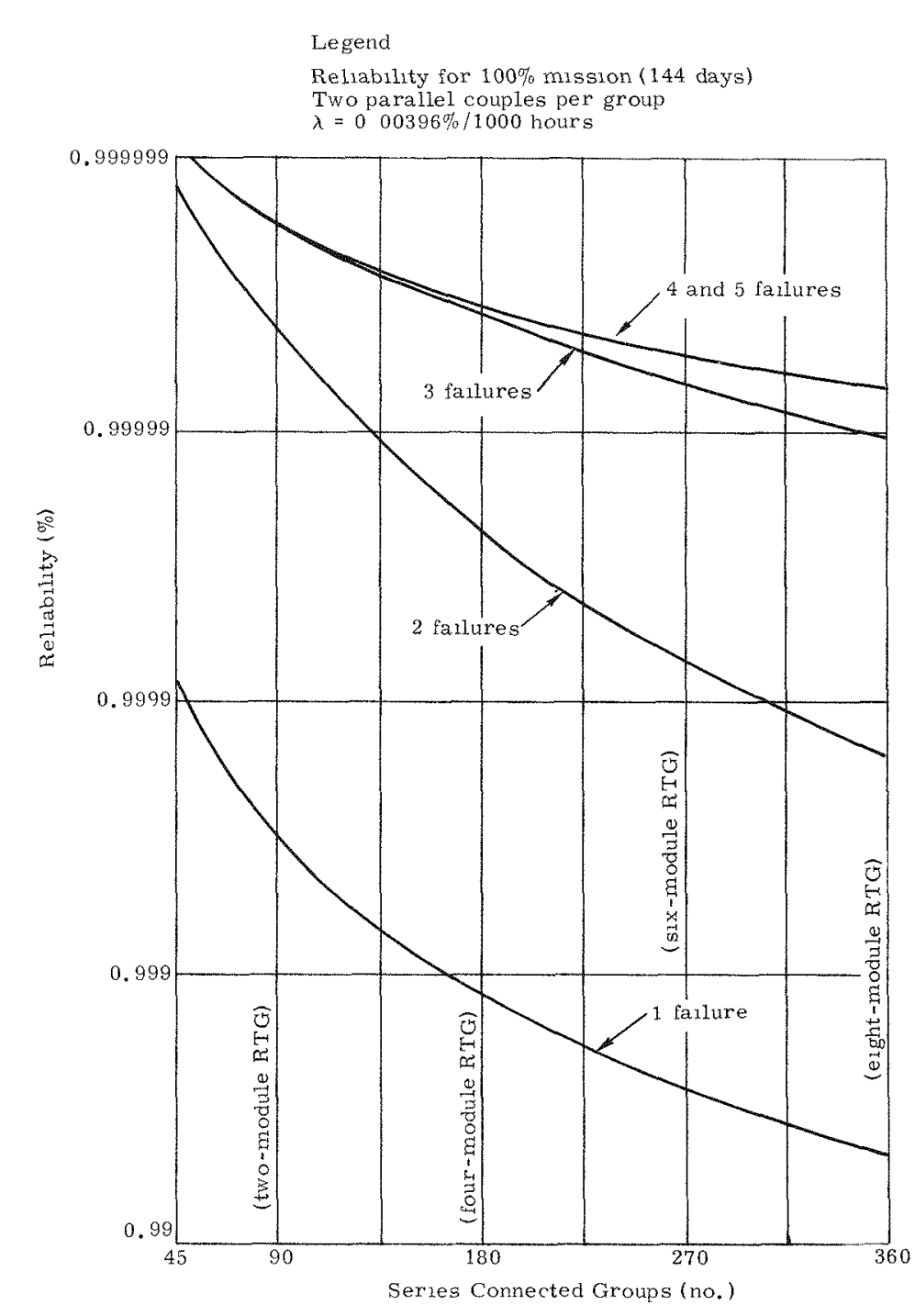

FIG. IV - 2. SNAP $29 \mathrm{~T} / \mathrm{E}$ COUPLE RELIABILITY 
percentage RTG power loss in that the failure of a couple affects its adjacent couple in the two-couple parallel group, as well as the remaining couples in the RTG.

A plot of percent power versus percent couple failures is shown in Fig. IV -3. It can be seen from this figure that percent couple failures at or below $5 \%$ result in a loss of power which is twice the percentage of couple failures (i.e., a 5\% loss of $\mathrm{T} / \mathrm{E}$ couples results in a $10 \%$ loss in RTG power output).

It should be noted that the power produced by a $\mathrm{T} / \mathrm{E}$ couple which is adjacent to a failed couple decreased due to the Peltier cooling effect (a current increase through the couple, causes a decrease in $\Delta T$ ), thus decreasing the power output. This is canceled, however, by the increase in $\Delta T$ across the remaining $T / E$ couples. The $\Delta \mathrm{T}$ will increase across all but the adjacent couple, due to the decrease in net output current which occurs after couple failure.

Referring to Table IV -1 , it can be seen that a predicted reliability of greater than 0.9998 can be allocated with $50 \%$ confidence, provided two couple failures are compensated for in the design. If it is assumed that the allocated number of 0.9998 is acceptable for system performance at the beginning of life, the SNAP 29 RTG must provide an additional amount of power necessary to compensate for the anticipated catastrophic failure of two $\mathrm{T} / \mathrm{E}$ couples.

It has been shown previously that the failure of two $\mathrm{T} / \mathrm{E}$ couples, which represent less than $5 \%$ of the total amount of $T / E$ couples for any of the assumed RTG configurations, will effect the RTG power output the same as if four T/E couples had failed. A list of reliability and percent power loss for the four-module RTG configurations for two allowed $T / E$ couple failures is given in Table IV -2. The percent additional power at beginning of life that is required to compensate for the predicted percent loss in power due to catastrophic couple failures is given by:

$$
\mathrm{P}_{\mathrm{ADD}}(\%)=\frac{\mathrm{x}}{1-\mathrm{x}} \times 100
$$

where $\mathrm{x}$ is the predicted percent loss. As an example, the two-module RTG configuration would require:

$$
\mathrm{P}_{\mathrm{ADD}}=\frac{0.0222}{1-0.0222} \times 100=2.27 \%
$$

\section{TABLE IV -2}

\begin{tabular}{|c|c|c|}
\hline $\begin{array}{c}\text { RTG } \\
\text { Configuration } \\
\end{array}$ & $\begin{array}{c}\text { Total } \\
\text { Couples (No.) } \\
\end{array}$ & $\begin{array}{c}\text { BOL } \\
\text { Power Los } \\
\end{array}$ \\
\hline Two-module & 180 & 2.22 \\
\hline Four-module & 360 & 1.11 \\
\hline Six-module & 540 & 0.74 \\
\hline Eight-module & 720 & 0.55 \\
\hline
\end{tabular}

Percent of BOL Power Loss Assuming Two-Couple Failures

This investigation indicates that the success of a 144 -day mission, as effected by castrophic failure of $T / E$ couples in either a two-, four-, six-or eight-module RTG configuration, will have a minimum predicted reliability of greater than 0.99984 , provided two $\mathrm{T} / \mathrm{E}$ couple failures are allowed and compensated for. The percent of additional power necessary at beginning of life to compensate for the anticipated loss

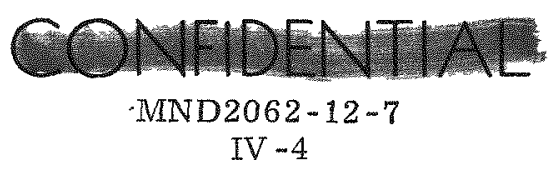




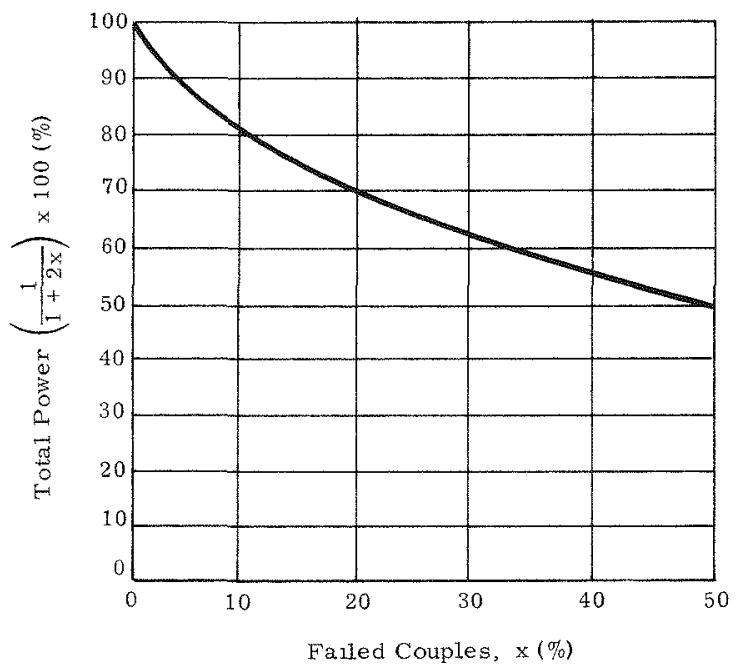

Percentage of failed couples $=x$

Number of series groups $=n$

Number of couple falures, $F=2 n x$

FIG. IV -3. PERCENT RTG POWER AS A FUNCTION OF PERCENT COUPLE FAILURES

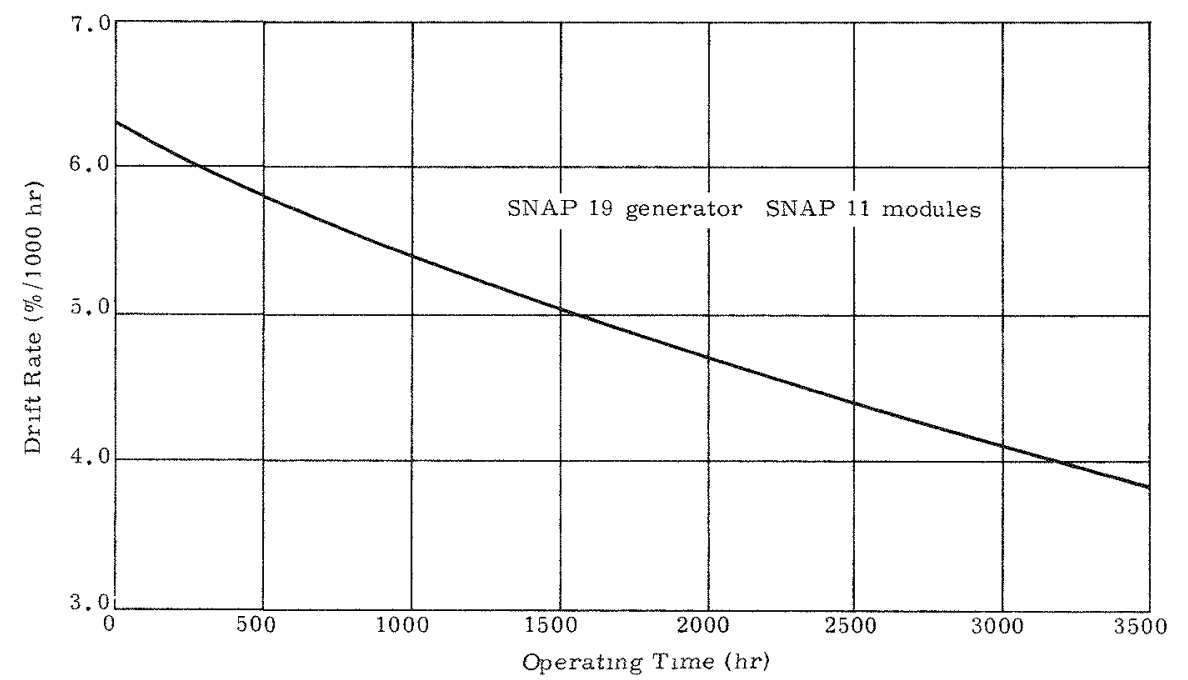

FIG. IV -4. DRIFT RATE VERSUS TIME FOR 2N-3P THERNOELECTRIC POWER AT 1050

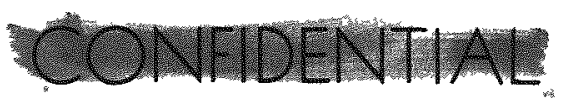

MND2062-12-7

IV -5 
of two T/E couples is dependent on the RTG configuration, i. e., the number of modules used. The maximum additional percent of power required to compensate for a two-couple catastrophic failure is $2.27 \%$ (two-module RTG configuration).

\section{b. RTG electric power output}

This study presents a preliminary prediction of the electric power output for the four modular configurations. The prediction provides the target against which generator performance may be evaluated and the criterion necessary to conduct power trade off studies. There is no mission power output requirement or goal included in the program contract requirements.

The effect of catastrophic couple failures on reliability and power output has been included in the previous paragraph. The total power output reliability is determined from a combination of these two effects along with all other factors contributing to failures or drift. These considerations will be covered in future reports when EOL power predictions become available.

Calculated power output values have been based on data from the following sources:

(1) SNAP 29 piston-heat sink T/E module performance tests currently being conducted

(2) Beginning-of-life power characteristics of the SNAP 29 production T/E couples.

Table IV-3 summarizes the predicted power output values for the four-module RTG configurations at beginning of life. End of operating life of 144 days is not included since the available data from life tests of the SNAP $29 \mathrm{~T} / \mathrm{E}$ modules are not sufficient to permit the establishment of a drift rate. The associated upper and lower three sigma limits are also included.

\section{TABLE IV -3}

RTG Power Output Characteristics (BOL)

RTG Configurations

\begin{tabular}{|c|c|c|c|c|}
\hline Distribution & Two-Module & Four-Module & $\underline{\text { Six-Module }}$ & Eight-Module \\
\hline $\begin{array}{l}\text { USL (watts) } \\
(3 \sigma)\end{array}$ & 208.78 & 416.78 & 624.35 & 831.70 \\
\hline$\frac{\text { Mean (watts) }}{(\bar{X})}$ & 204.28 & 410.42 & 616.56 & 822.70 \\
\hline $\begin{array}{l}\text { LSL (watts) } \\
(3 \sigma)\end{array}$ & 199.78 & 404.06 & 608.77 & 813.70 \\
\hline
\end{tabular}

The BOL predictions in Table IV -3 are based on data from the SNAP $29 \mathrm{~T} / \mathrm{E}$ module and $T / E$ couple tests. A potential growth of power exists since the production $T / E$ couple power output has been increased with experience and additional production controls. Also, the $I^{2} R$ copper losses in the diaphragm module (if selected) are calculated to be lower than those for the piston-heat sink configuration.

The upper and lower three sigma limit values (USL and LSL) in Table IV -3 are based on data from the SNAP 29 piston-heat sink module tests.

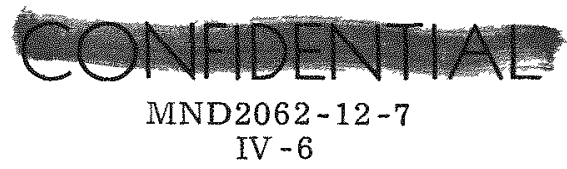


The BOI mean power output for the RTG configurations has been predicted using data obtained by measuring the modified SNAP 29 piston-heat sink T/E modules. The modifications account for the improvements realized in recent production $\mathrm{T} / \mathrm{E}$ couples. Four of the five modules under test were used as the source of data. The output power of one of the modules was sufficiently different from the other four that the data from it were omitted. The predicted power output for the four modules, taking into consideration the specific $\mathrm{T} / \mathrm{E}$ couple lots used, was 107.36 watts with a measured average output of 104.05 watts (see CP 3232). The measured output was approximately $3.1 \%$ lower than the predicted value.

Table IV-4 indicates the development of the values specified for mean BOL values included in Table IV -3 .

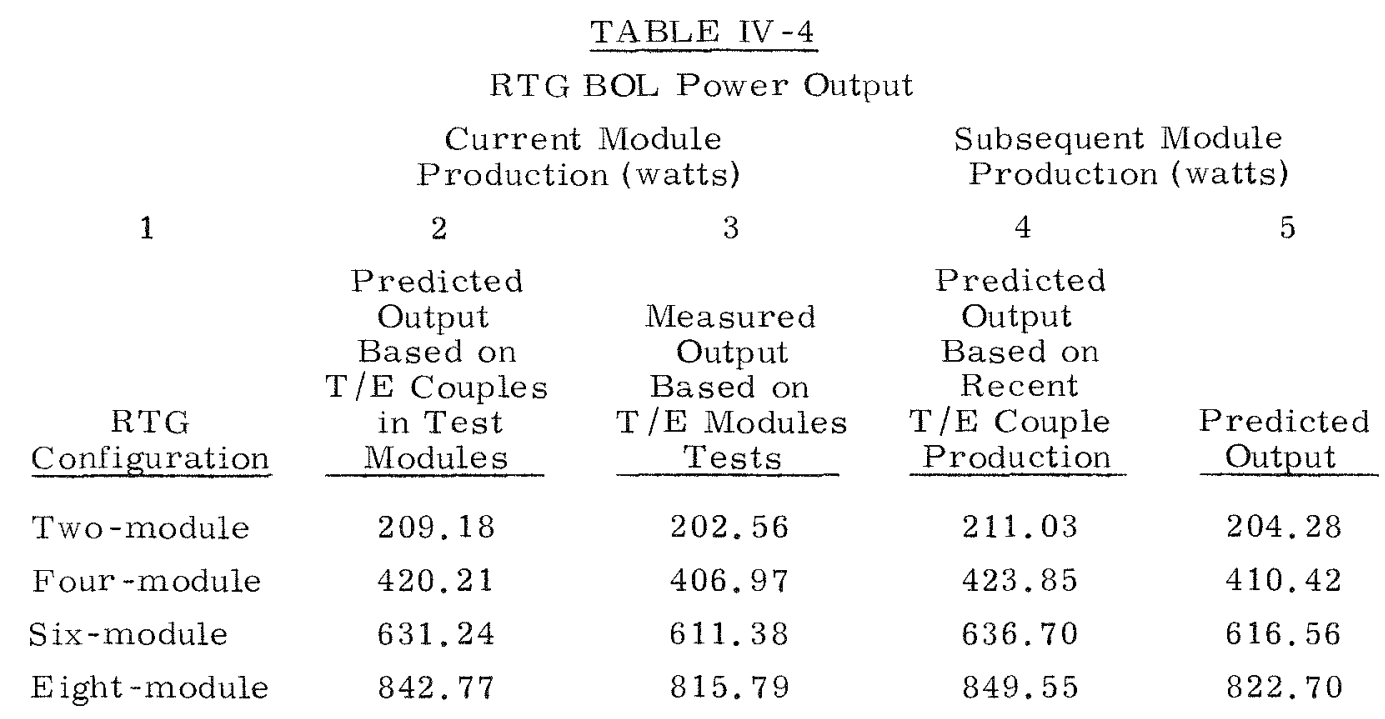

Column 2 of Table IV-4 summarizes the power output of the RTG based on the module values after taking into consideration the number of modules in the RTG and the $\mathrm{I}^{2} \mathrm{R}$ losses in the interconnecting wiring. The losses were calculated to be 5.54 , $9.23,12.92$ and 16.61 watts for the two-, four-, six-and eight-module RTG, respectively.

Column 4 of Table IV-4 indicates the RTG power output that would be predicted using current $\mathrm{T} / \mathrm{E}$ couple production. Since experience shows that actual output power is approximately 3.1\% lower than predicted, the values in Column 4 have been reduced to represent this factor and are presented in Column 5 .

The standard deviation, USL and LSL, for the RTG BOL power output was developed from data generated from the tests of four piston-heat sink T/E modules using the following equation:

$$
\sigma_{\mathrm{G}}=\sigma_{\mathrm{m}} \sqrt{\mathrm{n}}
$$

where

$$
\begin{aligned}
& { }_{G}^{\sigma_{G}}=\text { standard deviation at } \mathrm{RTG} \text { level } \\
& { }_{\mathrm{m}}=\text { standard deviation of } \mathrm{T} / \mathrm{E} \text { module }(1.06 \text { watts) } \\
& \mathrm{n}=\text { number of modules in } \mathrm{RTG}
\end{aligned}
$$

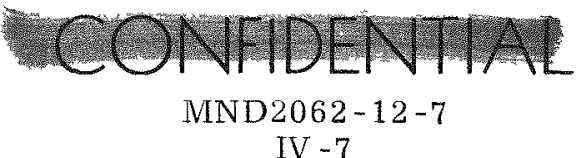




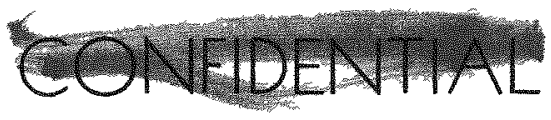

The standard deviation, and corresponding three sigma values, are shown in Table IV -5 and used to develop the values specified in Table IV -7 .

\section{TABLE IV -5}

RTG BOL Sigma Limits (watts)

\begin{tabular}{|c|c|c|}
\hline $\begin{array}{c}\text { Module } \\
\text { Configuration } \\
\end{array}$ & $\begin{array}{c}\text { Standard } \\
\text { Deviation } \\
\text { (watts) } \\
\end{array}$ & $\begin{array}{c}3 \text { Sigma } \\
\text { (watts) } \\
\end{array}$ \\
\hline Two-module & 1.499 & 4.497 \\
\hline Four-module & 2.120 & 6.360 \\
\hline Six-module & 2.596 & 7.789 \\
\hline Eight-module & 2.998 & 8.994 \\
\hline
\end{tabular}

\section{DESIGN EVALUATION AND CONTROL--CONTROL POINT 3232}

\section{Electric Power Drift Rate}

A drift rate that may be applied to the SNAP 29 program for prediction purposes cannot be made with any degree of accuracy using data from the current $T / E$ module test program. A well-developed rate, representive of SNAP 11 and SNAP 19, has been developed and is shown in Fig. IV -4 . It is a graphical presentation of the power drift characteristic of $2 \mathrm{~N}-3 \mathrm{P}$ units as modified to account for a hot junction temperature of $1050^{\circ} \mathrm{F}$. The drift rate at 3500 hours is $3.83 \% / 1000 \mathrm{hr}$. This rate appears to be significantly higher than that to be expected from SNAP $29 \mathrm{~T} / \mathrm{E}$ module tests so that its use would result in unrealistic end-of-life power predictions.

Figure IV -5 is a plot of the measured power readings corrected to $1050^{\circ} \mathrm{F}$ hot junction temperature collected from the SNAP 29 piston-heat sink module test data. Development of a drift rate from these readings is judged to be inconclusive due to the limited operating time. All evidence, however, indicates that the drift rate curve would be lower than that shown on Fig. IV -4. An extrapolation of the drift rate to 3500 hours would have no validity whatsoever.

A continuation of the $T / E$ module test program for at least 3500 hours is required in order to obtain a realistic drift rate at that time. The need is further amplified since data from other programs are not applicable due to the potential improvement in drift rate expected by the SNAP 29 technology.

During the initial period, the power readings may not follow a smooth curve and thus the use of first measured power readings do not necessarily provide valid data for calculating drift characteristics. The approach is to treat the data by smoothing and extrapolating the smoothed data through the initial region to intercept the power $y$ axis. This intercept is the true beginning-of-life power. In this analysis, insufficient time has been accumulated to develop a true beginning-of-life reading.

The drift characteristics of $2 \mathrm{~N}-3 \mathrm{P}$ thermoelectric devices designed and fabricated before development of the SNAP 29 technology has been determined from the following sources:

(1) SNAP 11 modules (3)

(2) SNAP 19 generator (1)

(3) SNAP $29 \mathrm{~T} / \mathrm{E}$ development couples (9).

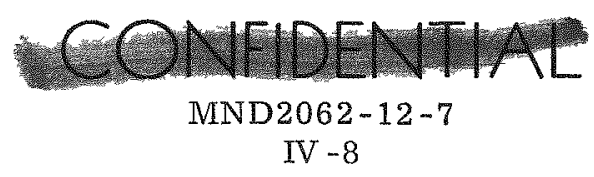


Figure IV -6 is the family of curves relating drift rate, hot junction temperatures and operating time using data developed from SNAP 11 and 19 sources. The curves provide the basis for developing the drift rate at a hot junction temperature of $1050^{\circ} \mathrm{F}$ and for the SNAP 29 operating life of 144 days (3456 hours).

Figure IV-7 is developed from the data shown in Fig. IV -6 . It shows the drift rate as a function of hot junction temperature for 3500 hours.

Figure IV -8 is also developed from data presented in Fig. IV -6 . It shows the druft rate versus time at a hot junction temperature of $1050^{\circ} \mathrm{F}$ as a solid line. The dotted line curves show the correlation to other program test results.

\section{T/E Couple Power Output Characteristics}

Figure IV-9 is a graphical presentation of the initial (beginning of life) power output characteristics of the SNAP 29 type $2 \mathrm{~N}-3 \mathrm{P}$ cupped thermoelectric couples, $\mathrm{P} / \mathrm{N}$ 466A $1341002-19$, using applicable data from 13 of the first $16 \mathrm{~T} / \mathrm{E}$ couple production lots. Data from lot 29-001, qualification run, and 29-002, preproduction run, were excluded due to changes in fabrication processes and controls. Lot 29-004 was rejected and therefore its data have been excluded. The mean ( $\bar{X})$ is 1.330 watts with a standard deviation $\left(\sigma_{c}\right)$ of 0.062 watt. The upper and lower three sigma limits are 1.516 and 1.144 watts, respectively. The data were obtained from measurements on 50 samples randomly selected from production lots 29-003 and 29-005 through $29-016$.

The values shown are corrected to an open circuit voltage ( $\mathrm{E}_{\text {oc }}$ ) of 0.1664 volt which is the mean value based on a random selection of 56 samples from production. The standard deviation associated with that $E_{\mathrm{OC}}$ is 0.0027 volt.

Table IV-6 illustrates the rising trend of mean T/E couple power output as addltional lots of couples are fabricated. For convenience, the average power is derived for each succeeding production lot in groups of four.

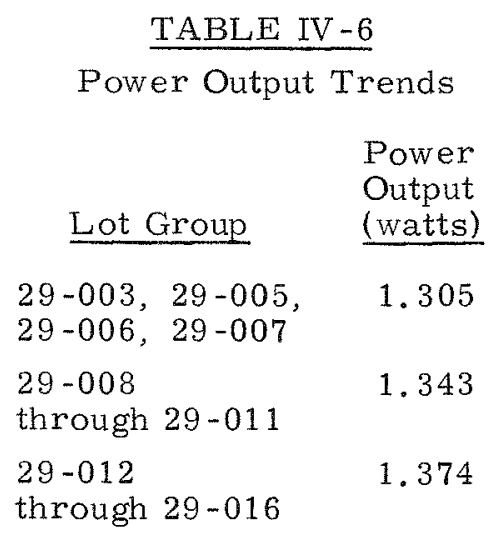

\section{Predicted T/E Module Power Characteristics}

Table IV -7 presents the predicted power output for the piston-heat sink module, $\mathrm{P} / \mathrm{N}$ 466A1341000-49, at beginning of life. No end-of-life power output characterisitics are presented since insufficient data are available from $\mathrm{T} / \mathrm{E}$ module tests to develop a drift rate. The associated upper and lower three sigma limits are included.

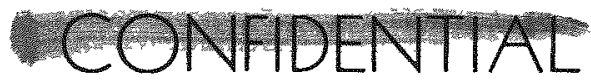




\section{TEONFDENTAA}
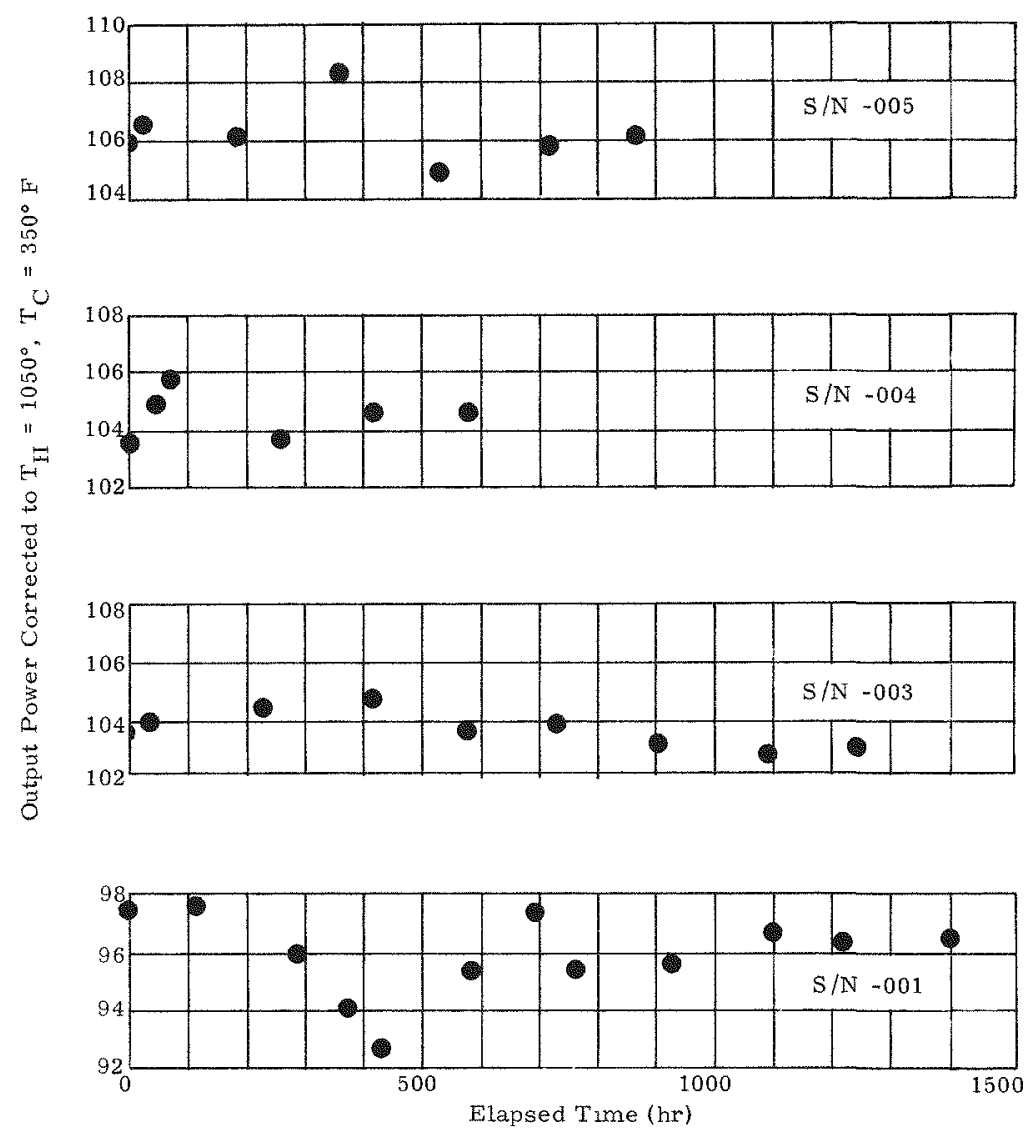

FIG. IV -5. SNAP 29 POWER OUTPUT

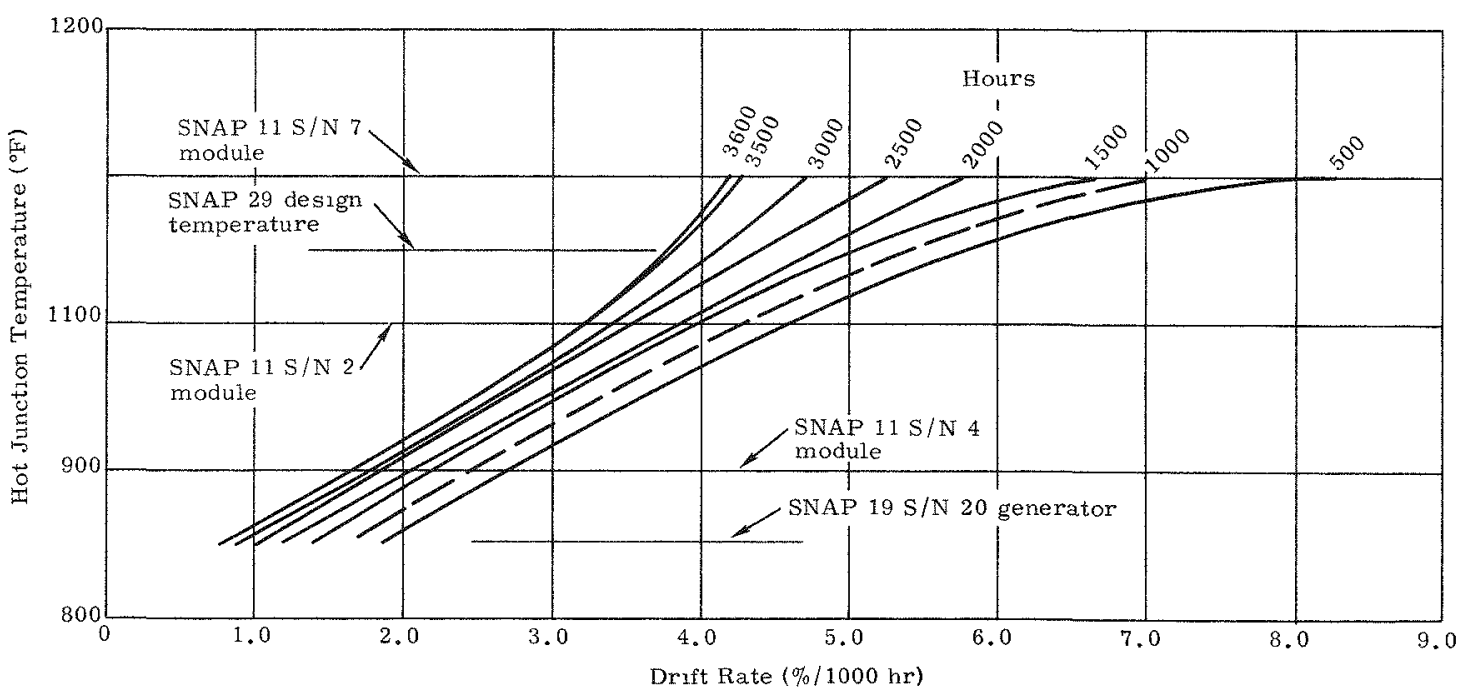

FIG. IV-6. THERMOELECTRIC $2 N-2 P$ DRIFT RATE VERSUS HOT JUNCTION TEMPERATURE AND TIME

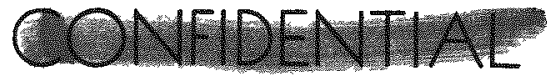

MND2062-12-7

IV -10 


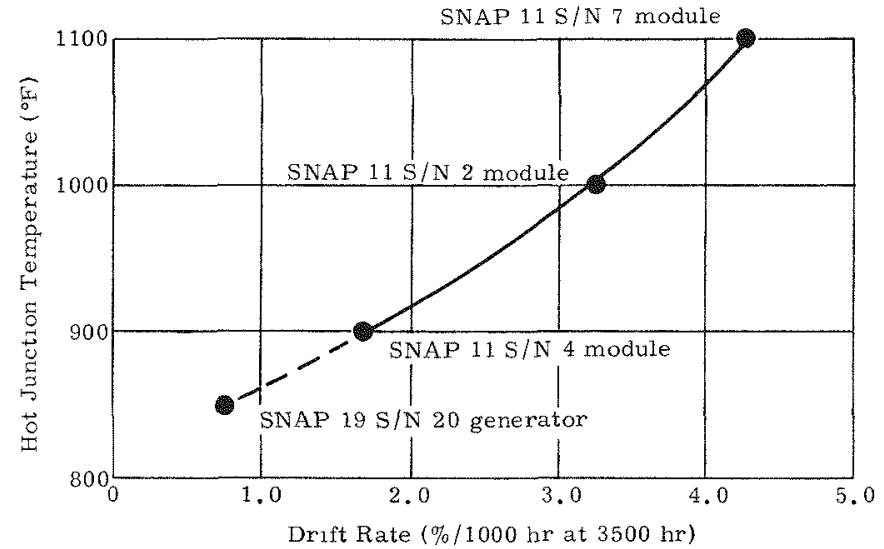

FIG. IV -7. THERMOELECTRIC 2N-3P DRIFT RATE VERSUS HOT JUNCTION TEMPERATURE AT 3500 HOURS

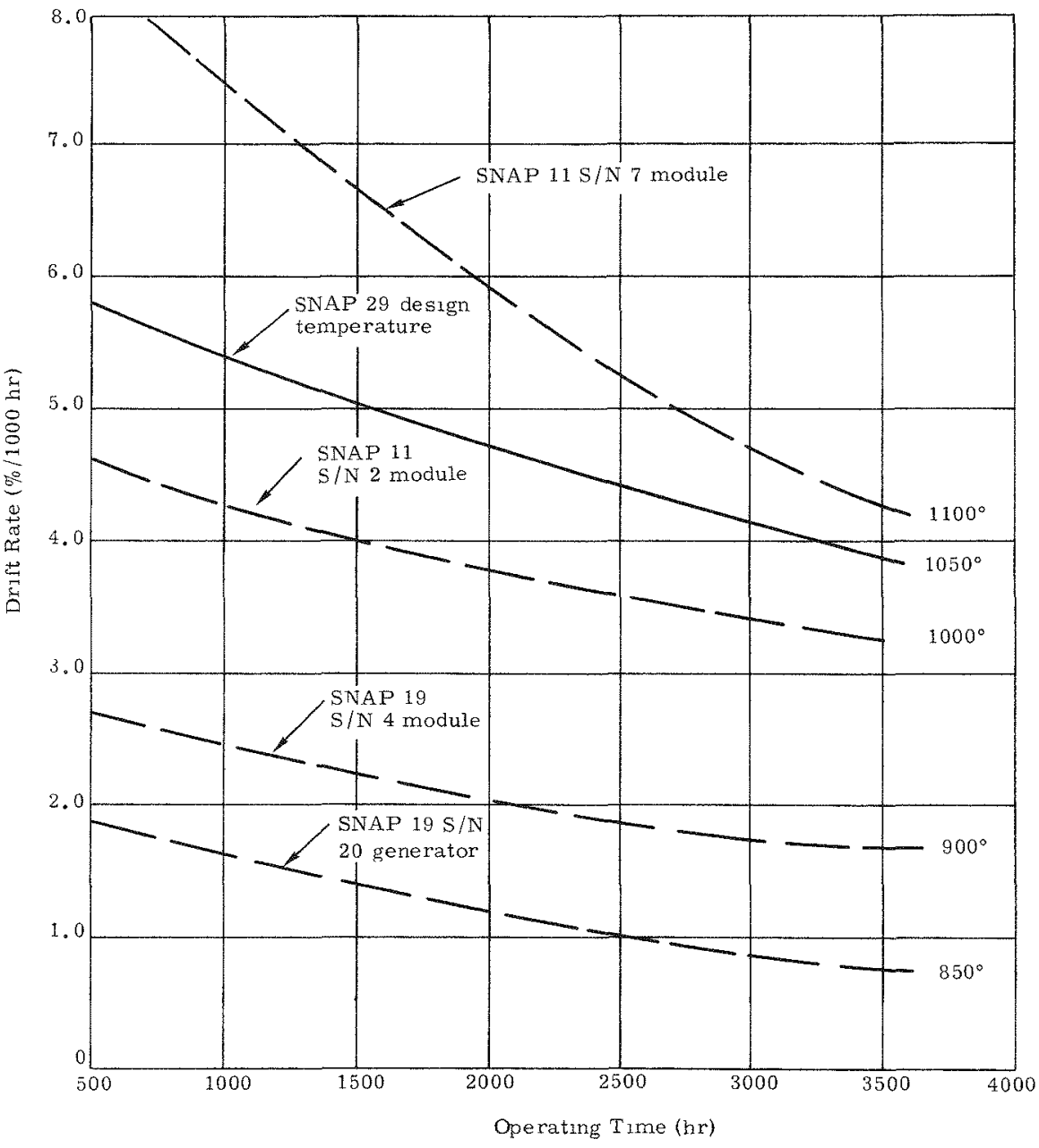

FIG. IV -8. THERMOELECTRIC 2N -3P DRIFT RATE VERSUS TIME, AT 1050 HOT JUNCTION TEMPERATURE

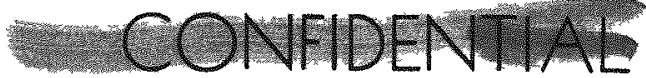

MND2062-12-7

IV -11 
$\overline{\mathrm{X}}=1.330 \mathrm{watts}$

$\sigma=0062$ watt

Voltage (open curcuit)

$\bar{x}=0.1660$ volt

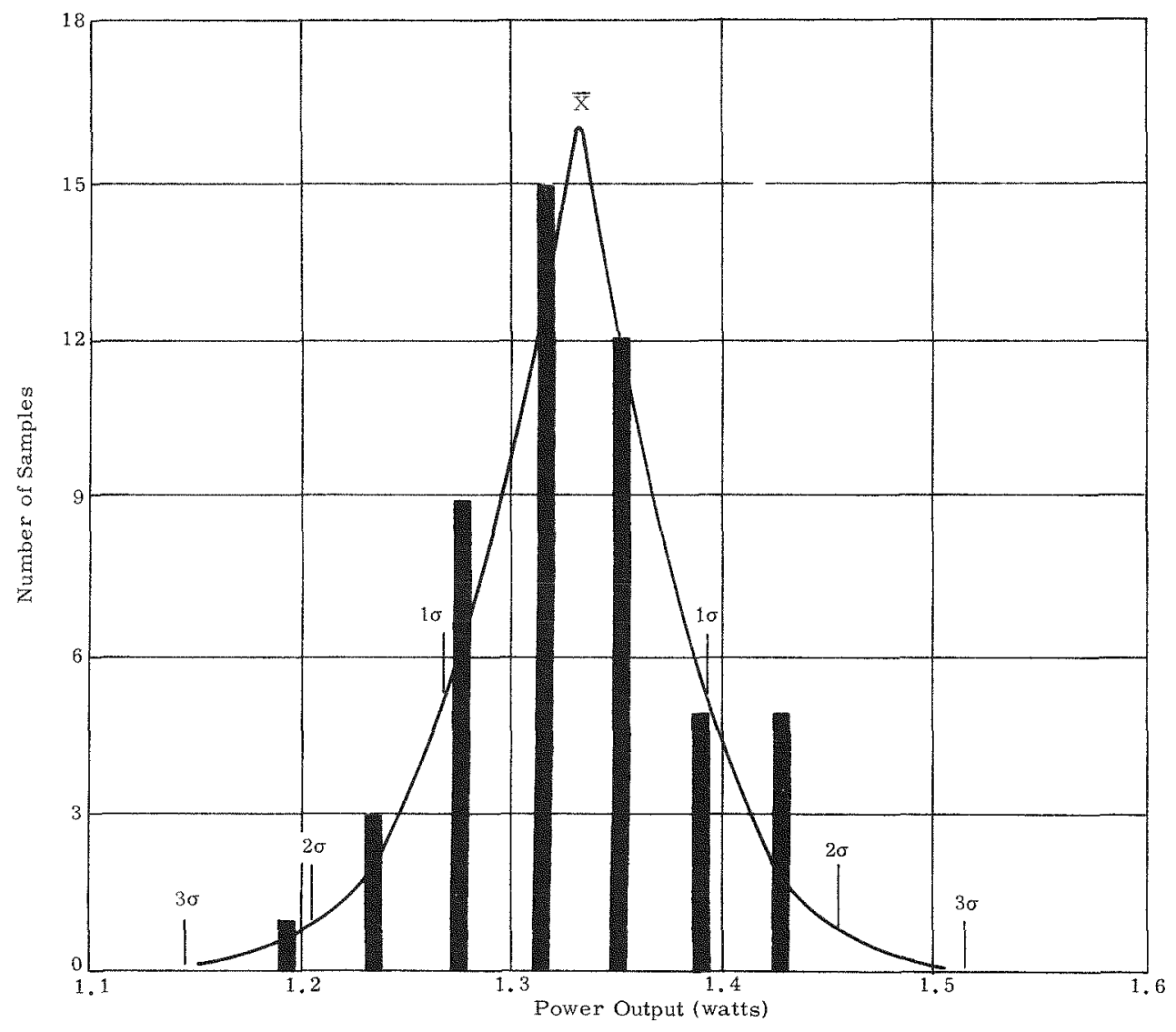

FIG. IV -9. SNAP 29 T/E COUPLE POWER OUTPUT DISTRIBUTION

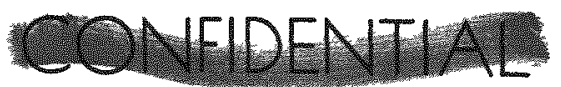

MND2062-12-7

IV -12 
Separate calculations for the diaphragm module, $\mathrm{P} / \mathrm{N} 466 \mathrm{~A} 1341060-9$, have not as yet been prepared since detail copper wire and strap resistance values are not available. The difference is expected to be small and slightly in favor of the diaphragm module.

TABLE IV -7

Predicted T/E Module

Power Characteristics

Item $\quad$ BOL (watts)

$\begin{array}{lr}\text { Mean }(\bar{X}) & 108.27 \\ \begin{array}{l}\text { Standard } \\ \text { deviation }(\sigma)\end{array} & 0.59 \\ \text { USL }(3 \sigma) & 110.04 \\ \text { LSL }(3 \sigma) & 106.50\end{array}$

The beginning-of-life mean power output was calculated for the piston-heat sink $T / E$ module using the equation:

$$
P_{B O L}=\left(\frac{E_{B O L}{ }^{2}}{R_{T}}\right)=\left(\frac{E_{B O L}{ }^{2}}{R_{I}+R_{C}+R_{B}}\right)
$$

where

$$
\begin{aligned}
& E_{B O L}=\text { module voltage at matched load } \\
& R_{I}=\text { resistance due to } T / E \text { couples and circuitry } \\
& R_{C} \quad=\text { resistance due to straps and copper leads }=0.00674 \text { ohm } \\
& R_{B} \quad=\text { resistance due to cold end bonds }=0.00562 \mathrm{ohm}
\end{aligned}
$$

The development of the values for $\mathrm{Eq}(\mathrm{IV}-1)$ follows:

$$
E_{B O L}=\frac{E_{O C} \times m}{2}
$$

where

$$
\begin{array}{ll}
E_{O C} & =\text { open circuit voltage of } \mathrm{T} / \mathrm{E} \text { couples } \\
\mathrm{m} & =\text { number of series couple groups } \\
\mathrm{E}_{\mathrm{BOL}} & =\frac{0.1664 \times 45}{2}=3.744 \text { volts } \\
\mathrm{R}_{\mathrm{I}} & =\frac{\left(\mathrm{E}_{\mathrm{BOL}}\right)^{2}}{\mathrm{P}_{\text {gross }}}=\frac{\left(\mathrm{E}_{\mathrm{BOL}}\right)^{2}}{\mathrm{P}_{\mathrm{C}} \times \mathrm{N}}
\end{array}
$$

where

$$
\begin{aligned}
& \mathrm{P}_{\mathrm{C}} \quad=\text { power output of } \mathrm{T} / \mathrm{E} \text { couple } \\
& \mathrm{N} \\
& \mathrm{R}_{\mathrm{I}} \quad=\frac{(3.744)^{2}}{1.330 \times 90}=0.11710 \mathrm{ohm}
\end{aligned}
$$

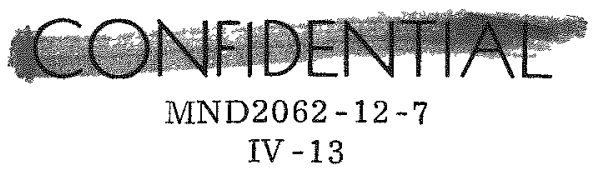


Substituting values into Eq (IV-1) results in:

$$
\mathrm{P}_{\mathrm{BOL}}=\frac{3.744^{2}}{0.11710+0.00674+0.00562}=\frac{3.744^{2}}{0.12946}=108.27 \text { watts }
$$

The standard deviation, USL and LSL values at three sigma, were calculated from the equation:

$$
\text { Standard deviation }\left(\sigma_{m}\right)=\sigma_{c} \sqrt{n}
$$

where

$$
\begin{aligned}
\sigma_{\mathrm{m}} & =\text { standard deviation of module power } \\
\sigma_{\mathrm{c}} & =\text { standard deviation of } \mathrm{T} / \mathrm{E} \text { couple power } \\
\mathrm{n} & =\text { number of } \mathrm{T} / \mathrm{E} \text { couples } / \text { module }
\end{aligned}
$$

Substituting values into the equation yields:

$$
\begin{aligned}
\sigma_{\mathrm{m}} & =\sqrt{90} \quad 0.062 \\
& =9.4868+0.062 \\
& =0.588 \text { watt }
\end{aligned}
$$

The three sigma limit becomes 1.765 watts ( $3 \times 0.588)$. This three sigma value is added and subtracted from the BOL and EOL mean value to obtain a predicted LSL and USL shown in Table IV -1 .

\section{Electric Heater Program and Analysis}

Failure analysis have been initiated on the Sanders and TRW heaters. The results of this analysis, along with evaluation of the test results, are planned for the next quarter.

\section{TEST PROGRAM DEFINITION AND EVALUATION - - CONTROL POINT 3233}

\section{Assessment of T/E Module Power Output}

Table IV-8 presents a comparison of the measured and predicted beginning-oflife power output for each of the five individual $\mathrm{T} / \mathrm{E}$ modules.

The measured power readings have been corrected to $1050^{\circ}$ to $350^{\circ} \mathrm{F}$ but have not been corrected to account for instrumentation and test program variations. These readings may change with the inclusion of smoothing/extrapolation techniques. How ever, insufficient operating time has been accumulated to implement these techniques.

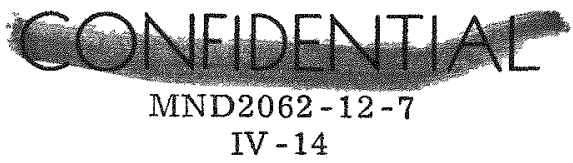


TABLE IV -8

\begin{tabular}{ccccc} 
Predicted Versus Measured T/E Module Power \\
$\begin{array}{c}\text { Generator } \\
\text { S/N }\end{array}$ & $\begin{array}{c}\text { Predicted } \\
\text { Net Power } \\
\text { (watts) }\end{array}$ & $\begin{array}{c}\text { Measured } \\
\text { Power } \\
\text { (watts) }\end{array}$ & $\begin{array}{c}\text { Difference } \\
\text { (predicted } \\
\text { - measured) }\end{array}$ \\
\cline { 1 - 1 } 001 & 105.24 & & 97.40 & 7.84 \\
002 & 105.97 & 103.80 & 2.17 \\
003 & 107.69 & 103.60 & 4.09 \\
004 & 106.74 & 103.20 & 3.54 \\
005 & 109.03 & 105.60 & 3.43
\end{tabular}

Table IV -9 presents the results of averaging the measured and predicted beginningof-life power output for the family of piston-heat sink modules. Since module S/N 001 performance differs considerably from the others, the summary is prepared in two parts, namely, S/N 001 through 005 and S/N 002 through 005 with the latter considered more representative. The average measured power is approximately $3.1 \%$ below the predicted value. The standard deviations are, except for the effect of S/N 001 , reasonably identical and within the accuracy that may be expected from the limited data available.

TABLE IV -9

Summary of Predicted and Measured T/E Module Power

$$
\begin{gathered}
\text { Modules S/N } \\
002 \text { Through } 005
\end{gathered}
$$

$\quad \underline{\text { Item }}$
Mean $\overline{\mathrm{X}}$
Standard
deviation

USL $(3 \sigma)$

LSL $(3 \sigma)$
Predict Measured

107.36

1.32

111.32

103.40
104.05

1.06

107.23

100.87
Modules S/N

001 Through 005

The predicted BOL power output for a $\mathrm{T} / \mathrm{E}$ module, based on the average power output of all production couples, is 108.27 watts with a standard deviation of 0.59 watt. However, since each of the subject modules are fabricated from an earlier couple production with slightly lower power output levels and from different lots each having different power characteristics, a separate prediction has been calculated and is shown in Table IV -10. The gross power is calculated from the average $T / E$ couple for the specific power output. Losses are from cold end bonds and $I^{2} R$.

Table IV-11 presents the results of the summary of the means and standard deviations for the two catagories previously developed (module S/N 001 through S/N 005 and $S / N 002$ through $S / N$ 005) and compares them to the predicted values. The study shows that the measured power output is approximately $3.1 \%$ lower than the predicted.

Future modules, either of the piston-heat sink or diaphragm construction, are expected to exhibit between one to two watts improvement due to the increased per formance of later $\mathrm{T} / \mathrm{E}$ couple production. In addition, the diaphragm module is expected to have a slightly lower $I^{2} \mathrm{R}$ copper loss due to internal construction differences.

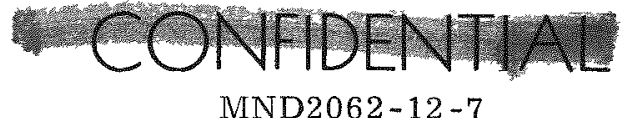


TABLE IV -10

Predicted T/E Module Power Output at BOL

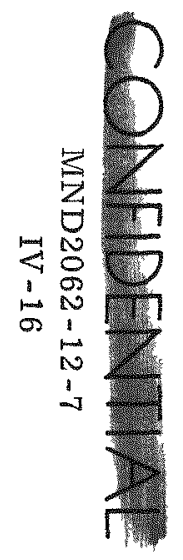

\begin{tabular}{ccccccc}
$\begin{array}{c}\text { Generator } \\
\text { S/N }\end{array}$ & Lot No. & Quantity & $\begin{array}{l}\text { Watts/ } \\
\text { Couple }\end{array}$ & $\begin{array}{c}\text { Gross } \\
\text { Power } \\
\text { (watts) }\end{array}$ & $\begin{array}{c}\text { Losses } \\
\text { (watts) }\end{array}$ & $\begin{array}{c}\text { Net } \\
\text { Power }\end{array}$ \\
\cline { 1 - 2 } 001 & $29-003$ & 90 & 1.2890 & 116.01 & 10.77 & 105.24 \\
002 & $29-005$ & 66 & 1.307 & 116.89 & 10.92 & 105.97 \\
& $29-006$ & 24 & 1.276 & & & \\
003 & $29-007$ & 78 & 1.324 & 118.99 & 11.30 & 107.69 \\
& $29-008$ & 12 & 1.312 & & & \\
004 & $29-006$ & 7 & 1.276 & 117.83 & 11.09 & 106.74 \\
& $29-008$ & 83 & 1.312 & & & \\
005 & $29-006$ & 14 & 1.276 & 120.63 & 11.60 & 109.03 \\
& $29-009$ & 12 & 1.268 & & &
\end{tabular}

\section{TABLE IV -11}

Average Power Output Evaluation

T/E Couple Data

\section{$\underline{\text { Lots }}$}

Predicted

Average

all

production

lots

Measured

Module

$\mathrm{S} / \mathrm{N} 001$

through

$\mathrm{S} / \mathrm{N} 005$

29-003

29-005

29-006

29-007

29-008

29-009

$29-010$

Measured

Module

$\mathrm{S} / \mathrm{N} 002$

through

$\mathrm{S} / \mathrm{N} 005$
29-005

29-006

29-007

$29-008$

29-010
T/E Module (predicted)

T/E Module (measured)

\begin{tabular}{|c|c|c|c|c|}
\hline $\begin{array}{l}\text { Gross } \\
\text { Power } \\
\end{array}$ & Losses & $\begin{array}{c}\text { Net } \\
\text { Power }\end{array}$ & $\begin{array}{c}\text { Net } \\
\text { Power }\end{array}$ & $\begin{array}{c}\text { Predicted - } \\
\text { Measured }\end{array}$ \\
\hline 119.70 & 11.43 & $\begin{array}{l}\bar{X}= \\
108.27 \\
\sigma= \\
0.59\end{array}$ & NA & NA \\
\hline 118.07 & 11.13 & $\begin{array}{l}\bar{X}= \\
106.94 \\
\sigma= \\
1.49\end{array}$ & $\begin{array}{l}\bar{X}= \\
102.72 \\
\sigma= \\
3.11\end{array}$ & $\begin{array}{l}\Delta \text { power }= \\
4.22\end{array}$ \\
\hline 118.58 & 11.22 & $\begin{array}{l}\bar{X}= \\
107.36 \\
\sigma= \\
1.32\end{array}$ & $\begin{array}{l}\bar{X}= \\
104.05 \\
\sigma= \\
1.06\end{array}$ & $\begin{array}{l}\Delta \text { power }= \\
3.31\end{array}$ \\
\hline
\end{tabular}

0.062

1. 289

1. 307

1.276

1.324

1. 312

1. 268

1.368

1. 307

1.276

1. 324

1.312

1.268

1. 368 


\section{AEROSPACE GROUND EQUIPMENT SYSTEM--CONTROL POINT 2000}

The AGE system for the SNAP 29 consists of the equipment necessary to service, test, check out and transport the RTG system.

The objective of the AGE system is to develop equipment which will demonstrate the AGE capability of checking out and transporting the RTG and heat source and loading and unloading the heat source in the RTG.

Tasks to be conducted are:

CP 2200--Fuel Handling Machine

CP 2400--Transportation and Handling Equipment

CP 2600--Field Test Equipment

AGE effort was rescheduled and replanned as a result of the SNAP 29 program redirection. As a result of this rescheduling, no design effort will be expended in the AGE area until November 1968. 


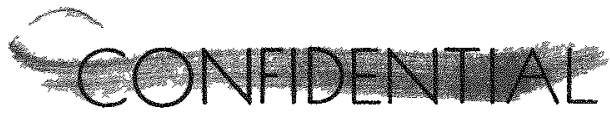

BLANK

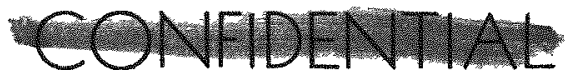

ININD2062-12-7

$\mathrm{V}-2$ 


\section{SAFETY EVALUATION AND INTEGRATION-- CONTROL POINT 3300}

\section{A. SUMMARY OF SIGNIFICANT ACCOMPLISHMENTS}

There were nine major items of work accomplished during this period:

(1) Analysis of analog heating data

(2) Analysis of analog motion data

(3) Determination of impact test drop altitudes

(4) Determination of spinning edge-on trajectory and heating data

(5) Completion of hypersonic force and moment wind tunnel test for two- and four-module fuel blocks

(6) Completion of hypersonic aeroheating wind tunnel test for two- and fourmodule fuel blocks

(7) The fuel matrix impact evaluation tests were completed

(8) Phase I of the fuel block drop tests was completed

(9) Two SNAP 29 partial fuel blocks were included in Project PYRO tests.

A summary of each of these items follows; the detailed description of these and other accomplishments will be discussed under the separate control point headings.

The fuel block peak heating data from the six-degree-of-freedom analog motion study were analyzed. The heating results are defined in terms of peak stagnation heat rate and the associated block motions at the time of peak heating for various initial conditions.

The inertial and aerodynamic effects on the fuel block motions as shown by the six-degree-of-freedom analog motion study were analyzed. The types of motions resulting from various initial conditions and the predominant factors affecting reentry in the edge-on mode were investigated.

Release altitudes for the fuel block Phase I impact tests at the Tonopah Test Range were determined. Minimum release altitude to attain terminal velocity was determined.

Trajectories and aerodynamic heating were determined for all the modular fuel blocks having a spinning, edge-on re-entry mode. The results are based on the wind tunnel force and moment and heating data described later in this report.

The hypersonic force and moment test of the two-module (aspect ratio $=3.16$ ) and the four-module (aspect ratio $=1.74$ ) fuel block configuration was conducted in the AEDC Tunnel B during October and November 1967. The purpose of this test was to provide experimental aerodynamic data for use in determination of a minimumsized fuel block. Six-component aerodynamic coefficients were obtained for angles of attack from $0^{\circ}$ to $90^{\circ}$ at seven angles of roll. A test report presenting the results obtained has been prepared.

The hypersonic aeroheating test of the two-module and the four-module fuel block configurations was completed in November 1967. Ninety-four thermocouples were

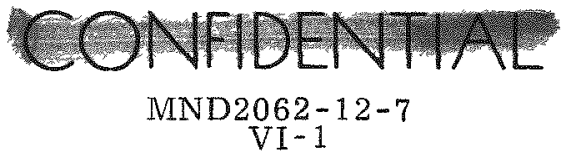


used to determine heat rates over the forward facing flat plate surfaces and hemispherical leading edges. The model was exposed to a Mach 8 airstream. Tests were conducted at angles of attack from $0^{\circ}$ to $90^{\circ}$ at four roll angles.

The testing and evaluation of fuel matrices subjected to typical shock pulses were completed. Twenty specimens were tested. The objective of the impact test was to compare and evaluate two different matrix sintering temperatures as well as basic matrix resistance to impact.

Phase I of the fuel block drop tests was completed on November 29, 1967. Two eight-module graphite fuel blocks were tested. Evaluation of the capsule damage is still in progress.

Partial SNAP 29 fuel blocks were included in two Project PYRO tests. In both tests, detonation occurred prematurely and no quantitative data were collected. The fuel block damage was minor in both cases and the fuel block used in these tests was available for future tests.

\section{B. SAFETY EVALUATION AND INTEGRATION-- CONTROL POINT 3310}

\section{Downwind Diffusion}

This effort was reactivated on October 1st. A study on available analysis methods was completed in December with two conclusions: (1) existing methods and statistical correlations are adequate for dose prediction out to a few kilometers from the ground release location and (2) for realistic dose prediction at greater distances downwind, the effects of topography and time-dependent, three-dimensional winds must be treated. The Defense Land Fallout Implementation Code (DELFIC) is most appropriate in the long-range case, since it already has built-in models for orography and the sea breeze. Conversion and checkout of DELFIC on the IBM 360/44 were initiated, and topographic maps and rawinsonde data were ordered. Pasquill's turbulent diffusion estimates of cloud width and height were converted to the form $\sigma / v(\sigma=$ standard deviation of wind speed, $v$, in lateral or vertical direction), as required for input to DELFIC. A modified Pasquill equation for predicting Gaussian plume propagation to $100 \mathrm{~km}$ range will be used for backup and comparison with DELFIC results.

A study was made which considered the Green Gulch project and the Weather Information Network and Display (WIND) system. The diffusion equation developed for the Vandenberg area, as part of the Green Gulch project was applied to an examination of the hazard to nearby populated areas from a launch pad release of radioactivity. Special consideration was given to the topography as, combined with the area climatology, it affects the possible hazard.

Conditions unfavorable to launching the SNAP 29 system have a very low occurrence frequency. The weather data gathering and analysis by the WIND system (perhaps with some extension) should be able to preclude launching under unfavorable conditions. Even under unfavorable conditions, the exposure of the town of Lompoc, the Federal Correction Institution and the industrial and residential area of Vandenberg has low probability.

It was found that if a cloud of activity from the release of $0.10 \%$ of the load of one capsule were to reach the industrial and residential area, an equivalent whole body dose of 10 millirem might be received by 30,000 persons.

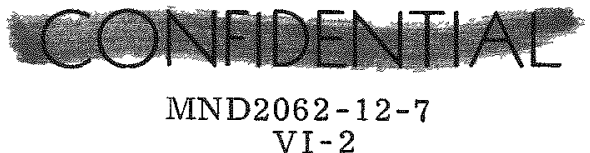




\section{Atmospheric Agglomeration, Transport and Removal}

A study was made on factors influencing transport and removal of submicron particles in the quiescent environment. The study compared the relative importance of several deposition mechanisms and concluded that gravitational sedimentation, Brownian motion, thermophoresis and electrical charge effects were the more significant. A study of removal mechanisms from the nonquiescent environment was begun. The results will be combined with precipitation scavenging models for more realistic removal predictions for the total environment.

Existing computer models for stratospheric transport and removal were reviewed. The four-season DASA model developed under Project STREAK was selected for SNAP 29 fine particle, high-altitude release application. The STREAK code was ordered through the AEC. The release hazards study based on the two-stage fallout model which is now available is continuing and will be compared with results from the more elaborate STREAK code.

\section{Dose-Response Study}

An intermediate phase has been reached in the dose-response study, and the reprogramming of the existing model has begun. Preliminary results show the program to be functioning as expected, and the model construction difficulties mentioned in the last quarterly report appear to have been resolved. The model will have the added advantage of being able to examine some of the basic assumptions that are included in the new ICRP lung model.

\section{Probabilistic Study}

A study was conducted to estimate the probability of the fuel block being edge-on at maximum stagnation heating during re-entry.

The mission probability study was initiated with the generating of sequence-ofevents flow networks.

\section{Intact Source Analysis}

The radiation environment for a four-module fuel block and for an array of 12 bare fuel capsules was determined. The fuel block radiation field was employed in a PDN analysis of the block.

A study to calculate the random recovery time of an intact source was completed. The object of the study was to find a relation between the recovery time and the local population density in the region where the source has landed. This recovery time model was included in the PDN analysis of the intact source.

\section{Deep-Ocean Diffusion}

A preliminary effort was made to estimate quantitatively, the concentration that might appear in the upper layer of the ocean from deposition of radioactivity on the bottom of the deep ocean. A box model similar to that of Broecher* was used. Because of the short life of Po-210 and the slow rate of vertical diffusion, the concentration in the upper mixed layer will not exceed $10^{-9}$ times that in a bottom layer of uniform concentration.

*J. Geophys. Res. 71:5827

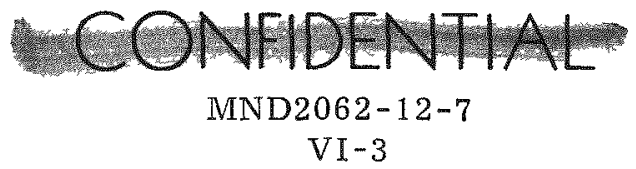


7. Error Analysis

A two-phase re-entry error analysis program was formulated. Phase I will consider the four representative classes of motion which are now being analyzed (edge-on, broadside, oscillating and tumbling). Variables to be considered are those which affect the external heating rates and resultant maximum fuel clad temperature but do not significantly alter the motion. For each aerodynamic variable, a probability will be assigned and the function which relates the variable to the external heating rate will be determined. For each thermal variable, a probability will be assigned and a function which relates the variable to the maximum temperature in the fuel clad will be determined. Occurrence probabilities will be assigned to the four motions. This information will be embodied in a Monte Carlo computer program.

As part of the larger error analysis study, a flight dynamics investigation was made to provide a means of estimating re-entry flight dynamics for cases where analog runs are not available, and to determine which vehicle parameters had the greatest effect on the re-entry motion. Theory* was applied to the eight-module fuel block for tumbling re-entry. The theory presents maximum and minimum envelopes of re-entry motion for given initial conditions. Good agreement was shown between the approximate theory and the analog results. The vehicle parameter of greatest significance was shown to be:

$$
B=\left(\frac{C_{D}^{A}}{m}\right)\left(B \sin \gamma_{i}\right)\left(\frac{I}{A \ell C_{m_{\max }}}\right)
$$

where:

$$
\begin{array}{ll}
\mathrm{C}_{\mathrm{D}} & =\text { drag coefficient } \\
\mathrm{A} & =\text { reference area } \\
\mathrm{m} & =\text { vehicle mass } \\
\mathrm{B} & =\text { atmosphere constant } \\
\gamma_{\mathrm{i}} & =\text { initial flight path angle } \\
\mathrm{I} & =\text { vehicle moment of inertia about tumbling axes } \\
\ell & =\text { reference length } \\
\mathrm{C}_{\mathrm{m}_{\max }} & =\text { maximum value of moment coefficient }
\end{array}
$$

For a given value of $B$, the re-entry motion is predicted to be independent of the particular values of $\mathrm{C}_{\mathrm{D}}$, $\mathrm{A}$, etc.

A method** for approximating the re-entry motion of a spinning vehicle $\left(\mathrm{P}_{0} \neq 0\right)$ at initial angle of attack has been used. Although the assumptions made in this

*Tobak, M. and Peterson, V. L., "Theory of Tumbling Bodies Entering Planetary Atmospheres with Application to Probe Vehicles and the Australian Tectites," NASA TR R-203, 1964.

** Tobak, M, and Peterson, V. L., "Angle of Attack Convergence of Spinning Bodies Entering Planetary Atmospheres at Large Inclinations to the Flight Path," NASA TR R-210, 1964.

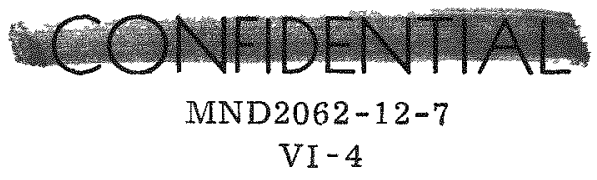


analysis are not directly applicable to a flat-plate configuration, the results of this study and the one described earlier indicate that approximate theory can be used to estimate re-entry flight altitudes of the fuel block when initial pitch or yaw rates are present but roll rate is zero. As yet no method has been found that would handle the case of initial roll rate.

\section{AERODYNAMIC ANALYSES AND TESTS-- CONTROL POINT 3320}

\section{Analog Aeroheating Study}

An analysis was made of the heating data obtained from the six-degree-of-freedom analog motion study conducted in August 1967. The heating results are defined in terms of the values of peak stagnation heating rate, $\dot{q}_{\max } \sqrt{R}$, and total heat, $Q_{\text {total }}$ $\sqrt{R}$. The highest values of heating were observed in conjunction with an initial condition of edge-on spinning $\left(\eta \approx 90^{\circ}\right)$. The motion accompanying these highest heating levels, as depicted during the event of peak stagnation heating rate, is also characterized by an edge-on flight condition (total angle of attack, $\eta \approx 90^{\circ}$ ).

The degree of heating and accompanying edge-on motion is decreased as the initial attitude approaches a broadside condition $\left(\eta_{0} \approx 0^{\circ}\right)$ or as roll rate, $\mathrm{p}_{0}$, approaches zero. For the cases with an initial edge-on spinning motion, the level of heating and accompanying edge-on motion were reduced by the application of initial finite values of pitch rate, $\mathrm{q}_{0}$, and/or yaw rate, $\mathrm{r}_{0}$.

A summary of the effect of roll rate in conjunction with pitch or yaw rate on the value of peak stagnation heating rate is given in Figs. VI- 1 through VI-4 for both the eight-module fuel block (aspect ratio $=1.095$ ) and the two-module fuel block (aspect ratio $=3.16)$. The maximum level of peak stagnation heating given previously, 3.16 , adjusted for a 300,000-foot altitude initial condition, is also shown on the graphs for reference purposes. It should be noted that the analog runs were made from an initial altitude of 300,000 feet to minimize the computer running time. Comparison runs were made for an initial altitude of 400,000 feet, with only minor changes in the resulting heating and motions. In Figs. VI-1 and VI-2, the region containing the range of values for which a near edge-on attitude still persists at peak heating is noted by a cross-hatch area. In general, for the level of roll rate ( $p_{0}=5 \mathrm{rad} / \mathrm{sec}$ ) presented in Figs. VI-3 and VI-4, the motions at peak heating are characterized as coning or wobbling with a mean total angle of attack value equal to the initial value. The larger the pitch and/or yaw rates for a given roll rate, the greater the dispersion from the mean motion characteristics discussed above.

Figures VI-5 through VI-7 present the effect of combinations of initial roll, pitch and yaw rates in conjunction with an initial edge-on attitude on the motion at the time of peak heating rate in terms of maximum and minimum total angle of attack for both the eight-module and two-module fuel blocks. A comparison of the curves for the twomodule and eight-module blocks shows the former to have lower heating values than the latter. This is due to the combined effect of ballistic coefficient and motion characteristics. It is important to note that the higher stagnation heating rates for the edge-on spinning re-entry must be combined with the surface heating distributions to determine the capsule temperature.

\section{Analog Motion Study}

The results of the analog six-degree-of-freedom motion study were analyzed with respect to the body motions of the fuel block for various initial conditions.

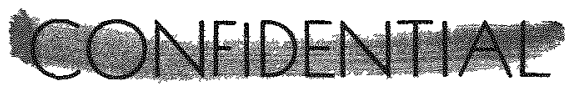

MND2062-12-7

VI -5 


\section{CONFIDENTHA}

$h_{0} \quad 300000 \mathrm{tt} \quad r_{0}=25700 \operatorname{lps} \gamma_{0}=-3.0^{\circ}$

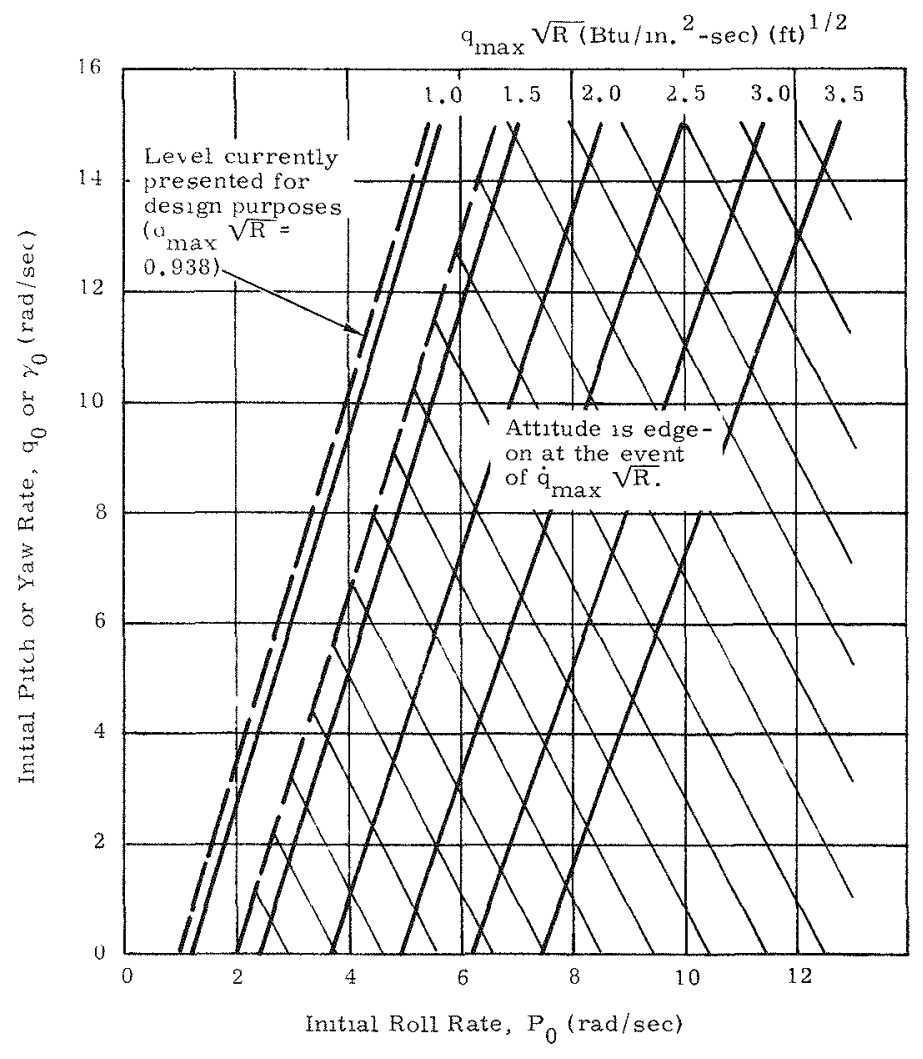

FIG. VI-1. SNAP 29 FUEL BLOCK (ASPECT RATIO = 1095 ) MAXIMUM STAGNATION HEATING RATE (1-FOOT RADIUS SPHERE) WITH MITIAL ATTITUDE EDGE-ON $\left(\eta_{0}=89^{\circ}\right)$

FIG. VI-2, SNAP 29 FUEL BLOCK (ASPECT RATIO $=3,16$ ) MAXIMUVI STAGNATION HEATING RATE (1-FOOT RADIUS SPHERE) WITH INITIAL ATTITUDE EDGE-ON $\left(\eta_{0}=89^{\circ}\right)$
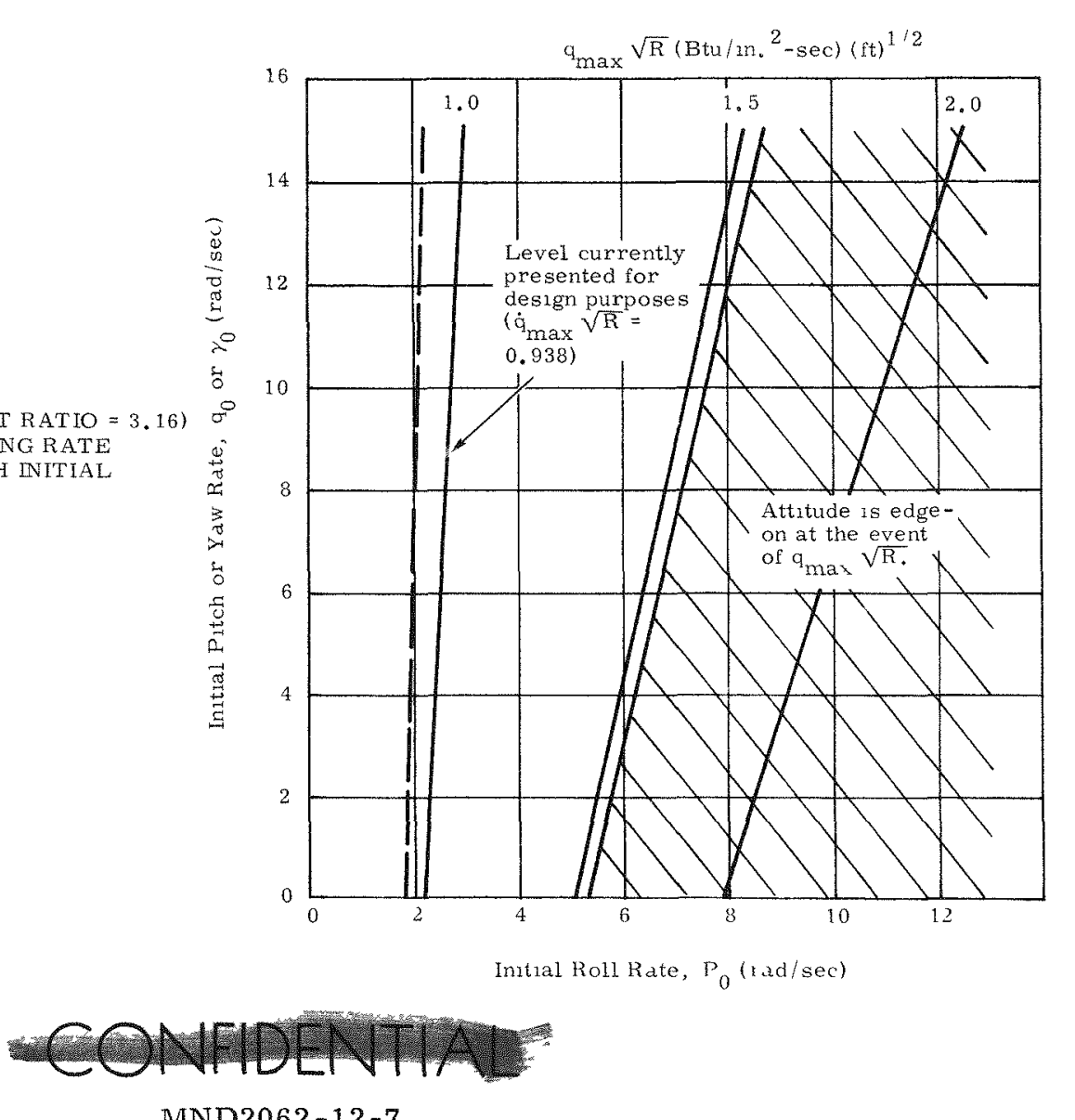

MND2062-12-7

VI -6 

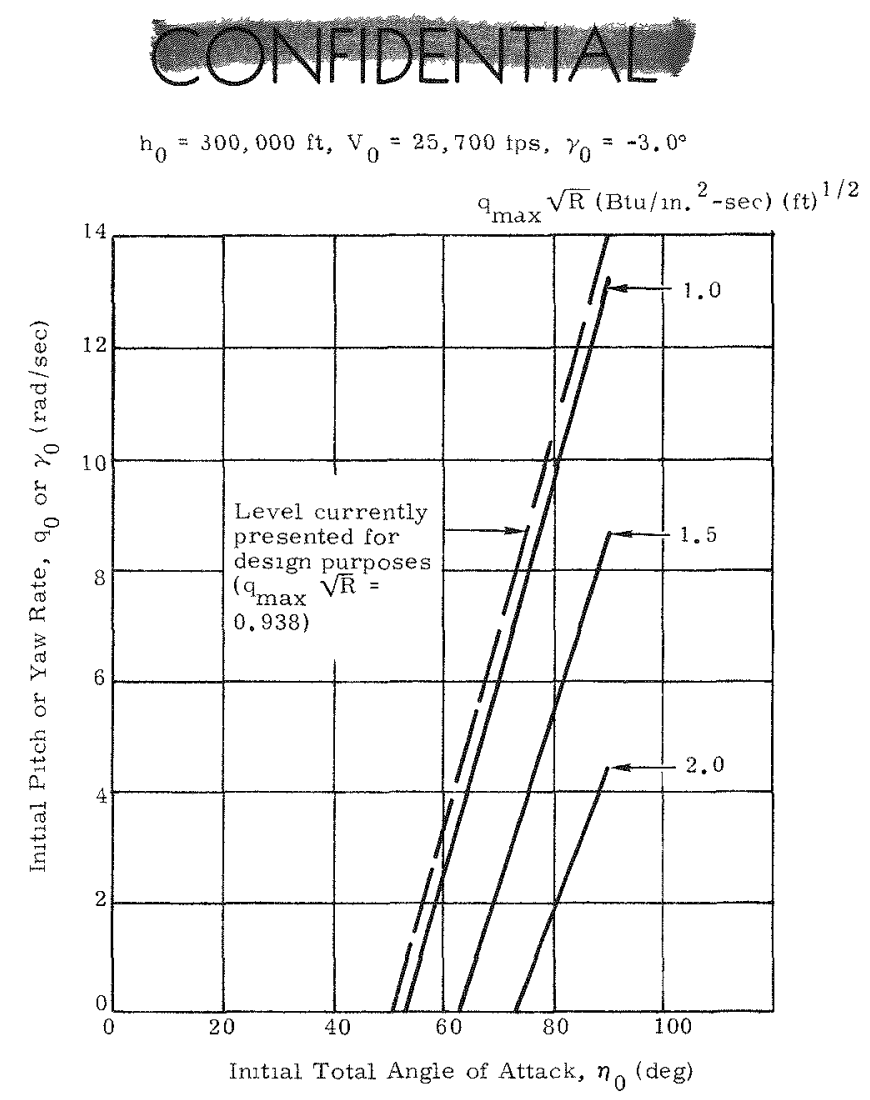

FIG. VI-3. SNAP 29 FUEL BLOCK (ASPECT RATIO = 1.095) MAXIMUM STAGNATION HEAT ING RATE (1-FOOT RADIUS SPHERE) WITH INITIAL ROLL RATE, $\mathrm{P}_{0}$ AT I IVE
RADIANS PER SECOND

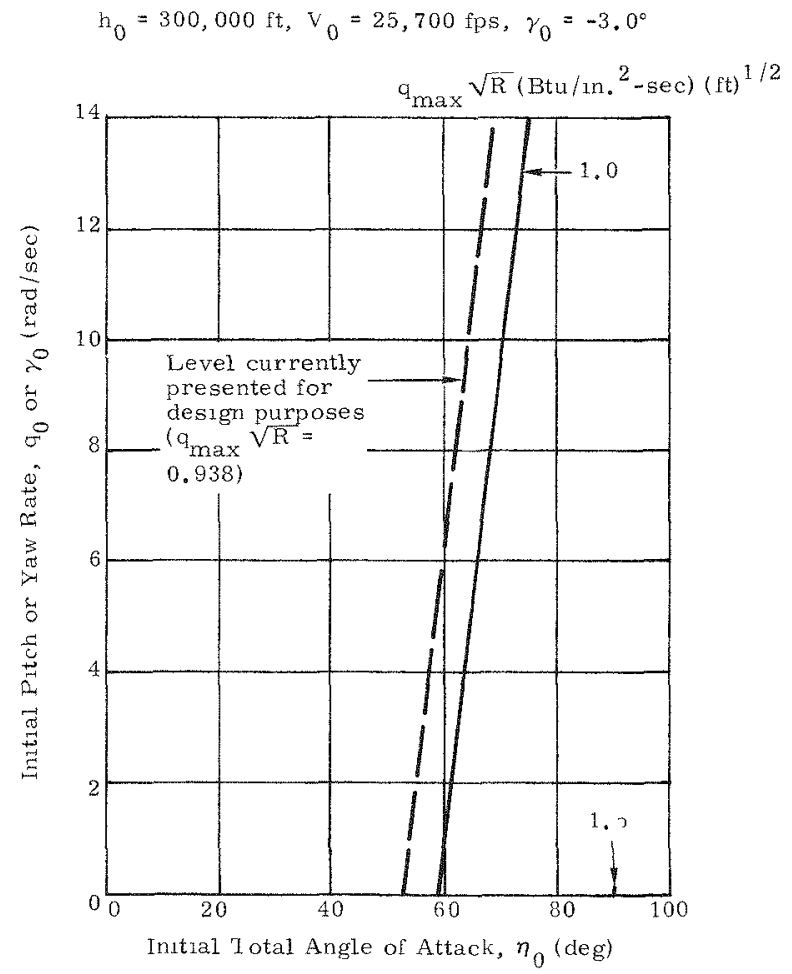

I IG. VI-4. SNAZ 29 FUEL BLOCK (ASPECT RAZIO 3.16) MAXIMUM STAGRATION IMAT ING RATE (1-FOOT RADIUS SPHERE) WITH INITIAL ROLL RAIE, P AT I IV RADIANS PER SECOND

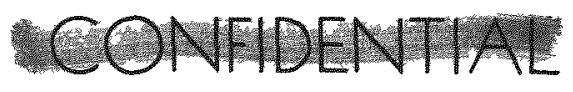

MND2062-12-7

VI -7 


\section{CONFIDENTAL}

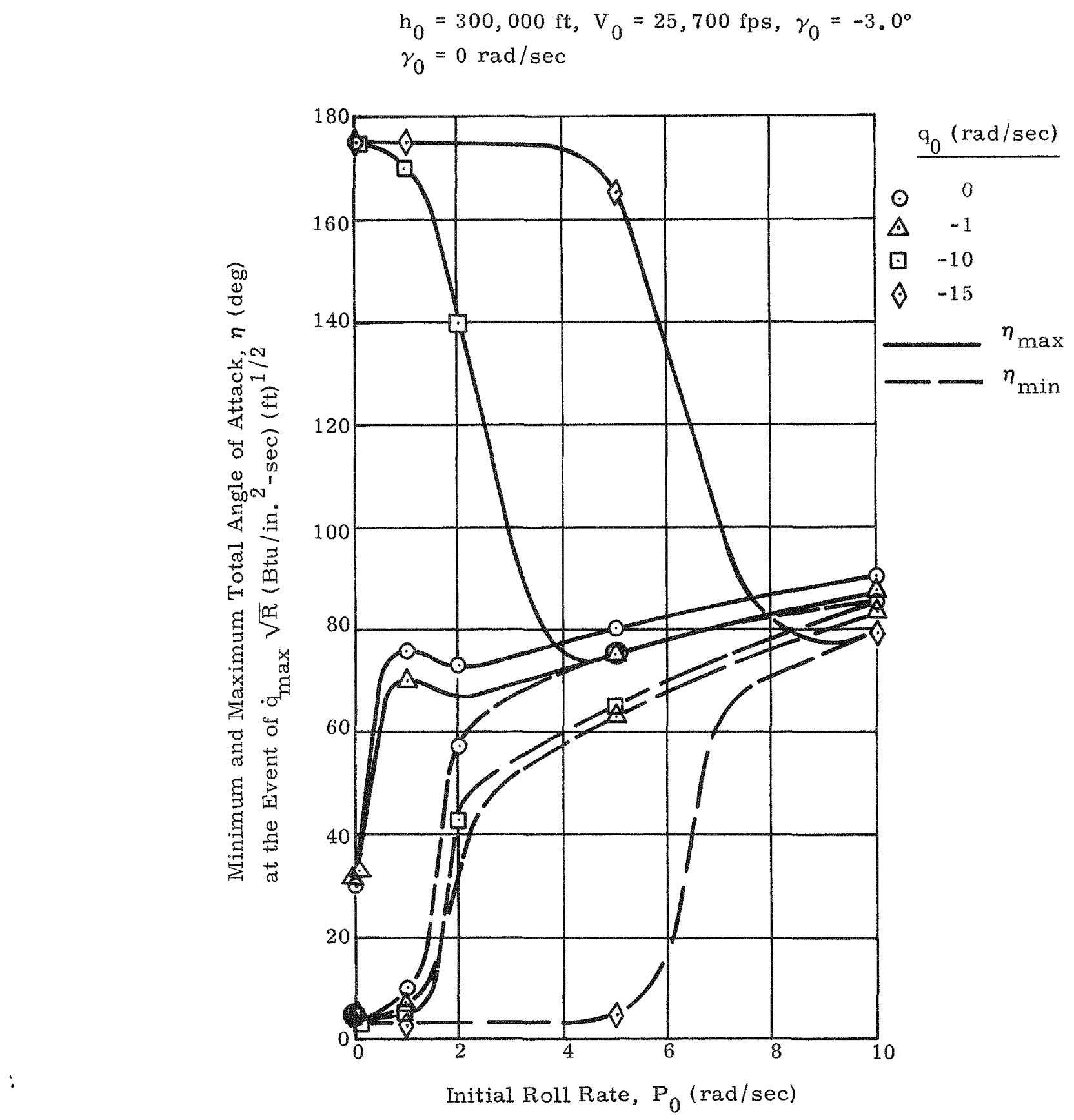

FIG. VI-5. SNAP 29 FUEL BLOCK (ASPECT RATIO $=1.095$ ) INITIAL ROLL RATE EFFECT $\left(\eta_{0}=89^{\circ}, \xi_{0}=0^{\circ}\right)$

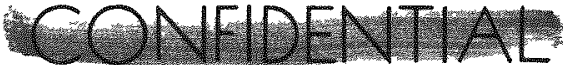

INND2062-12-7

VI-8 


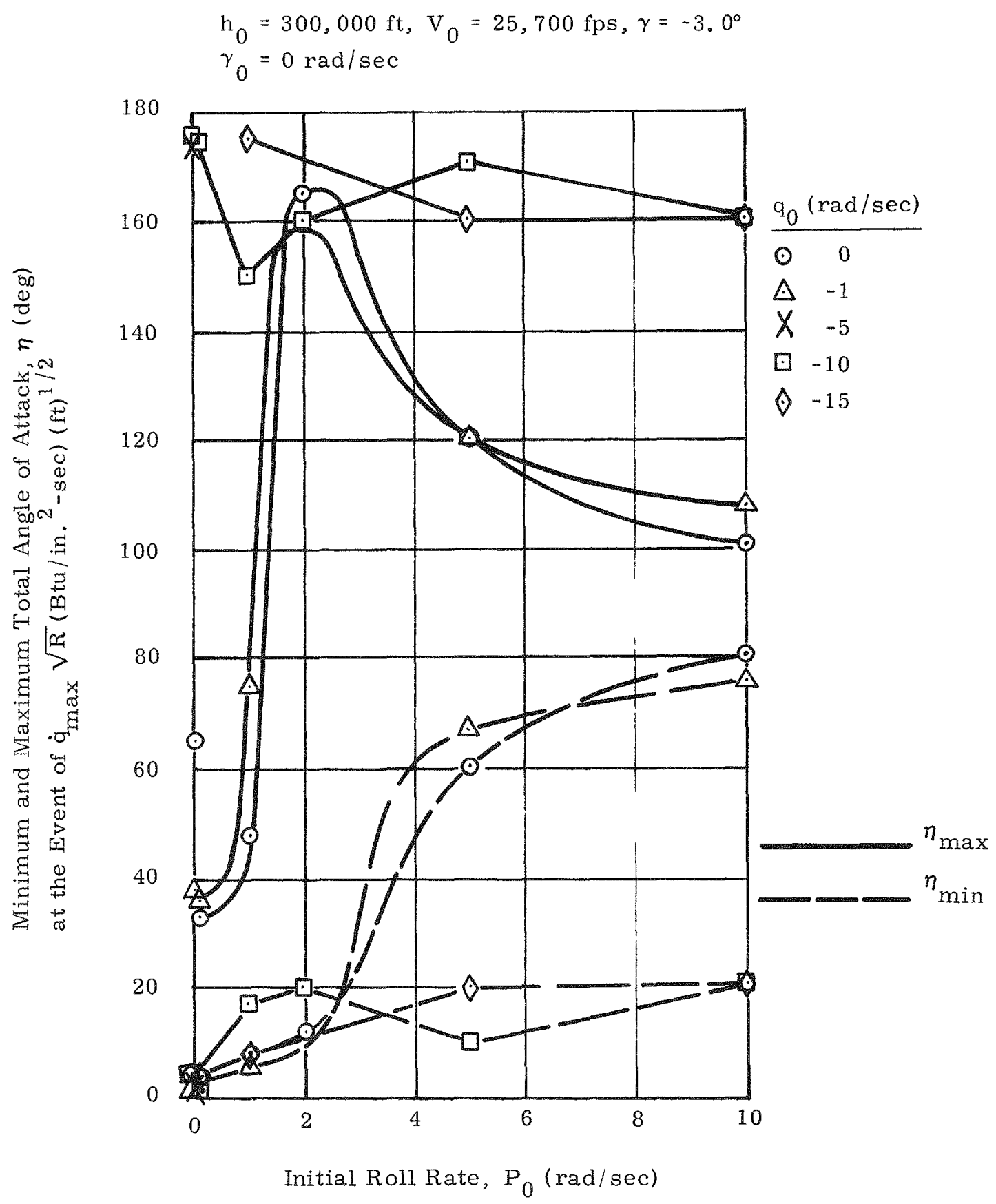

FIG. VI-6. SNAP 29 FUEL BLOCK (ASPECT RATIO $=3.16$ ) INITIAL ROLL RATE EFFECT $\left(\eta_{0}=89^{\circ}, \xi_{0}=0^{\circ}\right)$ 


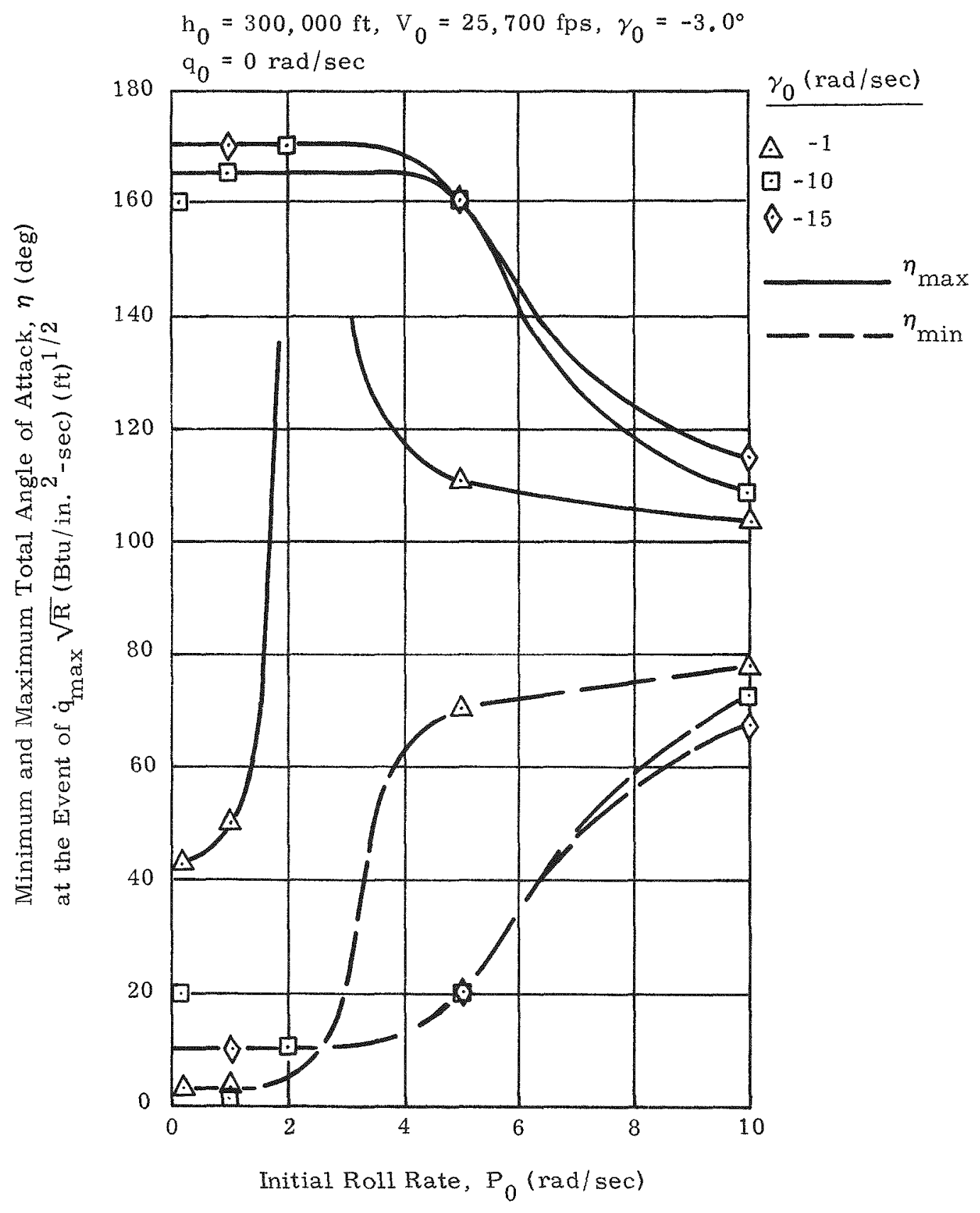

FIG. VI-7. SNAP 29 FUEL BLOCK (ASPECT RATIO $=3.16$ ) INITIAL ROLL RATE EFFECT $\left(\eta_{0}=89^{\circ}, \xi_{0}=90^{\circ}\right)$

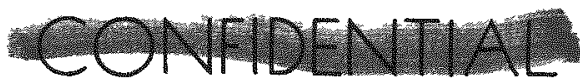

MND2062-12-7

VI-10 
The estimated inertial characteristics, static aerodynamic test data, and estimated aerodynamic damping coefficients were presented in the Fourth Quarterly Progress Report. The results of the motion study reported here were described in the November 1967 Monthly Progress Report. A summary of the motion categories follows:

(1) Fuel block assumes an attitude broadside to the oncoming airstream. Both oscillatory and coning motions of any degree can occur about this attitude.

(2) Fuel block tumbles relative to the oncoming airstream. The body axis about which it tumbles is a function of the direction in which the initial rates are imparted as well as the inertial and aerodynamic characteristics of the block.

(3) Fuel block assumes an attitude with its edge into the airstream. The block will normally be spinning and wobbling in this orientation. The degree of spin and wobble depends upon the magnitudes and directions of the initial rates and inertial characteristics. It appears possible that the block could assume a propeller motion with the same edge always facing the oncoming airstream. However, the duration of such a motion is considered to be small.

(4) Fuel block cones at orientations between those of broadside and edge-on as a function of initial orientation. The inertial characteristics of the block are predominant for sufficiently high rates of roll (spin).

Since the motion category where the edges of the fuel block are directed into the airstream appears to give high stagnation heat rates, the predominant factors influencing this motion were investigated. The aerodynamic moments are small for the edge-on re-entry mode. The following parameters appear to be of greatest significance:

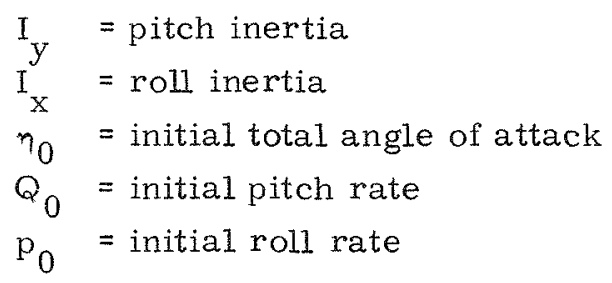

For an assumed initial total angle of attack, $\eta_{0}=90^{\circ}$ (edge-on), the important parameters are the ratios of pitch inertia to roll inertia, and pitch rate to roll rate. The effect of these ratios on the resulting minimum and maximum total angle of attack values (assuming zero aerodynamic moment and equal moment of inertia about the pitch and yaw axis symmetry in roll plane) is shown in Fig. VI-8. The degree of edge-on motion can be seen to become less severe as the inertia ratio and rate increase.

The eight-module fuel block configuration has an estimated ratio of pitch-to-roll inertia of 0.5. Figure VI-9 shows a comparison of the angle of attack envelopes for the analog results and values for computed pure gyroscopic motion for an initial altitude of 300,000 feet and edge-on orientation. The aerodynamic effects are seen to be insignificant at the lower ratios of pitch-to-roll rate. Figure VI-10 shows the effect of aspect ratio for the edge-on motion at an altitude of 300,000 feet. It can be seen that the high aspect ratio block (two-module) reduces the tendency for edge-on

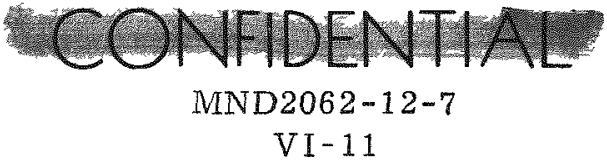




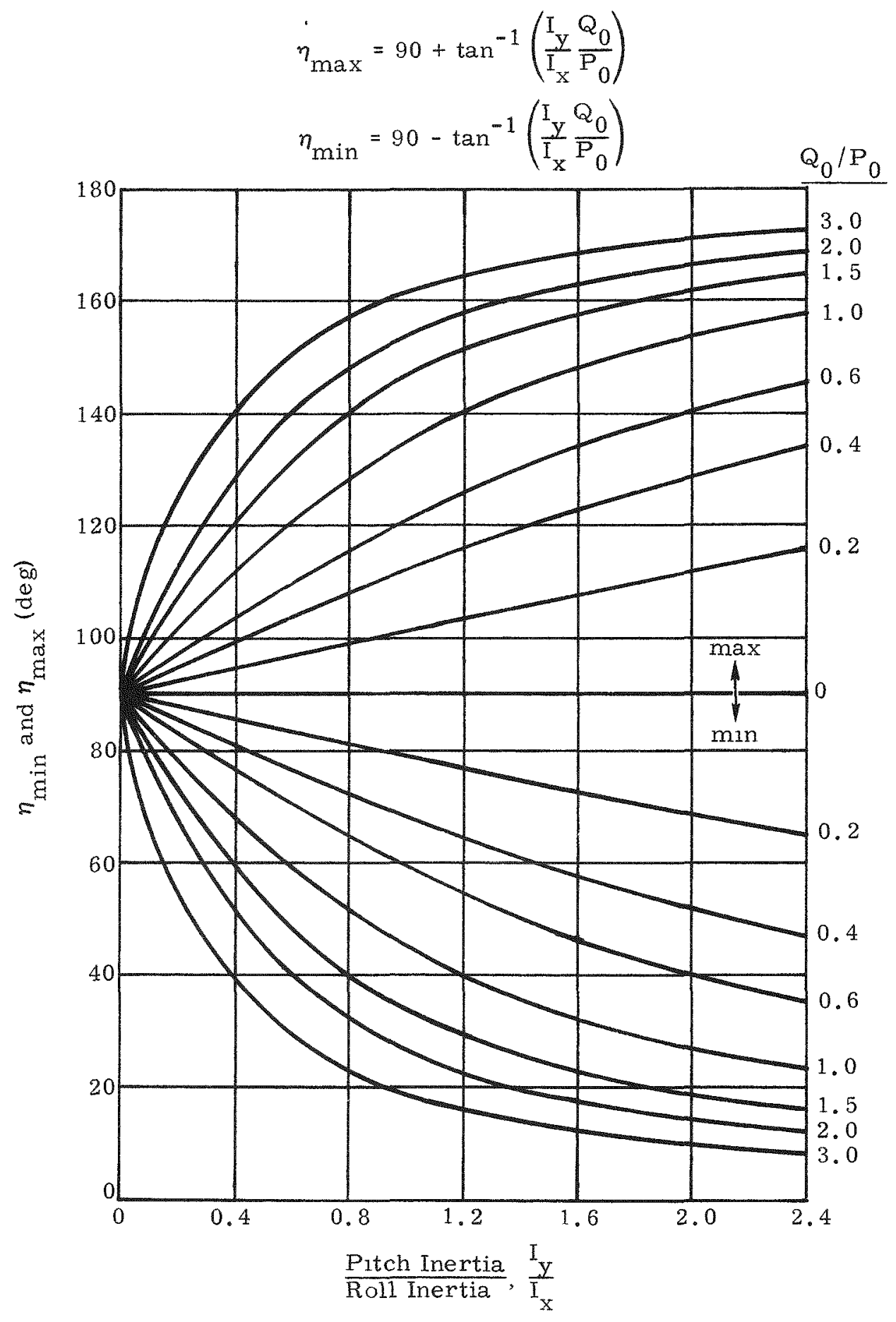

FIG. VI-8. GYROSCOPIC CONING MOTION $\left(I_{y}=I_{z}\right) \eta_{0}=90^{\circ}$ 


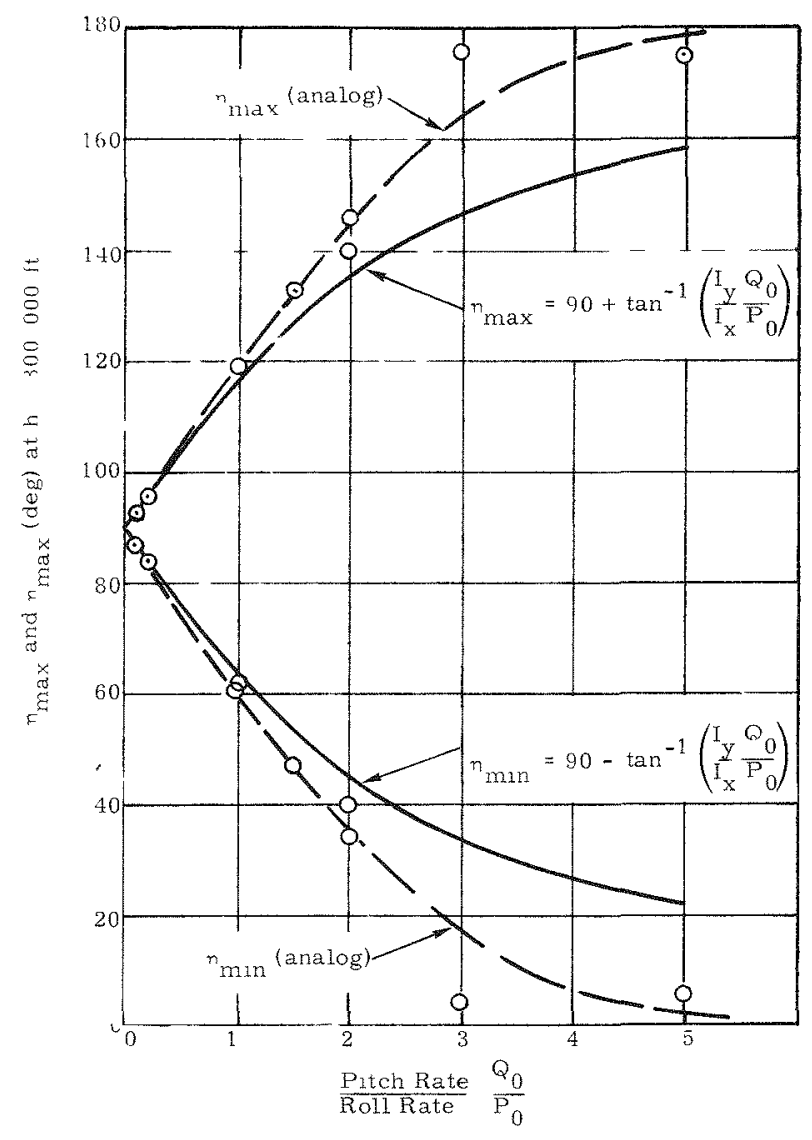

FIG. VI-9. SNAP 29 FUEL BLOCK (ASPECT R ATIO $=1.095) \eta_{0}$ $=90^{\circ} \quad I_{y}=I_{L} \quad I_{y} / I_{x}=0.5$

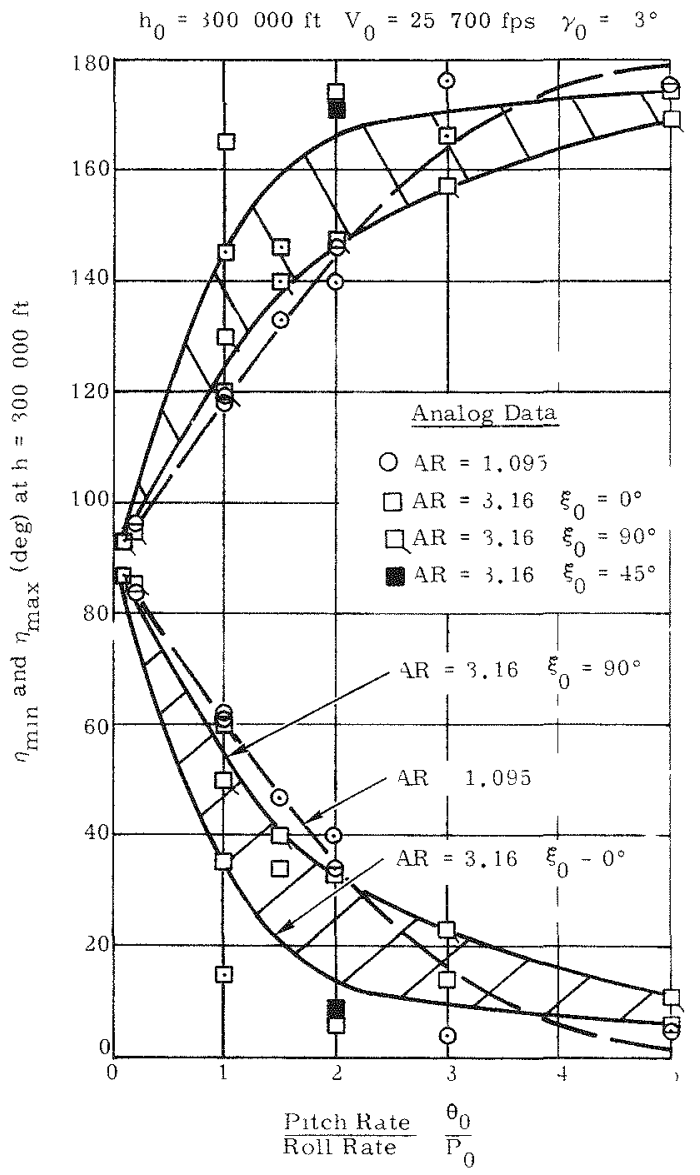

1 IG $V I-10 \quad$ SN $1 P^{\prime} 20+\mathrm{ULL}$ I3LOCh $10 \quad 90^{\circ}$ 
orientation, and is more dependent upon the direction in which the rotational rate is applied. The maximum total angle of attack envelopes for the two fuel blocks for cases of planar motion were determined as a function of altitude, $h$, initial orientation, $\eta_{0}$ and $\xi_{0}$, and initial rotation rate, $\dot{\theta}_{0}$. A typical plot at the event of $\dot{q}_{\max }{ }^{1 s}$ shown in Fig. VI-11.

\section{Impact Test Release Altitude Study}

A study was performed to determine the minimum release altitude to attain terminal velocity for the Phase I impact tests in November 1967 at the Tonopah Test Range. Results of drop tests performed in the summer of 1966 were analyzed to determine the average drag coefficient and the subsonic motions of the fuel block. In those tests, the eight-module fuel block went into a tumbling mode around a diagonal axis with a resulting $\overline{\mathrm{C}}_{\mathrm{D}}=1.3$. Although the blocks were dropped with varying initial conditions (broadside to wind, edge-on and imposed rotation) the tumbling mode always developed after some varying amount of time.

The variations in velocity with altitude for various assumed initial altitudes were determined for $\overline{\mathrm{C}}_{\mathrm{D}}=1.3$ and for $\overline{\mathrm{C}}_{\mathrm{D}}=0.9$, and are shown in Figs. VI-12 and VI-13. The $\overline{\mathrm{C}}_{\mathrm{D}}=0.9$ was assumed to simulate a drop in which tumbling did not develop immediately upon release. It was recommended that the Phase I fuel blocks be released at an altitude of 6500 feet ( 1250 feet above ground) with an imposed diagm onal rotation.

4. Trajectories and Heating for Modular Blocks During Spinning, Edge-On Re-entry

Recent six-degree-of-freedom analog motion studies have indicated a combination of initial conditions that would result in the SNAP 29 fuel blocks re-entering in an edge-on spinning mode. Also, aerodynamic force and moment data and aerodynamic heating distribution data were obtained on a four-module block and a two-module (high aspect ratio) block in AEDC Tunnel B during October and November 1967. Average drag coefficients for the spinning, edge-on re-entry mode were determined for the configurations tested and estimated for the other modular fuel blocks. Using current values of geometric dimensions and estimated weights, the characteristics of the modular blocks are:

\begin{tabular}{|c|c|c|c|c|c|c|c|}
\hline $\begin{array}{c}\text { Module } \\
\text { Configuration } \\
\text { No. of } \\
\text { Blocks } \\
\end{array}$ & $\begin{array}{l}\text { Length } \\
\text { (in.) }\end{array}$ & $\begin{array}{l}\text { Width } \\
\text { (in.) }\end{array}$ & $\begin{array}{c}\text { Reference } \\
\text { Area } \\
\left(\mathrm{ft}^{2}\right) \\
\end{array}$ & $\begin{array}{l}\text { Weight } \\
\text { (1b) }\end{array}$ & $\begin{array}{c}\text { Aspect } \\
\text { Ratio } \\
\end{array}$ & $\begin{array}{c}\text { Average } \\
\text { Drag } \\
\text { Coefficient } \\
\overline{\mathrm{C}}_{\mathrm{D}} \\
\end{array}$ & $\mathrm{W} / \overline{\mathrm{C}}_{\mathrm{D}^{\mathrm{A}}}$ \\
\hline 8 & 35.63 & 32.68 & 8.09 & 100.44 & 1.09 & 0.0401 & 309 \\
\hline 6 & 32.68 & 27.20 & 6.18 & 76.75 & 1.20 & 0.0459 & 271 \\
\hline 4 & 32.68 & 18.79 & 4.27 & 52.40 & 1.74 & 0.0586 & 209 \\
\hline 2 (1ow AR) & 18.79 & 17.39 & 2.27 & 28.05 & 1.08 & 0.0770 & 160 \\
\hline 2 (high AR) & 32.68 & 10.35 & 2.36 & 28.05 & 3.16 & 0.0893 & 133 \\
\hline
\end{tabular}

A11 blocks are 1 inch thick.

Based on the above data, re-entry trajectory and continuum stagnation point heating time histories were determined from the UB-088 digital trajectory program for the five modular fuel blocks spinning edge-on at an initial nominal design re-entry

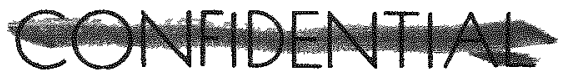

MND2062-12-7

VI -14 
$\mathrm{h}_{0}=300,000 \mathrm{ft}, \mathrm{V}_{0}=25,700 \mathrm{fps}, \gamma_{0}=-3^{\circ}$
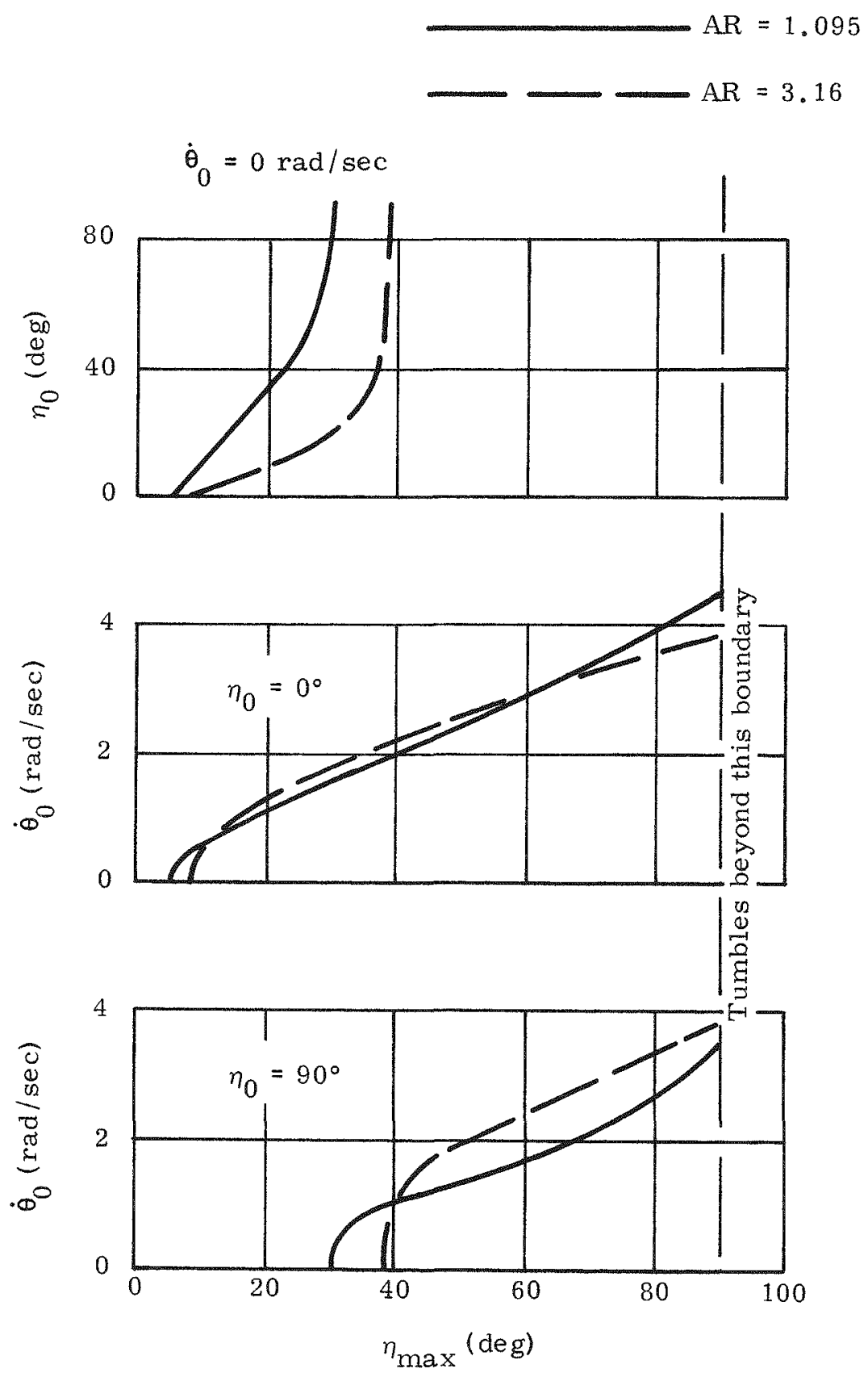

FIG. VI-11. SNAP 29 FUEL BLOCK, PLANAR MOTION VALUES FOR $\dot{\mathrm{q}}_{\text {max }}$ EVENT
$\left(\mathrm{h}=240,000\right.$ to $\left.220,000 \mathrm{ft}, \mathrm{P}_{0}=0 \mathrm{rad} / \mathrm{sec}\right)$

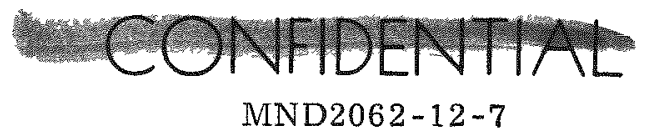

VI-15 


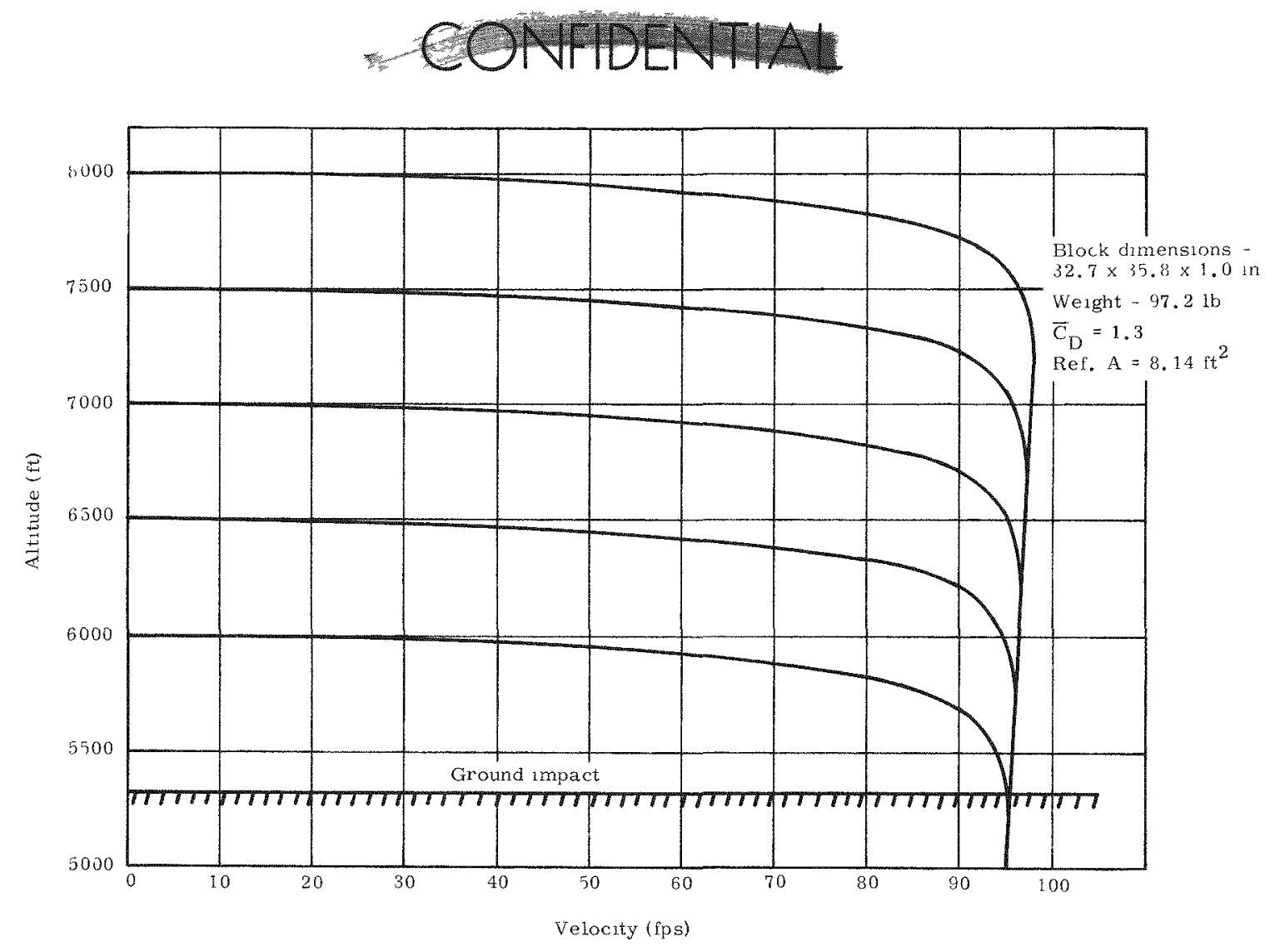

FIG. VI 12. SNAP 29 (EIGHT MODULE) FUEL BLOCK DESCENT AT TONOPAH TEST RANGE

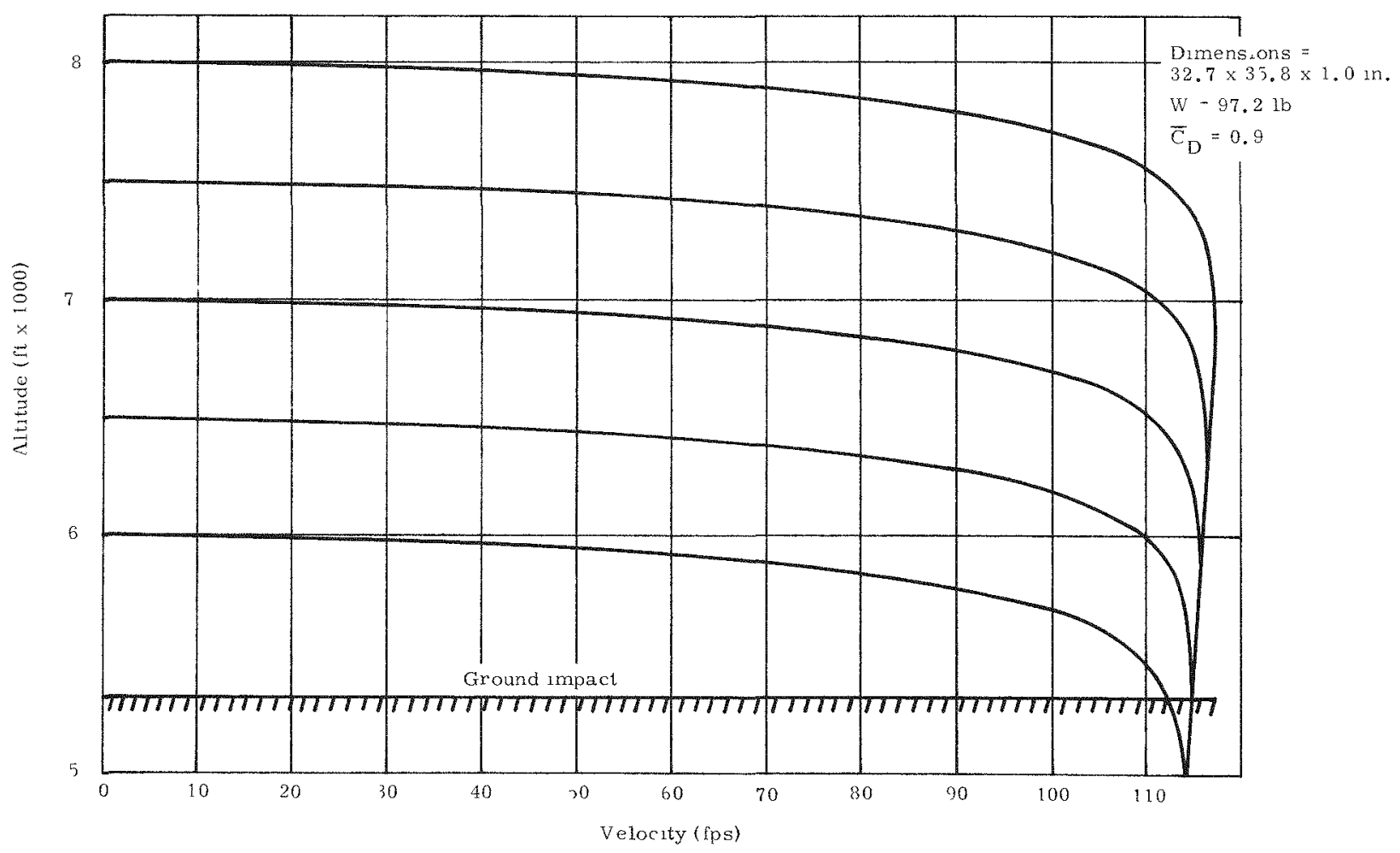

I IG. VI 13. SNAP 29 (EIGHT MODULE) FULL BLOCK DESCENT AT TONAPAH TEST R ANGE

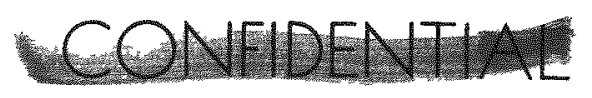

MND2062-12-6

VI-16 
angle, $\gamma$, of $-3.0^{\circ}$. Comparable data were obtained for the eight-module block spinning edge-on for an orbital decay re-entry angle of $-0.1^{\circ}$. Time histories of the continuum stagnation point heating rate and the integrated heating rate, or total heat, are shown in Figs. VI-14 and VI-15, respectively. Velocity and altitude as a function of time are shown in Figs. VI-16 and VI-17, respectively, for all modular blocks at a re-entry angle of $-3.0^{\circ}$. Comparable data for the eight-module block at a re-entry angle of $-0.1^{\circ}$ are shown in Figs. VI-18 (stagnation heating rate), VI-19 (total heat), and VI-20 (velocity and altitude).

The aerodynamic heating distribution, $\dot{q} / \dot{q}_{\text {stag }} \sqrt{R}$, has been determined using heat rate data obtained in AEDC Tunnel $B$ at Mach Number 8 and a Reynolds number of $0.64 \times 10^{6}$ per foot. Data at an angle of attack of $90^{\circ}$ and for various roll angles were plotted versus nondimensional block ordinates and faired. The distribution theory of Lees was used as a guide for fairing around the thin and sparsely instrumented model edge. An arithmetic averaging technique was used to determine the heating during the spinning, edge-on re-entry mode. No difference in heating was observed for the two aspect ratio blocks tested at an angle of attack of $90^{\circ}$, and this result was assumed to be valid for all the aspect ratio blocks. The heating distribution for all blocks containing a 0.5 -inch radius corner is presented in Table VI-1 as a function of distance in inches from the corner. An estimate is also given in Table VI-2 for blocks containing chamfered corners. This study is reported in detail in Report 3321-24.

\section{TABLE VI-1}

SNAP 29 Fuel Block (0.5-inch radius corners)

$\left(\dot{\mathrm{q}} / \dot{\mathrm{q}}_{\mathrm{S}} \sqrt{R}\right)_{\text {full scale }}$ all a spect ratios

$\eta=90^{\circ}$ (spinning, exactly edge-on)

$X=$ Distance (inches) measured from block edges

\begin{tabular}{l|c|c|c|c|c|c|c|c|c}
$\mathrm{X}$ & 0 & 0.3 & 0.75 & 1.25 & 1.75 & 2.5 & 3.5 & 4.5 & 5.5 \\
\hline \hline 0 & 1.370 & 1.320 & 1.225 & 1.195 & 1.178 & 1.163 & 1.151 & 1.145 & 1.140 \\
0.3 & 1.320 & 1.090 & 0.830 & 0.755 & 0.717 & 0.689 & 0.660 & 0.652 & 0.648 \\
0.75 & 1.225 & 0.830 & 0.275 & 0.210 & 0.190 & 0.170 & 0.162 & 0.155 & 0.150 \\
1.275 & 1.194 & 0.752 & 0.210 & 0.150 & 0.125 & 0.113 & 0.106 & 0.105 & 0.104 \\
1.825 & 1.175 & 0.714 & 0.180 & 0.126 & 0.107 & 0.092 & 0.085 & 0.082 & 0.079 \\
2.5 & 1.163 & 0.689 & 0.166 & 0.111 & 0.096 & 0.085 & 0.078 & 0.075 & 0.072 \\
3.225 & 1.154 & 0.671 & 0.160 & 0.109 & 0.091 & 0.080 & 0.074 & 0.070 & 0.067 \\
3.875 & 1.149 & 0.660 & 0.157 & 0.107 & 0.089 & 0.076 & 0.071 & 0.066 & 0.063 \\
4.6 & 1.144 & 0.652 & 0.155 & 0.105 & 0.087 & 0.074 & 0.068 & 0.063 & 0.060 \\
5.325 & 1.140 & 0.649 & 0.154 & 0.104 & 0.085 & 0.072 & 0.065 & 0.060 & 0.059
\end{tabular}




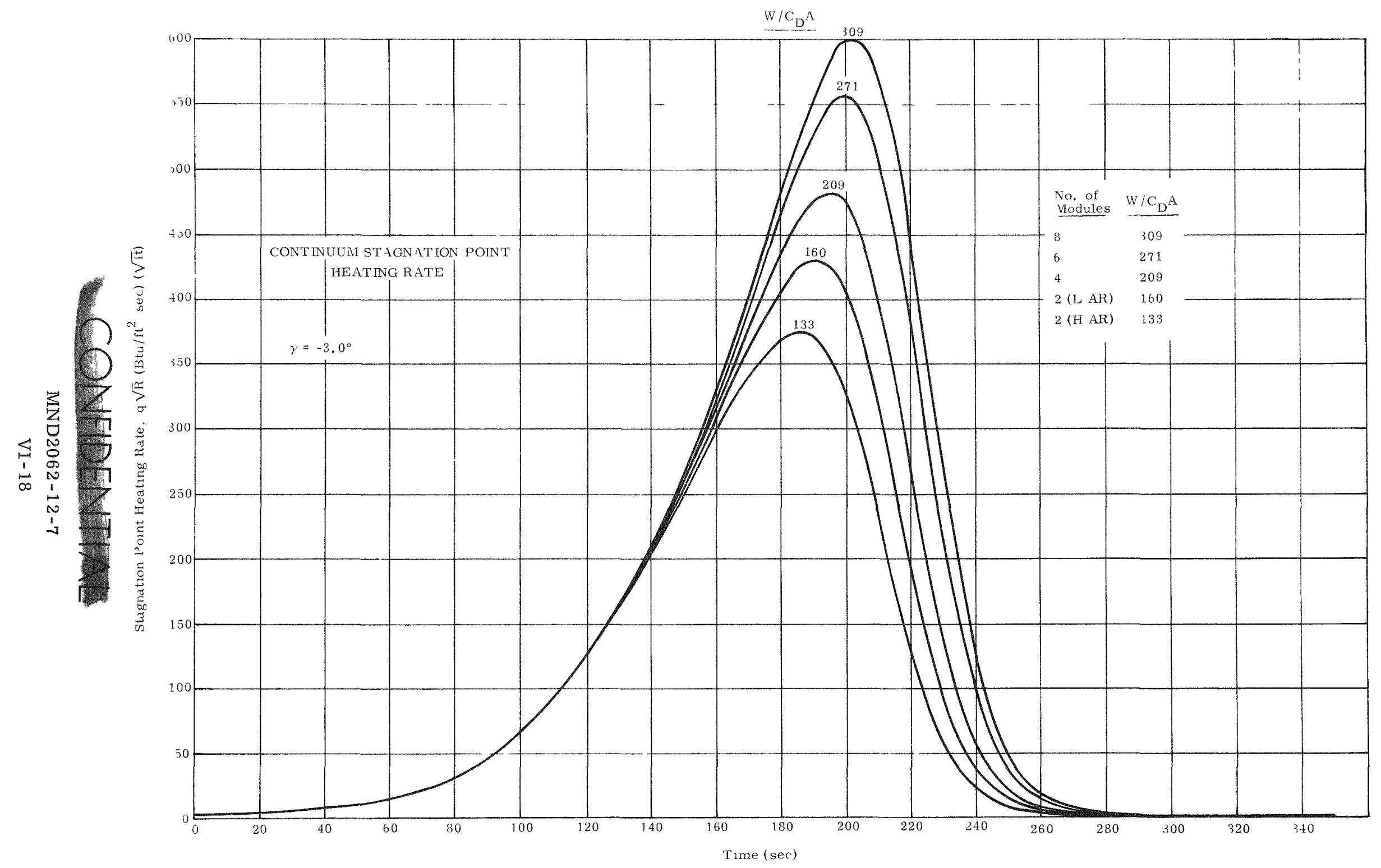

FIG. VI 14. SNAI 29 MODULAR FUEL BLOCKS EDGE ON SPINNING RE ENTRY 

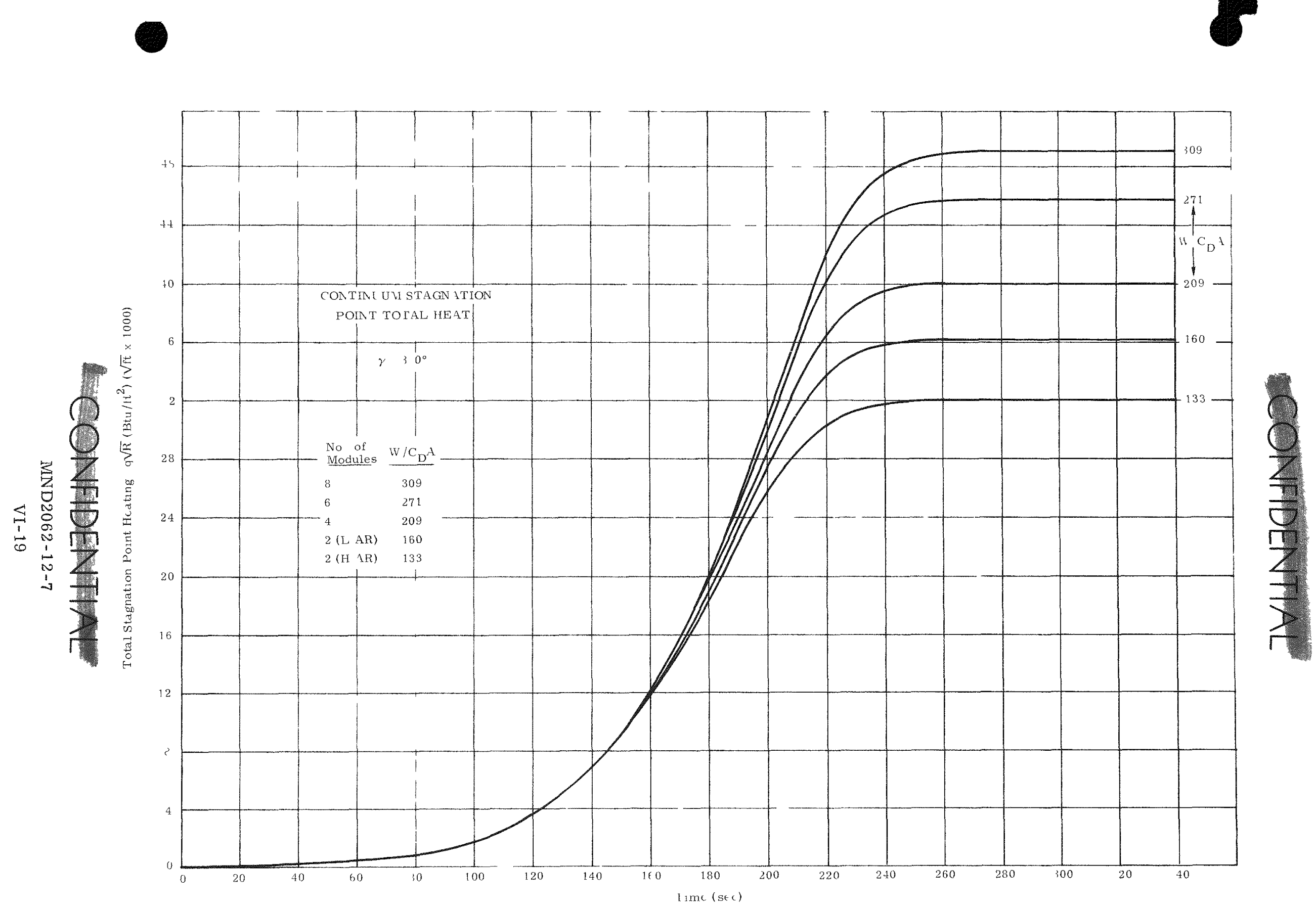

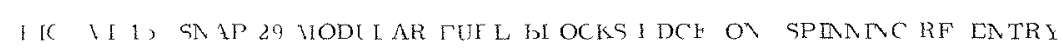




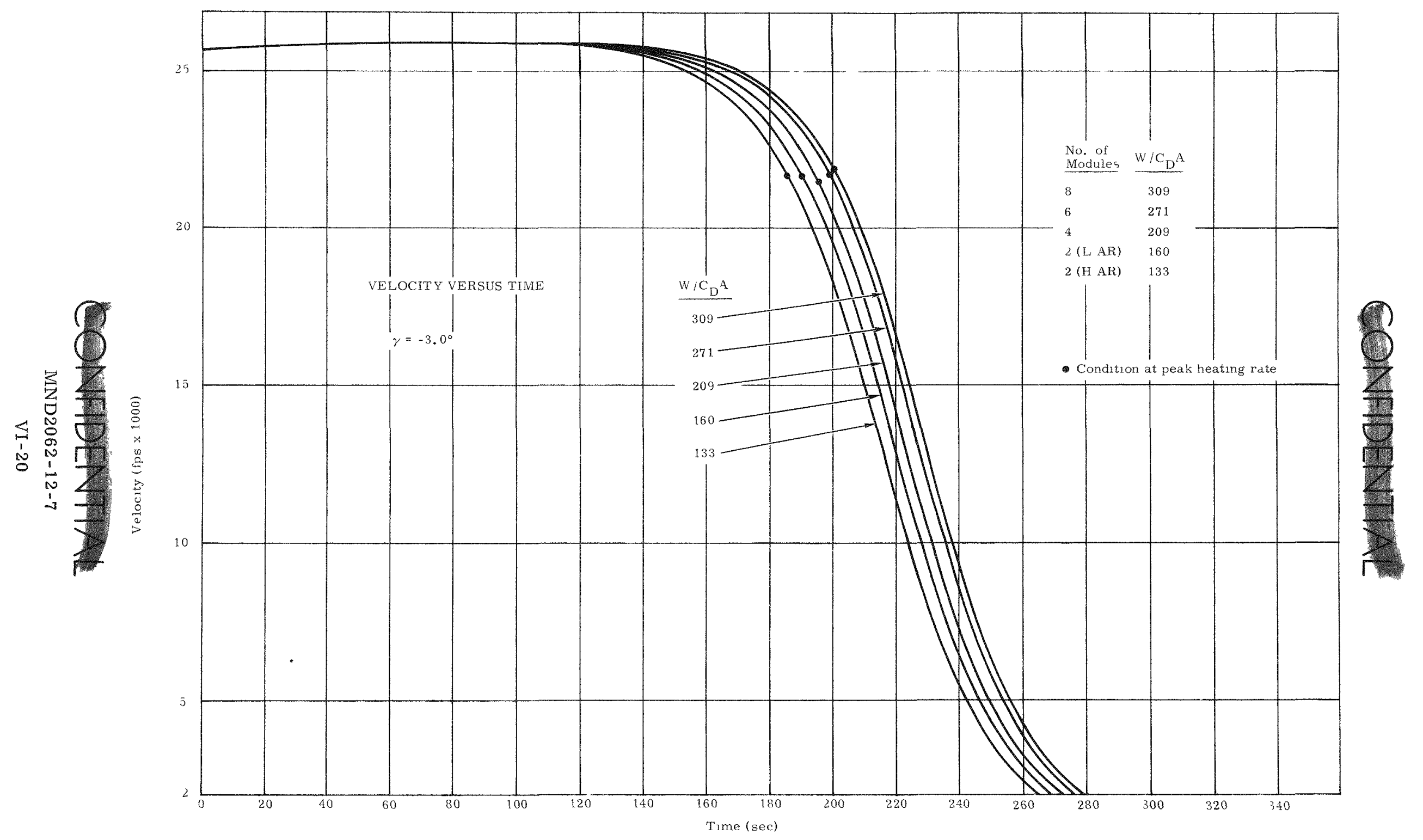

HIG. VI-16. SNAP 29 WIODULAR EUEL BLOCKS EDGE-ON, SPINNING RE ENTRY 


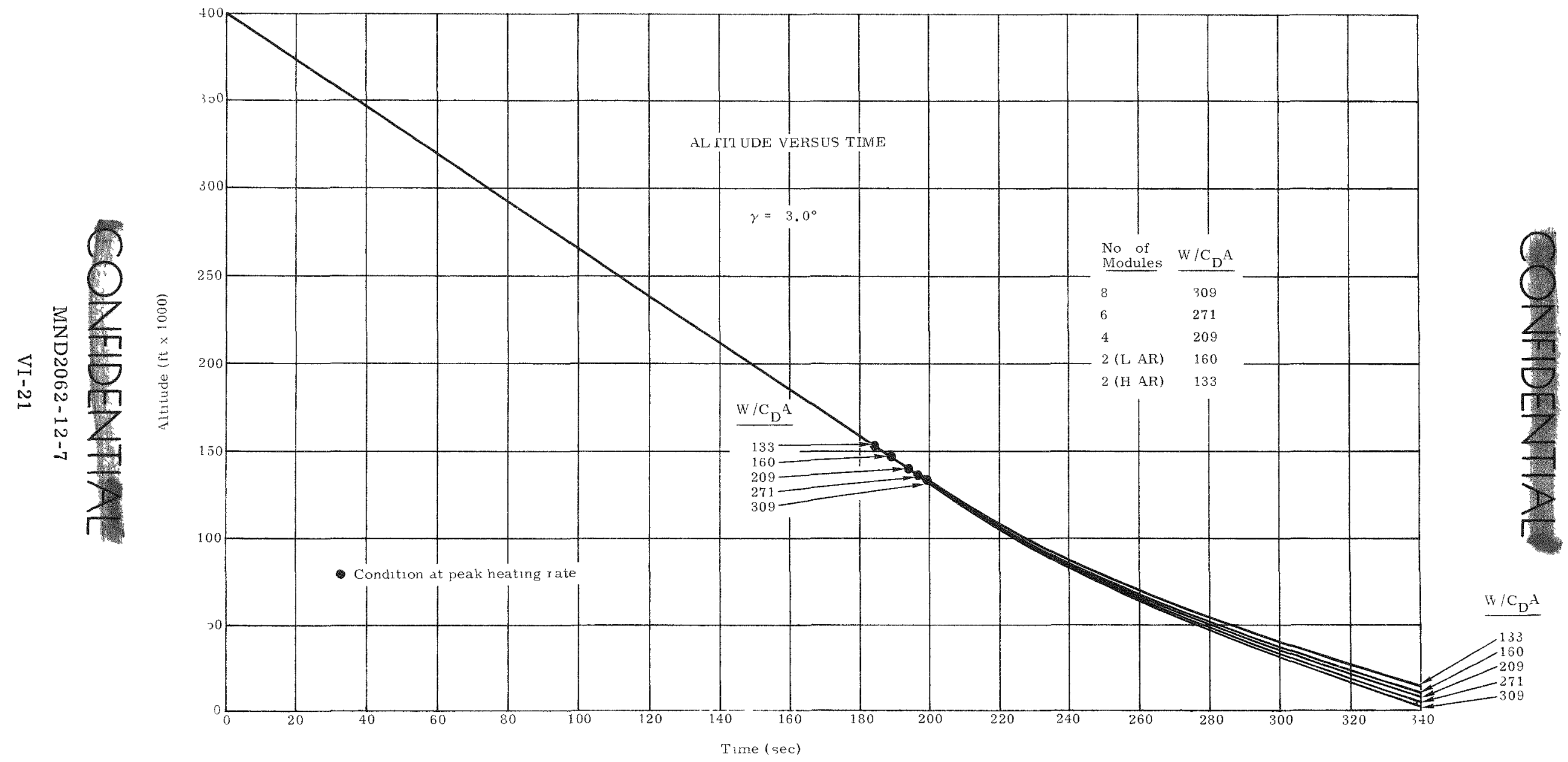

I IG. VI 17. SNAP 29 MODULAR I UEL BLOCKS LDGE ON SPINNING RE ENTRY 


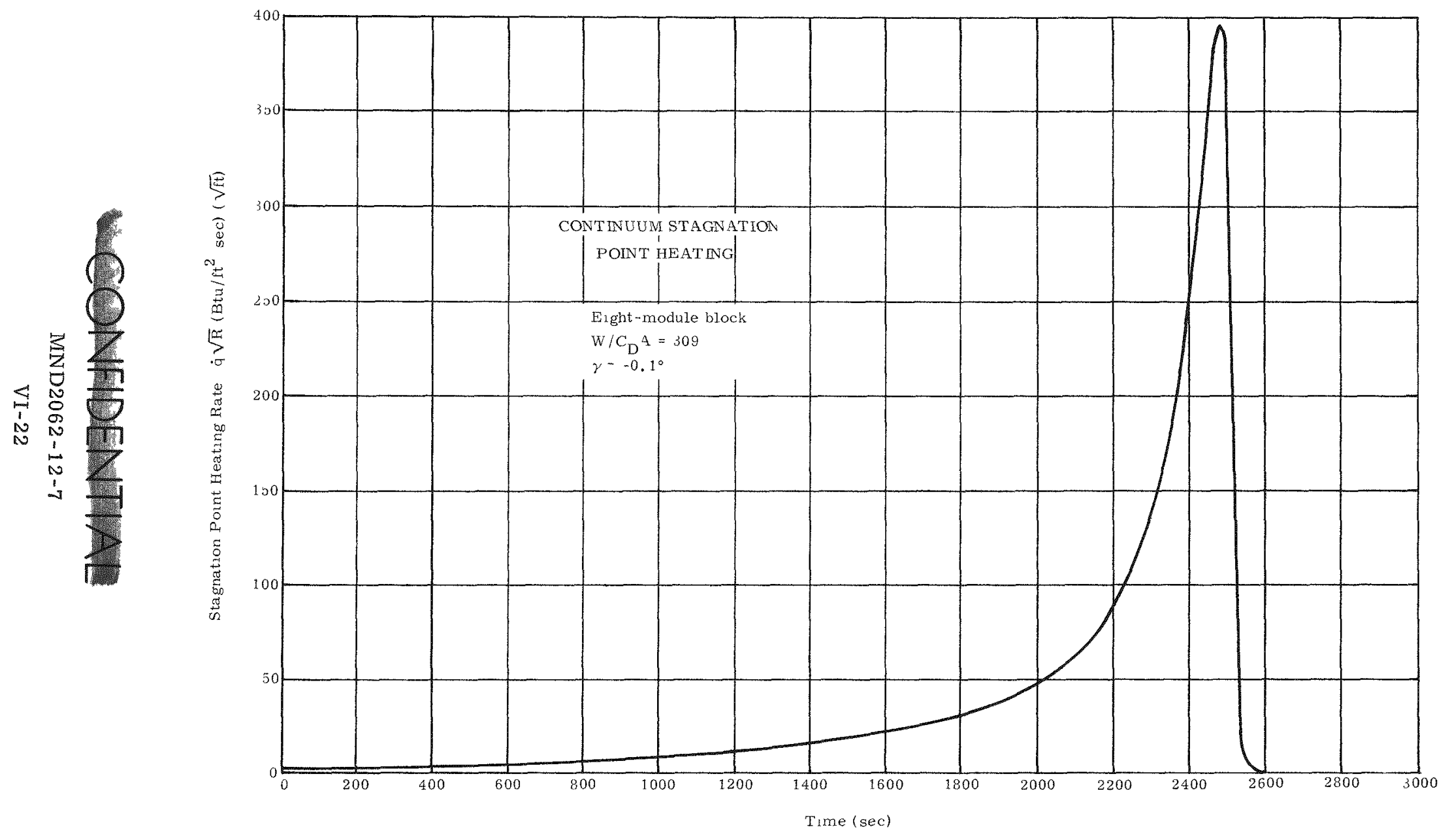

FIG VI-18. SNAY 29 MODULAR TUEL BLOCKS EDGE ON SPINNING RE ENTRY 



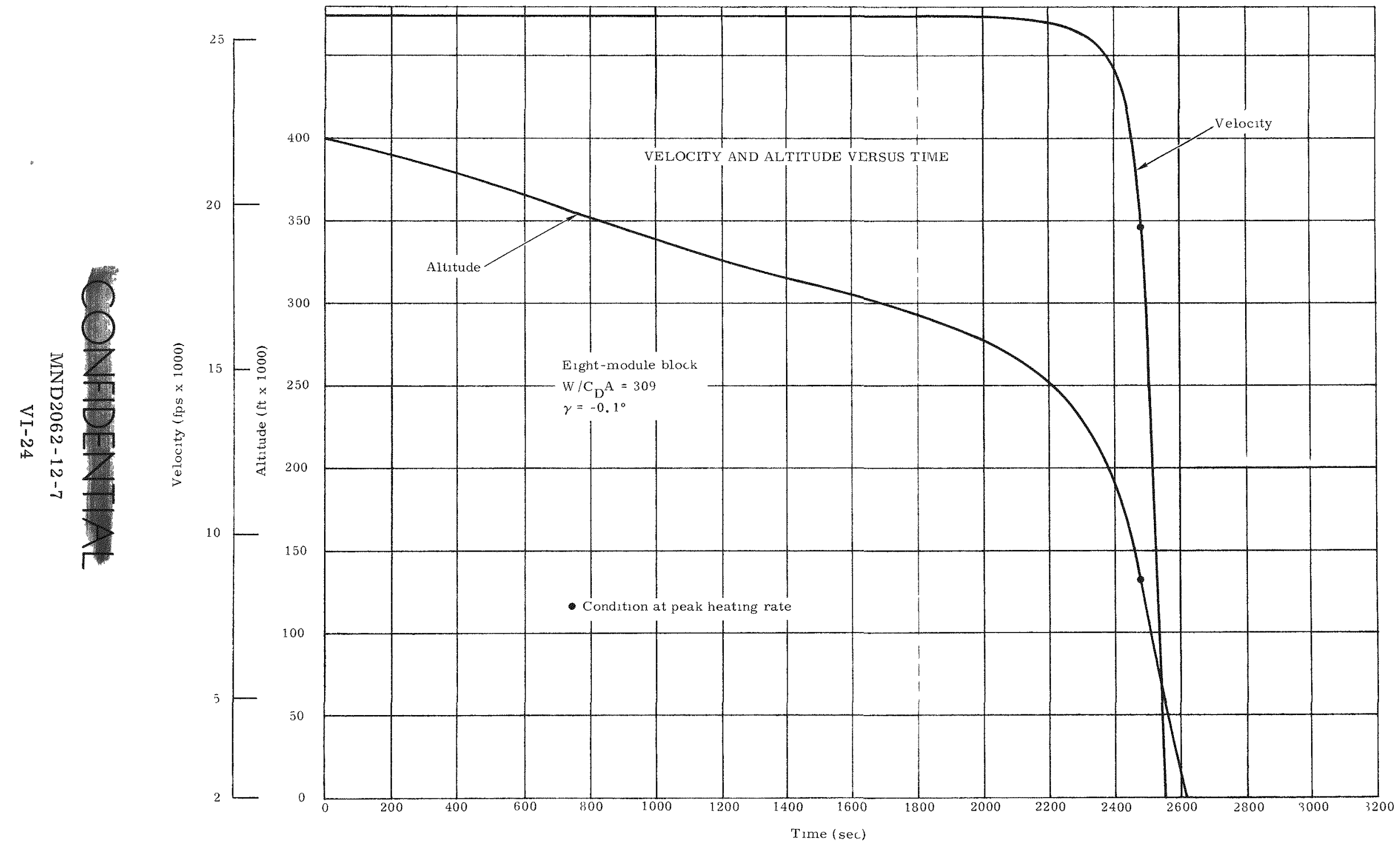

1 1G. VI 20. SNAP 20 MODULAR FUEL BLOCKS EDGE-ON, SPINNING RE-ENTRY 


\section{TABLE VI-2}

SNAP 29 Fuel Block (chamfered corners)

$\left(\dot{\mathrm{q}} / \dot{\mathrm{q}}_{\mathrm{S}} \sqrt{\mathrm{R}}\right)_{\text {full scale }} \sim$ all aspect ratios

$\eta=90^{\circ}$ (spinning, exactly edge-on)

$\mathrm{X}=$ Distance (inches) measured from block edges

\begin{tabular}{l|c|c|c|c|c|c|c|c|c}
$\mathrm{X}$ & 0 & 0.3 & 0.75 & 1.25 & 1.75 & 2.5 & 3.5 & 4.5 & 5.5 \\
\hline 0 & & & & & & 1.270 & 1.187 & 1.165 & 1.152 \\
0.3 & & & & & 1.287 & 0.820 & 0.715 & 0.680 & 0.660 \\
0.75 & & & & 1.201 & 0.580 & 0.210 & 0.170 & 0.160 & 0.155 \\
1.275 & & & 1.206 & 0.500 & 0.170 & 0.125 & 0.110 & 0.105 & 0.104 \\
1.825 & 1.370 & 1.260 & 0.315 & 0.170 & 0.115 & 0.092 & 0.085 & 0.082 & 0.079 \\
2.5 & 1.235 & 0.790 & 0.210 & 0.130 & 0.100 & 0.085 & 0.078 & 0.075 & 0.072 \\
3.225 & 1.190 & 0.723 & 0.175 & 0.115 & 0.095 & 0.080 & 0.074 & 0.070 & 0.067 \\
3.875 & 1.171 & 0.694 & 0.165 & 0.110 & 0.090 & 0.076 & 0.071 & 0.066 & 0.063 \\
4.6 & 1.160 & 0.675 & 0.160 & 0.106 & 0.087 & 0.074 & 0.068 & 0.063 & 0.060 \\
5.325 & 1.152 & 0.661 & 0.156 & 0.105 & 0.085 & 0.072 & 0.065 & 0.060 & 0.059
\end{tabular}

5. Trajectories and Heating for Modular Fuel Blocks During Re-entry Modes Other Than Spinning Edge-on

Comparable data to those described in Para 4 are being generated for modular blocks re-entering in the following modes:

(1) Broadside

(2) Oscillating

(3) Tumbling

\section{Wind Tunnel Force and Moment Tests}

The hypersonic force and moment test of the two-module and four-module configurations was conducted in the AEDC Tunnel B during October and November 1967. Tunnel time amounted to 20.7 hours. The models shown in Figs. VI-21, VI-22 and VI-23 were tested at a Mach number of 8.0 and a Reynolds number from 400,000 to 800,000 per foot. Six-component aerodynamic coefficients were obtained for angles of attack from $0^{\circ}$ to $90^{\circ}$ at seven angles of roll. Summary plots showing the variation of force and moment coefficients with angle of attack for the seven roll angles tested are presented as Figs. VI-24 and VI-25 for the configurations tested. Similar data for the eight-module configuration obtained in a previous test are included in Fig. VI-26 for comparison. Figure VI-27 shows the axes and nomenclature used for the forces and moments presented. "Comparison of the curves indicates that changing the aspect ratio of the fuel block has minor effect on the moment coefficients but significant effect on the axial force.

\section{Wind Tunnel Aeroheating Tests}

The hypersonic aeroheating test of two modular fuel block configurations was conducted in the AEDC Tunnel B (Mach Number 8) on November 10, 1967 using

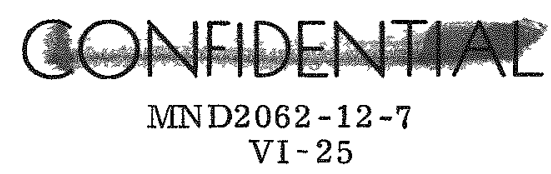



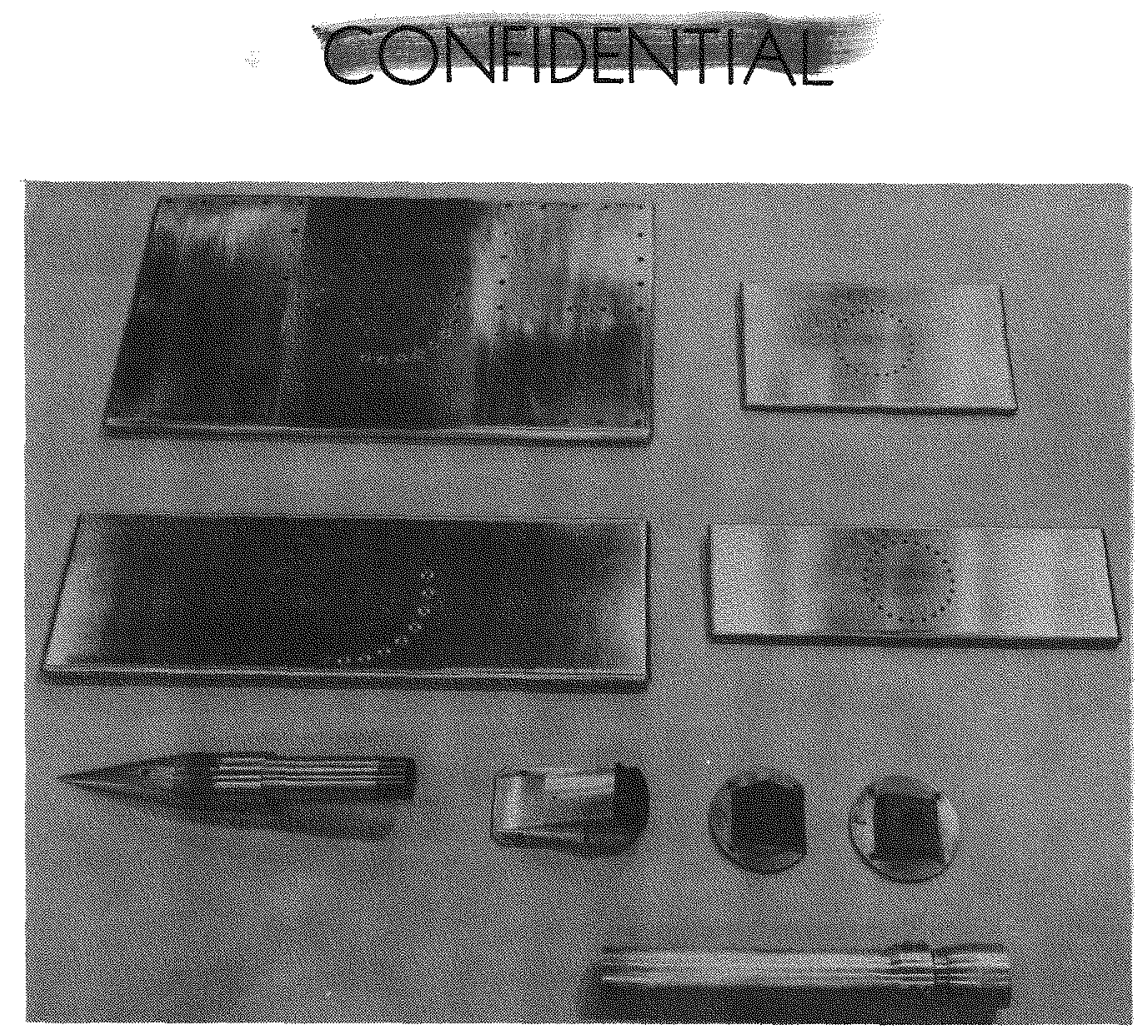

FIG. VI-21. WIND TUNNEL MODELS OF TWO-MODULE AND FOUR-MODULE FUEL BLOCK CONFIGURATTONS WITH STING ADAPTERS USED IN HYPERSONIC FORCE AND
MOMENT TEST

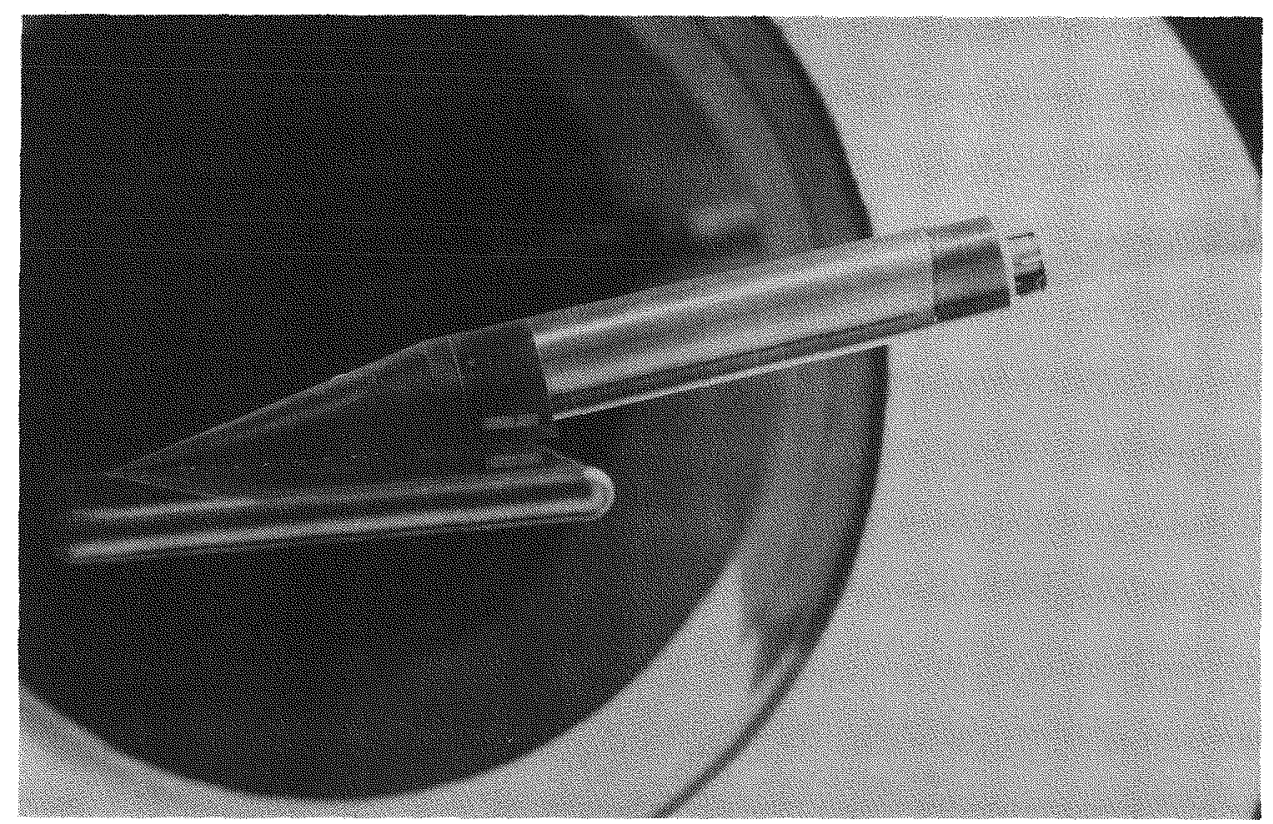

FIG. VI-22. SEVENTY -FOUR PERCENT SCALE MODEL OF TWO-MODULE FUEL BLOCK CONEIGURATION BNSTALLED IN AEDC TUNNEI B

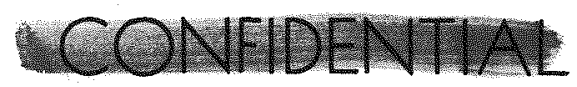

MND2062-12-7 


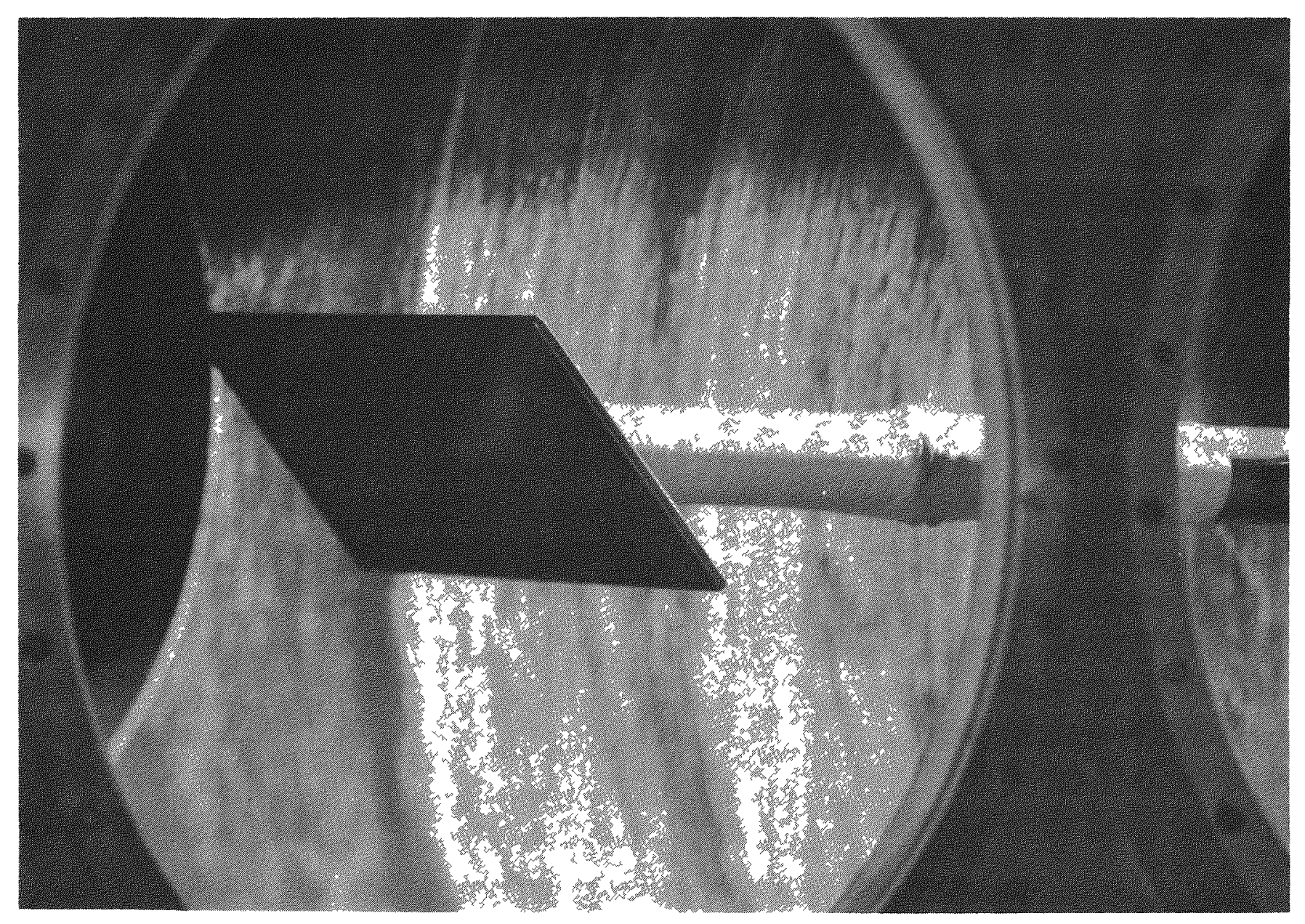

FIG. VI-23. THIRTY-SEVEN PERCENT SCALE MODEL OF FOUR-MODULE FUEL BLOCK CONFIGURATION INSTALLED IN AEDC TUNNEL B 

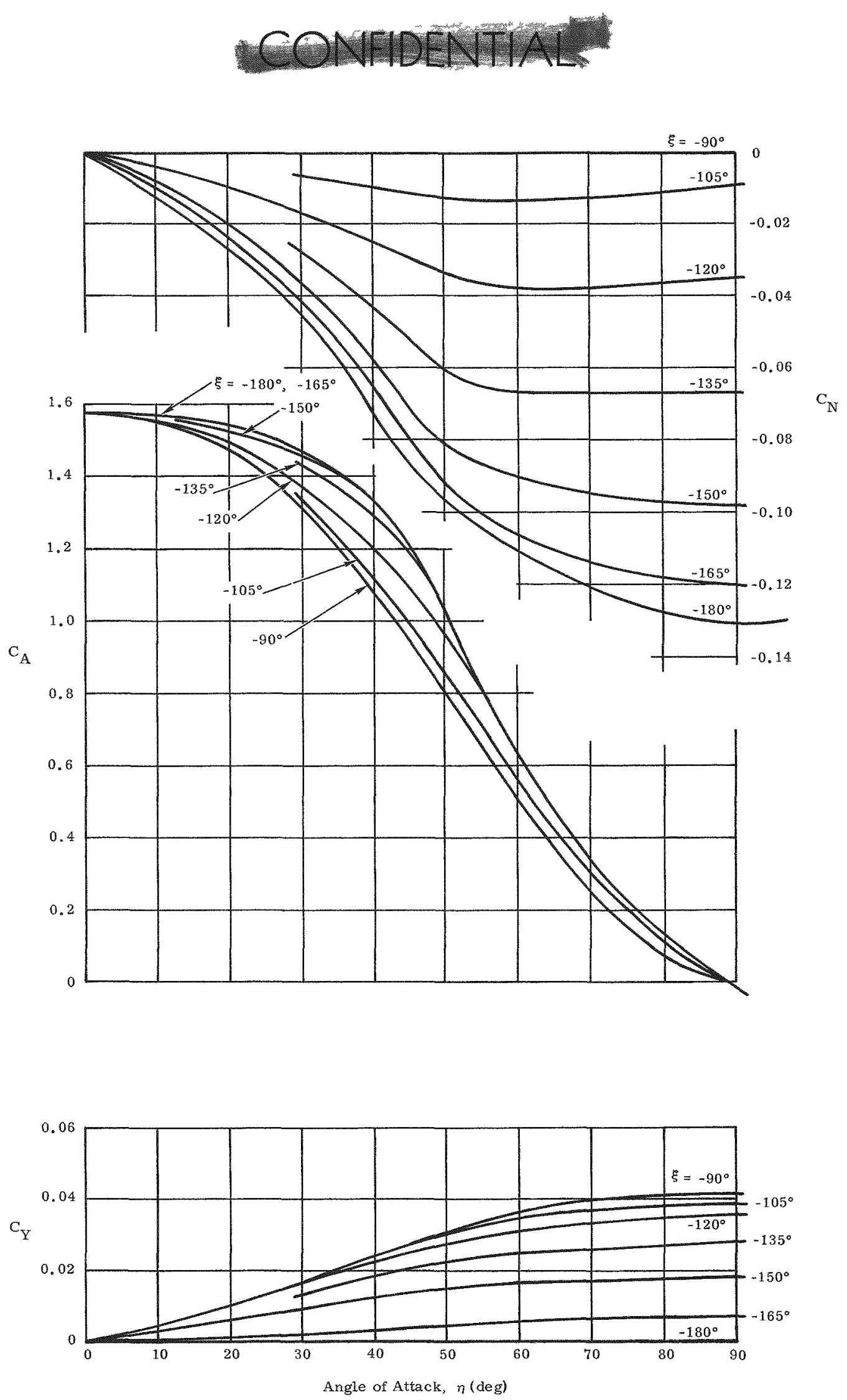

FIG. VI-24. SUMMARY OF AERODYNAMIC COEFFICIENTS FOR TWO-MODULE (ASPECT RATIO $=3.2$ ) FUEL BLOCK CONFIGURATION--CONFIGURATION $M^{2}$

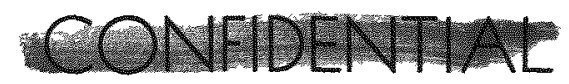

MND2062-12-7 

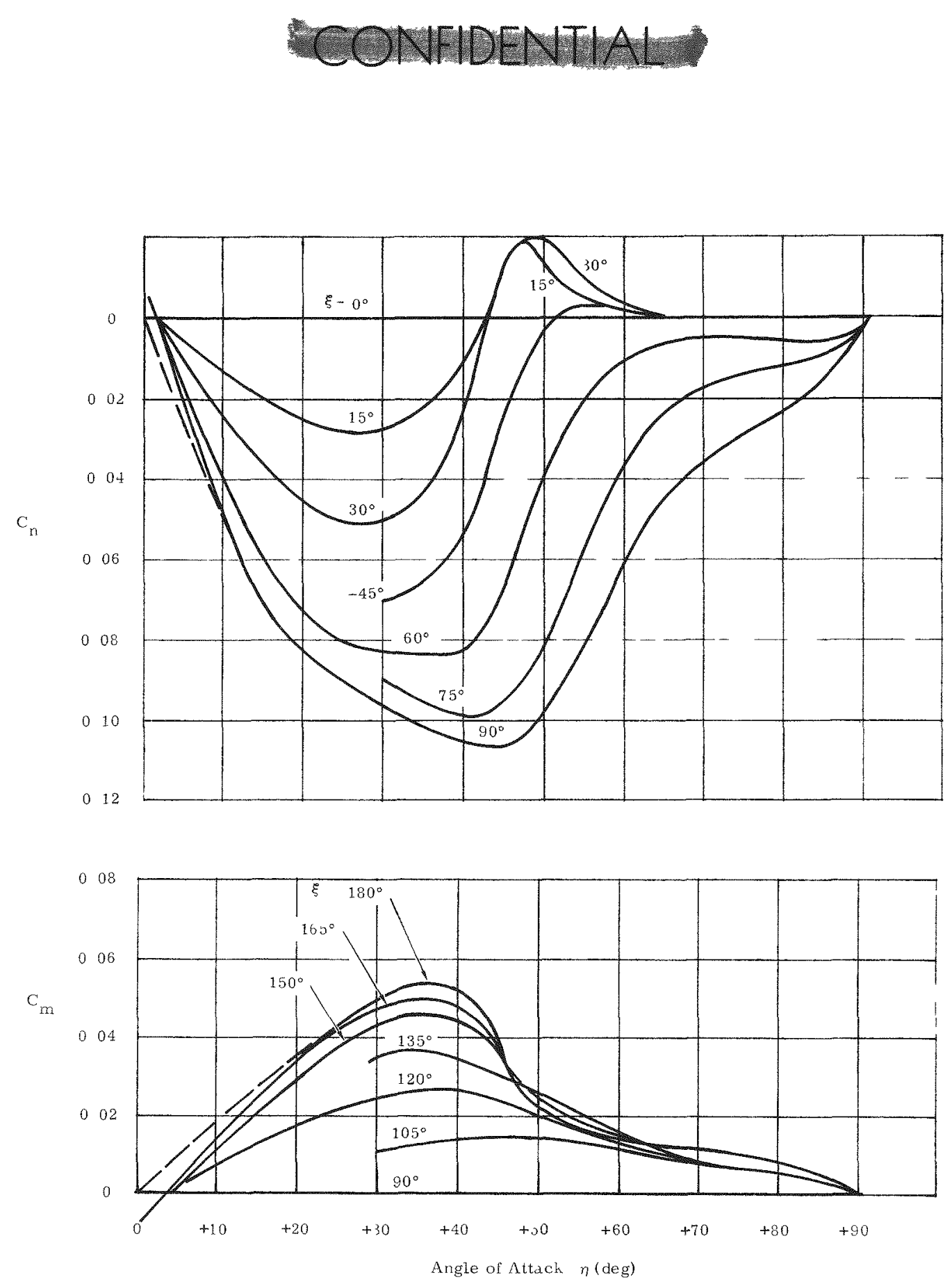

HIG. VI 24. (continued) 


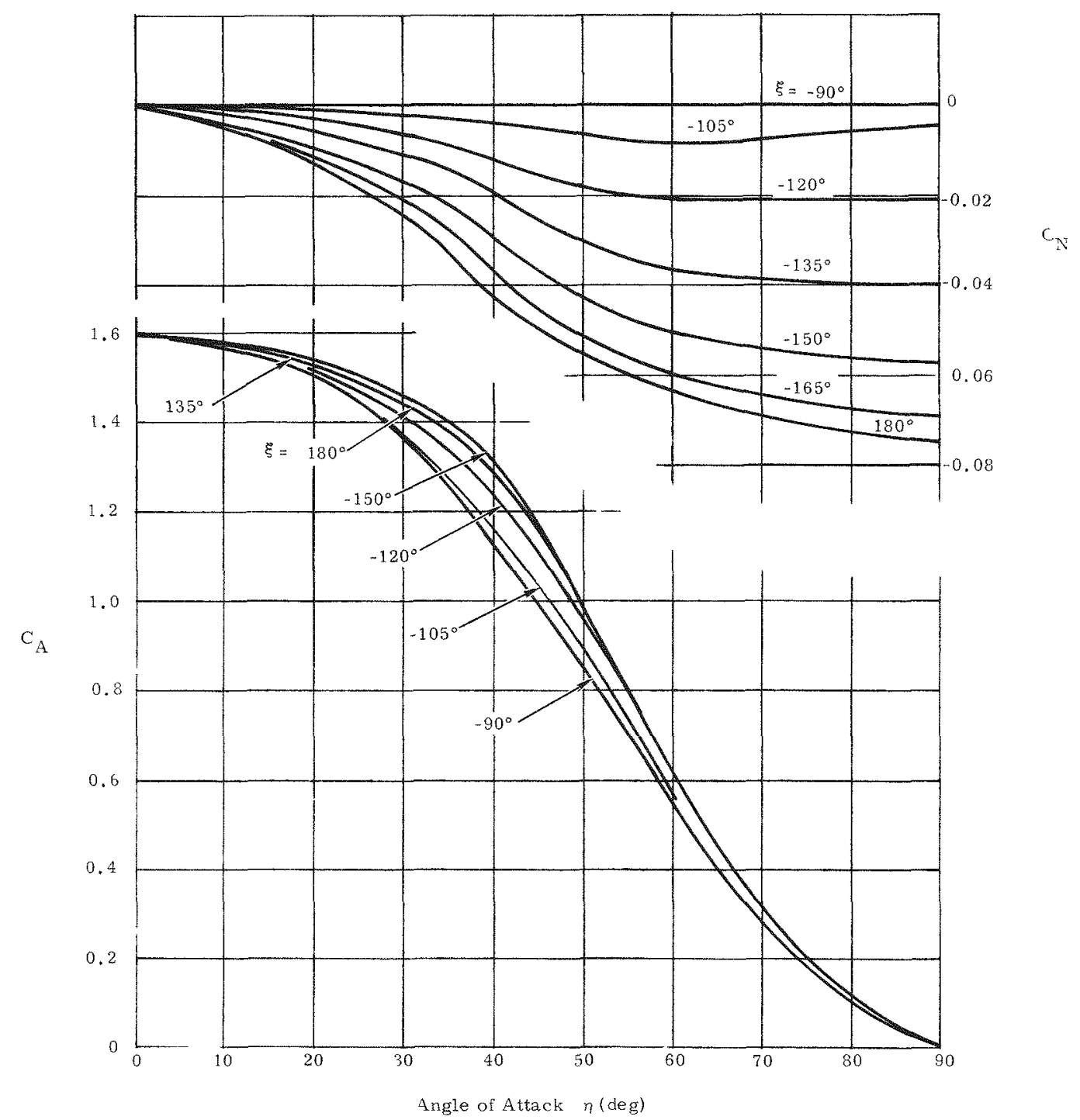

1 IG. VI 25. SUMMARY OF AERODYNAMIC COEFIICIENTS FOR FOUR-NODULE ( ISPECT RATIO $=1$.74) FUEL BLOCK CONI IGURATION - CONFIGURATION $M^{3}$ 

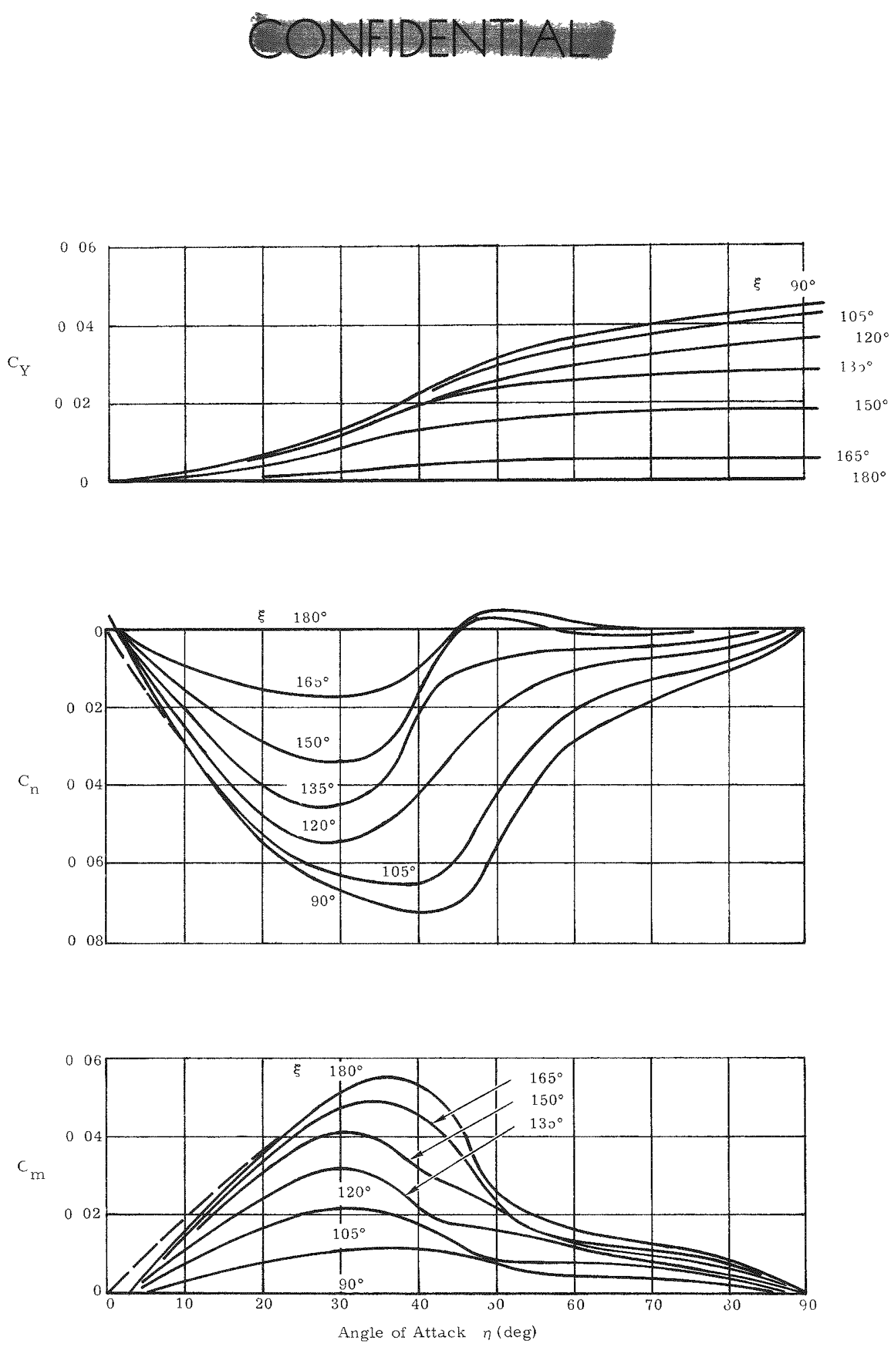

l IG VI 25. (continued)

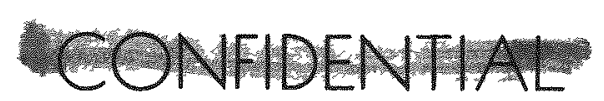

MND2062-12-7

VI-3 1 

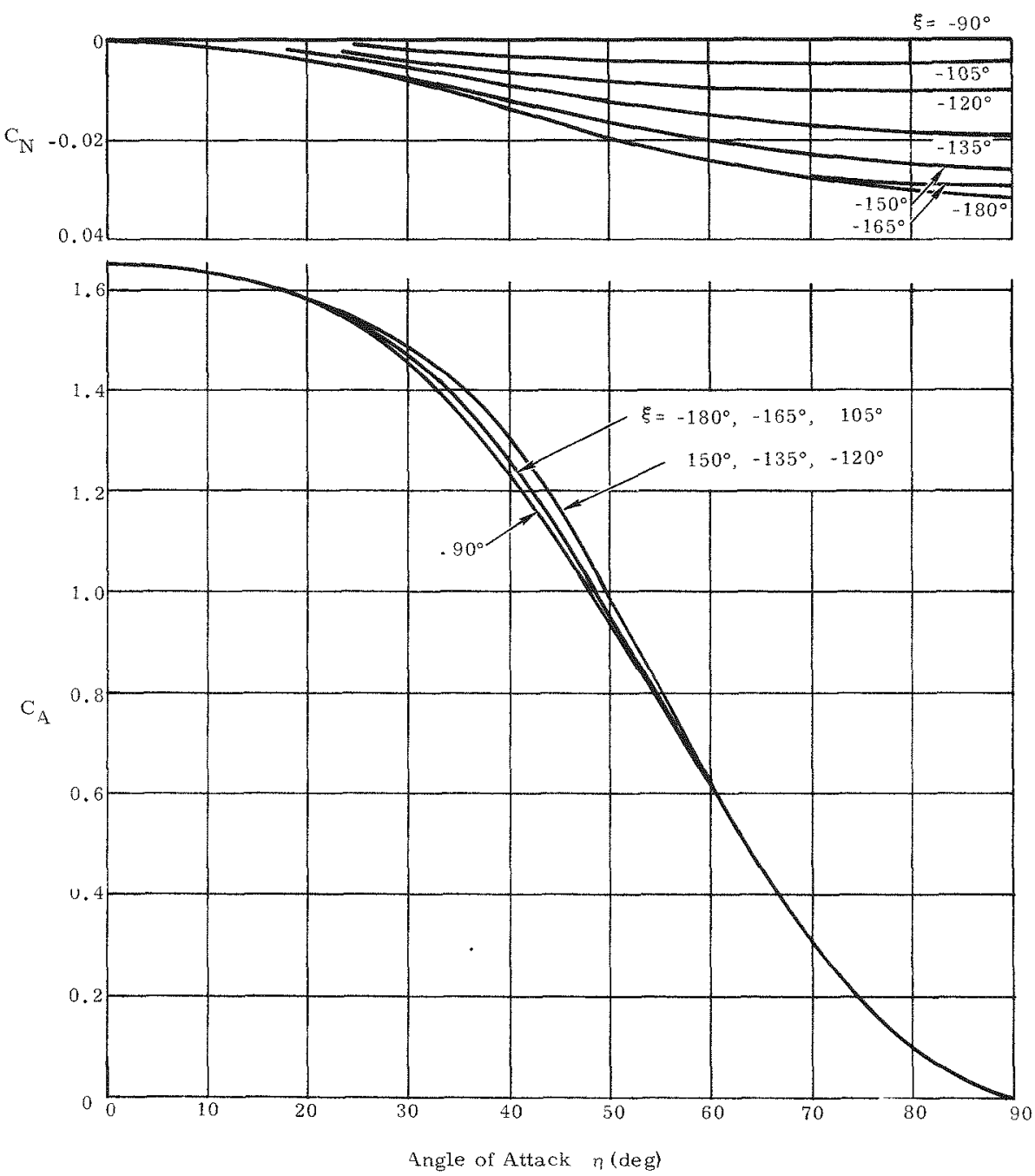

PIG. VI 26. SUMMARY OF AERODYNAMIC COEFFICIENTS FOR EIGHT -IVIODULE ( ISPECT RATIO $=1.094)$ FUEL BLOCK CONFIGUR ATION--CONFIGUR ITION E ${ }^{1}$

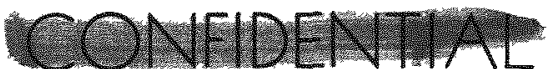

MND2062-12-7

$\mathrm{VI}-32$ 

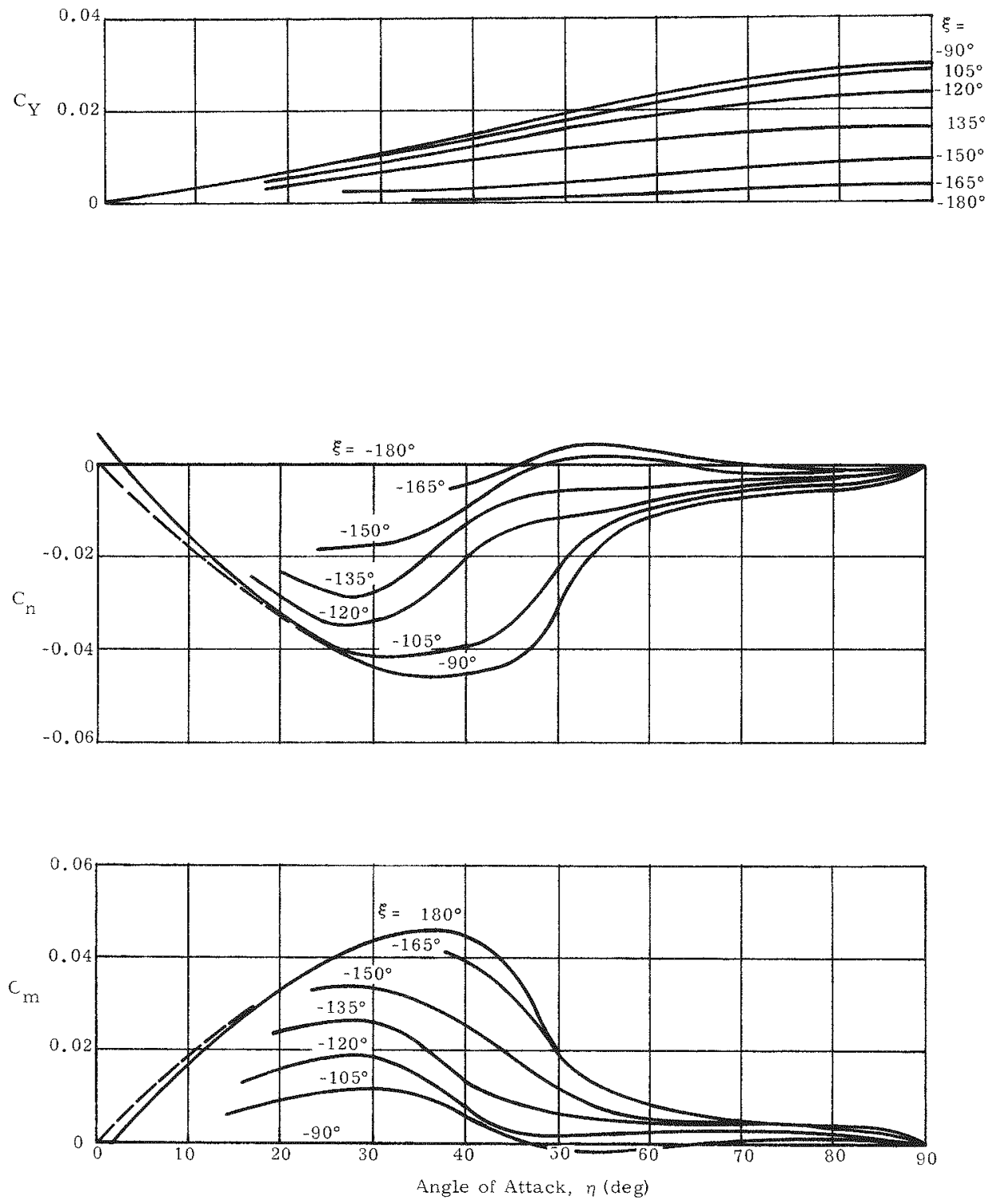

FIG. VI-26, (continued) 

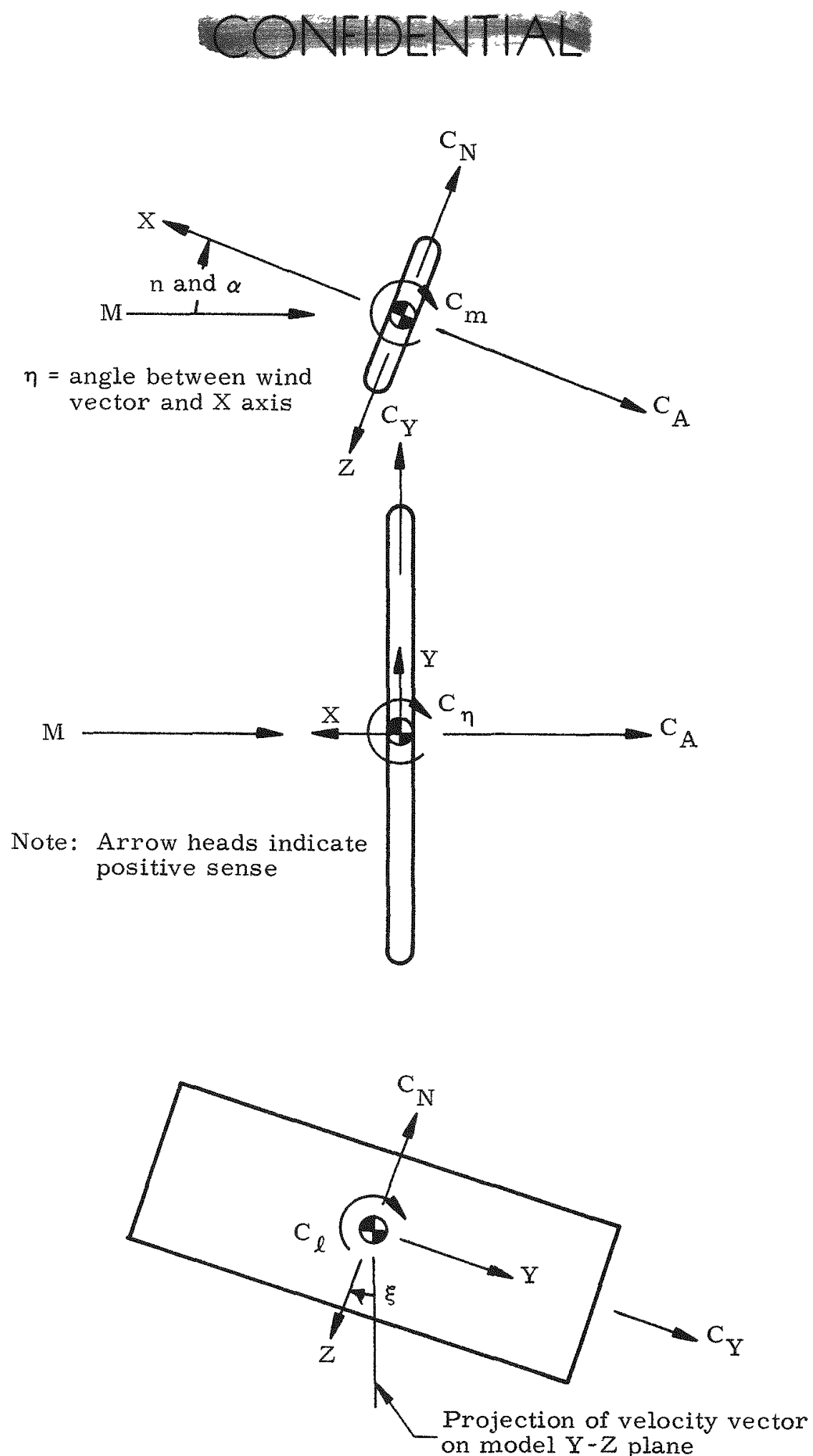

FIG. VI-27. AXIS SYSTEMI FOR AERO DYNAIMIC COEFFICIENTS

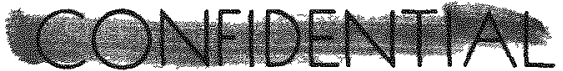

MND2062-12-7

$\mathrm{VI}-34$ 
13.6 hours of tunnel test time. A two-module fuel block was simulated with a scaled model 0.4 inch thick by 12.072 inches in length and 4.128 inches in width. Inconel skin, 0.037 inch thick, was formed to the outside fuel block dimensions. Ninetyfour chromel-alumel thermocouples were welded to the thin skin and were used to determine heat rates over the forward-facing flat plate surface and the leading edge. A Mach 8 airstream was used. As shown in Fig. VI-28, the basic two-module block was converted to a four-module block model by means of a 3.368 inch wide noninstrumented extension. The two-module configuration installed in AEDC Tunnel B is shown in Fig. VI-29. Data were obtained at a constant Reynolds number of 640,000 per foot for the following attitudes:

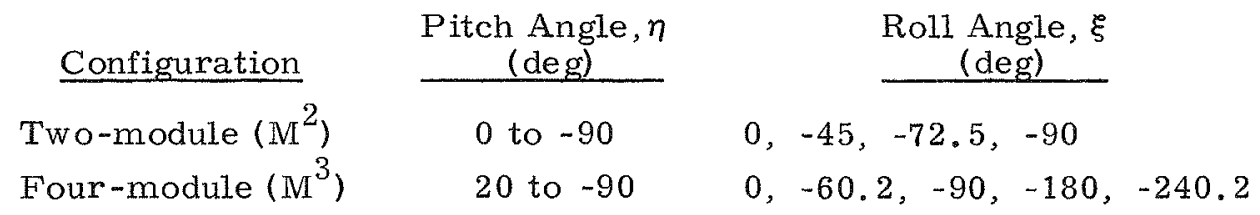

The large model frontal area generally prevented flow establishment in the tunnel at pitch angles lower than $20^{\circ}$ for the four-module configuration.

Al1 corrected test data were received from the facility and have been plotted and faired in their basic form. Cross plots have been started to make correlations which will provide inputs to an integration procedure to average heating rates over the angular oscillations of the fuel block.

Figure VI-30 presents a plot at zero roll angle of the variation of heat rate ratio, $\dot{\mathrm{q}} / \dot{\mathrm{q}}_{\text {st, }}$ versus pitch angle, $\eta$, for a fixed location 0.38 inch (model scale) aft of the leading edge on the mid span. The circle symbols are data as received from the tunnel for the two-module $\left(\mathrm{M}^{2}\right)$ fuel block. The square symbols are data from the four-module $\left(\mathrm{M}^{3}\right)$ configuration. At angles of pitch greater than $45^{\circ}$, a shock wave is attached to the leading edge of the plate and heating rates are dependent only on the surface distance from the leading edge; hence, data at this fixed location are independent of aspect ratio. At angles of pitch less than $45^{\circ}$, the effect of aspect ratio and, more significant, width and span dimensions becomes important. Takıng the test data at $\eta=0$ from the two-module configuration, the reference width and aspect ratio factors were used to fair four-module block data.

F1gure VI-31 has been prepared from Fig. VI-30 by taking into account model scale and estimating data for other aspect ratios from the data acquired in the wind tunnel test. This is descriptive of the static pitch case at zero roll for a location 0.95 inch aft of the leading edge of the full-scale fuel blocks. As would be expected, the larger blocks give lower heating rates for the static case at pitch angles between $0^{\circ}$ and $45^{\circ}$.

\section{Wind Tunnel Rotating Tests}

Test specifications for the hypersonic rotating forces scorch and aerodynamic damping test have been published as Martin Marietta. Drawing 466A3322080. Planning conferences were held at AEDC on October 12 and November 2, 1967, to define responsibility for design and fabrication of the test fixture and models. It was agreed that $A E D C$ would design the test fixture and Martin Marietta would fabricate the components peculiar to the SNAP 29 test. Martin Marietta would design and build all models. AEDC has completed design of the test fixture and submitted drawings to Martin Marietta for fabrication of components. Martin Marietta has sent preliminary model drawings to AEDC for comment and approval. The

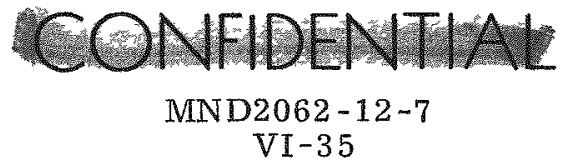




\section{CONFADENTAL}

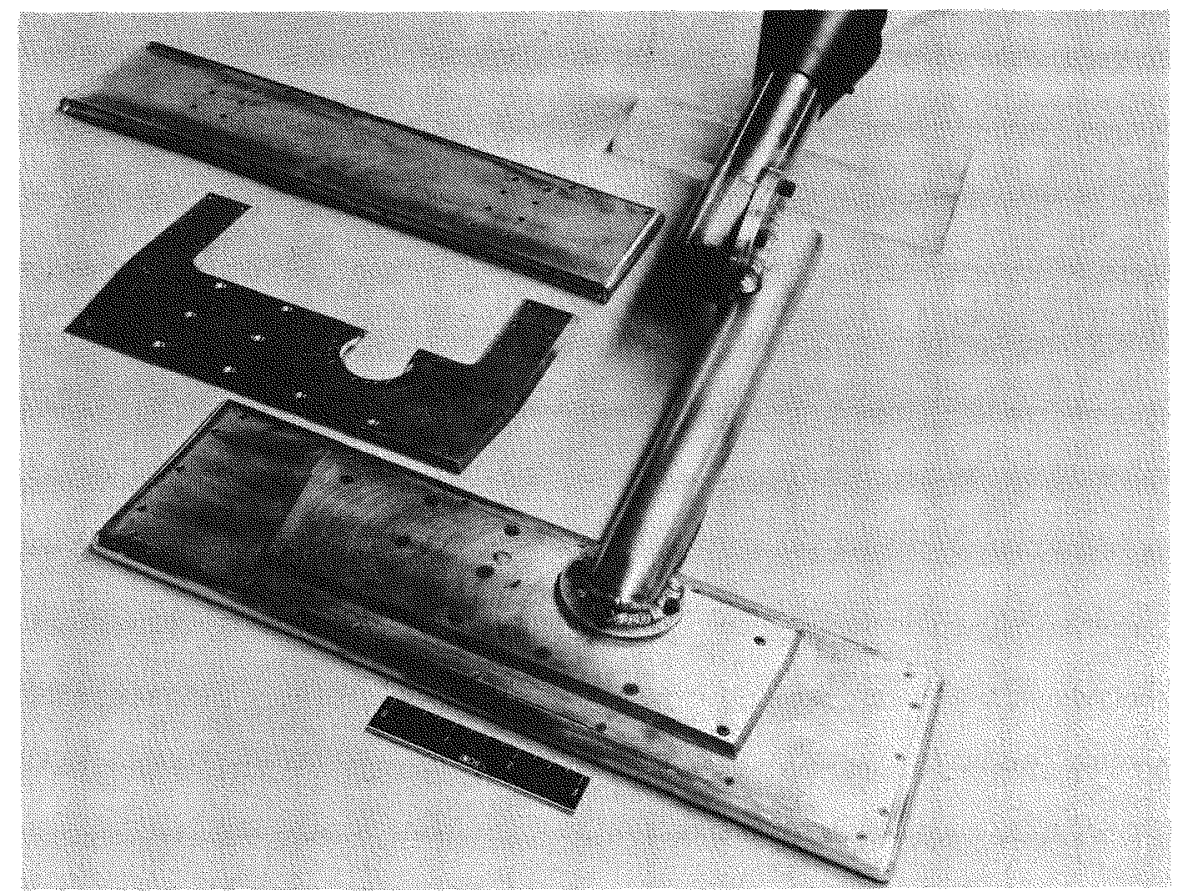

FIG. VI-28. FORTY PERCENT SCALE TWO-MODULE (ASPECT RATIO $=3.2$ ) FUEL BLOCK AEROHEATING MODEL WITH UNINSTR UMENTED EXTENSION TO MAKE A

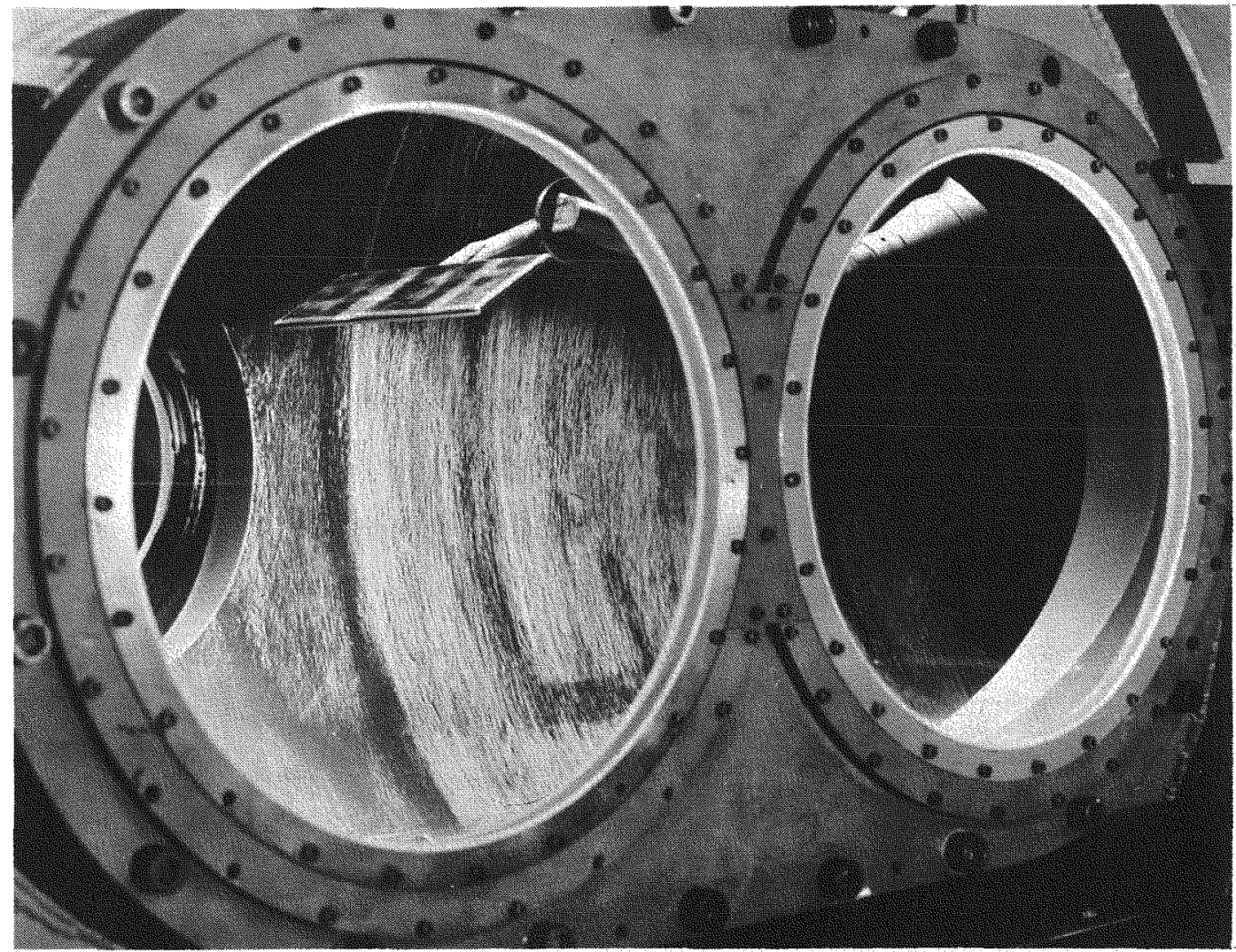
FIG. VI-29. FORTY PERCENT SCALE TWO-MODULE FUEL BLOCK AEROHEATING MODEL
INSTALLED IN AEDC TUNNEL B

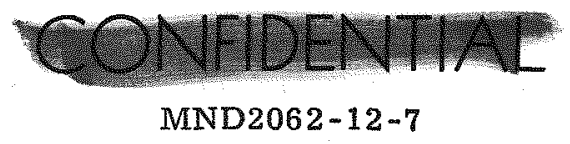

VI-36 


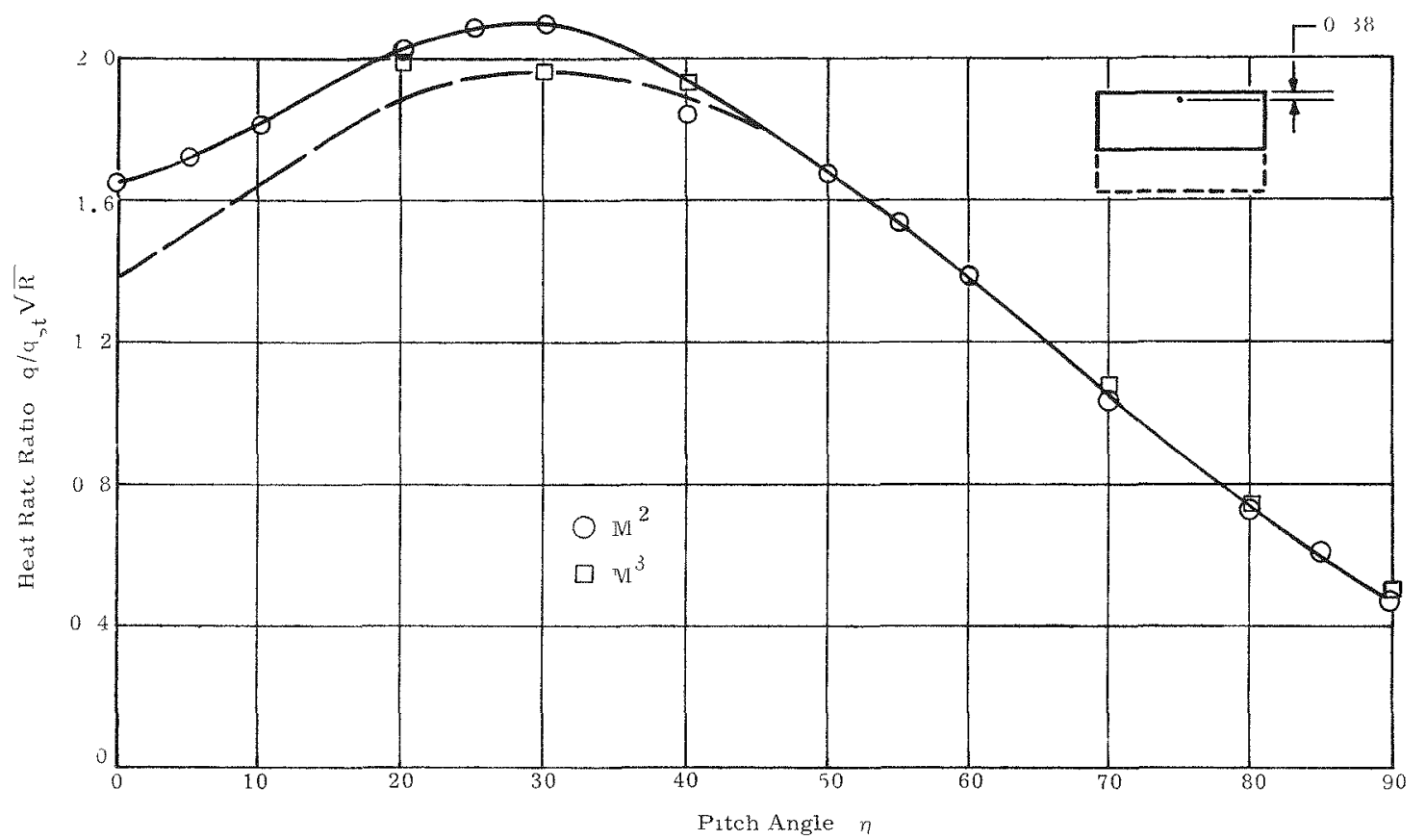

ГIG. VI 30. q/a St VERSUS $n$ I OR LOCATION 0.38 INCH FROM LEADING EDGE ON SPAN CENTERLINE MACH 8 \& 0

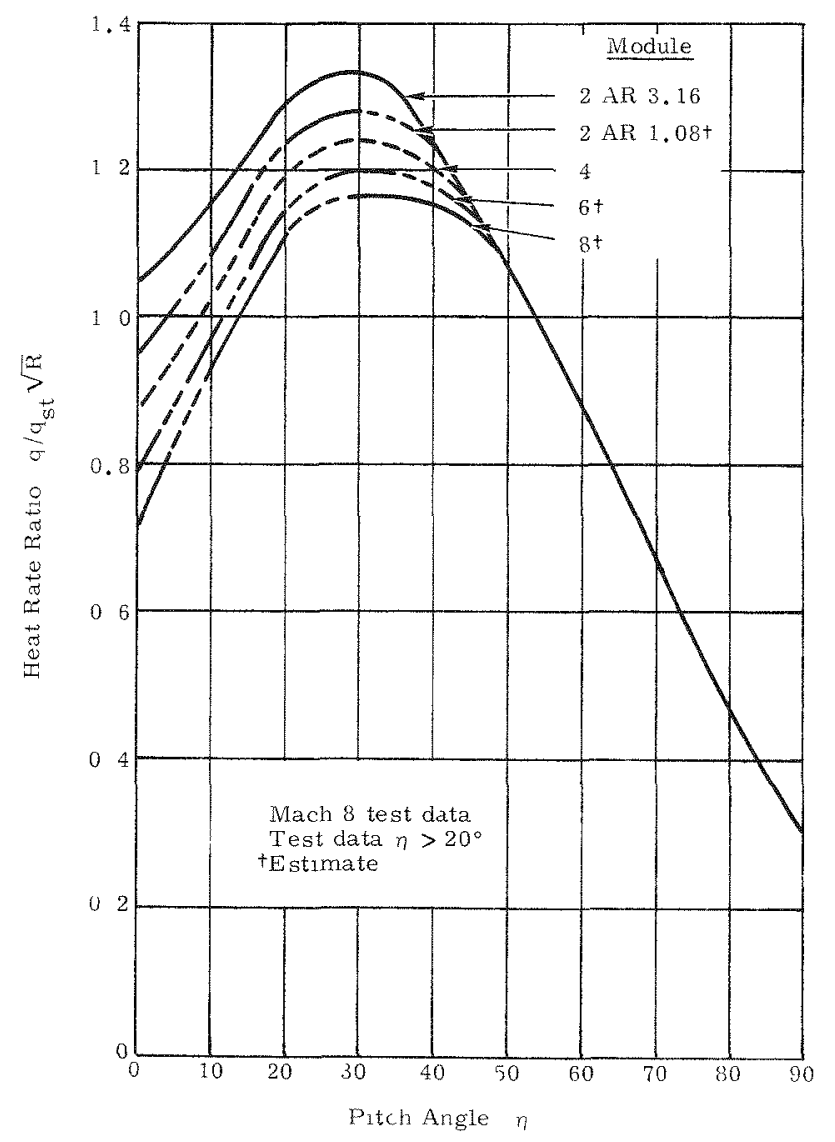

1 IG. VI 31. $\mathrm{q} / \mathrm{a}_{\text {St }}$ VL RSUS $\eta \mathrm{I}$ OR LOCAIION 0 9) IACH I ROM LEADING LDGI ON SP IN CPNTLRLINE $\xi \quad 0 \quad S / R-245$

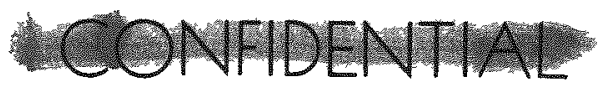

MND2062-12-7 
rotating force and damping tests are scheduled to be conducted in Tunnel $B$ and the scorch test in Tunnel C during April 1968.

\section{Wind Tunnel Test Plans}

The wind tunnel test plan for the fuel block was reviewed and consideration was given to adding five new tests to the existing test program. These tests were designed to provide experimental data: (1) on pitch damping for the fuel block at or near the edge-on flight condition by means of a forced oscillation test, (2) on roll and yaw damping by means of rotation tests about the $x$-axis and the $z$-axis, (3) on damping and unrestrained motions by means of free flight tests and (4) on the effect of rotation on the aerodynamic heating of the fuel block by means of a rotating heat transfer test. An order of priority for the new tests and the tests in the program plan was established based on technical requirements.

\section{IMPACT AND BURIAL TESTING AND ANALYSES-- CONTROL POINT 3330}

\section{Fuel Matrix Impact Tests}

Evaluation of the effects of impacting fuel matrices was completed. Twenty test specimens (ten sintered at $1000^{\circ} \mathrm{C}$ and ten at $1500^{\circ} \mathrm{C}$ ) were impact tested on the drop hammer machine in the Central Environment Laboratory at Martin Marietta. All specimens were subjected to a shock typical of re-entry impact on granite, nominally a half-sine pulse of $30,000 \mathrm{~g}$ over a $60 \mu \mathrm{sec}$ duration.

Of the 20 test specimens, eight were exposed to axial loads and 12 to radial loads. No structural damage was observed for the axial tests. In the radial tests, the matrix containers suffered slight bends due to the curvature of the impact face of the hammer. This was expected, however, and preliminary assessment has revealed no significant damage.

\section{Fuel Block Drop Tests}

Drop tests of two graphite fuel blocks were performed at the Tonopah Test Site in Tonopah, Nevada, on November 29. An Air Force helicopter performed a total of eight drops from an altitude of 1250 feet above terrain (see discussion in Section C). Six aluminum dummy blocks were dropped to check the helicopter positioning and to checkout equipment. Four of these calibration blocks impacted the concrete pad. Of the graphite blocks, one hit the pad and one impacted the dry lake bed.

Two graphite fuel block models measuring about 1 × $33 \times 36$ inches and weighing 97 pounds (Ref. Dwg. No. 466A3331016 -029) were fabricated and tested. One block contained 8 prototype fuel capsules and 16 bronze capsules, and the second block held 12 prototype and 12 bronze capsules.

All specimens were released with an initial rotation imparted about a diagonal axis. Although the aerodynamic motions of all blocks appeared similar, different impact orientations were observed. The dominant impact mode was on a corner. In addition, edge-on and flat impacts were observed during the calibration drops.

Although final assessment of the prototype capsules is not complete, preliminary indications are that no ruptures occurred. However, considerable bending, twisting and flattening effects were observed.

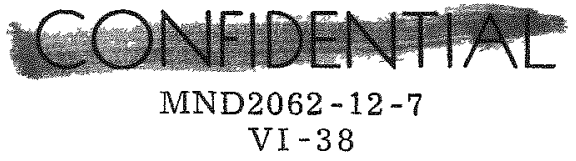




\section{Fuel Block Sled Impact Tests}

Facility modifications and calibrations were completed for the water jet impact tests. The test procedure was received from Sandia and approved. A SNAP 29 test representative was sent to the site to assist in the tests. Minor difficulties involving braking techniques and obstructed pressure lines have been resolved. On December 21, 1967, the first test on an instrumented graphite block was run. The results are being evaluated.

\section{Dynamic Data Development}

Test plans for the dynamic data development of fuel block and capsule materials were published. The test will determine the structural properties of these materials at predicted impact temperatures. The results will be used in the impact analysis work.

\section{Impact Analyses}

Refinement of data from high-speed motion pictures of impacting graphite was suspended in favor of a more concentrated effort on development of a threedimensional response analysis of an impacting plate.

In pursuing a stable numerical solution to the three-dimensional impact problem, the code existing in September 1967 was expanded to create a finer mesh. The resulting solution was slightly more stable, but still unacceptable. It was noted that the mesh points on the boundary near corners and edges were most unstable. This could not be corrected using the same approach, i.e., satisfying static stress and displacement relations on the boundary at each time step after the internal mesh points were computed from dynamic response considerations. Therefore, the boundary mesh points were considered to have mass and to respond dynamically. This was accomplished by modifying the internal mesh point equations so they could be computed by backward or forward differences, depending on the boundary location of each mesh point. After the new boundary equations were derived and inserted into the modified computer code, a radical lack of coupling between the displacements became evident. Further investigations showed this to be inherent in the approach used.

A different approach was suggested by the contents of Report WAPD-TM-555, "DUZ-1: A Program for Solving Axisymmetric and Plane Elasticity Problems on the Philco-2000," January 1966. This particular approach, based upon energy considerations, promised to lead to consistent equations applicable to corners and edges, as well as elsewhere in the finite difference mesh. A new computer code was developed to solve the equations. In the present state (about $80 \%$ checked out), the results look promising for short times, but the stability of the solution is inadequate. Checkout is to be completed in the next quarter.

Finally, one other method of computing displacements on the boundaries of the impacting plate is being considered. The method uses equations derived from considerations of forces acting on finite volumes along the boundary. Those equations reflect a more exact approximation of the forces, both inertial and strain induced, acting at and near the boundaries. Programming and checkout of the solution are not near enough to completion to allow a judgment of results at this time.

In the first quarter of 1968, the effort devoted to three-dimensional impact analysis will be reduced in favor of evaluating test results and studying graphite fracture.

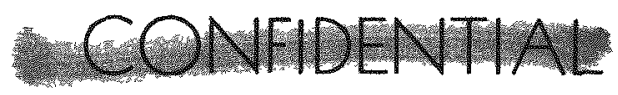

MND2062-12-7

VI -39 


\section{E. THERMAL AND STRUCTURAL ANALYSES AND TESTS--} CONTROL POINT 3340

\section{Launch Abort Tests}

The Phase II portion of the Launch Abort Environment Test Plan was released.

A simulated SNAP 29 fuel block, clad with five mils of nickel and containing five simulated capsules, was included in two Project PYRO 25, 000-pound drop tests. One test resulted in an early drop with only one propellant on board and no data were recorded. The second test resulted in a low TNT equivalent of $\sim 0.14 \%$. In both tests, damage to the SNAP 29 test article was negligible; with slight refurbishing, the block can be used in the last of the series of 25,000-pound tests to be conducted in January 1968.

Three blocks with simulated capsules and 1000 -watt heaters have been prepared for use in a series of Project PYRO tests to be conducted in the first quarter of 1968. These tests will involve 1200 -pound quantities of various propellants (cryogenic, mono-, hypergolia, etc.), simulating types and volumes to be found in space craft configurations. 


\section{MOUND LABORATORY EFFORT IN SUPPORT OF SNAP 29}

As part of an extensive radioisotope fuels development effort being conducted at Mound Laboratory, a Po-210 program has been defined and implemented in support of the total SNAP 29 effort. This program comprises the radioisotope fuel and fueled heat source fabrication for the SNAP 29 RTG Interface responsibilities among Martin Marietta, Mound and the AEC are identified in Specification MN-2062-4, Rev. A, "RTG Nuclear Fuel and Fuel Encapsulation Interface Plan, SNAP 29 Power Supply System."

The program being conducted at the Mound Laboratory is summarized in outline form as follows:

\section{FUEL COMPATIBILITY}

Potential container materials for polonium fuel forms are being evaluated at elevated temperatures in support of the SNAP 29 program.

\section{C-Capsule Program}

In a series of $1000^{\circ} \mathrm{C}$ tests, six capsule material-fuel combinations have been examined: tantalum-polonium metal; tantalum-gadolinium polonide; tantalum-10\% tungsten-polonium metal; tantalum-10\% tungsten-gadolinium polonide; Haynes-25polonium metal; and Haynes-25-gadolinium polonide.

\section{$\underline{H-C a p s u l e ~ P r o g r a m}$}

Compatibility of tantalum and tantalum-10\% tungsten with gadolinium polonide has been established at $1000^{\circ} \mathrm{C}$ by the $\mathrm{C}$-series tests. Because of the possibility that the fuel operating temperature for the SNAP 29 system may exceed $1000^{\circ} \mathrm{C}$, the $\mathrm{H}$-series of tests at $1200^{\circ} \mathrm{C}$ was initiated. The $\mathrm{H}$-series will be identical to the $\mathrm{C}$-series except for the difference in temperature.

\section{E-Capsule Program}

This series is a test of the compatibility of tantalum with gadolinium polonide in a helium-purged vacuum furnace environment at the nominal temperature of $1500^{\circ} \mathrm{C}$.

\section{FUEL PROPERTIES (PO AND GdPO AND Ta MATRIX)}

\section{Information Constraining Safety Conclusions}

(1) Gaseous environment reactivity

(2) Aqueous environment reactivity

(3) Mechanical stability of Ta matrix--GdPo system using GdTe simulation

(4) Thermal conductivity of Ta matrix

(5) Capsule burial studies

\section{Information Constraining Final Confirmation of Fuel Form}

(1) Fuel form vapor pressure

(2) Phase equilibrium of $\mathrm{GdPo}_{1-\mathrm{x}} \mathrm{Pb}_{\mathrm{x}} \mid \mathrm{x}=1$ system

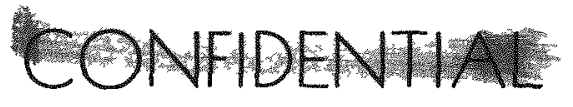

MND2062-12-7

VII -1 


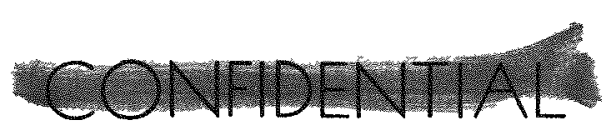

(3) Gas blanket experiment

(4) Fuel matrix studies

(5) Die-pressed matrix strength studies

(6) Hydrostatically pressed matrices

Poloniun Fuel Properties Status Summary

MATERIAL WELD AND BRAZE STUDIES FOR CAPSULES AND HEAT SOURCE (COMBINED MARTIN MARIETTA/MOUND PROGRAMI)

Capsule Weld Development

(1) Tantalum inner liner weld qualification

(2) Tantalum-10\% tungsten liner weld qualification

(3) Capsule clad weld qualification

Capsule-Fuel Block Assembly Process

COLD ENCAPSULATION LINE

Fixture Development and Line Installation

Forty-Capsule Weld Qualification

Heat Source Assembly Qualification

Fabrication of Impact Reliability Test Specimens

HOT ENCAPSULATION FACILITY

Fixture Development and Line Installation

(1) Fuel Loading

(2) Capsule cooling

Qualification of Hot Capsule Fabrication Techniques

Qualification of Heat Source Fabrication Techniques

Production of One Demonstration Heat Source

PREPARATION OF FINAL PRODUCT SPECIFICATION FUELING AND ASSEMBLY OF HEAT SOURCES AS AUTHORIZED

\section{A. SUMMARY OF SIGNIFICANT ACCOMPLISHMENTS}

The $\mathrm{H}$-capsule, $1200^{\circ} \mathrm{C}$ tests were terminated because of a water leak in the vacuum furnace. Corrosion, apparently due to the fuel, was found on several of the compatibility capsules which were under test 39 days. A new set of capsules was fabricated and the tests will be re-initiated.

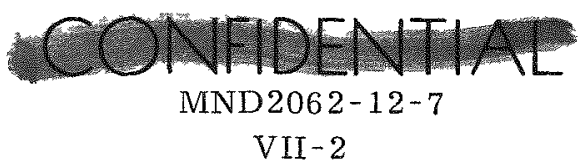




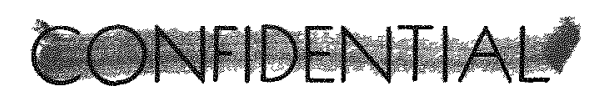

Two follow - on experiments to the polonium air exposure test No. 2 were conducted. In the first, a stainless steel outer body, similar to the one used in the test, was heated in air at about $900^{\circ} \mathrm{C}$ for several hours without showing the corrosion effects evident in the test capsule. Particulate matter produced by burning a tantalum-gadolinium telluride matrix averaged 0.1 to 0.2 micron in diameter. These particles were found in clumps on the filter and it cannot be determined whether agglomeration occurred before or after collection on the filter.

No damage to the matrices was apparent after end-on impact of the five-inch matrix segments. No significant dimensional changes were noted in several tantalum-gadolinium matrices after a one-week storage period.

A successful method has been developed for polonium fueling of tantalum-gadolinium matrices in an inert atmosphere. A table of polonium fuel properties is included in the report and will be updated as additional information is available.

Welding parameters were developed for each of the five end cap designs being evaluated for the $\mathrm{Ta} / 10 \% \mathrm{~W}$ capsule strength member. Cap design 001 was chosen for the strength member.

\section{B. FUEL COMPATIBILITY}

\section{H-Capsule Program}

Compatibility of tantalum and $\mathrm{Ta} / 10 \% \mathrm{~W}$ with gadolinium polonide has been established at $1000^{\circ} \mathrm{C}$ by the $\mathrm{C}$-series tests. Due to the present system design, a fuel operating temperature of $1100^{\circ} \mathrm{C}$ or above is expected. The H-series of compatibility tests at $1200^{\circ}$ $\mathrm{C}$ was initiated in an attempt to establish compatibility at or above the SNAP 29 operating temperature.

\section{a. Experimental data}

Capsule design for the $\mathrm{H}$-capsules was identical to that for the C-capsules. Loading data for the original series of $\mathrm{H}$-capsules are shown in Table VII-1.

On October 8, 1967 the copper heater shell of the vacuum furnace developed a water leak while the furnace was operating at $1200^{\circ} \mathrm{C}$. This failure resulted in extensive damage to the furnace and formation of an adherent black scale on the surfaces of the $\mathrm{Ta} / 10 \% \mathrm{~W}$ outer capsules.

Because of the decrease in power density and difficulty in removing the oxide scale from the outer bodies, it was decided to re-initiate the $1200^{\circ} \mathrm{C}$ tests with a new set of capsules. Since the oxidized capsules were not to be used in further testing, several were examined for container corrosion.

Three $\mathrm{Ta} / 10 \% \mathrm{~W}$ capsules, $(\mathrm{H}-5, \mathrm{H}-6$ and $\mathrm{H}-7$ ) that contained gadolinium polonide for 39 days at $1200^{\circ} \mathrm{C}$, were prepared for metallographic examination. $\mathrm{The} \mathrm{Ta} / 10 \% \mathrm{~W}$ control capsule $(\mathrm{H}-4)$, which was sealed along with the fueled capsules, was also prepared for examination. The control capsule was at temperature for 22 days before the furnace failure occurred. Table VII-1 summarizes the test history of these four capsules.

A qualitative measure of the ductility of the four capsules was obtained by performing simple bend tests. The test procedure consisted of bending a 1/8-inch wide sector of the 0.02 -inch thick annulus $\left(\theta=180^{\circ}\right)$ with a pair of pliers. In each case the sector tested was located about 1/4-inch above the base of the capsule. Sectors obtained from

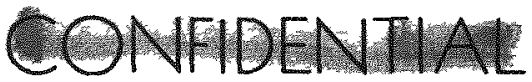

MND2062-12-7

VII -3 


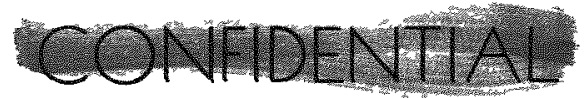

the fueled capsules fractured with negligible plastic deformation. However, the sector cut from Control Capsule $\mathrm{H}-4$ bent without fracturing. The bend radius of the central sector was measured metallographically and found to be 0.02 inch. That is, a $1 \mathrm{~T}$ ductile bend was obtained.

\section{TABLE VII-1}

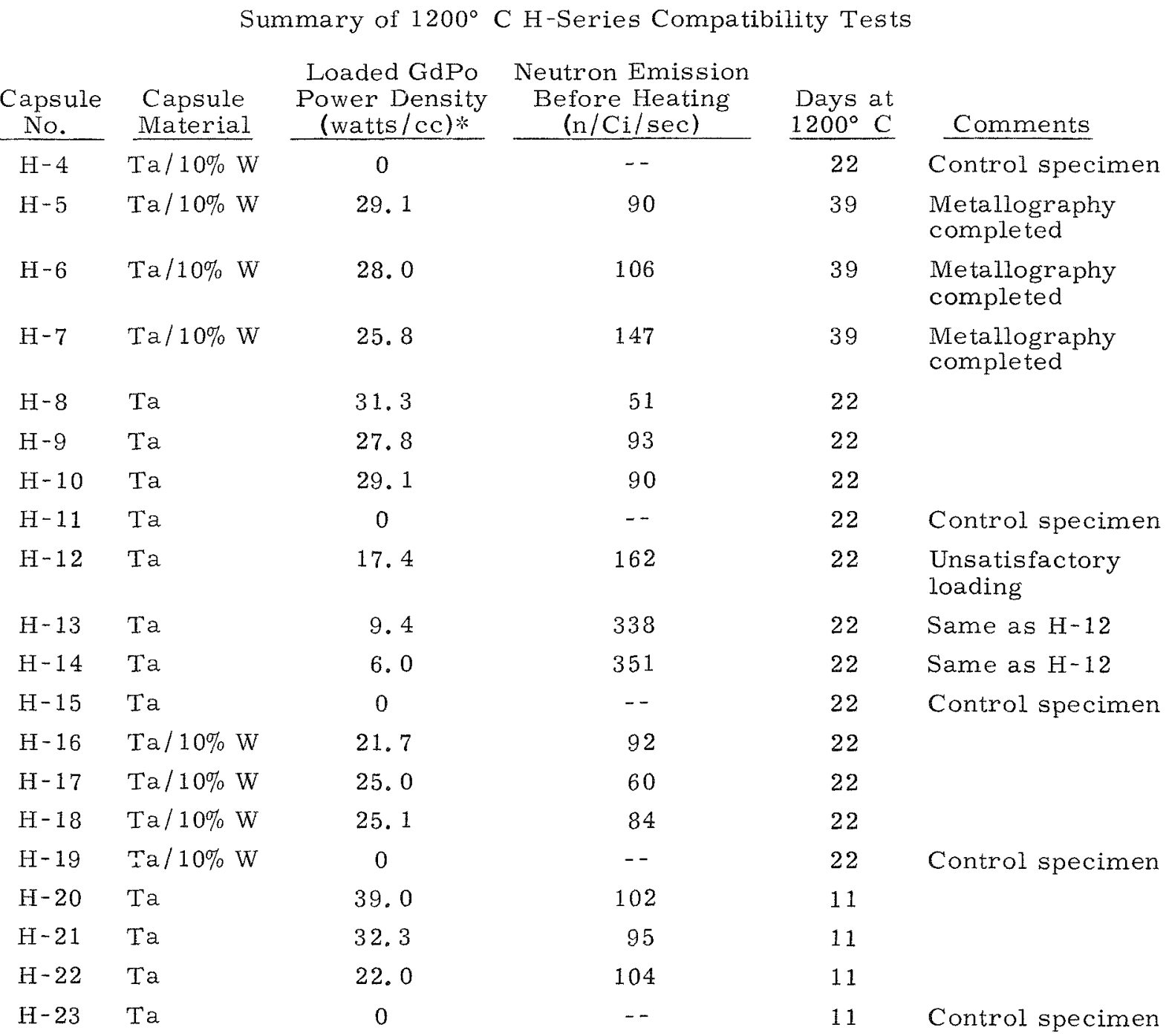

*Power density based on calorimetric measurement of fuel in the capsule; capsule volume $=0.26 \mathrm{cc}$.

Metallographic examination of the three fuel-containing capsules revealed that the $\mathrm{Ta} / 10 \% \mathrm{~W}$ was corroded. The mode of attack was primarily intergranular, although localized regions of surface corrosion were also found. Figure VII-1 is representative of the corrosion found in these capsules.

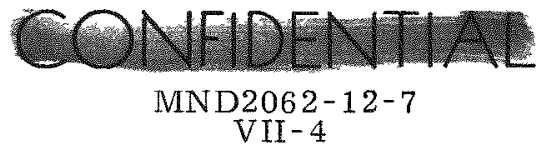




\section{CONEIDENTIAL}

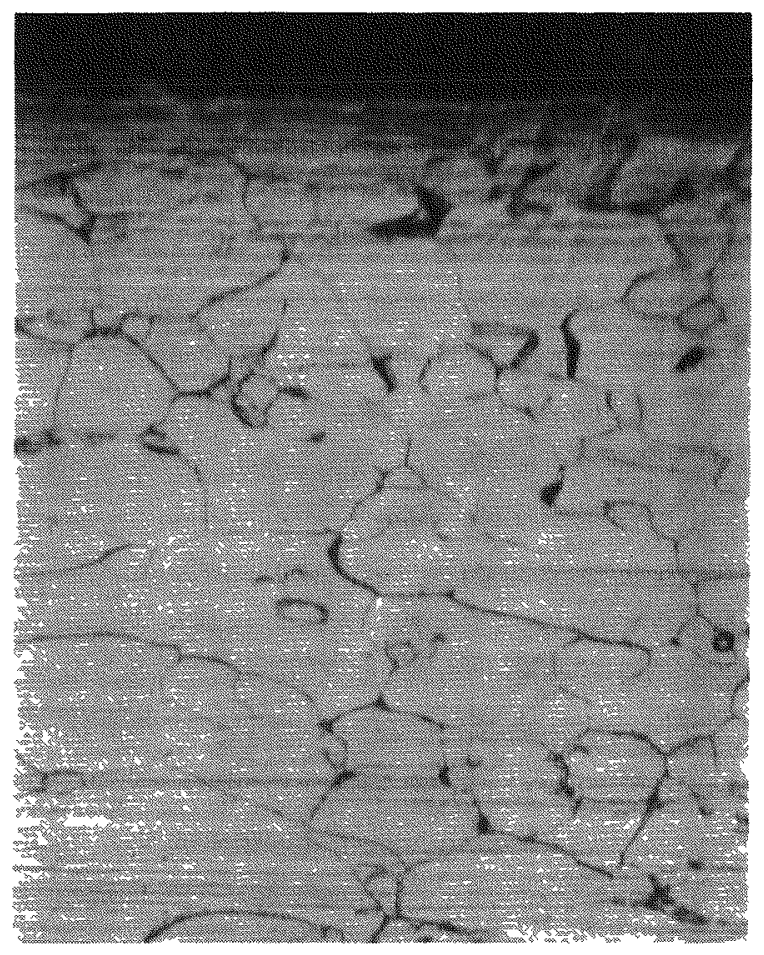

FIG. VII-1. LONGITUDINAL SECTION OF WALL OF SPECIMEN H -6 SHOWING EXTENSIVE INTERGRANULAR CORROSION. REGION IS LOCATED ABOUT 1/4-INCH ABOVE BASE OF CAPSULE

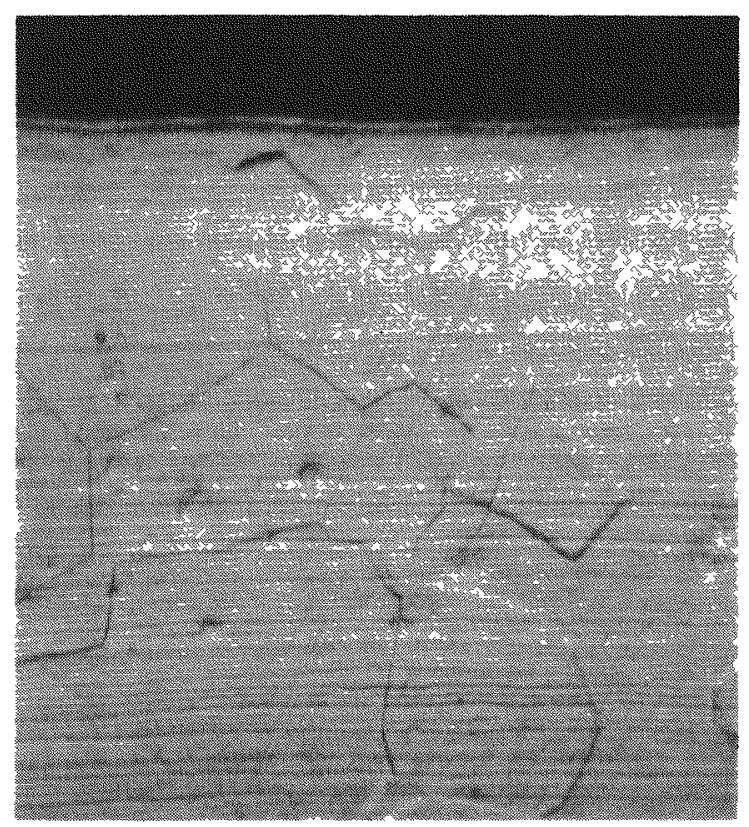

Base of Capsule

FIG. VII-2. BASE OF Ta--10\% W CONTROL CAPSULE H-4

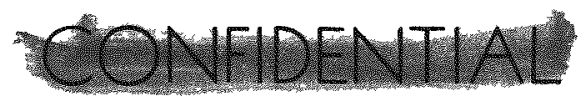

MND2062-12-7

VII -5 
The extent of the intergranular corrosion varied among the three capsules and at different locations within each capsule. The attack area was always found at the base of the capsules upon which the fuel rested. Penetration varied from three mils at the base of H-5 to complete penetration of the 20-mil thick base of $\mathrm{H}-6$. The cylindrical walls of Specimen $\mathrm{H}-6$ also appeared to be completely penetrated by intergranular corrosion in some regions. About one mil of intergranular attack was also measured at the top end cap of H-5. Since the top end cap is one-half inch above the gadolinium polonide, vapor transport of the corroding media most probably occurred.

No microstructure anomalies were observed in Control Specimen $\mathrm{H}-4$, as illustrated by Fig. VII-2. The grain boundaries were free of a second phase, and no suboxide or nitride precipitates were found. The absence of second phase particles, plus good ductility in the control capsule, indicates that the Ta/10\% $\mathrm{W}$ outer capsules did protect the inner test capsules from contamination when the vacuum furnace developed the water leak.

Because of the negative compatibility results for the 39-day specimens, the tantalum and $\mathrm{Ta} / 10 \% \mathrm{~W}$ capsules that contained gadolonium polonide for 22 days at $1200^{\circ} \mathrm{C}$ will be examined.

Assembly of additional $\mathrm{H}$-series test capsules is currently in progress. Six capsules have been loaded with gadolinium polonide. Thermal testing of these six capsules will be initiated as soon as the vacuum furnace is in operation. The loading data for the six capsules are given in Table VII-2. The low power densities of Specimens $\mathrm{H}-24$ and $\mathrm{H}-26$ will require the addition of another group of three fueled capsules and one control capsule to the already scheduled 16 specimens.

\section{TABLE VII-2}

GdPo Loading Data for New H-Series Capsules

\begin{tabular}{|c|c|c|c|}
\hline $\begin{array}{l}\text { Specimen } \\
\text { No. } \\
\end{array}$ & $\begin{array}{c}\text { Capsule } \\
\text { Composition } \\
\end{array}$ & $\begin{array}{l}\text { As-Loaded Power } \\
\text { Density (watts/cc) }\end{array}$ & $\begin{array}{l}\text { As-Loaded Neutron } \\
\text { Flux }(\mathrm{n} / \mathrm{Ci} / \mathrm{sec}) \\
\end{array}$ \\
\hline $\mathrm{H}-24$ & $\mathrm{Ta}$ & 19.6 & 64 \\
\hline $\mathrm{H}-25$ & $\mathrm{Ta}$ & 27.2 & 110 \\
\hline $\mathrm{H}-26$ & $\mathrm{Ta}$ & 17.4 & 215 \\
\hline $\mathrm{H}-27$ & $\mathrm{Ta}$ & Control Capsule & -- \\
\hline $\mathrm{H}-28$ & $\mathrm{Ta} / 10 \% \mathrm{~W}$ & 34.0 & 78 \\
\hline $\mathrm{H}-29$ & $\mathrm{Ta} / 10 \% \mathrm{~W}$ & 32.2 & 93 \\
\hline $\mathrm{H}-30$ & $\mathrm{Ta} / 10 \% \mathrm{~W}$ & 31.2 & 521 \\
\hline $\mathrm{H}-31$ & $\mathrm{Ta} / 10 \% \mathrm{~W}$ & Control Capsule & -- \\
\hline
\end{tabular}

\section{b. Conclusions}

The apparent conclusion to be drawn from the data is that $\mathrm{Ta} / 10 \% \mathrm{~W}$ is significantly corroded by gadolinium polonide. Further testing will be done to confirm this conclusion. It may be possible to make some estimate of the rate of the corrosion by metallographic examination of the $\mathrm{Ta} / 10 \% \mathrm{~W}$ capsules which were under test for 22 days.

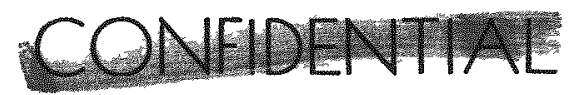




\title{
CONAIDENFAL
}

\author{
C. FUEL PROPERTIES
}

1. Gaseous Environmental Reactivity

Investigations of the dispersion of polonium from SNAP 29-type systems are under way at Mound Laboratory. Polonium air exposure test No. 2 was carried out in July, 1967. A topical report concerning this test has been issued. Most of the results of the test were also reported in the SNAP 29 Power Supply System Fourth Quarterly Progress Report. Additional data from this test and the results of two follow-on tests are reported.

\section{a. Experimental data}

A chemical analysis for gadolinium was carried out on the residue from the fuel used in air exposure test No. 2. Some of the residue was previously used for X-ray analyses; therefore it was not possible to analyze $100 \%$ of the material. The amount of gadolinium found was 191.1 milligrams or $93.1 \%$ of the amount used in preparation of the fuel form.

During polonium fuels air exposure test No. 2, the end cap of the stainless steel outer body became corroded in the vicinity of the pin hole. The pin hole subsequently enlarged to an irregular opening much larger than originally intended. This deterioration was not expected, since Type 304 stainless steel from which the capsule was constructed is considered to have good oxidation resistance at the temperatures to which it was exposed during the test. For this reason, a similar capsule was tested at the approximate test temperature.

A stainless steel outer body, intended to be used as a backup for the one used during air exposure test No. 2 and fabricated from the same stock material, was continuously heated in air at $800^{\circ}$ to $900^{\circ} \mathrm{C}$ for 25 days. The capsule was periodically removed from the furnace and visually inspected for evidence of change in the appearance of the region around the pin hole. At the termination of the 25-day heating period, photomicrographs were prepared of the pin hole and surrounding depression in the end cap. By comparing these photomicrographs with one made on the same capsule prior to heating it was observed that an oxide scale had partially closed the hole, but the diameter of the hole had not enlarged. The corrosion of the metal in this region was found, by mechanical probing, to be limited to a slight skin oxide coating and was not severe enough to cause gross embrittlement or failure.

An experiment was carried out to gain information regarding the probable character of the airborne particulate material released upon atmospheric exposure of a mock fuel specimen under simulated SNAP 29 thermal conditions. The test was carried out to facilitate the selection of a suitable method of particle size analysis. This test employed a simulated fuel form composed of an annular compact of gadolinium telluride in a tantalum matrix of the approximate SNAP 29 configuration. The sample represented one segment of the fuel loading for a capsule. In this experiment the mock fuel was heated to $860^{\circ} \mathrm{C}$ and unrestrictively exposed to air ( $i$. e., no containment vessel) for two hours. During the exposure, airborne particulate was collected on a membrane filter having 1.2 micron +0.3 pores. Portions of the collected particulate matter were subjected to particle size analysis by microscopic techniques. In conjunction, chemical analyses were carried out on the airborne deposit as well as the residual ash resulting from the atmospheric decomposition of the mock fuel specimen.

The airborne particulate matter formed a rather thick cake deposit on the filter disc. Some material also collected on the walls of the quartz vessel housing the test specimen during the experiment. Microscopic examination of the filter disc

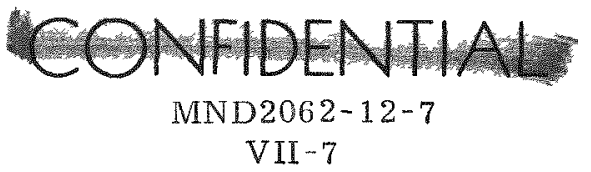




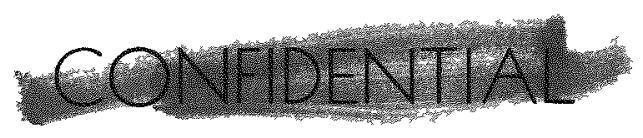

revealed the cake to be made of agglomerates of submicron particles (0. 1 to 0.2 micron diameters). Emission spectroscopic analysis of a portion of the airborne particulate showed the primary constituent to be tellurium oxide with a trace of tantalum oxide. The residual ash left by the decomposed mock fuel contained the three starting elements gadolinium, tellurium and tantalum.

\section{b. Conclusions}

The corrosion which occurred on the stainless steel capsule of the actual test assembly was much more severe than that observed in the heating of the duplicate stainless steel outer body. Apparently the corrosion observed on the actual test capsule was caused by a combination of factors directly related to the test process. Whether the chemical changes involved more than simple oxidation is not known. The stainless steel end cap became noticeably bulged during the exposure. This distortion could have accelerated attack of the stainless steel by atmospheric oxygen or any other agent, since it would repetitively expose unreacted surfaces. It is not likely that polonium vapor was the corrosive agent, even if it were present. Polonides are routinely synthesized in Type 304 stainless steel tubes at $900^{\circ}$ to $950^{\circ} \mathrm{C}$ without visible evidence of attack on the tubes.

The chemical analysis data for the fuel residue support the previous conclusion that gadolinium polonide was not released from the capsule during air exposure test No. 2. The $93.1 \%$ recovery of gadolinium from the residue is a reasonably conclusive value, since the residue had been physically disturbed and samples removed for $\mathrm{X}$-ray analysis. If the polonium released had been in the form of gadolinium polonide, approximately 64 milligrams of gadolinium or $31 \%$ of the gadolinium used, would have been involved.

It is not clear from the results of the particle size experiment whether agglomeration of the 0.1 to 0.2 micron particles occurred prior to or following deposition of the material on the filter. This particle size is consistent with material produced by other physico-chemical reactions involving combustion, distillation and sublimation. Additional experiments will be carried out in an attempt to define the basic particle size more clearly.

\section{Mechanical Stability of Ta Matrix-GdPo System}

Mound Laboratory supplied 20 five-inch matrix loaded inner liners to Martin Marietta for impact testing. Six of the items were returned to Mound for matrix evaluation after end-on impacts.

There has been some indication that matrices swell after fabrication. The fit of the matrices into the inner liner could be seriously affected by this swelling, if the exact amount of dimensional changes is not determined.

\section{a. Experimental data}

The radiographic inspection report for the six impact capsules returned to Mound is shown in Table VII-3. Reports for both before and after the impact tests are included for comparison. The impact tests were designed to simulate end-on impact at 100 to $150 \mathrm{fps}$ at a temperature of approximately $1000^{\circ} \mathrm{F}\left(538^{\circ} \mathrm{C}\right)$. As indicated in Table VII-3, matrices sintered at $1000^{\circ}$ and $1500^{\circ} \mathrm{C}$ were tested. No significant differences in impact behavior were noticed between matrices sintered at the two temperatures. Some bulging of the inner liner side walls did occur as indicated by the radial gaps between the matrices and the walls after impact.

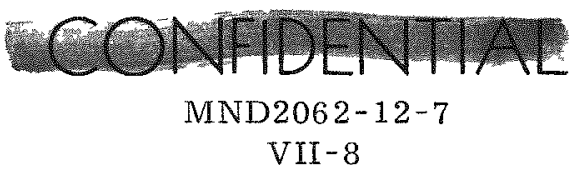


TABLE VII - 3

Radiographic Inspection of Impacted SNAP 29 Matrices

\begin{tabular}{|c|c|c|}
\hline $\begin{array}{c}\text { Capsule } \\
\text { No. }\end{array}$ & $\begin{array}{l}\text { Total Gap } \\
\text { Between } \\
\text { Matrices } \\
\text { (in.) } \\
\end{array}$ & $\begin{array}{c}\text { Condition of } \\
\text { Matrices } \\
\end{array}$ \\
\hline $\begin{array}{l}\text { 1-Before impact } \\
1000^{\circ} \mathrm{C} \text { sintered }\end{array}$ & 0.030 & $\begin{array}{l}\text { No visible defects in } \\
\text { matrices }\end{array}$ \\
\hline 1-After impact & 0.030 & $\begin{array}{l}\text { No visible defects in } \\
\text { matrices; } 0.002 \text { in. gap } \\
\text { between tube wall and } \\
\text { matrices at end of capsule }\end{array}$ \\
\hline $\begin{array}{l}\text { 2-Before impact } \\
1000^{\circ} \mathrm{C} \text { sintered }\end{array}$ & $<0.010$ & One matrix chipped \\
\hline 2-After impact & $<0.010$ & One matrix chipped \\
\hline $\begin{array}{l}\text { 5-Before impact } \\
1000^{\circ} \mathrm{C} \text { sintered }\end{array}$ & 0.015 & No visible defects \\
\hline 5-After impact & 0.015 & $\begin{array}{l}\text { One matrix chipped; } 0.002 \\
\text { in. gap between tube wall } \\
\text { and matrices at end of cap- } \\
\text { sule }\end{array}$ \\
\hline $\begin{array}{l}\text { 6-Before impact } \\
1000^{\circ} \mathrm{C} \text { sintered }\end{array}$ & 0.010 & Crack visible in one matrix \\
\hline 6-After impact & 0.010 & $\begin{array}{l}\text { Two matrices chipped; } \\
0.003 \text { in. gap between tube } \\
\text { wall and matrix at end of } \\
\text { capsule }\end{array}$ \\
\hline $\begin{array}{l}\text { 14-Before impact } \\
1500^{\circ} \mathrm{C} \text { sintered }\end{array}$ & 0.015 & Crack visible in one matrix \\
\hline 14-After impact & 0.010 & No visible defects \\
\hline $\begin{array}{l}\text { 17-Before impact } \\
1500^{\circ} \mathrm{C} \text { sintered }\end{array}$ & 0.045 & No visible defects \\
\hline 17-After impact & 0.040 & $\begin{array}{l}\text { No visible defects, } \\
0.008 \text { in. gap between } \\
\text { tube wall and matrix at } \\
\text { end of capsule }\end{array}$ \\
\hline
\end{tabular}

Ten pure tantalum and 10 16/1 weight ratio tantalum/gadolinium telluride (fuel simulant) matrices were fabricated for a dimensional stability test. These matrices were not sintered and were stored in an argon atmosphere. Table VII- 4 shows the results of length and outside diameter measurements made on the matrices initially upon removal from the die and after one week storage. The measurements were made to the nearest 0.0005 inch. As indicated in Table VII -4 , there is a consistent initial increase of about 0.0005 inch of the matrix outside diameter over the die outside

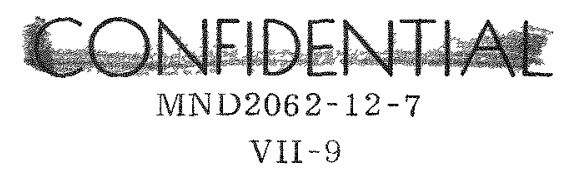


dlameter dimension. No such measurement is possible with the length, since the matrices are not pressed to a set length. After a period of one week in storage, no consistent increase is apparent in either the length or outside diameter of the matrices. The matrices will be stored for several additional weeks with dimensional measurements made each week.

\section{TABLE VII -4}

Dimensional Analysis of Matrices

\begin{tabular}{ccccc} 
Item $^{(1)}$ & \multicolumn{2}{c}{ Outside Diameter (in.) } & \multicolumn{2}{c}{ Length (in.) } \\
No. & Initial & 1 Week & Initial & 1 Week \\
1 & 0.5120 & 0.5130 & 0.3340 & 0.3340 \\
2 & 0.5130 & 0.5130 & 0.3495 & 0.3500 \\
3 & 0.5130 & 0.5130 & 0.3645 & 0.3650 \\
4 & 0.5130 & 0.5130 & 0.3370 & 0.3380 \\
5 & 0.5130 & 0.5130 & 0.3850 & 0.3860 \\
6 & 0.5120 & 0.5130 & 0.3480 & 0.3480 \\
7 & 0.5125 & 0.5130 & 0.3530 & 0.3510 \\
8 & 0.5130 & 0.5130 & 0.3830 & 0.3820 \\
9 & 0.5130 & 0.5130 & 0.4000 & 0.3980 \\
10 & 0.5130 & 0.5130 & 0.3720 & 0.3720 \\
11 & 0.5130 & 0.5130 & 0.3690 & 0.3700 \\
12 & 0.5130 & 0.5130 & 0.3220 & 0.3200 \\
13 & 0.5120 & 0.5130 & 0.3750 & 0.3760 \\
14 & 0.5130 & 0.5130 & 0.3040 & 0.3040 \\
15 & 0.5130 & 0.5130 & 0.3120 & 0.3120 \\
16 & 0.5130 & 0.5130 & 0.3760 & 0.3770 \\
17 & 0.5130 & 0.5130 & 0.3270 & 0.3280 \\
18 & 0.5130 & 0.5130 & 0.3490 & 0.3480 \\
19 & 0.5130 & 0.5140 & 0.3110 & 0.3140 \\
20 & 0.5130 & 0.5130 & 0.3140 & 0.3130
\end{tabular}

(1) Items 1 through 10 are tantalum matrices; 11 through 20 are $16 / 1$ weight ratio tantalum/gadolinium telluride.

${ }^{(2)}$ Original die outside diameter was $0.5125 \pm 0.0005$ inch.

b. Conclusions

Matrices sintered at $1000^{\circ} \mathrm{C}$ apparently have enough strength to withstand end-on re-entry impact. Side impact and vibration tests are still to be conducted.

During a period of one week, unsintered matrices, loaded with simulated fuel, did not show appreciable swelling. Dimensional tests using matrices sintered at $1000^{\circ} \mathrm{C}$ and also polonium-fueled matrices are planned.

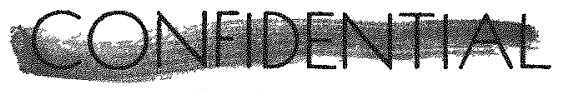




\section{Fuels Synthesis and Loading}

A method of reacting polonium in inert atmosphere with gadolinium contained in pressed tantalum matrices is under investigation. It is desirable to load the matrices in an inert atmosphere rather than vacuum, because high vacuum handling procedures are complicated in a manipulator facility such as the planned polonium encapsulation line.

a. Experimental data

Analytical data from two sealed can experiments in which polonium was loaded into gadolinium-tantalum matrices are shown in Table VII-5. The nominal atmosphere in the glove boxes in which the cans were loaded was helium, although an oxygen analysis of the atmosphere was not carried out. Even if $3000 \mathrm{ppm}$ of oxygen were present in the helium trapped in the reaction can, less than $1 \mathrm{ppm}$ of oxygen would be added to the weight of the tantalum ring containing the gadolinium. The cans and lids were made of Type 304 stainless steel. The seal was obtained by screwing the lids down on a soft annealed copper crush gasket placed between the lid and can. The sealed cans were heated in a muffle furnace to $950^{\circ} \mathrm{C}$ for one hour to complete the reaction.

\section{TABLE VII -5}

Sealed Can Polonium Loading Data

Initial polonium ( $\mathrm{C} i$ )

Polonium neutron flux $(\mathrm{n} / \mathrm{sec} / \mathrm{Ci})$

Reacted polonium (Ci)

Fuel neutron flux $(\mathrm{n} / \mathrm{sec} / \mathrm{C}$ )

Polonium reacted $(\%)$

\begin{tabular}{ccc} 
Experiment I & Experiment II \\
\cline { 1 - 1 } & & 2503 \\
90 & & 41 \\
625 & & 2390 \\
370 & & 190 \\
92.3 & & 95.5
\end{tabular}

*All values are for October 27,1967

The polonium used in these experiments was distilled off platinum gauzes and collected in the reaction cans. In future experiments platinum gauzes containing the polonium will be sealed in the can with the matrices.

\section{b. Conclusions}

The percent of the polonium reacted is a measure of the efficiency of the reaction. In each experiment a $10 \%$ excess over the stoichiometric amount of gadolinium was added to the matrices. For instance, in Experiment I (Table VII-5) enough gadolinium was present in the matrix to combine with 745 curies of polonium. Only 677 curies of polonium were added to the can and only 625 curies actually reacted. The percent quoted in Table VII-5 is the percent of the polonium added to the can which actually reacted with the matrix. A value of $90 \%$ or greater is considered good for vacuum loading techniques; therefore, the values of 92 and $96 \%$ for this work are good loadings. The technique looks very promising and will be studied extensively.

Plans are being made to lower the reaction temperature from $950^{\circ}$ to $700^{\circ} \mathrm{C}$ to determine if the reaction will remain as efficient. It is desirable to lower the temperature because lower operating temperatures will not gall the threads of the screwon lid. Galling of the lid makes its removal difficult.

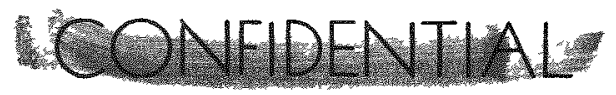

MND2062-12-7

VII -11 
An attempt will also be made to lower the neutron count of the fuel by shortening the handling time. This should reduce the chance of oxidizing both the gadolinium and the polonium.

\section{Po Fuel Properties Status Summary}

Mound Laboratory has established a research program to measure basic physical and chemical properties of polonium fuels. Table VII-6 presents a summary of the data compiled to the present for gadolinium polonide in a tantalum matrix. It is planned to up-date this information for the SNAP 29 fuel form in each SNAP 29 Quarterly Progress Report.

\section{TABLE VII-6}

\section{Polonium Fuels Property List}

1. Neutron spectrum and emission rate

2. Half-life

3. Alpha spectrum and emission rate

4. Gamma spectrum and emission rate

5. X-ray spectrum and emission rate

6. Impurities in fuel form

7. Chemical reactions and rates in air as a function of pressure

8. Chemical reactions and rates in fresh water

9. Chemical reactions and rates in seawater or equivalent

10. Chemical reactions and rates in soil (model to be specified by Martin Marietta)

11. Chemical reactions and rates with capsule materials

12. Chemical reactions and rates with graphite

13. Solubility constants of reaction products

14. Density of predominant reaction products

15. Vapor pressure of GdPo and PoO

16. Melting point

17. Boiling point

18. Heat of fusion

19. Heat of vaporization

20. Specific heat

21. Thermal conductivity of matrix

22. Heat of reaction of GdPo with oxygen

23. Reactions and reaction rates with propellants and propellant reaction products to be specified by Martin Marietta

24. Fuel state as a function of environmental conditions to be determined by Martin Marietta

25. Density of GdPo

26. Stoichiometry of GdPo

27. Specific activity of Po

28. Matrix density (final product)

29. Volume ratio of GdPo to matrix material

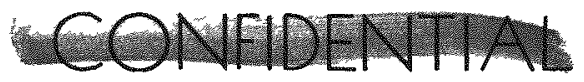

MND2062-12-7

VII -12 
TABLE VII-6 (continued)

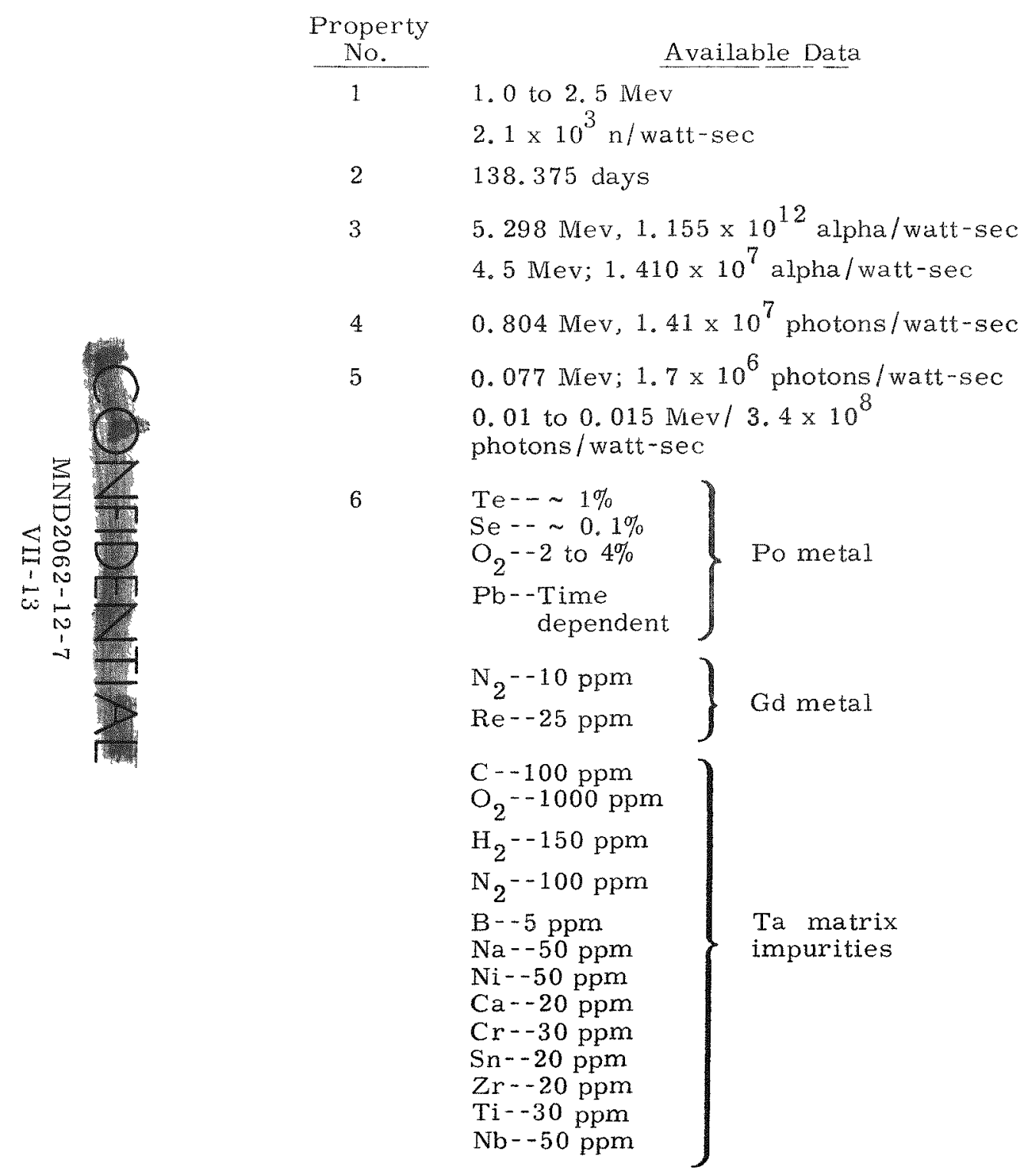




\section{TABLE VII-6 (continued)}

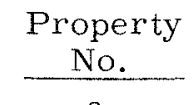

6

(continued)

d)

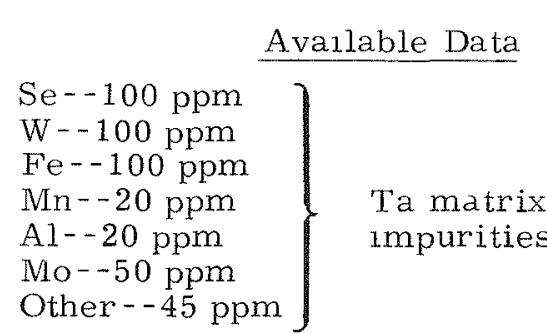

7

Rate of oxidation of Po in GdPo-Ta matrix

$\approx 50 \mathrm{Ci} / \mathrm{hr}$

8

9

10

11

12

13

14

15

16

$$
\begin{aligned}
& \mathrm{GdPo}_{\text {melting point }}=1675^{\circ} \mathrm{C} \\
& \mathrm{Ta}_{\text {melting point }}=2996^{\circ} \mathrm{C}
\end{aligned}
$$

Date for

New Data

$7 / 69$

$4 / 69$

$4 / 69$

$8 / 68$

$4 / 69$

$9 / 69$

$2 / 68$

For: $\mathrm{GdTe} \rightarrow \mathrm{Gd}(\mathrm{g})+\mathrm{Te}(\mathrm{g})$

$\log P_{\text {total }}=\frac{-2.4372 \pm 0.1253 \times 10^{-4}}{T_{O_{K}}}+7.37 \pm 0.76$

17

\section{Comments}

Data maximum rate during 1st hour

of air exposure test No. 2

Mound has no plans to determine this property

Schedule not determined

Estimate for GdPo on basis of that for GdTe. Data available in GdPo data sheets

Data available on GdPo in Ta matrix data sheets

Data for $\mathrm{Gd}-\mathrm{Po}-\mathrm{Pb}$ system available in GdPo data sheets

To be calculated from GdPo vapor pressure measurements 


\section{TABLE VII-6 (continued)}

Property

No.

18

19

$$
\text { For: } \mathrm{Gd}(\mathrm{Te})_{3} \rightarrow \mathrm{Ge}(\mathrm{g})+\mathrm{Te}(\mathrm{g})
$$

$\Delta \mathrm{H}_{(\mathrm{v})}=111.5 \pm 5.7 \mathrm{cal} / \mathrm{mole}$

For Ta: $\Delta H_{(v)}=0.995$ to $1.021 \mathrm{kcal} / \mathrm{gm}$

20

Sp H, GdPo at $25^{\circ} \mathrm{C}=0.034 \mathrm{cal} / \mathrm{gm}^{-\circ} \mathrm{C}$

$\mathrm{Sp} \mathrm{H}$; GdPo at $1000^{\circ} \mathrm{C} \simeq 0.038 \mathrm{cal} / \mathrm{gm}^{-{ }^{\circ} \mathrm{C}}$

$\mathrm{Sp} \mathrm{H}$; GdPo at $2000^{\circ} \mathrm{C} \simeq 0.043 \mathrm{cal} / \mathrm{gm}^{-\circ} \mathrm{C}$

Sp H, Ta matrix at $25^{\circ} \mathrm{C}=0.034 \mathrm{cal} / \mathrm{gm}^{\circ}{ }^{\circ} \mathrm{C}$

21

For 50:1 Ta: GdPo wt ratio at $293^{\circ} \mathrm{K}$

$Q=8.2 \times 10^{-2} \mathrm{cal}\left(\mathrm{sec}^{-\mathrm{cm}^{-}}{ }^{\circ} \mathrm{C}\right)$

For 10:1 Ta: GdPo wt ratio at $293^{\circ} \mathrm{K}$

$\mathrm{Q}=7.2 \times 10^{-2} \mathrm{cal}$

\section{Date for}

New Data

$4 / 69$

23

24

25

26
For GdPo: density $=9.78 \mathrm{gm} / \mathrm{cc}$

$1: 1$
$2 / 68$

$2 / 68$

$4 / 69$

$2 / 68$

\section{Comments}

Data available in GdPo in Ta matrix data sheets. GdPo data to be calculated from GdPo vapor pressure measurements

Estimate available in GdPo in Ta matrix data sheets. To be calculated from GdPo vapor pressure measurements

Estimate available in GdPo in Ta matrix data sheets

Calculated from $\mathrm{PoO}$ vapor pressure measurements

Mound has no plans to determine this property

4/69 Gd-Po-Pb phase diagram available in GdPo data sheet. Thermal profile test will provide more data. Adequate environmental conditions not defined for thermal profile test

Data available in GdPo data sheet

Data available in GdPo data sheet 
TABLE VII-6 (continued)

Property No.

Available Data $4500 \mathrm{Ci} / \mathrm{gm}$

For 50:1 Ta: GdPo wt ratio:

$10.4 \mathrm{gm} / \mathrm{cc}$ at $63 \%$ theoretical density

For 10:1 Ta: GdPo wt ratio:

$10.3 \mathrm{gm} / \mathrm{cc}$ at $64 \%$ theoretical density

For 10:1 Ta: GdPo volume ratio:

$9.91 \mathrm{gm} / \mathrm{cc}$ at $62 \%$ theoretical density
Date for

New Data

Data available in Po metal data sheets

Data available in GdPo in Ta matrix data sheets

Smaller ratio than $10 / 1$ may require fur ther testing of fueling technique 


\section{MATERIAL WELD AND BRAZE STUDIES FOR CAPSULES AND HEAT SOURCES}

\section{Capsule Weld Development}

Mound Laboratory and Martin Marietta are engaged in a joint weld development program to choose an end cap and to develop welding parameters for the SNAP 29 capsule strength member. Two electron beam welded and three tungsten inert gas welded end cap designs were evaluated. One of the tests involves bursting, by hydraulic pressure, three test specimens of each of the five welded end cap designs. Martin Marietta has performed burst tests on similar sets of specimens welded at Martin Marietta and Mound.

\section{a. Experimental data}

All weld development and burst test welding was done using 0.500 inch OD $\mathrm{Ta}-10 \% \mathrm{~W}$ tubing and end caps to fit. Welding parameters for each of the five designs were first developed. The burst test specimens were then fabricated by making five welds of each of the five end cap designs. The first and last welds on each design were example welds and used a short section of Ta-10\% $\mathrm{W}$ tubing. The second, third and fourth welds on each design involved welding the end caps on burst test assemblies (Martin Marietta Drawing 466A1141016).

Welding parameters for each design, radiographic inspection reports, dimensional analysis and micrographs of the burst test series welds were included in the Mound SNAP 29 monthly report for October, 1967. Mound's recommendations for end cap design selection were also included in this report.

Although there were wide differences in burst pressures, all the test specimens were judged satisfactory on the burst test basis.

\section{b. Conclusions}

Based on handling and welding experience at Mound and Martin Marietta, Designs 005 and 007 were disqualified from further consideration. TIG welded end cap Design 001 was mutually agreed upon for the SNAP 29 liner. It was also agreed that a slight modification will be made in the design of this end cap.

The thickness of the vertical member of the end cap next to the tube wall will be increased from 0.012 to 0.020 inch. This modification should improve the strength and welding characteristics of the joint.

Mound will make several welds using the 001 design end caps of the final liner dimensions in order to verify the welding parameters.

\section{E. POLONIUM FUELS ENCAPSULATION FACILITY}

Design of chill blocks for use in the transfer and welding operations involving fueled SNAP 29 capsules is being carried out at Mound Laboratory. It is planned to keep the capsule components in chill blocks as much as possible during the SNAP 29 heat source fabrication. This should tend to eliminate temperature excursions which might cause deterioration of the fuel and container materials.

Design and drawings for the first nine boxes in the SNAP 29 heat source fabrication line have been completed. A request for bids on these items has also been released. The fueled capsules will be fabricated in this portion of the line. The design and drawings for Box 10, in which the fuel block will be loaded and sealed, have been delayed due to lack of loading, sealing and handling information.

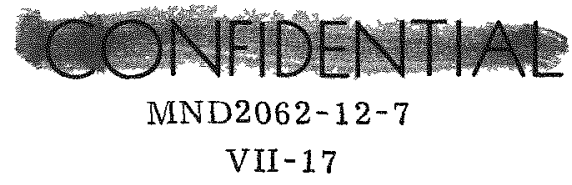




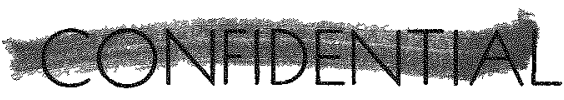

BLANK

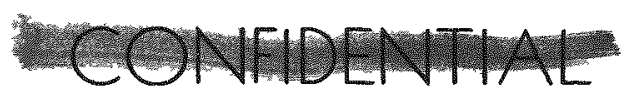

MND2062-12-7

VII - 18 
APPENDIX A

\section{COMPONENT DEVELOPMENT PHASE - THERMAL CONTROL SUBSYSTEM}

\section{A. INTRODUCTION}

This appendix documents the evolution of the thermal control subsystem design and presents the final system design parameters and characteristics. Included are analytical and test results, final design criteria and operating characteristics of all major system components, as well as those predicted for the overall system. The report is concerned primarily with the results of the Control Point 1540 Component Development Phase.

\section{System Function}

The function of the thermal control system is to maintain the module hot junction temperature within specified limits during the operating life of the generator. Since the thermal inventory of the generator varies from beginning of life (BOL) to end of life (EOL) because of the decay of the isotope, the thermal control system must "dump" the excess heat at BOL, and must provide for a minimum heat loss (parasitic losses) at EOL. In addition, the thermoelectric couple system must compensate for different environments such as air to vacuum operation, changes in ambient temperatures, day-night operation, etc.

\section{System Description}

The thermal control system performs its required function by dumping excess heat from the fuel block through a series of six shutters which cover one face of the fuel block (see Fig. A -1). The angular position of the shutters is determined by a linear actuator operating through a spring-loaded linkage. The spring provides a closing force and preload at the EOL position (shutters closed). The linkage also contains a latching device which locks the shutters in the wide open ( $90^{\circ}$ position) in the event of a malfunction which causes the fuel block to overheat.

The actuator position is a function of module hot plate temperature, which is directly related to the hot junction temperature. This temperature is sensed by a liquid metal reservoir integral with the hot plate. Expansion or contraction of the liquid metal $(\mathrm{NaK})$ determines actuator position.

\section{System Development}

Development of the complete system is achieved in three phases as follows:

(1) CP 1540--Component Development

(2) CP 1530--Design Verification

(3) CP 1520--Demonstration System

This appendix is concerned with the results of the component development phase, wherein individual system components are subjected to various structural and environmental tests. The results of these tests form the basis for the design verification system configuration. This is shown in block diagram form in Fig. A - 2 .

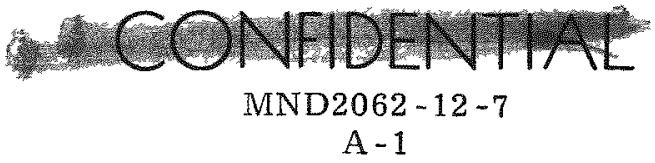



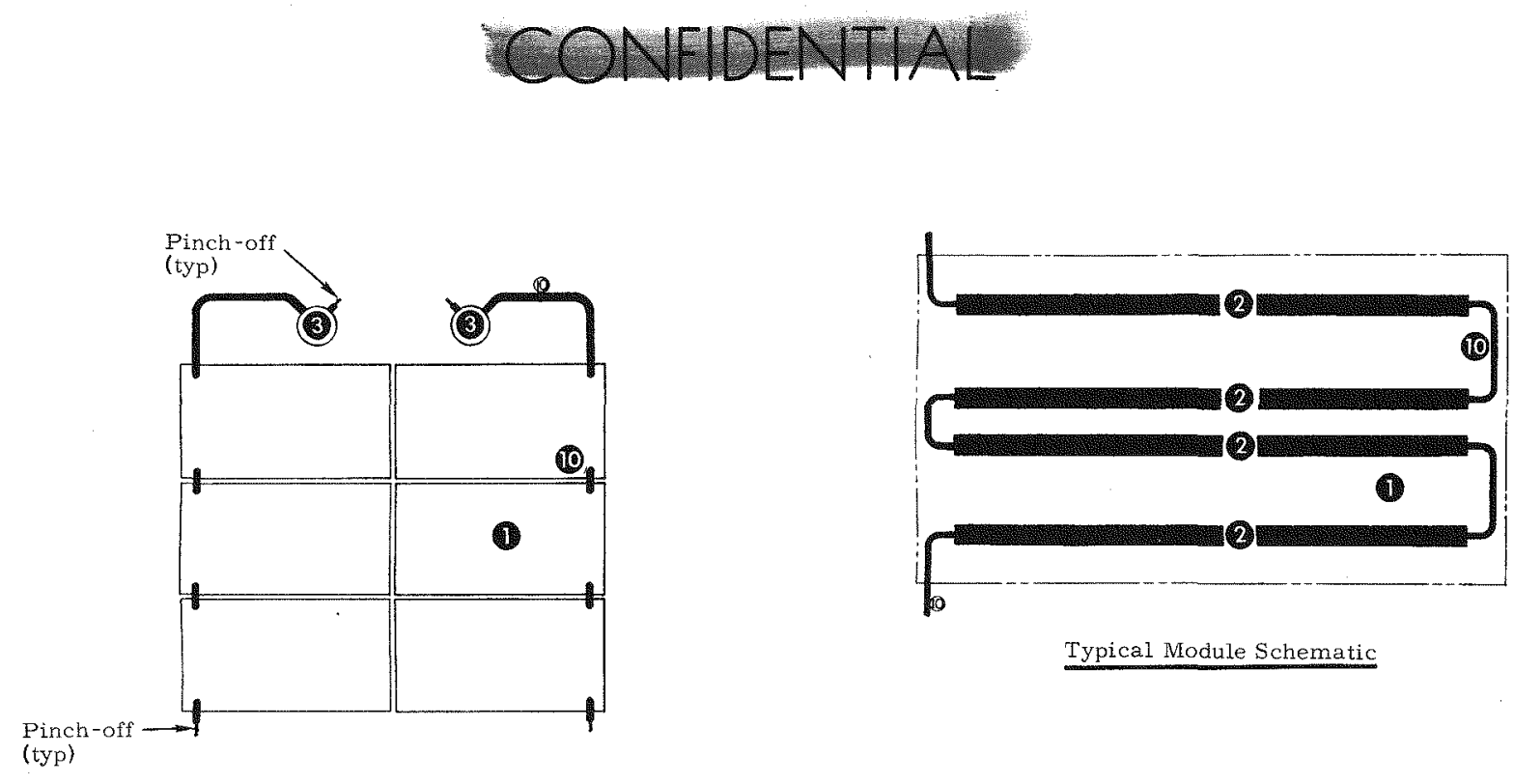

Typical Module Schematic

Typical Six-Module Arrangement
(1) Niodule hot plate
(2) NaK reservoir
(3) Actuator
(4) Separable link
(5) Quadrant
(6) Linkage
(2) Shutter
(8) Flex cable
(9) RTG housing
(10) Interconnecting tubing
(1) Return spring
(12) Bearing
(13) Latch

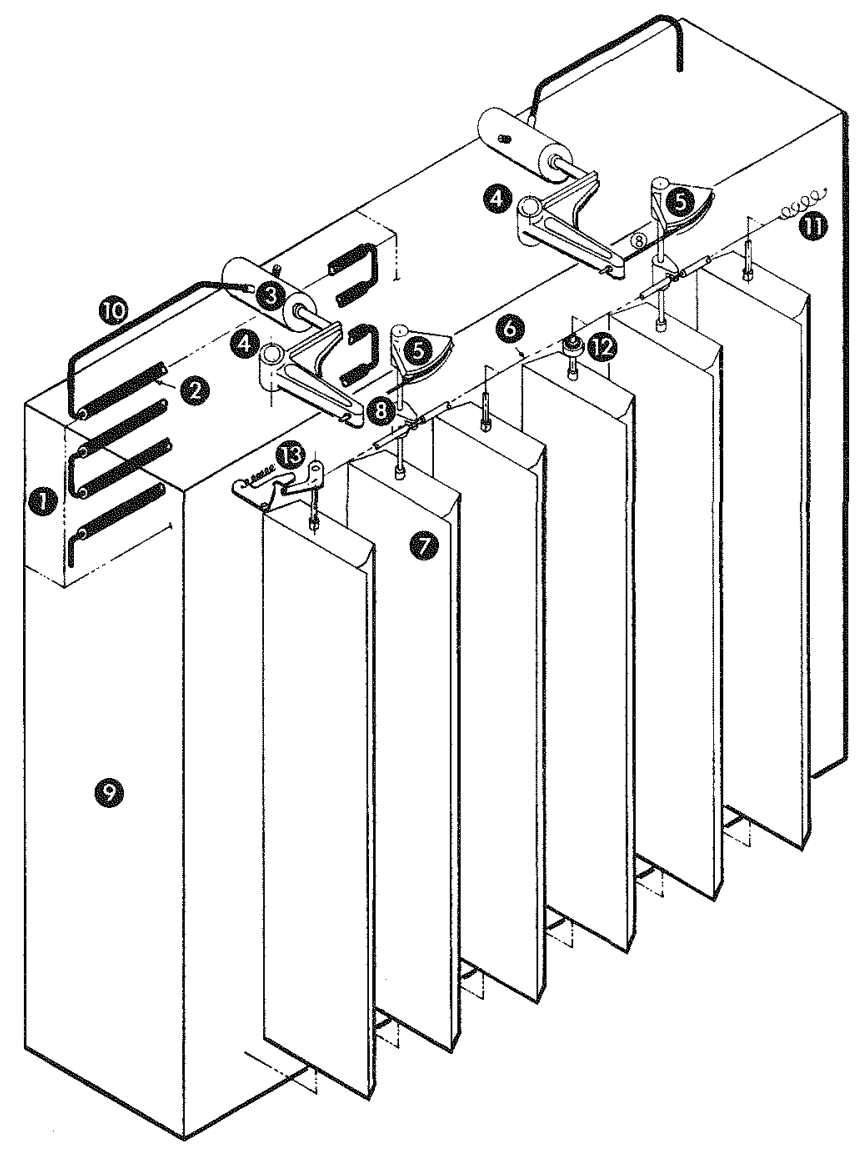

FIG. A-1. SCHEMATIC DIAGRAM THERMAL CONTROL SYSTEM

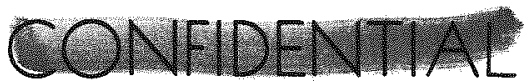

MND2062-12-7

A -2 
The individual tests performed under CP 1540 are as follows:

(1) Actuator room temperature burst test (performed by vendor)

(2) Reservoir-tubing burst test, room temperature

(3) Actuator cycling test

(4) Actuator burst test

(5) Bearing lubricant evaluation test

(6) Preliminary shutter vibration test, room temperature

(7) Shutter vibration test

(8) Shutter performance test.

These tests are described in detail in Section C.

In addition to the tests, several design improvements were incorporated during the CP 1540 phase as a result of a continuous mechanical and thermal design analysis. The major results of these analyses were a change from stainless steel shutter construction to titanium, the addition of a separable link to the linkage system and the incorporation of the $\mathrm{NaK}$ reservoirs as an integral part of the module.

\section{B. SUMMARY}

\section{Actuator Design}

The results of the test program indicate that the design of the actuator, manufactured by the Flexible Metal Hose Company, is adequate to meet the cycling and pressure requirements for this application. The performance of the specimens which simulated the actuator sliding joints in the lubricant evaluation test, however, indicates that the use of solid film lubricants on the external joint is desirable to reduce the "stick-slip" effects which were prevalent because of the relatively high coefficient of friction. The drawing will be modified to include this for the CP 1530 series actuators.

\section{Shutter Design}

The basic structural adequacy of the titanium shutter design was demonstrated in the three hours of vibration to which a three-shutter assembly was subjected. However, the design of Haynes -25 foil insulation covering should be modified to incorporate relief notches in order to compensate for differential thermal expansion effects which caused several cracks to appear in the test specimens. These will be incorporated into the CP 1530 design.

\section{Bearings}

Tungsten diselenide, $\mathrm{WSe}_{2}$, with a sodium silicate binder was chosen as the primary lubricant. The performance of the binder was demonstrated to be adequate in the shutter vibration tests.

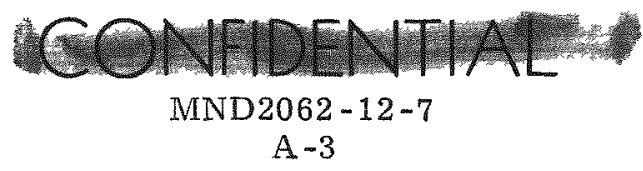




\section{NaK Keservoir}

The NaK reservoir design has undergone several changes in concept during the CP 1540 phase, primarily as a result of changes in the module design. The original design was subjected to a burst test, which demonstrated the structural adequacy of the design. The succeeding designs with the reservoirs brazed into the modules should provide at least equal structural margins, since the tubes are supported by the module hot plate. They do however have the disadvantage of a larger number of welded joints. However, since these were not involved in the failure mode of the orıginal design, a similar margin of safety is anticipated.

The results of the various development tests indicate that, structurally, a considerable margin of safety is inherent in the design. The actuator burst test results, for example, indicate that the strength of the actuator is an order of magnitude greater than the operating pressure. This suggests the possibility of reducing material thicknesses to save weight. However, examination of the failure mode in the burst tests shows the bellows to be the weak point. Since the material thickness is nominally 4 mils, it is not practical to reduce this because it may result in a reduced cyclic life and also excessive volumetric deflection.

System performance margins remain to be tested in the CP 1530 designverification series. Analysis indicates that the system will show similar margins during performance tests.

\section{COMPONENT DEVELOPIMENT}

The major portion of work conducted in the CP 1540 phase was concerned with component development tests, wherein individual system components were subjected to vibration and thermal-vacuum environmental tests to determine design adequacy. In addition, design analysis was performed to reflect the adequacy of design with respect to the total system performance. These are discussed in the following paragraphs.

\section{Actuators}

The NaK actuators, 466A1541015, which provide both power and position inputs to the shutters, are among the principal system components. For this reason, two actuators are used in the system, interconnected through the linkage in such a manner that, upon failure of one, the other may still open the shutter to the full emergency position $\left(90^{\circ}\right)$, if required.

The basic actuator design, Fig. A-3, chosen for this system was previously used on the SNAP 11 program and on the Phase I portion of SNAP 29. The original manufacturer, The Aeroflex Corporation, declared bankruptcy during the present program, and consequently it became necessary to find another source. The Flexible Metal Hose Corporation was selected to design and manufacture the actuators used for this program.

\section{Actuator Operation}

NaK surrounds the external portion of the actuator primary bellows (see Fig. A-3) and fills the interior of the adjusting bellows, entering through the internal passages in the actuators. With no external load, the natural spring characteristic of the primary bellows retains the piston rod in the retracted position. NaK pressure operating through the effective piston area $\left(0.16\right.$ in. $\left.{ }^{2}\right)$ must be great enough

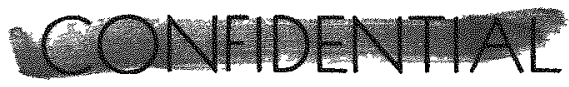




\section{- CONFIDENTIAL}

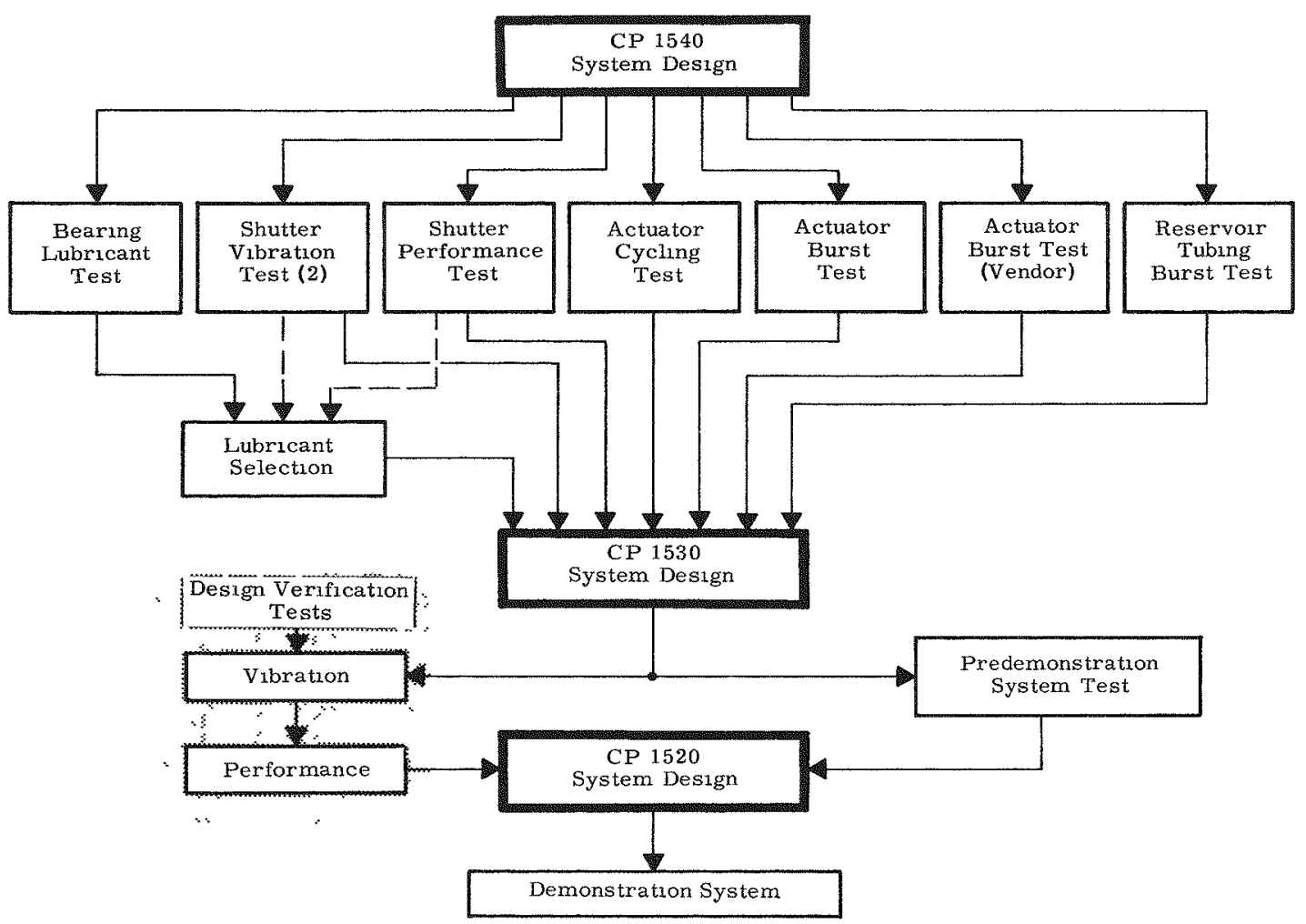

FIG. A-2. EVOLUTION OF DESIGN T/C SYSTEM

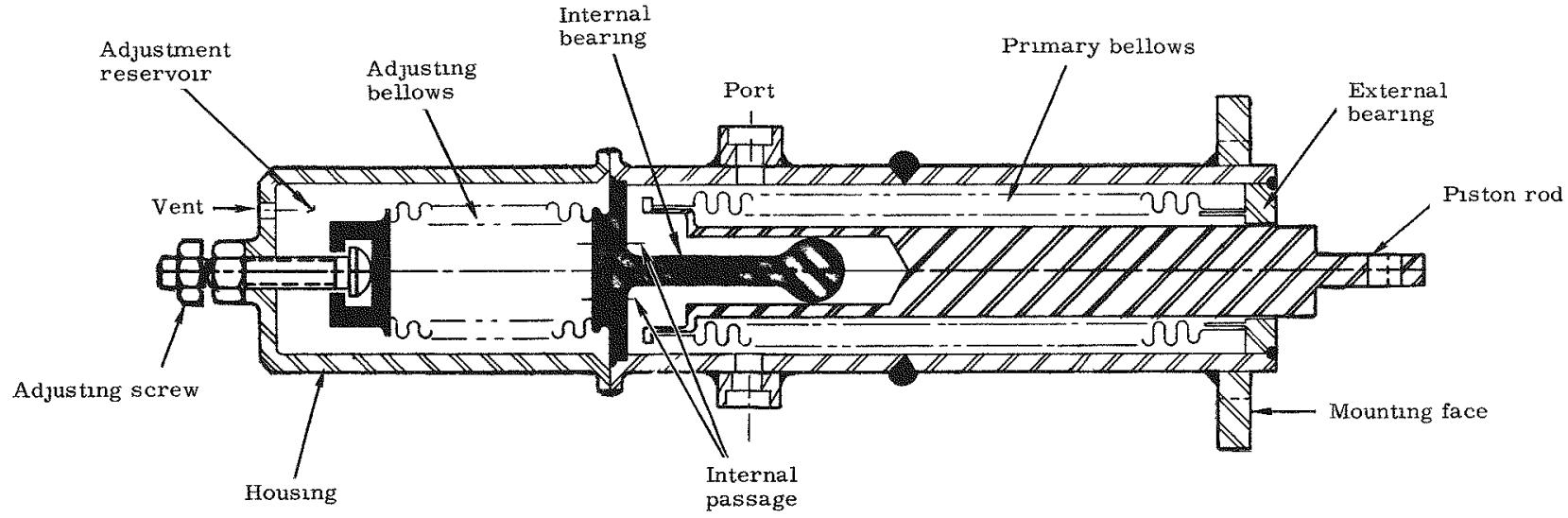

FIG. A -3. NaK ACTUATOR THERMAL CONTROL SYSTEM

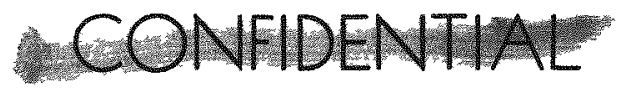

MND2062-12-7

A -5 
to overcome the bellows spring force (45 $\mathrm{lb} / \mathrm{in}$. ) plus any external load. The total actuator stroke is 0.375 inch, and the total displacement is 0.060 cubic inch. The function of the adjusting bellows is to provide an adjustment of the piston rod position during system installation by varying the system volume. A total adjustment volume of 0.06 cubic inch is provided by this bellows.

\section{Actuator Tests}

Component development tests were conducted on a total of 13 actuators during the CP 1540 phase. These consisted of vendor tests conducted on one actuator as required by the procurement drawing, 466A1541015, and cycling and burst tests conducted by Martin Marietta to determine the limits of the design. The latter tests were conducted at operating temperature and used silicone oil as the working fluid. The various tests are described in the following paragraphs.

a. Actuator room temperature burst test

Tests were performed by the actuator vendor, The Flexible Metal Hose Corporation, on one actuator as required by Drawing 466A1541015. The tests consisted of a creep test and a burst test, both at room temperature, using water as the test fluid. The purpose of these tests was to verify the structural integrity of the basic actuator design.

Creep rate at room temperature was determined to be $1.95 \%$ at 1550 psig for one hour. This was within drawing requirements. The actuator internal volume, determined during this test, was 0.47 cubic inch.

Failure occurred at 2700 psig during the burst test. The point of failure was internal and consequently was not determined by the vendor. The actuator was $\mathrm{X}$-rayed at Martin Marietta, and the failure point was determined to be in the main bellows near the point of attachment to the actuator piston.

This test is reported in Report 1540-29, dated May 22, 1967.

b. Actuator cycling test

Tests were performed on nine actuators to determine the cyclic limits of the actuators. The actuators were tested in three cyclic modes with three actuators included in each mode. The cyclic frequency was constant at $1 \mathrm{cps}$ for each mode. The tests were conducted at a nominal temperature of $400^{\circ} \mathrm{F}$ utilizing oil as the working fluid. The various modes are:

Mode A: Three actuators were cycled for a minimum of 115,200 cycles at a nominal 0.125-inch amplitude. The test was continued on one actuator for a total of 133,548 cycles. No failures occurred. This test simulated the amplitudes anticipated during the orbital portion of the mission. Cycling was conducted with the bellows extended to the mid-stroke position of the actuator.

Mode B: Three actuators were cycled for a minimum of 3000 cycles at a nominal 0.188-inch amplitude. No failures occurred. This test simulated the amplitudes anticipated during ground operations (system assembly, checkout and test). The test cycles were conducted with the bellows extending from the retracted position to the mid-stroke position, which represents the room temperature to operating temperature range.

Mode C: Three actuators were cycled for a minimum of 150 cycles at the fullstroke (0.375-inch) amplitude. Again no failures occurred. This test simulated

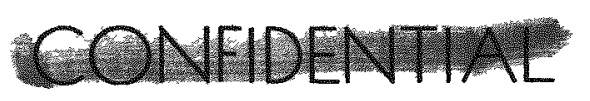

MND2062-12-7

A -6 
the emergency condition whereby the shutters are required to open $90^{\circ}$. This condition could occur once during the operating life and once during ground test.

\section{c. Actuator burst tests}

In addition to the room temperature hydrostatic burst test performed by the vendor, six additional actuators were tested to failure by Martin Marietta. Three of the actuators were new, three had previously been tested in Mode $\mathrm{C}$ of the cycling test. The burst tests were conducted at $400^{\circ} \mathrm{F}$, also utilizing oil as the working fluid. The six actuators all failed between $3500 \mathrm{psig}$ and $3700 \mathrm{psig}$. The failure point in all six actuators was the adjusting bellows.

\section{Actuator Design Discussion}

The results of the burst tests, 466A1543720, indicate that a considerable margin of safety exists, since the burst pressures were higher than the anticipated operating pressures by an order of magnitude. The consistency of failure at the adjusting bellows in the Martin Marietta tests indicates that this is the weak point of the design. Examination of the actuator cross section, Fig. A-3, discloses that more clearance exists between the housing and the adjusting bellows than exists between the primary bellows and the piston rod. This results in less support for the adjusting bellows, and consequently it is prone to failure. However, X-ray examination of the vendor's test specimen indicated that failure occurred in the primary bellows. The fact that this failure occurred at approximately $1000 \mathrm{psi}$ lower than the se bellows withstood in the other tests indicates a different failure mechanism existed. The failure occurred in the plane of the actuator ports and consequently could have been instigated by a sudden pressure impulse.

For possible future applications where a higher operating pressure is desired, it is suggested that the housing diameter be reduced in the area of the adjusting bellows to provide a closer fit and consequently more support for the bellows.

The bearing lubricant evaluation test also included two specimens representing the actuator piston rod external and internal joints. The purpose of this test was to determine the suitability of these chrome plated joints for the thermal-vacuum environment. These specimens were tested for a total of 3600 cycles during a 90 -day period. The static friction coefficients for both specimens were high, ranging from 0.212 to 0.635 , with an average of 0.498 for the external bearing specimen. The internal bearing specimen friction was even higher, ranging from 0.345 to $>1.11$, with an average of 0.710 . The test was not entirely representative of the internal bearing joint, since this is actually immersed in NaK, which will act as a lubricant. Both specimens exhibited considerable "stick-slip" motion during the test because of the high friction coefficients. Because of this, the actuator drawing, 466A1541015, will be revised for the CP 1530 series to include the surface application of a solid film lubricant to the piston rod. In addition, the linkage design will be modified to prevent the actuator piston from reacting any side loads which may be transmitted through the linkage.

\section{NaK Reservoir and Tubing}

The NaK reservoir and tubing assembly, 466A1541014, which forms the sensing and transmission elements of the NaK system, is also one of the principal system components. For this reason, it is necessary to verify the structural design of the assembly, which includes several welded joints.

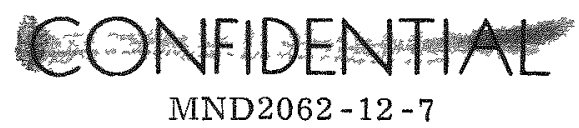

A -7 


\section{a. NaK reservoir and tubing burst test}

One assembly, consisting of two reservoirs and their associated interconnecting tubing, was hydrostatically tested to failure at room temperature as part of the requirements of the assembly drawing, 466A1541014.

Failure occurred in one of the reservoir tubes at a pressure of 12,000 psig. Yield occurred at approximately 10,000 psig. Both reservoir tubes were deformed such that their diameter increased from 0.625 inch to approximately 0.715 inch. This test is described in Report 1540-23.

\section{b. Nak reservoir and tubing design discussion}

The original reservoir tubing design shown in $466 \mathrm{~A} 1541014$ consists of two $5 / 8$ inch diameter tubes which are interconnected with each other and the actuator by $1 / 8$ inch diameter tubing. As originally designed, the reservoir tubing wall thickness was 0.049 inch. The results of the burst test permitted this to be reduced to 0.035 -inch wall thickness. Additional design changes resulted from the changes in basic module design which are discussed in Section D, Paragraph 2.

\section{Shutters}

The six shutters used in the system provide the means of varying the fuel block area exposed for rejection of excess heat. The shutters have undergone consider able design changes since their inception, primarily in an effort to reduce their weight, and also to reduce parasitic heat losses.

The basic shutter design (see Fig. A-4) consists of primary structure, covered with Min-K insulation and supported at each end by trunnions which permit rotation.

As originally conceived the primary structure was a framed structure. How ever, to increase stiffness and overall strength, this was changed to a stainless steel honeycomb, as shown on Drawing 466A1541010. The weight of this shutter was approximately 7 pounds. In an attempt to reduce the weight, titanium honeycomb was used, resulting in a weight of 4.38 pounds (eight-module RTG size).

Three tests were performed during this phase: a room temperature vibration test on one stainless steel shutter, a high temperature vibration test and a thermalvacuum performance test. These are described in the following paragraphs.

\section{a. Shutter tests}

Structural dynamic tests were performed on both major shutter types, the stainless steel shutter, 466A1541010, and the titanium shutter, 466A1541011. Thermalvacuum performance tests were also conducted on the titanium shutter design to determine parasitic heat losses through the shutters.

\section{b. Preliminary shutter vibration test}

Room temperature vibration tests were performed on one stainless steel shutter, 466A1541010, in order to determine design adequacy. During the tests, the shutter exhibited a tendency to loosen the end plates which retained the Min-K insulation. This resulted in a change in the titanium shutter design (466A1541011) which provided more axial support for the Min-K, thereby removing the loads from the end plates.

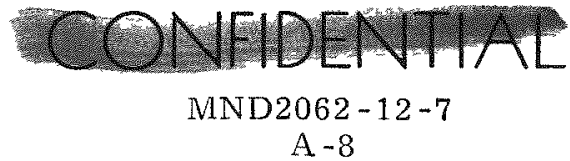




\section{c. High temperature shutter vibration test}

Three shutters, portions of the interconnecting linkage and the shutter hinge bearings were subjected to sine and random vibration tests. The assembly was heated to a maximum temperature of $1140^{\circ} \mathrm{F}$ resulting from a simulated fuel block heat source. The shutters were installed at an angle of $45^{\circ}$, and the actuators were dynamically simulated by means of a "cantilevered beam" spring which provided a stiffness approximately equal to the combined actuator and NaK system.

The shutters were subjected to $3 \mathrm{~g}$ and 4-1/2 $\mathrm{g}$ sinusoidal vibration for 20 minutes in each major axis. In addition they were subjected to random vibration at $10 \mathrm{~g}$ and $29.1 \mathrm{~g}$ for six minutes in each axis. Additional tests at $32,34.9,39.3$ and $43.6 \mathrm{~g}$ levels were conducted in one axis. At the conclusion of these tests, the shutters were still in operating condition. Several relatively minor local failures occurred, the principal one being the appearance of cracks in the Haynes-25 foil (see Fig. A-4). Considerable Min-K dust was expelled from the shutters during the high level random vibration tests, particularly in the $39.3 \mathrm{~g}$ and $43.6 \mathrm{~g}$ levels. Examination of the shutters following the tests indicated that the $M i n-K$ slabs were cracked and broken in several places. However, sufficient $M i n-K$ remained to ensure proper shutter performance.

Figures A-5 and A-6 depict the angular excursions of the shutters during the tests. These were of interest primarily because of the possibility of latching the shutters in the $90^{\circ}$ position during vibration. As can be seen, the maximum amplitude was $+15^{\circ}$. With the shutters in their extreme "normal" position of $60^{\circ}$, this additional $15^{\circ}$ excursion does not result in latching.

\section{d. Shutter thermal-vacuum test}

An assembly of three shutters, together with portions of the linkage and their hinge bearings were subjected to a thermal-vacuum test to determine the parasitic heat losses in the end-of-life, (shutter closed) position. These tests were conducted at various heat source temperatures ranging from $1100^{\circ} \mathrm{F}$ (nominal) to $1700^{\circ} \mathrm{F}$ (nominal). The shutter inner and outer face temperatures for various heat source temperatures, as obtained from this test, are shown in Figs. A-7 and A-8. test.

Figure A-9 depicts the bearing and linkage temperatures measured during this

During this test, the Haynes -25 foil on the shutters developed cracks similar to those obtained during the vibration tests.

\section{e. Shutter design discussion}

The results of the vibration tests verified the basic structural design adequacy of the titanium shutters. The total vibration time during the se tests was approximately 3.1 hours, as opposed to the anticipated operational vibration duration of 6 minutes.

The appearance of the cracks in the Haynes -25 foil in both the vibration and thermal performance tests eliminated vibration as the cause and indicated that a thermal condition was the cause. An analysis was performed which indicated that, due to temperature difference between the inner and outer faces as well as the difference in thermal expansion coefficients of the two materials, a large differential in length occurs between the inner and outer faces. Since the titanium structure is considerably stiffer than the Haynes -25 foil, the foil must deflect. The presence of the stiffening beads in the foil acted as a bellows to absorb this differential. How ever, since the beads ended before reaching the edges of the Haynes -25 surface,

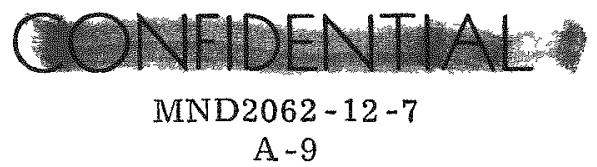




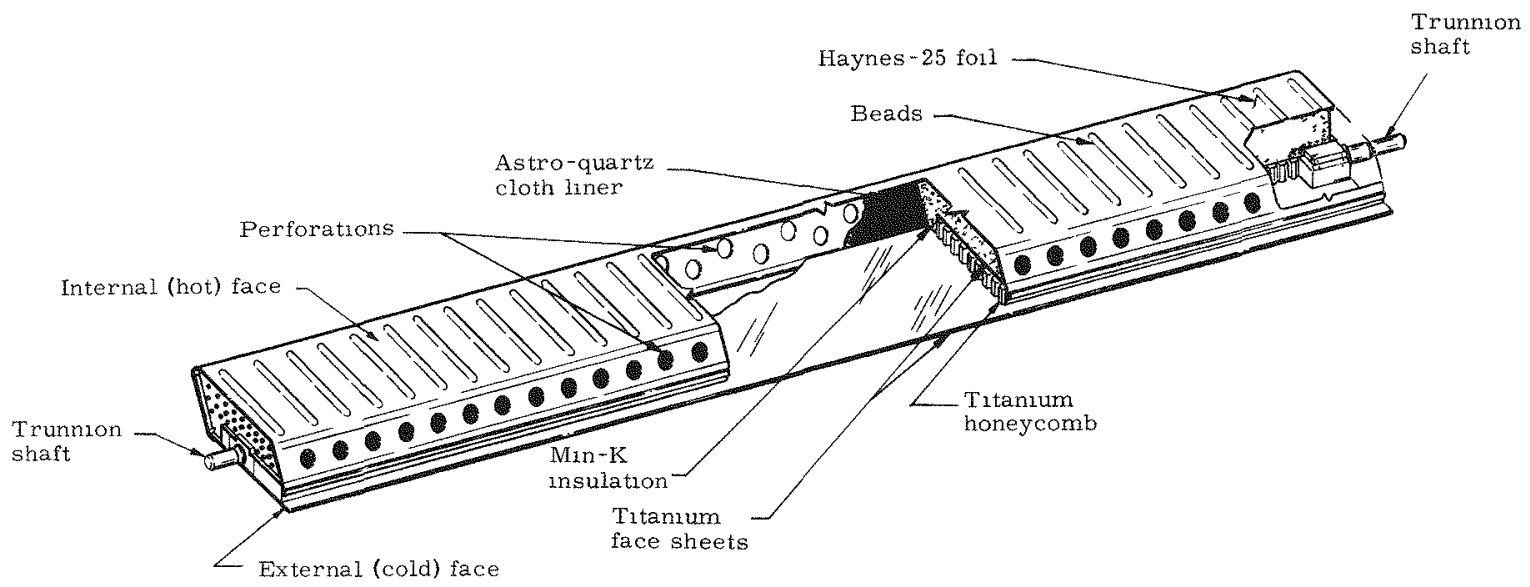

FIG. A-4. TITANIUM SHUTTER --THERMAL CONTROL SUBSYSTEM

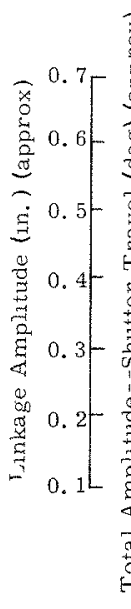

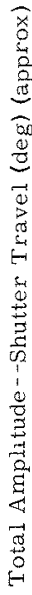

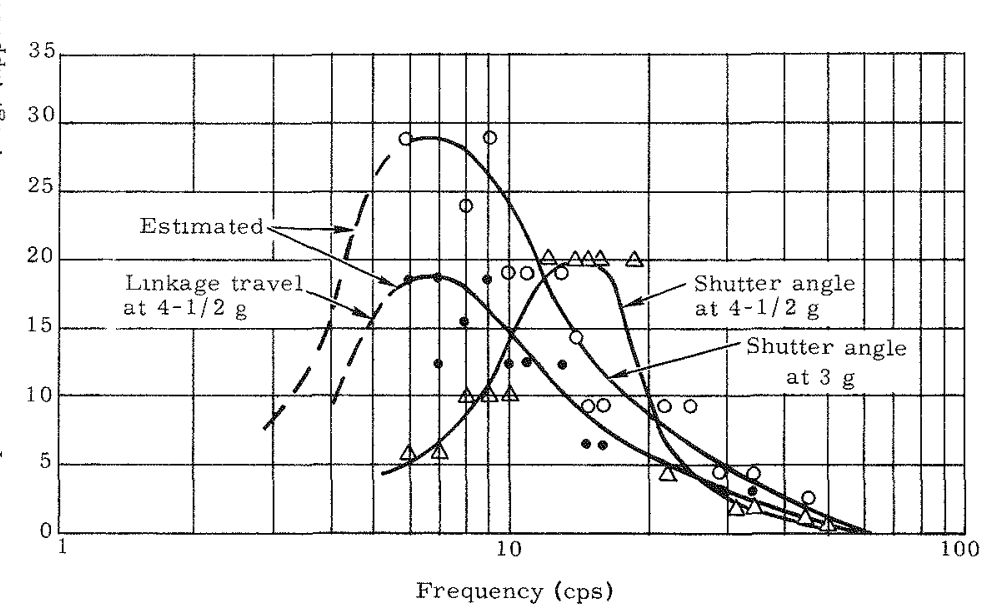

FIG, A-5. SHUTTER DISPLACEMENT VERSUS FREQUENCY (SINUSOIDAL VIBRATION)

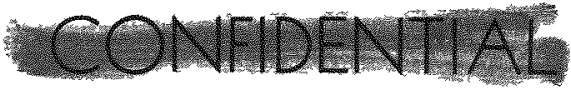

MND2062-12-7 
Note Visual data obtained during random vibration tests.

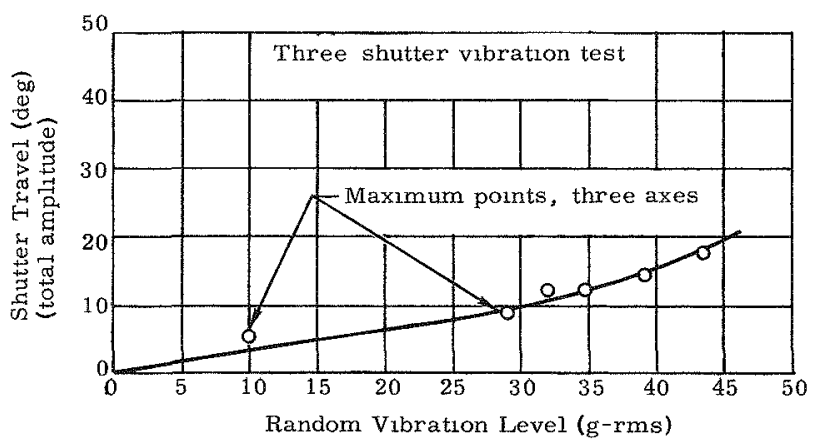

FIG A 6. SHUTTER DISPLACEMENT VERSUS RANDOM VIBRATION LEVEL,

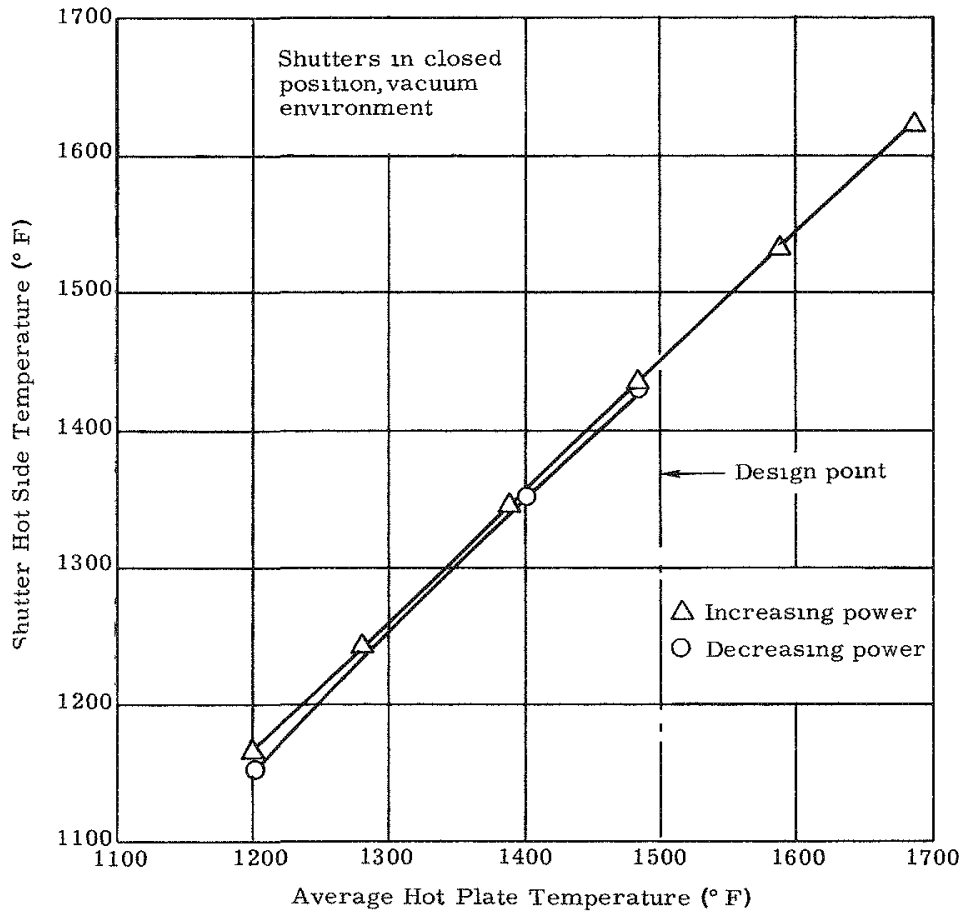

FIG. A 7. SHUTTER HOT SIDE TEMPERATURE VERSUS HEAT SOURCE TEMPERATURE

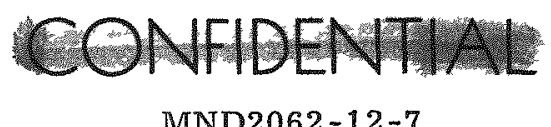



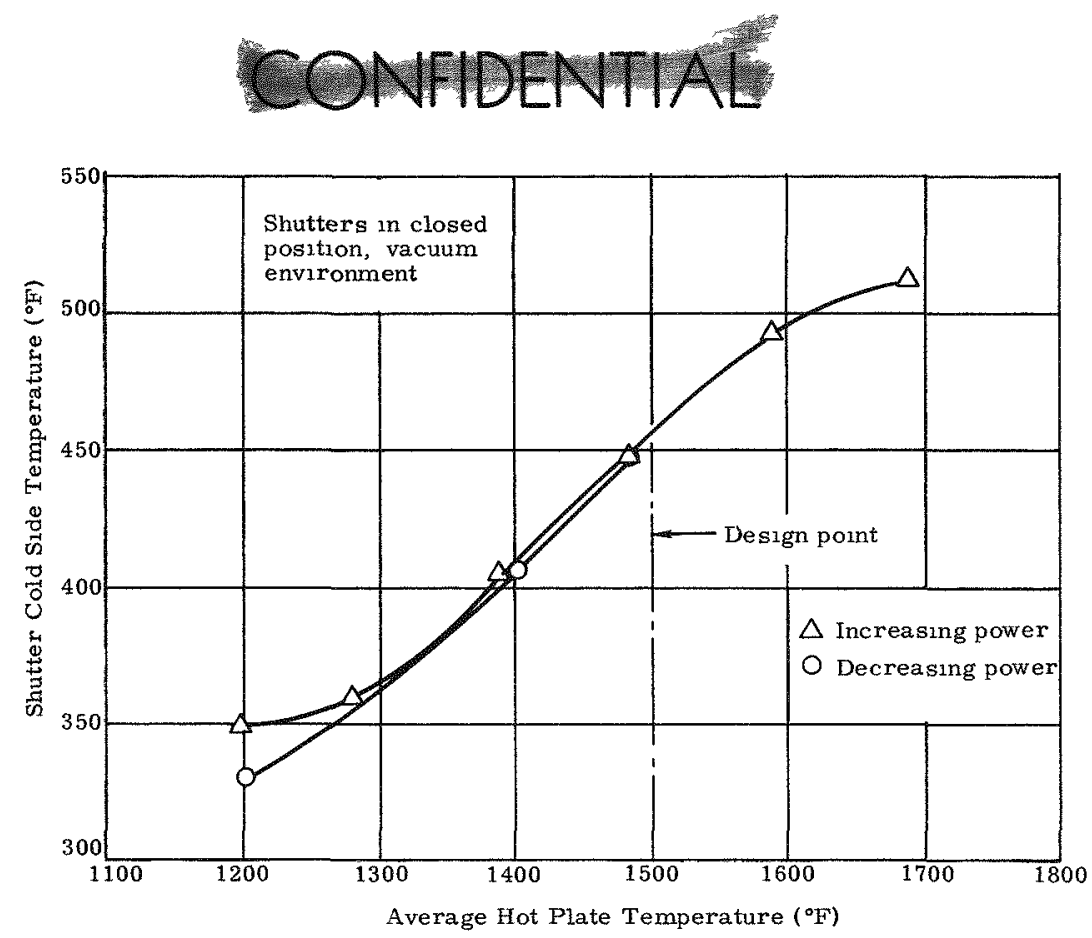

FIG. A-8. SHUTTER COLD SIDE TEMPERATURE VERSUS HEAT SOURCE TEMPERATURE

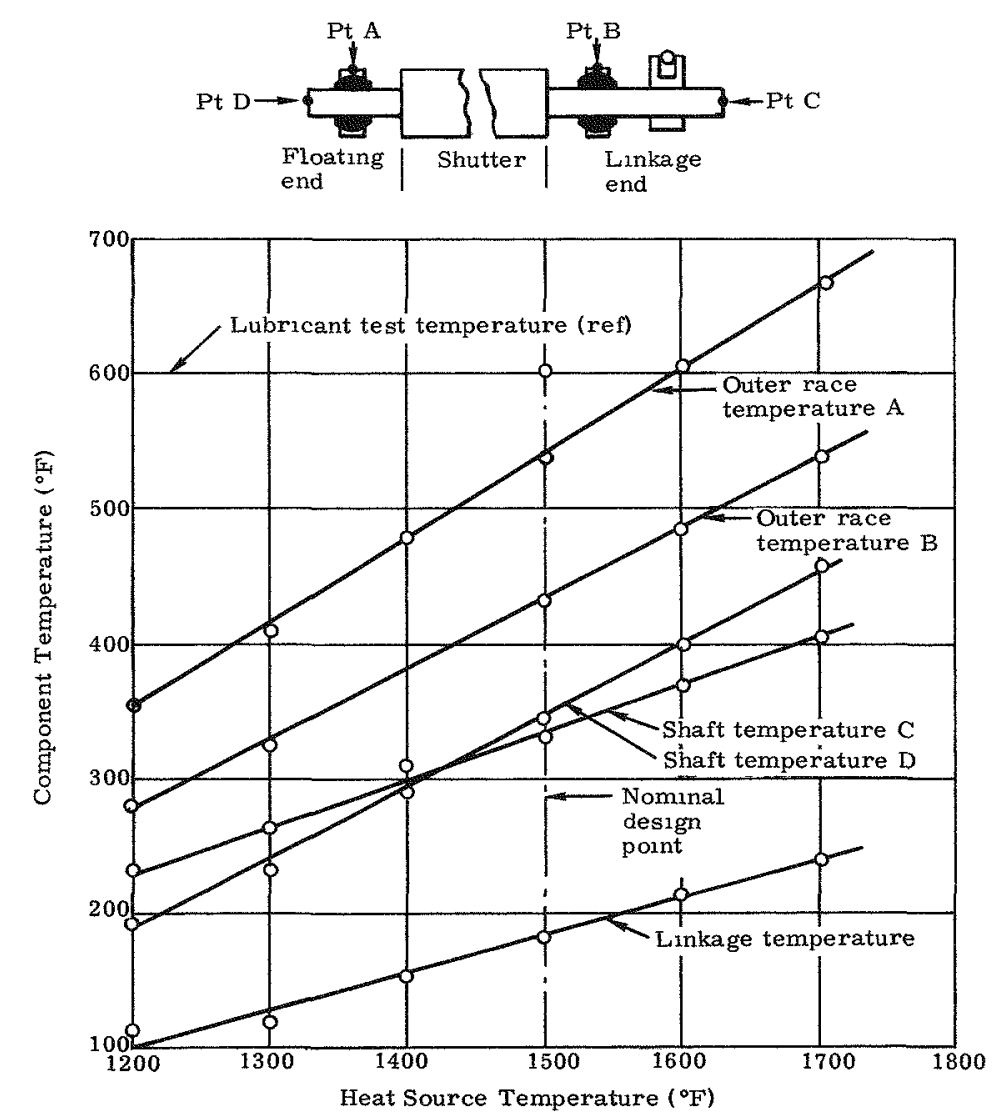

FIG. A-9. COMPONENT TEMPERATURE VERSUS HEAT SOURCE TEMPERATURE-SHUTTER THERMAL VACUUM TEST

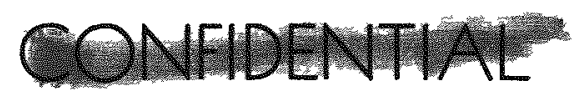

MND2062-12-7 


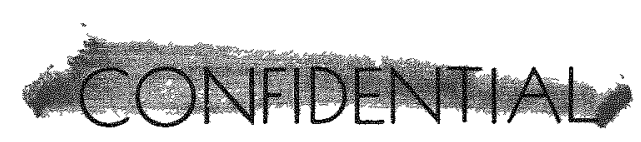

crimps and cracks appeared. The solution to this problem consists of adding notches at intervals along the length to permit the Haynes foil to deflect and absorb this differential. This modification will be incorporated in the CP 1530 shutter design.

\section{Bearings}

Because of the environment to which they are subjected during their operating Iife, the shutter hinge bearings cannot be selected from standard off-the-shelf bearings. The bearıngs cannot utilize conventional organic oil or grease-type lubricants, instead solid film lubricants are required. I test program was conducted to evaluate several solid film lubricants in a 90-day thermal-vacuum test. In addition, bearings coated with a solid film lubricant were included in the shutter vibration test to verify the adequacy of the binder material which is common to several of the lubricants evaluated.

\section{a. Bearing tests}

The bearings were involved in two tests, the lubricant evaluation test and the shutter vibration test. Bearings were also included in the shutter thermal performance test, from which the bearing design operating temperatures were verified.

\section{b. Bearing lubricant evaluation test}

This was a 90 -day thermal-vacuum test whose purpose was to evaluate several lubricant substrate combinations at the load, temperature and cyclic duty cycles to be encountered during orbital operation. The test specimens were designed to simulate the shutter trunnion shaft-to-bearing inner race bore joint. All specimens completed the 3600 -cycle test without failure. Friction coefficients obtained during the test are shown in Fig. A-10.

\section{c. Vibration test}

The bearings included in the shutter vibration test withstood the three-hour vibration test without structural failure. This verified the structural design adequacy of the bearing inner and outer races, as well as that of the shutter trunnion shaft. The lubricant used on the bearing and shaft was Molykote X-15, a commercial molybdenum disulfide lubricant which utilizes sodium silicate as the binder. This was chosen because of its ready availability and because the binder is common to several of the other lubricants involved in the evaluation. Considerable wear of the lubricant occurred during the three hours of vibration; however, none of the coated surfaces flaked or chipped off and some lubricant remained, which verified the choice of binder.

\section{d. Bearing design discussion}

The basic bearing design chosen for this application is a plain, spherical, selfaligning bearing utilizing a split outer race. This was chosen in preference to a conventional ball or roller bearing because it provides fewer development problems than the more highly stressed rolling element bearings.

The bearings are manufactured by Martin Marietta, utilizing tools and techniques developed for similar bearings used on the PRIME vehicle.

The substrate materials used are René 41 nickel alloy for the outer race and Lescalloy $B G-42$ for the inner race. The latter material is a modified Type $440-\mathrm{C}$

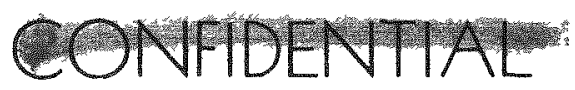


corrosion resistant steel specifically designed for bearing and gear applications. It is usable to temperatures of approximately $900^{\circ} \mathrm{F}$ for long periods, providing a margin of $300^{\circ} \mathrm{F}$ over the design point for this application. The upper limit of the Rene 41 bearings of this design is greater than $1500^{\circ} \mathrm{F}$.

The lubricant selected for this application is tungsten diselenide with a sodium silicate binder. This was selected because of its inherently lower friction characteristics and because of its good oxidation, thermal vacuum, chemical and radiation stability characteristics. The other lubricants involved in the selection were as follows:

(1) Molykote X-15 (molybdenum disulfide and graphite in a sodium silicate binder).

(2) Tungsten disulfide (sodium silicate binder).

(3) Electrodeposited gold.

(4) Boeing X-88 gold alloy.

(5) Silver-palladium alloy $(80 \% \mathrm{Ag}, 20 \% \mathrm{Pd})$.

A more complete discussion is presented in Report 1540-38.

\section{SYSTEM ANALYSIS}

Design analysis was continuously performed during the CP 1540 phase in order to determine the performance of the components when integrated into a complete system. In addition, design analysis effort was expended to study and evaluate advanced and alternate system concepts.

\section{Actuator Performance Analysis}

The basic relationships and physical constants involved in the performance of the NaK actuator are derived in Paragraph 1a. Following this, the system is analyzed for loads and operating pressures and for actuator deflection versus temperature changes.

\section{a. Basic relationships}

The following assumptions are made:

(1) $V_{T}$ includes the total volume of $\mathrm{NaK}$.

(2) The temperature of the actuator and interconnecting tubing is constant.

(3) No loss of pressure occurs between actuator and reservoir.

Referring to Fig. $A-11$, the net piston travel $\left(X-X_{0}\right)$, due to a $\Delta T$ of the reservoir, is a result of the volumetric expansion of the NaK minus the losses incurred by expansion of the reservoir and by compression of the $\mathrm{NaK}$ due to a change in $\mathrm{F}$ as a result of a change in $X$.

Letting $\phi$ be the cubical expansion coefficient of NaK, the total expansion of $\mathrm{NaK}$ due to $\mathrm{a}+\Delta \mathrm{T}$ is as follows:

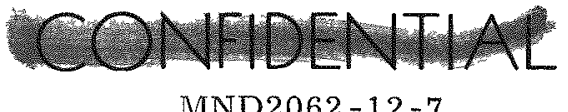




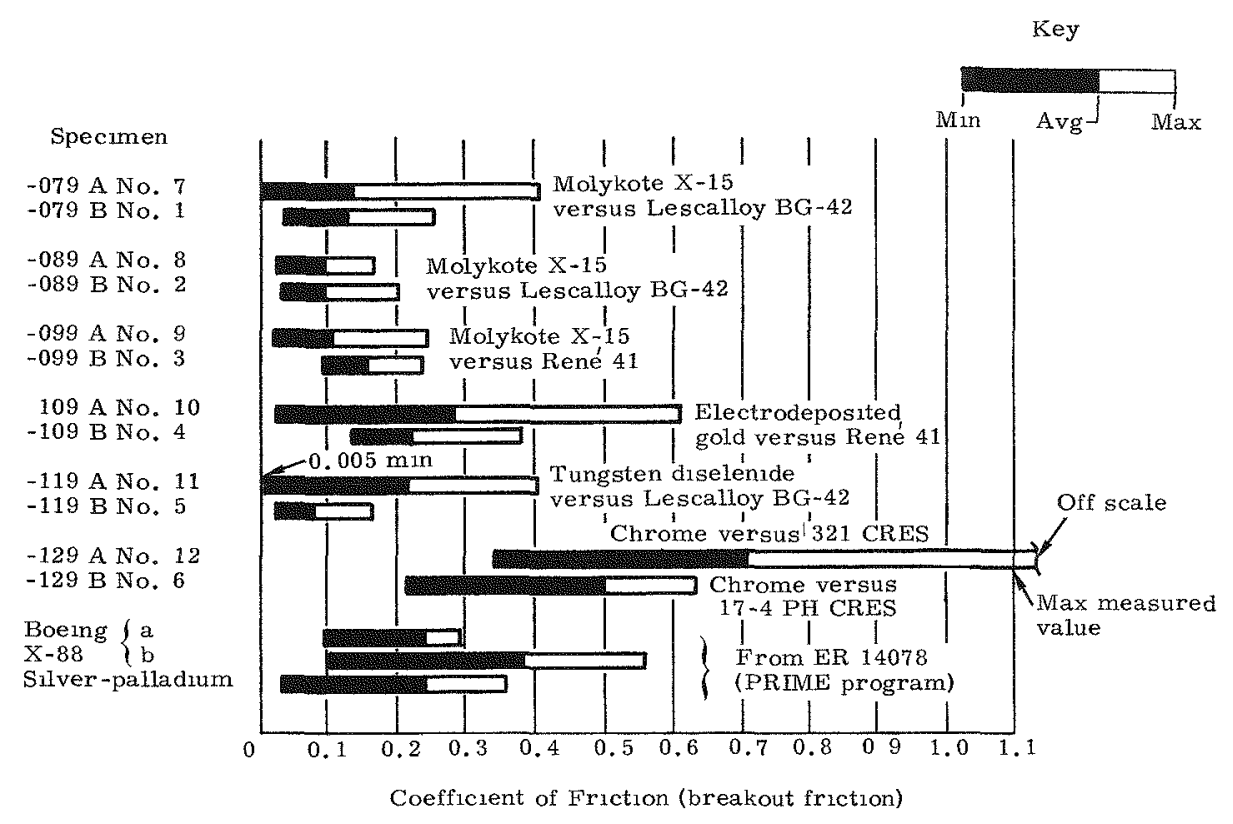

FIG. A-10. STATIC FRICTION COEFFICIENT 90-DAY THERMAL-VACUUM TEST

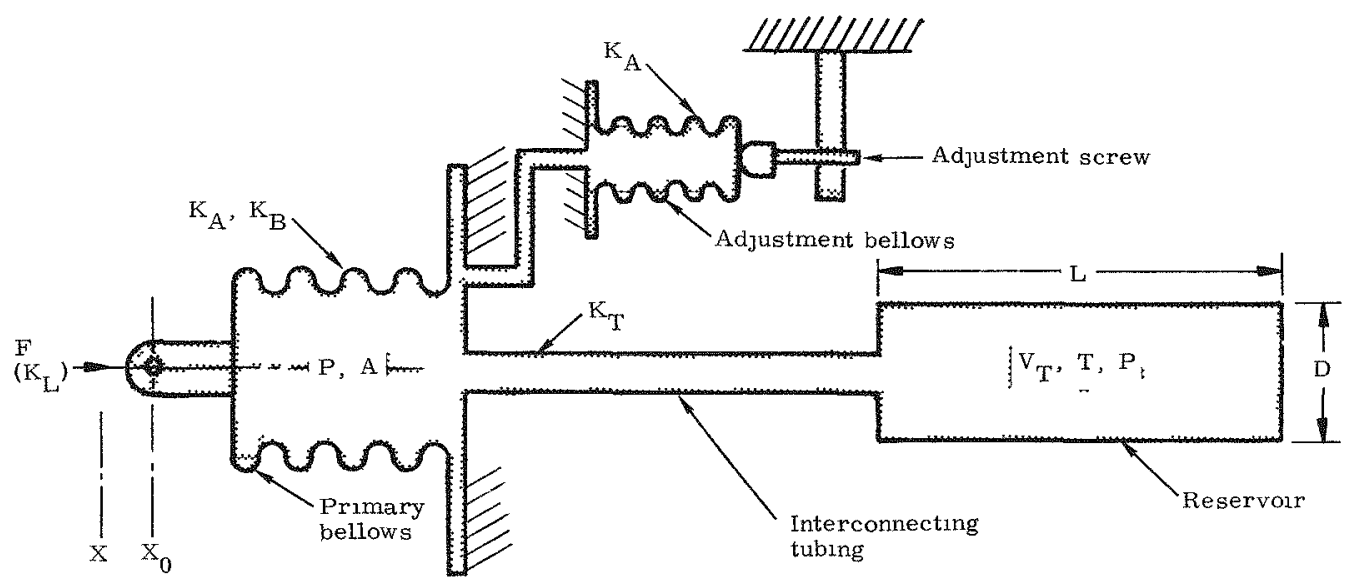

FIG A-11. SCHEMATIC DIAGRAM ACTUATOR--RESERVOIR SYSTEM

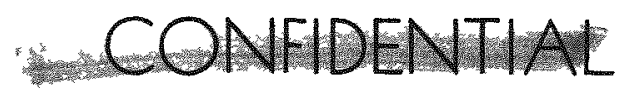

MND2062-12-7 


$$
\mathrm{V}_{\mathrm{a}}=\mathrm{V}_{\mathrm{T}}(\phi)(\Delta \mathrm{T})
$$

The change in system volume due to thermal expansion of the reservoir tubes:

$$
V_{b}=\frac{\pi}{4} D^{2} L\left(2 \Delta T C+\Delta T^{2} C^{2}\right)+\frac{\pi}{4} D^{2} L\left(C \Delta T+2 \Delta T^{2} C^{2}+\Delta T^{3} C^{3}\right)
$$

which reduces to:

$$
V_{b}=\frac{\pi}{4} D^{2} L\left(3 C \Delta T+3 \Delta T^{2} C^{2}+\Delta T^{3} C^{3}\right)
$$

The change in $\mathrm{NaK}$ volume due to change in pressure resulting from changes in external load:

Let

$$
\begin{aligned}
\beta & =\text { bulk modulus of NaK } \\
\beta & =\frac{\Delta P}{\Delta V / V_{T}} \text { (by definition) } \\
\Delta V & =V_{C}=\text { change in volume } \\
\Delta P & =\text { change in pressure }=\frac{\Delta F+X K_{B}}{A} \\
\Delta F & =X K_{L} \\
\Delta P & =\frac{X\left(K_{L}+K_{B}\right)}{A} \\
V_{C} & =V_{T}\left[\frac{X\left(K_{L}+K_{B}\right)}{A \beta}\right]
\end{aligned}
$$

The change in system volume due to change in pressure (structural deflection):

Since the reservoir tubes are brazed in place, their volume will be considered to be constant. The remaining structure subject to deflection with change of pressure consists of the interconnecting tubing and the actuator primary and adjusting bellows. Since they act in series, the total stiffness may be expressed $\mathrm{K}_{\mathrm{S}}$, where $\mathrm{K}_{\mathrm{S}}=\left(\mathrm{K}_{\mathrm{A}}+\mathrm{K}_{\mathrm{T}}\right)=$ in. ${ }^{3} / \mathrm{psi}$.

$$
\begin{aligned}
& V_{d}=\frac{K_{S} \Delta P}{A} \\
& \Delta P=\frac{X\left(K_{L}+K_{B}\right)}{A} \\
& V_{d}=\frac{K_{S}(X)\left(K_{L}+K_{B}\right)}{A^{2}}
\end{aligned}
$$

Combining $\mathrm{V}_{\mathrm{a}}, \mathrm{V}_{\mathrm{b}}, \mathrm{V}_{\mathrm{c}}$ and $\mathrm{V}_{\mathrm{d}}$ to obtain the net volume change with respect to $\Delta \mathrm{T}$.

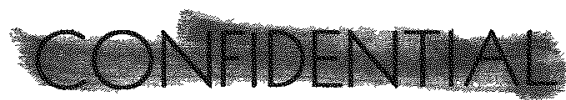




$$
\begin{aligned}
\Delta V= & V_{a}-V_{b}-V_{c}-V_{d} \\
\Delta V= & V_{T}(\phi)(\Delta T)-\frac{\pi}{4} D^{2} L\left(3 C \Delta T+3 C^{2} \Delta T^{2}+C^{3} \Delta T^{3}\right) \\
& -V_{T}\left[\frac{X\left(K_{L}+K_{B}\right)}{A \beta}\right]-\frac{K_{S}(X)\left(K_{L}+K_{B}\right)}{A^{2}}
\end{aligned}
$$

Actuator travel $=\Delta X=\frac{\Delta V}{A}$

$$
\begin{aligned}
& \therefore \Delta X=\frac{V_{T}}{A}(\phi)(\Delta T)-\frac{\pi D^{2} L}{4 A}\left(3 C \Delta T+3 \Delta T^{2} C^{2}+\Delta T^{3} C^{3}\right) \\
& -\frac{V_{T}}{\beta}\left[\frac{X\left(K_{L}+K_{B}\right)}{A^{2}}\right]-\frac{1}{A}\left[\frac{K_{S}(X)\left(K_{L}+K_{B}\right)}{A^{2}}\right]=\frac{V_{T}}{A}(\phi)(\Delta T) \\
& -\frac{\pi D^{2} L}{4 A}\left(3 C \Delta T+3 \Delta T^{2} C^{2}+\Delta T^{3} C^{3}\right)-\frac{X\left(K_{L}+K_{B}\right)}{A^{2}}\left[\frac{V_{T}}{\beta}+\frac{K_{S}}{A}\right] \\
& \Delta X=\frac{\frac{V_{T}}{A}(\phi)(\Delta T)-\frac{\pi D^{2} L}{4 A}\left(3 C \Delta T+3 C^{2} \Delta T^{2}+\Delta T^{3} C^{3}\right)}{1+\frac{\left(K_{L}+K_{B}\right)}{A^{2}}\left[\frac{V_{T}}{\beta}+\frac{K_{S}}{A}\right]}
\end{aligned}
$$

Assuming

$$
\begin{aligned}
& \frac{\pi D^{2} L}{4 A}=V_{T} \text {, this becomes } \\
& \Delta X=\frac{\frac{V_{T}}{A}(\phi)(\Delta T)-\frac{V_{T}}{A}\left(3 C \Delta T+3 C^{2} \Delta T^{2}+C^{3} \Delta T^{3}\right)}{1+\frac{\left(K_{L}+K_{B}\right)}{A^{2}}\left[\frac{V_{T}}{\beta}+\frac{K_{S}}{A}\right]}
\end{aligned}
$$

neglecting the $C^{2}$ and $C^{3}$ terms because they are of a very small order of magnitude, the equation reduces to:

$$
\Delta X=\frac{\frac{V_{T}}{A}(\Delta T)(\phi-3 C)}{1+\left(\frac{K_{L}+K_{B}}{A^{2}}\right)\left(\frac{V_{T}}{\beta}+\frac{K_{S}}{A}\right)}
$$

where:

$$
\begin{aligned}
& \mathrm{V}_{\mathrm{T}}=\text { total system volume at initial conditions }\left(\mathrm{in} .{ }^{3}\right) \\
& \mathrm{A}=\text { actuator area }\left(\mathrm{n} .{ }^{2}\right) \\
& \phi \quad=\text { coefficient of cubical expansion of } \mathrm{NaK}\left(\frac{\mathrm{in.}^{3}}{\text { in. }^{3}-{ }^{\circ} \mathrm{F}}\right)
\end{aligned}
$$

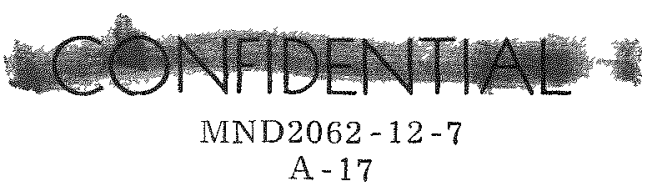


$\mathrm{D}=$ diameter of reservoir tube (in.)

$\mathrm{L} \quad=$ total combined length of reservoir tube (in.)

$\mathrm{C}=$ coefficient of expansion, reservoir tube material (in./in. $-{ }^{\circ} \mathrm{F}$ )

$\mathrm{K}_{\mathrm{L}}=$ linkage spring constant, referred to actuator (1b/in.)

$\mathrm{K}_{\mathrm{S}}=$ structural volumetric spring constant (in. ${ }^{3} / \mathrm{psi}$ )

$\mathrm{K}_{\mathrm{A}}$ = actuator volumetric spring constant (in. ${ }^{3} / \mathrm{psi}$ )

$\mathrm{K}_{\mathrm{T}}$ = tubing spring constant (in. ${ }^{3} / \mathrm{psi}$ )

$\beta=$ bulk modulus, $\mathrm{NaK}$ (psi)

$\mathrm{K}_{\mathrm{B}}$ = bellows spring constant (1b/in.)

Values of the various physical constants described above are shown in Table A-1.

TABLE A-1

System Physical Constants

\begin{tabular}{|c|c|c|c|}
\hline Parameter & Symbol & Constant & Units \\
\hline Total system volume & $\mathrm{V}_{\mathrm{T}}$ & 14.7 & in. ${ }^{3}$ \\
\hline Actuator area & $\mathrm{A}$ & 0.16 & in. ${ }^{2}$ \\
\hline $\begin{array}{l}\text { Coefficient of } \\
\text { cubical expansion-- } \\
\text { NaK }\end{array}$ & $\phi$ & $1.79 \times 10^{-4}$ & in. ${ }^{3} /$ in. $^{3}-{ }^{\circ} \mathrm{F}$ \\
\hline Bulk modulus - -NaK & $\beta$ & $1.38 \times 10^{5}$ at $1150^{\circ} \mathrm{F}$ & -- \\
\hline Reservoir tube ID & $\mathrm{D}$ & 0.480 & in. \\
\hline $\begin{array}{l}\text { Total length } \\
\text { reservoir tube }\end{array}$ & $\mathrm{L}$ & $\begin{array}{l}78.42 \\
\text { (6 tubes, } 13.07 \text { long) }\end{array}$ & in. \\
\hline $\begin{array}{l}\text { Coefficient of } \\
\text { expansion--reservoir } \\
\text { tube material }\end{array}$ & $\mathrm{C}$ & $\begin{array}{l}10.3 \times 10^{-6} \\
\text { (Type } 321 \text { CRES steel) }\end{array}$ & in. $/$ in. $-{ }^{\circ} \mathrm{F}$ \\
\hline $\begin{array}{l}\text { Linka ge-spring } \\
\text { constant referred } \\
\text { to actuator }\end{array}$ & $\mathrm{K}_{\mathrm{L}}$ & $\begin{array}{l}28.5\left(0^{\circ} \text { to } 90^{\circ}\right) \\
50.6\left(0^{\circ} \text { to } 60^{\circ}\right) \\
62.5\left(0^{\circ} \text { to } 30^{\circ}\right) \\
38.7\left(30^{\circ} \text { to } 60^{\circ}\right)\end{array}$ & $1 \mathrm{~b} / \mathrm{in}$. \\
\hline $\begin{array}{l}\text { Bellows spring } \\
\text { constant }\end{array}$ & $\mathrm{K}_{\mathrm{B}}$ & $\begin{array}{l}45 \mathrm{max} \\
40.5 \mathrm{nom} \\
36 \mathrm{~min}\end{array}$ & 1b/in. \\
\hline $\begin{array}{l}\text { Volumetric spring } \\
\text { constant fluid } \\
\text { structure }\end{array}$ & $\mathrm{K}_{\mathrm{S}}$ & $\begin{array}{l}\text { Same as } \mathrm{K}_{\mathrm{A}} \text { below, if } \\
\mathrm{K}_{\mathrm{T}} \text { is neglected }\end{array}$ & in. ${ }^{3} / \mathrm{psi}$ \\
\hline $\begin{array}{l}\text { Actuator volumetric } \\
\text { spring constant }\end{array}$ & $\mathrm{K}_{\mathrm{A}}$ & $6.8 \times 10^{-6}$ & in. ${ }^{3} / p s i$ \\
\hline $\begin{array}{l}\text { Interconnecting } \\
\text { tubing, volumetric } \\
\text { spring constant }\end{array}$ & $\mathrm{K}_{\mathrm{T}}$ & $\begin{array}{l}5.82 \times 10^{-8} \\
\text { Type } 321 \text { CRES steel } \\
\text { tube- } 0.125 \text { dia., } \\
0.017 \text { wall thickness } \\
\text { at } 1200^{\circ} \mathrm{F}, 40 \text { in. } \\
\text { long }\end{array}$ & in. ${ }^{3} / \mathrm{psi}$ \\
\hline
\end{tabular}




\section{b. Actuator load analysis}

The actuator external loads are generated by two sources. These sources are the shutter closing springs and the unbalanced shutter dynamic loads during launch vibration. An additional load is generated by the actuator bellows, acting as a spring, which appears as an external load to the working fluid. All external loads on the actuator piston rod are reacted by the working fluid ( $\mathrm{NaK}$ ) acting through the piston area.

Spring loads. The shutter closing spring loads are reacted by the actuator acting through the shutter linkage. Because of the short arm lengths and large angular travels, the linkage provides a nonlinear mechanical ratio between the spring and actuator. A schematic diagram of the linkage is shown in Fig. A-12.

Table A-2 presents a tabulation of the linkage moment arms, spring forces and actuator loads at various shutter positions. The latter are shown for two conditions, one in which both actuators are sharing the load, the other in which one actuator is taking the entire load. Figure A-13 is a plot of actuator pressure for both normal and emergency modes, including the effects of the bellows and the springs.

Dynamic loads. Dynamic loads are induced upon the system by launch vibrations acting on unbalanced masses of the shutters. Since the shutters are reasonably symmetrical, these loads are small. Assuming the entire weight of the shutter is acting at a point $1 / 4$ inch off the axis of rotation, the loads for $30 \mathrm{~g}$ result in a pressure of 2360 psig (for all six shutters) which is conservative. The CP 1530 design will be reviewed to consider this effect.

The effects of vibration on shutter position were observed during the shutter vibration tests and are shown in Figs. A-5 and A-6.

\section{c. Actuator performance}

The principal function of the actuators is to position the shutters in order to allot sufficient excess heat to be rejected to maintain the thermoelectric hot junction temperature between $1050^{\circ} \mathrm{F}$ and $1070^{\circ} \mathrm{F}$. Thermal analysis conducted to date has indicated that approximately $75 \%$ of the total heat rejection capability occurs at a shutter angle of $45^{\circ}$. This indicates that, during normal operation, the shutters will not exceed a $45^{\circ}$ angle permitting the shutter travel to be divided into two ranges, a normal range and an emergency range. In the normal range, the $\mathrm{T} / \mathrm{C}$ system maintains the hot junction temperature between $1050^{\circ} \mathrm{F}$ and $1070^{\circ} \mathrm{F}$. In the emergency range, a greater temperature excursion is permitted, since this indicates that a fallure has occurred elsewhere in the various RTG systems.

For design purposes, a maximum shutter angle of $60^{\circ}$ was chosen as the upper Imit of the normal range, $i . e$. , shutter position is $60^{\circ}$ open with a $1070^{\circ} \mathrm{F}$ hot shoe temperature. This provides a margin of approximately $15^{\circ}$ to account for variations in emissivities, etc., and still be capable of rejecting at approximately $75 \%$ of the maximum rate.

Since the total system volume is limited to 14.7 cubrc inches (see Section 4 Paragraph 2), any increase in the ratio of shutter travel to $\Delta T$ must be accomplished by changes in the linkage ratio. This is undesirable, since it results in increased sensitivity, which could lead to instability and excessive "hunting." It is more desirable to decrease the ratio, if possible. This possibility will be investigated in the design verification tests, CP 1530, where the complete system can be checked both in air and in vacuum environments.

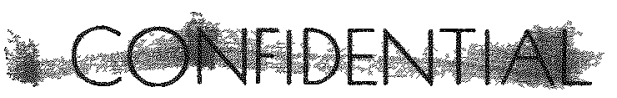

IVND2062-12-7

A -19 
TABLE A - 2

Linkage and Spring Load Analysis

$F_{A}=F_{S}[R], \quad R=\frac{e}{c} \times \frac{b}{a}$

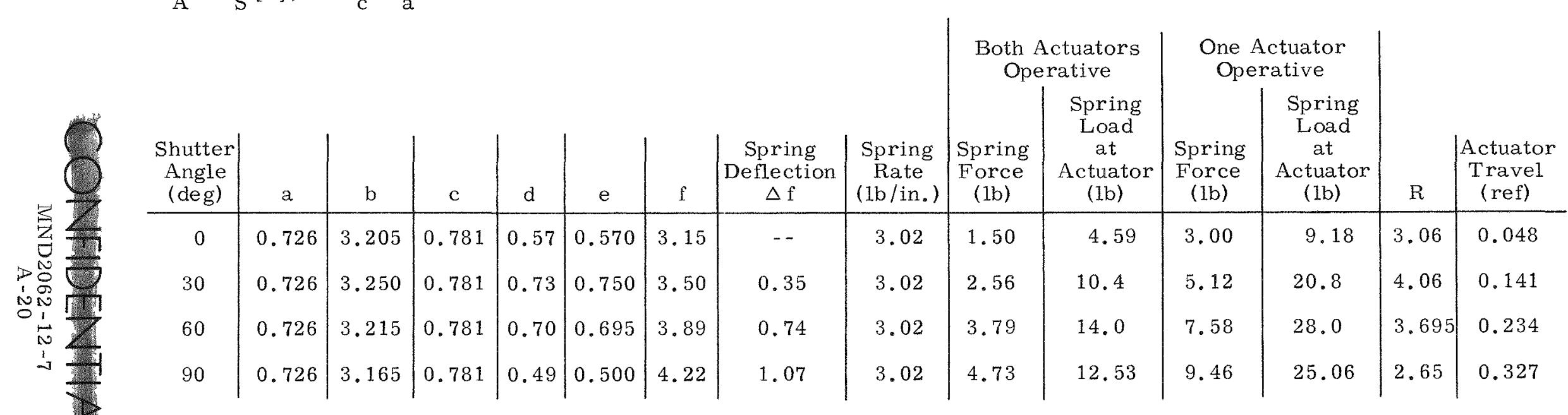

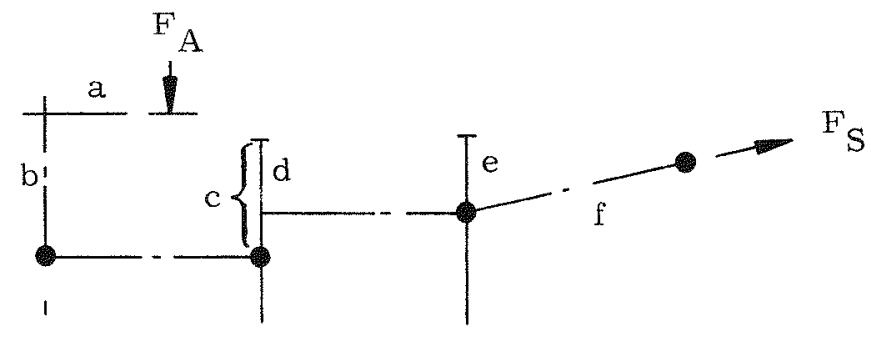


Figure A-14 presents a plot of shutter travel versus temperature change, and also of actuator travel versus shutter position. As can be seen, the total actuator travel required for $90^{\circ}$ shutters is less than 0.375 inch. Half the difference, 0.048 inch, is applied to each end, resulting in the shutters closing before the actuator completely retracts. This permits the springs to hold the shutters closed without bucking the actuator. It also results in additional travel remaining to ensure that the $90^{\circ}$ position is reached because of unknowns such as deviations of the bulk modulus of NaK from the straight line curve shown in Fig. A-18, or from other variables. One of these variables is the hydraulic capacitance of the interconnecting tubing ( $\mathrm{K}_{\mathrm{T}}$ of Table $\mathrm{A}-1$ ) which appears negligible, but which, in an emergency condition with unknown structural temperatures, may become significant. This is discussed in more detail in Section $F$.

\section{Module-Reservoir Relationship}

Since the function of the reservoir is to sense temperature changes of the module hot plate, the relationship of the reservoir to the module is of prime importance.

As orlginally conceived, the reservoirs consisted of two large tubes which were inserted vertically through a column of modules, as shown in Fig. A-15. With the progression of module design, this concept was changed to that shown in Fig. A-16 and also in Fig. A-1, wherein the reservoir tubes are integral with the module hot plate. Further design studies have resulted in only two modules containing active reservoirs. Figure A-17 depicts this version for the six-module RTG configuration. This configuration has the advantage of permitting individual modules to be replaced in the RTG housing without cutting $\mathrm{NaK}$ lines. It also has the advantage of permitting the reservolr, interconnecting tubing and actuator to be assembled, checked and fllled with NaK prior to installation in the housing. While this could theoretically be accomplished in the previous configuration with all modules containing active reservoirs, it is a considerably more precarious operation. The principal dis advantage of this configuration consists of the limited reservoir capacity imposed by the envelope of the module. Any increases required by future test and analysis results would necessitate a change in linkage ratio which provides a similar result but which makes the system more sensitive. System stability will be investigated, both analytically and by test in the next phase, the CP 1530 Design Verification phase.

\section{Linkage Analysis}

The function of the linkage is to connect the actuators to the shutters, provide the closing force to the shutters and to latch the shutters in the $90^{\circ}$ open position in the event of an emergency condition. Figure A-12 provides a schematic diagram of the linkage system.

\section{a. Linkage description}

The actuators provide an opening force to a bell crank. The bell crank is connected to a shutter shaft by means of a cable and cable quadrant. The purpose of the cable is to permit one actuator to override the other in order to open the shutters in an emergency condition. All the shutters are interconnected by adjustable push rods and bell cranks. The shutter closing springs provide the closing force through the push rod links. One push rod is provided with an extended end and pin which rides on a spring-loaded cam. When the shutters reach the $90^{\circ}$ position, the pin enters a slot to form the lock for the emergency condition. The force geometry is such that the joint is self-locking and cannot be overridden by a closing force on the linkage.

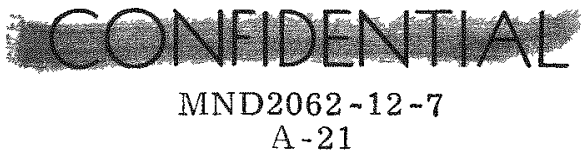




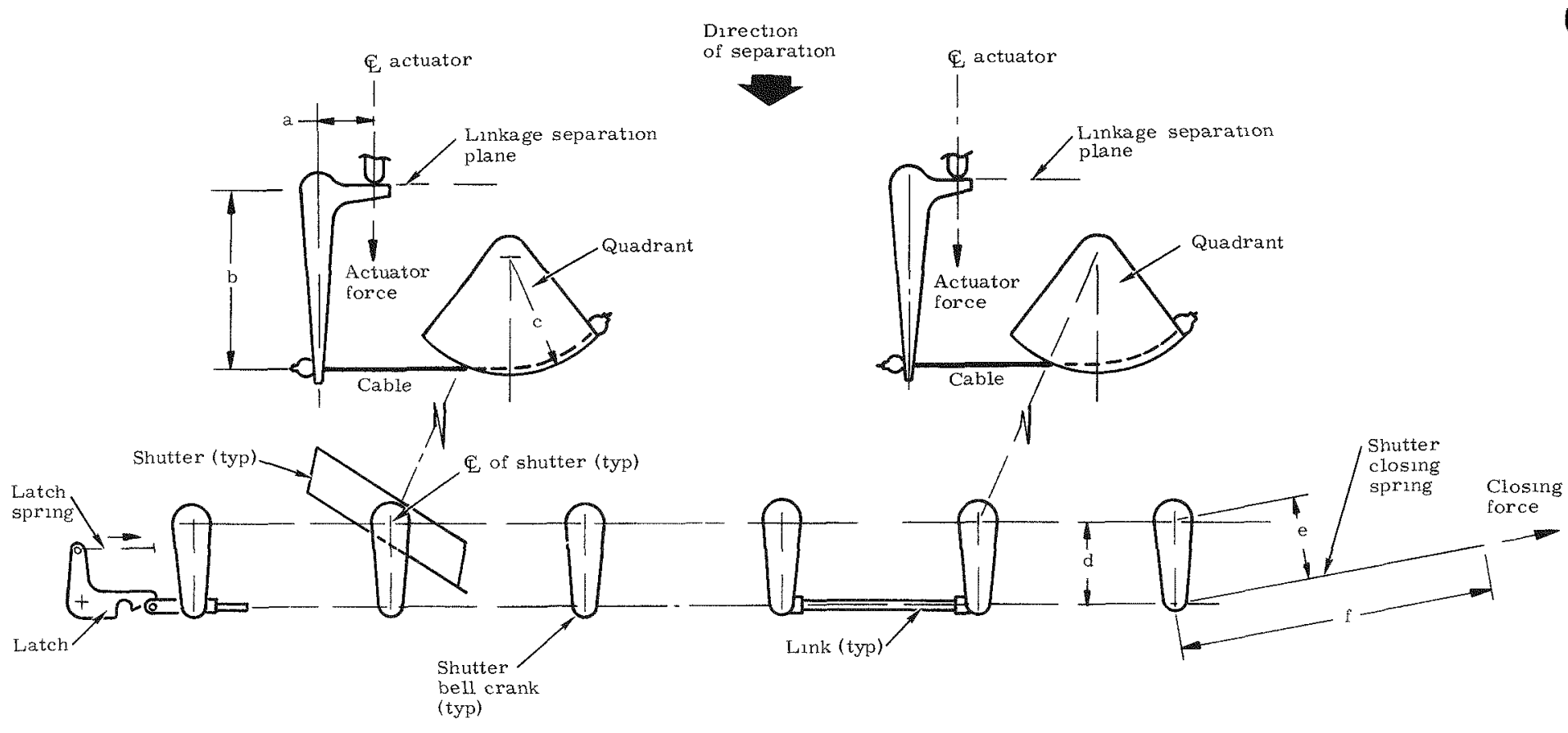

FIG. A-12. SCHEMATIC DIAGRAM THERMAL CONTROL LINKAGE

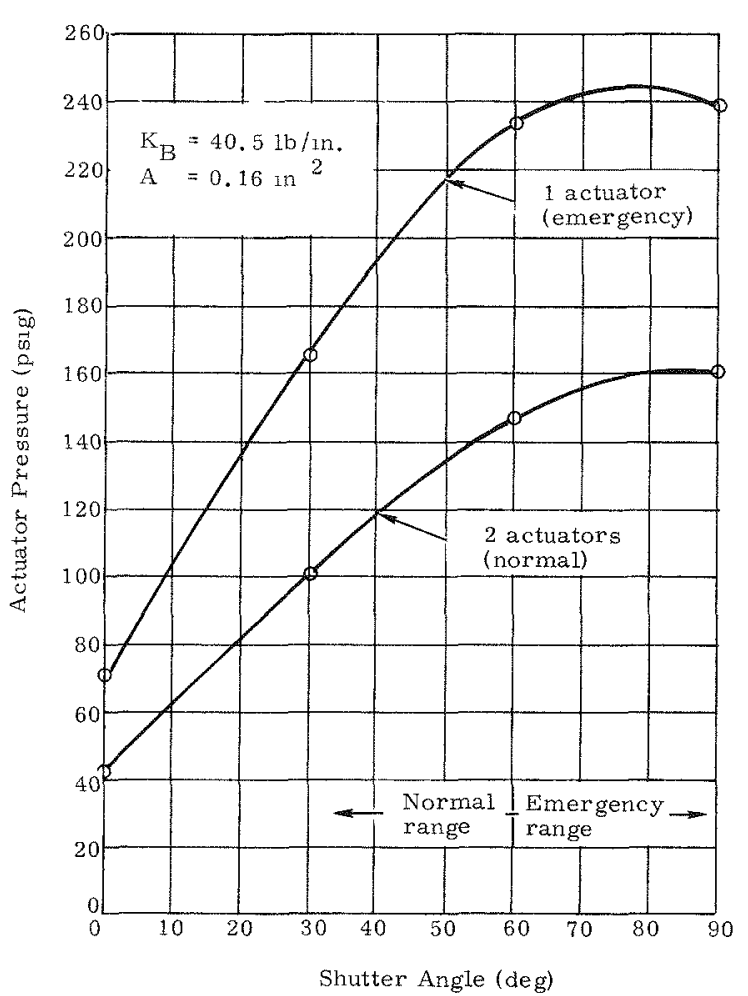

FIG. A 13. ACTUATOR INTERNAL PRESSURE

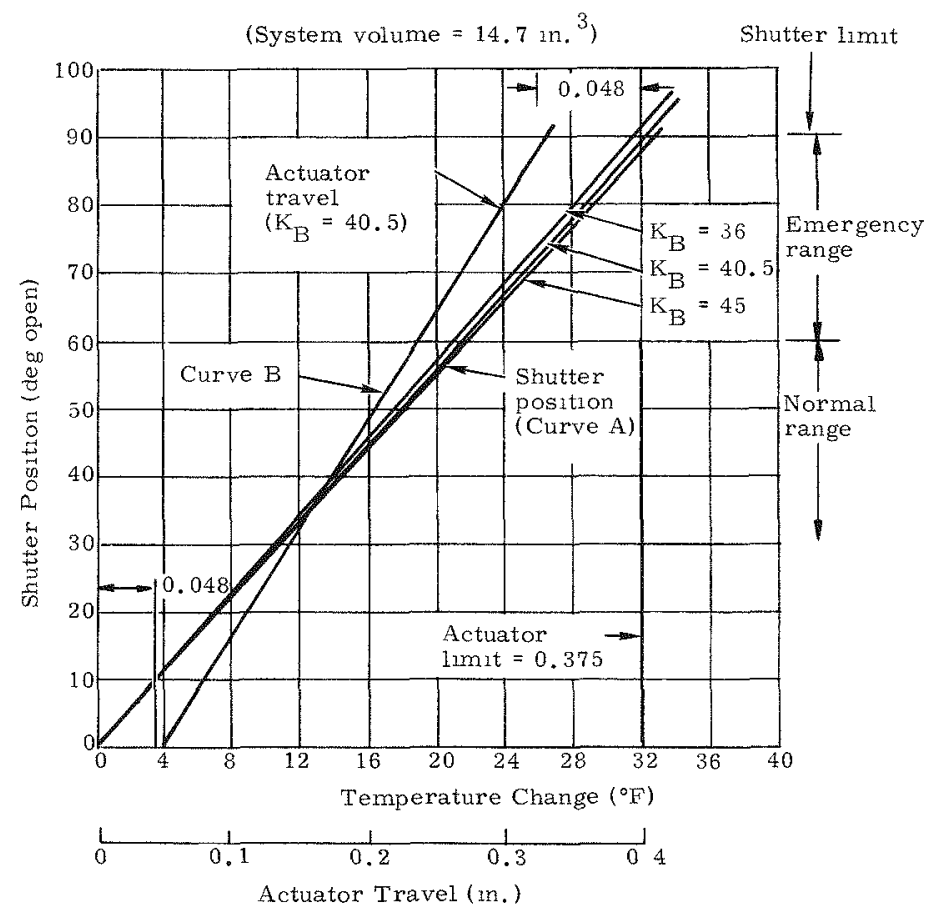

FIG. A-14. SHUTTER POSITION A VERSUS TEMPERATURE CHANGE SHUTTER POSITION B VERSUS ACTUATOR TRAVEL

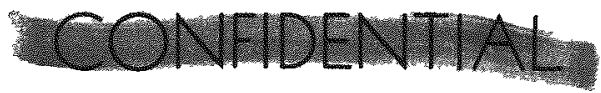

MND2062-12-7 


\section{CONFIDENTIAL}

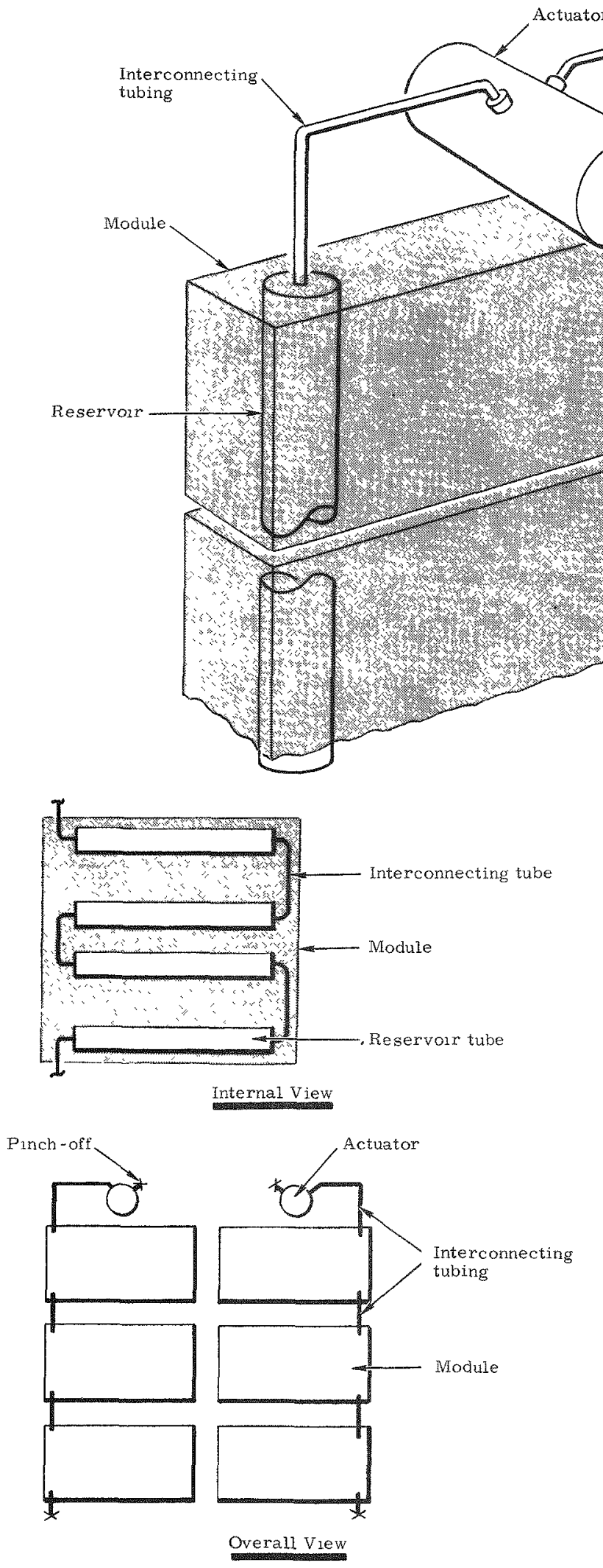

FIG. A 16. RESERVOIR-MODULE SCHEMATIC DIAGRAM
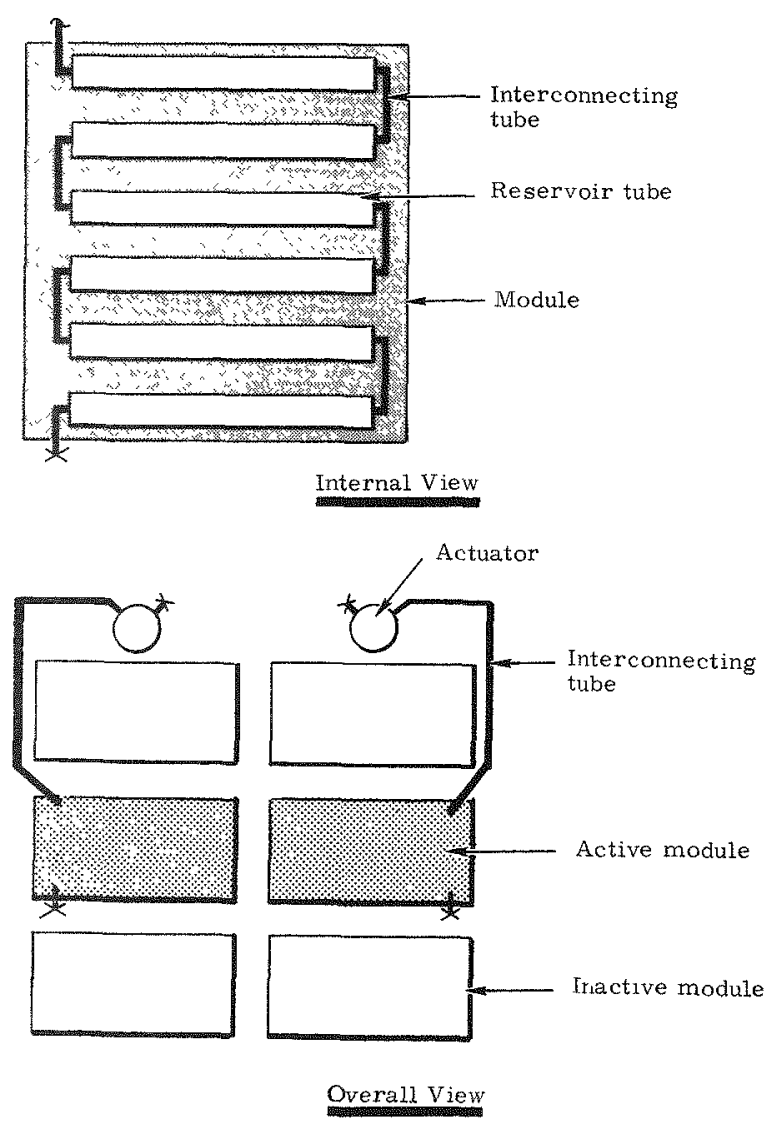

FIG. A-17. FIIAL RESERVOIR-MODULE SCHEMATIC DIAGRAM

\section{- CONFIDENAFAL}


The purpose of the lock in the $90^{\circ}$ open position is to prevent a fuel block overheat condition in the event of loss of all or part of the heat rejection system. A thermal analysis is currently being conducted to verify the requirement for this latch. If it is no longer required, because of the change from a NaK circulating heat rejection system to heat pipes, the lock will be eliminated. The lock is undesirable because of weight considerations and because of the danger of inadvertent locking, especially during launch vibrations. The shutter angular oscillations during vibration tests were checked, and the results are shown in Figs. A-5 and A-6. The maximum amplitude occurred during sinusoidal vibration and was of $+15^{\circ}$ magnitude. Since the maximum shutter angle during normal operation is $60^{\circ}$, a margin of $15^{\circ}$ is present during vibration.

\section{b. Separation requirements}

The fuel block must be separated from the RTG during the re-entry period. The most feasible separation mode is where the fuel block is ejected through the face of the RTG, which requires that the shutters and portions of the linkage also be separated to clear the fuel block. As originally designed, the entire $T / C$ system was separated with the shutters by severing the NaK lines. This was an undesirable condition, since it could not be readily checked out and because it was unreliable.

During the evolution of design, the linkage was redesigned to provide a positive separation joint as shown in Fig. A-12. In this concept, the separation plane is at right angles to the direction of separation, resulting in separation at "first motion" without relative sliding between components. Since the forces are always in one direction, no positive connection is required, and therefore no components need be broken to separate.

\section{System Weight Analysis}

One of the primary objectives maintained during the development of the system has been to obtain a minimum weight system. The component which contributes the major portion of the system weight, the shutters, has been continuously revised to reduce its weight. This has resulted in a weight reduction from 7.0 pounds to 4.38 pounds (for the eight-module size), a reduction of $38 \%$. This can be reduced even more, depending on the RTG size (two-, four-, six- or eight-modules). Table A-3 presents the various shutter weights for each of these RTG sizes.

The total system weight is 22 pounds, for which a breakdown based upon a sixmodule RTG size is shown in Table A-4.

\section{E. SYSTEM DEVELOPMENT}

The results of the CP 1540 Component Development phase will be incorporated into the CP 1530 Design Verification system. Included in this phase of development will be two major tests; the system design verification test, in which a complete thermal control system will be subjected to structural dynamic tests, as well as in-air and in-vacuum performance tests. This will be the first test of a complete system. Also included in this phase will be the predemonstration RTG system, which will also utilize a complete thermal control system.

\section{Heat Pipe Thermal Control System}

As part of the continuous analysis effort, an advanced thermal control system utilizing heat pipes was studied. These heat pipes utilized sodium and argon as the working fluids. Sodium acted as the heat transfer medium and argon as the

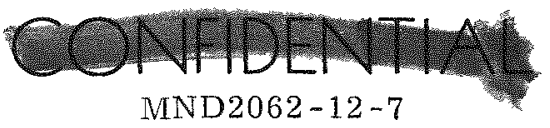

A -24 
TABLE A-3

Shutter Weight Analysis

Shutter Description

\begin{tabular}{|c|c|c|c|c|c|c|c|}
\hline RTG Size & $\begin{array}{l}\text { Shutter } \\
\text { Length* } \\
\quad \text { (in.) }\end{array}$ & $\begin{array}{l}\text { Honeycomb } \\
\text { Dimensions } \\
\text { (in.) }\end{array}$ & $\begin{array}{l}\text { Shutter } \\
\text { Dellection** } \\
\text { (in.) }\end{array}$ & $\begin{array}{l}\text { Natural } \\
\text { Frequency } \\
\quad(\text { cps })\end{array}$ & $\begin{array}{l}\text { Weight } \\
\text { per } \\
\text { Shutter } \\
\text { (1b) }\end{array}$ & $\begin{array}{l}\text { Total No. } \\
\text { of } \\
\text { Shutters }\end{array}$ & $\begin{array}{l}\text { Total System } \\
\text { Shutter Weight } \\
\text { (1b) }\end{array}$ \\
\hline $\begin{array}{l}\text { Two-modules } \\
\text { stacked horizontally }\end{array}$ & 8.27 & $\begin{array}{l}0.012 \text { facing } \\
0.25 \text { height }\end{array}$ & 0.029 & 169 & 1.20 & 6 & 7.20 \\
\hline Four-modules & 16.88 & $\begin{array}{l}0.012 \text { facing } \\
0.375 \text { height }\end{array}$ & 0.18 & 68 & 2.13 & 6 & 12.78 \\
\hline Six-modules & 25.06 & $\begin{array}{l}0.012 \text { facing } \\
0.50 \text { height }\end{array}$ & 0.427 & 44.4 & 2.94 & 6 & 17.64 \\
\hline $\begin{array}{l}\text { Eight-modules } \\
\text { (existing shutter) }\end{array}$ & 33.72 & $\begin{array}{l}0.020 \text { facing } \\
0.50 \text { height }\end{array}$ & 0.87 & 30.8 & 4.38 & 6 & 26.88 \\
\hline \multicolumn{8}{|c|}{$\begin{array}{l}\text { Notes: } * 1 \text {. Length of shutter proper. Length to pivot points not shown. } \\
* * 2 \text {. At } 67 \mathrm{~g} \text { load. }\end{array}$} \\
\hline \multicolumn{8}{|c|}{ TABLE A-4 } \\
\hline \multirow{2}{*}{\multicolumn{8}{|c|}{$\begin{array}{l}\text { System Weight Analysis } \\
\text { (based on six-module RTG) }\end{array}$}} \\
\hline & & & & & & & \\
\hline \multicolumn{3}{|c|}{ Component } & $\begin{array}{l}\text { Unit } \\
\text { Weight (1b) }\end{array}$ & $\begin{array}{l}\text { No. of } \\
\text { Units }\end{array}$ & \multicolumn{2}{|c|}{$\begin{array}{l}\text { Total } \\
\text { Weight (lb) }\end{array}$} & \\
\hline \multicolumn{3}{|c|}{ Shutter } & 2.94 & 6 & \multicolumn{2}{|c|}{17.64} & \\
\hline & \multicolumn{2}{|c|}{ Actuator } & 0.45 & 2 & \multicolumn{2}{|c|}{0.90} & \\
\hline & \multicolumn{2}{|c|}{ NaK } & $0.0272 \mathrm{lb} / \mathrm{in}^{3}$ & 29.4 in. $^{3}$ & \multicolumn{2}{|c|}{0.80} & \\
\hline & \multicolumn{2}{|c|}{ Bearings } & 0.052 & 12 & \multicolumn{2}{|c|}{0.62} & \\
\hline & \multicolumn{2}{|c|}{$\begin{array}{l}\text { Linkage and } \\
\text { brackets }\end{array}$} & -- & - & \multicolumn{2}{|c|}{3.90} & \\
\hline & $\begin{array}{l}\text { Tubi } \\
\text { (1) } \mathrm{I}\end{array}$ & $\begin{array}{l}8 \text { OD } \\
800017017 \\
1 \text { thickness) }\end{array}$ & 0.0495 & 2 & \multicolumn{2}{|c|}{0.099} & \\
\hline & \multicolumn{2}{|c|}{$\begin{array}{l}\text { (2) Reservoir } \\
(1 / 2 \text { OD } x 0.010 \\
\text { wall thickness) }\end{array}$} & 0.342 & 2 & \multicolumn{2}{|c|}{0.684} & \\
\hline & \multicolumn{2}{|c|}{ Welds (estimated) } & -- & -- & \multicolumn{2}{|c|}{0.30} & \\
\hline & \multicolumn{2}{|c|}{ Springs } & 0.015 & 4 & \multicolumn{2}{|c|}{0.06} & \\
\hline \multicolumn{3}{|c|}{$\begin{array}{l}\text { Total system } \\
\text { weight }\end{array}$} & & & \multicolumn{2}{|c|}{$22.00 \mathrm{lb}$} & \\
\hline
\end{tabular}


control medium, varying effective radiator area as a function of sodium vapor pressure. This concept is theoretically feasible; however, it results in a system which is considerably heavier (approximately 20 pounds) than the existing system. In addition, it results in an increased fuel capsule temperature, which at the present time cannot be tolerated. The results of this study are reported separately.

\section{F. DESIGN CONSTRAINTS}

\section{NaK Properties}

The working fluid requirements for this application are as follows:

(1) The fluid must be radiation resistant, i.e., prolonged exposure to nuclear radiation will not affect the molecular structure or any of the basic physical properties of the material.

(2) The fluid must have a high coefficient of thermal expansion. (The operation of the system is dependent upon changes in volume of the working fluid.)

(3) The fluid must be capable of withstanding prolonged exposure to high tem perature without degradation of its physical properties and without creating deposits such as carbon or varnish within the system.

(4) The fluid must have a very low vapor pressure-temperature relationship.

(5) The fluid must remain liquid throughout the entire operational temperature range $\left(+35^{\circ} \mathrm{F}\right.$ to approximately $\left.1250^{\circ} \mathrm{F}\right)$.

(6) The fluid must be compatible with common structural materials which will contain it.

Additional properties which are desirable are ready availability, nontoxicity, easy handling, low cost and high bulk modulus.

The above requirements eliminate most of the ordinary fluids such as water, oils and other organic fluids. Gases are not applicable because of high working pressures, compressibility and large volumes required. This results in the choice of liquid metals as the working fluid. NaK 78 was chosen for this application because of its low vapor pressure, low freezing point and relatively good compatibility with structural materials. It has the disadvantages of being relatively compressible and also of being highly reactive with both oxygen and water, which makes it difficult to handle.

The working fluid for the thermal control system is NaK 78 , the near eutectic alloy of sodium and potassium. Because of difficulties in handling this material, it is difficult to obtain actual material properties, particularly those of less general interest such as bulk modulus. Those shown in Fig. A-18 were obtained from Dr. Robert Werner, MSA Research, for NaK 77 which should be reasonably close to those of $\mathrm{NaK}$ 78. However, since only two points are available, a straight-line relationship must be assumed. This could be a source of error for the predicted system performance. Other properties of $\mathrm{NaK}$ are shown in Table A-5.

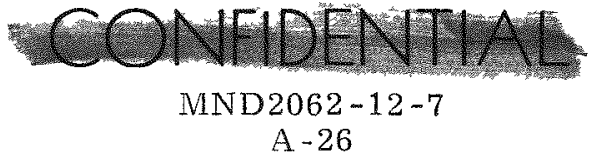


TABLE A-5

NaK Properties

\section{Property}

(1) Composition

(2) Coefficient of cubical expansion

(3) Bulk modulus ( $\mathrm{NaK} 77$ )

$$
\begin{array}{r}
100^{\circ} \mathrm{F} \\
1000^{\circ} \mathrm{F}
\end{array}
$$

(4) Density

$$
\begin{aligned}
& 212^{\circ} \mathrm{F} \\
& 932^{\circ} \mathrm{F}
\end{aligned}
$$

(5) Vapor pressure

$$
\begin{array}{r}
441^{\circ} \mathrm{F} \\
801^{\circ} \mathrm{F} \\
981^{\circ} \mathrm{F} \\
1161^{\circ} \mathrm{F} \\
1341^{\circ} \mathrm{F} \\
1521^{\circ} \mathrm{F}
\end{array}
$$

\section{(6) Freezing point}

\section{Values}

$78 \%$ potassium, $22 \%$ sodium

$$
1.79 \times 10^{-4} \mathrm{in.}^{3} / \mathrm{in}^{3}{ }^{\circ} \mathrm{F}
$$

$750 \times 10^{3}$

$225 \times 10^{3}$

$0.847 \mathrm{gm} / \mathrm{cc}$ (experimental)

$0.850 \mathrm{gm} / \mathrm{cc}$ (calculated)

$0.751 \mathrm{gm} / \mathrm{cc}$ (experimental)

$0.754 \mathrm{gm} / \mathrm{cc}$ (calculated)

$$
\begin{aligned}
& 1.81 \times 10^{-3} \mathrm{~mm}-\mathrm{Hg}, 3.5 \times 10^{-5} \mathrm{psi} \\
& 5.06 \mathrm{~mm}-\mathrm{Hg}, 9.8 \times 10^{-2} \mathrm{psi} \\
& 31.87 \mathrm{~mm}-\mathrm{Hg}, 0.617 \mathrm{psi} \\
& 136.5 \mathrm{~mm}-\mathrm{Hg}, 2.64 \mathrm{psi} \\
& 431.85 \mathrm{~mm}-\mathrm{Hg}, 8.46 \mathrm{psi} \\
& 1099.52 \mathrm{~mm}-\mathrm{Hg}, 21.3 \mathrm{psi} \\
& -10^{\circ} \mathrm{C}+14^{\circ} \mathrm{F}
\end{aligned}
$$

\section{Tube Capacitance}

Tube capacitance (change in volume with change in pressure) can create an undesirable effect on the actuator performance as well as on system stability. The main reservoir tubes are brazed in place in the module hot plate, which should provide sufficient support to enable these tubes to be considered rigid with respect to capacitance. However, the interconnecting tubes are radially unsupported and are therefore subject to radial deflection. By keeping the size of these tubes as small as practicable, the effects of capacitance become negligible, as shown in Fig. A -19 .

This same effect also occurs with the actuator bellows (primary and adjusting). The value for $\mathrm{K}_{\mathrm{A}}$ shown in Table A-1 was calculated by replacing the bellows with an equivalent tube (same $O D$ and wall thickness) whose length was three times the total bellows length in order to account for convolutions. The resultant capacitance of $6.8 \times 10^{-6}$ in. $3 / \mathrm{psi}$ was used in the performance analysis and should be of approximately the correct value.

\section{Trapped Gases}

Gases trapped in the system during filling can act as an additional "spring" in the loop which will detract from the actuator output. This additional "softness" may lead to excessive shutter oscillations during vibration which, in an extreme case, can result in a locked-open shutter condition.

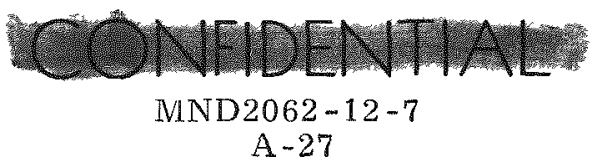




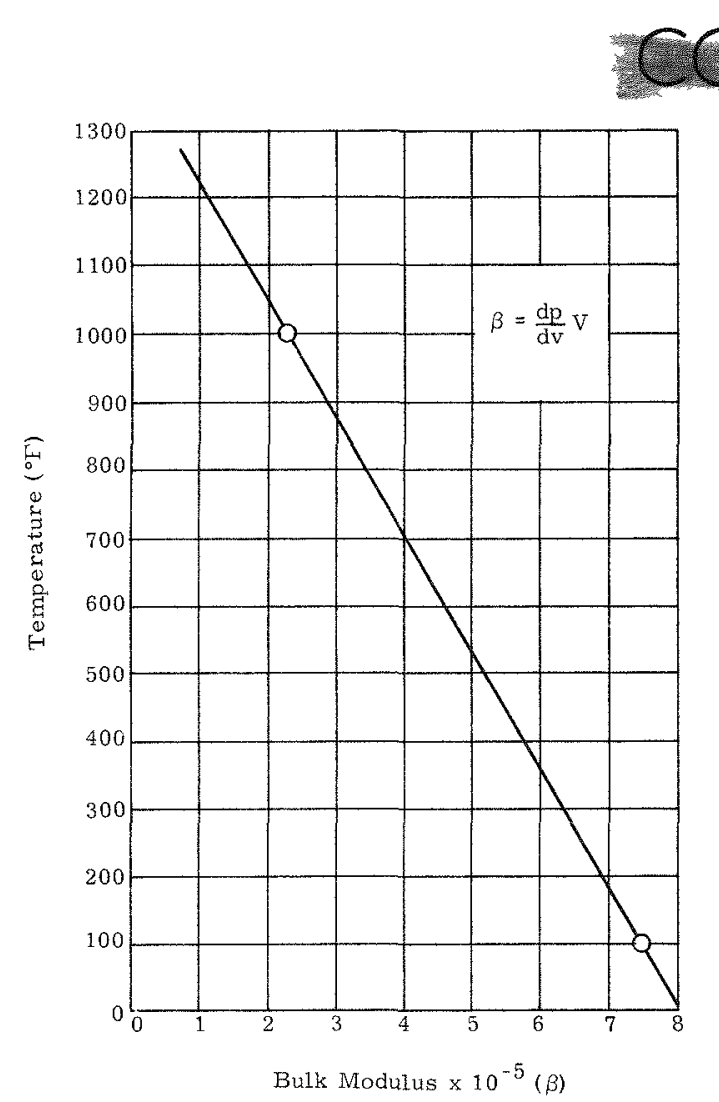

FIG. A-18, BULK MODULUS--NaK 77

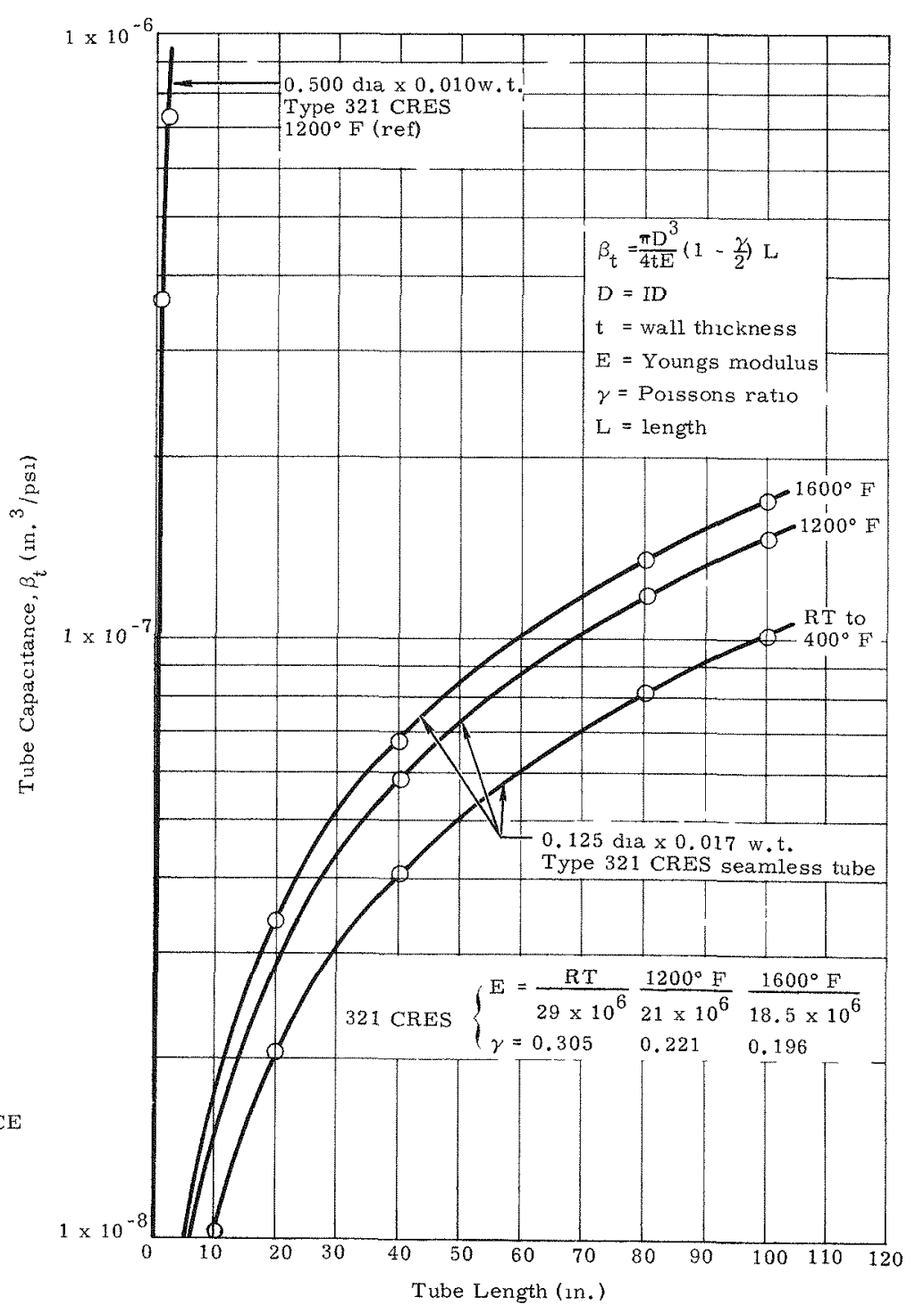

FIG. A-19. TUBE CAPACITANCE

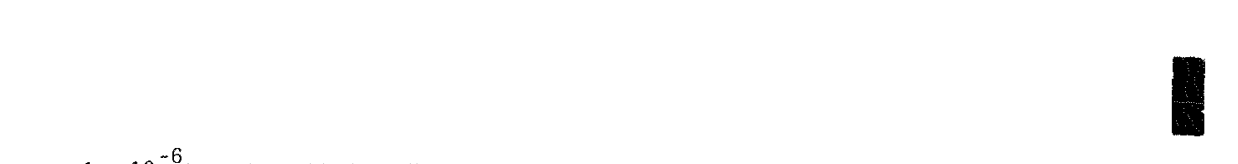


In order to minimize, or eliminate, trapped gases, the system filling procedure must include evacuation cycling of the system, preferably at a high temperature prior to the addition of the working fluid. In addition, the procedure must provide for a means of checking the system for trapped gas prior to final sealing.

The procedure for filling the design-verification systems will include a stiffness check, whereby the spring rate will be checked against a curve of allowable stiffness. This will be accomplished by measuring actuator deflection with a known load applied externally. In order to eliminate the errors associated with estimating the polytropic exponents to calculate stiffness, the stiffness check will be conducted over a one-hour period to allow the use of the isothermal gas laws.

The maximum allowable trapped gas volume and the filling procedure will be provided during the next phase, the CP 1530 Design Verification.

\section{Design Environment}

\section{a. Life}

The system is designed for a total operating life of 144 days, consisting of 54 days ground operating life and 90 days orbital life. In addition, the system is designed for the operating life which is accumulated during manufacturing and assembly operations on both the component and system levels.

\section{b. Ambient pressure}

The system is designed for operation in an ambient pressure ranging from sealevel pressure (14.7 psia nominal) to orbital vacuum conditions of $1 \times 10^{-10}$ tor $x$. This includes the comparatively rapid depressurization which occurs during the launch period.

\section{c. Ambient temperatures}

The complete RTG which includes this system is designed for the following ambient temperature environments:

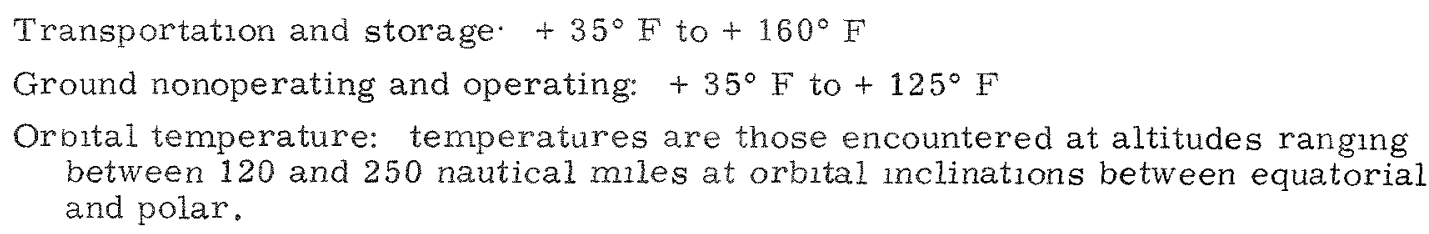

During all operating periods, the system wll be exposed to temperatures generated within the $\mathrm{RTG}$ which will range from $1200^{\circ} \mathrm{F}$ to approximately $400^{\circ} \mathrm{F}$.

\section{d. Vibration}

The system is designed to meet a test vibration environment as defined in the RTG Design Criteria, MND-2062-1000, Rev. A.

e. Shock, acceleration and acoustic

As defined in RTG Design Criteria.

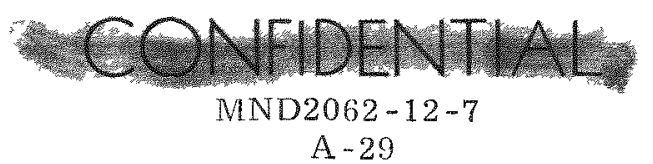




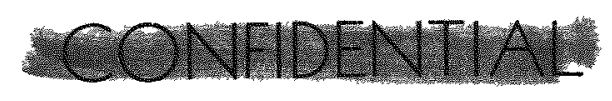

\section{f. Nuclear radiation}

At the present time, the total RTG size (number of modules) has not been established. Consequently, the isotope source size and geometry is not available to establish the specific nuclear radiation dose to which the system will be exposed. However, the spectrum will be that of polonium which consists primarily of $5 \mathrm{Mev}$ alpha particles and its associated $X$-ray spectrum. In addition, the spectrum contains gamma radiation of approximately $0.8 \mathrm{Mev}$ and a small percentage of neutrons of approximately 1 to 2 Mev energy.

A more complete definition of the spectrum and dose rate will be avallable during the next design phase when the heat source geometry is established.

\section{Temperature Measurement}

During normal operation, the thermal control system must maintain the thermoelectric hot shoe temperatures between $1050^{\circ} \mathrm{F}$ and $1070^{\circ} \mathrm{F}$. This requires that the NaK reservoirs in the module hot plate operate at approximately $1200^{\circ} \mathrm{F}$. In order to properly install, adjust, and measure the performance of the system, it will be necessary to measure the actual temperature with a total accuracy of approximately $1^{\circ} \mathrm{F}$. The measurement system recommended to perform this task during the CP 1530 phase consists of the following:

(1) Precision temperature sensors located on significant temperature monitor locations.

(2) A special temperature sensor lead wire system which will suppress variable lead wire resistance effects.

The sensor extension wires will pass through different temperature zones which will exist along the wire runs between the temperature sensor locations and the sensor readout equipment.

(3) An accurate sensor readout equipment and associated temperature control system.

The precision temperature sensor type will be a resistance temperature detector (RTD). The actual sensing element of the RTD will be a platinum wire-wound resistance encased and sealed as a surface temperature sensor unit. The RTD will have a minimum calibration accuracy of $0.1 \%$ over the operational temperature band and a calibration repeatability variation of less than 100 parts per million. These characteristics will allow very precise temperature resolutions of measurements taken with a number of the same type sensors for further data analysis. The time constant of the RTD will be between 1.5 to 2 seconds.

Special considerations will be given to the arrangement of the sensor lead wire system. Of singular importance will be the wire gauge, the type of insulation and the sensor unit-to-lead wire (sensor extension wires to the readout equipment) interface. The gauge of the lead wire must be of the correct size in order to prevent heat conduction away from the sensing element to prevent distortion of the prevailing temperature condition at the measurement point. Insulation material of the lead wires must be of the nonoutgassing, high temperature type so that no decrease in wire insulation resistance will occur with aging. The interface between sensor unit and lead wire must be made so that no contact resistance variation takes place over a long period of time or any possible thermoelectric junctions or other effects of dissimilar metals at elevated temperatures are introduced at the points of joining. As mentioned above, to avoid errors caused by lead wire resistance variations, a four wire balanced system is contemplated.

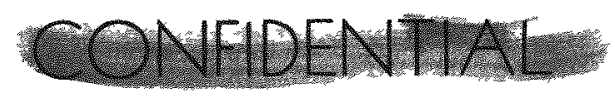

MND2062-12-7

A. -30 
As RTD readout equipment, a triple bridge type is under consideration. This type is a modified Wheatstone bridge or essentially a double Kelvin bridge. Using this type of bridge configuration in conjunction with the four-wire system, errors due to lead wire resistance variations are reduced by a factor greater than 100 in comparison with three-wire or other lead wire configurations.

\section{G. REFERENCES}

The following drawings and specifications represent the CP 1540 hardware and test designs.

\section{Drawings}

a. Components

$466 \mathrm{~A} 1541001$

$466 \mathrm{~A} 1541004$

466A 1541010

466A 1541011

466A 1541014

466A 1541015

b. Test fixtures and specimens

$466 \mathrm{~A} 1544000$

$466 \mathrm{~A} 1544001$

$466 \mathrm{~A} 1544002$

$466 \mathrm{~A} 1544004$

466A 1544005

$466 \mathrm{~A} 1544006$

$466 \mathrm{~A} 1544007$

$466 \mathrm{~A} 1544008$

Actuator
Shutter Hinge Bearıng

Thermal Control Linkage

Shutter Assembly

Shutter Assembly

NaK Reservoir and Tubing Assembly

Shutter Test Fixture

Shutter Performance Test Fixture

Bearing Test Specimen

Bearing Test Fixture

Shutter Vibration Test Fixture

Actuator Cycling Test Fixture

Actuator Burst Test Fixture

Actuator Cycle Drive Mechanism

2. Process Specifications

$466 \mathrm{~A} 1543011$

$466 \mathrm{~A} 1543019$

$466 \mathrm{~A} .1543021$

$466 \mathrm{~A} 1543022$

$466 \mathrm{~A} 1543023$

$466 \mathrm{~A} 1543024$

$466 \mathrm{~A} 1543026$

3. Test Specifications

$466 \mathrm{~A} 1543010$

466A 1543012

$466 \mathrm{~A} 1543013$

$466 \mathrm{~A} 1543017$

466A1543018

$466 \mathrm{~A} 1543020$
Resistance Spot Welding Haynes -25

Resistance Spot Welding Titanium to Haynes -25

Application of Molykote X-15 Lubricant

Application of Tungsten Diselenide Dry Film Lubricant Vacuum Brazing Titanium Honeycomb

Annealing René 41

Heat Treatment of Lescalloy BG-42 (440C-M)

Shutter Vibration Test

Bearing Lubricant Evaluation Test

Shutter Vibration Test--Three-Shutter Assembly

NaK Actuator Overpressure Test

Shutter Thermal Performance Test

NaK Actuator Cycling Test

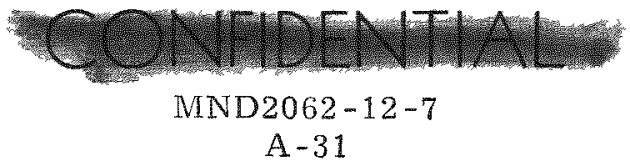


BLANK

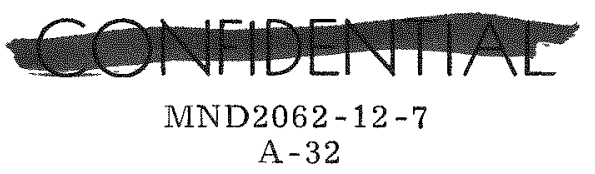




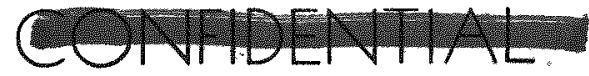

\section{APPENDIX B}

\section{SHUTTER HINGE BEARING DESIGN}

One of the primary elements of the SNAP 29 thermal control system are the six shutters, the position of which determines the fuel block area exposed for heat rejection.

Each of the six shutters is pivoted on two hinge bearings, one at each end of the shutter shaft. The function of these bearings is to permit angular rotation of the shutter while compensating for structural deflection of the shutter and support structure, to react radial and axial shutter loads, and to compensate for unequal thermal expansion between the shutter and support structure. The bearings must provide a minimum of frictional resistance to rotation while operating at a temperature of $600^{\circ} \mathrm{F}$, both in air (sea level) and during hard vacuum ( $1 \times 10^{-10}$ torr) conditions.

This document provides a summary of the design techniques, test philosophy and test results from which the final bearing design was evolved.

Included are the environmental requirements, design relations, test philosophy and description, test results and lubricant selection criteria involved in the design of the bearings for the SNAP 29.

\section{A. BEARING DESIGN}

A plain, spherical, self-aligning bearing was selected for this design because of its capacity for carrying higher loads in a smaller envelope than either a ball or roller bearing (Fig. B-1). In addition, this type bearing presents fewer development problems and has a higher growth capacity for the environment than the ball or roller bearings.

Design redundancy is provided by permitting rotation to occur about either the bearing bore (shaft), or about the bearing inner and outer races. The primary mode is about the inner race and shaft, since this represents least work for a given friction coefficient. In this mode the ball surface is utilized only to compensate for mis alignment.

The axial shutter loads are reacted by one bearing, the other permitting axial motion to compensate for linear dimensional changes due to structural deflections and thermal expansion.

\section{Loads and Environment}

\section{a. Temperature}

The bearings are designed for a nominal temperature of $600^{\circ} \mathrm{F}$, based upon thermal analysis.

\section{b. Pressure}

The design ambient pressure environment for the bearings consists ot 54 days at sea level ambient pressure (at operating temperature) followed by 90 days hard vacuum environment (approximately $1 \times 10^{-10}$ torr), also at operating temperatures.

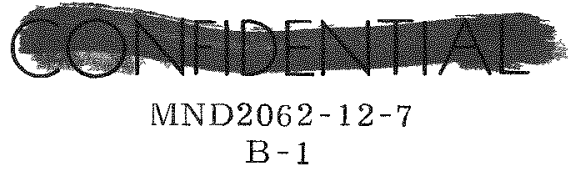




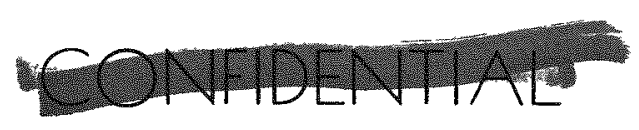

\section{c. Vibration and shock}

The Titan III vibration environment was chosen for design purposes since the actual launch vehicle for the SNAP 29 is not defined. The Titan III spectrum represents a typical, large launch vehicle. Testing under this spectrum includes sinusoidal vibrations at $3000 \mathrm{cps}$ at a $4-1 / 2 \mathrm{~g}$ level, and random vibration to a $29.1 \mathrm{~g} \mathrm{rms} \mathrm{level.} \mathrm{Total} \mathrm{vibra-}$ tion time is approximately six minutes.

\section{d. Loads}

The largest bearing radial and axial loads are imposed by the vibration environment and generated by the shutters. Because of the unknown magnification factors imposed by the combined housing and support truss system, a design limit load of $67 \mathrm{~g}$ and an ultimate load of $100 \mathrm{~g}$ was imposed as the load criteria.

Static loads on the ground are created by the unbalanced reactions to the spring, linkage and actuator system which determine the radial loads; and by the shutter weight which determines the axial loads.

Zero $g$ conditions during the 90-day orbit period eliminate the axial loads. However, the unbalanced linkage loads remain. The largest unbalanced linkage load occurs at the connection between the linkage and the cable quadrant and equals 0.2 pound. A value of 0.5 pound was chosen for design and test purposes, to include variables such as friction which may tend to add to the 0.2-pound load.

A complete load summary is presented in Table B-1.

e. Life

The total angular travel during normal operation is 60 degrees. For emergency operation, this is increased to 90 degrees. Approximately seven complete 60-degree cycles are anticipated during the life of the system. In addition, approximately 1500 small amplitude (<10 degrees) cycles are anticipated.

\section{f. Radiation environment}

The radiation environment imposed by the proximity of the fuel to the bearings consists primarily of $5 \mathrm{Mev}$ alpha particles and its associated $\mathrm{X}$-ray spectrum. In addition, the spectrum consists of gamma radiation of approximately $0.8 \mathrm{Mev}$, and a small percentage of neutrons of approximately 1 to $2 \mathrm{Mev}$ energy.

Since the size of the RTG and its consequent fuel loading is not presently defined, the total dose rate cannot be defined. Therefore, for design and lubricant selection purposes, radiation resistant lubricants must be selected, based on a comparative order of merit which is based upon available published data.

\section{Analysis}

\section{a. Bearing stress}

The bearing design is dictated by the following relationships:

(1) Maximum compressive stress

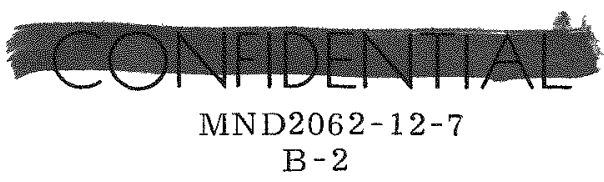


TABLE B-1

Bearing Load Summary

\begin{tabular}{|c|c|c|c|c|}
\hline Bearing and Load Condition & $\begin{array}{r}\text { Ultimate } \\
\text { Radial }\end{array}$ & $\begin{array}{c}\text { Load (lb) } \\
\text { Axıal }\end{array}$ & $\begin{array}{c}\text { Ultimate Unit Load } \\
\text { Based on Projected Area } \\
\text { (psi) }\end{array}$ & $\begin{array}{c}\text { Ultimate Maximum Elastic } \\
\text { Compressive Stress (Hertz) } \\
\text { (psi) }\end{array}$ \\
\hline \multicolumn{5}{|l|}{ Static Ground Condition } \\
\hline Linkage end bearing & 0.5 & 6.57 & 32.2 & 2,940 \\
\hline Linkage end shaft & 0.5 & -- & 4. 49 & 421 \\
\hline Floating end bearing & 0.5 & -- & 2.45 & 2,450 \\
\hline \multicolumn{5}{|l|}{ Launch Condition } \\
\hline Linkage end bearing & 219 & 438 & $\begin{array}{l}2410 \\
\text { (resultant } \\
\text { load) }\end{array}$ & $\begin{array}{l}26,200 \\
\text { (resultant } \\
\text { load) }\end{array}$ \\
\hline Linkage end shaft & 219 & - & 1974 & 8,850 \\
\hline Floating end bearing & 219 & -- & 1075 & 18,900 \\
\hline \multicolumn{5}{|l|}{ Orbital Condition } \\
\hline Linkage end bearing & 0.5 & -- & 2.45 & 2,450 \\
\hline Linkage end shaft & 0.5 & - & 4. 49 & 421 \\
\hline Floating end bearing & 0.5 & - & 2.45 & 2,450 \\
\hline
\end{tabular}




$$
\mathrm{S}_{\mathrm{c}}=0.918 \sqrt[3]{\frac{\left(\frac{\mathrm{D}_{1}-\mathrm{D}_{2}}{\mathrm{D}_{1} \mathrm{D}_{2}}\right)^{2} \mathrm{P}}{\left[\frac{1-\gamma_{1}^{2}}{\mathrm{E}_{1}}+\frac{1-\gamma_{2}^{2}}{\mathrm{E}_{2}}\right]}}
$$

(2) Radius of contact circle

$$
a=0.721 \sqrt[3]{(P)\left(\frac{D_{1} D_{2}}{D_{1}-D_{2}}\right)\left[\frac{1-\gamma_{1}^{2}}{E_{1}}+\frac{1-\gamma_{2}^{2}}{E_{2}}\right]}
$$

where:

$$
\begin{aligned}
\mathrm{S}_{\mathrm{C}} & =\text { maximum compressive stress }(\mathrm{psi}) \\
\mathrm{D}_{1} & =\text { spherical diameter outer race }\left(\mathrm{in}_{0}\right) \\
\mathrm{D}_{2} & =\text { spherical diameter inner race }(\mathrm{in} .) \\
\mathrm{P} & =\text { radial load }(\mathrm{b}) \\
\gamma_{1}, \gamma_{2} & =\text { Poisson's ratio, inner and outer race materials } \\
\mathrm{E}_{1}, \mathrm{E}_{2} & =\text { modulus of elasticity, inner and outer race materials }
\end{aligned}
$$

Table B-1 presents the results of the basic bearing analysis.

b. Substrate requirements

The requirements for the substrate materials are as follows:

(1) Strength and toughness at the operating temperature conditions

(2) High "hot" hardness at the operating temperatures

(3) Compatibility with the lubricant

(4) Corrosion resistant

(5) Readily machined or formed.

Figure B-2 depicts the approximate useful temperature range for several materials which are applicable to this bearing. These materials, except for the Haynes-25, have been used for previous bearing applications. The Haynes-25 was considered for the shaft material, and consequently was included for evaluation.

\section{c. Lubricant requirements}

A lubricant is required between the shaft and bearing rubbing surfaces, and between the inner and outer races of the bearing. This maintains a minimum coefficient of friction, and prevents cold welding effects from occurring, as well as reduces wear and protects the substrates from corrosion.

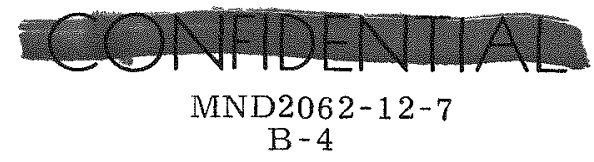




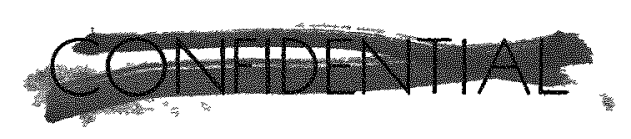

The environment to which the bearings are subjected during their operating life precludes the use of conventional organic oil or grease-type lubricants, and necessitates the use of solid film lubricants. In general, these are characterized by comparatively low wear lives and high friction coefficients. However, when compared to the friction of vacuum cleaned surfaces from which adsorbed surface films, oxides, etc., have been removed, their friction coefficients are lower by an order of magnitude.

Figure B-2 depicts the operating temperature characteristics of several solid film lubricants which are applicable to this environment. These are:

(1) Niolykote X-15

(2) Tungsten disulfide

(3) Tungsten diselenide

(4) Boeing $X-88$ gold alloy

(5) Electrodeposited gold

(6) Silver-palladium alloy

These lubricants are of two basic types, one consisting of a dispersion of the lubricant in a binder (Items 1,2 and 3) which bonds the material to the substrate. The other type (Items 4, 5 and 6) consists of a direct plating or bonding of the lubricant, usually a metal or alloy, to the substrate. These lubricants are described in more detail in Section B-1.

The Boeing X-88, and silver-palladium alloys have been previously evaluated at the Martin Marietta Corporation (Ref. B-1) for a similar application on the PRIME vehicle. Consequently, sufficient information is available to allow extrapolation to the SNAP 29 application.

Since the friction and wear characteristics of solid lubricants are a function of load, velocity and type of motion it is necessary that the data used to evaluate them be based upon identical or similar test parameters. Most published data available for these lubricants are, unfortunately, based upon high loads, high velocity and continuously rotating motion which is in direct opposition to the parameters of this application which are very low loads, low speeds and intermittant oscillating motion. In addition, no vibration data are available on any of the lubricants, except that generated for the PRIME program. For these reasons, an evaluation test was conducted to determine the performance of these lubricants.

\section{Tests}

As previously described, the state of the art of solid film lubricants is such that it was necessary to perform an evaluation test of several of the lubricants, the purpose of which was to obtain friction data and determine the wear life of these lubricants at the loads, duty cycle and temperature-pressure environments of this application. In addition, vibration tests at the actual loading conditions were performed to determine the adherance of the lubricants to the substrate.

\section{a. Test philosophy}

Lubricant evaluation tests were performed at thermal-vacuum conditions which simulated orbital flight. The test specimen completely simulated the shaft-toinner race joint of the bearing, which is the primary rotating interface. Tests were

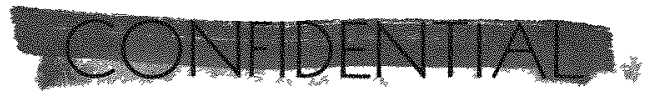

MND2062-12-7

$\mathrm{B}-5$ 


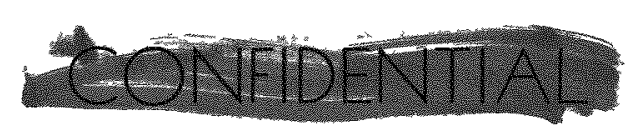

performed on 12 specimens, 10 of which represented bearing lubricants; the remaining two represented the actuator sliding joints. The silver-palladium and Boeing X-88 lubricants were not tested because of data available from PRIME. The tungsten disulfide lubricant was not tested because all available data indicate that its performance is intermediate between the Molykote X-15 and the tungsten diselenide.

Six bearings and shafts were also included in the shutter dynamic tests which provided vibration data with actual loads. An additional six bearings were also included in the shutter thermal-vacuum performance tests which provided verification of the bearing operating temperatures which were originally determined analytically.

\section{b. Test description}

The lubricant evaluation tests were performed simultaneously on 12 specimens as previously described. These specimens consisted of six double-ended shafts driven in oscillatory motion at an amplitude of \pm 30 degrees, and at a frequency of $2 \mathrm{cpm}$. The specimens were maintained at a nominal temperature of $600^{\circ} \mathrm{F}$, except for the actuator specimens which were operated at a nominal temperature of $400^{\circ} \mathrm{F}$. The specimens were radially loaded at a nominal load of 0.5 pound which simulated the orbital loads. The test duration was 90 days, at a pressure between $5 \times 10^{-5}$ and $1 \times 10^{-6}$ torr. The test fixture (Fig. B-3) was designed to completely isolate the friction measuring device from the driving device. Test specimen and test fixture drawing numbers are $466 \mathrm{~A} 1544002$ and $466 \mathrm{A1544004}$, respectively. The test specification is $466 \mathrm{~A} 1543012$.

The specimens tested were limited to six specimens of Molykote X-15 with three combinations of substrate and rubbing surface materials. Two specimens of tungsten diselenide and two specimens of electrodeposited gold were also included. Table B-2 provides a description of the substrate, lubricant and rubbing surface combinations. Table B-3 provides the composition of the substrate materials. Two specimens representing the chrome-plated actuator joints were also included.

Vibration tests (Specification 466A1543013) were conducted on an assembly of three shutters, resulting in tests of six bearings. Since the shutters were present, the bearings were tested with an actual dynamic mass. The lubricant was Molykote $\mathrm{X}-15$, the shaft and inner race substrates were Lescalloy BG-42. Outer race substrate was René 41. The Molykote $X-15$ was used in these tests because its binder was sodiur silicate which was common also to the tungsten diselenide.

Verification of the $600^{\circ} \mathrm{F}$ nominal bearing design temperature was obtained in the shutter thermal-vacuum performance tests (Specification 466A1543018). Six bearings identical with those included in the vibration tests were utilized for this test.

\section{c. Test results}

The two principal areas of interest in the lubricant evaluation test are the wear and the friction coefficients. The wear is utilized as the primary basis of evaluation because it is important that the lubricant remain effective throughout the 90-day orbital period. Friction coefficients (breakout friction) were the secondary basis of evaluation. Other factors considered included oxidation, chemical, vacuum and radiation stability.

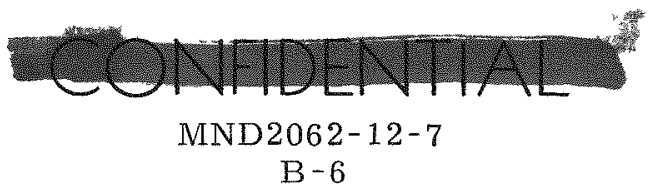


FIG. B-1. BEARING GEOMETRY
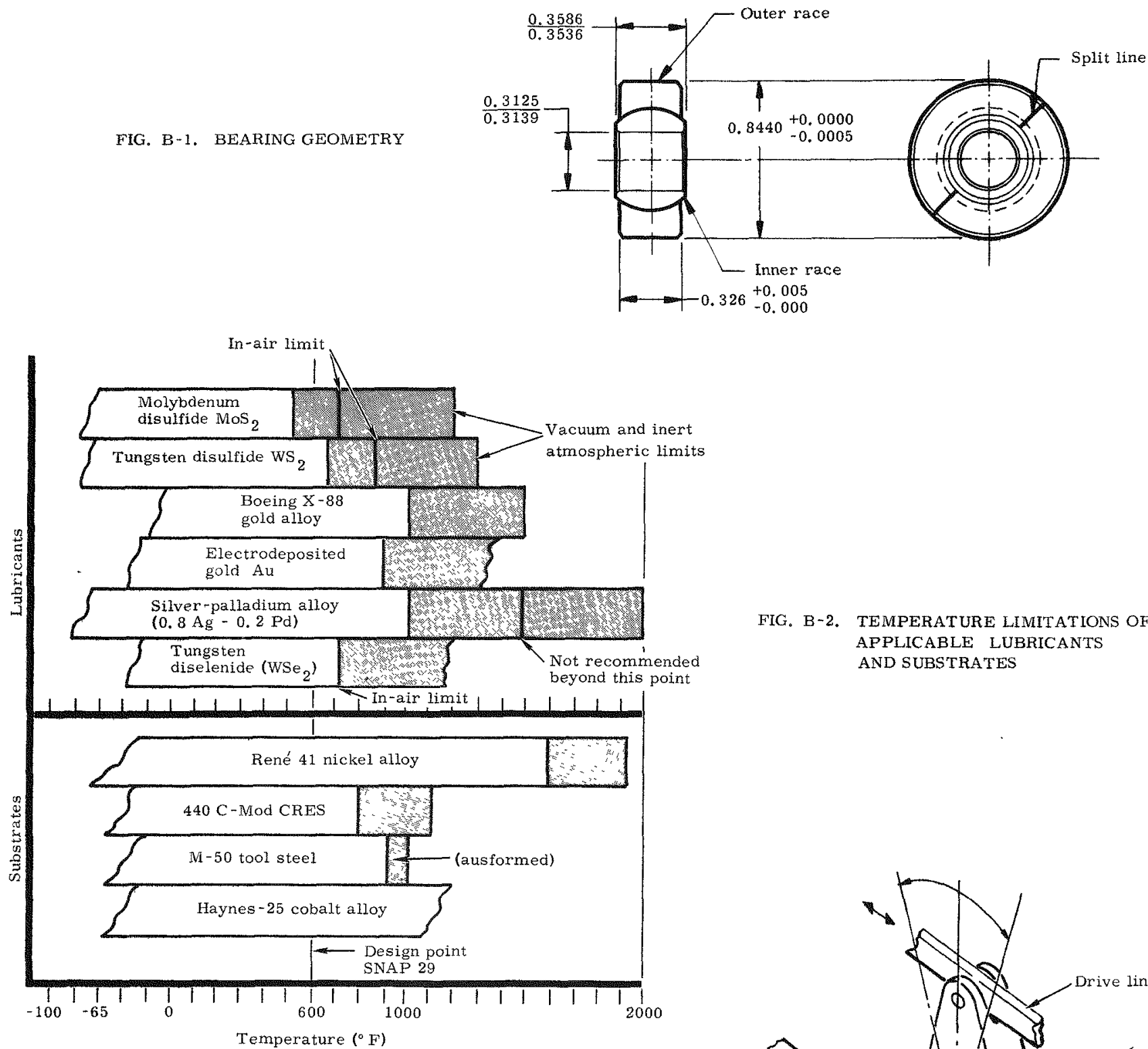

FIG.B-2. TEMPERATURE LIMITATIONS OF APPLICABLE LUBRICANTS AND SUBSTRATES

Note: Shaded areas require investigation for individual application parameters

FIG. B-3. SCHEMATIC DIAGRAM TEST FIXTURE

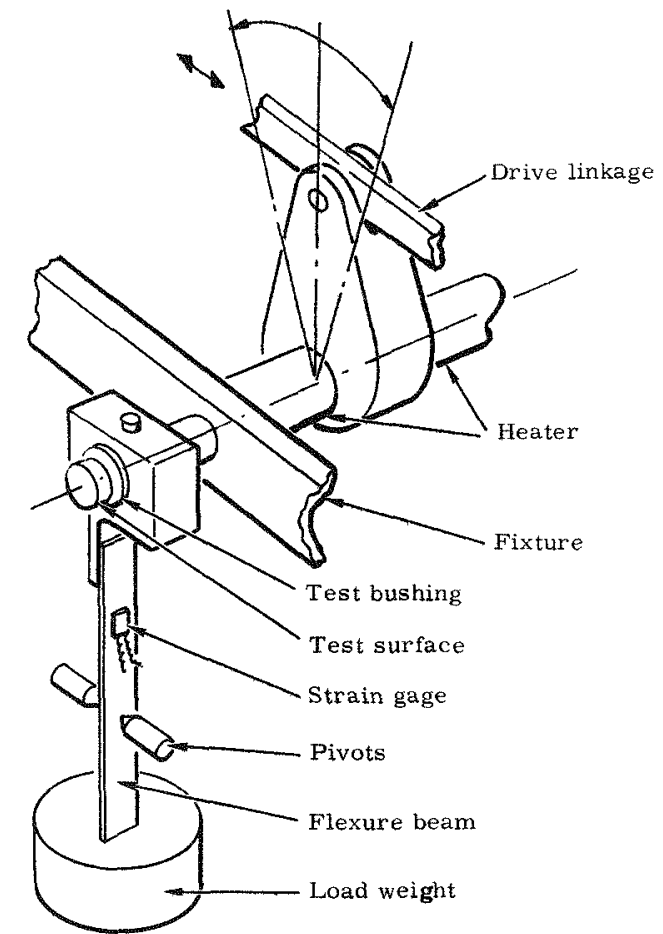




\section{TABLE B-2}

Test Specimen Description

466A 1544002

Assembly No. Substrate Material $-079(\mathrm{~B})$ -079 (A)

Haynes - 25

-089 (B)

$-089(A)$

$-099(B)$

$-099(\mathrm{~A})$

-109 (B)

-109 (A)

$-119(\mathrm{~B})$

-119 (A)

$-129(\mathrm{~B})$

$-129(\mathrm{~A})$
M-50 stee

MI-50 steel

Lescalloy BG-42

17-4PH CRES steel

17-4PH CRES steel
Lescalloy $\mathrm{BG}-42$
Lubricant and Binder

Molykote X-15, Sodium silicate

Molykote X-15, sodium silicate

Molykote X-15 sodium silicate

Electrodeposited gold

Tungsten diselenide sodium silicate

\section{Chrome plate over} nickel strike

Chrome plate over nickel strike
Rubbing Surface (Bushing) Material

Lescalloy $\mathrm{BG}-42$

Lescalloy BG-42

René 41

René 41

Lescalloy BG-42

17-4PH CRES steel

Type 321 CRES steel

\section{TABLE B-3}

Bearing Substrate Material Composition

\begin{tabular}{llllllllllll}
\multicolumn{1}{c}{ Material } & $\underline{\mathrm{Fe}}$ & $\underline{\mathrm{C}}$ & $\underline{\mathrm{Ni}}$ & $\underline{\mathrm{Co}}$ & $\underline{\mathrm{Mo}}$ & $\underline{\mathrm{W}}$ & $\underline{\mathrm{Cr}}$ & $\underline{\mathrm{V}}$ & $\underline{\mathrm{Si}}$ & $\underline{\mathrm{Mn}}$ & $\underline{\mathrm{Other}}$ \\
René 41 & $5(\max )$ & $0.12(\mathrm{M})$ & Balance & 11 & 10 & -- & 19 & -- & $-\cdots$ & $-\cdots$ & 6 \\
Haynes-25 & $3(\max )$ & 0.10 & 10 & Balance & -- & 15 & 20 & -- & -- & -- & 3 \\
Lescalloy BG-42 & Balance & 1.15 & $0.40(\mathrm{M})$ & -- & 4.00 & -- & 14.50 & 1.20 & 0.30 & 0.50 & 0.04 \\
M-50 & Balance & 0.81 & -- & -- & 4.25 & -- & 4.00 & 1.00 & 0.15 & 0.25 & 0.05
\end{tabular}




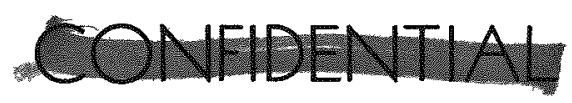

Examination of the specimens (Figs. B-4 through B-7) indicates a very slight amount of wear, most of the wear having occurred on the high spots, leaving them with a few polished spots. None of the specimens established a wear track or seat during the 3600 -cycle test. The gold specimen, No. 4, showed the most wear, with a seat approximately $\mathbf{5 0 \%}$ established.

Figure B-8 and Tables B-4 and B-5 present the wear results and original coating thicknesses. As can be seen, most of the specimens indicated growth rather than wear. This was attributed to several causes, rather than a single one. Both the Molykote X-15 and tungsten deselenide lubricants utilize sodium silicate as the binder, which has a tendency to be slightly deliquescent. Because of the very slight amount of wear, both types of specimens appeared to grow, due to absorbed moisture from the atmosphere. The growth of the gold specimen can be attributed to the formation of an oxide film, evidently caused by residue from the plating solution. Since the film was not worn away in the measurement planes, it appeared as a growth. The order of magnitude of growth of the chrome specimens was so small that it most probably was due to repeatibility errors of measurement. In no case was the growth large enough to affect the performance of the specimens.

\section{TABLE B-4}

Bearing Lubricant Evaluation Test Specimens

\begin{tabular}{|c|c|c|c|c|c|c|c|}
\hline \multirow{2}{*}{$\begin{array}{l}\text { Specimen } \\
\text { Assembly }\end{array}$} & \multirow{2}{*}{$\begin{array}{c}\text { Lubricant } \\
\text { (ref) }\end{array}$} & \multicolumn{4}{|c|}{ Coating Thickness (in.) } & \multirow{2}{*}{$\begin{array}{c}\text { Average } \\
\text { Thickness } \\
\text { (in.) }\end{array}$} & \multirow{2}{*}{$\begin{array}{l}\text { Specimen } \\
\text { Test No. }\end{array}$} \\
\hline & & $\underline{A-A}$ & $\underline{B-B}$ & $\mathrm{C}-\mathrm{C}$ & $D-D$ & & \\
\hline$-079(\mathrm{~A})$ & $X-15$ & 0.0015 & 0.0016 & 0.0016 & 0.00125 & 0.0015 & 7 \\
\hline$-079(\mathrm{~B})$ & $X-15$ & 0.00115 & 0.0010 & 0.0010 & 0.0009 & 0.0010 & 1 \\
\hline-089 (A) & $X-15$ & 0.0008 & 0.0009 & 0.0009 & 0.0011 & 0.0009 & 8 \\
\hline$-089(\mathrm{~B})$ & $X-15$ & 0.00095 & 0.00095 & 0.0011 & 0.0008 & 0.0010 & 2 \\
\hline$-099(\mathrm{~A})$ & $x-15$ & 0.0010 & 0.00075 & 0.00085 & 0.0008 & 0.0008 & 9 \\
\hline$-099(B)$ & $x-15$ & 0.0008 & 0.00087 & 0.00087 & 0.0011 & 0.0009 & 3 \\
\hline-109 (A) & $\mathrm{Au}$ & 0.00050 & 0.00057 & 0.00048 & 0.00065 & 0.0006 & 10 \\
\hline-109 (B) & $\mathrm{Au}$ & 0.0009 & 0.0009 & 0.0009 & 0.00085 & 0.0009 & 4 \\
\hline$-119(\mathrm{~A})$ & $\mathrm{WSe}_{2}$ & 0.00065 & 0.0007 & 0.0008 & 0.00075 & 0.0007 & 11 \\
\hline$-119(B)$ & $\mathrm{WSe}_{2}$ & 0.0015 & 0.0018 & 0.0016 & 0.0015 & 0.0014 & 5 \\
\hline $\begin{array}{l}-129(\mathrm{~A}) \\
-129(\mathrm{~B})\end{array}$ & $\begin{array}{l}\mathrm{Cr} \\
\mathrm{Cr}\end{array}$ & $\begin{array}{l}0.0004 \\
0.0006\end{array}$ & $\begin{array}{l}0.00038 \\
0.00062\end{array}$ & $\begin{array}{l}0.00038 \\
0.00062\end{array}$ & $\begin{array}{l}0.0003 \\
0.0007\end{array}$ & $\begin{array}{l}0.00038 \\
0.0006\end{array}$ & $\begin{array}{r}12 \\
6\end{array}$ \\
\hline
\end{tabular}

Maximum, minimum and average breakout friction coefficients are shown in Fig. B-9 and Table B-6. The average values represent approximately 500 individual measurements each. As can be seen from Fig. B-9, the performance of the Molykote X-15 was relatively consistent, the average values for six specimens falling between 0.10 and 0.158 . The largest dispersion occurred with Specimen No. 7. The two tungsten diselenide specimens exhibited a somewhat larger range of average values, ranging from 0.074 to 0.214 . The overall range of Specimen No. 5 was relatively narrow, and that of Specimen No. 11 was considerably greater, approximating that of the Molykote X-15 specimen, No. 7. The similar spread of points for these two specimens indicates the probability that the original coating mixture was insufficiently agitated during application, resulting in an unequal distribution of lubricant and binder. The higher coefficients of these two specimens are probably those of the binders.

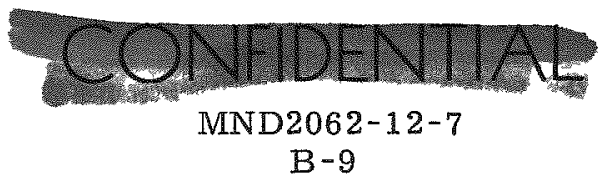


TABLE B-5

Wearing Measurements

Bearing Lubricant Evaluation Test

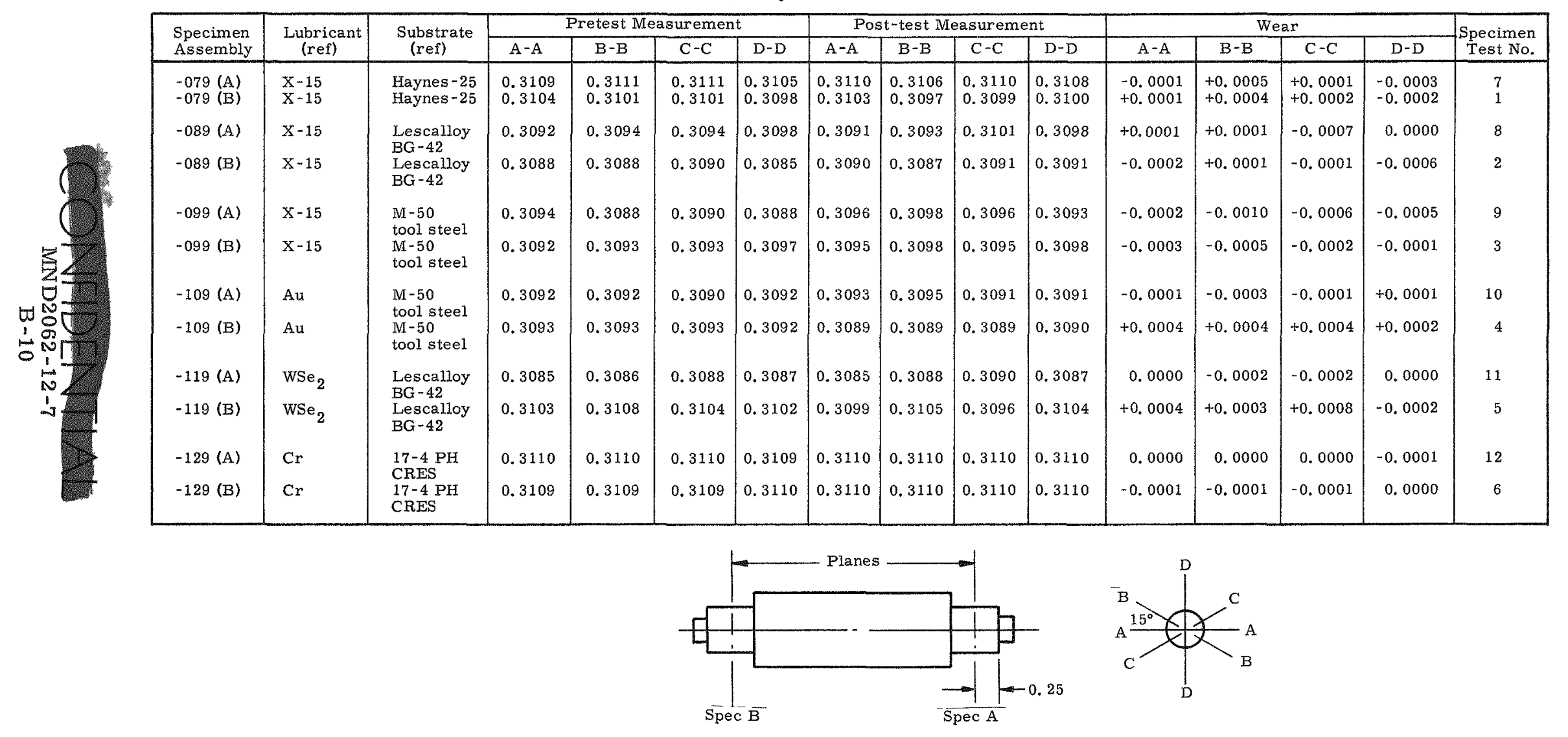


TABLE B-6

Friction Coefficients

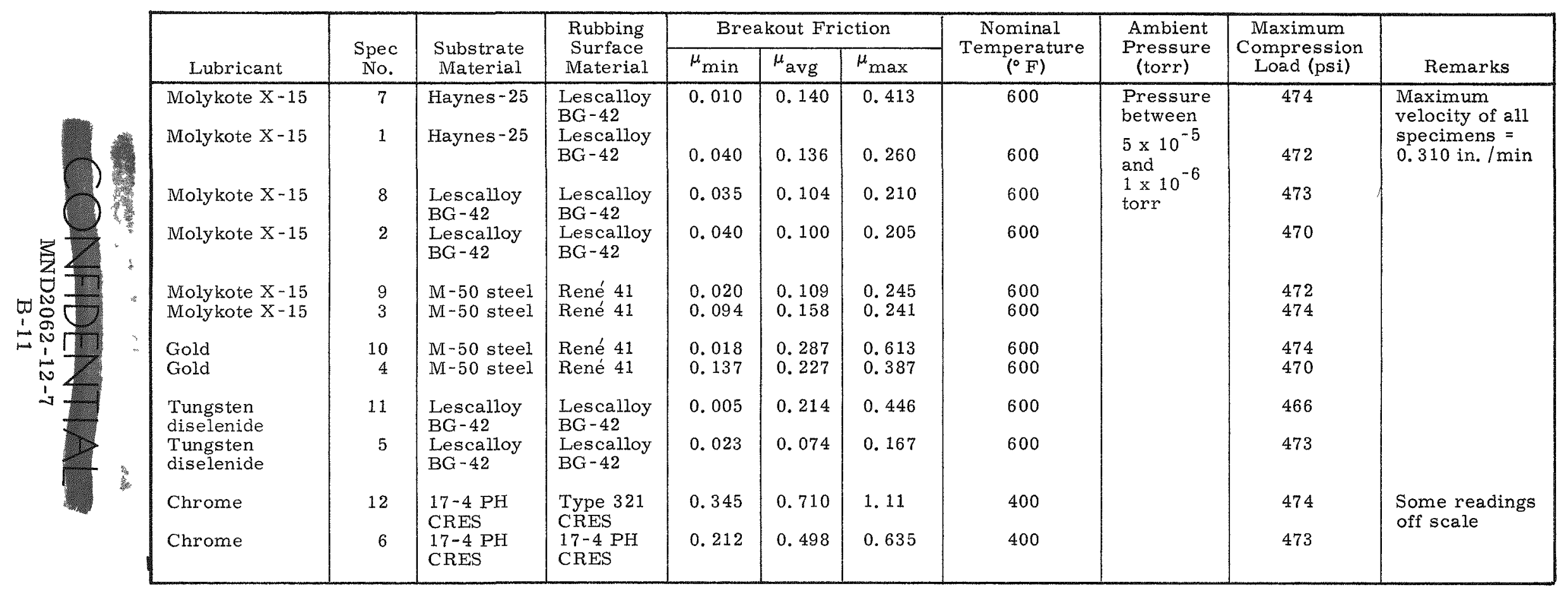




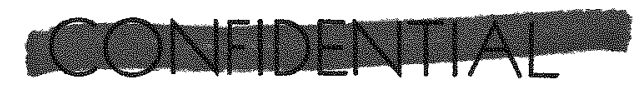

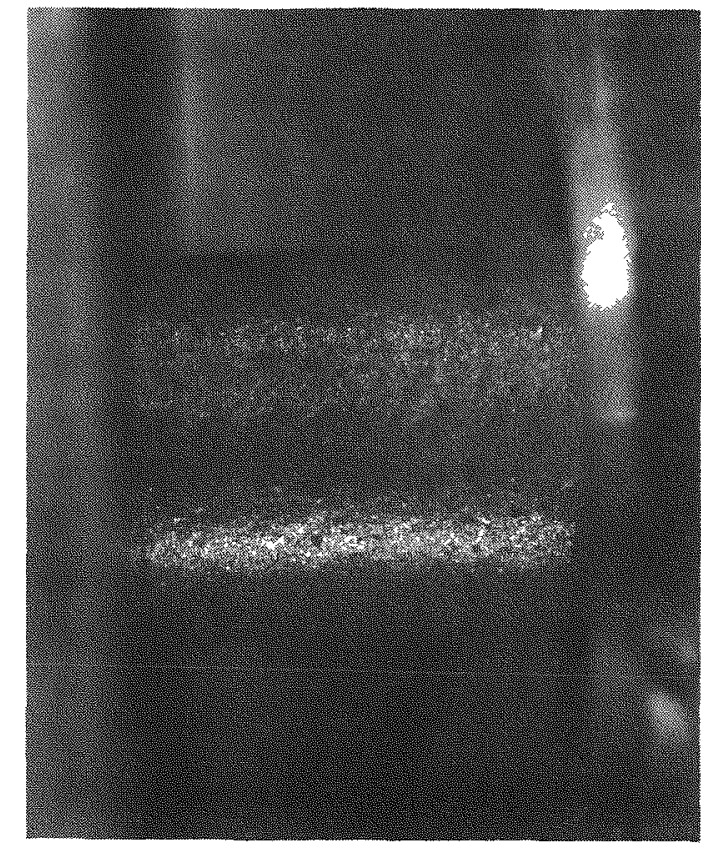

FIG. B-4. SPECIMEN NO. 5--TUNGSTEN DISELENIDE LUBRICANT LESCALLOY BG 42 SUBSTRATE BEFORE TEST

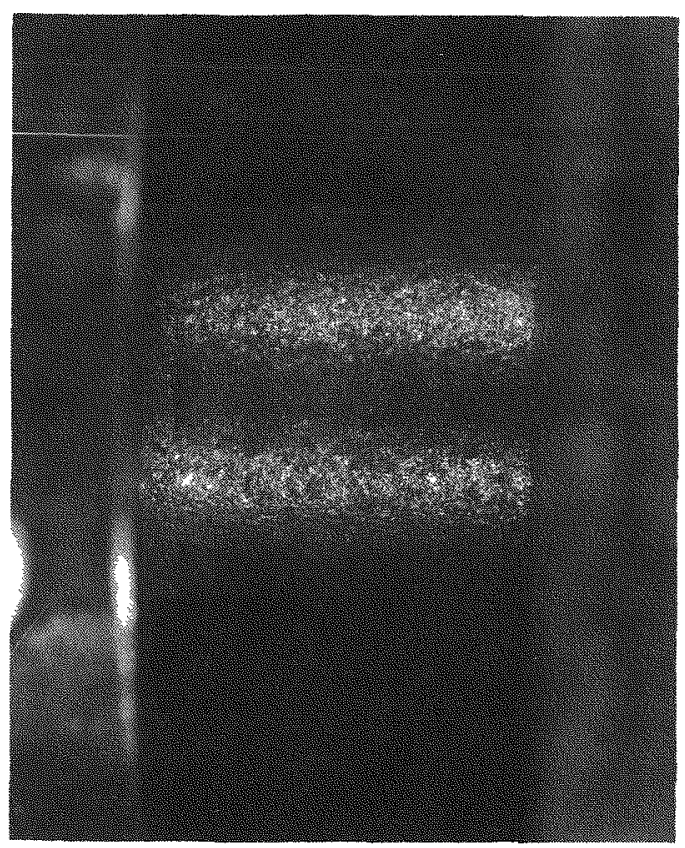

FIG. B-6. SPECIMEN NO. 11 BEFORE TEST

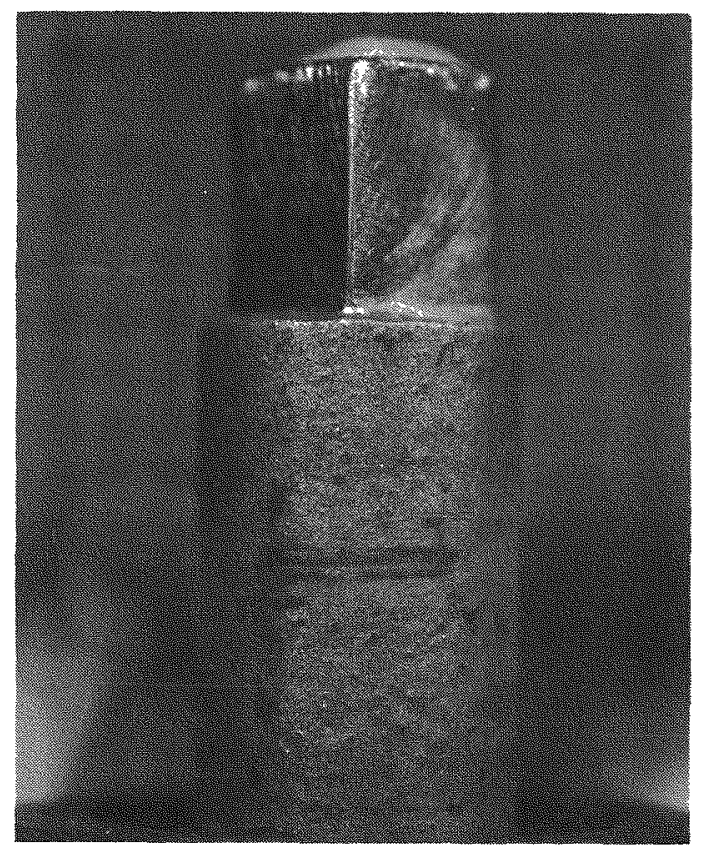

FIG. B-5. BEARING HEATER COMBINATION NO. 5 AFTER TEST

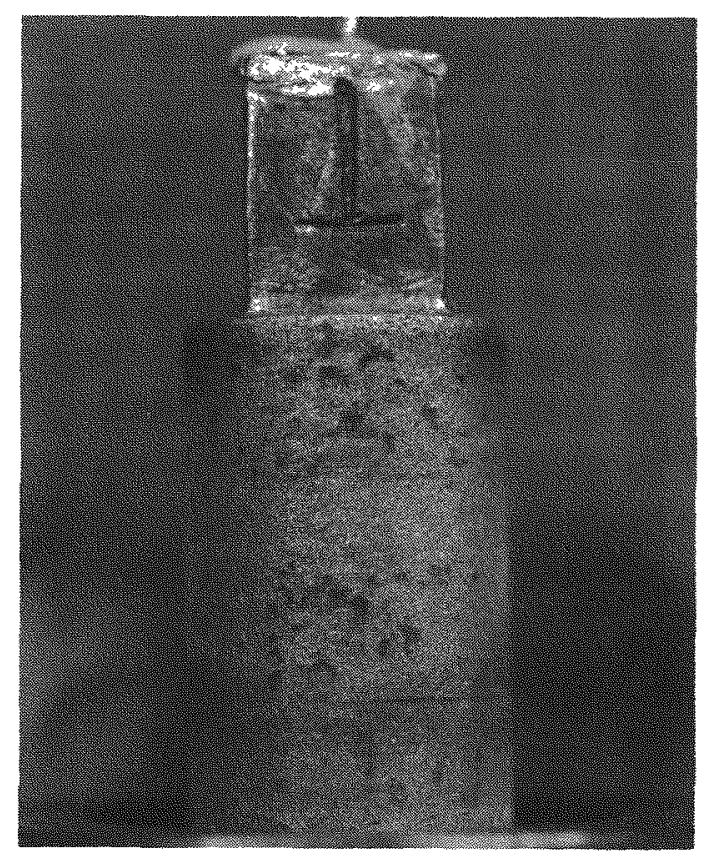

FIG. B-7. SPECIMEN NO. 11 AFTER TEST

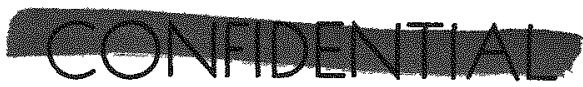

MND2062-12-7

B-12 

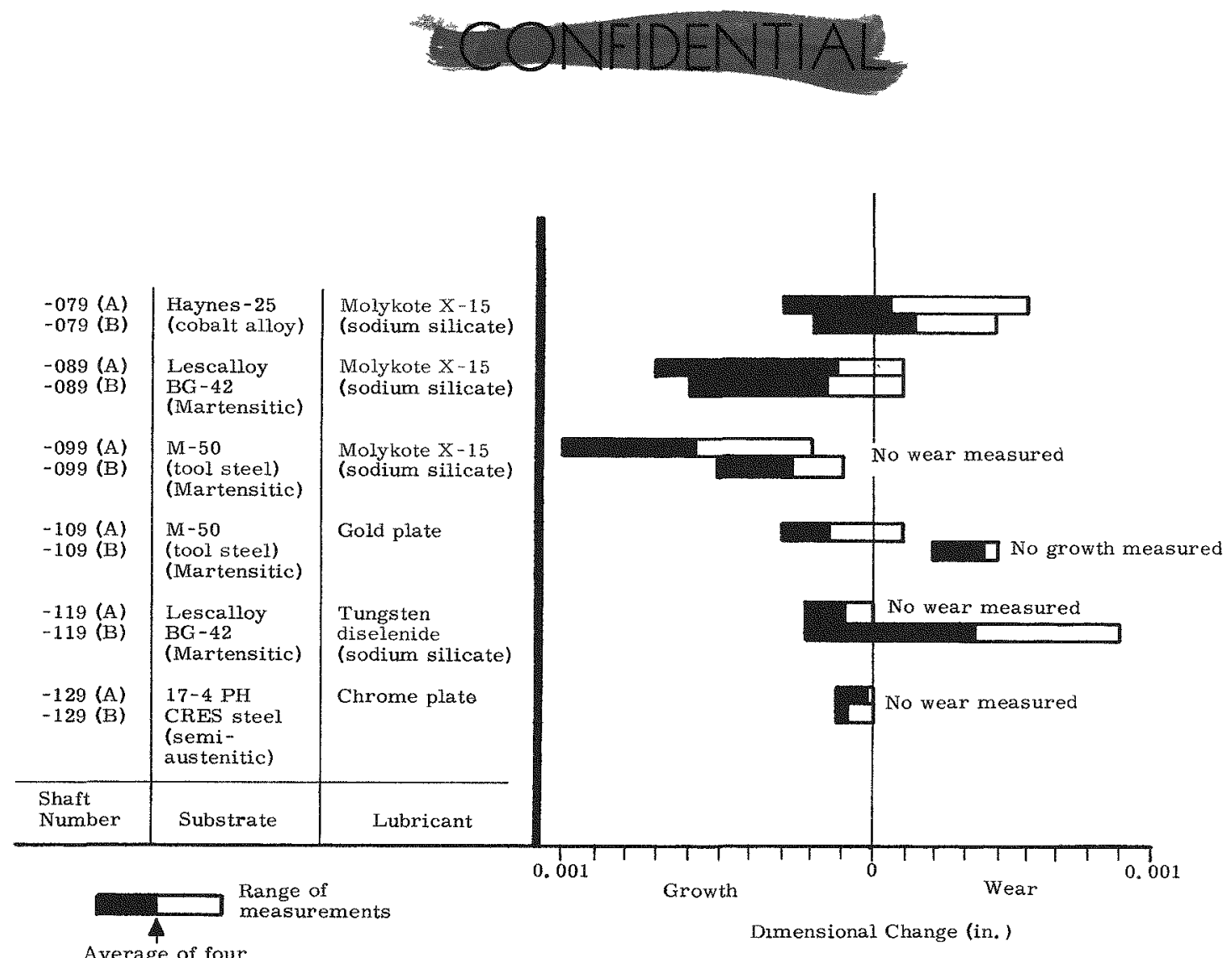

FIG. B-8. WEAR MEASUREMENTS

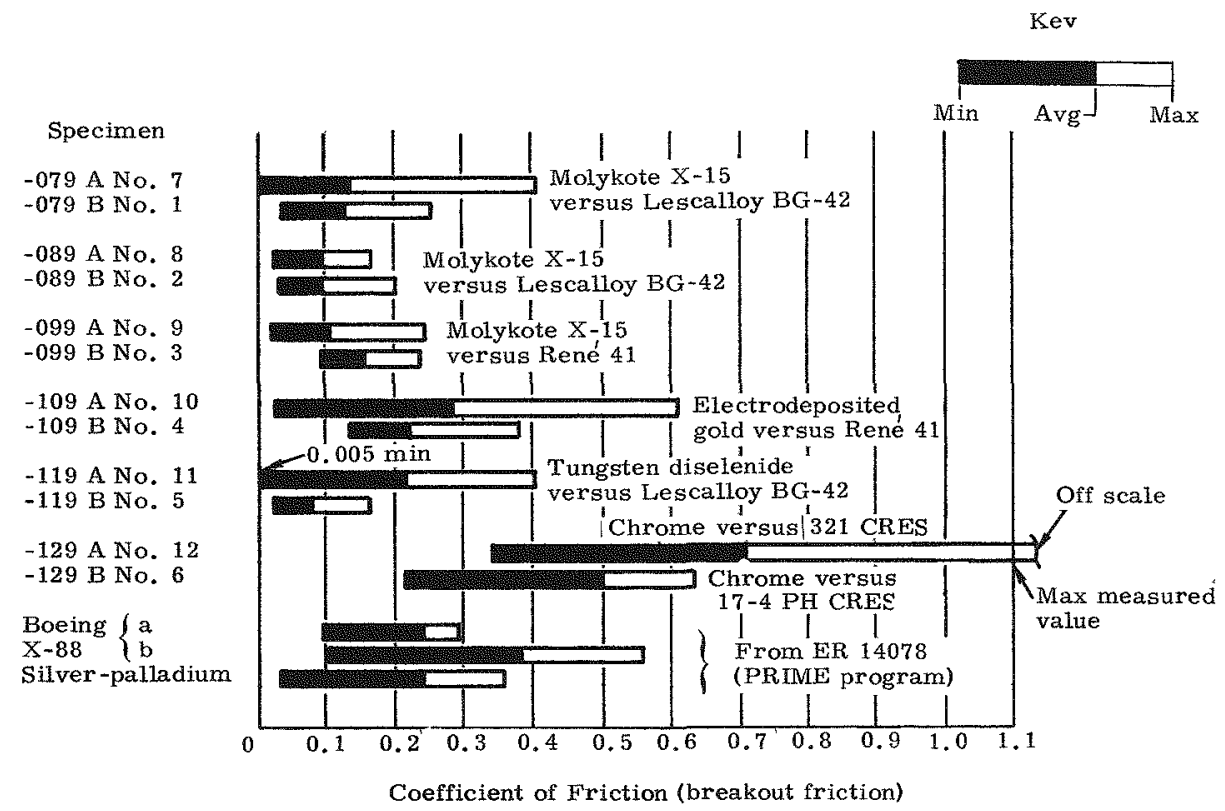

FIG, B-9. STATIC FRICTION COEFFICIENT

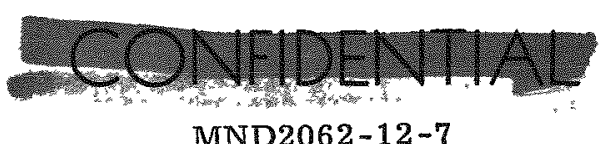

$\mathrm{B}-13$ 


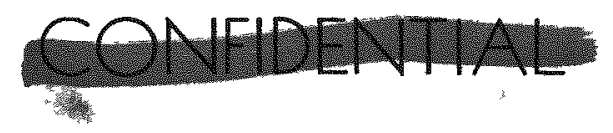

The breakout friction coefficients of the gold specimens were relatively high when compared to the Molykote and tungsten diselenide lubricants. However, they are typical of soft metal films as evidenced by comparison to the Boeing X-88 and silver-palladium films shown in Fig. B-9. The lower values shown for Specimen No. 10 are probably due to the presence of the oxide film which contributed to the large spread of data for this specimen.

The friction coefficients of the chrome plated specimens were considerably higher than those of the other specimens. The effects of the two different rubbing surface materials are clearly evident in Fig. B-9. The maximum friction coefficient for Specimen No. 12 was so great as to go off scale for several points, exceeding a value of 1.0. Previously published data, Ref. B-2, indicates that values of 2.0 or greater can be achieved by chrome plated surfaces in a vacuum. Cold welding of this joint did not occur since the specimens were observed during this period and relative motion between the shaft and rubbing surface was perceptible.

The six specimens included in the three-hour vibration test all survived without chipping away the lubricant completely. Considerable wear occurred during the test. A typical specimen is shown in Figs. B-10 through B-12. Wear measurements were not made. Since the total time of exposure to vibration was approximately three hours, compared to approximately six minutes during launch, an adequate margin of safety is indicated.

Bearing outer race and shaft temperatures obtained in the shutter thermal vacuum test are shown in Fig. B-13. For the nominal heat source temperature of $1500^{\circ} \mathrm{F}$, the maximum bearing temperature was $540^{\circ} \mathrm{F}$, which verifies the analytical prediction (and test temperature) of $600^{\circ} \mathrm{F}$ nominal.

The individual friction versus number of cycles curves for Specimen Nos. 2, 5, 8 and 11 are shown in Figs. B-14 through B-17. Those for the remaining specimens may be found in the lubricant evaluation test report, 466 A1543612.

\section{B. LUBRICANT DESCRIPTIONS}

The following are brief descriptions of the lubricants considered for this application.

\section{Molykote X-15}

This is a commercial lubricant supplied by the Alpha-Molykote Corporation. Its composition is approximately $71 \% \operatorname{MoS}_{2}, 7 \%$ graphite and $22 \%$ sodium silicate binder. It approximates a series of lubricants originally developed by Devine at the Naval Research Laboratory. Similar formulations are also available from several other commercial sources.

The primary lubricating element is molybdenum disulfide $\left(\operatorname{MoS}_{2}\right)$ which is one of the more widely known solid film lubricants. The in-air temperature limit of the $\mathrm{MoS}_{2}$ is approximately $750^{\circ} \mathrm{F}$, after which the rate of oxidation increases rapidly. The oxide, $\mathrm{MoO}_{3}$, is an abrasive, and its presence will cause rapid wear. Wear rate begins to increase at approximately $500^{\circ} \mathrm{F}$ for resin-bonded $\mathrm{MoS}_{2}$ lubricants, and consequently must be investigated for individual applications at temperatures greater than $500^{\circ} \mathrm{F}$. By changing to silicate-bonded $\mathrm{MoS}_{2}$, the useful life may be extended to approximately $750^{\circ} \mathrm{F}$ (in-air). In vacuum environments, the useful temperatures may be extended to approximately $1000^{\circ} \mathrm{F}$, depending on load, life, etc.

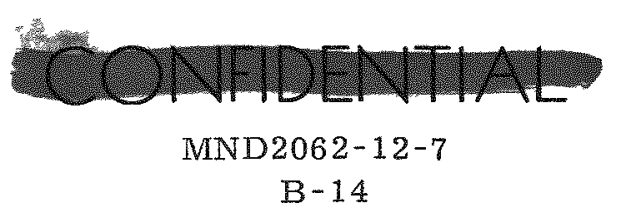




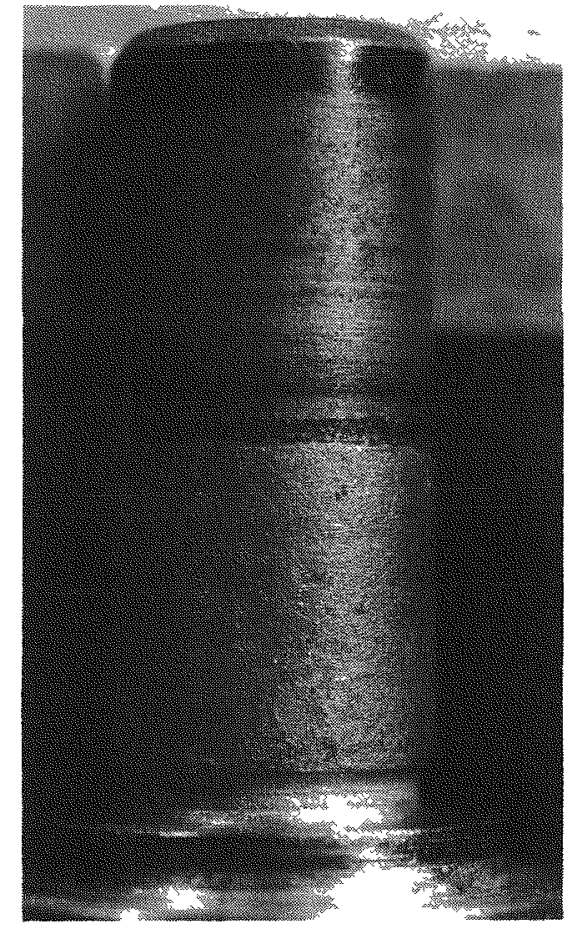

FIG. B 10. SHAF'T A-3 AFTER VIBRATION TEST

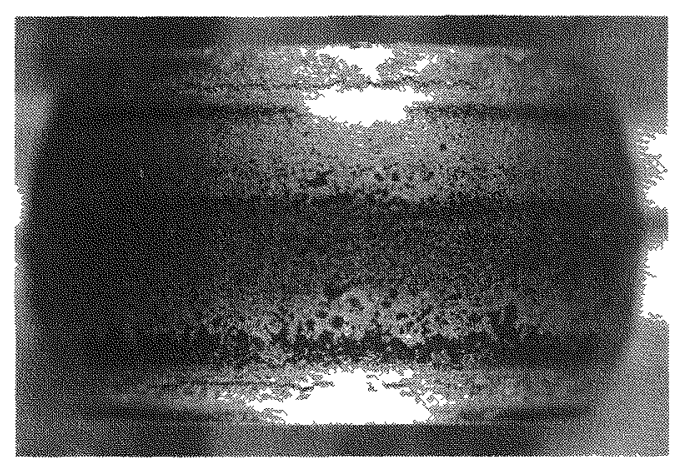

FIG. B-11. INNER RACE AFTER VIBRATION TEST

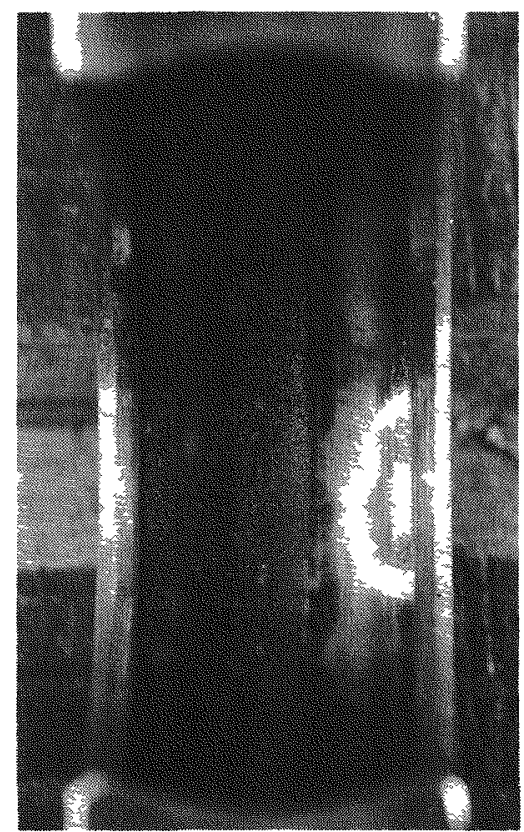

FIG. B-12, OUTER RACE HALF AFTER VIBRATION TEST
FIG. B-13 COMPONENT TEMPERATURE SHUTTER THERMALVACUUM TEST 
Lubricant: tungsten diselenide

Binder: Sodium silicate

Rubbing surface: Iescalloy $\mathrm{BG}-42$

Time: 90 day

Temperature: $600^{\circ} \mathrm{F}$ (nom)

Pressure: between

$5 \times 10^{-5}$ and $1 \times 10^{-6}$ torr

Motion: oscillation at $+30^{\circ}$ amplitude

Radial load: 0.624 pound, $473 \mathrm{psi}$ (Hertz)
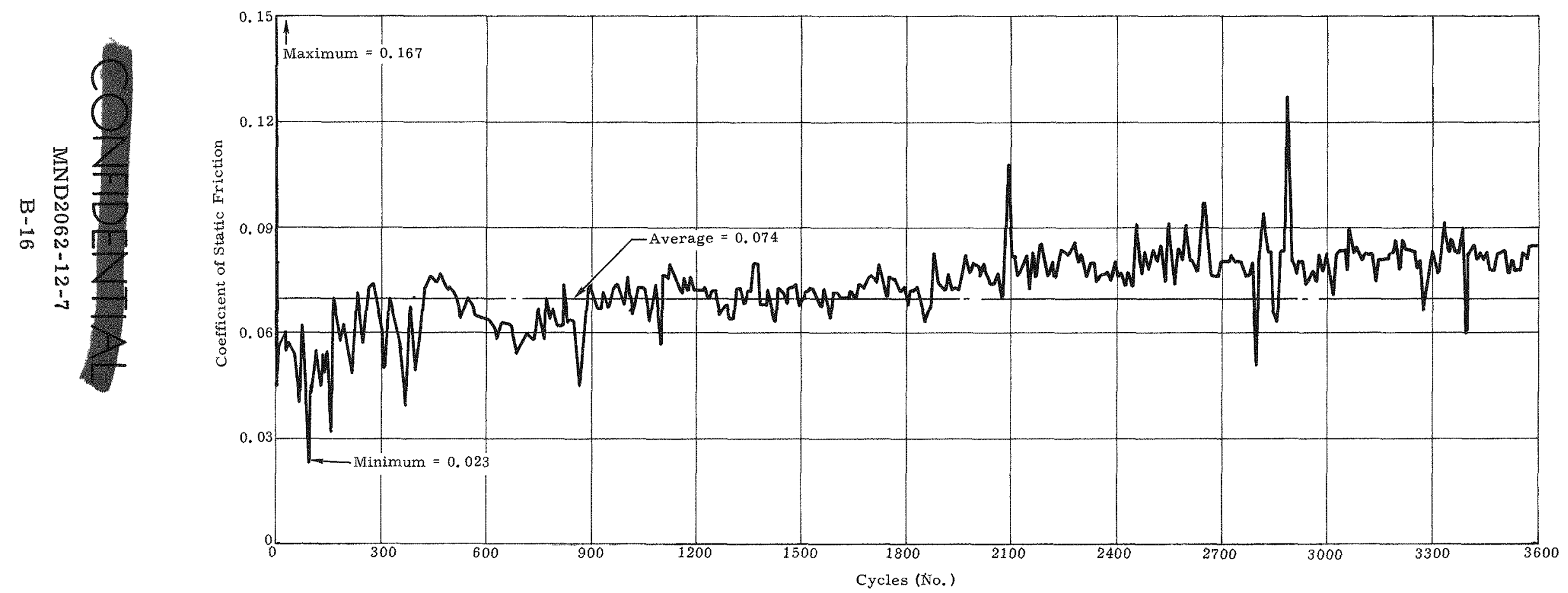

FIG. B-14. SPECIMEN NO. 5 

Lubricant. Molykote X-15

Binder. Sodium sillicate

Rubbing surface: Lesca $110 y$ BG-42

Environment:

Time: 90 days

Temperature: $600^{\circ} \mathrm{F}$ (nom)

Pressure: between

$5 \times 10^{-5}$ and $1 \times 10^{-6}$ torr

Motion: oscillation at $\pm 30^{\circ}$ amplitude

Radial load: 0.620 pound, 470 psi (Hertz)

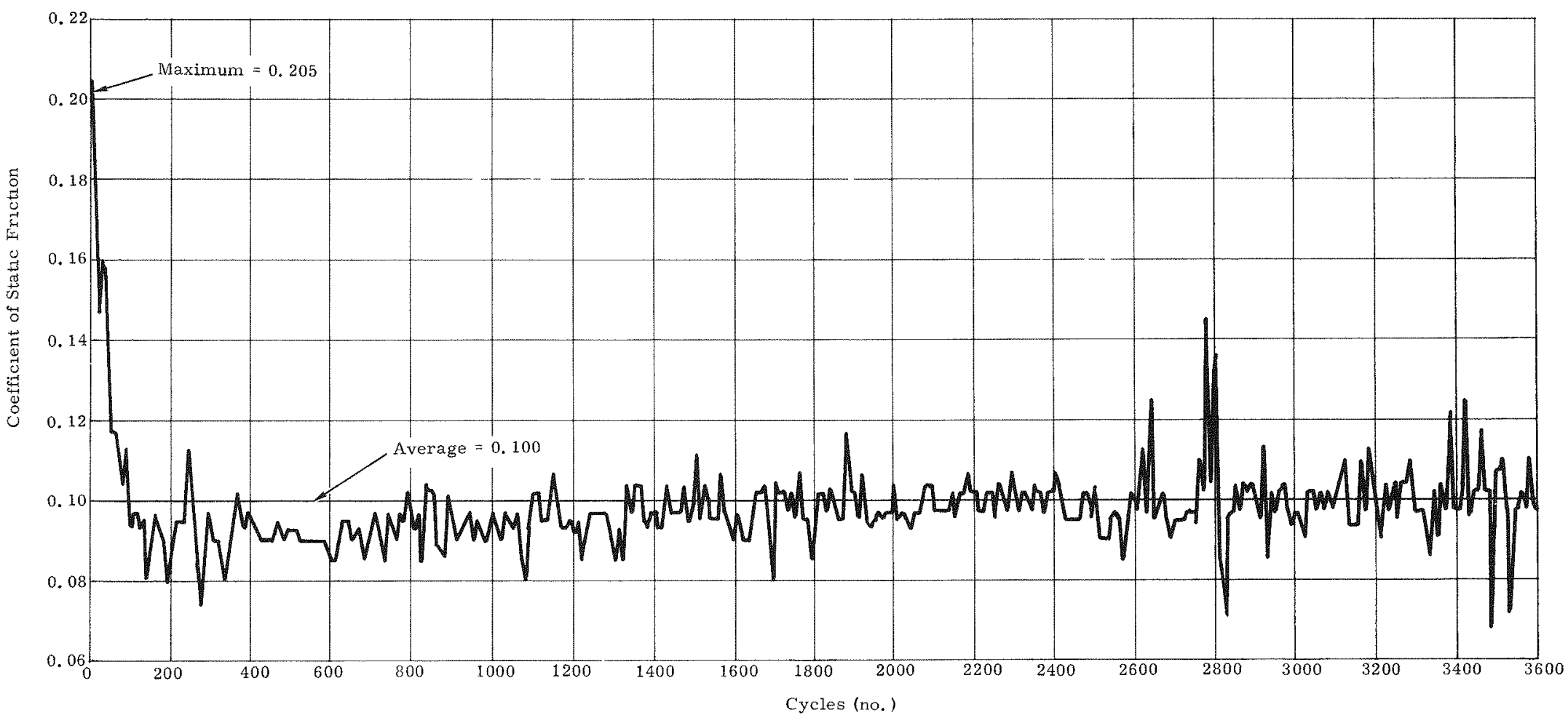

FIG. B-16. SPECIMEN NO. 2 
Lubricant: Molykote X-15

Substrate: Lescalloy BG-42

Rubbing surface: Lescalloy BG-42

Environment:

The: 90 days $00^{\circ} \mathrm{F}(n \mathrm{n})$

Pressure. between

$5 \times 10^{-5}$ and $1 \times 10^{-6}$ torr

Motion: oscillation at $+30^{\circ}$ amplitude

Radial load: 0.624 pound 473 psi (Hertz)
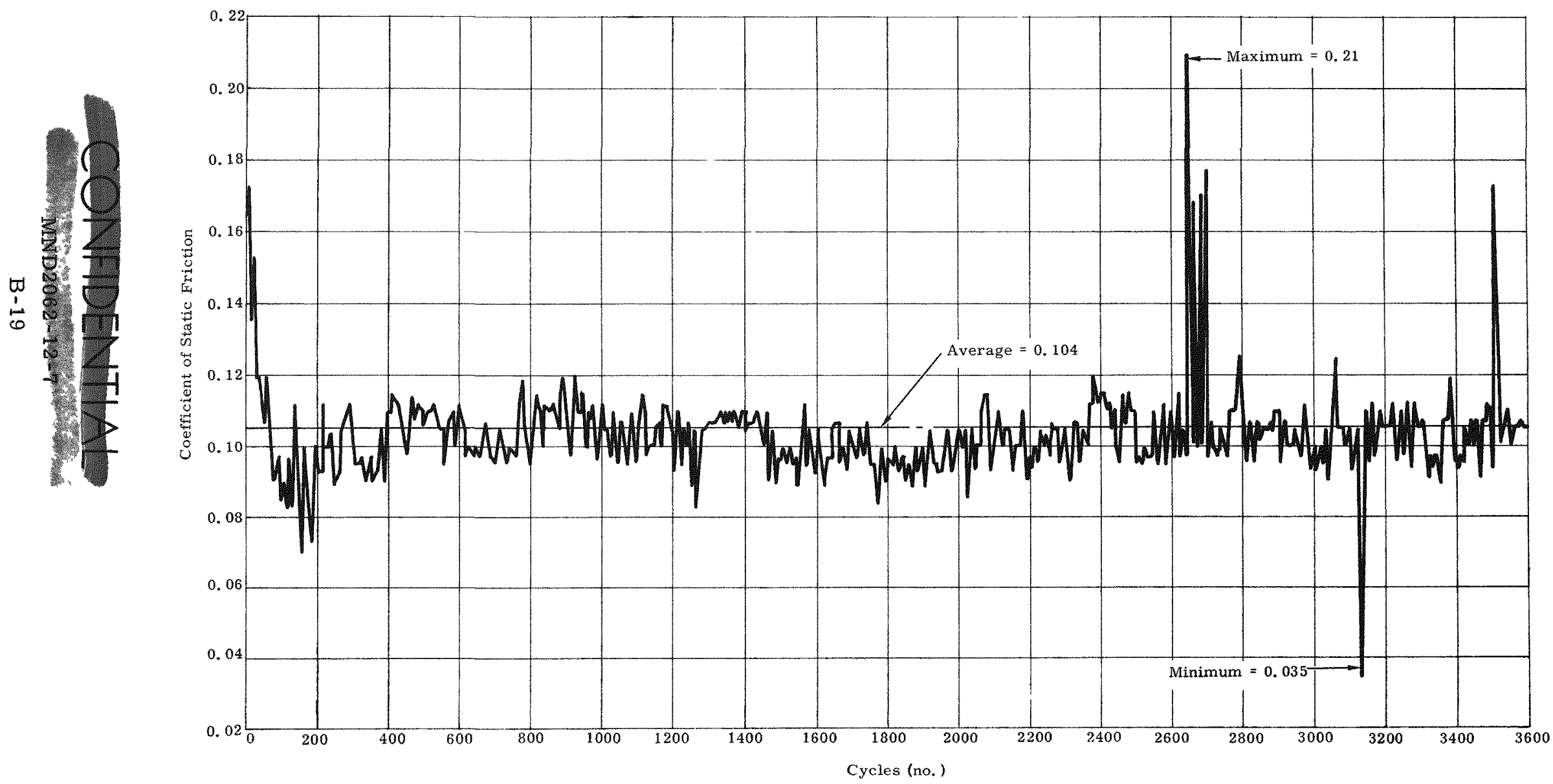

FIG. B-17. SPECIMEN NO. 8 


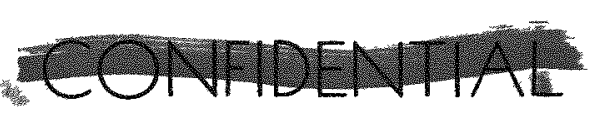

2. Tungsten Disulfide, WS 2

This material is similar to $\mathrm{MloS}_{2}$ and has the advantage of being usable at temperatures approximately $100^{\circ} \mathrm{F}$ higher than those of the $\operatorname{MoS}_{2}$. Its rate of outgassing in vacuum environments is less than that of the $\mathrm{MoS}_{2}$.

3. Tungsten Diselenide, WSe $_{2}$

The selenide lubricant family is considerably newer than the sulfides. In general, they have the advantage of providing friction coefficients approximately $50 \%$ lower than the $\mathrm{MoS}_{2}$ or WS $\mathrm{W}_{2}$ type lubricants, and are considerably more vacuum stable than either of the sulfides. The in-air limits for tungsten diselenide are approximately the same as for the $\operatorname{MoS}_{2}$. However, the oxide film forms a protective coating which serves to

limit further oxidation.

\section{Boeing $X-88$ Gold Alloy}

This was developed for the DynaSoar vehicle and utilized on the PRIME vehicle hinge bearings. It consists of alternate layers of René 41 oxide and gold. Total film thickness is controllable to $\pm 1 / 2 \mathrm{mil}$, in the thickness range of 0.001 to 0.002 inch. It is suitable for hard vacuum and in-air applications to temperatures of approximately $1500^{\circ} \mathrm{F}$; however, it becomes load sensitive above $1200^{\circ} \mathrm{F}$. It provides higher

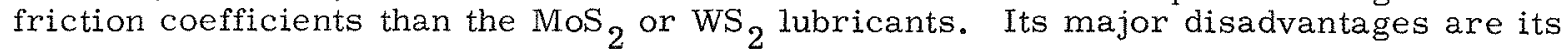
high cost and complexity of application.

\section{Electrodeposited Gold}

This has been tested under low load, oscillating motion conditions at room temperature for the PRIME program. Its friction characteristics are similar to those of the Boeing $X-88$. Its cost is considerably less than that of the Boeing X-88 and has the additional advantage of being more readily applied.

\section{Silver-Palladium Alloy}

This material has been tested to $2000^{\circ} \mathrm{F}$, at which point it was still effective as a lubricant. However, upon cooling in static conditions from temperatures above $1500^{\circ} \mathrm{F}$, it has the tendency to act as a solder. For this reason it is not recommended for use at above $1500^{\circ} \mathrm{F}$. It displays a higher wear rate (approximately double) than the Boeing $\mathrm{X}-88$, but a somewhat lower friction coefficient.

\section{CONCLUSIONS}

\section{Lubricant Selection}

The primary criteria involved in the selection of the lubricant system for this application are as follows:

(1) Wear life

(2) Frictional properties

(3) Stability--oxidation, chemical, vacuum, radiation.

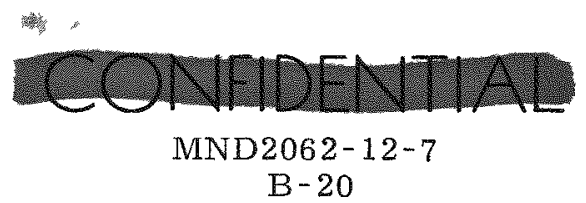


The results of the 90-day, 3600-cycle, thermal-vacuum test indicate that the wear life of all the lubricants involved in the test was sufficient for this application. None of the lubricants wore enough to complete the wear track The Molykote X-15 and the tungsten diselenide lubricants did little more than polish the high spots. The gold lubricant provided the most wear, establishing approximately $50 \%$ of its estimated wear track pattern. Since the Molykote X-15 and tungsten diselenide lubricants showed such excellent wear results, the gold will not be considered. The results of the shutter vibration test, wherein the bearings were subjected to a total of three hours of vibration and still maintained some of the coating, verified the choice of a sodium silicate binder, which is common to both the Molykote $X-15$ and the tungsten diselenide.

The frictional properties of the Molykote $X-15$ and the tungsten diselenide are shown in Figs. B-14 through B-17, and in Table B-6. From previously published data, it is expected that the $W^{2} S_{2}$ would operate at a lower friction coefficient than the Molykote $\mathrm{X}-15$. This is verified by comparing the average value for Specimen No. 5 (Table B-6) to that of either Specimen No. 2 or 8. The results of Specimen No. 11, WSe 2 , are relatively high and erratic. As can be seen from Fig. B-15, the friction of this specimen appears to be affected by two factors. One provides a basic pattern starting at approximately $\mu=0.16$ near the beginning of the test, increasing near the midjle of the test, and finally levelling off at a value of approximately 0.24 near the end. Super. imposed upon this appears an erratic pattern ranging from a high of 0.446 to a low of 0.005 . Examination of the specimen. Fig. B -7 , reveals the presence of a deep scratch in the bearing area, such as would be created by a foreign particle with consequent plowing action. This is the probable cause of the erratic pattern, although the offending particle was not found at disassembly of the specimen. (A similar scratch, although even deeper, was noted in Specimen $\mathrm{No}_{\text {. }} 5$ (Fig. B-5), which did not affect performance. However, traces of WSe 2 oxide were noted in this scratch, indicating that it occurred prior to the start of the test,) The basic pattern indicates a relatively high value of friction coefficient for this material. This could be the result of a lubricant poor mixture caused by insufficient agitation at the time of application which allowed the heavier lubricant particles to settle in the mixture. For these reasons the results of Specimen No. 11 are doubtful, and will not be considered in the evaluation.

The stability of the two lubricants is determined primarily from previously published data. The radiation stability of MoS 2 , which is the principal ingredient of Molykote X-15, is reported in Ref. B-3. Mos, was found to be stable after exposure to gamma doses of $878 \times 10^{12} \mathrm{ergs} / \mathrm{gC}$, and after exposure to a mixed reactor flux with a neutron dose of $3.66 \times 10^{20}$ nvt. Tungsten diselenude has been found stable after exposure to a fast neutron flux of $10^{13} \mathrm{nv}$ and $10^{8}$ roentgen/hr gamma radiation for 79 hours (Ref. B-4). It may therefore be concluded that both lubricants are radiation stable.

Reference $\mathrm{B}-4$, however, states that MoS $_{2}$ tends to corrode nickel-based alloys after exposure to high radiation levels, whereas WSe 2 does not.

While both the Molykote $X-15$ and the tungsten diselenide showed no effects from the 90-day vacuum exposure, it is reported in Ref. B-5 that tungsten diselenide shows little tendency to outgas in a vacuum of $10^{-12}$ torr at temperatures between $25^{\circ}\left(73.6^{\circ} \mathrm{F}\right.$ ) and $500^{\circ} \mathrm{C}\left(866^{\circ} \mathrm{F}\right)$. The MoS 2 on the other hand tends to liberate sulfur at elevated temperatures in hard vacuum.

The oxidation stability of both MoS $_{2}$ and WSe, are reported in Ref. B-5 to be identical at $350^{\circ} \mathrm{C}$. The WSe $2_{2}$ however, forms a protective film of WO 3 which retains a relatively low friction coefficient $(0.2$ to 0.3$)$ whereas the $\mathrm{MoS}_{2}$ forms $\mathrm{MoO}_{3}$ which is abrasive.

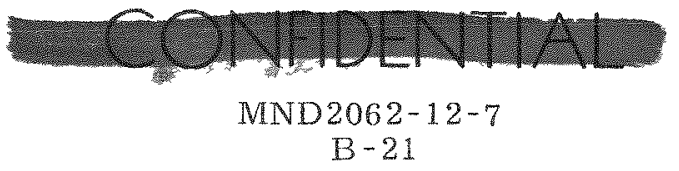


Chemically both the $\mathrm{MoS}_{2}$ and WSe ${ }_{2}$ lubricants are stable (Ref. B-5), being attacked only by hot concentrated nitric, sulfuric and hydrochloric acids; by free fluorine and chlorine and by the alkali metals ( $\mathrm{Li}, \mathrm{Na}, \mathrm{K}$, etc.). However, the $\mathrm{WSe}_{2}$ has the advantage of not tending to form sulfides with nickel alloys at elevated temperatures in air environments.

The tungsten diselenide, $\mathrm{WSe}_{2}$, is therefore selected as the primary lubricant for this application, with the Molykote X-15 as a backup lubricant. Both lubricant systems utilize sodium silicate as the binder. A brief summary of the various criteria for each lubricant is shown in Table B-7.

\section{Substrate Selection}

\section{a. Outer race}

The process utilized in the manufacture of the two outer race halves involves cold forming the material around tool steel sizing balls. This is accomplished in several steps, because of the considerable amount of cold working involved, with an annealing stage between steps.

René 41 nickel alloy was selected as the outer race material because of its ability to be cold worked to a considerable degree before requiring annealing, thus reducing the number of steps (and the consequent manufacturing cost). The other materials involved would have required so many annealing stages that the process would not be practical from either a metallurgical standpoint (excessive grain growth) or from a cost standpoint. An alternate technique, hot forming, would involve an extra investment in tools and development procedures.

Additional properties of the René 41 which make it desirable for this application include its corrosion resistance and its high temperature strength and hardness. This material has been used in this type bearing at temperatures above $1500^{\circ} \mathrm{F}$ thereby providing a considerable temperature margin of safety.

\section{b. Inner race}

The material selected for use as the inner race substrate is Lescalloy BG-42 manufactured by the Latrobe Steel Company. This is a modified Type $440-\mathrm{C}$ corrosion resistant steel containing $4 \%$ molybdenum. It is a special steel, designed specifically for bearing and gear application.

This material was selected because of its compatibility with both the primary and secondary lubricants, its corrosion resistance and because its coefficient of thermal expansion is close to that of the René 41 outer race.

\section{Actuator Joints}

Two specimens were included in the test to simulate the actuator sliding joints. These consisted of a 17-4 PH CRES steel substrate, with chrome plate acting as the lubricant. The rubbing surfaces were 17-4 PH CRES (Specimen No. 6) and Type 321 CRES (Specimen No. 12) steels. The 17-4 Ph simulated the external joint Fig. B-18) and the Type 321 simulated the internal joint.

The friction coefficients obtained during the test were considerably higher than those of the other specimens (Fig. B-19). Several points went off the scale for the Type 321, Specimen No. 12. However, vacuum welding did not occur. Because of the high coefficients of friction, considerable stick-slip motion was prevalent.

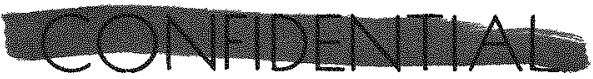

MND2062-12-7

B -22 


\section{TABLE B-7}

Lubricant Evaluation Summary

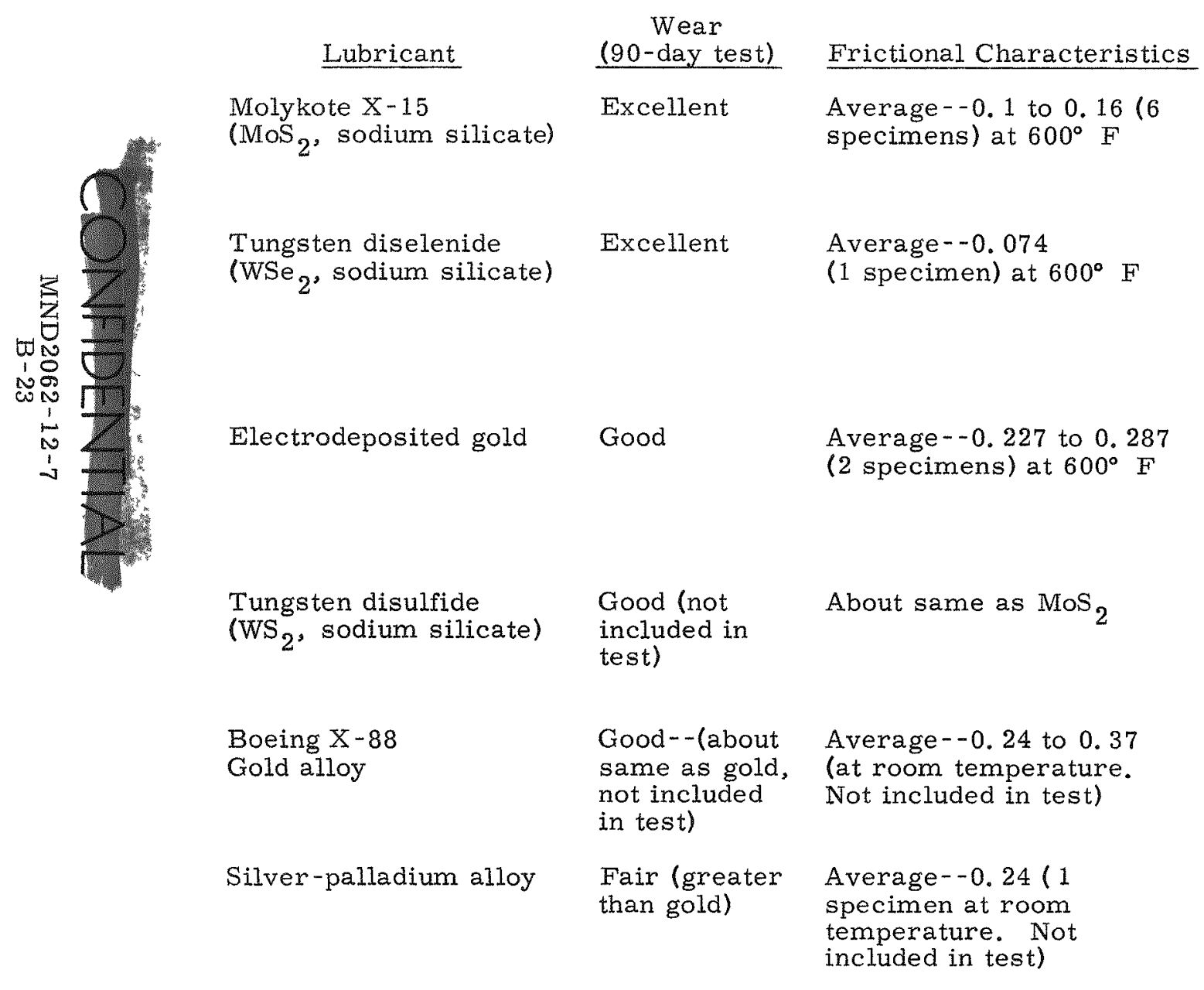

\begin{tabular}{|c|c|c|c|}
\hline \multicolumn{4}{|c|}{ Stability } \\
\hline Oxidation & Chemical & Vacuum & Radiation \\
\hline $\begin{array}{l}\text { Limit-- } \\
750^{\circ} \mathrm{F} . \\
\text { Oxide } \\
\text { abrasive }\end{array}$ & $\begin{array}{l}\text { Reacts with } \\
\text { nickel alloys }\end{array}$ & $\begin{array}{l}\text { Liberates } \\
\text { sulfur }\end{array}$ & Stable \\
\hline $\begin{array}{l}\text { Limit-- } \\
750^{\circ} \mathrm{F} \text {. } \\
\text { Oxide not } \\
\text { abrasive }\end{array}$ & Good & Excellent & Stable \\
\hline Good & $\begin{array}{l}\text { Good. } \\
\text { Reacts with } \\
\text { nickel at } \\
\text { high tempera- } \\
\text { ture }\end{array}$ & Excellent & Stable \\
\hline $\begin{array}{l}\text { Limit-- } \\
900^{\circ} \mathrm{F} \text {. } \\
\text { Oxide not } \\
\text { abrasive }\end{array}$ & Good & Good & Stable \\
\hline Good & Good & Excellent & Stable \\
\hline Good & $\begin{array}{l}\text { Good. } \\
\text { Reacts with } \\
\text { nickel at } \\
\text { high tempera- } \\
\text { ture }\end{array}$ & Excellent & Stable \\
\hline
\end{tabular}




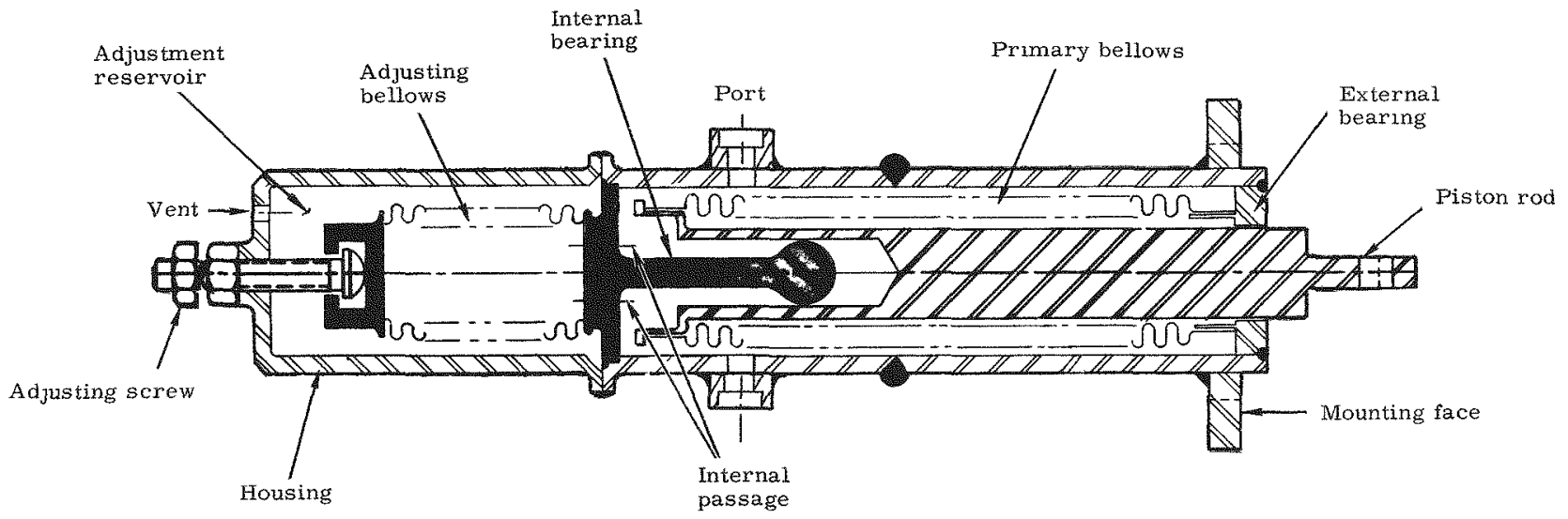

FIG. B-18. ACTUATOR SCHEMATIC

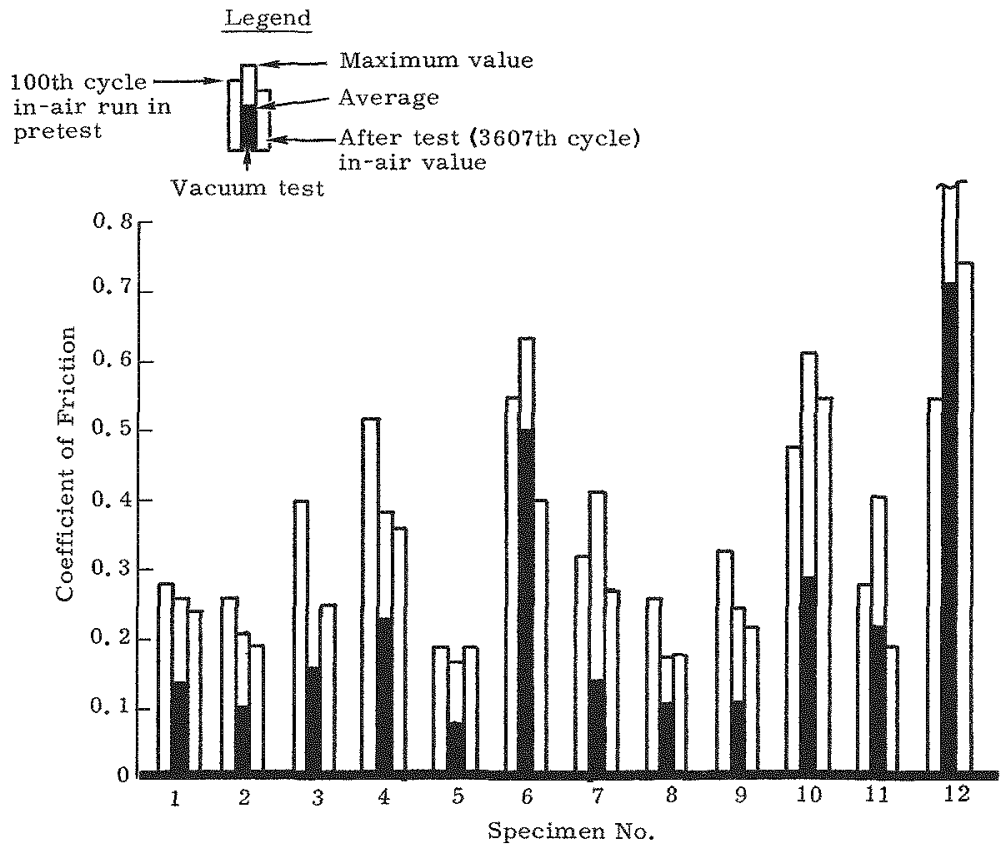

FIG. B-19. COMPARISON OF IN-AIR AND IN-VACUUM FRICTION

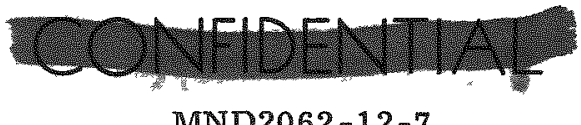

$B-24$ 
The actuator internal joint, represented by Specimen No. 12, will be immersed in NaK during operation. Consequently some measure of lubrication will be provided which should serve to decrease the overall friction coefficient. Wear, as determined by test, will be negligible (Fig. B-8).

The actuator external joint, which indicates a comparatively high coefficient of friction (Figs. B-9 and B-18), should be modified to include the application of a solid lubricant coating (such as hand rubbing, tumbling or burnishing with $\mathrm{MoS}_{2}$ or $\mathrm{WSe}_{2}$ powder) during assembly. This will decrease the overall friction level and also reduce the stick-slip effects. The actuator-linkage design should be modified to eliminate or minimize any side loads reacted by this joint.

\section{REFERENCES}

The following documents pertain to the material discussed in this report. 1. Martin Marietta Specifications
(1) 466A1543012, "Test Specification for Shutter Bearing Lubricant/ Substrate Evaluation Test."
(2) 466A1543512, "Test Procedure, Shutter Bearing Lubricant Evaluation Test."
(3) 466A1543021, "Process Specification, Application of Molykote X-15 Lubricant."
(4) 466A1543022, "Process Specification, Application of Tungsten Diselenide Dry-Film Lubricant."
(5) 466A1543612, "Test Report, Shuter Bearing Lubricant Evaluation Test."

\section{Martin Marietta Drawings}

(1) 466A1541001, "Bearing, Self-Aligning, Shutter Assembly."

(2) 466A1544002, "Test Specimen, Thermal Vacuum Shutter Bearing Test."

(3) 466A1544004, "Test Fixture, Thermal Vacuum Shutter Bearing Test."

(4) 466A1545200, "Instrumentation, Vacuum Bearing Test."

\section{Bibliography}

B-1 Gischlar, G., "High Temperature Bearing Development Tests." Martin Marietta Corporation, ER 14078, 1966

B-2 Rabinowitz, E., Friction and Wear of Materials. John Wiley \& Sons, N.Y., 1965

B-3 Campbe11, M. E., Loser, J. B. and Sneegas, E., "Solid Lubricants." NASA SP-5059, 1966

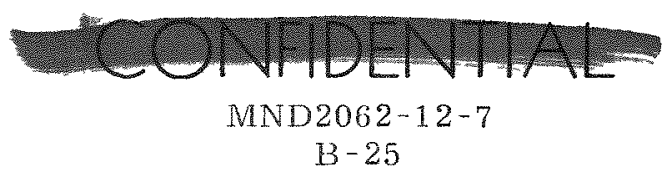




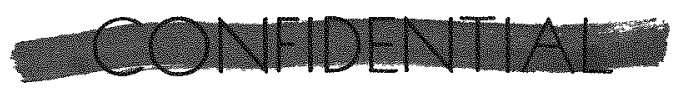

B-4 Bemol Inc., Technical Sheet No. 207, June 1965

B-5 Magie, P. M., "Properties and Potentials of Heavy-MetalDerivative Solid Lubricants." ASLE Preprint 66AM2B3, 1966

B-6 Bisson, E. E. and Anderson, W. J., "Advanced Bearing Technology." NASA SP-38, 1964

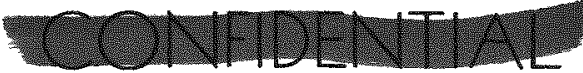

MND2062-12-7

$\mathrm{B}-26$ 